\title{
Acoustic Telemetry Studies of Juvenile Chinook Salmon Survival at the Lower Columbia Projects in 2006
}

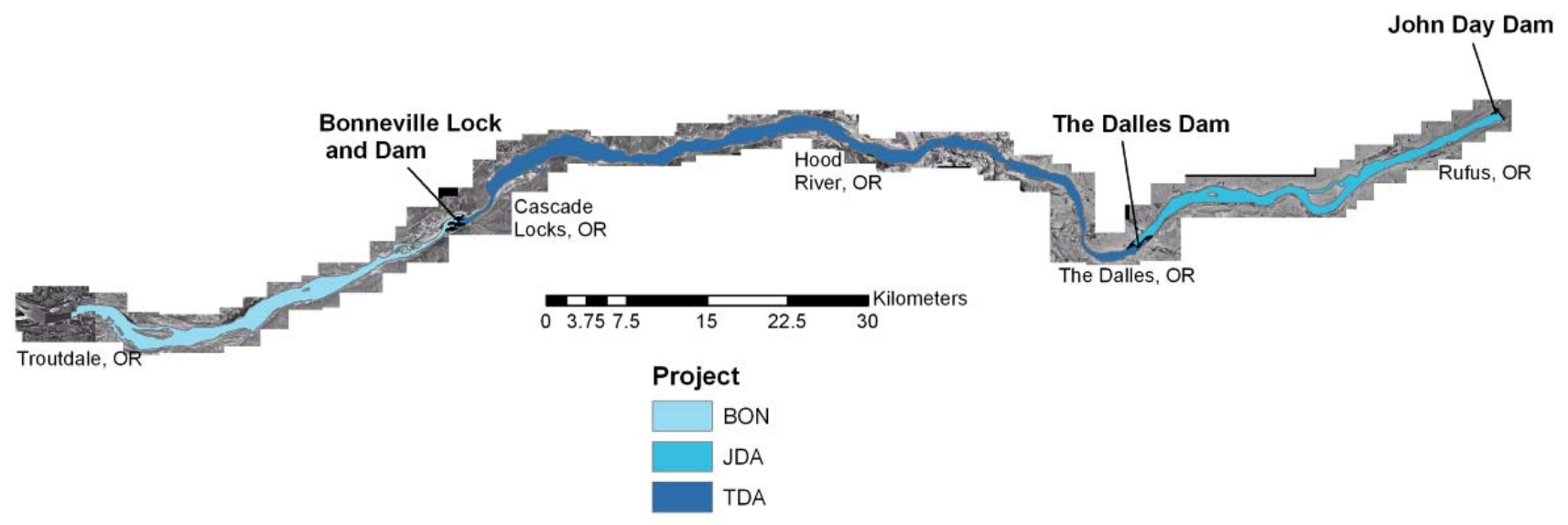

G.R. Ploskey, M.A. Weiland, J.S. Hughes, S.R. Zimmerman, R.E. Durham, E.S. Fischer, J Kim, R.L. Townsend, J.R. Skalski, R.L. McComas

FINAL REPORT

December 2007

Prepared for the

U.S. Army Corps of Engineers

Under a Related Services Agreement

With the U.S. Department of Energy

Contract DE-AC05-76RLO1830

\section{Pacific Northwest} National Laboratory

Operated by Battelle for the

U.S. Department of Energy 


\title{
DISCLAIMER
}

This report was prepared as an account of work sponsored by an agency of the United States Government. Neither the United States Government nor any agency thereof, nor Battelle Memorial Institute, nor any of their employees, makes any warranty, express or implied, or assumes any legal liability or responsibility for the accuracy, completeness, or usefulness of any information, apparatus, product, or process disclosed, or represents that its use would not infringe privately owned rights. Reference herein to any specific commercial product, process, or service by trade name, trademark, manufacturer, or otherwise does not necessarily constitute or imply its endorsement, recommendation, or favoring by the United States Government or any agency thereof, or Battelle Memorial Institute. The views and opinions of authors expressed herein do not necessarily state or reflect those of the United States Government or any agency thereof.

\author{
PACIFIC NORTHWEST NATIONAL LABORATORY \\ operated by \\ BATTELLE \\ for the
}

UNITED STATES DEPARTMENT OF ENERGY

under Contract DE-AC05-76RL01830

Printed in the United States of America

Available to DOE and DOE contractors from the

Office of Scientific and Technical Information,

P.O. Box 62, Oak Ridge, TN 37831-0062;

ph: (865) 576-8401

fax: (865) 576-5728

email: reports@adonis.osti.gov

Available to the public from the National Technical Information Service,

U.S. Department of Commerce, 5285 Port Royal Rd., Springfield, VA 22161

ph: (800) 553-6847

fax: (703) 605-6900

email: orders@ntis.fedworld.gov

online ordering: http://www.ntis.gov/ordering.htm 


\title{
Acoustic Telemetry Studies of Juvenile Chinook Salmon Survival at the Lower Columbia Projects in 2006
}

\author{
G. R. Ploskey \\ M. A. Weiland \\ J. S. Hughes \\ S. R. Zimmerman \\ R. E. Durham \\ E. S. Fischer ${ }^{(a)}$ \\ $\mathrm{J} \mathrm{Kim}^{(\mathrm{a})}$ \\ R. L. Townsend ${ }^{(b)}$ \\ J. R. Skalski ${ }^{(b)}$ \\ R. L. McComas(c)
}

FINAL REPORT

December 2007

Prepared for the U.S. Army Corps of Engineers

Portland District, Portland, Oregon

Under a Related Services Agreement

with the U.S. Department of Energy

Contract DE-AC05-76RL01830

Pacific Northwest National Laboratory

Richland, Washington 99352
(a) Pacific States Marine Fisheries Commission
(b) University of Washington
(c) National Marine Fisheries Service 



\section{Summary}

In 2006, the Portland District of the U.S. Army Corps of Engineers (USACE) contracted with the Pacific Northwest National Laboratory (PNNL) to conduct three studies using acoustic telemetry to estimate detection probabilities and survival of juvenile Chinook salmon at three hydropower projects on the lower Columbia River. The primary goals were to estimate detection and survival probabilities based on sampling with Juvenile Salmon Acoustic Telemetry System (JSATS) equipment, assess the feasibility of using JSATS for survival studies, and estimate sample sizes needed to obtain a desired level of precision in future studies.

\section{Tagging}

We conducted acoustic-telemetry survival studies on yearling and sub-yearling Chinook salmon at John Day Dam (JDA), The Dalles Dam (TDA), and Bonneville Dam (BON). We surgically implanted 2,501 yearling Chinook salmon in spring and 2,502 sub-yearling Chinook salmon in summer with passive integrated transponder (PIT) and JSATS acoustic tags. Fish were collected and tagged at the John Day Dam Smolt Monitoring Facility (SMF), and unintentional tagging mortality averaged $0.6 \%$ in spring and $0.7 \%$ in summer.

Tagging seasons encompassed the peaks of the spring and summer runs of juvenile Chinook salmon. The spring tagging season was from May 13 to June 6, 2006, and targeted the yearling Chinook run, which peaked between May 20 and June 1, 2006. A 95-mm minimum length limitation on tagging did not restrict the lengths of fish that could be tagged in the spring, and the length frequencies of tagged and untagged yearling Chinook salmon in the juvenile bypass system (JBS) samples were very similar. The summer tagging season was from June 11 to July 13, 2006, and targeted the subyearling Chinook run, which peaked around July 1 . The 95 -mm minimum tagging length effectively eliminated about $23 \%$ of the run-of-river sub-yearlings from the sample because they were too small to tag without increasing tagging mortality. Tagging must include 80 to $100 \mathrm{~mm}$ subyearlings to be fully representative of the runof-river population at JDA in summer.

All fish tagged in this study and released at or below JDA were implanted with JSATS tags that transmitted a coded signal transmitting once every 5 seconds ( $5 \mathrm{~s}$ tags) that were expected to last about 30 days, and fish that were released into the Snake River by other studies were implanted with tags that transmitted once every $10 \mathrm{~s}$. We conducted a tag-life study using $10010 \mathrm{~s}$ tags and $1005 \mathrm{~s}$ tags randomly sampled from lots allocated to survival studies. The tag-life study verified that most tags lasted about as long as expected. All 10-s tags sampled from lots of tags implanted in Snake River fish lasted at least 57 days relative to an expected 55 days, and all the 5-s tags exceeded the expected 30-day life by about 5 days. No tag-life correction was needed or used for the 2006 survival studies in spring or summer because over $99 \%$ of tagged fish exited the study area before tags expired. Tag life and survivorship curves are presented in Appendix A. 


\section{Fish Releases and Detection Histories}

In spring, we made eight releases each at three JDA locations: JDA Turbine Intake 9C (totaling 497 yearlings), the Front Roll downstream of Turbine 9C (500 yearlings), and the JDA Tailrace (481 yearlings). The Front Roll and Tailrace releases at JDA were designed to serve as controls for turbinereleased fish in a paired-release survival model. We also made eight releases totaling 978 yearlings into the TDA Tailrace. In addition to our releases, a separate tag-effects study made two releases totaling 996 yearling Chinook salmon into the Lower Granite Dam (LGR) Tailrace on the Snake River, and an estuary survival study made four releases totaling 972 yearlings into the BON Tailrace.

In summer, we made five releases totaling 299 subyearlings in the JDA Tailrace and 10 releases totaling 2,179 subyearlings into the TDA Tailrace. A Lower Monumental Dam survival study made 10 releases totaling 1,949 subyearlings into the tailrace of Little Goose Dam (LGS) on the Snake River, and the Estuary Survival Study made 10 releases totaling 2,002 subyearlings into the BON Tailrace.

We deployed three arrays of JSATS autonomous hydrophones in the tailwater of each dam and detections of tagged fish were used to develop spatial and temporal detection histories for every released tag to populate various survival models. An array is a group of hydrophones deployed across the entire width of the river to detect live, acoustically tagged fish passing downstream. Rules for classifying a series of properly decoded signals as a tag detection were as follows:

1. Tag codes were detected downstream of the release site.

2. Tag codes were detected after the release date and time.

3. Tag-decode intervals were 8 to 32 seconds for 10 -s tags and 3 to 22 seconds for 5 -s tags.

4. There were four tag decodes in $120 \mathrm{~s}$ for 10-s tags and four decodes in $60 \mathrm{~s}$ for 5 -s tags.

Downstream survival arrays detected no intentionally tagged and released dead fish out of 23 released below JDA, 45 below TDA, and 30 below BON.

\section{Detection and Survival Results}

Results obtained in spring and summer 2006 accomplished the study goals listed above. Based on detection histories, we estimated detection and survival probabilities using a variety of single and pairedrelease models, and results for preferred array combinations are presented in Table S.1. The JDA Tailrace releases were used to populate single-release survival models for downstream reaches and for post-hoc pairing with TDA Tailrace releases to populate a paired-release model for estimating TDA Project survival. Similarly, our TDA Tailrace releases and BON Tailrace releases by the Estuary Survival Study were used to populate single-release models for downstream reaches and also were paired to create a post-hoc, paired-release model for evaluating BON Project survival. Multi-node detections contributed to high detection probabilities for Columbia River releases in the JDA and TDA tailwaters, in contrast to lower detection probabilities observed at arrays in the BON Tailwater (Table S.2). Part of the low detectability in the BON Tailwater resulted from equipment problems but some of it was undoubtedly related to relatively shallow bathymetry, islands, and extensive sand bars, which limit the range of sound propagation. 
Table S.1. Detection and Survival Probability by Season, Release Location, and Reach, with Information on Numbers of Fish, Effect of Interest, Number of Dams Passed, and Survival Models. Numbers in parentheses after probabilities are lower and upper 95\% confidence intervals (Cls).

\begin{tabular}{|c|c|c|c|c|c|c|c|c|}
\hline Season & \begin{tabular}{|c|} 
Release \\
Location
\end{tabular} & $\begin{array}{l}\text { Number } \\
\text { of Fish }\end{array}$ & Reach & Effect & $\begin{array}{c}\text { Dams } \\
\text { Passed }\end{array}$ & Model & $\begin{array}{l}\text { Detection } \\
\text { Probability }\end{array}$ & $\begin{array}{c}\text { Survival } \\
\text { Probability }\end{array}$ \\
\hline Spring & LGR TR & 996 & To $1 \mathrm{~J}$ & & 5 & Single & $89.6 \%(86.7,92.5)$ & $48.7 \%(45.6,51.9)$ \\
\hline Spring & LGR TR & 996 & $1 \mathrm{~J}$ to $1 \mathrm{~T}$ & & 1 TDA & Single & $77.0 \%(72.9,81.1)$ & $87.7 \%(84.5,91.0)$ \\
\hline Spring & JDA FR & 497 & To $1 \mathrm{~J}$ & & & Single & $98.9 \%(98.0,99.9)$ & 98.3\% (97.1, 99.5) \\
\hline Spring & JDA FR & 497 & $1 \mathrm{~J}$ to $1 \mathrm{~T}$ & & 1 TDA & Single & $91.7 \%(89.2,94.3)$ & $92.9 \%(90.6,95.3)$ \\
\hline Spring & JDA IN & 500 & To $1 \mathrm{~J}$ & & 1 JDA & Single & $96.1 \%(94.2,98.0)$ & $87.7 \%(84.8,90.6)$ \\
\hline Spring & JDA IN & 500 & $1 \mathrm{~J}$ to $1 \mathrm{~T}$ & & 1 TDA & Single & $92.0 \%(89.3,94.7)$ & 93.4\% $(90.9,95.8)$ \\
\hline Spring & JDA TR & 481 & To $1 \mathrm{~J}$ & & & Single & $97.8 \%(96.4,99.2)$ & 97.5\% (96.0, 98.9) \\
\hline Spring & JDA TR & 481 & $1 \mathrm{~J}$ to $1 \mathrm{~T}$ & & 1 TDA & Single & 93.4\% $(91.0,95.7)$ & $94.3 \%(92.1,96.4)$ \\
\hline Spring & JDA TR & 481 & To $1 \mathrm{~T}$ & & 1 TDA & Single & 93.4\% $(91.0,95.7)$ & $91.8 \%(89.4,94.3)$ \\
\hline Spring & TDA Virtual & 1,079 & $\begin{array}{l}\text { Forebay } \\
\text { to } 1 \mathrm{~T}\end{array}$ & \begin{tabular}{|l} 
TDA Dam \& \\
Tailwater
\end{tabular} & 1 TDA & Single & $93.0 \%(91.4,94.6)$ & $94.7 \%(93.4,96.1)$ \\
\hline Spring & TDA TR & 978 & To 1T & & & Single & $97.5 \%(96.5,98.5)$ & 98.9\% $(98.3,99.6)$ \\
\hline Spring & TDA TR & 978 & $1 \mathrm{~T}$ to $2 \mathrm{~T}$ & & & Single & $99.5 \%(98.9,100.1)$ & $99.2 \%(98.5,99.9)$ \\
\hline Spring & TDA TR & 978 & To 1B & & $1 \mathrm{BON}$ & Single & $63.3 \%(59.8,66.9)$ & $90.0 \%(87.2,92.9)$ \\
\hline Spring & BON Virtual & 957 & \begin{tabular}{|l|}
$\begin{array}{l}\text { Forebay } \\
\text { to 1B }\end{array}$ \\
\end{tabular} & \begin{tabular}{|l|} 
BON Dam \& \\
Tailwater \\
\end{tabular} & $1 \mathrm{BON}$ & Single & $63.6 \%(60.1,67.2)$ & $91.9 \%(89.1,94.6)$ \\
\hline Spring & BON TR & 972 & To 1B & & & Single & $76.0 \%(72.8,79.2)$ & $85.1 \%(82.4,87.7)$ \\
\hline Spring & BON B2CC* & 78 & To 1B & & $1 \mathrm{BON}$ & Single & $61.1 \%(48.6,73.5)$ & $94.6 \%(84.6,104.6)$ \\
\hline Spring & BON B2JBS* & 42 & To 1B & & $1 \mathrm{BON}$ & Single & $53.3 \%(35.5,71.2)$ & $89.3 \%(73.0,105.6)$ \\
\hline Spring & BON Spill* & 134 & To 1B & & $1 \mathrm{BON}$ & Single & $63.5 \%(54.3,72.8)$ & $94.1 \%(87.1,101.1)$ \\
\hline Spring & \begin{tabular}{|l|} 
JDA FR \& \\
JDA TR
\end{tabular} & $\begin{array}{l}497 \\
481\end{array}$ & To $1 \mathrm{~J}$ & FR to TR & & Paired & $98.4 \%(97.5,99.2)$ & $101.0 \%(99.0,102.9)$ \\
\hline \multirow{2}{*}{ Spring } & \multirow{2}{*}{$\begin{array}{l}\text { JDA IN \& } \\
\text { JDA FR }\end{array}$} & \multirow{2}{*}{$\begin{array}{l}500 \\
497\end{array}$} & \multirow{2}{*}{ To $1 \mathrm{~J}$} & \multirow{2}{*}{ Intake to FR } & & \multirow{2}{*}{ Paired } & $96.1 \%(94.2,98.0)$ & \multirow{2}{*}{$89.2 \%(86.1,92.4)$} \\
\hline & & & & & & & 98.9\% $(98.0,99.9)$ & \\
\hline Spring & \begin{tabular}{|l|} 
JDA IN \\
\& JDA TR \\
\end{tabular} & $\begin{array}{l}500 \\
481 \\
\end{array}$ & To 1J & Intake to TR & & Paired & $97.0 \%(95.8,98.1)$ & $89.9 \%(86.6,93.2)$ \\
\hline \multirow{2}{*}{ Spring } & \multirow{2}{*}{$\begin{array}{l}\text { JDA TR \& } \\
\text { TDA TR }\end{array}$} & 481 & \multirow{2}{*}{ To $1 \mathrm{~T}$} & \multirow{2}{*}{ TDA Project } & \multirow{2}{*}{1 TDA } & \multirow{2}{*}{ Paired } & \begin{tabular}{|l|}
$93.4 \%(91.0,95.7)$ \\
\end{tabular} & \multirow{2}{*}{$92.9 \%(90.2,95.4)$} \\
\hline & & 978 & & & & & $97.5 \%(96.5,98.5)$ & \\
\hline \multirow{2}{*}{ Spring } & \multirow{2}{*}{$\begin{array}{l}\text { TDA TR \& } \\
\text { BON TR } \\
\end{array}$} & 978 & \multirow{2}{*}{ To 1B } & \multirow{2}{*}{ BON Project } & \multirow{2}{*}{$1 \mathrm{BON}$} & \multirow{2}{*}{ Paired } & $63.3 \%(59.8,66.9)$ & \multirow{2}{*}{$105.8 \%(96.6,115.1)$} \\
\hline & & 972 & & & & & $76.0 \%(72.8,79.2)$ & \\
\hline \multirow{2}{*}{ Spring } & \multirow{2}{*}{$\begin{array}{l}\text { BON B2CC } \\
\& \text { BON TR }\end{array}$} & 78 & To 1B & BON B2CC & $1 \mathrm{BON}$ & Paired & $61.1 \%(48.6,73.5)$ & $111.2 \%(98.9 .123 .5)$ \\
\hline & & 972 & & to BON TR & & & $76.0 \%(72.8,79.2)$ & \\
\hline Snring & BON B2 JBS & 42 & To $1 \mathrm{~B}$ & BON B2 JBS & variable & Paired & $53.3 \%(35.5,71.2)$ & $1050 \%(85.5,124.4)$ \\
\hline Spring & \& BON TR & 972 & $10 \mathrm{LB}$ & to BON TR & |variable & Paired & $76.0 \%(72.8,79.2)$ & $105.0 \%(85.5,124.4)$ \\
\hline Spring & BON Spill \& & 134 & ITo 1B & BON Spill to & variable & Paired & $63.5 \%(54.3,72.8)$ & $110.6 \%(1017.119 .6)$ \\
\hline Spring & BON TR & 972 & 10 1В & BON TR & variadie & Paired & $76.0 \%(72.8,79.2)$ & $110.0 \%(101.1,119.0)$ \\
\hline Summer & LGS TR & 1,949 & To $1 \mathrm{~J}$ & & 4 & Single & $94.8 \%(92.3,97.3)$ & $19.6 \%(8.6,30.6)$ \\
\hline Summer & LGS TR & 1,949 & $1 \mathrm{~J}$ to $1 \mathrm{~T}$ & & 1 TDA & Single & $99.4 \%(97.2,101.6)$ & $60.3 \%(40.0,80.7)$ \\
\hline Summer & JDA TR & 299 & To $1 \mathrm{~J}$ & & & Single & $82.8 \%(78.5,87.1)$ & $99.4 \%(98.5,100.4)$ \\
\hline Summer & JDA TR & 299 & $1 \mathrm{~J}$ to $1 \mathrm{~T}$ & & 1 TDA & Single & $98.8 \%(97.4,100.2)$ & $99.6 \%(98.8,100.4)$ \\
\hline Summer & TDA Virtual & 279 & \begin{tabular}{|l|} 
Forebay \\
to $1 \mathrm{~T}$
\end{tabular} & \begin{tabular}{|l|} 
TDA Dam \& \\
Tailwater \\
\end{tabular} & 1 TDA & Single & $98.8 \%(97.4,100.2)$ & $86.1 \%(82.0,90.2)$ \\
\hline Summer & TDA TR & 2,179 & To 1T & & & Single & $99.2 \%(98.7,99.6)$ & $97.0 \%(96.2,97.7)$ \\
\hline Summer & TDA TR & 2,179 & $1 \mathrm{~T}$ to $2 \mathrm{~T}$ & & & Single & $100 \%(100,100)$ & $95.8 \%(95.0,96.7)$ \\
\hline Summer & BON Virtual & 2,022 & \begin{tabular}{|l|}
$\begin{array}{l}\text { Forebay } \\
\text { to 1B }\end{array}$ \\
\end{tabular} & \begin{tabular}{|l|} 
BON Dam \& \\
Tailwater \\
\end{tabular} & $1 \mathrm{BON}$ & Single & $81.3 \%(79.2,83.5)$ & 86.9\% (85.0, 88.8) \\
\hline Summer & BON TR & 1,957 & To 1B & & & Single & $82.4 \%(80.5,84.3)$ & $94.7 \%(93.3,96.1)$ \\
\hline Summer & BON B2CC* & 91 & To 1B & & $1 \mathrm{BON}$ & Single & $87.7 \%(79.8,95.7)$ & $95.3 \%(89.1,101.4)$ \\
\hline Summer & \begin{tabular}{|l} 
BON B2 \\
JBS*
\end{tabular} & 189 & To 1B & & $1 \mathrm{BON}$ & Single & $82.3 \%(75.3,89.4)$ & $90.7 \%(84.6,96.8)$ \\
\hline
\end{tabular}




\begin{tabular}{|c|c|c|c|c|c|c|c|c|}
\hline Season & $\begin{array}{c}\text { Release } \\
\text { Location }\end{array}$ & $\begin{array}{l}\text { Number } \\
\text { of Fish }\end{array}$ & Reach & Effect & $\begin{array}{c}\text { Dams } \\
\text { Passed }\end{array}$ & Model & $\begin{array}{l}\text { Detection } \\
\text { Probability }\end{array}$ & $\begin{array}{c}\text { Survival } \\
\text { Probability }\end{array}$ \\
\hline Summer & BON Spill* & 706 & To 1B & & $1 \mathrm{BON}$ & Single & $82.3 \%(78.7,85.9)$ & $85.8 \%(82.5,89.1)$ \\
\hline \multirow{2}{*}{ Summer } & \multirow{2}{*}{\begin{tabular}{|l|} 
BON B2CC* \\
\& BON TR
\end{tabular}} & \multirow{2}{*}{$\begin{array}{r}991 \\
1,957\end{array}$} & \multirow{2}{*}{ To 1B } & \multirow{2}{*}{$\begin{array}{l}\text { B2CC to } \\
\text { BON TR }\end{array}$} & \multirow{2}{*}{ variable } & \multirow{2}{*}{ Paired } & $87.7 \%(79.8,95.7)$ & \multirow{2}{*}{$100.6 \%(94.0,107.2)$} \\
\hline & & & & & & & $82.4 \%(80.5,84.3)$ & \\
\hline \multirow[b]{2}{*}{ Summer } & \multirow{2}{*}{$\begin{array}{l}\text { BON B2 } \\
\text { JBS* \& BON } \\
\text { TR }\end{array}$} & \multirow{2}{*}{$\begin{array}{r}189 \\
1,957\end{array}$} & \multirow[b]{2}{*}{ To 1B } & \multirow{2}{*}{\begin{tabular}{|l} 
B2 JBS to \\
BON TR
\end{tabular}} & \multirow[b]{2}{*}{ variable } & \multirow[b]{2}{*}{ Paired } & $82.3 \%(75.3,89.4)$ & \multirow[b]{2}{*}{$95.9 \%(89.3,102.4)$} \\
\hline & & & & & & & $82.4 \%(80.5,84.3)$ & \\
\hline \multirow{2}{*}{ Summer } & \multirow{2}{*}{$\begin{array}{l}\text { BON Spill* } \\
\text { \& BON TR }\end{array}$} & \multirow{2}{*}{$\begin{array}{r}706 \\
1,957\end{array}$} & \multirow{2}{*}{ To 1B } & \multirow{2}{*}{$\begin{array}{l}\text { Spill to BON } \\
\text { TR }\end{array}$} & \multirow{2}{*}{ variable } & \multirow{2}{*}{ Paired } & 93.4\% (91.0, 95.7) & \multirow{2}{*}{$90.6 \%(86.9,94.4)$} \\
\hline & & & & & & & $82.4 \%(80.5,84.3)$ & \\
\hline \multirow{2}{*}{ Summer } & \multirow{2}{*}{$\begin{array}{l}\text { JDA TR \& } \\
\text { TDA TR }\end{array}$} & \multirow{2}{*}{$\begin{array}{r}299 \\
2,179\end{array}$} & \multirow{2}{*}{ To 1T } & \multirow{2}{*}{ TDA Project } & \multirow{2}{*}{1 TDA } & \multirow{2}{*}{ Paired } & 93.4\% (91.0, 95.7) & \multirow{2}{*}{ 84.9\% (76.1, 93.8) } \\
\hline & & & & & & & $97.5 \%(96.5,98.5)$ & \\
\hline \multirow{2}{*}{ Summer } & \multirow{2}{*}{$\begin{array}{l}\text { TDA TR \& } \\
\text { BON TR }\end{array}$} & 2,179 & \multirow{2}{*}{ To 1B } & \multirow{2}{*}{ BON Project } & \multirow{2}{*}{$1 \mathrm{BON}$} & \multirow{2}{*}{ Paired } & $63.3 \%(59.8,66.9)$ & \multirow{2}{*}{$85.2 \%(80.4,90.1)$} \\
\hline & & 1,957 & & & & & \begin{tabular}{|l|}
$76.0 \%(72.8,79.2)$ \\
\end{tabular} & \\
\hline
\end{tabular}

Table S.2. Means and Standard Errors of Mean Detection Probabilities for Columbia River Releases of Chinook Salmon in Spring and Summer 2006. These estimates were calculated from pooled detection estimates.

\begin{tabular}{|c|r|r|r|r|r||}
\hline \hline Statistic & To 1J & To 1T & To 2T & To 1B & To 2B \\
\hline \multicolumn{7}{|c|}{ Spring } \\
\hline Mean & 96.2 & 91.3 & 99.7 & 67.6 & 72.5 \\
\hline SE of Mean & 3.1 & 5.3 & 0.3 & 5.9 & 5.9 \\
\hline Mean & 97.2 & 99.0 & 100.0 & 80.2 & N/A \\
\hline SE of Mean & 2.4 & 0.2 & 0.0 & 11.4 & N/A \\
\hline \hline
\end{tabular}

A Z-test indicated that the single-release survival estimate for Intake-released yearlings was significantly lower than that for yearlings released in the Front Roll $(\mathrm{Z}=-6.385 ; \mathrm{P}<0.0001 ; \mathrm{n}=8)$, and it was significantly lower than that for yearlings released in the Tailrace $(Z=-5.843 ; P<0.0001 ; n=8)$. However, single release-survival estimates from the Front Roll and Tailrace releases to the primary array did not differ significantly $(\mathrm{Z}=1.131<1.645 ; \mathrm{P}=0.129 ; \mathrm{n}=8)$. A paired-release survival estimate for yearlings passing through Intake $9 \mathrm{C}$ to the Tailrace was significantly lower than a paired-release estimate for yearlings released in the Front Roll and then traveling to the Tailrace release site $(\mathrm{Z}=-4.945 ; \mathrm{P}<$ $0.0001 ; \mathrm{n}=8$.

We compared the probability of fish being detected on any one of three downstream JSATS survival arrays with reported probabilities from some previous radio telemetry studies. The 2006 JSATS arrays usually performed as well as or better than radio telemetry arrays in the JDA and TDA tailwaters, and underperformed radio arrays in the BON Tailwater, particularly in spring. Most of the probabilities of detection on at least one of all arrays in a tailwater exceeded $80 \%$ for each method, which was sufficient to provide confidence in survival estimates. The probability of detection on one of three arrays includes survival and detection probabilities because fish may die or pass all three arrays undetected but alive.

Our effort at modeling the required sample sizes for future studies relied on observed detection and survival probabilities to estimate precision as a function of sample size (Appendix G, H, I, and J). This approach assumes that equal effort will be expended to detect fish, e.g., similar numbers of autonomous nodes with similar ranges of detection. These tables should be useful for conducting power analyses for future studies that have a specific study design in mind. However, it does not and cannot account for the 
potential benefits of increasing detection probabilities by increasing the number of nodes or node performance. Based upon high detection probabilities for the JDA and TDA tailwater arrays, there is little room for improving detection by increasing the number of autonomous receivers at these projects.

However, deploying additional nodes below BON, where detection probabilities averaged $67.6 \%$ in spring and $80.2 \%$ in summer, has the potential to significantly increase detectability and to reduce the need for large numbers of tags for future studies employing paired-release models. Modeling for BON indicates that high precision can be obtained for single-release models with the existing sampling effort and a reasonable number of tags in either season. However, modeling precision for paired-release models indicated that buying a lot more tags will not improve precision significantly. The density of detection nodes below BON will have to be increased to achieve a one-half $95 \%$ CI of $2 \%$ on paired-release survival estimates with a reasonable number of tags. The tradeoff between buying tags and buying autonomous nodes can easily be calculated and compared to find an optimum balance between detectability and sample size. Our recommendation is to make certain that arrays are populated fully or even overpopulated with receivers to assure high detection probabilities before buying more tags to increase precision, because the latter usually will be much more costly than the former until a high detection probability is achieved.

The choice of array locations and spacing between arrays can provide savings for future studies seeking to evaluate survival at multiple projects. We deployed nine survival arrays (three per tailwater) to thoroughly assess detection and survival probabilities, but our results indicate that all survival estimates could have been obtained with just six arrays. Those arrays would include

1. One in the JDA Tailwater, serving as a primary survival array (1J) and as a TDA forebay array.

2. Two in the TDA Tailwater (2006 arrays $1 \mathrm{~T}$ and $3 \mathrm{~T}$ ), where $1 \mathrm{~T}$ would serve as a secondary for JDA releases or as a primary for TDA virtual and tailrace releases, and 3T would serve as a tertiary for JDA releases, a secondary for TDA virtual and tailrace releases, and as a forebay array for constructing BON virtual releases.

3. Three in the BON Tailwater.

We compared survival estimates calculated from detections on "as planned" arrays in each tailwater (Appendix K) with estimates based on detections on "preferred" arrays in Table S.1 and found no significant differences in any estimates. Therefore, we recommend that future studies maximize return on investment by using the six arrays described above when multiple projects are being studied. Our results

also indicate that, if a single study is planned, three survival arrays can be located in a single tailwater and can be relatively close together without detriment, as long as detections cannot be made simultaneously on two successive arrays. However, spreading out three arrays within a pool will provide greater inference about survival in the first two river reaches.

\section{Tests of Model Assumptions}

There were no significant trends in detection probabilities or survival through time in spring, so we were able to pool estimates for the season, but in summer there was a significant decline in survival through time. The value of pooled survival estimates for summer is questionable, given apparent decreases in survival or residualization. The decline in survival during summer has been observed before (e.g., Counihan et al. 2006a). 
Paired release models assume that treatment and control release groups pass through the common river reach at about the same time of day and under similar conditions. In spring, the paired release models for JDA releases were the only pairs designed and planned before the 2006 study began and, although homogeneity tests were significant because of Chi square test sensitivity to large sample sizes, we know that treatment and control fish mixed and experienced similar tailwater conditions relative to time of day. Survival processes also were stable throughout the spring season.

However, there were significant departures from mixing for pairings of JDA Tailrace and TDA Tailrace Releases and for pairings of TDA and BON tailrace releases, respectively, because these pairings were made post hoc without benefit of planning to synchronize timing. Research at the three projects was originally conceived and proposed as separate pilot studies, and post-hoc pairing was our way of trying to get the most from available data. Nevertheless, spring data from the next reach downstream of the reach from TDA to Array 1T (i.e., from 1T to $2 \mathrm{~T}$ ) suggest that survival processes were stable regardless of differences in the time of arrival. In addition, high river flow throughout spring 2006 resulted in a consistency of discharge among days and among hours that may not occur in an average or low-flow year, and this likely contributed to stability in survival processes. Similarly, survival estimates for TDA and BON tailrace releases from Array 1B to 2B did not differ from each other and had no seasonal trend, which again suggests that survival processes were stable for the two release groups in spring.

In summer, mixing violations for post-hoc pairings of JDA and TDA releases may not have been as detrimental as goodness-of-fit-tests indicated, although we acknowledge that mixing could be improved. The JDA and TDA Tailrace releases used to estimate project survival for TDA showed significant $(P<$ 0.001) departures from mixing in summer, primarily because releases after June 27 in the TDA Tailrace had no treatment counterparts. Violations raised concerns about interpreting pair-release project survival models for TDA, so we recomputed estimates using only data acquired during the period of concurrent releases, and the resulting survival estimate of $82.9 \%(95 \% \mathrm{CI}=78.6,87.2)$ did not differ significantly from the estimate based on all releases (85.2\%; 95\% CI =82.8, 87.7). Hourly time-of-arrival data indicated that the slowest and fastest fish from the JDA or TDA groups could arrive any hour of the day, but there was a 4-h difference in mean arrival time that may have affected survival conditions. A summer paired-release estimate of $\mathbf{8 3 . 7 \%}$ for BON Project survival for concurrent releases is considered reliable because subyearlings in the concurrent summer releases from TDA and BON tailraces traversed the BON Tailwater at about the same time of day, even though all release data indicated significant differences in arrival distributions. However, the point estimate is not particularly meaningful given the significant decrease in survival during summer.

Because of mixing violations observed for some of the post-hoc paired releases, we used time-oftravel estimates as a function of river discharge each season to derive equations for predicting appropriate lag times between upstream and downstream releases as a function of river discharge. In the future, researchers can use derived equations as a starting place to predict appropriate lag times from forecasts of river discharge. Data on travel times from years with a lower range of discharge also should be consulted to increase the appropriateness of lag estimates for normal to low-water years. River discharge was higher than average throughout spring and the first half of summer.

Survival models assume that upstream and downstream detections do not affect estimates of detection or survival, and Burnham et al. (1987) Test 2 and Test 3 are used to evaluate that assumption. There is 
some question about whether these tests are appropriate for active tag studies that have high detection probabilities and no physical mechanism like recapture or re-handling to cause the effect.

In spring, two out of the three JDA releases had significant $(\mathrm{P}<0.10$ Burnham et al. 1987) Test 2 results, but none of the tests was significant for the JDA, TDA, and BON Tailrace releases. This was not surprising because there was no physical mechanism associated with detections to affect downstream detection performance. For the Intake 9C release, pooled data had a highly significant Test $2(\mathrm{P}=$ 0.0001), but the Chi square test statistic was only significant in one of six tests (16.7\%) on releases that could be calculated (83.3\% were not significant). The other release with a significant Test 2 for pooled releases was the JDA Tailrace. Only three of eight release could be calculated, and of those, only one of three was significant. None of the Burnham et al. (1987) Test 3 results were significant for any of the release groups tested.

In summer, none of the calculable Burnham et al. (1987) Test 2 results were significant, and only one Test 3 was significant, indicating that the capture history to Array 2T had an effect on detection at Array 1B. Very high detection probability upstream arrays (pooled estimate $=99.1 \%$ to $100 \%$ ) relative to a lower probability of $81.5 \%$ for Array $1 \mathrm{~B}$ may have produced the false-positive result. When we ran the Test 3 on 10 individual releases, only one was significant out of the four that were calculable.

\section{Survival Trends by River Reach and Among Seasons}

We made plots of survival from the point of release to each array but the last in the study area, and they showed that most losses occurred in reaches with dams rather than in reaches between dams each season, and losses were higher in summer than in spring. The reach survival between arrays from JDA to TDA and TDA to BON showed high levels of survival. Mortality for non-dam reaches usually was $<5 \%$. Losses of JDA-released subyearlings in the reach including TDA during the summer were three times greater than those observed in spring for yearlings. The loss of subyearlings in the reach including BON (Array $3 t$ to $1 \mathrm{~B}$ ) was nearly double that observed for yearlings in spring.

\section{Temporal Trends in Summer}

A significant decline in survival estimates for many releases during summer suggests that many fall subyearling Chinook salmon stopped migrating or died. Examples are shown in Figures S.1 through S.4. The possibility of residualization in upstream areas is supported by results of the Lower Monumental Fall Chinook Salmon Behavioral Study (Cook et al. 2007). Because of the reduction in apparent survival, data from replicate releases should not be pooled but analyzed separately to properly characterize the betweenrelease variability.

The fact that losses for non-dam reaches are much lower than for reaches with dams suggests that residualization is not a dominant factor causing losses in the lower river. Smaller size and lower energy reserves in subyearlings likely makes them more susceptible to stress and death. For fish of the lengths that we tagged in summer (>95 mm), the tag-effects study showed minimal tagging mortality, although it was slightly higher than that observed for yearlings (Rich Brown, PNNL, Personal Communication). 

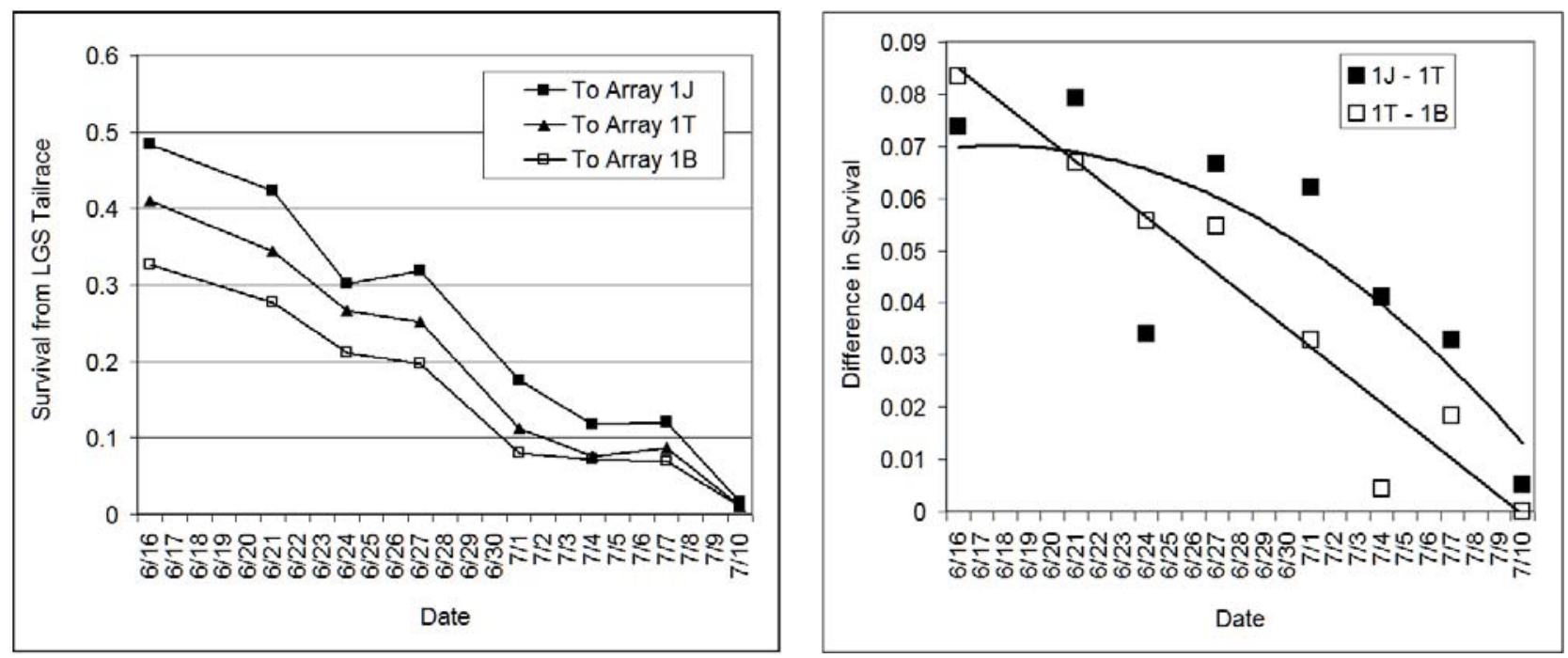

Figure S.1. Apparent Survival of Subyearling Chinook Salmon Released from Lower Goose Tailrace in Summer Down to Primary Arrays in the JDA, TDA, and BON tailwaters (Left) and Differences in Survival Between Successive Primary Arrays (Right).

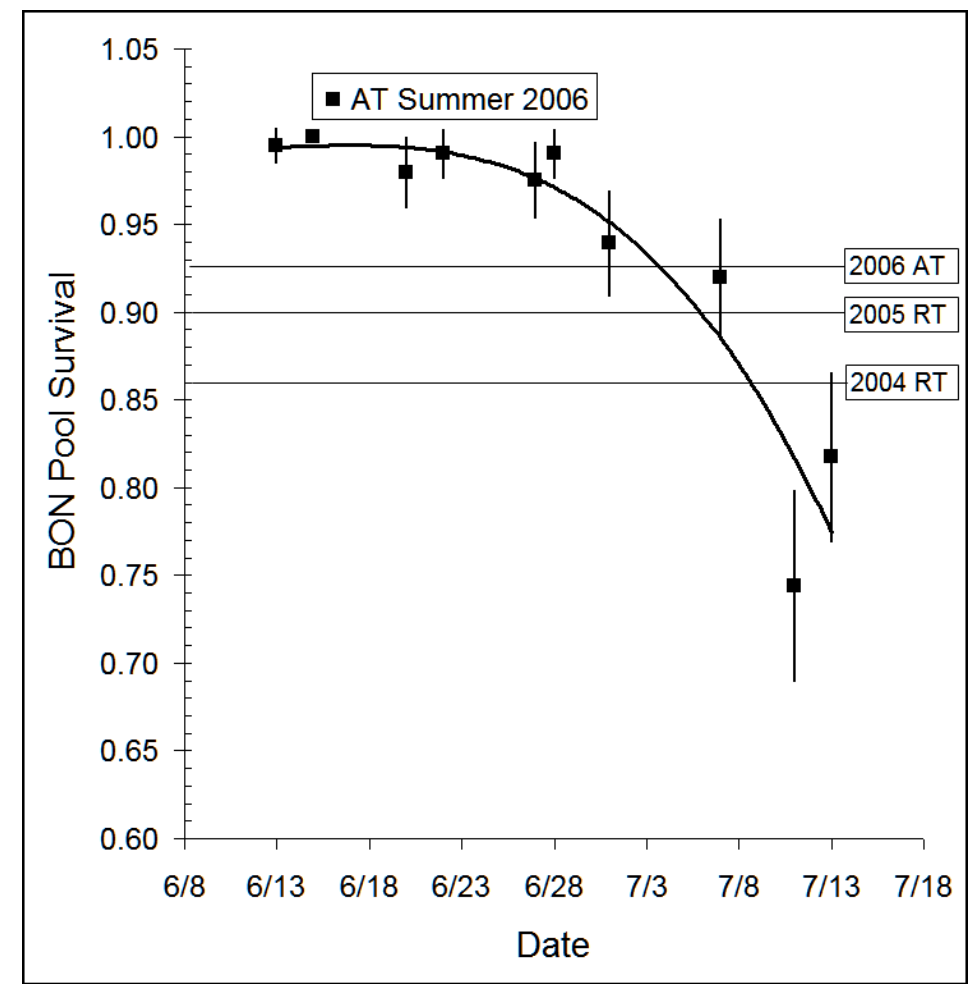

Figure S.2. Apparent Survival of Subyearling Chinook Salmon Released from the TDA Tailrace in Summer Down to Array 3T just above BON. Vertical bars are $95 \%$ Cls. Horizontal lines show means for this study (2006 AT) and for the 2004 and 2005 radio telemetry (RT) studies (after Counihan et al. 2006a and b). 


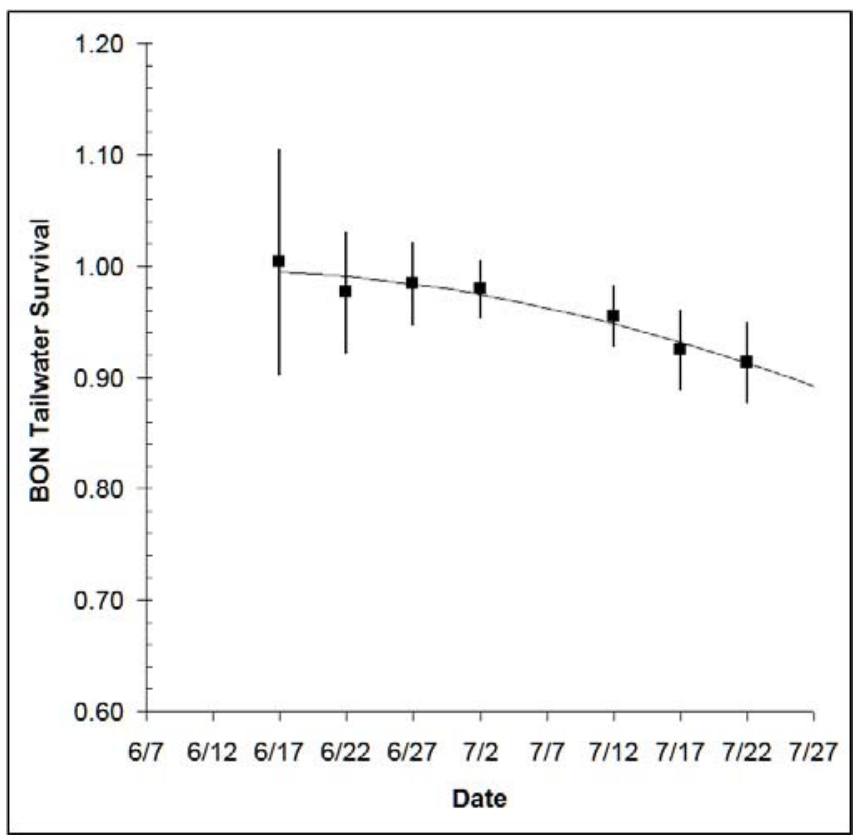

Figure S.3. Apparent Survival of Subyearling Chinook Salmon Released from the BON Tailrace in Summer Down to Array 1B. Vertical bars are 95\% Cls.

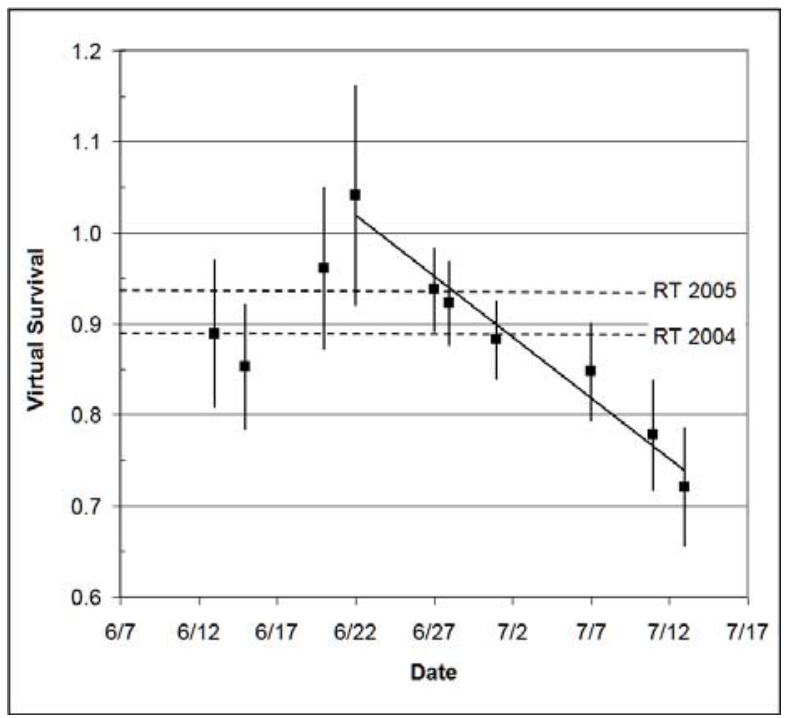

Figure S.4. Apparent Survival of Subyearling Chinook Salmon Regrouped at Array 3T above BON. Vertical bars are 95\% Cls. Horizontal lines show means for the 2004 and 2005 radio telemetry (RT) studies (after Counihan et al. $2006 \mathrm{f}$ and g).

\section{Bonneville Route-Specific Survival Based on Pooled Releases}

In spring, fish were regrouped as they passed through the Bonneville spillway, B2 JBS, and B2CC regardless of release location to obtain enough detections for route-specific survival estimates and even then sample sizes were low. We could not distinguish between survival rates of yearlings passing the B2CC, B2 JBS, and spillway because of the low precision of the estimates due to small sample sizes. The 
estimate for the B2 JBS of $89.3 \%$ did not differ from estimates for the B2CC of $94.6 \%$ or from the spillway estimate of $94.1 \%$, according to overlapping 95\% CIs. Single-release survival estimates for yearling Chinook salmon passing the BON spillway during the day (96\%) was 9\% higher than that of fish passing at night (88\%), but completely overlapping 95\% confidence intervals suggest that this difference was not significant. Daytime was defined as from 0600 through 2100 hours each season, and the remaining hours of the day were assigned as nighttime hours. Spill was consistently high (to gas cap) 24 h per day, so diel shifts in spill would not have been a major driving factor in spring 2006.

In summer, there were few surprises in the single-release estimates of survival for the B2CC, B2 JBS, and spillway. Survival at the spillway decreased almost $15 \%$ in summer relative to a $5 \%$ drop in spring, but the summer estimates for the B2CC and B2 JBS did not differ from spring estimates. Based upon non-overlap of $95 \%$ confidence intervals, the B2CC estimate of $95.2 \%$ was significantly different from a 85.8\% estimate for the spillway, but the B2CC estimate did not differ from the B2-JBS estimate of $90.7 \%$, and the B2 JBS estimate did not differ from that of the spillway. Poor precision associated with the small number of detected fish (91 at the B2CC, 189 at the B2 JBS, and 706 at the spillway) made it difficult to detect differences of less than about $10 \%$. Paired release estimates of survival for each of the three routes also had overlapping 95\% confidence intervals.

\section{Survival by Spill Condition at Bonneville in Summer}

Our comparison of subyearling survival during three different spill conditions, which occurred in three successive two-week periods over the course of the summer, was confounded by an independent decline in survival as summer progressed and river discharge decreased. The earliest spill condition from June 14 through June 25 happened to be 24-h spill to the gas cap ranging from 96,000 to 149,000 cfs, and it had the highest single-release survival estimate $(96.0 \%$; $95 \% \mathrm{CI}=88.7,103.4)$. The paired release estimate for the 24-h gas cap spill condition was $97.0 \%(95 \% \mathrm{CI}=86.3,107.6)$. The next condition was 24-h spill ranging from 63,000 to 83,000 cfs, which occurred from June 26 through about July 5, and it was associated with a lower, although not significantly lower, single-release survival estimate (87.8\%; $95 \% \mathrm{CI}=82.6,93.0)$ than the high-spill condition. A paired release estimate for the 24 -h $<80,000 \mathrm{cfs}$ spill condition was $89.4 \%(95 \% \mathrm{CI}=83.4,95.4)$. The third condition was a Bi-Op spill of 75,000 cfs during the day and spill to the gas cap at night. It lasted through the end of the summer releases from July 6 through August and not surprisingly was associated with a significantly lower single-release survival estimate of 78.3\% (95\% CI =73.1, 83.5), which probably would have occurred regardless of spill treatment. A paired-release estimate for the Bi-Op spill condition was 83.6\% (95\% CI = 77.3, 89.9). Precision was higher for the single-release estimate than it was for the paired-release estimate.

There are several comparisons of results that reinforce our conclusion that survival trends for BON spillway-passed subyearlings were not related to spill condition. First, survival estimates for the 24-h gas-cap spill condition and the 24-h low-spill condition did not differ significantly, probably because both occurred before a summer decline in survival was obvious. Second, survival estimates associated with 75,000 cfs spill during the day and gas-cap spill at night did not differ significantly and were low (75.8$80.02 \%$ ) because they occurred in mid to late summer when survival was low. In short, subyearlings that migrate in early summer had better survival than those migrating in later summer, regardless of spill condition at BON. 
If there is a desire to test different spill conditions in summer, the confounding effect of migration timing must be considered and eliminated from the experimental design. We recommend confining tests of spill conditions to early summer periods or late summer periods to avoid a confounding effect.

\section{Travel Time and Rate}

Travel times and rates were primarily a function of river discharge, particularly when discharge was above 250,000 cfs (Figure S.5), as it was in spring and early summer. Relations between travel time and discharge were much weaker when river discharge was $<250,000 \mathrm{cfs}$, a level that first appeared after June 26 and continued throughout summer 2006. This period coincided with declining survival estimates associated with increased mortality or residualization of subyearlings. Travel times were slower in summer than they were in spring, particularly at downstream locations (Figure S.6). On average, subyearlings released at JDA took 10 hours longer than yearlings to make it from the first array below JDA to the last array below BON. For TDA Tailrace releases, subyearlings took an average of 5 hours longer than yearlings to reach the last array below BON. Longer travel times have the potential to increase exposure to predation.

Travel times were useful for identifying delays at dams when specific routes could be identified. At JDA, egress times were significantly and inversely correlated with river discharge. Egress time was about an hour longer for fish released at minimum discharge (311,000 cfs) than it was for fish released at maximum discharge (387,000 cfs). Egress times did not differ between turbine and front-roll releases. The time it took fish to traverse the BON forebay until they were detected passing the dam was much longer (4.5-21.6 times longer) for fish using the B2 JBS than for fish using other routes, probably because of holding delays in gatewell slots. Delays are not desirable in late summer when survival estimates appear to decline significantly over time.

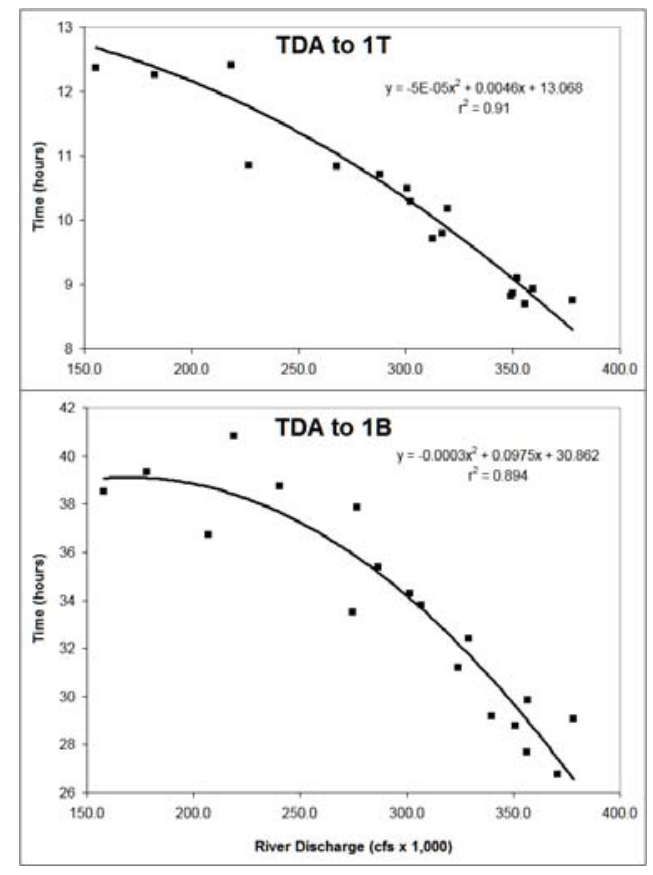

Figure S.5. Travel Time as a Function of River Discharge for the River Reach from TDA to Array 1T near Hood River and from TDA to Array 1B near Rooster Rock State Park below BON 


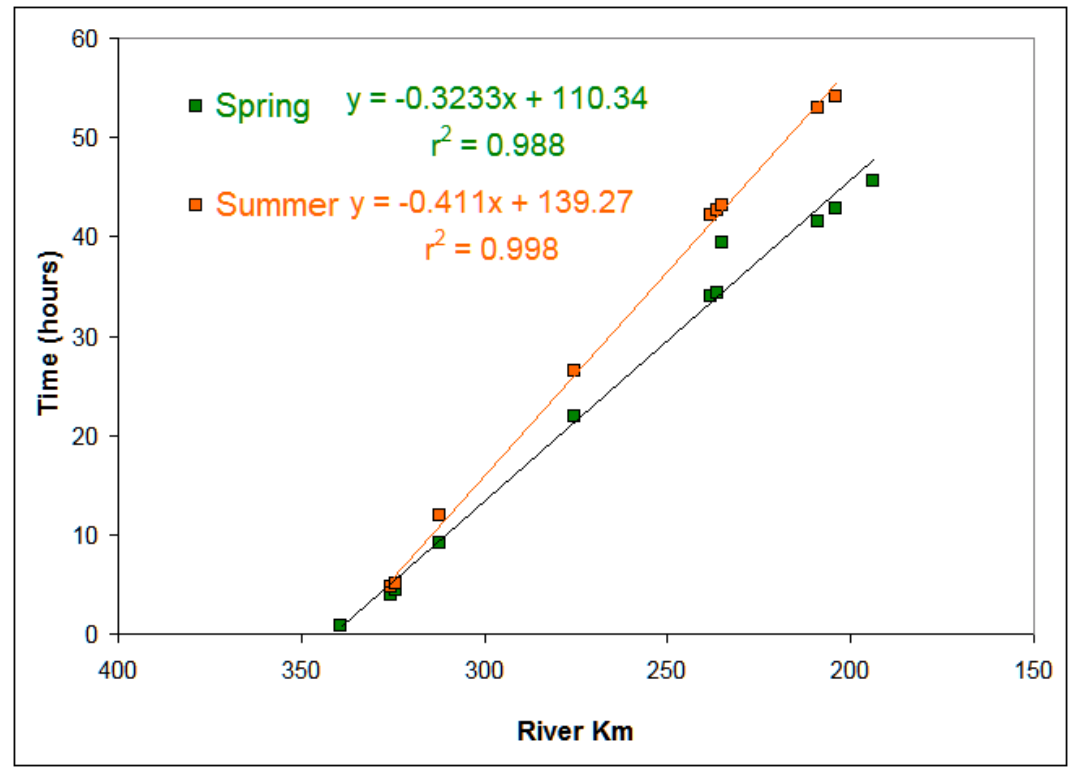

Figure S.6. Travel Time in Spring and Summer as a Function of River Kilometer

\section{Diel Distribution}

Fish regrouped at Array 3T in the BON forebay from all upstream releases and passed the dam at all hours of the day, because diel distributions of arrival from TDA and JDA Tailrace release locations complimented one another. Most TDA Tailrace-released fish arrived during hours when arrivals from the JDA Tailrace releases were low.

\section{Cross Channel Distribution}

A majority of fish were detected away from shore each season, and there was little evidence that subyearlings preferred to migrate near shore instead of in the middle of the river in summer. Only two of nine lateral distribution plots showed any skew toward shore in summer. The most reliable evidence came from primary arrays in each tailwater $(1 \mathrm{~J}, 1 \mathrm{~T}$, and $1 \mathrm{~B})$ because they each had five or six autonomous nodes. We worried a lot about tagged fish migrating around islands and avoiding detection in the BON Tailwater, but the percentage of detections on nodes sampling side channels was low in two of three locations. High detection percentages on Node 4 of Array 3B located at the upstream opening to Camas Slough formed by Lady Island made it the only exception.

\section{Physical Factors Affecting Array Detection Probabilities}

Arrays with very high detection probabilities had a majority of the detections on more than one node (2-5 nodes), and this was the case for five of nine arrays (1J, 3J, 1T, 2T, and 3T). The BON Tailwater arrays, which had the lowest detection probabilities (mean $=67.6 \%$ in spring and $80.2 \%$ in summer), received $80 \%$ or more detections on a single node. Array $1 \mathrm{~B}$ had $16 \%$ multiple node detections, showing that contributing factors of node density and bathymetry played a role in the poor performance of this array. Array 2B and 3B performed similarly in spring with only 9\% detections on multiple nodes. Both of these arrays had three nodes covering a 650-m transect across the river and a backwater node separate from the main transect. Separate nodes for sampling side channels would not allow for simultaneous 
detections on the side channel node and other nodes in the main channel, but multiple node detections should have occurred on the other three nodes.

The 2006 single- and multi-node detection results indicate that the best location for an array is at a cross section that is deep and narrow, and the worst location is one with extensive shallows, uneven bathymetry, and islands to limit sound propagation and maximize multi-path signals. Primary factors affecting array performance include the shape (depth and width) of the river cross section and node density. In 2006, multiple detections were more common at upstream locations that tended to be deeper and narrower than locations below BON, where finding narrow cross sections without bars, islands, and side channels was difficult.

Examination of scatter plots of detection probability regressed on physical variables provided useful observations for making recommendations for deploying acoustic receivers. Our examination of correlations of observed average detection probabilities with several physical factors (Table S.3) led us to recommend the following to provide a reasonable chance of achieving detection probabilities $>80 \%$ in future studies.

1. Arrays should be located at the narrowest and deepest (mean depth $>14 \mathrm{~m}$ ) cross sections available, after allowing enough travel distance to avoid detecting dead fish on an array. There was a significant negative correlation between detection probability and river width and a positive correlation between the probability and mean depth.

2. We recommend deploying enough autonomous nodes to keep inter-nodal distances $<150 \mathrm{~m}$, so that node densities are at least six per km of river width.

3. Offshore distances to the first node on either side of the river should not exceed $100 \mathrm{~m}$.

Limiting offshore distance to $50 \mathrm{~m}$ and inter-node distances to $100 \mathrm{~m}$ (i.e., node density $\approx 10 / \mathrm{km}$ ) would provide completely overlapping coverage so that the loss of any single node would not diminish detection probability and the loss of two adjacent nodes would only leave a small breach in coverage. An example approaching such a deployment was Array $1 \mathrm{~T}$ in the TDA Tailwater. This array had $82 \%$ of detections occurring on multiple nodes because the width of the river at this array location was only 500 $\mathrm{m}$ and five nodes were deployed there, so the inter-node spacing with five nodes was $100 \mathrm{~m}$.

Table S.3. Correlations Between Mean Detection Probability and Physical Characteristics of the Survival Arrays.

\begin{tabular}{|l|c|c|}
\hline \multicolumn{1}{|c|}{ Variable } & $\mathbf{r}$ & $\mathbf{P}$ \\
\hline River Width (Km) & -0.78041 & 0.0002 \\
\hline Mean Offshore Distance (m) & -0.74197 & 0.0006 \\
\hline Inter-node Distance (m) & -0.58771 & 0.0131 \\
\hline Node Density (Nodes / Km) & 0.58124 & 0.0144 \\
\hline Mean Depth (m) & 0.52399 & 0.0309 \\
\hline Mean Number of Nodes & -0.17649 & 0.4980 \\
\hline SE Depth (m) & 0.00485 & 0.9853 \\
\hline
\end{tabular}




\section{Survival and Dam Operations, Rate of Travel, Water Temperature}

Significant positive correlations of survival probabilities with travel rates of some releases in spring and with travel rate and discharge in summer made sense but relations were not consistent for all releases. We were reassured by significant positive correlations of survival with rate of travel for all three JDA releases in spring and for the JDA Tailrace release of subyearlings in summer. Explained variation ranged from $21 \%$ to $50 \%$. However, we were puzzled that the same correlations were not observed for TDA Tailrace releases in spring or summer.

The strong decline in survival of subyearlings in summer would make correlations with discharge and temperature very likely but is not indicative of cause and effect. Loss of fish to residualization (reverse smoltification) in summer could produce spurious correlations of apparent survival with discharge and water temperatures, simply because there usually is a downward trend in discharge and an upward trend in water temperature during summer. Sorting out cause and effect would require more information than is available from this study. 


\section{Preface}

The U.S. Army Corps of Engineers (USACE) Portland District (CENWP), contracted with the Pacific Northwest National Laboratory (PNNL), Richland, Washington, to conduct acoustic telemetry survival studies at three Columbia River Projects in 2006. PNNL is operated by Battelle - Pacific Northwest Division for the U.S. Department of Energy. PNNL assembled a study team consisting of staff from PNNL, the Pacific States Marine Fisheries Commission (PSMFC), the University of Washington, and the National Marine Fisheries Service. The Portland District provided all funding and oversight.

\section{Acknowledgments}

Many people made valuable contributions to this study and deserve acknowledgment. Mr. Dennis Schwartz served as the USACE Contracting Officers Representative (COTR) for the Bonneville Dam portion of the study and Mr. Brad Eppard was the COTR for the John Day and The Dalles portions. Both provided valuable coordination between researchers and the CE hydropower project personnel, and Brad also contributed valuable recommendations to improve the study design and execution and furnished dam operations data.

Ben Hausman, Tim Darland, Tammy Mackey, and Jonathon Rerecich with the Bonneville Project provided pre-work safety orientations and assistance and coordination whenever needed.

Terry Hurd and Miro Zindol provided similar assistance and coordination for the John Day Project, and Erin Kovalchuk with the Project was helpful in providing information about the Smolt Monitoring Facility (SMF).

Project Biologist Greg Kovalchuk of PSMFC provided smolt-collection training and was very helpful in making fish collection and scheduling of SMF activities run smoothly. Laura Cowger (PSMFC), who often worked processing fish for the SMF, was also very helpful.

Many PNNL staff assisted with various aspects of the study including management (Geoff McMichael), surgery training (Rich Brown), tag-life monitoring (Kathleen Carter), fish tagging (Kate Deters, Ian Welch, Scott Titzler), fish release (Ian, Kate, Chris Eiler, Garrett Mckinney), deployment and retrieval of autonomous nodes or fish-release mechanisms (Kyle Bouchard, Scott Titzler, Fenton Kahn, Chris Eiler), database entry and management (Jessica Vucelick), and development of tracking algorithms (Daniel Deng). Dr. David Geist was the Ecology Group Manager within PNNL and a valuable source of support and information, and Dr. Charlie Brandt was the Program Line Manager.

Terry Goss (PSMFC), helped with fish collection, tagging, and release. Carl Schilt, with LGL Limited, Inc., helped anesthetize fish before surgery in spring. Sonic Concepts in Seattle, Washington, fabricated electronic tags and receiving hydrophones and repaired broken hydrophones when needed. Precision Acoustic Systems, also in Seattle, conducted node acceptance tests for PNNL. Cascade Aquatics, Inc., of Ellensberg, Washington, activated and delivered the acoustic tags. Schlosser Machine Shop fabricated anchors for autonomous nodes and The Dalles Iron Works made aluminum floats for a fish release hose. SDS Lumber Company dropped a 1,000 pound anchor in the John Day Tailrace to anchor the downstream end of a tailrace release hose. Cliff Pereira and Brad Eppard provided detailed reviews that improved the quality of the report. 
Acoustic Telemetry Studies of Juvenile Chinook Salmon Survival at the Lower Columbia Projects in 2006 


\section{Acronyms and Abbreviations}

$\begin{array}{ll}\text { AIC } & \text { Akaike Information Criterion } \\ \text { B1 } & \text { Bonneville Powerhouse 1 } \\ \text { B2 } & \text { Bonneville Powerhouse 2 } \\ \text { B2CC } & \text { Bonneville Powerhouse 2 Corner Collector } \\ \text { B2 JBS } & \text { Bonneville Powerhouse 2 Juvenile Bypass System } \\ \text { BKD } & \text { Bacterial Kidney Disease } \\ \text { BON } & \text { Bonneville Dam } \\ \text { BPA } & \text { Bonneville Power Administration } \\ \text { CENWP } & \text { U.S. Army Corps of Engineers, Portland District } \\ \text { CF } & \text { compact flash } \\ \text { cfs } & \text { cubic feet per second } \\ \text { CI } & \text { Confidence interval (95\% unless specified otherwise) } \\ \text { CJS } & \text { Cormack-Jolly-Seber model } \\ \text { COTR } & \text { Contracting Officers Representative } \\ \text { CSv } & \text { comma-separated variables } \\ \text { DART } & \text { Data Access in Real Time } \\ \text { FCRPS } & \text { Federal Columbia River Power System } \\ \text { g } & \text { grams } \\ \text { GB } & \text { gigabyte } \\ \text { JBS } & \text { juvenile bypass system } \\ \text { JDA } & \text { John Day Dam } \\ \text { JSATS } & \text { Juvenile Salmon Acoustic Telemetry System } \\ \text { LGR } & \text { Lower Granite Dam } \\ \text { LGS } & \text { Little Goose Dam } \\ \text { LRT } & \text { likelihood ratio tests } \\ \text { mm } & \text { millimeter } \\ \text { ml } & \text { milliliter } \\ \text { milligrams per liter } \\ \text { tricaine methanesulfonate } \\ \text { mean sea level }\end{array}$


NOAA National Oceanic and Atmospheric Administration

PA pre-anesthetic

PDF portable document file

PIT passive integrated transponder tag

PNNL Pacific Northwest National Laboratory

PSMFC Pacific States Marine Fisheries Commission

PR paired release

Rkm river kilometer

RT radiotelemetry

s second

SAS Statistical Analysis System

SMF Smolt Monitoring Facility

SR single release-recapture

SYC sub-yearling Chinook salmon

TDA The Dalles Dam

TR tailrace

USACE U.S. Army Corps of Engineers

YC yearling Chinook salmon 


\section{Contents}

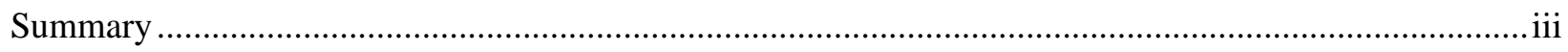

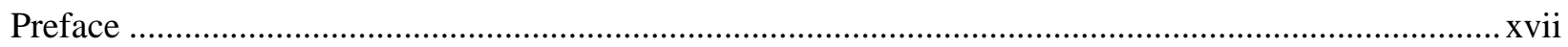

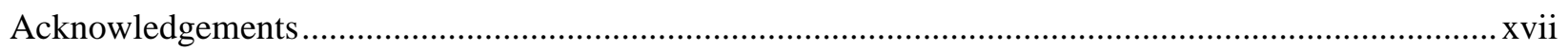

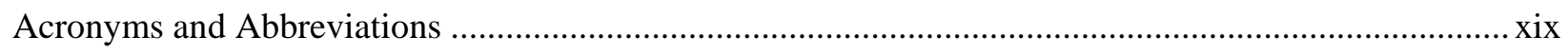

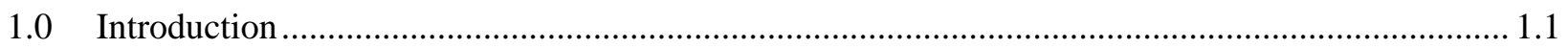

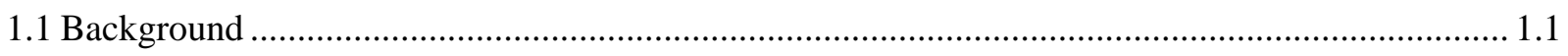

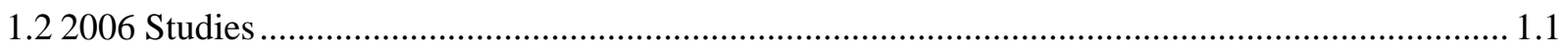

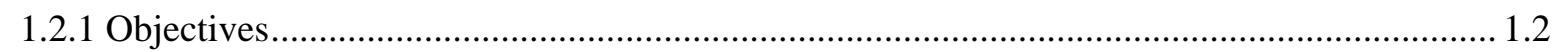

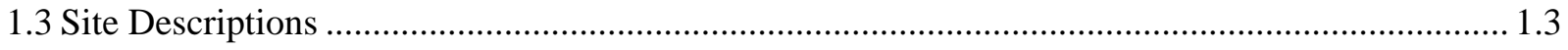

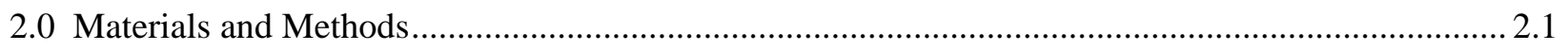

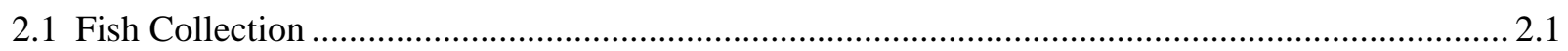

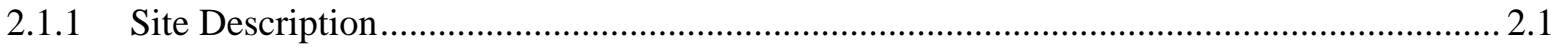

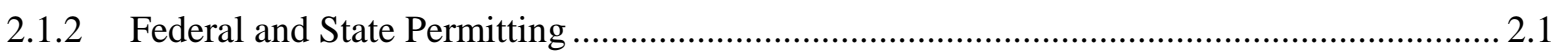

2.1.3 Sampling Methods ................................................................................................ 2.1

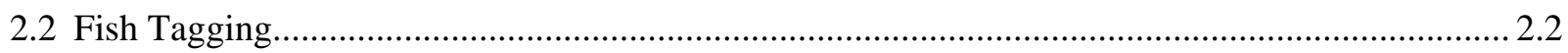

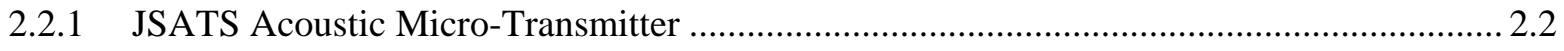

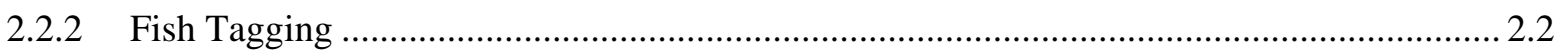

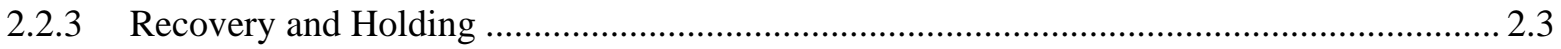

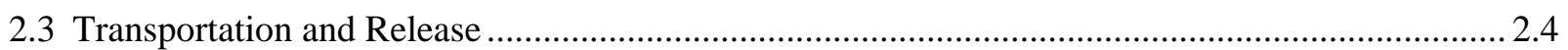

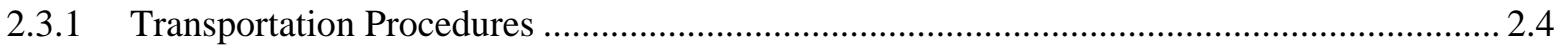

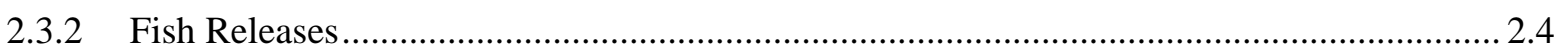

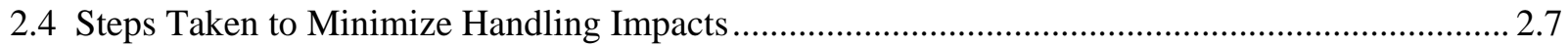

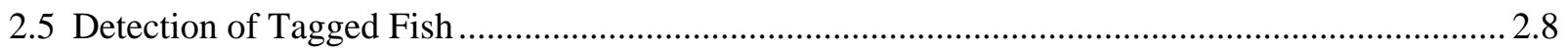



2.5.2 Arrays and Release Locations ................................................................................... 2.9

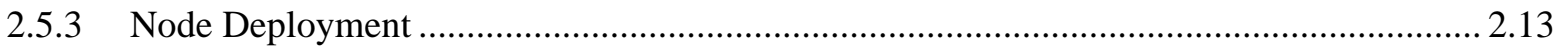

2.5.4 Node Retrieval, Servicing, and Redeployment ............................................................. 2.14

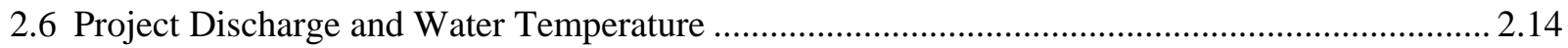

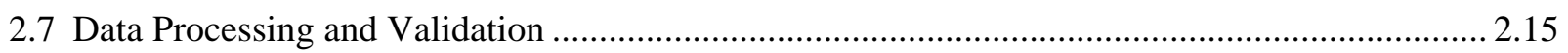

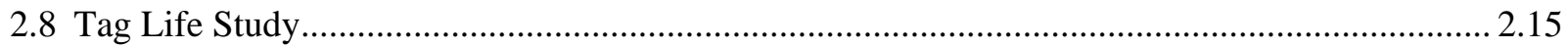

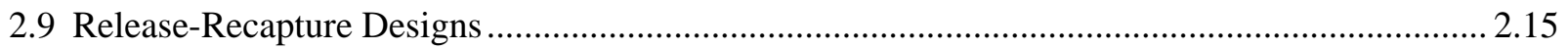

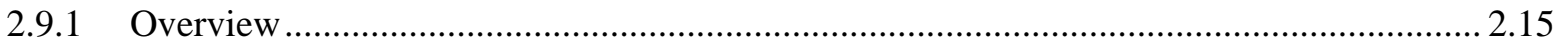

2.9.2 Yearling Chinook Salmon Smolts............................................................................ 2.18

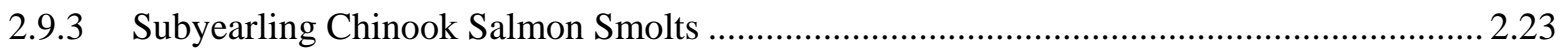

2.9.4 Bonneville Dam Route Specific Estimates in Spring and Summer .................................. 2.26

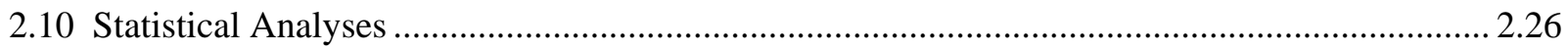

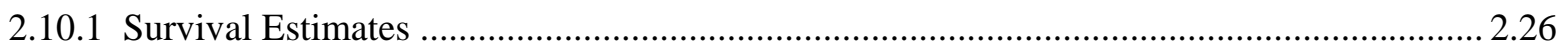




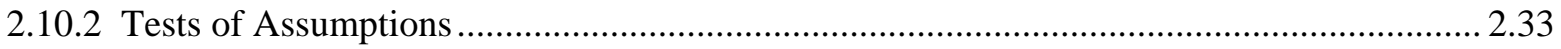

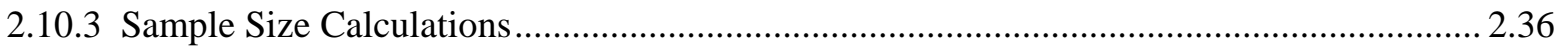

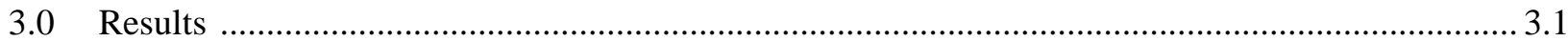

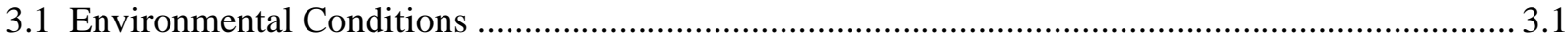

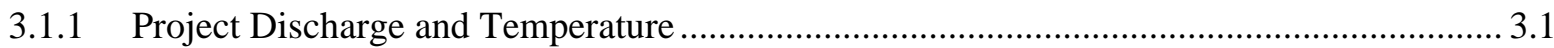

3.1.2 Run Timing of Smolt Species Composition........................................................................ 3.2

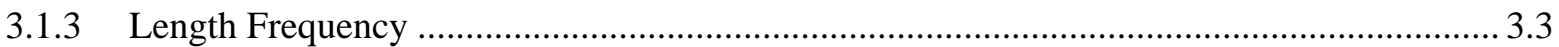

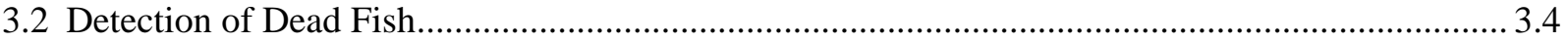

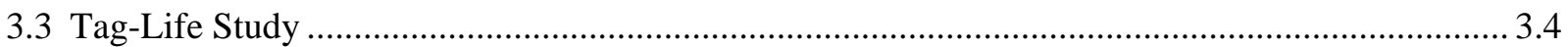

3.4 Detection and Survival of Yearling Chinook Salmon in Spring .................................................. 3.8



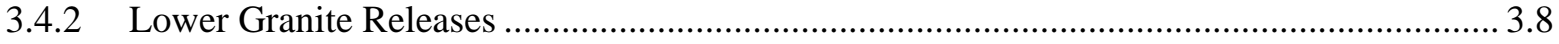

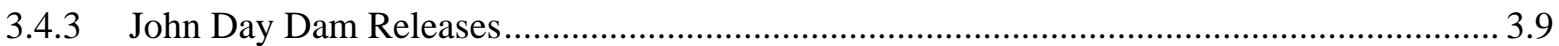

3.4.4 The Dalles and Bonneville Tailrace Releases ................................................................... 3.12

3.4.5 Virtual Releases from The Dalles and Bonneville Forebays ............................................. 3.16

3.4.6 The Dalles and Bonneville Project Passage Survivals ........................................................ 3.19

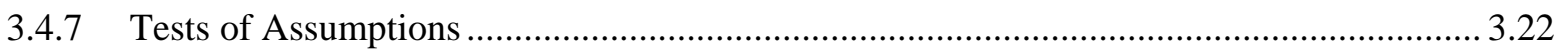



3.4.9 Bonneville Route-Specific Survival (Pooled Releases) ...................................................... 3.24

3.5 Detection and Survival of Subyearling Chinook Salmon in Summer .............................................2. 3.26

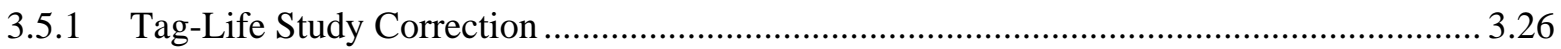

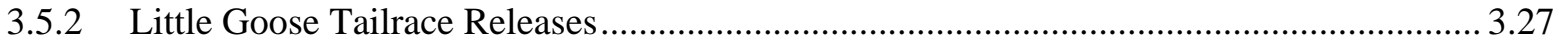

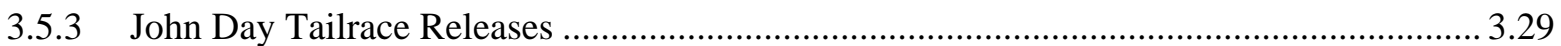

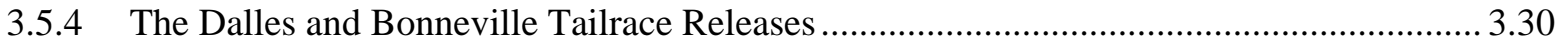

3.5.5 Virtual Releases from The Dalles and Bonneville Forebays ........................................... 3.32

3.5.6 The Dalles and Bonneville Project Passage Survivals ....................................................... 3.35

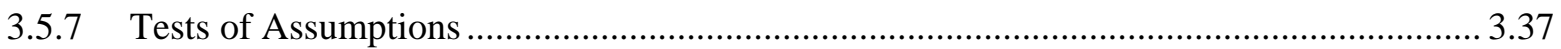

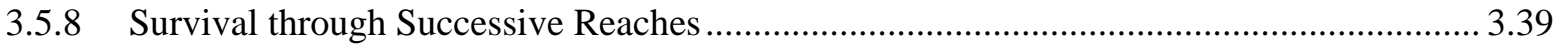

3.5.9 Bonneville Route-Specific Survival (Pooled Releases) .................................................... 3.39

3.6 Comparison of Estimates Using Preferred versus As-Planned Arrays ......................................... 3.43

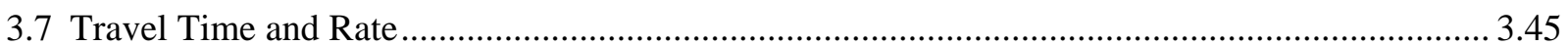

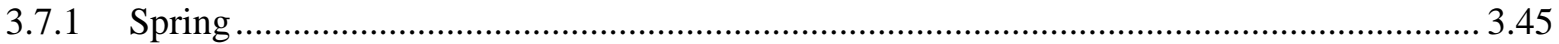

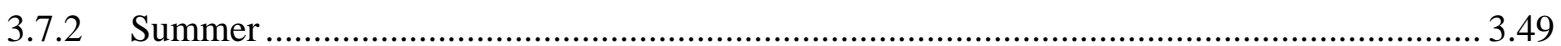

3.8 Using Time of Travel to Lag Paired Releases in Future Studies ................................................ 3.52

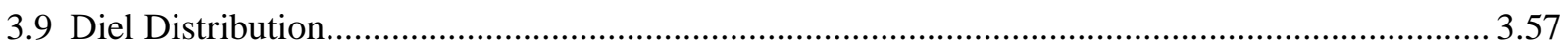

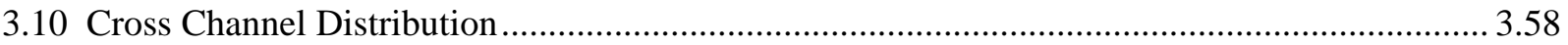

3.11 Physical Factors Affecting Array Detection Probabilities ..................................................... 3.60

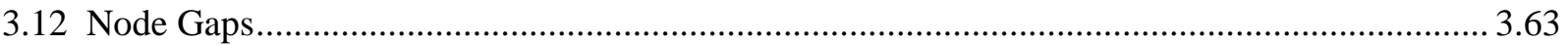

3.13 Survival and Dam Operations, Rate of Travel, Water Temperature .......................................... 3.65




3.15 Detection History Data for Every Acoustic Tag .....................................................................66

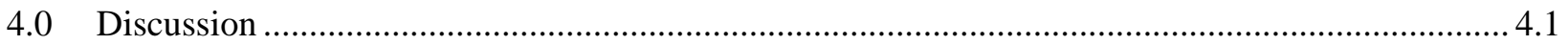

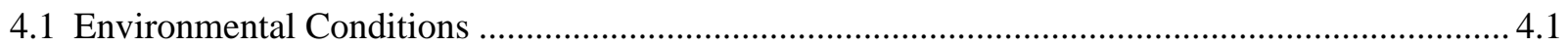

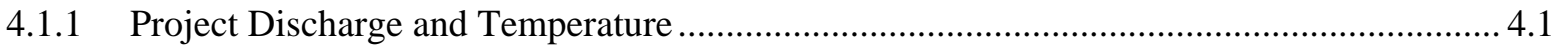

4.1.2 Run Timing of Smolt Species Composition.................................................................... 4.1

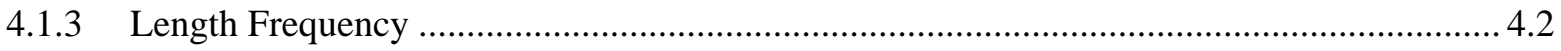

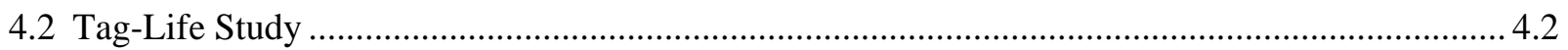

4.3 Detection Probabilities and Required Sample Sizes ............................................................... 4.2

4.4 Detection and Survival of Yearling Chinook Salmon in Spring ................................................. 4.6

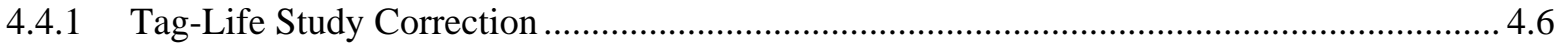

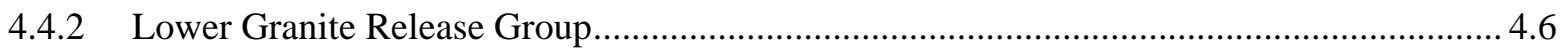

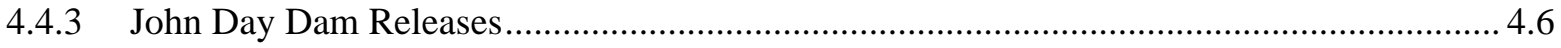

4.4.4 The Dalles and Bonneville Tailrace Releases ................................................................. 4.7

4.4.5 Virtual Releases from The Dalles and Bonneville Forebays ............................................. 4.7

4.4.6 The Dalles and Bonneville Project Passage Survivals ....................................................... 4.8

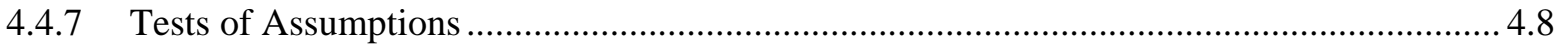

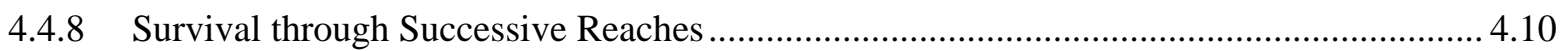

4.4.9 Bonneville Route-Specific Survival (Pooled Releases) .................................................... 4.10

4.5 Detection and Survival of Subyearling Chinook Salmon in Summer ......................................... 4.11

4.5.1 Tag-Life Study Correction ............................................................................................. 4.11

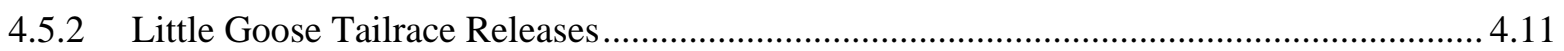

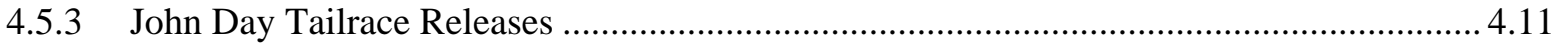

4.5.4 The Dalles and Bonneville Tailrace Releases .................................................................. 4.12

4.5.5 Virtual Release from The Dalles and Bonneville Forebays ................................................ 4.14

4.5.6 The Dalles and Bonneville Project Passage Survivals ........................................................ 4.14

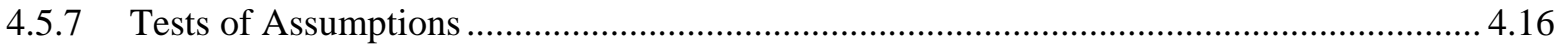

4.5.8 Survival through Successive Reaches ............................................................................. 4.16

4.5.9 Bonneville Route-Specific Survival (Pooled Releases) .................................................... 4.17

4.6 Comparison of Estimates Using Preferred vs. As-Planned Arrays .............................................. 4.18

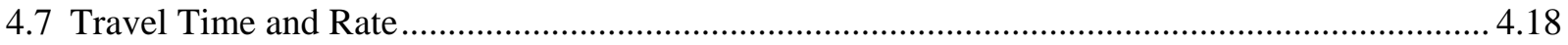

4.8 Using Time of Travel to Lag Paired Releases in Future Studies .............................................. 4.18

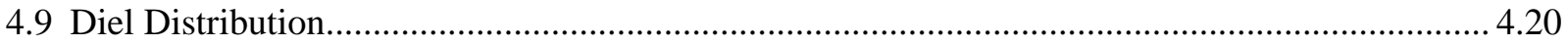

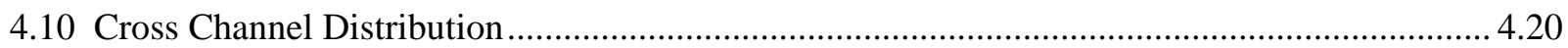

4.11 Physical Factors Affecting Array Detection Probabilities ...................................................... 4.21

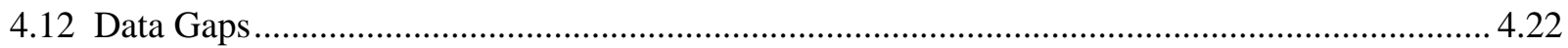

4.13 Survival and Dam Operations, Rate of Travel, Water Temperature .......................................... 4.23

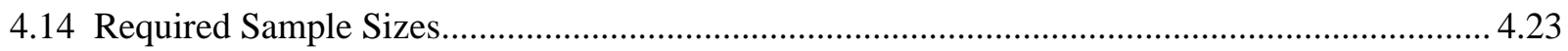

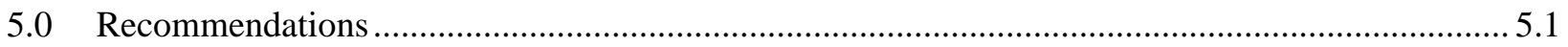


6.0 References

[All appendixes are on accompanying CD.]

Appendix A. Tables of all Fish Tagging and Release Data

Appendix B. Yearling Chinook Salmon Tag-Life Analysis Including Fitted Survivorship Curve and Arrival Time Vs. Tag Survivorship Plots

Appendix C. Forward-Sequential Model Selection Results for Acoustic-Tag Release Pairs in the 2006 Acoustic-Tag Survival Studies through John Day, The Dalles, and Bonneville Projects for Yearling Chinook Salmon

Appendix D. Tests of Mixing and Goodness-of-Fit for Yearling Chinook Salmon Release Groups...... D.1

Appendix E. Tag-Life Survivorship Curve and Comparisons of Arrival Distributions Versus Tag Life for Subyearling Chinook Salmon

Appendix F. Forward-Sequential Model Selection Results for Acoustic-Tag Release Pairs in 2006 Acoustic-Tag Survival Studies through John Day, The Dalles, and Bonneville Projects for Subyearling Chinook Salmon.

Appendix G. Tests of Mixing and Goodness of Fit for Subyearling Chinook Salmon Release Groups

Appendix H. Tables of Detection Frequencies and Estimates of Detection and Survival for AsPlanned Arrays

Appendix I. Model Estimates of One-Half 95\% Confidence Intervals on Detection and Survival Statistics for Yearling Chinook Salmon Based on Single-Release Survival Models for Spring 2006

Appendix J. Model Estimates of One-Half 95\% Confidence Intervals on Detection and Survival Statistics for Yearling Chinook Salmon Based on Paired-Release Survival Models for Spring 2006

Appendix K. Model Estimates of One-Half 95\% Confidence Intervals on Detection and Survival Statistics for Subyearling Chinook Salmon Based on Single-Release Survival Models for Summer 2006 ....

Appendix L. Model Estimates of One-Half 95\% Confidence Intervals on Detection and Survival Statistics for Subyearling Chinook Salmon Based on Paired-Release Survival Models for Summer 2006

Appendix M. Detection History for 2006 


\section{Figures}

Figure 1.1. Tailwaters Below the Three Dams in this Study 1.4

Figure 1.2. Aerial View of John Day Dam 1.4

Figure 1.3. Aerial View of The Dalles Dam at rkm 307.8 1.5

Figure 1.4. Plan View of the Bonneville Dam Project. 1.5

Figure 2.1. JSATS Acoustic Micro-Transmitter with Ruler for Scale

Figure 2.2. Closing of Incision Using a 5-0 Vicryl Suture with a C-3 Needle. ...................................... 2.3

Figure 2.3. Post Surgery Holding Tank with Recovery Buckets ........................................................... 2.4

Figure 2.4. Release Apparatus for Turbine Intake 9C Releases at JDA in Spring................................. 2.6

Figure 2.5. Side (left) and Bottom (right) View of a Node Top …........................................................ 2.9

Figure 2.6. Columbia River with Yellow Circles Indicating Waypoints at Autonomous Node Locations for the Four JDA Tailwater Arrays s.

Figure 2.7. Columbia River with White Triangles Marking a Tailrace Release Location Below TDA and Yellow Circles Marking Waypoints of Autonomous Node Locations in Four TDA Tailrace Arrays

Figure 2.8. Columbia River with Yellow Circles Marking Waypoints of Autonomous Node Locations for BON Survival Arrays 1B, 2B, and 3B in the Tailwater and White Triangles Marking the BON Tailrace Release Locations .

Figure 2.9. Node Rigging without the 120-Pound Anchor Shown 6 to $12 \mathrm{ft}$ below the Acoustic Release...

Figure 2.10. Autonomous Node Retrieval .

Figure 2.11. Release-Recapture Locations for the Single Release-Recapture (SR) Analyses of the Lower Granite Release Groups of Yearling Chinook Salmon.

Figure 2.12. Release-Recapture Locations for the Single-Release (SR) and Paired-Release Analyses of the John Day Release Groups

Figure 2.13. Release-Recapture Locations for the Single-Release (SR) Analysis of TDA and BON Tailrace Releases ....

Figure 2.14. Virtual (V) Releases of Fish from 3J and 3T Used to Estimate Dam Passage Survival at TDA and BON Dams...

Figure 2.15. Release-Recapture Locations for Paired-Release (PR) Studies to Estimate TDA and BON Project Passage Survivals for Yearling Chinook Salmon Smolts.

Figure 2.16. Release-Recapture Locations for the Single-Release (SR) Analysis of Reach Survival for Subyearling Chinook Salmon Smolts Below Little Goose Dam

Figure 2.17. Release-Recapture Locations for the Single Releases (SR) Analyses of Reach Survival for Subyearling Chinook Salmon Smolts at JDA, TDA, and BON.

Figure 2.18. Illustration of Tag-Life Survivorship Curves Versus Cumulative Arrival Distributions of Smolts to a Detection Site. 
Figure 2.19. Scenario of a Single Release-Recapture Design Used to Estimate Smolt Passage Survival.....

Figure 2.20. Scenario of a Paired Release-Recapture Design Used to Estimate Smolt Passage Survival.....

Figure 3.1. Ten-Year Average Daily Project Discharge (kcfs) versus 2006 Daily Project Discharge for JDA, TDA, and BON

Figure 3.2. Ten-Year Average Forebay Water Temperature $\left({ }^{\circ} \mathrm{C}\right)$ versus 2006 Temperature by day at JDA, TDA, and BON.

Figure 3.3. Smolt Monitoring Program (SMP) Passage Index for March 1 - July 31, 2006, based on Data from the JDA Smolt Monitoring Facility

Figure 3.4. Length Frequency of Tagged and Untagged Run-of-River Yearling Chinook Salmon during Spring Tagging at the JDA Smolt-Monitoring Facility in 2000.

Figure 3.5. Length Frequency of Tagged and Untagged Sub-Yearling Chinook Salmon during Summer Tagging at the JDA Smolt-Monitoring Facility in 2006.

Figure 3.6. Estimated Time to Failure of Tags Transmitting Once Every 10 Seconds Like Those Implanted in Juvenile Chinook Salmon Released below LGR in Spring and below LGS in Summer

Figure 3.7. Estimated Time to Failure of Tags Transmitting Once Every 5 Seconds Like Those Implanted in Juvenile Chinook Salmon Released at JDA, TDA, and BON in Spring and Summer.

Figure 3.8. Estimated Time to Failure of Tags Transmitting Once every 10 Seconds Like Those Implanted in Chinook Salmon Released at LGR in Spring and LGS in Summer. 3.6

Figure 3.9. Estimated Time to Failure of 24 10-Second Tags Activated on July 15, 2006

Figure 3.10. Estimated Tag Life of 10-Second Tags, Excluding Those Activated on July 15, 2006 ....... 3.7

Figure 3.11. Summary of Results for the Single Release-Recapture (SR) Analysis of the LGR Release Groups of Yearling Chinook Salmon

Figure 3.12. Summary of Results for the Single-Release and Paired-Release Analysis of the JDA Release Groups.

Figure 3.13. Summary of the Single-Release (SR) Analyses of TDA and BON Tailrace Releases....... 3.15

Figure 3.14. Summary of Single Release-Recapture Analyses of Virtual Releases of Yearling Chinook Salmon from the TDA and BON Forebays

Figure 3.15. Summary of the Paired-Release Studies to Estimate The Dalles and Bonneville Project Passage Survivals for Yearling Chinook Salmon Smolts

Figure 3.16. Plot of Median Hour of Arrival at Array 1J Below JDA Dam for Three Release Locations at JDA by Release Date.

Figure 3.17. Cumulative Percent of Primary Array Detections of Treatment and Reference Fish Used to Make Paired-Release Estimates of TDA Project Survival in Spring 2006.

Figure 3.18. Spring Survival Percentages for Tagged Fish from Release Location to each Survival Array except the Last.

Figure 3.19. Summary of Single-Release Analysis of Reach Survival for Subyearling Chinook 3.28 
Figure 3.20. Release-Recapture Locations for the Single Releases Analyses of Reach Survival for Subyearling Chinook Salmon Smolts at JDA, TDA, and BON.

Figure 3.21. Summary of Single Release-Recapture Analysis of Virtual Releases of Subyearling Chinook Salmon from the TDA and BON Forebays

Figure 3.22. Summary of Single-Release Estimates of Survival that were Paired to Estimate TDA and BON Project Passage Survivals for Subyearling Chinook Salmon Smolts.

Figure 3.23. Plot of Dates of Release and Detections on Array 1T for Tagged Fish Released in the JDA Tailrace and TDA Tailrace

Figure 3.24. Plot of Dates of Release and Detections on Array 1B for Tagged Fish Released in the TDA Tailrace and BON Tailrace

Figure 3.25. Summer Survival for Subyearling Chinook Salmon from Release Location to Each Successive Array, Except the Last.

Figure 3.26. Spill Pattern during Summer 2006 .

Figure 3.27. Trends in Survival during Summer 2006.

Figure 3.28. Median Time of Travel from Release Point through the Last Array in Spring 2006

Figure 3.29. Median Time of Travel through All Reaches. 3.52

Figure 3.30. Median Travel Time as a Function of River Discharge for JDA Releases to Array 1J, JDA and TDA Tailrace Releases to Array 1T, and TDA and BON Tailrace Releases to Array $1 \mathrm{~B}$ in Spring..

Figure 3.31. Median Travel Time as a Function of River Discharge for JDA and TDA Tailrace Releases to Array 1T, and TDA and BON Tailrace Releases to Array 1B in Summer ...... 3.54

Figure 3.32. Lag Time Required Between Pairs of Releases of Yearling Chinook Salmon from JDA as a Function of River Discharge in Spring 3.55

Figure 3.33. Lag Time Required Between Paired Releases of Yearling Chinook Salmon from JDA and TDA Tailrace as a Function of River Discharge in Spring 3.56

Figure 3.34. Lag Time Required Between Paired Releases of Yearling Chinook Salmon from TDA and BON Tailrace as a Function of River Discharge in Spring. 3.56

Figure 3.35. Lag Time Required Between Paired Releases of Subyearling Chinook Salmon from JDA and TDA Tailrace as a Function of River Discharge in Summer

Figure 3.36. Lag Time Required Between Paired Releases of Subyearling Chinook Salmon from TDA and BON Tailrace as a Function of River Discharge in Summer

Figure 3.37. Diel Distribution of Tagged Fish Arriving at TDA3 for Spring and Summer from the JDA Tailrace Release

Figure 3.38. Diel Distribution of Tagged Fish Arriving at TDA3 in Spring and Summer, from the TDA Tailrace Release.

Figure 3.39. Cross Channel Distribution of Detections at Each Survival Array in the JDA Tailwater, TDA Tailwater, and BON Tailwater

Figure 3.40. Distribution of Detections at the BON Spillway

Figure 3.41. Scatter Plot of Mean Detection Probability as a Function of Physical Factors that Affect Array Performance. 
Figure 3.42. Percent of Single and Multiple-Node Detections on Survival Arrays in Spring and Summer 2006

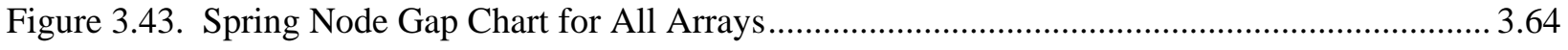

Figure 3.44. Summer Data Gap Chart for all Arrays ................................................................................64

Figure 3.45. Regression of Predicted One-half 95\% Confidence Intervals on Observed Estimates in the 2006 Study

Figure 4.1. Apparent Survival of Subyearling Chinook Salmon Released from Lower Goose Tailrace in Summer Down to Primary Arrays in the JDA, TDA, and BON Tailwaters (Left) and Differences in Survival Between Successive Primary Arrays (Right).

Figure 4.2. Apparent Survival of Subyearling Chinook Salmon Released from the TDA Tailrace in Summer Down to Array 3T just above BON

Figure 4.3. Apparent Survival of Subyearling Chinook Salmon Released from the BON Tailrace in Summer Down to Array 1B.

Figure 4.4. Apparent Survival of Subyearling Chinook Salmon Regrouped at Array 3T above BON .. 4.14

Figure 4.5. Apparent Survival of Subyearling Chinook Salmon Released above TDA Spill Bays in Summer 2004

Figure 4.6. Travel Time as a Function of River Discharge for the River Reach from TDA to Array 1T near Hood River and from TDA to Array 1B near Rooster Rock State Park below BON .

Figure 4.7. Travel Time in Spring and Summer as a Function of River Kilometer

Figure 4.8. One-half 95\% CI on Survival to a Primary Array (S1) as a Function of the Detection Probability to the Same Array (P1) 


\section{Tables}

Table 1.1. Lookup Table for Determining Distances between Locations Referenced in this Study 1.6

Table 2.1. Dates and Numbers of Yearling and Subyearling Chinook Salmon Tagged with JSATS Tags and Released in Other 2006 Studies.

Table 2.2. Numbers of Tagged and Released Numbers for Yearling Chinook Salmon in Spring 2006

Table 2.3. Numbers of Tagged and Released Numbers of Sub-Yearling Chinook Salmon in Summer 2006.

Table 2.4. Dilution of Poly-Aqua Used in Surgical Procedures

Table 2.5. Cell Probabilities Used in Parameterizing a Single-Release Model for Three River Reaches.....

Table 2.6. Cell Probabilities Used in Parameterizing a Single-Release Model for Three River Reaches and Tag-Life Correction

Table 2.7. Cell Probabilities Used in Parameterizing the Joint Likelihood for the Paired ReleaseRecapture Model for Three River Reaches and Tag-life Correction ....

Table 3.1. Detection Histories for each Release Group from Lower Granite Dam 3.8

Table 3.2. Cormack-Jolly-Seber, Single-Release Estimates of Survival and Detection Probabilities for each Group of Fish Released from LGR Tailrace.

Table 3.3. Detection Histories for Each Release Group at JDA

Table 3.4. Cormack-Jolly-Seber Single-Release Estimates of Survival and Detection Probabilities for each Group Released from JDA

Table 3.5. Modeled Estimates of Single-Release Survival and Detection Probabilities for each Paired-Release Group from John Day Dam

Table 3.6. Detection Histories for each Release Group from the TDA Tailrace

Table 3.7. Cormack-Jolly-Seber Singe-Release Estimates of Survival and Detection Probabilities for each Group Released from the TDA Tailrace.

Table 3.8. Detection Histories for each Release Group from the BON Tailrace

Table 3.9. Cormack-Jolly-Seber Single-Release Estimates of Survival and Detection Probabilities for each Group of Fish Released from the BON Tailrace.

Table 3.10. Detection Histories for each Virtual Release Group through TDA

Table 3.11. Cormack-Jolly-Seber Single-Release Estimates of Survival and Detection Probabilities for each Virtual Release Group through TDA.

Table 3.12. Detection History for each Virtual Release Group through BON 3.18

Table 3.13. Cormack-Jolly-Seber Single-Release Estimates of Survival and Detection Probabilities for each Virtual Release Group through BON

Table 3.14. Detection History for the Pooled Release Groups Used to Estimate TDA Project Survival. 
Table 3.15. Cormack-Jolly-Seber Single-Release Estimates of Survival and Detection Probabilities for the Pooled Release Groups Used to Estimate TDA Project Survival ......... 3.20

Table 3.16. Modeled Single-Release Estimates of Survival and Detection Probabilities for JDA and TDA Tailrace Releases Used to Estimate TDA Project Passage Survival

Table 3.17. Detection Histories for the Pooled Release Groups Used to Estimate BON Project Survival.

Table 3.18. Cormack-Jolly-Seber Single-Release Estimates of Survival and Detection Probabilities for the Pooled Release Groups Used to Estimate BON Project Survival

Table 3.19. Modeled Single-Release Estimates of Survival and Detection Probabilities for TDA and BON Tailrace Releases Used to Estimate BON Project Passage Survival

Table 3.20. Single-Release Survival and Detection Probabilities Based on Pooling of Releases from All Upstream Sites

Table 3.21. Day and Night Estimates of Single-Release Survival and Detection Probabilities for Fish Detected in the Spillway Forebay, Regardless of Upstream Release Location

Table 3.22. Detection Histories for each Release Group at Little Goose Dam.

Table 3.23. Cormack-Jolly-Seber Single-Release Estimates of Survival and Detection Probabilities for each Release Group of Subyearling Chinook Salmon Released from Little Goose Tailrace 3.28

Table 3.24. Detection Histories for the JDA Tailrace Releases in Summer 2006 3.29

Table 3.25. Cormack-Jolly-Seber Single-Release Estimates of Survival and Detection Probabilities for the JDA Tailrace Releases in Summer.

Table 3.26. Detection Histories for the TDA Tailrace Releases 3.31

Table 3.27. Cormack-Jolly-Seber Single-Release Estimates of Survival and Detection Probabilities for TDA Tailrace Release. 3.31

Table 3.28. Detection Histories for BON Tailrace Releases 3.32

Table 3.29. Cormack-Jolly-Seber Single-Release Estimates of Survival and Detection Probabilities for the Bonneville Tailrace release.

Table 3.30. Detection Histories for the TDA Virtual Releases at Array 3J.

Table 3.31. Cormack-Jolly-Seber Single-Release Estimates of Survival and Detection Probabilities for TDA Virtual Releases at Array 3J

Table 3.32. Detection Histories in the BON Tailwater for the Virtual Releases above BON in Summer.

Table 3.33. Cormack-Jolly-Seber Single-Release Estimates of Survival and Detection Probabilities for Virtual Releases above BON to the Primary Array in the Tailwater

Table 3.34. Detection Histories for the Pooled Release Groups Used to Estimate TDA Project Survival.

Table 3.35. Cormack-Jolly-Seber Estimates of Survival and Detection Probabilities for the Pooled Release Groups Used to Estimate TDA Project Survival.

Table 3.36. Detection Histories for the Pooled Release Groups Used to Estimate BON Project Survival. 
Table 3.37. Cormack-Jolly-Seber Single-Release Estimates of Survival and Detection Probabilities for the Pooled Release Groups Used to Estimate BON Project Survival

Table 3.38. Single-Release Survival and Detection Probabilities for Subyearling Chinook Salmon based on Pooled Releases from All Upstream Sites for Specific Passage Routes

Table 3.39. Single-Release Survival and Detection Probabilities for Subyearling Chinook Salmon Passing the BON Spillway after July 5 during the Day and Night Periods based on Pooled Releases from All Upstream Sites.

Table 3.40. Single-Release Survival and Detection Probabilities for Subyearling Chinook Salmon Passing the BON Spillway and Released in the Bonneville Tailrace during Three Periods with Different Spill Conditions

Table 3.41. Uncorrected Cormack-Jolly-Seber Estimates of Survival Probabilities Calculated from Preferred and As-Planned Arrays in Spring.

Table 3.42. Uncorrected Cormack-Jolly-Seber Estimates of Detection Probabilities Calculated from Preferred and As-Planned Arrays in Spring....

Table 3.43. Uncorrected Cormack-Jolly-Seber Estimates of Survival Probabilities Calculated from Preferred and As-Planned Arrays in Summer

Table 3.44. Uncorrected Cormack-Jolly-Seber Estimates of Detection Probabilities Calculated from Preferred and As-Planned Arrays in Summer

Table 3.45. Median Hours, Rate, and Distance of Travel from LGR Tailrace Release to Primary Arrays Below Each Project in Spring.

Table 3.46. Median Hours, Rate, and Distance of Travel from Release Site at JDA to the JDA Egress Array in Spring.

Table 3.47. Median Hours, Rate, and Distance of Travel from Array 3J to Array 1T through the TDA Project in Spring.

Table 3.48. Median Hours, Rate, and Distance of Travel through BON in Spring

Table 3.49. Spring Median Hours, Rate, and Distance of Travel from Array 3T Immediately above Boat Rock and BON Forebays to Specific Routes of Passage in Spring

Table 3.50. Median Hours, Rate, and Distance of Travel from Detection at Specific Routes to Array 1B below BON in Spring

Table 3.51. Median Hours, Rate, and Distance of Travel from the BON Tailrace to Array 1B, from Array 1B to 2B, and from Array 2B to 3B in Spring..

Table 3.52. Median Hours, Rate, and Distance of Travel from LGS Tailrace Release to Primary Arrays Below Three Projects in Summer .....

Table 3.53. Median Hours, Rate, and Distance of Travel from the JDA Tailrace Release Site to Array $1 \mathrm{~J}$ in Summer.

Table 3.54. Median Hours, Rate, and Distance of Travel from Array 3J through TDA to Array $1 \mathrm{~T}$ in Summer

Table 3.55. Summer Median time and Rate of Travel through BON 3.50

Table 3.56. Summer Median Time and Rate of Travel to Specific Routes at BON. 3.50 
Table 3.57. Summer Median Time and Rate of Travel through Specific Routes at Bonneville Dam Downstream to Array 1B.

Table 3.58. Travel Time for Subyearlings from the BON Smolt Monitoring Facility to Array 1B and from $1 \mathrm{~B}$ to $2 \mathrm{~B}$.

Table 3.59. Input Data, Simple Statistics, and Pearson Correlation Statistics for Physical Variables Affecting Detection Probabilities in 2006

Table 3.60. Pearson's Correlations on Survival Probabilities with Rate of Tagged Fish Travel, Forebay Water Temperature, and Discharge by JDA and TDA Release Locations for Spring 2006.

Table 3.61. Pearson's Correlations on Survival Probabilities with Rate of Tagged Fish Travel, Forebay Water Temperature, and Discharge by JDA and TDA Release Locations for Summer 2006

Table 4.1. Means and Standard Errors of Mean Detection Probabilities for Columbia River Releases of Chinook Salmon in Spring and Summer 2006.

Table 4.2. Probability of Tagged Yearling Chinook Salmon Being Detected at Least One of Three Arrays Downstream by JSATS Receivers in 2006 or by Radio Telemetry Receivers in Prior Studies in Spring....

Table 4.3. Probability of Tagged Subyearling Chinook Salmon Being Detected on at Least One of the Downstream Survival Arrays by JSATS Receivers in 2006 or by Radio Telemetry Receivers in Prior Studies in Summer 


\subsection{Introduction}

\subsection{Background}

Survival of juvenile salmonids passing the three lowermost dams on the Columbia River and associated river reaches has been an ongoing concern of the U.S. Army Corps of Engineers (USACE), Portland District (CENWP), and of the region. The Portland District is committed to increasing survival rates for fish passing its projects, and survival is one of the primary measures of success of management improvements at hydropower projects. The District is currently pursuing a transition from radio telemetry to acoustic telemetry for use in estimating project and dam passage behavior and survival. Acoustic telemetry is an attractive tool for several reasons. First, acoustic tags do not require an external antenna like those needed for radio-telemetry tags, and this makes them less invasive to the host. Second, hydrophones can detect fish throughout the water column, avoiding depth-detection biases sometimes observed with radio telemetry. Third, when deployed appropriately, acoustic telemetry can provide finescale two-dimensional (2D) and three-dimensional (3D) movement information to assess fish approach behavior and route of passage, as well as survival. Fourth, acoustic telemetry works in salt water as well as freshwater, so there is the potential to estimate survival out into the ocean. As part of this transition, the Portland District needed to conduct studies to evaluate detection capabilities, survival, and sample sizes required to provide desired levels of precision for future studies.

The Portland District directed and funded the development of the Juvenile Salmon Acoustic Telemetry System (JSATS) used in these studies, and there is hope that someday JSATS will allow researchers to assess survival at multiple hydropower projects and associated river reaches throughout the Snake and lower Columbia rivers. JSATS was first used for Columbia River Estuary survival studies conducted by the National Oceanic and Atmospheric Administration National Marines Fisheries Service (NOAA Fisheries) and PNNL in 2004 (McComas et al. 2004), 2005 (McComas et al. 2005), and 2006 (McComas et al. 2006). Before the study reported here, acoustic telemetry had only been used twice at Portland District projects, once at Bonneville Dam (BON) (Faber et al. 2001) and once at The Dalles Dam (TDA) (Cash et al. 2005) for describing fish passage and approach behavior. While acoustic telemetry studies near projects have been successful (Skalski et al. 2003a, 2003b), multi-project survival studies throughout a river system have not been attempted because of tag-life limitations at commonly used transmission rates.

All previous active tag survival studies on the lower river were conducted with radio telemetry. The use of radio telemetry to estimate survival of tagged fish at John Day Dam (JDA) was evaluated and deemed feasible in 1999 (Counihan et al. 2002a). Survival studies of smolt passage through JDA also were conducted in 2000 (Counihan et al. 2002b), 2002 (Counihan et al. 2006d), and 2003 (Counihan et al. 2006e). Reach survival was conducted from the release point above JDA to the JDA forebay and from JDA to the forebay of TDA (Counihan et al. 2002b and 2006a). Survival studies were conducted at TDA in 2002 (Counihan et al. 2006c), 2004 (Counihan et al. 2006a), and 2005 (Counihan et al. 2006b). Radio telemetry survival studies at BON were conducted in 2000 (Counihan et al. 2002b), 2002 (Counihan et al. 2003), 2004 (Counihan et al. 2006f), and 2005 (Counihan et al. 2006g).

\subsection{Studies}

In this report, we present acoustic telemetry survival studies for JDA, TDA, and BON as a single study because the primary goals were to estimate detection and survival probabilities based on sampling 
with JSATS equipment, to assess the feasibility of using JSATS for survival studies, and to estimate sample sizes needed to obtain a desired level of precision in future studies. The three studies were funded separately by the Portland District under the Anadromous Fish Evaluation Program, but they generally were executed as a single study with multiple objectives. Commonalities included surgically implanting yearling Chinook (YC) salmon in spring and sub-yearling Chinook (SYC) salmon in summer with JSATS tags that transmitted once every $5 \mathrm{~s}$ and assessing detection probabilities and survival from multiple release points through the study dams and tailwaters. River reach estimates were as important as projectspecific estimates for evaluating feasibility. There were elements of each study that were unique, but they were secondary to assessing the overall feasibility of the method and estimating required sample sizes for future survival studies. For example, we evaluated the passage rate, egress rate, and survival of fish passing through a single JDA turbine and the JDA Tailrace in spring. We estimated the survival of fish passing TDA, BON, and the BON spillway each season. Route-specific estimates also were made for the B2CC and the B2 Juvenile Bypass System (JBS) by using PIT tag detections from those routes to confirm the route of passage and to establish the population of tagged fish passing each route.

We released acoustically tagged fish in four locations in spring and two in summer and detected them on autonomous hydrophones deployed in arrays across the river at four locations below JDA and three each below TDA and BON. In spring, we had eight releases of tagged YC salmon into JDA Turbine 9C, the Turbine 9C discharge downstream of JDA, the JDA Tailrace, and the TDA Tailrace. In summer, we had five releases of SYC salmon into the JDA Tailrace and ten releases into the TDA Tailrace.

Other studies released JSATS-tagged YC and SYC salmon, and detections of some of those fish on our hydrophone arrays allowed us to estimate detection and survival probabilities for various reaches between JDA and Camas, Washington. The Tag Effects Study released 996 yearlings with tags that transmitted a coded signal once every $10 \mathrm{~s}$ below Lower Granite Dam in spring, and The Lower Monumental Reservoir Study released 1,949 sub-yearlings each with a 10-s tag below Little Goose Dam in summer. The Estuary Survival Study released fish with tags that transmitted once every $5 \mathrm{~s}$ into the BON Tailrace each season, and we used these as post-hoc control groups to formulate paired-release survival models for the Bonneville Project. In addition to release-specific estimates, we also made estimates based upon pooled detections above TDA and BON, and these virtual releases were used to estimate dam and tailwater survival.

\subsubsection{Objectives}

1. Surgically implant YC and SYC salmon with JSATS acoustic tags and PIT tags and release them in specific locations above and below JDA for estimating detection probabilities and survival for turbine-passed fish at JDA, reach survival through the TDA pool, and TDA Dam survival. Locations of the eight release groups of approximately equal numbers of YC salmon in spring included 1) Turbine Intake 9C (500 fish), 2) immediately downstream of Intake 9C discharge (Front Roll; 497 fish), and 3) in the tailwater several km downstream of the front roll discharge (481 fish). In summer, 299 tagged SYC salmon in five release groups of roughly equal size were put in the tailwater several kilometers downstream from the dam.

2. Surgically implant acoustic tags and pit tags in 978 YC salmon in spring and 2,179 SYC salmon in summer and release them along a transect across the river adjacent to the TDA Marina several kilometers below TDA to provide control releases for JDA treatment fish and treatment releases for estimating downstream reach survival and Bonneville Dam Survival. There were nine release groups of approximately equal size on different days in spring, and 10 release groups of approximately equal size on different days in summer. 
3. Deploy and maintain autonomous nodes in arrays in the JDA Tailwater, TDA Tailwater, and BON tailwater to detect acoustic tags passing downstream from upstream releases, as described in Objectives 1 and 2. Detections on the three arrays located in each of the three tailwaters were for estimating survival. Detections on the most upstream JDA tailwater array in spring were for estimating egress rates for fish released in a turbine, its front roll, and in the JDA tailwater. Detections on a BON spillway forebay array were for identifying tagged fish that had a high probability of passing the BON spillway.

4. Conduct a tag-life study on 1005 -s tags and 100 10-s tags randomly sampled from lots that will be used in all survival studies in 2006 and evaluate the need for tag-life corrections each season.

5. Estimate detection probabilities and survival by release group and pooled releases in a variety of ways:

a. By selecting different arrays to use as secondary and tertiary arrays in survival models for JDA and TDA. Compare survival estimates from each approach to see if the choice of secondary and tertiary arrays would have altered conclusions.

b. Estimate dam and tailwater survival, as described in Peven et al. (2005), for TDA and BON using fish detected on an array just above each project to form "virtual" releases through each dam.

c. Estimate project survival for TDA and BON from the point of release below the dam upstream to the primary array downstream of the project. This estimate includes survival of fish passing through the upstream pool, the project, and the tailwater. Develop posthoc, paired-release models in which detections of fish tagged and released below TDA are treated as reference releases for the treatment fish passing through TDA, and detections of fish tagged and released below BON are treated as reference releases for the treatment fish passing through BON. The ratio of these survival estimates provides a survival estimate for the upstream tailwater and the project, but excludes survival through the downstream tailwater.

d. Estimate route-specific survival estimates by forming virtual releases of fish detected at the B2CC and B2JBS by PIT tags and at the BON spillway by acoustic detections in the forebay. The spillway estimates also were examined by day and night and spill operational condition.

e. Make Cormack-Jolly-Sever single-release model estimates of survival for pooled release groups from each release point, including Snake River release points, through every reach in the study area using detection histories from successive sets of three arrays or from two arrays for the reach above the last array.

6. Host a workshop on using JSATS to estimate survival.

7. Estimate one-half $95 \%$ confidence intervals (CIs) associated with a range of different sample sizes of tagged fish given the detection probabilities and survival estimates from this study.

\subsection{Site Descriptions}

The study area covered $154 \mathrm{~km}$ of the lower Columbia River from JDA at river km (rkm) 347 downstream to Lady Island between Camas, Washington, and Troutdale, Oregon, at rkm 193. It included tailwaters below JDA, TDA, and Bonneville Dam (Figure 1.1). 


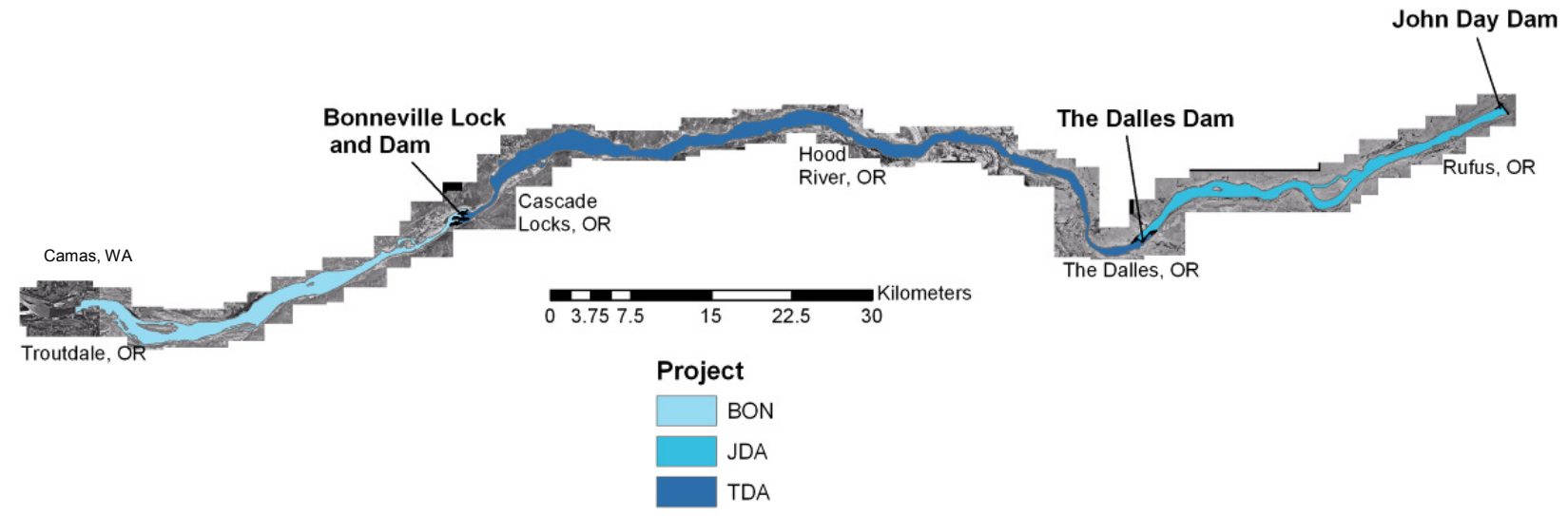

Figure 1.1. Tailwaters Below the Three Dams in this Study

John Day Dam is a single dam structure that consists of a 16 turbine-unit powerhouse on the Oregon side and a 20-bay spillway on the Washington side (Figure 1.2). The Smolt Monitoring Facility (SMF) below JDA served as the site for fish collection and tagging. Fish were released into Turbine Intake 9C, the front roll of Turbine 9 discharge downstream, and in the tailrace about $1.5 \mathrm{~km}$ downstream and across from the boat launch at Giles French Park. We deployed an egress detection array about $2.9 \mathrm{~km}$ downstream of JDA and survival detection arrays about 21.4, 22.8, and $34.6 \mathrm{~km}$ downstream of JDA. Detections of fish on the third survival array just above TDA were used to form virtual releases for estimating dam and tailwater survival for TDA.

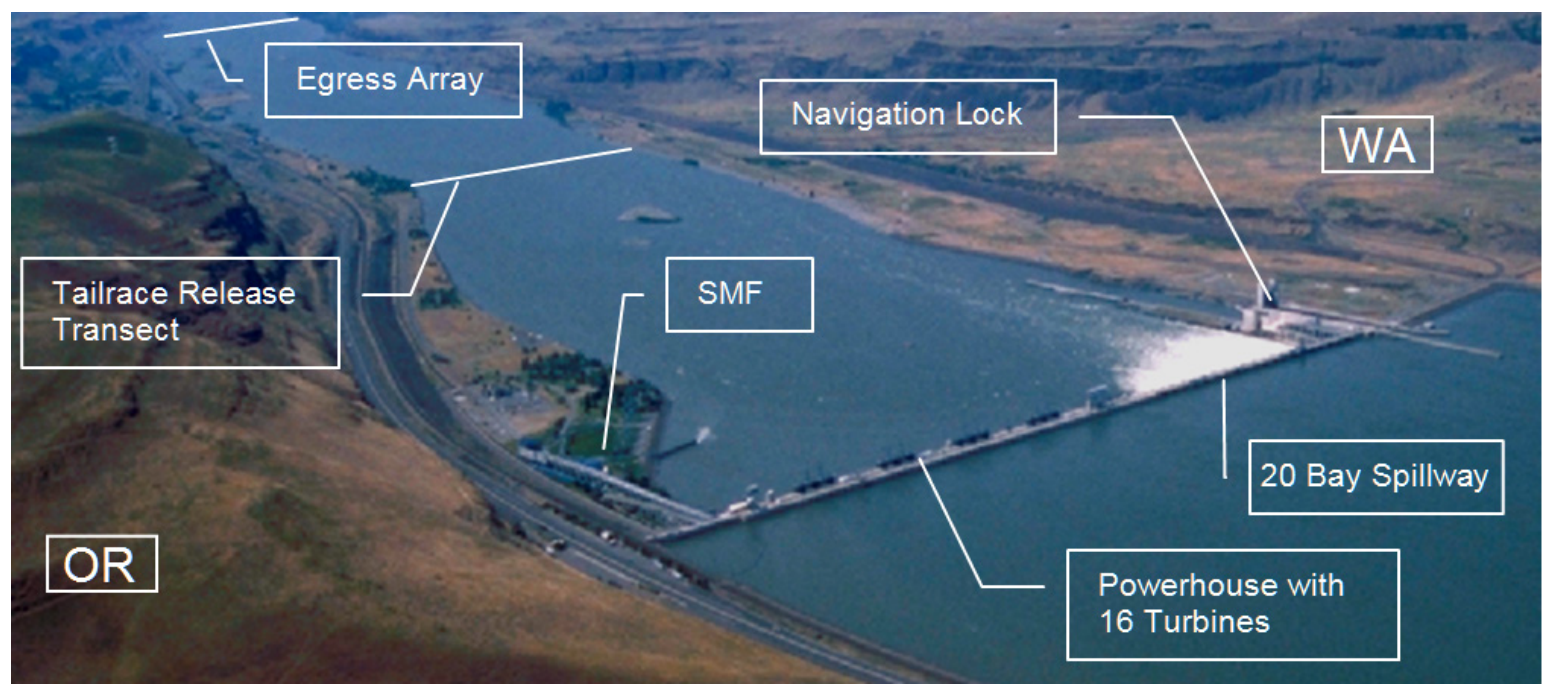

Figure 1.2. Aerial View of John Day Dam. SMF = Smolt Monitoring Facility.

The Dalles Dam is located at rkm 306 and consists of a 22-unit powerhouse, which runs parallel to the river channel, and a 23-bay spillway, which is perpendicular to the river channel and separated from the powerhouse by a non-flow section of dam (Figure 1.3). There was one fish release site located several kilometers below The Dalles Dam adjacent to The Dalles Marina. There were four detection arrays placed in the TDA Tailwater. The first three arrays were used to estimate survival down to Bonneville 
Dam, and the fourth array was located in the forebay of the BON spillway to detect fish passing there. The third array just above Boat Rock was used to detect tagged fish for virtual releases at BON.

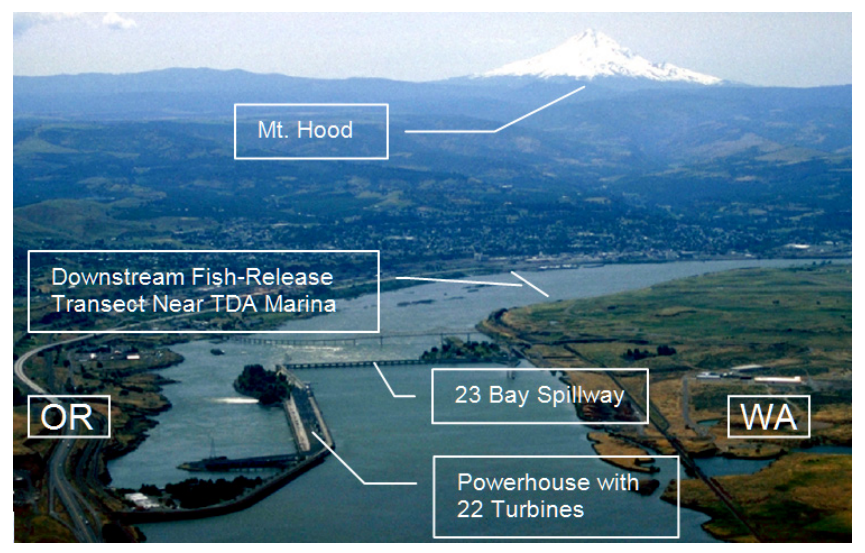

Figure 1.3. Aerial View of The Dalles Dam at rkm 307.8

Bonneville Lock and Dam consists of three dam structures that together complete a span of the Columbia River between Oregon and Washington at River Mile 146.1, about 40 miles east of Portland, Oregon (Figure 1.4). From the Oregon shore north toward Washington, the current project is composed of a navigation lock, a 10-turbine-unit First Powerhouse (B1), Bradford Island, an 18-gate spillway, Cascades Island, and an 8-turbine unit Second Powerhouse (B2). The Estuary Survival Study released fish into the Bonneville Smolt Monitoring Facility (SMF), and those fish entered the river at rkm 232.8. We deployed three detection arrays about 26.2, 31.0, and $41.2 \mathrm{rkm}$ below the SMF outfall.

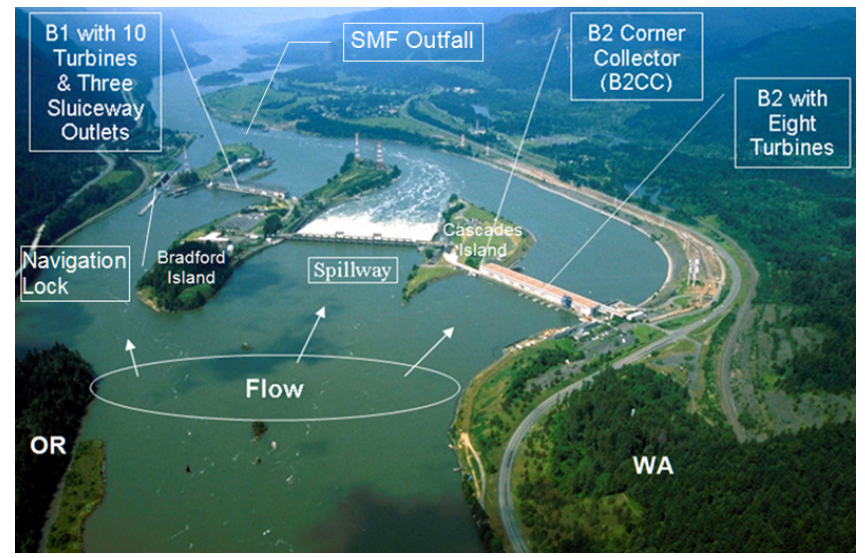

Figure 1.4. Plan View of the Bonneville Dam Project. The B1 sluiceway outlets and the B2 Corner Collector (B2CC) are surface overflow passage routes. Releases of fish from the Estuary Survival Study reentered the river at the SMF Outfall.

Throughout this report, we refer to locations on the river that are varying distances apart, so we created Table 1.1 to provide a quick reference to determine distances between locations. 
Table 1.1. Lookup Table for Determining Distances $(\mathrm{km})$ between Locations Referenced in this Study

\begin{tabular}{|c|c|c|c|c|c|c|c|c|c|c|c|c|c|c|c|c|c|c|c|c|c|c|c|c|c|c|}
\hline 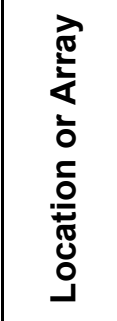 & 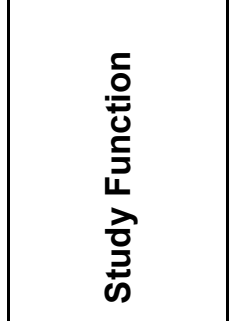 & 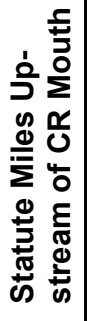 & 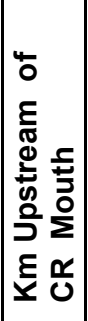 & $\begin{array}{l}\underline{x} \\
\underline{v} \\
\underline{S}\end{array}$ & 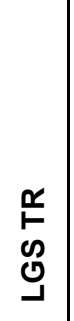 & 吅 & 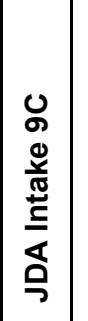 & 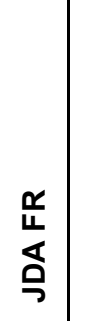 & $\begin{array}{l}\text { 足 } \\
\text { 品 }\end{array}$ & OJ & $1 \mathrm{~J}$ & $2 \mathrm{~J}$ & $3 \mathrm{~J}$ & 侣 & $\begin{array}{l}\text { 䒙 } \\
\text { 品 } \\
\text { - }\end{array}$ & 1T & $2 \mathrm{~T}$ & 3T & 㤐 & zo & 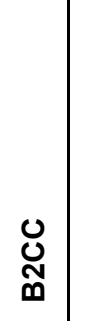 & 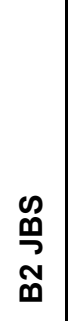 & $\begin{array}{l}\text { 足 } \\
\mathbf{z} \\
\text { ôn }\end{array}$ & 1B & 2B & $3 B$ \\
\hline & & & & 696.0 & 636.1 & 347.0 & \begin{tabular}{|l|l|}
347.0 & 3 \\
\end{tabular} & \begin{tabular}{|l|l|}
346.9 & 3 \\
\end{tabular} & \begin{tabular}{ll|l}
344.4 & 3 \\
\end{tabular} & 339.2 & 325.6 & 324.2 & 312.4 & 308.9 & 306.0 & 275.6 & 238.4 & 236.4 & 235.2 & \begin{tabular}{|l|l|l|}
234.4 & 2 \\
\end{tabular} & \begin{tabular}{|l|l|}
235.0 & 2 \\
\end{tabular} & $\left.232.8\right|_{2}$ & $232.8 \mathrm{z}^{2} \mathrm{x}$ & \begin{tabular}{l|l}
208.8 & 2 \\
\end{tabular} & \begin{tabular}{l|l}
204.0 & 1
\end{tabular} & 193.8 \\
\hline LGR TR & Release - Spr & 434.4 & 696.0 & 0.0 & \begin{tabular}{|l|} 
\\
\end{tabular} & 349.0 & \begin{tabular}{|l|l|}
349.0 & 3 \\
\end{tabular} & \begin{tabular}{|l|l|}
349.1 & 3 \\
\end{tabular} & \begin{tabular}{l|l}
351.6 & 3 \\
\end{tabular} & 356.8 & 370.4 & 371.8 & 383.6 & 387.1 & 390.1 & 420.4 & \begin{tabular}{|l|l|}
457.6 & \\
\end{tabular} & 459.6 & 460.8 & \begin{tabular}{|l|l|l|}
461.6 & 4 \\
\end{tabular} & \begin{tabular}{|l|l|}
462.6 & 4 \\
\end{tabular} & 463.2 & $463.2 \mathrm{|}$ & \begin{tabular}{ll|l}
487.2 & 4 \\
\end{tabular} & 492.0 5 & 502.2 \\
\hline LGS TR & Release - Sum & 393.1 & 636.1 & \begin{tabular}{|l|}
59.9 \\
\end{tabular} & 0.0 & \begin{tabular}{|l|l|}
289.12 & \\
\end{tabular} & \begin{tabular}{|l|l|l|}
289.1 & 2 \\
\end{tabular} & \begin{tabular}{|l|l|}
289.2 & 2 \\
\end{tabular} & \begin{tabular}{l|l}
291.7 & 2 \\
\end{tabular} & 296.9 & 310.5 & 311.9 & 323.7 & 327.2 & 330.2 & 360.5 & \begin{tabular}{|l|}
397.7 \\
\end{tabular} & 399.7 & 400.9 & $|401.7| 4$ & \begin{tabular}{|l|l|l}
4402.7 & 4
\end{tabular} & 403.3 & $403.3 \mid 4$ & \begin{tabular}{l|l}
427.3 & 4
\end{tabular} & $432.1 \mid 4$ & 442.3 \\
\hline JDA & Effects & 216.9 & 347.0 & 349.0 & 289.1 & 0.0 & 0.0 & 0.1 & 2.6 & 7.8 & \begin{tabular}{|l|}
21.4 \\
\end{tabular} & \begin{tabular}{|l|}
22.8 \\
\end{tabular} & 34.6 & 38.1 & 41.0 & 71.3 & \begin{tabular}{|l|}
108.6 \\
\end{tabular} & 110.6 & 111.8 & \begin{tabular}{|l|l|}
112.6 & 1 \\
\end{tabular} & \begin{tabular}{|l|l|}
113.6 & 1 \\
\end{tabular} & $114.2 \mid 1$ & \begin{tabular}{l|l}
114.2 & 1 \\
\end{tabular} & \begin{tabular}{l|l}
138.2 & 1 \\
\end{tabular} & $\begin{array}{lll}143.0 & 1 \\
\end{array}$ & 153.2 \\
\hline Intake 9C & Release - Spr & 216.9 & 347.0 & 349.0 & \begin{tabular}{|l|l|}
289.1 & \\
\end{tabular} & 0.0 & 0.0 & 0.1 & 2.6 & 7.8 & \begin{tabular}{|l|}
21.4 \\
\end{tabular} & \begin{tabular}{|l|}
22.8 \\
\end{tabular} & 34.6 & 38.1 & 41.0 & 71.3 & \begin{tabular}{|l|}
108.6 \\
\end{tabular} & 110.6 & 111.8 & \begin{tabular}{|l|l|}
112.6 & 1 \\
\end{tabular} & \begin{tabular}{|l|l|}
113.6 & 1 \\
\end{tabular} & 114.2 & \begin{tabular}{l|l}
114.2 & 1 \\
\end{tabular} & \begin{tabular}{l|l}
138.2 & 1 \\
\end{tabular} & \begin{tabular}{l|l}
143.0 & 1 \\
\end{tabular} & 153.2 \\
\hline JDA FR & Release - Spr & 216.8 & 346.9 & \begin{tabular}{|l|l|}
349.1 & \\
\end{tabular} & \begin{tabular}{|l|l}
289.2 \\
\end{tabular} & 0.1 & 0.1 & 0.0 & 2.5 & 7.6 & \begin{tabular}{|l|}
21.3 \\
\end{tabular} & \begin{tabular}{|l|}
22.6 \\
\end{tabular} & 34.5 & 38.0 & \begin{tabular}{|l|}
40.9 \\
\end{tabular} & 71.2 & \begin{tabular}{|c|}
108.5 \\
\end{tabular} & 110.5 & 111.7 & \begin{tabular}{|l|l|}
112.5 & 1 \\
\end{tabular} & \begin{tabular}{|l|l}
113.5 & 1 \\
\end{tabular} & 114.1 & \begin{tabular}{l|l}
114.1 & 1 \\
1
\end{tabular} & \begin{tabular}{l|l}
138.1 & 1
\end{tabular} & \begin{tabular}{l|l}
142.9 & 1 \\
\end{tabular} & 153.1 \\
\hline JDA TR & Release - Spr \& Sum & 215.2 & 344.4 & 351.6 & $291.7 \mid$ & 2.6 & 2.6 & 2.5 & 0.0 & 5.1 & \begin{tabular}{|c|}
18.8 \\
\end{tabular} & 20.1 & 32.0 & 35.5 & 38.4 & 68.7 & \begin{tabular}{|c|}
106.0 \\
\end{tabular} & 108.0 & 109.2 & \begin{tabular}{|l|l|l|}
110.0 & 1 \\
\end{tabular} & \begin{tabular}{|l|l|}
111.0 & 1 \\
\end{tabular} & 111.6 & \begin{tabular}{l|l}
111.6 & 1 \\
1
\end{tabular} & \begin{tabular}{l|l}
135.6 & 1 \\
\end{tabular} & \begin{tabular}{l|l}
140.4 & 1
\end{tabular} & 150.6 \\
\hline $0 \mathrm{~J}$ & JDA TR Egress & 212.0 & 339.2 & 356.8 & $296.9 \mid$ & 7.8 & 7.8 & 7.6 & 5.1 & 0.0 & \begin{tabular}{|l|}
13.6 \\
\end{tabular} & \begin{tabular}{|l|}
5.0 \\
\end{tabular} & 26.8 & 30.3 & 33.3 & 63.6 & \begin{tabular}{|l|l|}
100.8 \\
\end{tabular} & 102.8 & 104.0 & \begin{tabular}{|l|l|}
104.8 & 1 \\
\end{tabular} & \begin{tabular}{|l|l|}
105.8 & 1 \\
\end{tabular} & 106.4 | 1 & $106.4[1$ & \begin{tabular}{l|l|l}
130.4 & 1 \\
\end{tabular} & 135.211 & 145.4 \\
\hline $1 \mathrm{~J}$ & Survival & 203.5 & 325.6 & 370.4 & 310.5 & 21.4 & 21.4 & 21.3 & 18.8 & 13.6 & 0.0 & 1.4 & 13.2 & 16.7 & 19.6 & 49.9 & \begin{tabular}{|c|}
87.2 \\
\end{tabular} & 89.2 & 90.4 & 91.2 & \begin{tabular}{|c|}
92.2 \\
\end{tabular} & 92.8 & \begin{tabular}{l|l}
92.8 & 1 \\
1
\end{tabular} & \begin{tabular}{l|l}
116.8 & 1 \\
\end{tabular} & \begin{tabular}{l|l}
121.6 & 1 \\
1
\end{tabular} & 131.8 \\
\hline $2 \mathrm{~J}$ & Survival & 202.6 & 324.2 & 371.8 & 311.9 & 22.8 & 22.8 & \begin{tabular}{|l|l|}
22.6 \\
\end{tabular} & 20.1 & 15.0 & 1.4 & 0.0 & 11.8 & 15.3 & 18.3 & 48.6 & \begin{tabular}{|c|}
85.8 \\
\end{tabular} & 87.8 & 89.0 & 89.8 & 90.8 & \begin{tabular}{|c|}
91.4 \\
\end{tabular} & \begin{tabular}{l|l}
91.4 & 1
\end{tabular} & \begin{tabular}{l|l}
115.4 & 1 \\
\end{tabular} & \begin{tabular}{l|l}
120.2 & 1 \\
\end{tabular} & 130.4 \\
\hline $3 \mathrm{~J}$ & Survival & 195.2 & 312.4 & 383.6 & 323.7 & 34.6 & 34.6 & 34.5 & 32.0 & 26.8 & 13.2 & 11.8 & 0.0 & 3.5 & 6.4 & 36.8 & 74.0 & 76.0 & 77.2 & 78.0 & 79.0 & 79.6 & \begin{tabular}{c|c|c|c|}
799.6 & 1 \\
1
\end{tabular} & \begin{tabular}{l|l}
103.6 & 1 \\
\end{tabular} & \begin{tabular}{l|l}
108.4 & 1 \\
1
\end{tabular} & 118.6 \\
\hline TDA & Effects & 193.1 & 308.9 & 387.1 & 327.2 & 38.1 & 38.1 & 38.0 & 35.5 & 30.3 & 16.7 & 15.3 & 3.5 & 0.0 & 2.9 & 33.3 & 70.5 & 72.5 & 73.7 & 74.5 & 75.5 & 76.1 & \begin{tabular}{l|l}
76.1 & 1 \\
\end{tabular} & \begin{tabular}{l|l}
100.1 & 1 \\
\end{tabular} & \begin{tabular}{l|l}
104.9 & 1 \\
\end{tabular} & 115.1 \\
\hline TDA TR & Release - Spr \& Sum & 191.2 & 306.0 & 390.1 & 330.2 & 41.0 & 41.0 & 40.9 & 38.4 & 33.3 & 19.6 & \begin{tabular}{|l|}
18.3 \\
\end{tabular} & 6.4 & 2.9 & 0.0 & 30.3 & 67.6 & 69.6 & 70.8 & 71.6 & 72.6 & 73.2 & 73.2 & \begin{tabular}{l|l}
97.2 & 1 \\
\end{tabular} & \begin{tabular}{l|l}
102.0 & 1 \\
10
\end{tabular} & 112.2 \\
\hline $1 T$ & Survival & 172.3 & \begin{tabular}{|l|}
275.6 \\
\end{tabular} & \begin{tabular}{|c|}
420.4 \\
\end{tabular} & 360.5 & 71.3 & 71.3 & \begin{tabular}{ll|}
71.2 \\
\end{tabular} & 68.7 & 63.6 & 49.9 & 48.6 & 36.8 & 33.3 & 30.3 & 0.0 & 37.2 & 39.2 & 40.4 & \begin{tabular}{|l|}
41.2 \\
\end{tabular} & 42.2 & 42.8 & 42.8 & 66.8 & 71.6 & 81.8 \\
\hline $2 \mathrm{~T}$ & Survival & 149.0 & 238.4 & \begin{tabular}{|l|l|}
457.6 & -10 \\
\end{tabular} & \begin{tabular}{|c|}
397.7 \\
\end{tabular} & $|108.6| 1$ & \begin{tabular}{|l|l|l|l|}
108.6 & 1 \\
\end{tabular} & \begin{tabular}{|l|l|l|}
108.5 & 1 \\
\end{tabular} & \begin{tabular}{l|l}
106.0 & 1 \\
\end{tabular} & 100.8 & 87.2 & 85.8 & 74.0 & 70.5 & 67.6 & 37.2 & 0.0 & 2.0 & 3.2 & 4.0 & 5.0 & 5.6 & 5.6 & 29.6 & 34.4 & 44.6 \\
\hline $3 \mathrm{~T}$ & Survival & 147.8 & \begin{tabular}{|l|}
236.4 \\
\end{tabular} & \begin{tabular}{|l|l|}
459.6 & -1 \\
\end{tabular} & \begin{tabular}{|c|}
399.7 \\
\end{tabular} & \begin{tabular}{|c|c|c|}
110.6 & 1
\end{tabular} & \begin{tabular}{|l|l|l|l|}
110.6 & 1
\end{tabular} & \begin{tabular}{|l|l}
110.5 & 1 \\
\end{tabular} & \begin{tabular}{l|l}
108.0 & 1 \\
\end{tabular} & 102.8 & \begin{tabular}{|c|}
89.2 \\
\end{tabular} & \begin{tabular}{|c|}
87.8 \\
\end{tabular} & 76.0 & 72.5 & 69.6 & 39.2 & 2.0 & 0.0 & 1.2 & 2.0 & 3.0 & 3.6 & 3.6 & 27.6 & 32.4 & 42.6 \\
\hline $4 T^{*}$ & Detection & 147.0 & 235.2 & 460.8 & \begin{tabular}{|r|r}
400.9 \\
\end{tabular} & 111.8 & \begin{tabular}{|l|l|l|l|l}
111.8 & 1 \\
\end{tabular} & \begin{tabular}{|l|l|l|l|}
111.7 & 1 \\
\end{tabular} & \begin{tabular}{l|l}
109.2 & 1 \\
\end{tabular} & 104.0 & 90.4 & \begin{tabular}{|l|}
89.0 \\
\end{tabular} & 77.2 & 73.7 & 70.8 & 40.4 & 3.2 & 1.2 & 0.0 & 0.8 & 1.8 & 2.4 & 2.4 & 26.4 & 31.2 & 41.4 \\
\hline BON & Effects & 146.9 & 234.4 & \begin{tabular}{|l|l|}
461.6 & \multicolumn{1}{|c|}{$\mid$} \\
\end{tabular} & \begin{tabular}{|c|}
401.7 \\
\end{tabular} & \begin{tabular}{|l|l|}
112.6 & 1 \\
\end{tabular} & \begin{tabular}{|l|l|l|l|}
112.6 & 1
\end{tabular} & \begin{tabular}{|l|l}
112.5 & 1 \\
\end{tabular} & \begin{tabular}{l|l}
110.0 & 1 \\
\end{tabular} & 104.8 & 91.2 & \begin{tabular}{|c|}
89.8 \\
\end{tabular} & 78.0 & 74.5 & 71.6 & 41.2 & 4.0 & 2.0 & 0.8 & 0.0 & 1.0 & 1.6 & 1.6 & 25.6 & 30.4 & 40.6 \\
\hline B2CC & Effects & 146.8 & 235.0 & \begin{tabular}{|c|}
462.6 \\
\end{tabular} & \begin{tabular}{|l|}
402.7 \\
\end{tabular} & 113.6 & \begin{tabular}{|c|c|}
113.6 & 1 \\
\end{tabular} & \begin{tabular}{|l|l}
113.5 & 1 \\
\end{tabular} & \begin{tabular}{l|l}
111.0 & 1 \\
\end{tabular} & 105.8 & 92.2 & \begin{tabular}{|c|}
90.8 \\
\end{tabular} & 79.0 & 75.5 & 72.6 & 42.2 & 5.0 & 3.0 & 1.8 & 1.0 & 0.0 & 0.6 & 0.6 & 24.6 & 29.4 & 39.6 \\
\hline B2 JBS & Effects & 145.5 & 232.8 & \begin{tabular}{|c|}
463.2 \\
\end{tabular} & \begin{tabular}{|c|}
403.3 \\
\end{tabular} & \begin{tabular}{|c|}
114.2 \\
\end{tabular} & \begin{tabular}{|l|l|l|l|}
114.2 & 1 \\
\end{tabular} & \begin{tabular}{|l|l}
114.1 & 1 \\
\end{tabular} & \begin{tabular}{l|l}
111.6 & 1 \\
\end{tabular} & 106.4 & \begin{tabular}{|c|}
92.8 \\
\end{tabular} & \begin{tabular}{|c|}
91.4 \\
\end{tabular} & 79.6 & 76.1 & 73.2 & 42.8 & 5.6 & 3.6 & 2.4 & 1.6 & 0.6 & \begin{tabular}{c|c}
0.0 \\
\end{tabular} & 0.0 & 24.0 & 28.8 & 39.0 \\
\hline BON TR & Release - Spr \& Sum & 145.5 & 232.8 & \begin{tabular}{|c|}
463.2 \\
\end{tabular} & 403.3 & 114.2 & \begin{tabular}{|l|l|l|l|l}
114.2 & 1 &
\end{tabular} & \begin{tabular}{|l|l|}
114.1 & 1 \\
\end{tabular} & \begin{tabular}{l|l}
111.6 & 1 \\
\end{tabular} & 106.4 & 92.8 & \begin{tabular}{|c|}
91.4 \\
\end{tabular} & 79.6 & 76.1 & 73.2 & 42.8 & 5.6 & 3.6 & 2.4 & 1.6 & 0.6 & 0.0 & 0.0 & 24.0 & 28.8 & 39.0 \\
\hline $1 \mathrm{~B}$ & Survival & 130.5 & 208.8 & \begin{tabular}{|l|l|}
487.2 \\
\end{tabular} & \begin{tabular}{|l|l}
427.3 \\
\end{tabular} & \begin{tabular}{|l|l|l}
138.2 & 1 \\
1
\end{tabular} & \begin{tabular}{|l|l|l}
138.2 & 1 \\
\end{tabular} & \begin{tabular}{|l|l|l}
138.1 & 1 \\
\end{tabular} & \begin{tabular}{l|l}
135.6 & 1 \\
\end{tabular} & 130.4 & \begin{tabular}{|c|}
116.8 \\
\end{tabular} & \begin{tabular}{|c|}
115.4 \\
\end{tabular} & 103.6 & 100.1 & 97.2 & 66.8 & 29.6 & 27.6 & 26.4 & 25.6 & 24.6 & 24.0 & 24.0 & 0.0 & 4.8 & 15.0 \\
\hline $2 \mathrm{~B}$ & Survival & 127.5 & 204.0 & \begin{tabular}{|c|}
492.0 \\
\end{tabular} & 432.1 & 143.0 & \begin{tabular}{|l|l|l|}
143.0 & 1 \\
\end{tabular} & \begin{tabular}{|l|l}
142.9 & 1 \\
\end{tabular} & \begin{tabular}{l|l}
140.4 & 1 \\
\end{tabular} & 135.2 & 121.6 & 120.2 & 108.4 & 104.9 & 102.0 & 71.6 & 34.4 & 32.4 & 31.2 & 30.4 & 29.4 & 28.8 & 28.8 & 4.8 & 0.0 & 10.2 \\
\hline 3B & Survival & 121.1 & 193.8 & 502.2 & 442.3 & 153.2 & 153.2 & \begin{tabular}{|l|l}
153.1 & 1
\end{tabular} & \begin{tabular}{l|l}
150.6 & 1
\end{tabular} & 145.4 & 131.8 & 130.4 & 118.6 & 115.1 & 112.2 & 81.8 & 44.6 & 42.6 & 41.4 & 40.6 & 39.6 & 39.0 & 39.0 & 15.0 & 10.2 & 0.0 \\
\hline
\end{tabular}




\subsection{Materials and Methods}

\subsection{Fish Collection}

\subsubsection{Site Description}

Juvenile Chinook salmon were collected and tagged at the JDA SMF. The SMF is situated on the south side of JDA at the downriver edge of a fish bypass system where out-migrating juvenile salmon and other fishes are routed through a series of flumes and dewatering structures before reentering the Columbia River at an outfall located downstream of the facility.

\subsubsection{Federal and State Permitting}

Records were kept on all smolts handled and collected (both target and non-target species) for permit accounting. Collections were conducted in conjunction with routine sampling at the SMF to minimize handling impacts. Surgical candidates collected from routine SMF target sample sizes were accounted for under permits issued to the SMF. Additional fish needed to meet research needs (beyond SMF goals) were accounted for under separate Federal and State permits.

A federal scientific take permit was authorized for this study by the NOAA Fisheries Hydropower Division's Federal Columbia River Power System (FCRPS) Branch and administered by the National Oceanic and Atmospheric Administration, permit number 10-06 BAT. This permit was authorized under the 2004 FCRPS Biological Opinion.

The Oregon Department of Fish and Wildlife authorized take for this study under permit number OR 2006-3287. This permit was authorized under the 2004 FCRPS Biological Opinion.

All requirements and guidelines of both permits were met. Several amendments were made throughout the season to reflect variances in numbers of in-stream migrants. Reports of collection and release were reported to both agencies.

\subsubsection{Sampling Methods}

Juvenile fish were diverted from the bypass system and routed into a 1,795-gal holding tank within the SMF. About 250 smolts and other fishes were crowded with a panel net into a 20- by 24-inch preanesthetic (PA) chamber. Water levels in the PA chamber were lowered to about 8 inches (48 liters) to obtain the sample size necessary for tagging the following day. Fish were anesthetized with $60 \mathrm{~mL}$ of a stock tricaine methanesulfonate (MS-222) solution prepared at a concentration of $50 \mathrm{~g} \mathrm{~L}^{-1}$. Once induction was achieved, fish were routed into the examination trough. MS-222 was added as needed to maintain induction in the trough and PolyAqua ${ }^{\mathrm{TM}}$ was liberally used to reduce fish stress. Water temperatures were monitored between the main holding tank and examination trough and refreshed in the trough before a $2^{\circ} \mathrm{F}$ temperature difference was reached between the tank and the trough.

Once in the examination trough, smolts targeted for surgical procedures were evaluated under specific acceptance and rejection criteria, as follows.

Accept if:

- $\quad$ adipose-fin clipped

- $\quad$ sized $>95 \mathrm{~mm}$. 
Reject if:

- non-target species

- more than $20 \%$ descaling on any one side

- $\quad$ signs of prior surgery (for instance: radio tags, sutures, or PIT tag scars)

- positive readings when put through a PIT tag reader

- visible elastomer tag(s)

- gross signs of disease (such as Bacterial Kidney Disease [BKD]) or sub-dermal parasites.

Non-target and unacceptable fish were released to the river through the SMF holding system after a 30-min. recovery period. Accepted fish were counted into transfer buckets containing fresh river water and moved to one of three 80-gal pre-surgical holding tanks. Fish were held in the 80-gal circulars for 24 hours before surgery.

\subsection{Fish Tagging}

\subsubsection{JSATS Acoustic Micro-transmitter}

The JSATS acoustic micro-transmitter (acoustic tag, Figure 2.1) weighs $0.65 \mathrm{~g}$ in air and $0.37 \mathrm{~g}$ in water. The acoustic tag is $17 \mathrm{~mm}$ long and $5.5 \mathrm{~mm}$ wide. The tag must be activated prior to insertion into the fish. The acoustic tags used in this study and in the Estuary Survival Study, which released fish in the BON Tailrace, had a ping rate of 1 pulse every $5 \mathrm{~s}$ to provide an expected tag life of about 30 days. Chinook salmon smolts tagged and released into the Snake River all had JSATS tags that transmitted once every $10 \mathrm{~s}$ to provide a tag life of about 55 days.

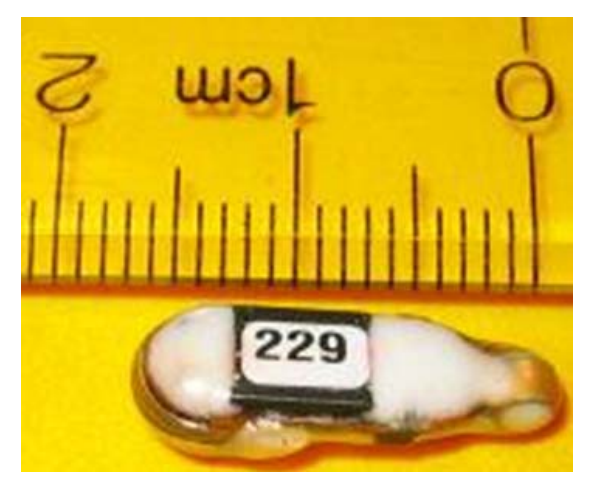

Figure 2.1. JSATS Acoustic Micro-Transmitter with Ruler for Scale

\subsubsection{Fish Tagging}

A team of six people participated in the tagging process to reduce the handling time from netting to post-surgery recovery. Fish were netted in small groups from the 80-gal holding tanks and placed in a 5gal "knockdown" bucket with water and a $20-\mathrm{mL}$ solution of $80 \mathrm{mg} / \mathrm{L}$ dilution of MS-222. Once a fish lost equilibrium, it was transferred to a processing table in a small container of river water. Each fish was measured (fork length $\pm 1 \mathrm{~mm}$ ), weighed ( $\pm 0.1 \mathrm{~g}$ ), and returned to the small transfer container along with an assigned PIT tag and an activated acoustic tag. Another biologist entered fork length, weight, and tag numbers in PNNL Tag-Tracker software, which added the data to an Access database. The data entry system minimizes errors by reading PIT-tag numbers with a PIT-tag reader and acoustic tag codes with a 
mobile hydrophone system. The transfer container, fish, and tags were assigned a recovery bucket number and routed to a surgeon for tag implantation.

During surgery, the fish was placed ventral side up and a gravity-fed anesthesia supply line was placed into the fish's mouth. The dilution of this “maintenance” line was $40 \mathrm{mg} / \mathrm{L}$. A 6-8 mm incision, using a \#10 or \#15 stainless steel surgical blade, was made ventrally, $3 \mathrm{~mm}$ from and parallel to the midventral line and equidistant from the pelvic girdle and pectoral fin. The PIT tag was inserted first followed by the acoustic tag. Both tags were inserted toward the anterior portion of the fish. Two interrupted sutures were used to close the incision. For yearling Chinook salmon, 5-0 vicryl sutures were used with a C-3 needle (Figure 2.2). For subyearlings, 5-0 vicryl sutures were also used but with an FS-2 needle. With the incision closed, fish were then taken to an oxygenated recovery bucket containing river water.

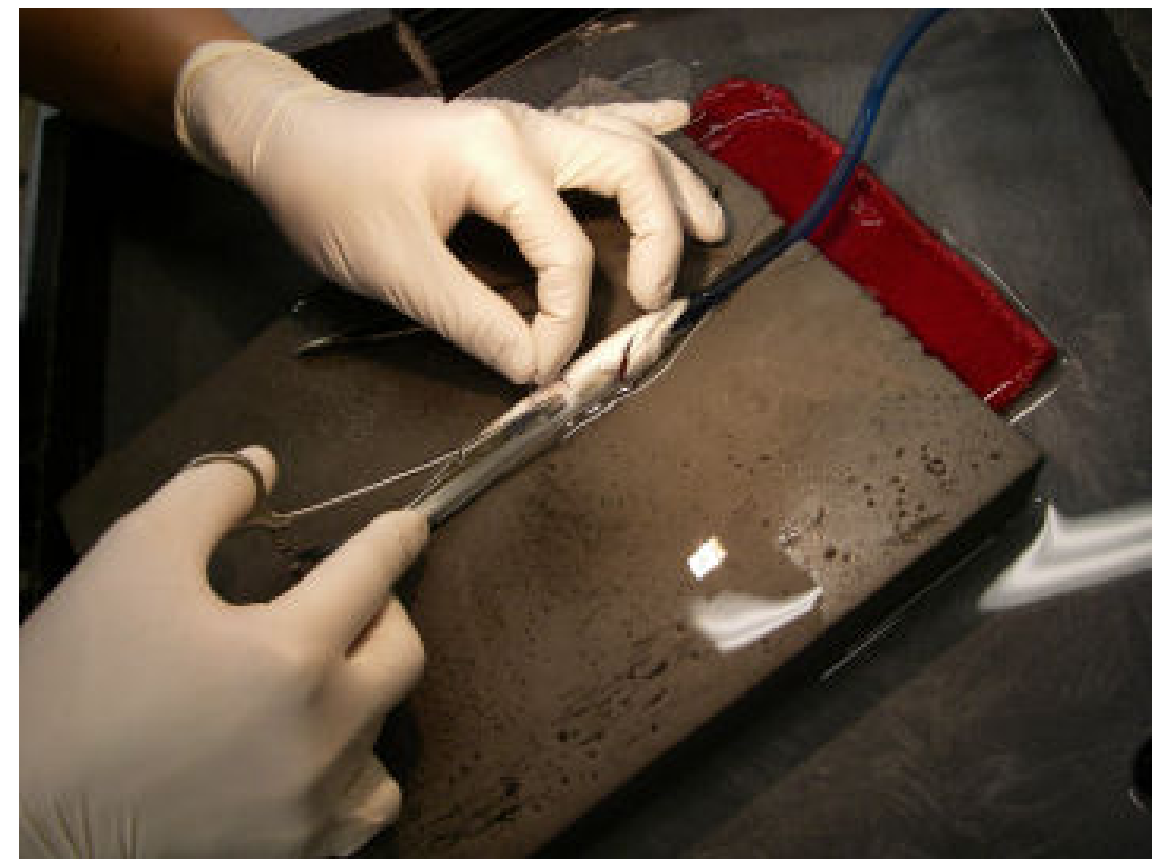

Figure 2.2. Closing of Incision Using a 5-0 Vicryl Suture with a C-3 Needle

\subsubsection{Recovery and Holding}

Tagged fish were placed in 4-gal oxygenated recovery buckets and closely monitored until fish had reestablished equilibrium. Each bucket held 5 to 10 fish depending on the number of fish to be released at each site. The buckets were then carried to a larger holding tank where they were supplied with a continuous feed of river water (Figure 2.3). Fish were held and monitored for 24 hrs prior to release. The large holding tank was insulated to keep the water temperature within acceptable limits. A water level, temperature, and dissolved oxygen monitoring system was installed to automatically call staff if waterquality conditions were undesirable for fish. Alert limits were set to a maximum of $21.7^{\circ} \mathrm{C}$ and a minimum of $7 \mathrm{mg} / \mathrm{L}$ of oxygen. 




Figure 2.3. Post-Surgery Holding Tank with Recovery Buckets

\subsection{Transportation and Release}

\subsubsection{Transportation Procedures}

A Wells Cargo trailer was outfitted with two 180-gal Bonar insulated totes and one 70-gal Bonar insulated tote. Each 180-gal tote could hold 12 4-gal fish buckets and the 70-gal tote could hold 6 fish buckets. Totes had snug-fitting lids and some extra space inside and behind a wood-frame separator so that ice could be added for cooling on hot days. A network of valves and plastic tubing were attached to $\mathrm{O}_{2}$ tanks for delivering oxygen to individual fish buckets from 2,200 psi $\mathrm{O}_{2}$ tanks in the trailer during transport.

Fish buckets were removed from the post-surgery holding tank and topped off with river water. They were then moved into the totes and an oxygen line was inserted into a hole in the top of the fish bucket. After all the buckets were loaded in the totes, each bucket was checked to make sure it was receiving $\mathrm{O}_{2}$.

\subsubsection{Fish Releases}

Other studies released yearling and subyearling Chinook salmon that were detected on receivers deployed in this study (Table 2.1). Numbers of fish tagged are listed in Table 2.2 (spring) and Table 2.3 (summer).

Table 2.1. Dates and Numbers of Yearling and Subyearling Chinook Salmon Tagged with JSATS Tags and Released in Other 2006 Studies

\begin{tabular}{|c|c|c|c|c||}
\hline Age Class & $\begin{array}{c}\text { Release } \\
\text { Location }\end{array}$ & $\begin{array}{c}\text { Release } \\
\text { Date }\end{array}$ & $\begin{array}{c}\text { Number } \\
\text { Released }\end{array}$ & Total \\
\hline Yearling & LGR Tailrace & $05 / 06 / 2006$ & 238 & \\
\hline Yearling & LGR Tailrace & $05 / 13 / 2006$ & 758 & 996 \\
\hline Sub-Yearling & LGS Tailrace & $06 / 16 / 2006$ & 195 & \\
\hline Sub-Yearling & LGS Tailrace & $06 / 21 / 2006$ & 195 & \\
\hline Sub-Yearling & LGS Tailrace & $06 / 24 / 2006$ & 195 & \\
\hline Sub-Yearling & LGS Tailrace & $06 / 27 / 2006$ & 195 & \\
\hline Sub-Yearling & LGS Tailrace & $07 / 01 / 2006$ & 195 & \\
\hline Sub-Yearling & LGS Tailrace & $07 / 04 / 2006$ & 195 & \\
\hline Sub-Yearling & LGS Tailrace & $07 / 07 / 2006$ & 194 & \\
\hline Sub-Yearling & LGS Tailrace & $07 / 10 / 2006$ & 192 & \\
\hline Sub-Yearling & LGS Tailrace & $07 / 14 / 2006$ & 198 & \\
\hline \hline Sub-Yearling & LGS Tailrace & $07 / 18 / 2006$ & 195 & 1,949 \\
\hline
\end{tabular}


Table 2.2. Numbers of Tagged and Released Yearling Chinook Salmon in Spring 2006

\begin{tabular}{|c|c|c|c|c|c|c|}
\hline Date & $\begin{array}{l}\text { Age } \\
\text { Class }\end{array}$ & $\begin{array}{l}\text { Number } \\
\text { Tagged }\end{array}$ & $\begin{array}{c}\text { Release } \\
\text { Date }\end{array}$ & $\begin{array}{l}\text { Release } \\
\text { Location }\end{array}$ & $\begin{array}{l}\text { Number } \\
\text { Released }\end{array}$ & Mortalities \\
\hline \multirow{4}{*}{$5 / 15 / 2006$} & \multirow{4}{*}{ Yearling } & \multirow{4}{*}{262} & \multirow{4}{*}{ 5/16/2006 } & JDA Intake 9C & 55 & 0 \\
\hline & & & & JDA Front Roll & 55 & 1 \\
\hline & & & & JDA Tailrace & 55 & 1 \\
\hline & & & & TDA Tailrace & 97 & 1 \\
\hline \multirow{4}{*}{$5 / 18 / 2006$} & \multirow{4}{*}{ Yearling } & \multirow{4}{*}{303} & \multirow{4}{*}{ 5/19/2006 } & JDA Intake 9C & 63 & 0 \\
\hline & & & & JDA Front Roll & 60 & 1 \\
\hline & & & & JDA Tailrace & 60 & 0 \\
\hline & & & & TDA Tailrace & 120 & 0 \\
\hline \multirow{4}{*}{$5 / 20 / 2006$} & \multirow{4}{*}{ Yearling } & \multirow{4}{*}{298} & \multirow{4}{*}{$5 / 21 / 2006$} & JDA Intake 9C & 58 & 0 \\
\hline & & & & JDA Front Roll & 60 & 1 \\
\hline & & & & JDA Tailrace & 60 & 0 \\
\hline & & & & TDA Tailrace & 120 & 0 \\
\hline \multirow{4}{*}{$5 / 22 / 2006$} & \multirow{4}{*}{ Yearling } & \multirow{4}{*}{298} & \multirow{4}{*}{ 5/23/2006 } & JDA Intake 9C & 68 & 0 \\
\hline & & & & JDA Front Roll & 70 & 0 \\
\hline & & & & JDA Tailrace & 70 & 0 \\
\hline & & & & TDA Tailrace & 90 & 0 \\
\hline \multirow{4}{*}{$5 / 24 / 2006$} & \multirow{4}{*}{ Yearling } & \multirow{4}{*}{212} & \multirow{4}{*}{$5 / 25 / 2006$} & JDA Intake 9C & 60 & 0 \\
\hline & & & & JDA Front Roll & 60 & 0 \\
\hline & & & & JDA Tailrace & 42 & 1 \\
\hline & & & & TDA Tailrace & 50 & 2 \\
\hline \multirow{4}{*}{$5 / 26 / 2006$} & \multirow{4}{*}{ Yearling } & \multirow{4}{*}{328} & \multirow{4}{*}{ 5/27/2006 } & JDA Intake 9C & 80 & 0 \\
\hline & & & & JDA Front Roll & 80 & 0 \\
\hline & & & & JDA Tailrace & 79 & 2 \\
\hline & & & & TDA Tailrace & 89 & 4 \\
\hline \multirow{4}{*}{$5 / 31 / 2006$} & & & & JDA Intake 9C & 60 & 0 \\
\hline & Youding & 297 & C/1/200द & JDA Front Roll & 60 & 0 \\
\hline & y earlıng & $26 /$ & $6 / 1 / 2006$ & JDA Tailrace & 80 & 1 \\
\hline & & & & TDA Tailrace & 67 & 0 \\
\hline & & & & JDA Intake 9C & 56 & 0 \\
\hline & & & & JDA Front Roll & 55 & 0 \\
\hline 6/2/2006 & Yearling & 320 & 6/3/2006 & JDA Tailrace & 54 & $14^{(\mathrm{a})}$ \\
\hline & & & & TDA Tailrace & 153 & 0 \\
\hline & & & & JDA Intake 9C & 0 & 0 \\
\hline 6 & Voprling & 212 & 6/5/2006 & JDA Front Roll & 0 & 0 \\
\hline $6 / 4 / 2006$ & Y earlıng & 212 & b/5/2006 & JDA Tailrace & 0 & 0 \\
\hline & & & & TDA Tailrace & 214 & 0 \\
\hline & & & & JDA Intake 9C & 500 & 0 \\
\hline & & & & JDA Front Roll & 500 & 3 \\
\hline Totals & Yearling & 2500 & Totals & JDA Tailrace & 500 & $19^{(\mathrm{b})}$ \\
\hline & & & & TDA Tailrace & 1000 & 7 \\
\hline
\end{tabular}


Table 2.3. Numbers of Tagged and Released Sub-Yearling Chinook Salmon in Summer 2006

\begin{tabular}{|c|c|c|c|c|c|c|}
\hline Date & $\begin{array}{l}\text { Age } \\
\text { Class }\end{array}$ & $\begin{array}{l}\text { Number } \\
\text { Tagged }\end{array}$ & $\begin{array}{c}\text { Release } \\
\text { Date }\end{array}$ & $\begin{array}{l}\text { Release } \\
\text { Location }\end{array}$ & $\begin{array}{l}\text { Number } \\
\text { Released }\end{array}$ & Mortalities \\
\hline \multirow{2}{*}{ 6/12/2006 } & \multirow{2}{*}{$\begin{array}{c}\text { Sub- } \\
\text { Yearling }\end{array}$} & \multirow{2}{*}{250} & \multirow{2}{*}{$6 / 13 / 2006$} & JDA Tailrace & 50 & 0 \\
\hline & & & & TDA Tailrace & 200 & 4 \\
\hline \multirow{2}{*}{$6 / 14 / 2006$} & \multirow{2}{*}{$\begin{array}{c}\text { Sub- } \\
\text { Yearling }\end{array}$} & \multirow{2}{*}{250} & \multirow{2}{*}{$6 / 15 / 2006$} & JDA Tailrace & 50 & 0 \\
\hline & & & & TDA Tailrace & 200 & 0 \\
\hline \multirow{2}{*}{ 6/19/2006 } & \multirow{2}{*}{$\begin{array}{c}\text { Sub- } \\
\text { Yearling }\end{array}$} & \multirow{2}{*}{250} & \multirow{2}{*}{$6 / 20 / 2006$} & JDA Tailrace & 50 & 0 \\
\hline & & & & TDA Tailrace & 200 & 4 \\
\hline \multirow{2}{*}{$6 / 21 / 2006$} & \multirow{2}{*}{$\begin{array}{c}\text { Sub- } \\
\text { Yearling }\end{array}$} & \multirow{2}{*}{250} & \multirow{2}{*}{ 6/22/2006 } & JDA Tailrace & 50 & 1 \\
\hline & & & & TDA Tailrace & 200 & 0 \\
\hline \multirow{2}{*}{ 6/26/2006 } & \multirow{2}{*}{$\begin{array}{c}\text { Sub- } \\
\text { Yearling }\end{array}$} & \multirow{2}{*}{300} & \multirow{2}{*}{ 6/27/2006 } & JDA Tailrace & 100 & 0 \\
\hline & & & & TDA Tailrace & 200 & 0 \\
\hline 6/27/2006 & $\begin{array}{c}\text { Sub- } \\
\text { Yearling }\end{array}$ & 200 & 6/28/2006 & TDA Tailrace & 200 & 0 \\
\hline 6/30/2006 & $\begin{array}{c}\text { Sub- } \\
\text { Yearling }\end{array}$ & 250 & 7/1/2006 & TDA Tailrace & 250 & 5 \\
\hline $7 / 6 / 2006$ & $\begin{array}{c}\text { Sub- } \\
\text { Yearling }\end{array}$ & 250 & 7/7/2006 & TDA Tailrace & 250 & 2 \\
\hline 7/10/2006 & $\begin{array}{c}\text { Sub- } \\
\text { Yearling }\end{array}$ & 250 & 7/11/2006 & TDA Tailrace & 250 & 4 \\
\hline 7/12/2006 & $\begin{array}{c}\text { Sub- } \\
\text { Yearling }\end{array}$ & 252 & 7/13/2006 & TDA Tailrace & 252 & 6 \\
\hline \multirow{2}{*}{ Totals } & \multirow{2}{*}{$\begin{array}{c}\text { Sub- } \\
\text { Yearling }\end{array}$} & \multirow{2}{*}{2502} & \multirow{2}{*}{ Totals } & JDA Tailrace & 300 & 1 \\
\hline & & & & TDA Tailrace & 2202 & $25^{(\mathrm{a})}$ \\
\hline
\end{tabular}

A Multiquip 270-gpm dewatering pump was used to pump water from the forebay up to an induction tank on deck (Figure 2.4) through a 4" suction hose and back into the gatewell slot of Turbine Intake 9C. The release hose was mounted to a scintillation frame at mid-depth (131.5 ft msl). When the induction tank and downstream hose were full of water, we poured a bucket of fish into the tank and pulled the standpipe in the center of the tank. The suction created by the downstream hose pulled the water and fish from the tank down into the intake slot. All releases occurred after 2100 hours.

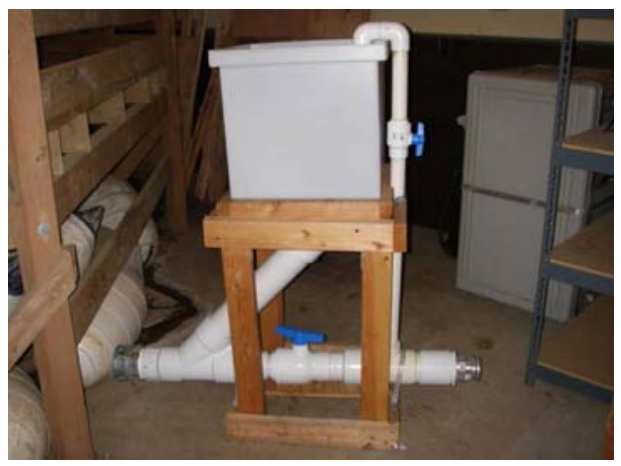

Figure 2.4. Release Apparatus for Turbine Intake 9C Releases at JDA in Spring

For boat releases, we moved the fish buckets from the transport totes into the stern of a boat. The boat operator maneuvered the boat to the release location and put the motor in neutral. Fish buckets were 
opened and checked for mortalities ("morts"). We scanned all dead fish with a BioMark portable transceiver PIT tag scanner so that identities could be established and recorded. We also recorded the release site, a number from 1 to 5 indicating relative distance from the Oregon shore and the time each bucket of tagged fish was emptied into the river.

\subsection{Steps Taken to Minimize Handling Impacts}

Numerous steps were taken to minimize the handling impacts of collection and surgical procedures. The collection of all tagged fish was done in conjunction with the JDA Smolt Monitoring Collection Facilities normal collection. The use of these already collected fish allowed us to minimize the impact of having to collect further fish to meet our quota for the day.

The number of personnel on hand was the biggest contributor to ensuring that all tagged fish were handled in a manner that was least intrusive on their survivability. Overall handling time was a consideration that was met with enough personnel to tag effectively and in a timely manner. Six people participated. One individual was responsible for anesthetizing fish and delivering them to be weighed and measured. Two people were responsible for weighing, measuring, and recording tagging data, and three did surgeries to implant fish with tags.

Several steps used in the actual tagging process also helped to minimize the handling impact on tagged fish. Sterilization of all surgical instruments was a continuous and emphasized protocol. Each surgeon used 3-4 complete sets of instruments. When a set was not being used it was placed in a 70\% ethanol solution for approximately 10 minutes. All instruments would be rotated before each use and for a duration of 10 minutes, to a solution of distilled water to "wash" all residual ethanol off before the instruments would be used for surgery. This allowed bacteria and other harmful particulates to not be introduced into the incision or suture areas. To counteract the disruption of the mucus membrane from the incision, Poly-Aqua was used to help replace the membrane that was removed from the fish's epidermal layers (Table 2.4). Local anesthetic was not used on the incision site due to its characteristic of further disrupting the mucus membrane.

Table 2.4. Dilution of Poly-Aqua Used in Surgical Procedures

\begin{tabular}{|c|c|}
\hline Volume of Water & Poly-Aqua \\
\hline $1 \mathrm{~L}$ & 0.15 \\
\hline $2 \mathrm{~L}$ & 0.30 \\
\hline $3 \mathrm{~L}$ & 0.45 \\
\hline $4 \mathrm{~L}$ & 0.60 \\
\hline $5 \mathrm{~L}$ & 0.75 \\
\hline $6 \mathrm{~L}$ & 0.90 \\
\hline $10 \mathrm{~L}$ & 1.50 \\
\hline $20 \mathrm{~L}$ & 3.00 \\
\hline $50 \mathrm{~L}$ & 7.50 \\
\hline 1 gallon & 0.60 \\
\hline 5 gallons & 2.80 \\
\hline 10 gallons & 5.70 \\
\hline 50 gallons & 28.40 \\
\hline
\end{tabular}


The actual surgical procedure was also designed in such a way as to minimize handling. The proximity of the incision to the midline was closely monitored to ensure that neither incisions nor sutures went through the midline.

Monitoring of all buckets containing anesthesia solution was a vital part of minimizing handling affects. Anesthesia buckets were kept to \pm 2 degrees of current river temperatures. Anesthesia solutions were either replaced or cooled with ice when temperatures exceeded protocols. Recovery buckets were also monitored in the same manner. Transportation of fish from the JDA Smolt Monitoring Facility to the TDA release site also warranted close monitoring of water temperatures and oxygen delivery to buckets.

\subsection{Detection of Tagged Fish}

\subsubsection{Nodes and Arrays, Defined}

Sonic Concepts' autonomous acoustic telemetry receiver (referred to hereafter as a node) consisted of two coupled parts. The top was made from Schedule 404 -inch-diameter PVC pipe that was capped at the top and had a fitting with male threading at the bottom (Figure 2.5). The cap was modified for water-tight seating of a hydrophone, and the body below the cap housed the analog and digital boards for processing detected tag signals. A lubricated 4-inch-diameter rubber o ring was fitted over the lower threaded end so it would form a water-tight seal when the node top was screwed together with the bottom. The node bottom was made from about $3 \mathrm{ft}$ of 4-inch-diameter PVC pipe and the upper end had a fitting with female threads for coupling it with the node top. The lower end of the node bottom was capped and a stainless steel harness was located just below the upper fitting so the node could be attached to an anchor system, which is described later. A 4x-power 15-second acoustic beacon was attached to the outside of the battery housing just below the threaded end of the housing. This beacon was used to determine the location of a node if it didn't surface after it was acoustically released from an anchor. Beacons also could be used to determine when an adjacent node disappeared.

Immediately before deployment, two 30-day lithium ion batteries were gently lowered into the node bottom with battery leads and secured in place with a battery retention device. Wire leads from the batteries were attached to connectors from the analog board in the node top. One end of a serial cable was connected to a plug from the board set in the node top and the other end was plugged into a laptop computer so that staff could communicate with the node, set its date and time, and verify detection of a beacon tag. Next, a 1-GB compact flash (CF) card was mounted in a slot on the board set, and the node top and bottom were screwed together until beveled edges of each piece compressed the o ring to form a watertight seal. The air space within the battery housing provided positive buoyancy, while the batteries provided ballast to help keep the node upright.

All autonomous hydroacoustic nodes were received from Sonic Concepts with either version 2005 or 2006 software and thoroughly tested by Precision Acoustic Systems (PAS) to ensure that nodes met acceptance-testing criteria. Functionality also was verified just before each deployment in the river.

An array is defined as a group of nodes deployed within 1 to $2 \mathrm{~km}$ of a specific river cross section to detect passing fish with acoustic tags. Most arrays had nodes that were deployed within $600 \mathrm{ft}$ of each other and within $300 \mathrm{ft}$ of the shore in a line across the river. However, additional nodes sometimes had to be deployed in entrances to or exits from side channels formed by islands downstream of BON. 


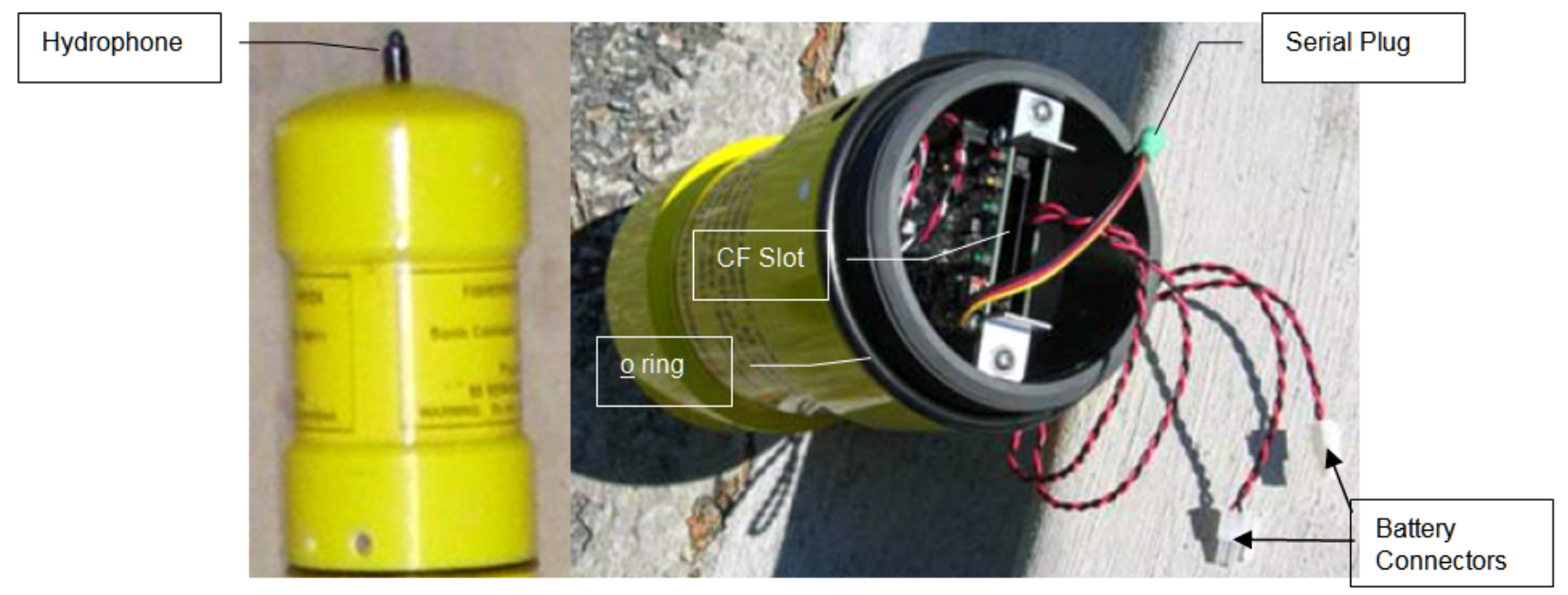

Figure 2.5. Side (left) and Bottom (right) View of a Node Top

\subsubsection{Arrays and Release Locations}

\subsubsection{John Day Dam and Tailwater}

The three release locations at JDA included the Turbine Intake 9C (rkm 347.0), the Front Roll (rkm 346.9) located 100 to $200 \mathrm{ft}$ off the downstream face of the dam at Unit 9, and the JDA Tailrace at rkm 344.4. An egress-detection array was deployed about $7.8 \mathrm{~km}$ below JDA near Giles French Landing (Figure 2.6) during the spring. It was used to estimate the time required for fish released in the turbine, front roll, and tailrace to leave the immediate tailrace area and not to estimate survival. The first array was located at about rkm 325.6, the second at rkm 324.2, and the third at rkm 312.4 (Figure 2.6). This was about 21.4, 22.8, and 34.6 rkm below JDA, respectively. The third array just above TDA was used to detect fish and establish virtual releases for TDA. Array locations were selected based upon bathymetric conditions favorable for acoustic detection of passing transmitters, and criteria included narrow river cross sections without islands or shallow bars.

\subsubsection{The Dalles Tailwater}

The TDA Tailrace release transect was located at rkm 306.0, about $1.7 \mathrm{rkm}$ downstream from TDA. The first TDA array was located at about rkm 275.6 (near the Bingen Marina), the second at rkm 238.4, and the third array at rkm 236.4 (Figure 2.7). These were about 33.3, 70.5, and 72.5 km below TDA, respectively. The third array just above Boat Rock was used to detect fish and establish virtual releases for BON. A fourth array was installed at the BON spillway forebay at rkm 235.0, which is about $73.9 \mathrm{rkm}$ downstream from TDA The first three arrays were for estimating detection and survival probabilities, and the fourth was for detecting fish passing through the BON spillway.

\subsubsection{Bonneville Dam and Tailwater}

The primary BON array was located at about rkm 208.8 near Rooster Rock State Park, Oregon; the secondary at rkm 204.0 near Washougal, Washington; and the tertiary at rkm 193.8 near Lady Island (Figure 2.8). The primary, secondary, and tertiary arrays were located about 26.2, 31.0, and $41.2 \mathrm{rkm}$ below the outfall of the SMF release site in the BON Tailrace at rkm 232.8. 


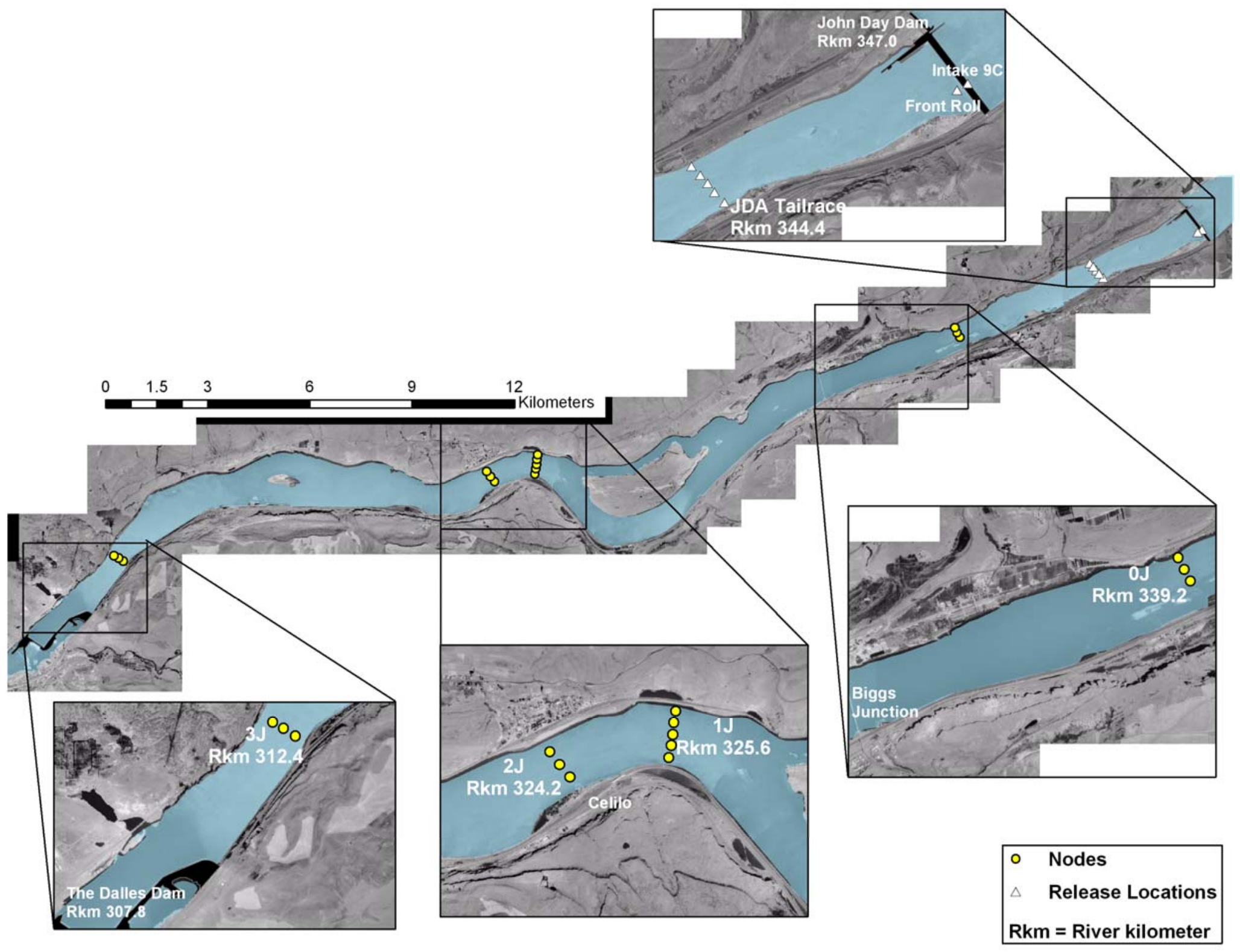

Figure 2.6. Columbia River with Yellow Circles Indicating Waypoints at Autonomous Node Locations for the Four JDA Tailwater Arrays. From right to left the arrays were JDA Egress (0J), and the JDA Primary (1J), 2J, and 3J. The Dalles Dam is located on the far left. In the upper right, white triangles mark the three JDA fish release locations: Intake 9c, Front roll, and JDA Tailrace. 


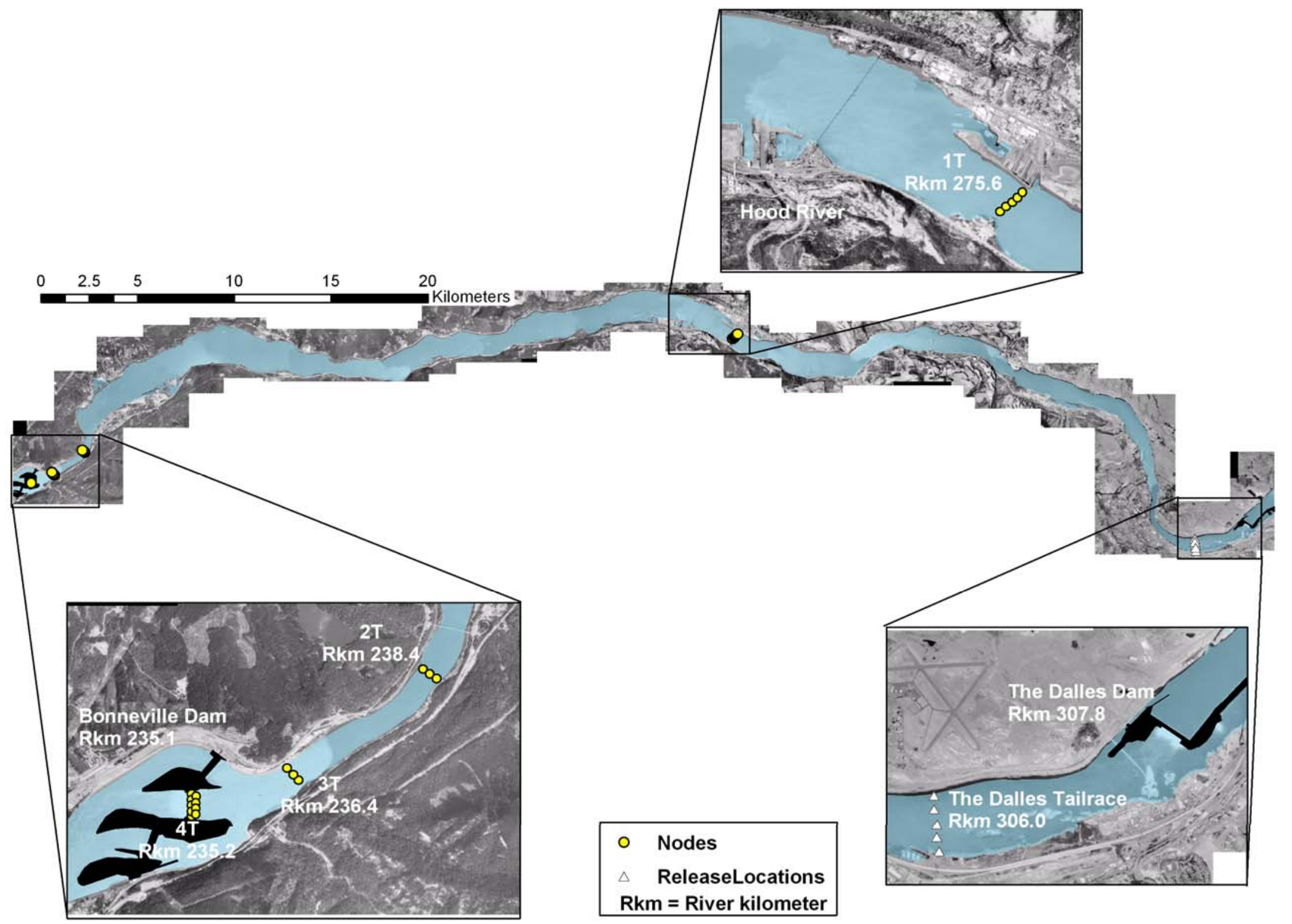

Figure 2.7. Columbia River with White Triangles Marking a Tailrace Release Location Below TDA and Yellow Circles Marking Waypoints of Autonomous Node Locations in Four TDA Tailrace Arrays. From right to left, the diagram shows The Dalles Dam, the tailrace release site, survival arrays $1 \mathrm{~T}, 2 \mathrm{~T}, 3 \mathrm{~T}$, and the BON Spillway detection array (4T). 


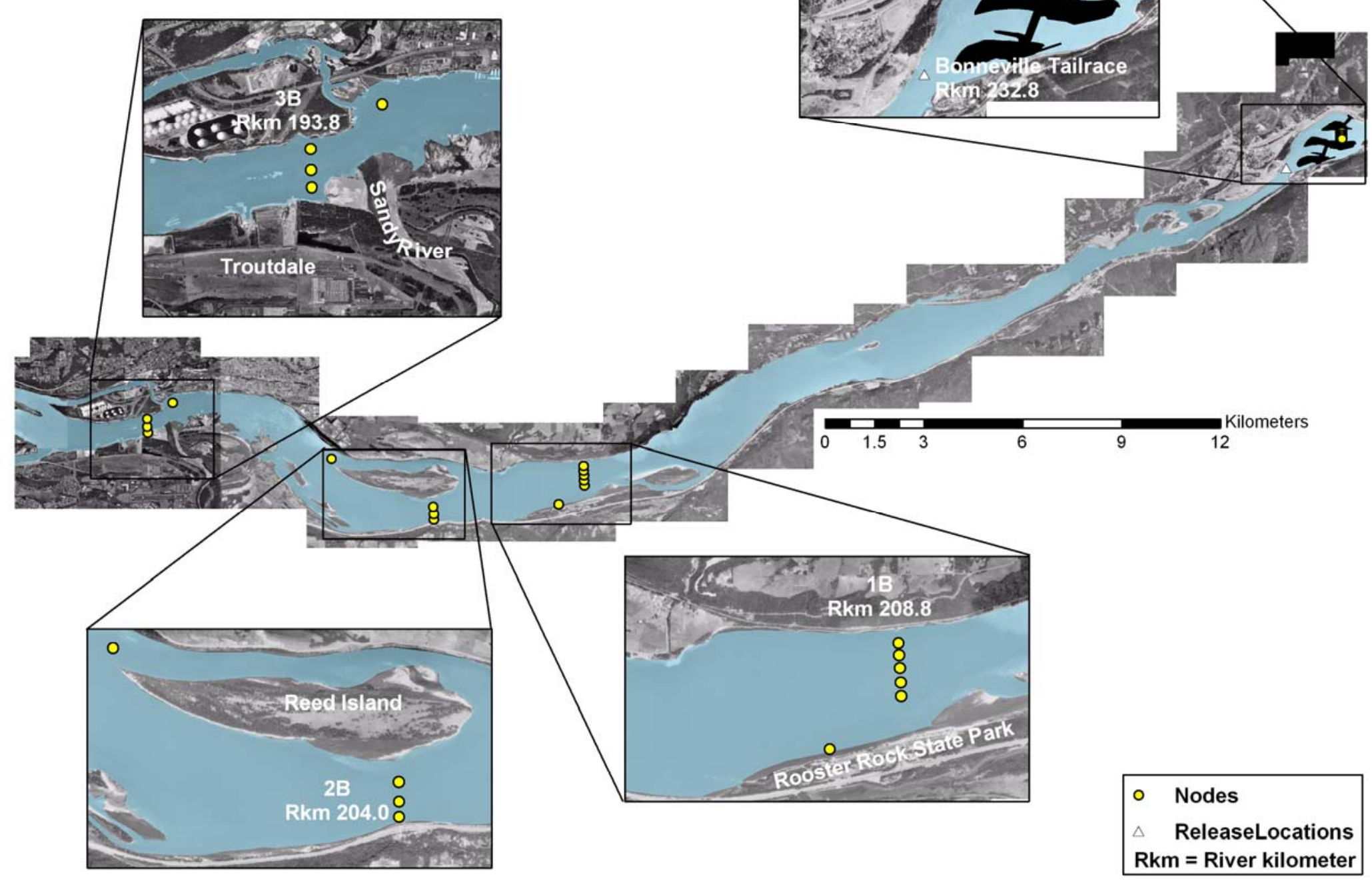

Figure 2.8. Columbia River with Yellow Circles Marking Waypoints of Autonomous Node Locations for BON Survival Arrays 1B, 2B, and 3B in the Tailwater (Left) and White Triangles Marking the BON Tailrace Release Location (Upper Right). Array 4T in the BON Spillway Forebay also is visible in the upper right. 
For both the spring and summer season, fish that were tagged and released for the acoustic telemetry project in the estuary were also used to supplement sample size for survival calculations throughout the BON arrays. These released fish were also used to estimate survival through the BON project using a paired release model. These fish were released from the JBS outfall at rkm 232.8 (Figure 2.8).

\subsubsection{Node Deployment}

After initial deployments, all autonomous nodes were rigged with the configuration shown in Figure 2.9. A 5-foot section of line with three 6-pound buoyancy floats was attached to a strap half way between the node tip and the battery housing bottom. An InterOcean Systems Model 11 acoustic release was attached to the other end of the 5-foot line. Either 6 or $12 \mathrm{ft}$ of cable was attached to the bottom of the acoustic release, depending on water depth and the other end of the cable was attached to a 120-lb anchor. The shorter 6- $\mathrm{ft}$ length was used in water $<40 \mathrm{ft}$ deep and the 12-ft length was used in water $>40 \mathrm{ft}$ deep.

During the initial deployments, a tag-line canister was attached to the acoustic release and filled with $250 \mathrm{ft}$ of nylon line that connected the release to the anchor. When the release was triggered, the node, floats, and release surfaced while line played out of the canister, and if retrieved quickly, the anchor could be recovered and reused. However, given high river flow in spring, the assembly usually only surfaced briefly before re-submerging, and then crews had to drag for nodes to retrieve them. Dragging can be a time consuming process, so the tag-line canister and anchor line were not used in subsequent deployments.

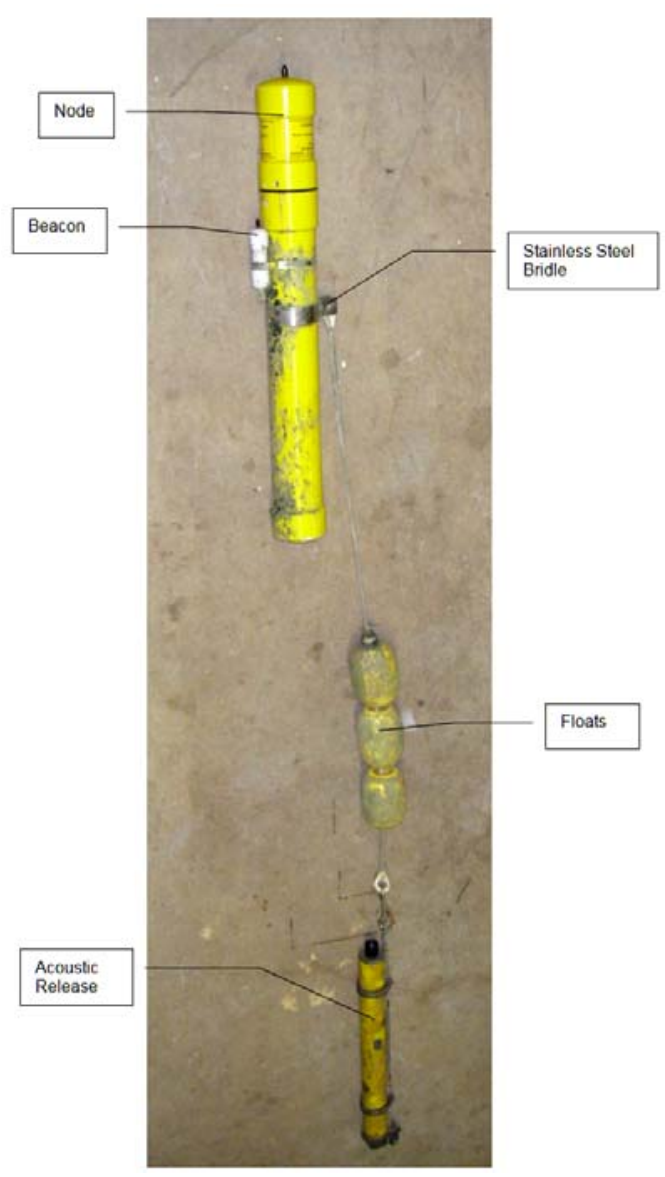

Figure 2.9. Node Rigging without the 120-Pound Anchor Shown 6 to $12 \mathrm{ft}$ below the Acoustic Release 


\subsubsection{Node Retrieval, Servicing, and Redeployment}

We tried to retrieve data from all nodes every week, but high river flows precluded this during some of the spring. Nodes were serviced to replenish the batteries every 4 weeks. The first step in servicing a node was to trigger its acoustic release by entering a release-specific code into a transceiver that transmitted an electrical signal to a underwater transducer, which in turn converted the electrical signal into code-specific acoustic transmissions to activate the release mechanism. Once the node, floats, and acoustic release surfaced, they were retrieved by boat (Figure 2.10). The next step was to dry the node with a towel, open it, dismount the compact flash (CF) card, and download data from the card to a laptop. We checked the data file to verify that the node collected data throughout its last deployment, records were continuous, and records included time stamps and tag detections. We replaced the CF card and batteries and redeployed the node. If the data were corrupt, the node top was replaced with a new one and the faulty top was sent to Sonic Concepts for repair. The most common problem was damage to the hydrophone tip. Nodes were serviced and redeployed until September 30, 2006, to provide maximum opportunity to detect late migrating subyearling Chinook salmon released on the Snake River.



Figure 2.10. Autonomous Node Retrieval

\subsection{Project Discharge and Water Temperature}

Project discharge data from automated data-acquisition systems for all three dams, including discharge by spill bay and turbine unit, were provided by the Portland District, USACE, in 5-minute increments. The 10-year (1996 to 2005) average discharge and forebay water temperature data were downloaded from the DART (Data Access in Real Time) website (http://www.cbr.washington.edu/dart). Five-minute discharge data were averaged by location and day and by location and hour and merged with temperature data and later with release-specific survival estimates for correlation analysis. 


\subsection{Data Processing and Validation}

Tag detection data were processed in two ways as a quality-control measure, and we found no significant difference in detection and survival estimates based upon detection histories generated by the two methods. One method involved using TagViz software, and the other involved processing data with programs written in Statistical Analysis System (SAS) code. Regardless of the method, tag, release, and detection data were merged into a single dataset, and the same rules were applied to detection data to identify array detection and generate detection histories for every tag. Those rules included the following:

1. Tags codes were detected downstream of the release site.

2. Tags codes were detected after the release date and time.

3. Decode intervals were 8 to $32 \mathrm{~s}$ for tags transmitting once every 10 seconds and from 3 to $22 \mathrm{~s}$ for tags transmitting once every 5 seconds.

4. Detection rates were four in $120 \mathrm{~s}$ for 10 -s tags and four in $60 \mathrm{~s}$ for 5 -s tags.

Unless otherwise noted, straight lines and curves on graphs are linear and quadratic fits using ordinary least squares after first establishing that there was little evidence of lack of fit using higher order polynomials.

\subsection{Tag Life Study}

Ninety-nine subyearling Chinook salmon from Priest Rapids Hatchery were surgically implanted with JSATS acoustic tags that transmitted once every 10 seconds (10 s tags) and another 100 were implanted with tags transmitting once every 5 seconds ( $5 \mathrm{~s}$ tags). The surgical implantation procedure followed the procedures outlined in Section 2.2.2 above. The fish were held in tanks at PNNL's on-site wetlab in Richland, WA. When a tagged fish died, the tag was re-implanted in another fish until the tag died. A JSATS mobile node was used to listen for tags daily and tag-life history data were compiled to produce tag-life curves, which indicate the percent of each tag type transmitting as a function of days since activation.

\subsection{Release-Recapture Designs}

\subsubsection{Overview}

Various release and recapture studies with yearling and subyearling Chinook salmon smolts were conducted in 2006.

\subsubsection{Definition of Metrics}

In this report, we define single-release reach survival estimates by the upstream and downstream boundaries of the reach of interest. Some additional definitions are needed to clarify paired-release survival metrics:

Forebay is the segment of river immediately upstream of a dam where operations at the dam are the primary contributing factor to velocity and direction of water flow. The upstream boundary of a forebay is where a significant alteration in water-flow allocation through dam operational changes affects water velocity or direction. The downstream boundary is the upstream face of the dam. Locations of forebay arrays for TDA and BON in this study were not selected based upon measurable hydraulic criteria, and in 
both cases probably were 1 to $3 \mathrm{~km}$ upstream of the hydraulic influence of each dam most of the time. There is no single location that would meet this definition all of the time.

Tailrace is the segment of river immediately downstream of the dam where dam operations are the primary factor affecting velocity and direction of flow. The upstream boundary of the tailrace is the downstream face of the dam and the downstream boundary is where operational changes at the dam no longer effect the direction of water flow and mixing from the spillway and powerhouse is complete. Our tailrace release locations below JDA and TDA were pretty close or slightly downstream of the downstream hydraulic influence of those dams most of the time, whereas the outfall release point below BON likely was still within the influence of that dam most of the time. There is no single location that would meet this definition all of the time.

Reservoir or Pool is the segment of river downstream of the tailrace of an upstream dam down to the forebay of the next dam downstream.

Tailwater is the segment of river downstream of the tailrace of an upstream dam down to the forebay of the next dam downstream or to the point where salt-water mixing occurs for the last dam in a series (e.g., BON). Tailwater is synonymous with reservoir or pool when it lies between two dams.

Project survival is the probability of survival from the upstream boundary of the reservoir or pool of a dam to the downstream boundary of the tailrace of the dam. Studies utilizing active tags typically use paired release survival models to estimate this parameter whereas studies utilizing PIT tags have typically used single-release survival models.

Dam survival is the probability of survival from the upstream boundary of the forebay to the downstream boundary of the tailrace and includes the forebay, all routes of passage, and the tailrace of a given dam. In this study, dam survival is loosely defined as being from a forebay detection line to the tailrace release location for reference release groups of fish.

Passage-route survival is the probability of survival for fish passing through any individual route (i.e., spillway, turbine, bypass, etc.) to the downstream boundary of the tailrace (release location of a tailrace reference group). In this study passage-route survival was estimated for fish passing Turbine Intake 9C at John Day Dam and those passing the spillway, B2 JBS, and B2 Corner Collector at Bonneville Dam.

\subsubsection{Yearling Detection and Survival Metrics}

For yearling Chinook salmon, we estimated detection probabilities and survival statistics for

1. LGR releases to Array $1 \mathrm{~J}$ and from Array $1 \mathrm{~J}$ to $1 \mathrm{~T}$ from detections at $1 \mathrm{~J}, 1 \mathrm{~T}$, and $2 \mathrm{~T}$ (single release model)

2. JDA Turbine Intake 9C, the 9C Front Roll, and Tailrace releases to $1 \mathrm{~J}$ and from $1 \mathrm{~J}$ to $1 \mathrm{~T}$ from detections at $1 \mathrm{~J}, 1 \mathrm{~T}$, and $2 \mathrm{~T}$ (single release model)

3. Paired release estimates for the JDA Intake 9C and Front Roll relative to each other and to the Tailrace release using detections at $1 \mathrm{~J}, 1 \mathrm{~T}$, and $2 \mathrm{~T}$. The paired-release estimate to the JDA Tailrace is a passage-route survival estimate, as defined above.

4. TDA Tailrace releases to $1 \mathrm{~T}$ and from $1 \mathrm{~T}$ to $2 \mathrm{~T}$ from detections at $1 \mathrm{~T}, 2 \mathrm{~T}$, and $1 \mathrm{~B}$ (single release model)

5. $\mathrm{BON}$ Tailrace releases to $1 \mathrm{~B}$ and from $1 \mathrm{~B}$ to $2 \mathrm{~B}$ from detections on $1 \mathrm{~B}, 2 \mathrm{~B}$, and $3 \mathrm{~B}$ (single release model) 
6. Virtual Releases from the TDA Forebay (Array 3J) to 1T and from 1T to 2T using 1T, 2T, and 1B detections (single release model)

7. Dam survival for TDA by post-hoc pairing of the pooled estimate for virtual releases from the TDA Forebay (Item 6 above) with the pooled estimate for TDA Tailrace releases (Item 4 above) in a paired release model

8. Virtual Releases from BON Forebay (4T) to $1 \mathrm{~B}$ and from $1 \mathrm{~B}$ to $2 \mathrm{~B}$ using $1 \mathrm{~B}, 2 \mathrm{~B}$, and $3 \mathrm{~B}$ detections (single release model)

9. Dam survival for BON by post-hoc pairing of the pooled estimate for virtual releases from the BON Forebay (Item 8 above) with the pooled estimate for BON Tailrace releases (Item 5 above) in a paired release model

10. TDA Project survival, as defined above, by post-hoc pairing of JDA Tailrace and TDA Tailrace releases in a paired-release model using detections at Arrays 1T, 2T, and 1B

11. The BON Project, as defined above, by post-hoc pairing of TDA Tailrace and BON Tailrace releases in a paired release model using detections at Arrays 1B, 2B, and 3B

12. Every study reach from release point to each successive array except the last array below Bonneville Dam (single release models)

13. BON spillway, B2 JBS, and B2CC survival based upon populations defined by acoustic detections at the spillway and PIT detections elsewhere and using acoustic detections at Arrays 1B, 2B, and 3B. These are passage-route survivals, as defined above.

\subsubsection{Subyearling Detection and Survival Metrics}

For subyearling Chinook salmon, we estimated detection probabilities and survival statistics for:

1. LGS releases to Array $1 \mathrm{~J}$ and from $1 \mathrm{~J}$ to $1 \mathrm{~T}$ from detections at $1 \mathrm{~J}, 1 \mathrm{~T}$, and $2 \mathrm{~T}$ (single release model)

2. JDA Tailrace releases to $1 \mathrm{~J}$ and from $1 \mathrm{~J}$ to $1 \mathrm{~T}$ from detections at $1 \mathrm{~J}, 1 \mathrm{~T}$, and $2 \mathrm{~T}$ (single release model)

3. TDA Tailrace releases to $1 \mathrm{~T}$ and from $1 \mathrm{~T}$ to $2 \mathrm{~T}$ from detections at $1 \mathrm{~T}, 2 \mathrm{~T}$, and $1 \mathrm{~B}$ (single release model)

4. BON Tailrace releases to $1 \mathrm{~B}$ from detections on $1 \mathrm{~B}$ and $2 \mathrm{~B}$ (single release model)

5. Virtual Releases from the TDA Forebay (Array 3J) to $1 \mathrm{~T}$ and from $1 \mathrm{~T}$ to $2 \mathrm{~T}$ using $1 \mathrm{~T}, 2 \mathrm{~T}$, and $1 \mathrm{~B}$ detections (single release model)

6. Dam survival for TDA by post-hoc pairing of the pooled estimate for virtual releases from the TDA Forebay (Item 5 above) with the pooled estimate for TDA Tailrace releases (Item 3 above) in a paired release model

7. Virtual Releases from the BON Forebay (Array $3 \mathrm{~T}$ ) to $1 \mathrm{~B}$ using detections at Arrays $1 \mathrm{~B}$ and $2 \mathrm{~B}$ (single release model)

8. Dam survival for BON by post-hoc pairing of the pooled estimate for virtual releases from the BON Forebay (Item 7 above) with the pooled estimate for BON Tailrace releases (Item 4 above) in a paired release model

9. After post-hoc pairing with BON Tailrace releases, division of estimates for fish in virtual forebay releases (Item 7 above) by estimates for fish released in the tailrace (Item 4 above) provides a pairedrelease estimate of dam survival for BON. 
10. TDA Project by post-hoc pairing of JDA Tailrace and TDA Tailrace releases in a paired release model using detections at Arrays 1T, 2T, and 1B

11. The BON Project by post-hoc pairing of TDA Tailrace and BON Tailrace releases in a paired release model using detections at Arrays $1 \mathrm{~B}$ and $2 \mathrm{~B}$

12. Every study reach from release point to each successive array except the last array below Bonneville Dam BON in summer (2B)

13. BON spillway, B2 JBS, and B2CC based upon populations defined by acoustic detections at the spillway and PIT detections at the B2 JBS and B2CC and using acoustic detections on Arrays 1B and 2B

14. BON spillway by spill condition or for day and night periods.

Survival estimates of fish passing through TDA and BON were estimated in two ways. First, the estimates were for fish released below the dam upstream (JDA or TDA); these include survival through the upstream pool, dam, and tailwater in a single-release model and through the upstream pool, dam, and tailrace in a paired-release model. The paired-release estimates are referred to as Project survival. Second, the estimates were for fish detected on the array just upstream of the dam; these virtual release estimates do not include survival through the upstream pool but do include the tailrace down to the release point for reference groups of fish. The estimates are for the dam and tailwater in single-release models or, if paired with tailrace release estimates in a post-hoc paired-release model, they represent dam survival.

For the primary arrays deployed below JDA and TDA, we could pick from among several arrays downstream to serve as secondary and tertiary arrays in survival calculations. Therefore, we made those calculations in two ways, first by picking the most independent arrays based upon longer river distances, and second by simply using the next two arrays in the same pool, regardless of distances. We compared the former estimates based on preferred arrays with the latter estimates based upon "as-planned" arrays to broaden choices for future studies. We present detailed methods for the preferred choice of arrays below. Calculations using "as planned” arrays would be similar and are not explicitly described to avoid redundancy.

When examining survival of fish passing the Bonneville Dam spillway, we assigned passage events to day and night categories based upon the time of last detection time in the forebay. Daytime was defined as from 0600 through 2100 hours each season, and the remaining hours of the day were assigned as nighttime hours.

\subsubsection{Yearling Chinook Salmon Smolts}

Various project-specific, release-recapture studies were performed in 2006. However, these sitespecific releases of smolts also provided the opportunity to estimate survival parameters at downstream sites during their outmigration. Therefore, the release groups were often used on more than one occasion to estimate smolt passage survival. A total of nine acoustic arrays located from below JDA to below BON were used to obtain downstream detection data in 2006.

\subsubsection{Lower Granite Release Group}

A total of 996 yearling Chinook salmon smolts were released below Lower Granite Dam on the Snake River (Figure 2.11). Reach survivals were estimated from the release location to the JDA primary array (i.e., 1J) and the TDA primary array, i.e., $1 \mathrm{~T}$ (Figure 2.11). The terminal detection location was the secondary array below TDA Dam (2T). 


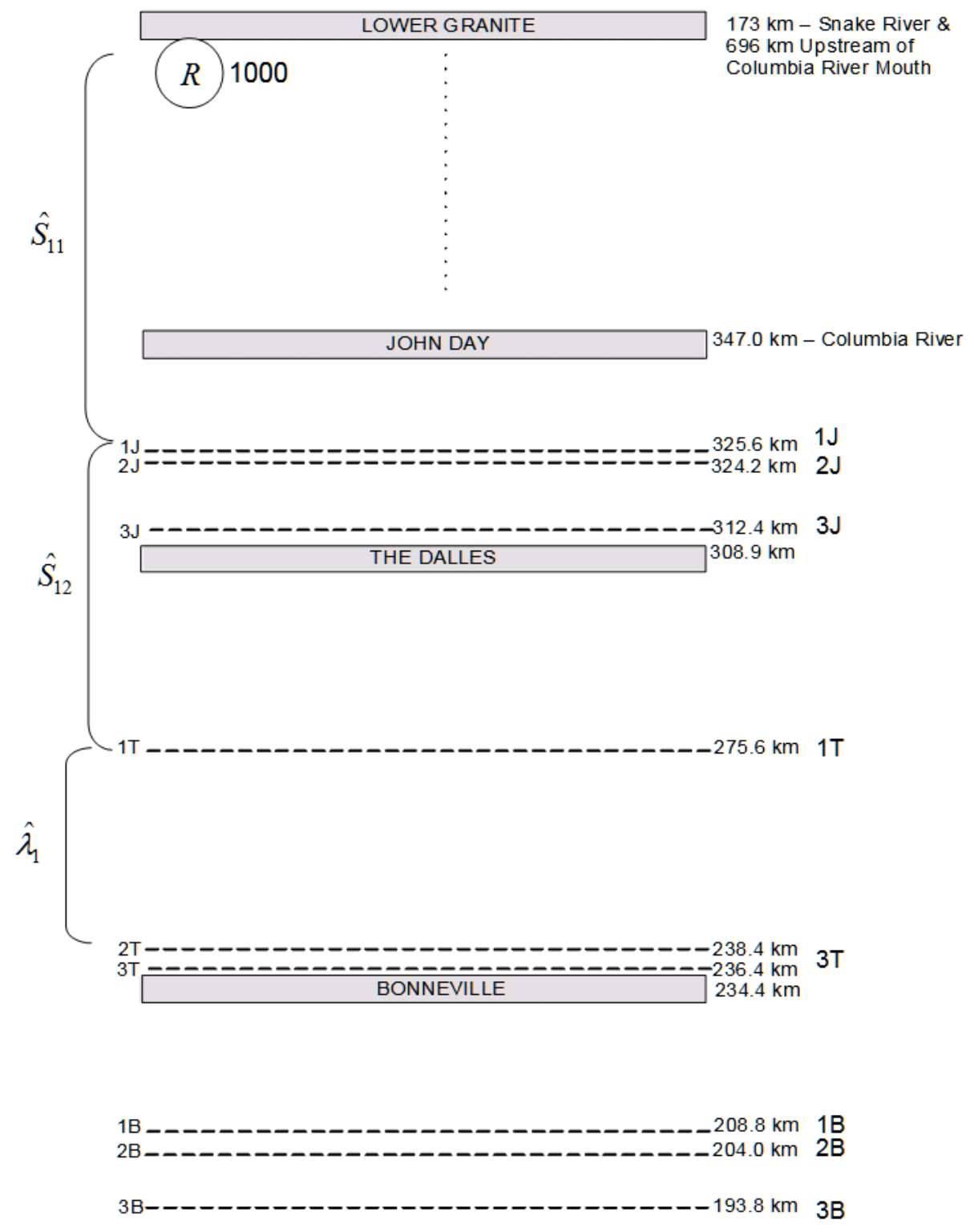

Figure 2.11. Release-Recapture Locations for the Single Release-Recapture (SR) Analyses of the Lower Granite Release Groups of Yearling Chinook Salmon

\subsubsection{John Day Dam Release Groups}

Three different release locations at JDA were used in the 2006 investigation of yearling Chinook salmon. These locations included releases (a) in the turbine, (b) in front of the turbine discharge, and (c) in the tailrace at JDA. At each location, between 481 and 500 yearling Chinook salmon smolts were tagged and released. These three release locations were used to generate three survival estimates based on the paired release-recapture (PR) model and another six survival estimates based on the single releaserecapture (SR) model (Figure 2.12). In all cases, the detection locations were at the JDA primary array (1J), and the TDA primary array (1T), and TDA secondary array (2T) (Figure 2.12). 


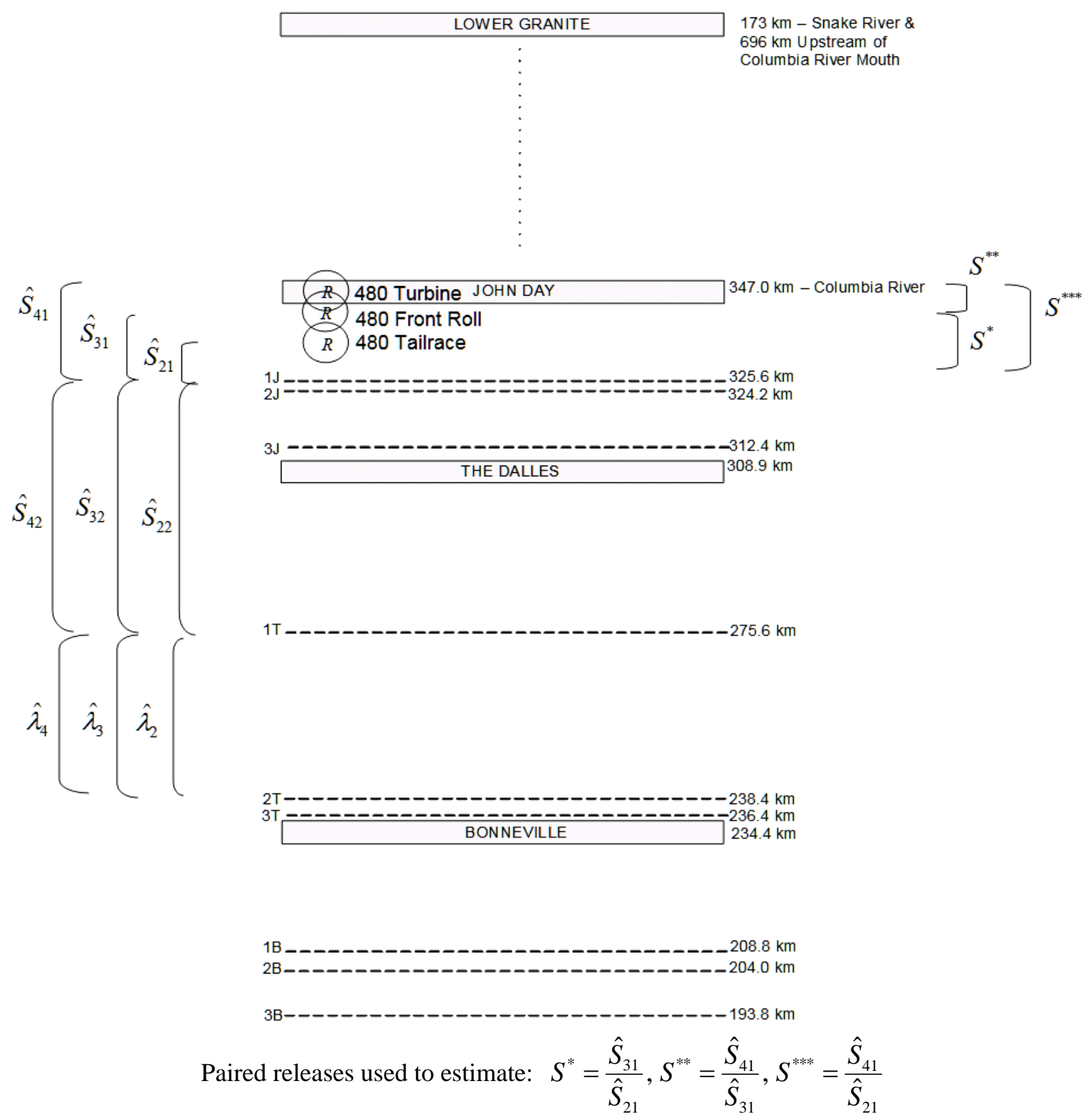

Figure 2.12. Release-Recapture Locations for the Single-Release (SR) and Paired-Release (PR) Analyses of the JDA Release Groups

\subsubsection{The Dalles and Bonneville Dams Tailrace Release Groups}

At the TDA Tailrace, 978 yearling Chinook salmon smolts were tagged and released, along with 972 below BON (Figure 2.13). These groups were analyzed as single releases. The tailrace releases were used to estimate survival from the release point to the primary and secondary arrays below each project using the single release-recapture model (Figure 2.13). 

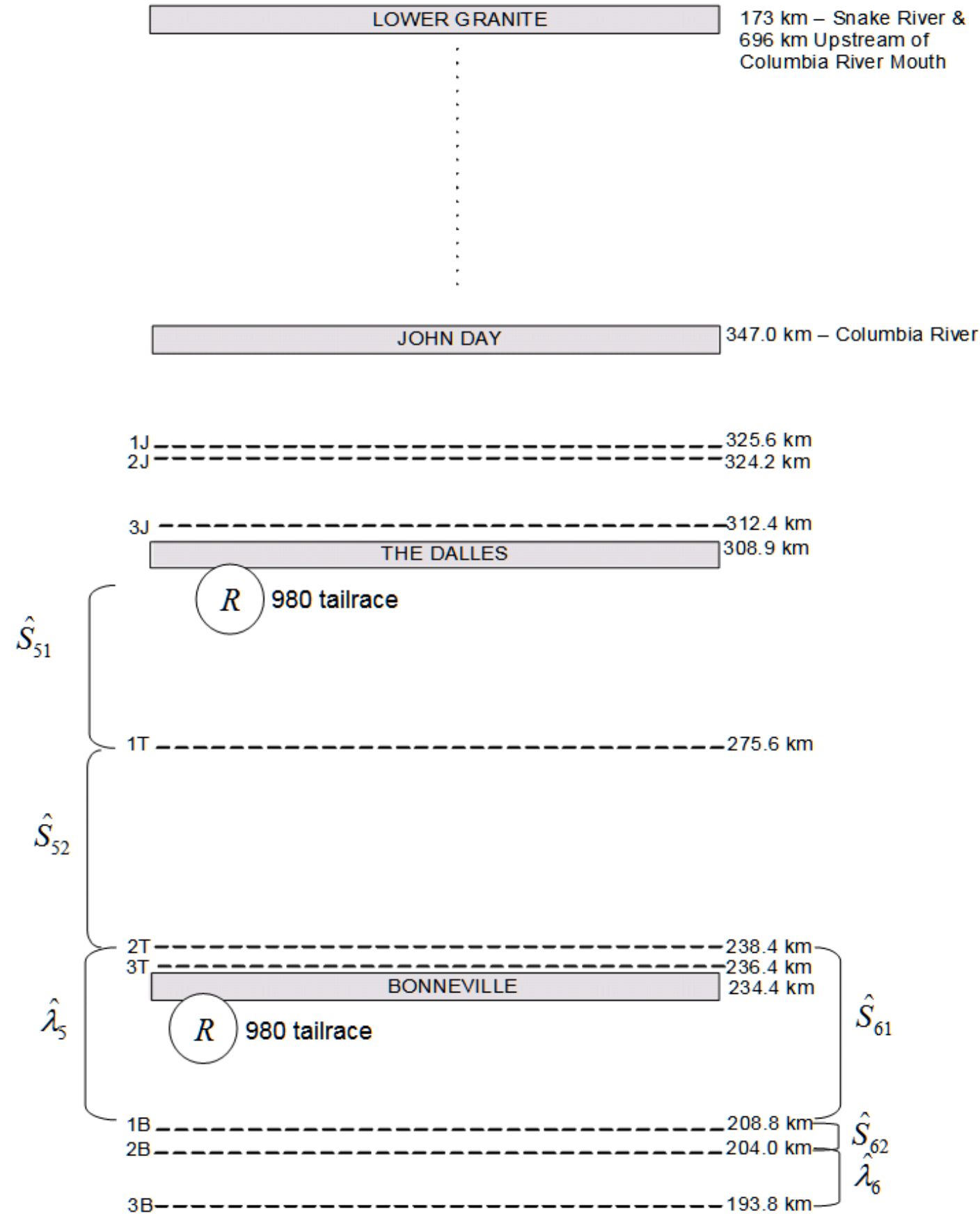

Figure 2.13. Release-Recapture Locations for the Single-Release (SR) Analysis of TDA and BON Tailrace Releases

\subsubsection{Virtual Releases to Estimate Dam Passage Survival at The Dalles and Bonneville}

The tertiary arrays above TDA (3J) and above BON (3T) were used to establish virtual release groups (Figure 2.14) to estimate dam passage survival. Fish released at JDA that were known to have survived to the tertiary array at $3 \mathrm{~J}$ constituted a virtual release group that was used to estimate passage survival through TDA based on detections at arrays 1T, 2T, and 1B. Fish released at TDA Tailrace that were known to have survived to the tailwater array at 3T constituted another release group that was used to 
estimate passage survival through $\mathrm{BON}$ using detections at 1B, 2B, and 3B. In both cases, the single release-recapture model was used to estimate reach survival.

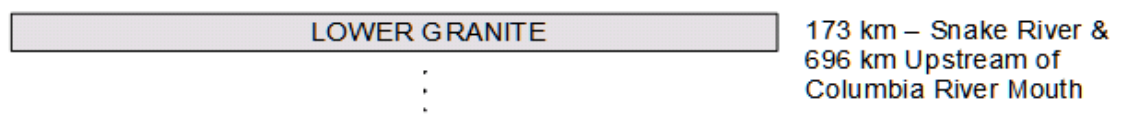

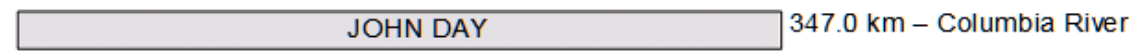

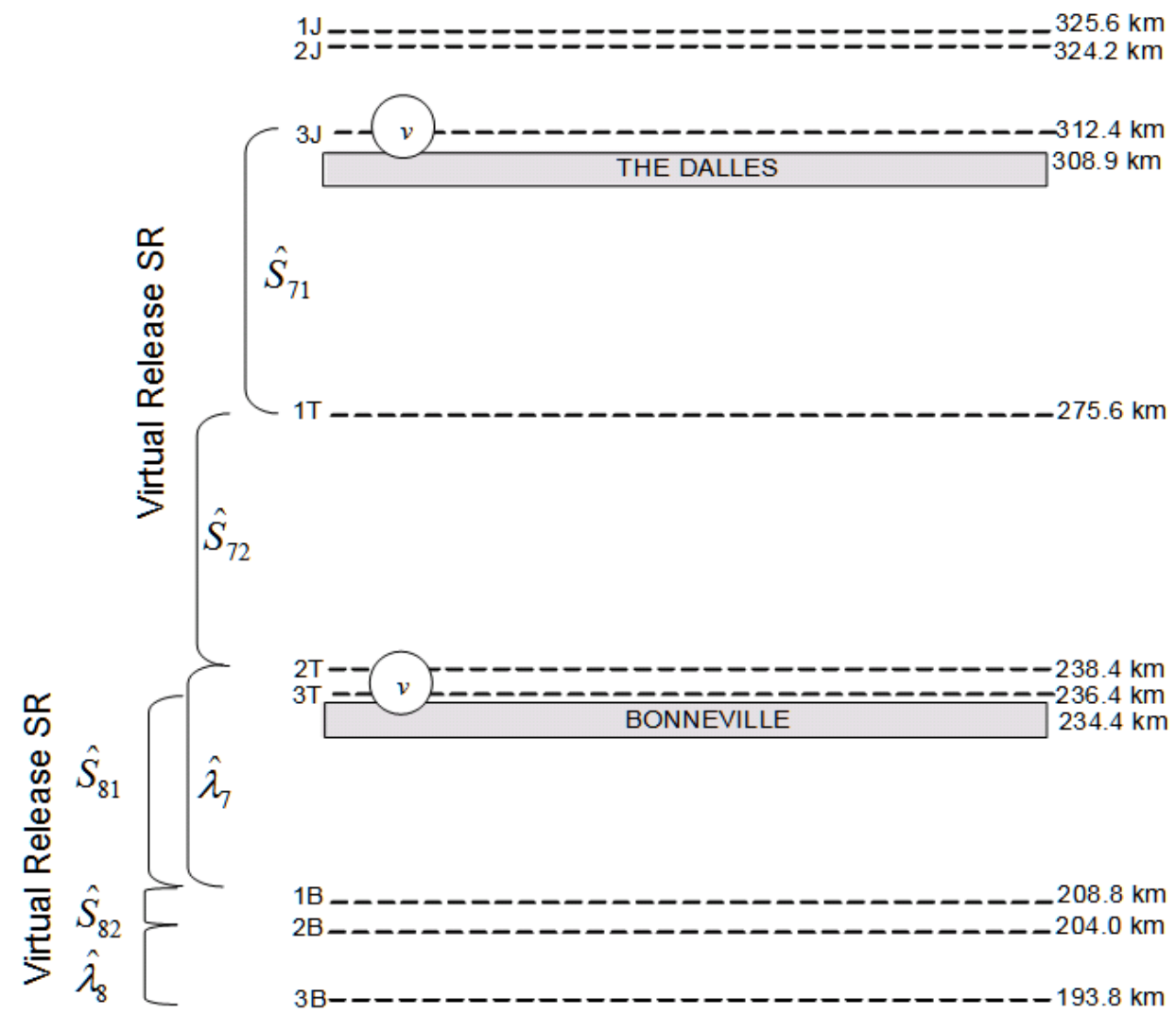

Figure 2.14. Virtual (v) Releases of Fish from $3 \mathrm{~J}$ and $3 T$ Used to Estimate Dam Passage Survival at TDA and BON Dams

\subsubsection{Project Survival Estimates at The Dalles and Bonneville}

The three tailrace releases below JDA, TDA, and BON dams were used to estimate project passage survival at TDA and BON (Figure 2.15). The paired release-recapture model was used to estimate survival at each project. Using the JDA and TDA Tailrace releases and detections at arrays 1T, 2T, and 1B, TDA project passage survival was estimated (Figure 2.15). Using the tailrace releases from TDA and $\mathrm{BON}$ and the detections at $1 \mathrm{~B}, 2 \mathrm{~B}$, and $3 \mathrm{~B}, \mathrm{BON}$ project passage survival was estimated. 


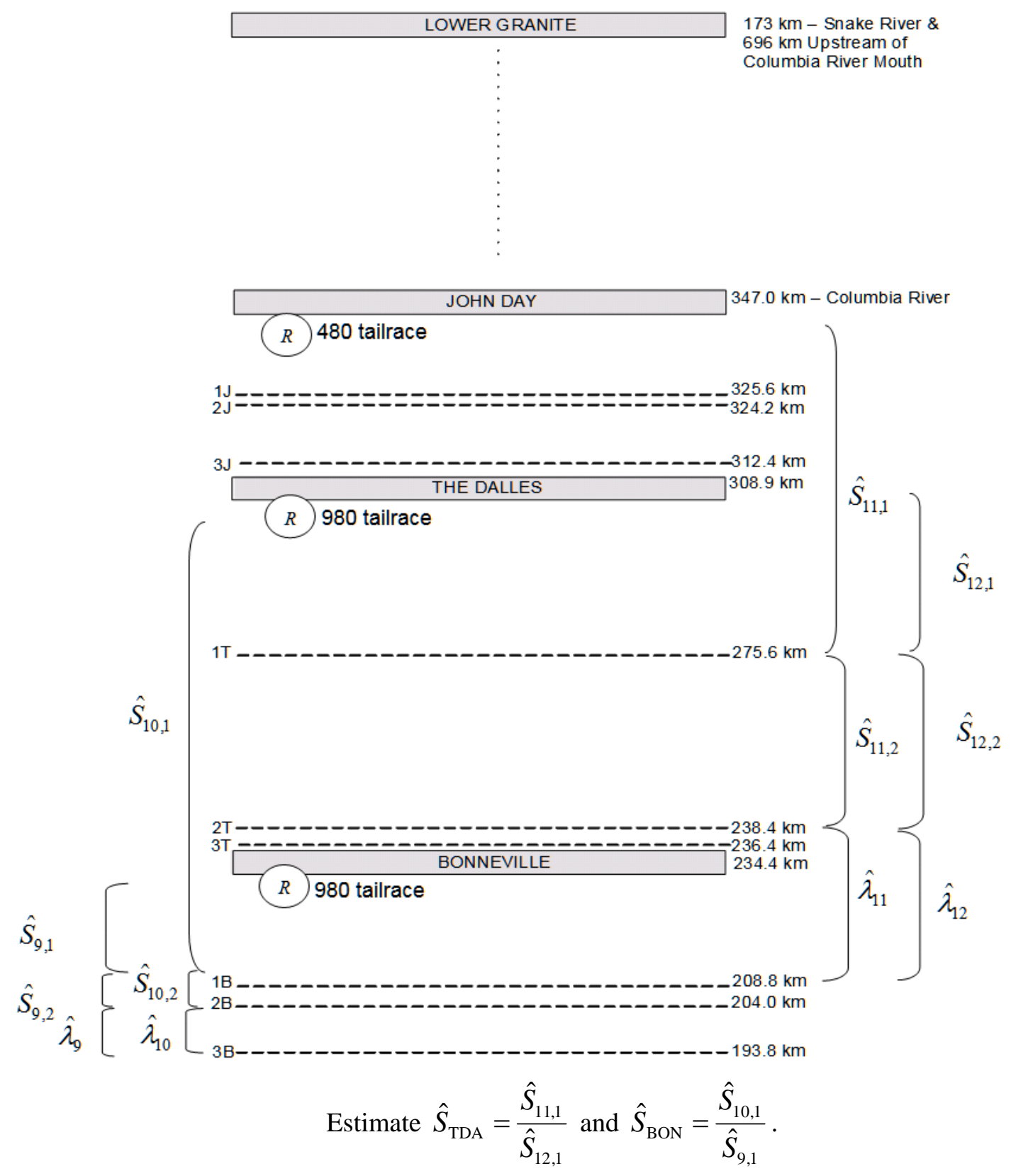

Figure 2.15. Release-Recapture Locations for Paired-Release (PR) Studies to Estimate TDA and BON Project Passage Survivals for Yearling Chinook Salmon Smolts

\subsubsection{Subyearling Chinook Salmon Smolts}

Four release locations - one below Little Goose Dam and the other three at the tailraces of JDA, TDA, and BON dams - were used to investigate reach passage survival for subyearling Chinook salmon smolts. A total of 1,949 subyearling Chinook salmon were released below Little Goose Dam, 299 below JDA, 2,179 below TDA, and 1,957 below BON. 


\subsubsection{Project-Specific Reach Passage Survivals}

Tagged fish released below Little Goose Dam were used to estimate reach survivals from the point of release to the JDA primary array (1J), and between primary array $1 \mathrm{~J}$ and $1 \mathrm{~T}$ below TDA (Figure 2.16). The tailrace release below JDA was used to estimate reach survivals between the point of release and primary array $1 \mathrm{~J}$ and between $1 \mathrm{~J}$ and $1 \mathrm{~T}$ (Figure 2.17). For the tailrace release below TDA and BON dams, survival was estimated from the point of release to the primary array (i.e., 1T or 1B) and between primary and secondary arrays (1T-2T) for TDA (Figure 2.17).



Figure 2.16. Release-Recapture Locations for the Single-Release (SR) Analysis of Reach Survival for Subyearling Chinook Salmon Smolts below Little Goose Dam 


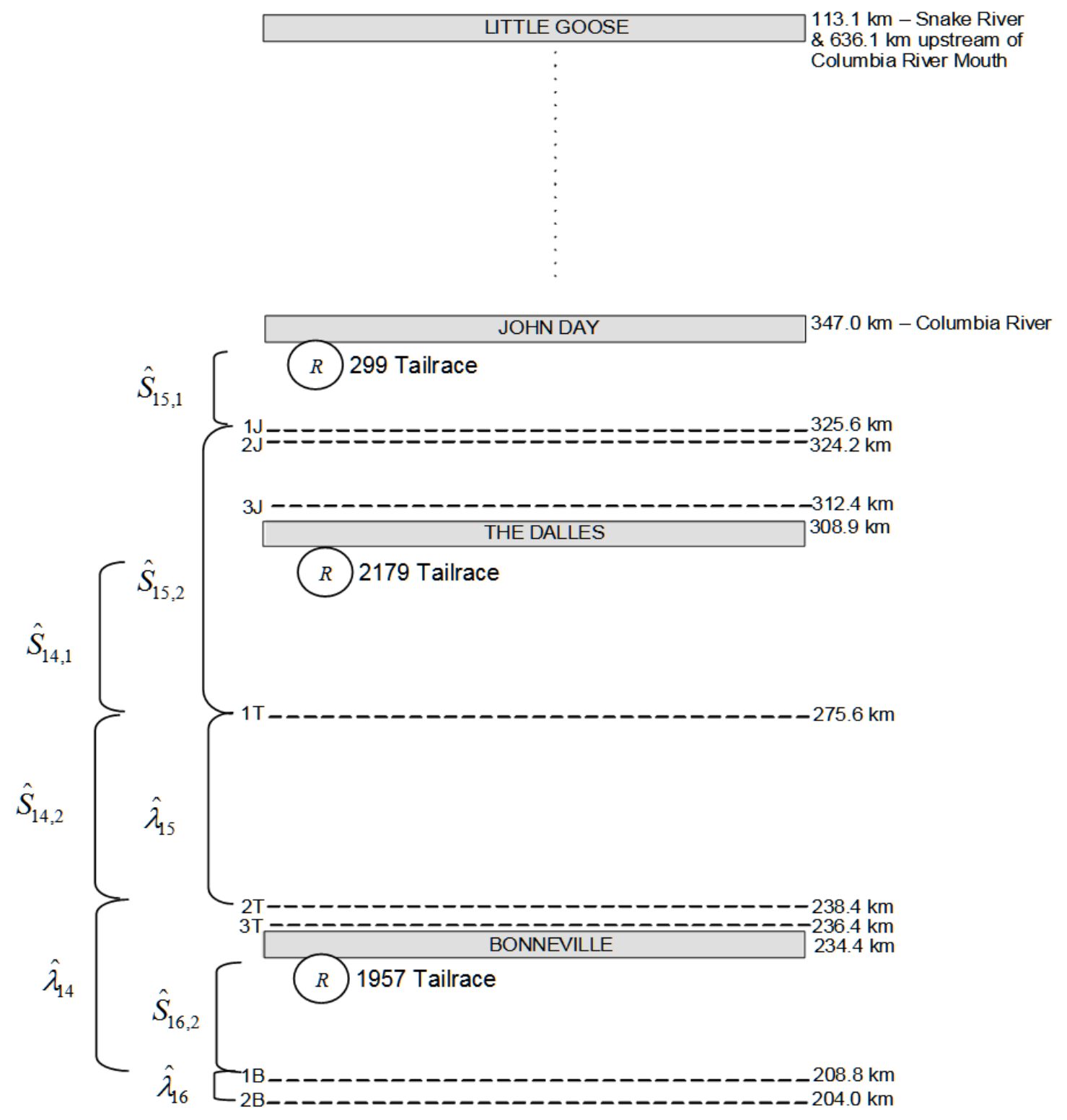

Figure 2.17. Release-Recapture Locations for the Single Release (SR) Analyses of Reach Survival for Subyearling Chinook Salmon Smolts at JDA, TDA, and BON

\subsubsection{Virtual Releases to Estimate Dam Passage Survival at The Dalles and Bonneville}

As with the yearling Chinook salmon, arrays above TDA (3J) and BON (3T) were used to establish virtual release groups (Figure 2.14) to estimate dam passage survival for subyearling Chinook salmon. Fish released at JDA that were known to have survived to the tertiary array $3 \mathrm{~J}$ ( 279 fish) constituted a virtual release group that was used to estimate passage survival through TDA using detections at arrays 1T, 2T, and 1B. Fish released at the TDA Tailrace that were known to have survived to the tertiary array at 3T (2,022 fish) constituted another release group that was used to estimate passage survival through $\mathrm{BON}$ using detections at $1 \mathrm{~B}, 2 \mathrm{~B}$, and $3 \mathrm{~B}$. In both cases, the single-release model was used to estimate reach survival. 


\subsubsection{Project Survival Estimates at The Dalles and Bonneville}

The three tailrace releases of subyearling Chinook salmon below JDA, TDA, and BON (Figure 2.17) were used to estimate project passage survival at TDA and BON, analogous to the calculation for yearling Chinook salmon shown in Figure 2.15. The paired release-recapture model was used to estimate survival at each project. We used JDA and TDA Tailrace releases and detections at arrays 1T, 2T, and 1B, to estimate The Dalles project passage survival. We used the tailrace releases from TDA and BON and the detections at $1 \mathrm{~B}$ and $2 \mathrm{~B}$ to estimate $\mathrm{BON}$ project passage survival.

\subsubsection{Bonneville Dam Route-Specific Estimates in Spring and Summer}

All fish that were released upstream of BON were used to estimate Juvenile Bypass (JBS) and B2 Corner Collector (B2CC) survival estimates using a pooled single release-recapture model. Pit-tagged smolts that were PIT detected at the B2CC and B2 JBS were compiled to produce survival and recapture probabilities based upon detections at Arrays 1B, 2B, and 3B in spring and at Arrays 1B and 2B in summer. The third array below BON was not functional in summer because the nodes there were used to fill in other nodes that were lost from upstream arrays.

Survival estimates at the BON spillway were calculated each season using a pooled-release-recapture model based upon detections of tagged fish from any release on acoustic receivers in the spillway forebay and subsequent detections at Arrays $1 \mathrm{~B}, 2 \mathrm{~B}$, and $3 \mathrm{~B}$ in spring and at Arrays $1 \mathrm{~B}$ and $2 \mathrm{~B}$ in summer. Receivers in the spillway forebay could detect tagged fish that were within about $300 \mathrm{ft}$ of spill gates, and those detected fish were assumed to have passed through the spillway, although they were not tracked to a specific final destination. Data on first detection and passage locations in previous radio telemetry studies indicate that that assumption was reasonable. Few fish first detected at the spillway passed at either powerhouse.

\subsection{Statistical Analyses}

\subsubsection{Survival Estimates}

The smolt survival estimates were based on two types of models, the single release-recapture (SR) models of Skalski et al. (1998) or the paired release-recapture (PR) models of Burnham et al. (1987). In essence, the paired-release models are a function of two separate single-release models. For this reason, the single-release model will be presented before the paired-release analysis.

For planned comparisons (JDA Intake, Front Roll, and Tailrace effects on survival), we used Z-test to test for significant differences. This test uses the property that maximum likelihood errors are asymptotically normally distributed, and the test has the form:

$$
Z=\frac{\hat{S}_{1}-\hat{S}_{2}}{\sqrt{\widehat{\operatorname{Var}}\left(\hat{S}_{1}\right)+\widehat{\operatorname{Var}}\left(\hat{S}_{2}\right)}}
$$

For the many unplanned comparisons, we simply looked for overlap or non-overlap in $1 / 295 \%$ confidence limits, because "exact” $P$-values would be unnecessary statistical window dressing in those cases.

\subsubsection{Single-Release Model}

In all cases where the single release-recapture model was used in spring (Figures 2.11-2.14) and below JDA and TDA in summer (Figure 2.16 and 2.17), there is a release location and three downriver detection locations. With the three detection locations, there are $2^{3}=8$ possible detection histories, 
resulting in the parameterization presented in Table 2.5. Note that there would be just four possible detection histories if two arrays were present, as was the case below, BON in summer.

The parameters in the release-recapture model are defined as follows:

$S_{1}=$ probability of surviving the first reach;

$p_{1}=$ probability of being detected at the first downstream detection site, given fish survival to that location;

$S_{2}=$ conditional probability of surviving the second reach, given fish survive the first reach;

$p_{2}=$ probability of being detected at the second downstream detection site, given fish survive to that location;

$\lambda=$ joint probability of a fish surviving to and being detected at the third downstream detection site, given fish survive to the second detection location.

An eight-celled, multinomial likelihood model with the cell probabilities described in Table 2.5 was used to estimate the five model parameters.

In the case of tag failure, the model parameterization in Table 2.5 was inadequate. A graph of the tag-life survivorship curve, superimposed on a cumulative smolt survival distribution (Figure 2.18), was used to visually check the need for tag-life correction. In other words, if fish arrival times to the last detection array were longer than the time to the first tag failure, survival estimates based on the parameterizations in Table 2.5 would be negatively biased, in which case tag-life corrections of fish survival estimates were necessary (Townsend et al. 2006). In the case of tag failure, additional parameters were needed in the release-recapture model (Table 2.5) based on the method of Townsend et al. (2006). A revised parameterization, taking into account tag failure, is presented in Table 2.6.

Additional tag-life parameters that were estimated from the tag-life survivorship curve included the following:

$L_{1}=$ probability a tag survives passage through the first reach;

$L_{12}=$ probability a tag survives passage through the first and second reaches (i.e., second reach);

$L_{123}=$ probability a tag survives passage through all three reaches (i.e., third reach).

The estimates of the survival and capture parameters were calculated using maximum likelihood estimation, treating the estimates of tag-life (i.e., $\hat{L}_{1}, \hat{L}_{12}$, and $\hat{L}_{123}$ ) as known constants. However, to calculate a realistic variance estimator for the survival parameters, the error in the estimation of the taglife probabilities was incorporated into an overall variance calculation. The variance of the survival estimates was calculated using the total variance formula

$$
\operatorname{Var}(\hat{S})=\operatorname{Var}_{\hat{L}}[E(\hat{S} \mid \underset{\sim}{\hat{L}})]+E_{\hat{L}}[\operatorname{Var}(\hat{S} \mid \underset{\sim}{\hat{L}})]
$$


Table 2.5. Cell Probabilities Used in Parameterizing a Single-Release Model for Three River Reaches

\begin{tabular}{|c|l|}
\hline \hline History $^{(\mathrm{a})}$ & \multicolumn{1}{c|}{ Probability of Occurrence } \\
\hline 111 & $S_{1} p_{1} S_{2} p_{2} \lambda$ \\
\hline 011 & $S_{1}\left(1-p_{1}\right) S_{2} p_{2} \lambda$ \\
\hline 101 & $S_{1} p_{1} S_{2}\left(1-p_{2}\right) \lambda$ \\
\hline 001 & $S_{1}\left(1-p_{1}\right) S_{2}\left(1-p_{2}\right) \lambda$ \\
\hline 110 & $S_{1} p_{1} S_{2} p_{2}(1-\lambda)$ \\
\hline 010 & $S_{1}\left(1-p_{1}\right) S_{2} p_{2}(1-\lambda)$ \\
\hline 100 & $S_{1} p_{1}\left[\left(1-S_{2}\right)+S_{2}\left(1-p_{2}\right)(1-\lambda)\right]$ \\
\hline 000 & $\left(1-S_{1}\right)+S_{1}\left(1-p_{1}\right)\left[\left(1-S_{2}\right)+S_{2}\left(1-p_{2}\right)(1-\lambda)\right]$ \\
\hline
\end{tabular}

(a) 1 denotes detection; 0 denotes no detection at each of three downstream detection locations.

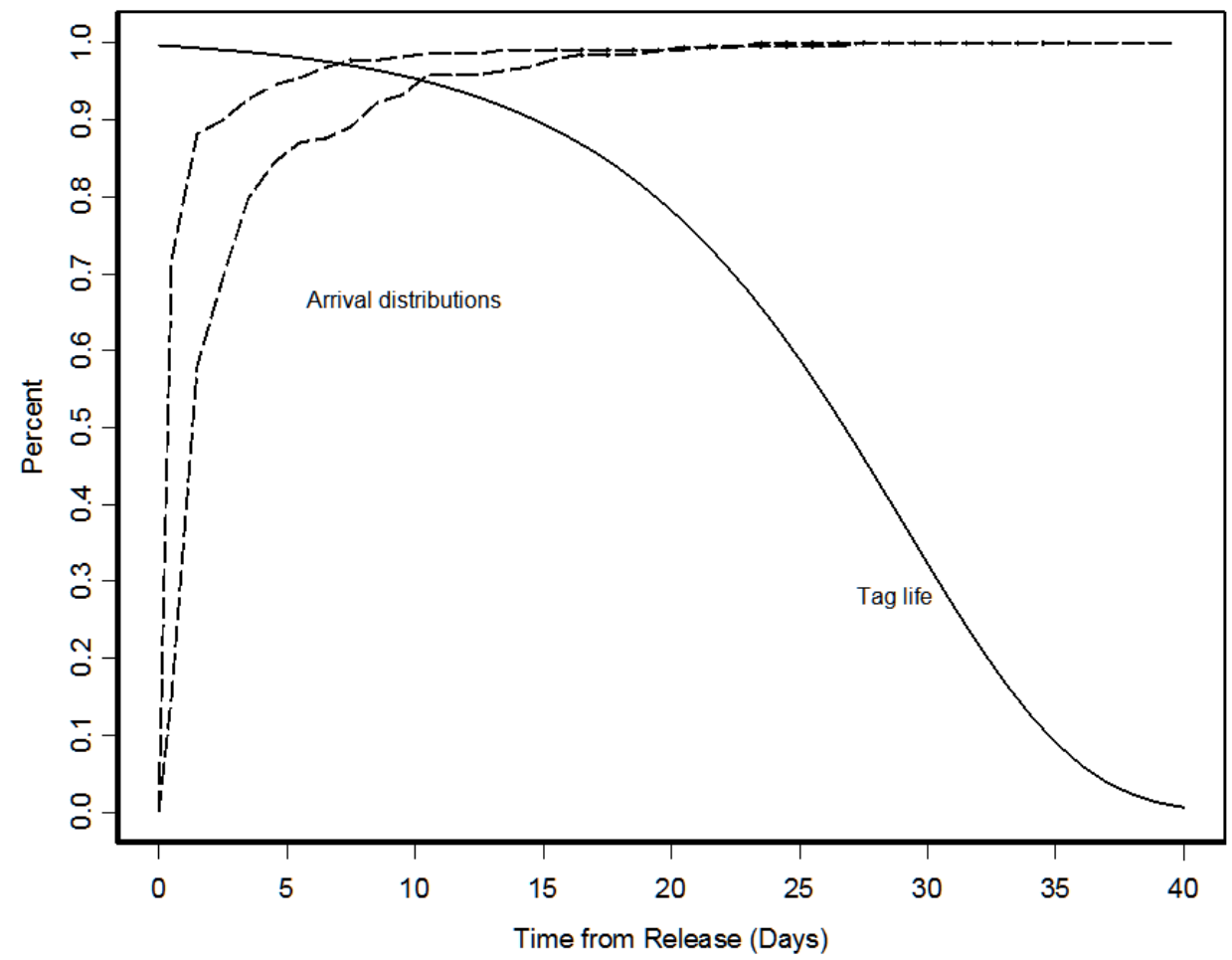

Figure 2.18. Illustration of Tag-Life Survivorship Curves (solid line) versus Cumulative Arrival Distributions (dashed lines) of Smolts to a Detection Site

The above variance was therefore estimated in stages using the expression

$$
\widehat{\operatorname{Var}}(\hat{S})=s_{\hat{S} \mid \hat{L}}^{2}+\operatorname{Var}(\hat{S} \mid \hat{\sim})
$$


The second term in Equation 2 was derived from the maximum likelihood model (2) conditioning on the tag-life probabilities (i.e., $\underset{\sim}{\hat{L}}$ ). The first variance component in Equation (2) was calculated using bootstrap resampling techniques (Efron and Tibshirani 1993). Alternative estimates of $\underset{\sim}{\hat{L}}$ were computed by bootstrapping both the observed tag-life data and travel-time data. For each estimated vector of taglife parameters, survival was estimated using the likelihood model. One thousand bootstrap estimates of the tag-life parameters were calculated, along with the corresponding conditional maximum likelihood estimates of survival. The first variance component in Equation (2) was then estimated by the quantity

$$
S_{\hat{S} \mid \hat{L}}^{2}=\frac{\sum_{b=1}^{1000}\left(\hat{S}_{b}-\hat{\bar{S}}\right)^{2}}{(1000-1)},
$$

where $\hat{S}_{b}=$ the $b$ th bootstrap estimate of survival $(b=1, \ldots, 1000)$ and

$$
\hat{\bar{S}}=\frac{\sum_{b=1}^{1000} \hat{S}_{b}}{1000} .
$$

Table 2.6. Cell Probabilities Used in Parameterizing a Single-Release Model for Three River Reaches and Tag-Life Correction

\begin{tabular}{||c|c||}
\hline History $^{(a)}$ & \multicolumn{1}{|c|}{ Probability of Occurrence } \\
\hline 111 & $S_{1} p_{1} S_{2} p_{2} \lambda L_{123}$ \\
\hline 011 & $S_{1}\left(1-p_{1}\right) S_{2} p_{2} \lambda L_{123}$ \\
\hline 101 & $S_{1} p_{1} S_{2}\left(1-p_{2}\right) \lambda L_{123}$ \\
\hline 001 & $S_{1}\left(1-p_{1}\right) S_{2}\left(1-p_{2}\right) \lambda L_{123}$ \\
\hline 110 & $S_{1} p_{1} S_{2} p_{2}\left(L_{12}-L_{123} \lambda\right)$ \\
\hline 010 & $S_{1}\left(1-p_{1}\right) S_{2} p_{2}\left(L_{12}-L_{123} \lambda\right)$ \\
\hline 100 & $S_{1} p_{1} L_{1}-S_{1} p_{1} S_{2} L_{12}+S_{1} p_{1} S_{2}\left(1-p_{2}\right)\left(L_{12}-L_{123} \lambda\right)$ \\
\hline 000 & $1-S_{1} L_{1} p_{1}-S_{1}\left(1-p_{1}\right) S_{2} L_{12}+S_{1}\left(1-p_{1}\right) S_{2}\left(1-p_{2}\right)\left(L_{12}-L_{123} \lambda\right)$ \\
\hline
\end{tabular}

(a) 1 denotes detection; 0 , not detected at each of three downstream detection locations.

Use of Equations (1) and (2) permitted us to examine the contribution of the sampling error in the taglife parameters to the overall variance in survival estimates. An asymptotic $(1-\alpha) 100 \%$ confidence interval for the survival estimate was computed as 


$$
\hat{S} \pm Z_{1-\frac{\alpha}{1}} \sqrt{\widehat{\operatorname{Var}}(\hat{S})}
$$

The individual replicate releases over the season were generally inadequate for survival analyses. The intent was to pool the data if feasible. $\mathrm{R} \times \mathrm{C}$ contingency table analyses based on observable capture histories were used to test for homogeneity of survival and detection processes. If significant $(P<0.10)$ heterogeneity were detected, then analyses were performed by release group. An overall survival estimate was computed according to the formula

$$
\hat{\bar{S}}=\frac{\sum_{i=1}^{k} W_{i} \hat{S}_{i}}{\sum W_{i}}
$$

where $k=$ number of replicate releases;

$$
\begin{aligned}
& \hat{S}_{i}=\text { survival estimates from the } i \text { th release pair }(i=1, \ldots, k) \text {; } \\
& \qquad w_{i}=\frac{1}{\left(\frac{\widehat{\operatorname{Var}}\left(\hat{S}_{i}\right)}{\hat{S}_{i}^{2}}\right)}=\frac{1}{\mathrm{CV}\left(\hat{S}_{i}\right)^{2}}
\end{aligned}
$$

with variance estimator

$$
\widehat{\operatorname{Var}}(\hat{\bar{S}})=\frac{\sum_{i=1}^{k} W_{i}\left(\hat{S}_{i}-\hat{\bar{S}}\right)^{2}}{(k-1) \sum_{i=1}^{k} W_{i}}
$$

It was found that by weighting simply inversely proportional to $\operatorname{Var}\left(\hat{S}_{i}\right)$, the weights are correlated with the point estimates, resulting in downward bias in the average survival. By using the relative variance, this correlation between the weights and the point estimate was minimized.

The weights (5) are appropriate if replicate survival estimates are estimating the same parameter value. In the case where there may be seasonal trends, it may be more appropriate to weight the replicate estimates by seasonal passage proportions in order to more accurately represent the run-of-river fish.

\subsubsection{Paired-Release Model}

The upstream and downstream releases (e.g., $R_{1}$ and $R_{2}$ ) of a paired release-recapture study function as two independent, single release-recapture investigations, which share one or more model parameters.

Define the following parameters:

$$
S_{i j}=\text { survival in the } j \text { th reach }(j=1,2) \text { for the } i \text { th release group }(i=1,2) \text {; }
$$


$p_{i j}=$ detection probability at the $j$ th detection site $(j=1,2)$ for the $i$ th release group $(i=1,2)$; $\lambda_{i}=$ joint probability of surviving and being detected in the last reach for the ith release group $(i=1,2)$;

$L_{i, 1}=$ probability tag is operational to the first detection site for the $i$ th release group $(i=1,2)$;

$L_{i, 12}=$ probability tag is operational through the first and second reaches for the ith release group $(i=1,2)$;

$L_{123}=$ probability tag is operational through the full set of three reaches for the ith release group $(i=1,2)$.

The parameterizations of the various capture histories for a three-reach, paired release-recapture study are summarized in Table 2.7. At a minimum, both releases were assumed to experience the same survival for the location of the downstream release to the first detection site, in which case, survival between release locations was estimated by the quotient

$$
\hat{S}=\frac{\hat{S}_{11}}{\hat{S}_{21}}
$$

with associated variance estimated based on the delta method (Seber 1982:7-9) of

$$
\begin{aligned}
\widehat{\operatorname{Var}}(\hat{S}) & \doteq\left(\frac{\hat{S}_{11}}{\hat{S}_{21}}\right)^{2}\left[\frac{\operatorname{Var}\left(\hat{S}_{11}\right)}{\hat{S}_{11}^{2}}+\frac{\operatorname{Var}\left(\hat{S}_{21}\right)}{\hat{S}_{21}^{2}}\right] \\
& \doteq \hat{S}^{2}\left[\widehat{\mathrm{CV}}\left(\hat{S}_{11}\right)^{2}+\widehat{\mathrm{CV}}\left(\hat{S}_{21}\right)^{2}\right]
\end{aligned}
$$

and where $\widehat{\operatorname{CV}}(\hat{\theta})=\frac{\sqrt{\operatorname{Var}(\hat{\theta})}}{\hat{\theta}}$

Subsequent downstream capture and survival parameters were estimated distinctly for each release. However, precision was enhanced if the parameterization of the joint likelihood model was reduced from the maximum shown in Table 2.7. If the paired releases shared common downstream detection or survival parameters, the joint likelihood model was re-parameterized by equating $p_{11}=p_{12}, S_{12}=S_{22}$, $p_{12}=p_{22}$, or $\lambda_{1}=\lambda_{2}$.

The paired release-recapture methods of Burnham et al. (1987) were used to find the most parsimonious models for estimating reach survival. Forward-sequential test procedures were used in model selection based on likelihood ratio tests (LRT) of nested models. The first test in the sequence evaluated whether $p_{11}=p_{21}=p_{1}$, assuming all other parameters of the paired releases were unique. If the LRT indicated that $p_{11} \neq p_{21}$, the next test in the sequence evaluated whether $S_{12}=S_{22}=S_{2}$. If the LRT indicated $S_{12} \neq S_{22}$, the next test in the sequence evaluated whether $\lambda_{1}=\lambda_{2}=\lambda$. At any stage in 
the testing, if the null hypothesis of homogeneity was not rejected, a reduced model was assumed. All parameters were assumed homogeneous at and below the location of no significance. This reduced model was then compared to the fully parameterized Cormack-Jolly-Seber (CJS) model to assess whether any unexplained heterogeneity between releases still existed. The LRT was performed at $\alpha=.10$. If the Pvalue for the LRT was $0.10 \leq P \leq 0.20$, the results from the LRT were compared to model selections recommended by the Akaike Information Criterion (AIC). In the case where LRT and AIC did not agree, the more parameterized of the recommended models was selected for the sake of robustness.

The intent was to pool replicate releases within the season prior to survival estimation. Tests of homogeneity were performed and weighted averages were calculated according to the procedures outlined in Section 3.10.1.

Table 2.7. Cell Probabilities Used in Parameterizing the Joint Likelihood for the Paired ReleaseRecapture Model for Three River Reaches and Tag-Life Correction

\begin{tabular}{|c|c|c|}
\hline Release & History $^{a}$ & Probability of Occurrence \\
\hline \multirow[t]{8}{*}{ Upstream $R_{1}$} & 111 & $S_{11} p_{11} S_{12} p_{12} \lambda_{1} L_{1,123}$ \\
\hline & 011 & $S_{11}\left(1-p_{11}\right) S_{12} p_{12} \lambda_{1} L_{1,123}$ \\
\hline & 101 & $S_{11} p_{11} S_{12}\left(1-p_{12}\right) \lambda_{1} L_{1,123}$ \\
\hline & 001 & $S_{11}\left(1-p_{11}\right) S_{12}\left(1-p_{12}\right) \lambda_{1} L_{1,123}$ \\
\hline & 110 & $S_{11} p_{11} S_{12} p_{12}\left(L_{1,12}-L_{1,123} \lambda_{1}\right)$ \\
\hline & 010 & $S_{11}\left(1-p_{11}\right) S_{12} p_{12}\left(L_{1,12}-L_{1,123} \lambda_{11}\right)$ \\
\hline & 100 & $S_{11} p_{11} L_{1,1}-S_{11} p_{11} S_{12} L_{1,12}+S_{11} p_{11} S_{12}\left(1-p_{12}\right)\left(L_{1,12}-L_{1,123} \lambda_{1}\right)$ \\
\hline & 000 & $\begin{array}{l}1-S_{11} L_{1,1} p_{11}-S_{11}\left(1-p_{11}\right) S_{12} L_{1,12}+S_{11}\left(1-p_{11}\right) S_{12}\left(1-p_{12}\right) \\
\quad \cdot\left(L_{1,12}-L_{123} \lambda_{1}\right)\end{array}$ \\
\hline \multirow[t]{8}{*}{ Downstream $R_{2}$} & 111 & $S_{21} p_{21} S_{22} p_{22} \lambda_{2} L_{2,123}$ \\
\hline & 011 & $S_{21}\left(1-p_{21}\right) S_{22} p_{22} \lambda_{2} L_{2,123}$ \\
\hline & 101 & $S_{21} p_{21} S_{22}\left(1-p_{22}\right) \lambda_{2} L_{2,123}$ \\
\hline & 001 & $S_{21}\left(1-p_{21}\right) S_{22}\left(1-p_{22}\right) \lambda_{2} L_{2,123}$ \\
\hline & 110 & $S_{21} p_{21} S_{22} p_{22}\left(L_{2,12}-L_{2,123} \lambda_{2}\right)$ \\
\hline & 010 & $S_{21}\left(1-p_{21}\right) S_{22} p_{22}\left(L_{2,12}-L_{2,123} \lambda_{2}\right)$ \\
\hline & 100 & $S_{21} p_{21} L_{2,1} 1-S_{21} p_{22}, S_{22} L_{2,12}+S_{21} p_{21} S_{22}\left(1-p_{22}\right)\left(L_{2,12}-L_{2,123} \lambda_{2}\right)$ \\
\hline & 000 & $\begin{array}{l}1-S_{21} L_{2,1} p_{21}-S_{21}\left(1-p_{21}\right) S_{22} L_{2,12}+S_{21}\left(1-p_{21}\right) S_{22}\left(1-p_{22}\right) \\
\quad \cdot\left(L_{2,12}-L_{2,123} \lambda_{2}\right)\end{array}$ \\
\hline
\end{tabular}

(a) 1 denotes detection; 0 denotes no detection at each of three downstream detection locations. 


\subsubsection{Tests of Assumptions}

\subsubsection{Single-Release Model}

Assumptions associated with the single-release model included the following:

A1. The test fish are representative of the population of inference.

A2. Test conditions are representative of the conditions of interest.

A3. The number of fish released is exactly known.

A4. Tag codes are accurately recorded at the time of tagging and at all detection sites.

A5. For replicated studies, data from different releases are statistically independent.

A6. The fate of each individual fish is independent of the fates of all other fish.

A7. All fish in a release group have equal survival and detection probabilities.

A8. Prior detection history has no effect on subsequent survival and detection probabilities.

Assumptions A1-A5 are pertinent for the validity of statistical inferences to the population of interest and to the proper conduct of the study. These assumptions (i.e., A1-A5) are largely satisfied by the appropriate capture, handling, marking, and release procedures of the study protocol. Post-release handling mortality could violate assumption A1 and tends to underestimate actual survival probabilities. Careful handling is therefore needed to avoid such bias and is the reason fish were held at least 24 hrs prior to release.

The key assumptions in constructing the multinomial likelihood are A6-A8, which imply that the fates (i.e., capture histories) of all tagged fish in a release group are independent, identically distributed, multiple Bernoulli trials. Assumptions A6-A8 are mathematical constraints in the formulation of likelihood [Equation (1)] and investigators have less direct control over them than assumptions A1-A5.

Lack of independence (A6) will not bias the point estimates but will result in the model estimates of variance underestimating the true variability. Conversely, individual heterogeneity (A7) will not bias the point estimates but will result in the model estimate of variance overestimating the true variance. Of more serious concern is whether assumption A8 is violated. However, in acoustic survival studies, the smolts are not recaptured physically; consequently, the process of the detection itself should have little effect on downstream detection or survival.

For the single release-recapture model to be valid, certain data patterns should be evident from the capture histories. For each release group, a series of tests of assumptions was performed to determine the validity of the model (i.e., goodness of fit). The data from a single release is summarized by an m-array matrix of the form below:

\begin{tabular}{|c|c|c|c|}
\hline \multirow{2}{*}{ Release Site } & \multicolumn{3}{|c|}{ Detection Site } \\
\cline { 2 - 4 } & $\mathbf{( 2 )}$ & $\mathbf{( 3 )}$ & $\mathbf{( 4 )}$ \\
\hline Initial (1) & $m_{12}$ & $m_{13}$ & $m_{14}$ \\
\hline$(2)$ & & $m_{23}$ & $m_{24}$ \\
\hline$(3)$ & & & $m_{34}$ \\
\hline$(4)$ & & & \\
\hline
\end{tabular}


The value of $m_{i j}$ is the number of smolts detected at site $i$ that are next detected at site $j$.

Burnham et al. (1987:65,71-74) present a series of tests of assumptions called Test 2 that examine whether upstream detections affect downstream survival and/or detection. For each release, a contingency table test was performed, as follows:

Test 2.2

\begin{tabular}{|c|c|}
\hline$m_{13}$ & $m_{14}$ \\
\hline$m_{23}$ & $m_{24}$ \\
\hline
\end{tabular}$\chi_{1}^{2}$

Tests were performed at $\alpha=0.10$. The multiple releases over the season were used to broaden the seasonal inference and not to add evidence that theoretical variances were reasonable. The individual daily releases also were too small for the purposes of independently estimating survival. At best, they might show some general seasonal trends if the trends are great enough and capture probabilities are high enough.

Burnham et al. (1987:65,74-77) also present a series of tests of assumptions called Test 3, which also examine whether upstream capture histories affect downstream survival and/or capture. For each release, a contingency table was constructed of the form:

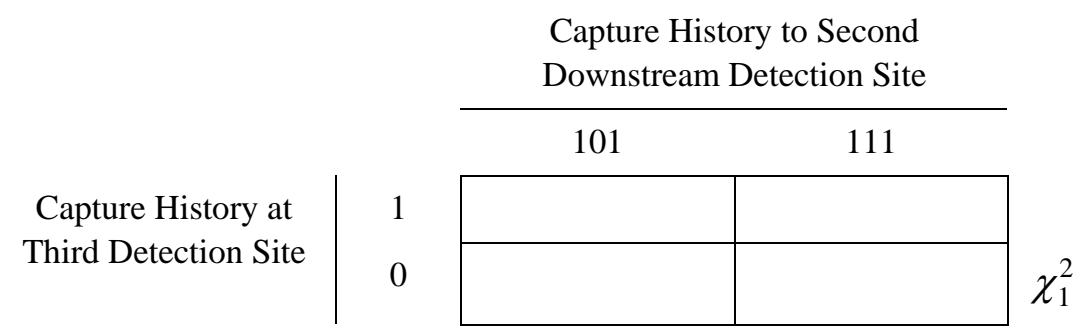

This contingency table tests whether detection at the first downstream detection site has a subsequent effect on the capture history at the third detection site.

\subsubsection{Paired-Release Model}

In order to estimate survival components from the paired releases, two additional assumptions beyond those of the single-release model are necessary for valid survival estimation. These assumptions are

A9. Survival in the lower river segments is conditionally independent of survival in the upper river segments.

A10. Releases $R_{1}$ and $R_{2}$ experience the same survival probabilities in the lower river segments they share in common.

Assumption A9 implies there is no synergistic relationship between survival processes in the two river segments. In other words, smolts that survive the first river segment are no more or less susceptible to mortality in the second river segment than smolts released in the second river segment. Assumption A10 is satisfied by in-river mixing of the release groups but can also be satisfied if the survival processes are stable over the course of smolt passage by the releases. A stable survival process might well be expected for one to a few days under similar flow and spill conditions.

The valid estimation of project survivals using the paired release-recapture data requires fulfilling the assumptions of the single release-recapture model for each release and the paired release-recapture model for each pair of releases. At each downstream detection site, the assumption of mixing among the 
releases of smolts (e.g., $R_{1}$ and $R_{2}$ ) was tested. An $\mathrm{R} \times \mathrm{C}$ contingency table test of homogeneous recoveries over time was performed using a table of the form:

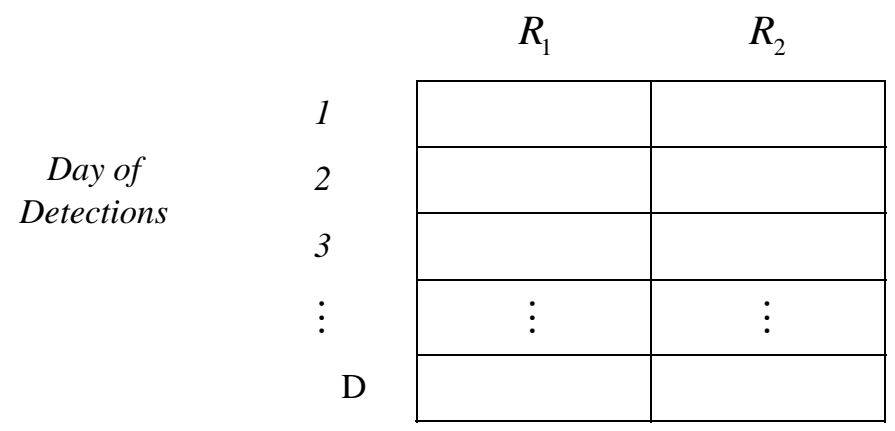

The chi-square test of homogeneous arrival timing was calculated for each of the paired releases (e.g., $R_{1}$ and $R_{2}$ ). Each test was performed at $\alpha=0.10$. The test of mixing could also have been performed using a two-sample Kolmogorov-Smirnov test (Conover 1980:368-376). The Kolmogorov-Smirnov test and the $\mathrm{R} \times \mathrm{C}$ contingency tests are asymptotically equivalent as shown by several investigators using Monte Carlo simulations. The major distinction is that the Kolmogorov-Smirnov test uses the cumulative distributions, which some people have trouble interpreting, while the $\mathrm{R} \times \mathrm{C}$ contingency tests use the discretized frequency distribution. To test whether releases with a paired-release (e.g., $R_{1}$ and $R_{2}$ ) had similar downstream survival and capture histories from the first detection site and below, likelihood ratio tests were performed to compare models. Sequential likelihood-ratio tests were used to help determine the most parsimonious model for the estimation of $p_{11}, p_{21}, S_{12}, S_{22}, p_{12}, p_{22}, \lambda_{1}$, and $\lambda_{2}$.

\subsubsection{Estimating Tag Life}

Two tag-life studies were performed from tags systematically sampled over the course of the tagging operations. One study consisted of 99 tags operating at a transmission rate of one pulse every 10 seconds. The other study consisted of 100 tags operating at a transmission rate of one pulse every 5 seconds. Tags released at JDA and points below used 5-s tags. Tags released in the vicinity of Lower Granite and Little Goose dams used 10-s tags. The tags were surgically implanted and monitored until complete tag failure.

The failure times or tag lives were recorded for each of the tags. A logistic function was used to model the tag-life data for yearling Chinook salmon. The logistic cumulative distribution function can be written as

$$
F(t)=\frac{1}{1+e^{\alpha+\beta t}},
$$

with probability density function

$$
f(t)=\beta F(t)(1-F(t))
$$

and survival function

$$
S(t)=\frac{1}{1+e^{\beta t-\alpha}}=1-F(t)
$$

The probability $(L)$ a tag was active at a particular detection location was estimated as follows: 


$$
L=\frac{\sum_{i=1}^{m} S\left(t_{i}\right)}{m} \text {, }
$$

where $m=$ number of tags detected at that location and $S\left(t_{i}\right)=$ the probability tag $i$ with arrival time $t_{i}$ was active. In some studies a two- or three-parameter Weibull function better fits tag survival curves.

\subsubsection{Sample Size Calculations}

\subsubsection{Introduction}

There is a one-to-one correspondence between the release-recapture study design, the desired level of precision, and the required sample size to achieve that precision. In fact, sample size calculations can only be performed within the context of a specific study design and a specified level of precision. Precision of survival $(S)$ studies is commonly expressed as the objective function

$$
P(|\hat{S}-S|<\varepsilon) \geq 1-\alpha,
$$

where the absolute error in estimation $(|\hat{S}-S|)$ is to be less than $\varepsilon,(1-\alpha) \cdot 100 \%$ of the time. For example, if the desired level of precision is to be within \pm 0.05 of the value of $S, 95 \%$ of the time, then

$$
P(|\hat{S}-S|<0.05) \geq 0.95
$$

The error in estimation is approximately equivalent to

$$
\varepsilon \approx Z_{1-\frac{\alpha}{2}} \cdot \operatorname{SE}(\hat{S})
$$

where

$\mathrm{SE}(\hat{S})=$ standard error for the estimate $\hat{S}$, i.e., $\mathrm{SE}(\hat{S})=\sqrt{\operatorname{Var}(\hat{S})}$,

$Z_{1-\frac{\alpha}{2}}=$ standard normal deviate corresponding to the probability $P(|\hat{Z}|<Z)=1-\alpha$.

For example, if precision is defined as $P(|\hat{S}-S|<\varepsilon)=0.95$, then $\varepsilon=1.96 \mathrm{SE}(\hat{S})$.

In other words, precision here is approximately equivalent to the half-width of a 95\% confidence interval.

Sample size calculations require initial "guesstimates" of the likely values for the survival rates and detection probabilities to be encountered during the study. In other words, you need to "know" the results of the study before you can design the study to obtain the results of the study. This logic has been described as "lifting one's self up by your bootstraps" (Robson and Regier 1964).

There are two possible solutions to the dilemma of sample size calculations. One approach is to use historical information upon which to base the design of future studies. The more historical information available, the more likely the parameter "guesstimates" will be reliable. The second approach is to bracket the "guesstimates" and subsequent sample size calculations with worse case, most likely, and best case scenarios. This is often the reason sample size curves rather than sample size values are presented. 


\subsubsection{Survival Study Scenarios}

There are two common scenarios for smolt survival studies. One approach is the single releaserecapture design (Figure 2.19); the other is the paired release-recapture design (Figure 2.20). If the objective is to simply monitor reach passage survival, the single release-recapture design may be adequate. However, any post-release handling mortality that is manifested will downwardly bias the survival estimate in the first one or few reaches. To isolate survival within a well-defined reach and eliminate the bias due to post-release handling mortality, a paired release design is typically used. This design requires a set of releases at the top and bottom of the reach of interest. Often the releases within a pair are staggered in time to facilitate downstream mixing. More fish will be needed for a paired-release than for a single-release design to achieve equal precision. Note there must be at least one detection array below the last reach where survival is to be estimated in either design.

Program SAMPLESIZE (http://www.cbr.washington.edu/paramEst/SampleSize/) can be used to provide sample size calculations for either the single-release or paired-release design.

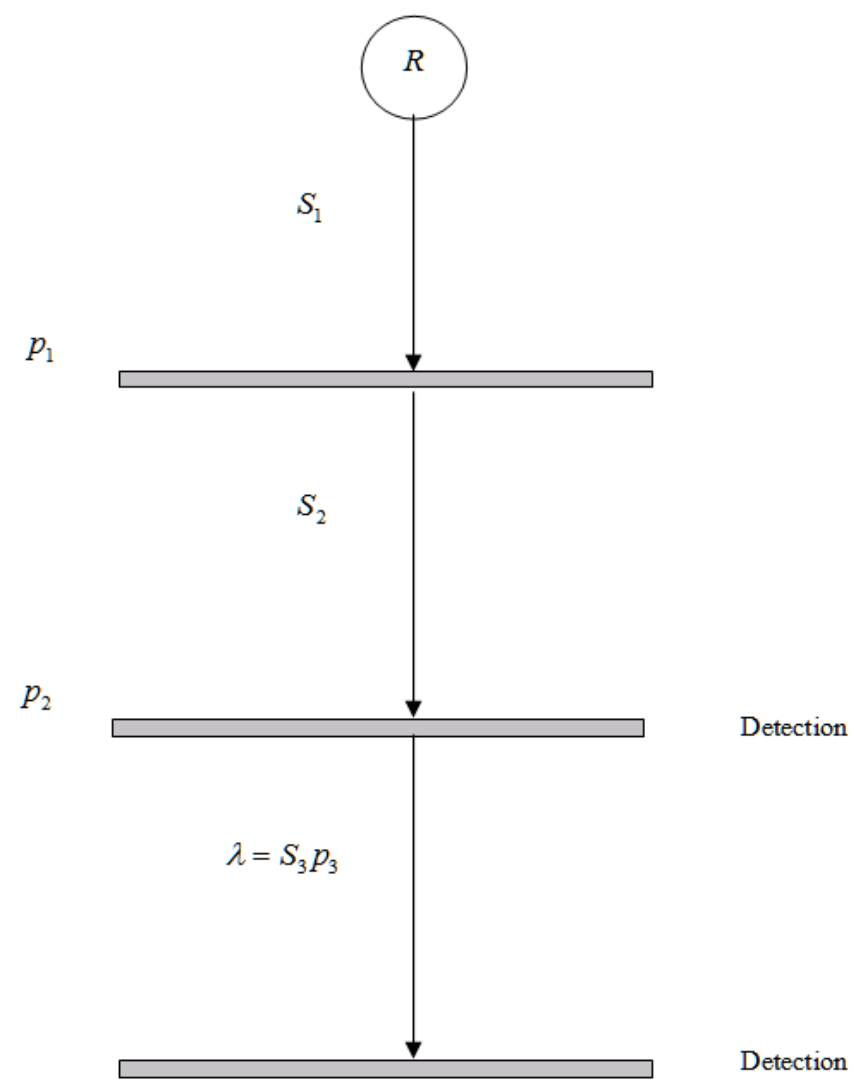

Figure 2.19. Scenario of a Single Release-Recapture Design Used to Estimate Smolt Passage Survival. Survival $\left(S_{i}\right)$ and detection $\left(p_{i}\right)$ parameters can be individually estimated for all but the last reach when only the joint probability of survival and detection (i.e., $\lambda=S_{i} p_{i}$ ) can be estimated. 


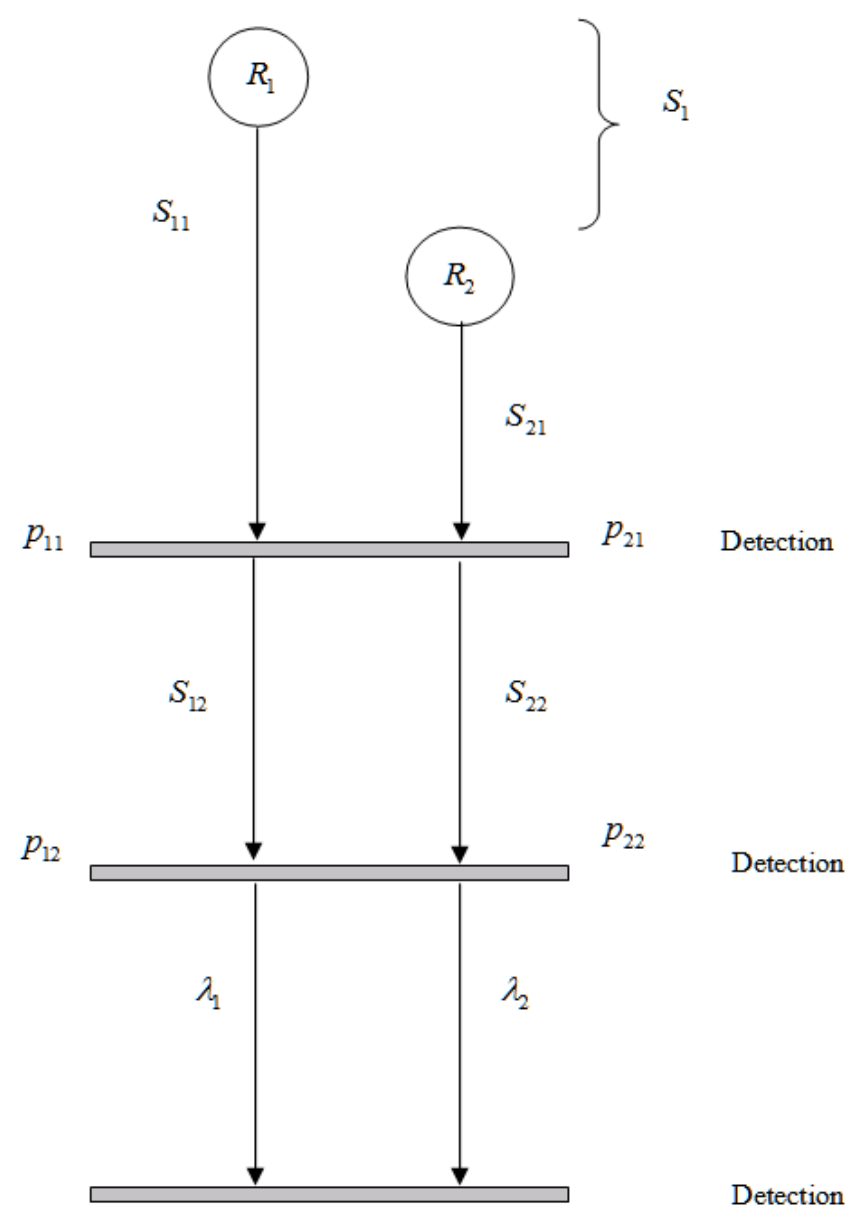

Figure 2.20. Scenario of a Paired Release-Recapture Design Used to Estimate Smolt Passage Survival. Survival $\left(S_{i j}\right)$ and detection $\left(p_{i j}\right)$ parameters can be estimated uniquely by reach and release group in all but the last reach where only the release-specific estimates of the joint probability of survival and detection $\left(\lambda_{i}\right)$ can be estimated. Survival in the first reach between release locations is estimated as $\hat{S}_{1}=\hat{S}_{11} / \hat{S}_{12}$.

\subsubsection{Replicate Survival Studies}

Often the release-recapture studies are replicated within a season for one or more reasons. One reason is to release tagged smolts throughout the breadth of the outmigration in order to make inferences to the entire migration season. Another reason is to effectively increase sample size while maintaining individual release sizes that are manageable. In both cases, the performance measure is the average survival estimate across $k$ replicates, i.e.,

$$
\hat{\bar{S}}=\frac{\sum_{i=1}^{k} \hat{S}_{i}}{k} .
$$

The variance of $\hat{\bar{S}}$ can be expressed as 


$$
\widehat{\operatorname{Var}}(\hat{\bar{S}})=\frac{\sigma_{S}^{2}+\frac{\sum_{i=1}^{k} \operatorname{Var}\left(\hat{S}_{i} \mid S_{i}\right)}{k}}{k},
$$

where $\sigma_{S}^{2}=$ natural variability in survival $(S)$ across time,

$\operatorname{Var}\left(\hat{S}_{i} \mid S_{i}\right)=$ measurement error associated with the ith estimate of survival (i.e., $\hat{S}_{i}$ ).

If natural variability is negligible (i.e., $\sigma_{S}^{2}=0, S_{1}=S_{2}=\ldots=S$ ), then variance formula (16) reduces to

$$
\operatorname{Var}(\hat{\bar{S}})=\frac{\operatorname{Var}(\hat{S} \mid S)}{k} .
$$

The implication of variance formula (17) is that sample size calculations for a replicated investigation can be based on the sample size calculations for a single trial and vice versa. Once an overall release size has been determined $(R)$, the release size per replicate $(k)$ is simply $R / k$. Program SAMPLE SIZE allows the specification of $\sigma_{S}^{2}$ as either zero or nonzero based on historical evidence. Runs of sample size in this study were based on a single year of estimates, and therefore we did not have an estimate of natural variability to input in the program.

\subsubsection{General Input to Program SAMPLESIZE}

No single set of sample size calculations can describe the entire range of potential survival study designs and scenarios. Program SAMPLESIZE, therefore, has a dynamic structure, allowing the user to specify the scenario(s) of interest. Considerations in the use of Program SAMPLESIZE include the following:

1. Specify the type of study (i.e., single-release, paired-release, balloon-tag).

2. Identify the magnitude of natural variability (i.e., $\sigma_{S}^{2}$ ).

3. Specify single trial $(k=1)$ or multiple replicates $(k>1)$.

4. Specify the anticipated parameter values:

a. Survival probabilities

b. Detection probabilities

c. Probability a smolt is removed from the river (i.e., fraction going into transportation barges)

5. Specify $(1-\alpha) \cdot 100 \%$ confidence interval, either $90 \%$ or $95 \%$.

The output of the program is the anticipated half-width of a $(1-\alpha) \cdot 100 \%$ confidence interval for the model parameters of interest. By specifying a range of input values for one of the parameters, a precision curve is generated (i.e., precision vs. parameter value). 
Acoustic Telemetry Studies of Juvenile Chinook Salmon Survival at the Lower Columbia Projects in 2006 


\subsection{Results}

\subsection{Environmental Conditions}

This section contains a description of environmental conditions during the 2006 study, including river discharge temperature relative to a 10-year average, smolt species composition at the JDA SMF, the length frequencies of tagged and run-of-river fish, and results of the tag-life study.

\subsubsection{Project Discharge and Temperature}

Ten-year (1996 to 2005) average discharges from all three dams were plotted with 2006 discharge from JDA, TDA, and BON by day. During spring, tagged fish were released when most of the discharge was higher than that of the 10-year average, but for summer releases, 2006 discharge was higher than the 10-year average at the beginning but lower towards the end of the releases (Figure 3.1).

Except for June 1, 3, and 5 release dates, the 2006 forebay water temperatures were higher than the 10-year average in spring and during the second half of summer (Figure 3.2). They were similar to a 10year average in early summer. There were data gaps for temperature between April 14 and 16 for 2006 on all three projects.

- BON 2006

- TDA 2006

—JDA 10-yr Average (2005-1996)



- JDA 2006

-BON 10-yr Average (2005-1996)

TD A 10-yr Average (2005-1996)

Figure 3.1. Ten-Year Average Daily Project Discharge (kcfs) versus 2006 Daily Project Discharge for JDA, TDA, and BON 

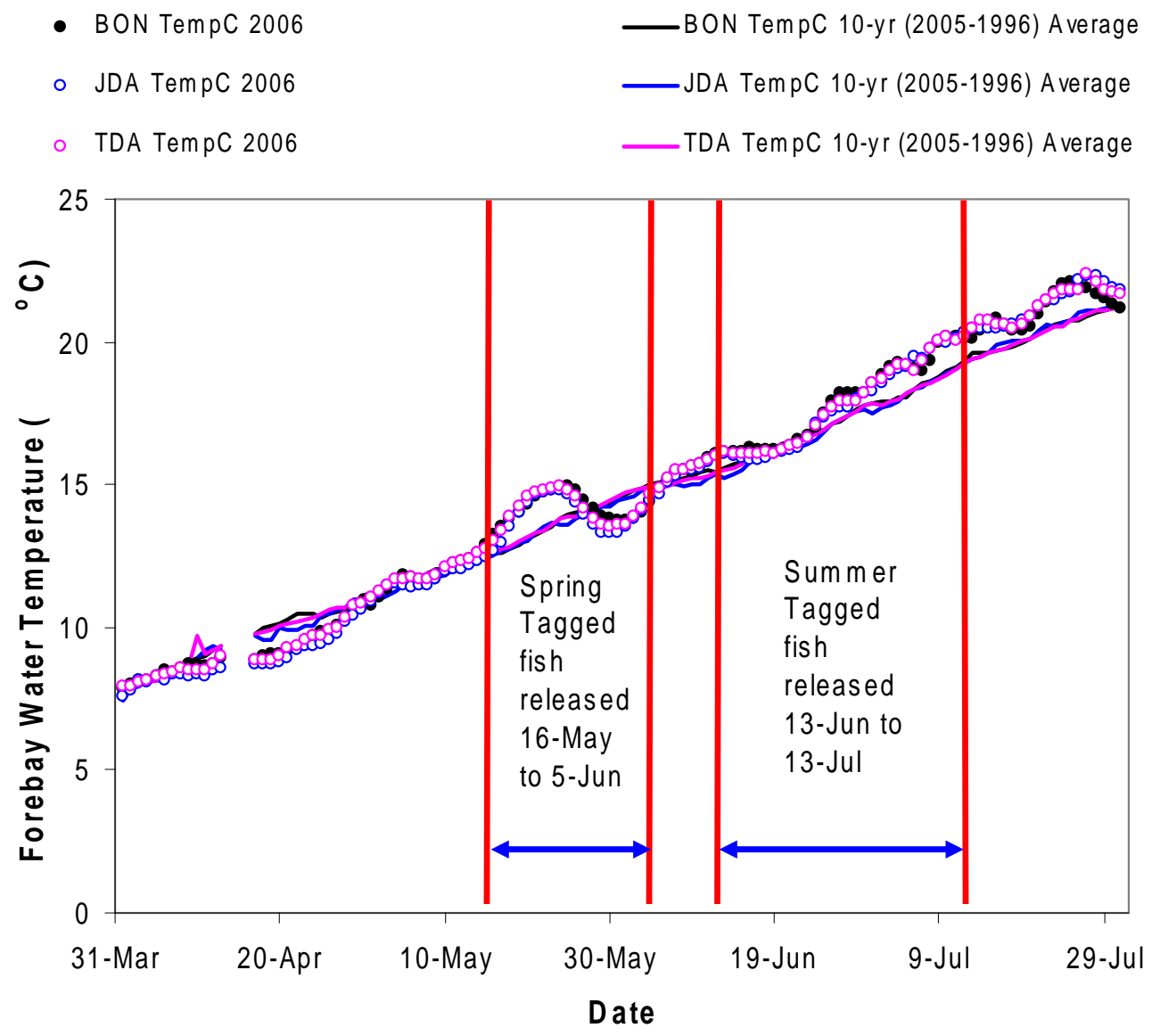

Figure 3.2. Ten-Year Average Forebay Water Temperature $\left({ }^{\circ} \mathrm{C}\right.$ ) versus 2006 Temperature by Day (April 1 through July 31) at JDA, TDA, and BON

\subsubsection{Run Timing of Smolt Species Composition}

The species composition of all downstream migrants arriving at JDA was calculated using data obtained from the JDA SMF. Both hatchery and wild stock were combined to display total salmonid run composition for 2006 (Figure 3.3). Spring collection for this study was conducted at the JDA SMF from May 14 to June 6, 2006. The composition of species arriving at the juvenile bypass during our collection period was inclusive of the major migration peak in spring for all downstream migrants. The percent composition of fish arriving at the JDA SMF in spring were yearling Chinook salmon (Oncorhynchus tshawytscha) 46\%, Coho salmon (O. kisutch) 6\%, Sockeye salmon (O. nerka) 10\%, Steelhead (O. mykiss) $34 \%$, and subyearling Chinook Salmon 4\%. A relatively strong run of Sockeye (10\%) was experienced during this year's collection season. Summer collection was from June 11 to July 13, 2006, and also was conducted at the JDA SMF. For summer, subyearling Chinook salmon was the dominant migrant with a total migration composition of $97 \%$. The peak of the subyearling Chinook salmon migration was experienced during the middle of our collection period. Though specific data were not available from DART, a large portion of collected subyearlings were unclipped, comprising both hatchery and wild stock. Unclipped subyearlings dominated the summer migration with a run composition of $86 \%$ while our targeted run, clipped subyearlings, made up only $14 \%$ of the subyearling run composition. 


\section{6}

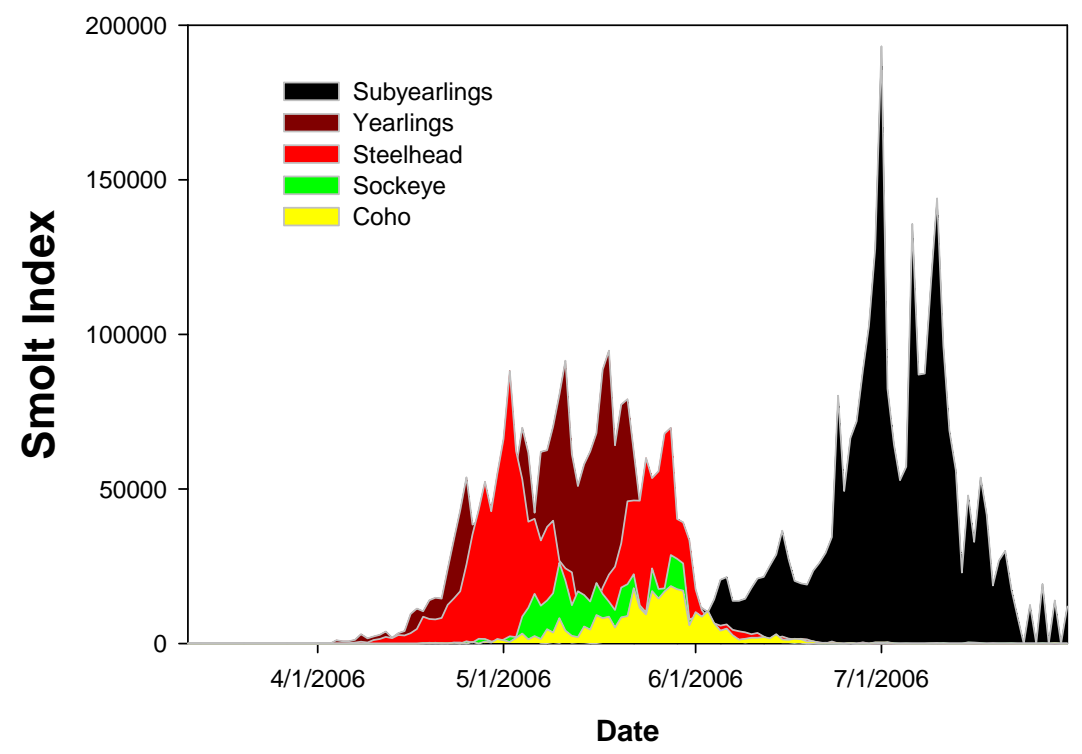

Figure 3.3. Smolt Monitoring Program (SMP) Passage Index for March 1 - July 31, 2006, based on Data from the JDA Smolt Monitoring Facility. Data were obtained from the DART website in December 2006 (http://www.cbr.washington.edu/dart/dart.html).

\subsubsection{Length Frequency}

We compared length frequencies of 2,498 tagged yearling Chinook salmon with those of run-of-river fish collected at the JDA SMF in spring, and yearlings of all lengths were tagged in proportion to their relative abundance in the run sampled by the juvenile bypass system (Figure 3.4).

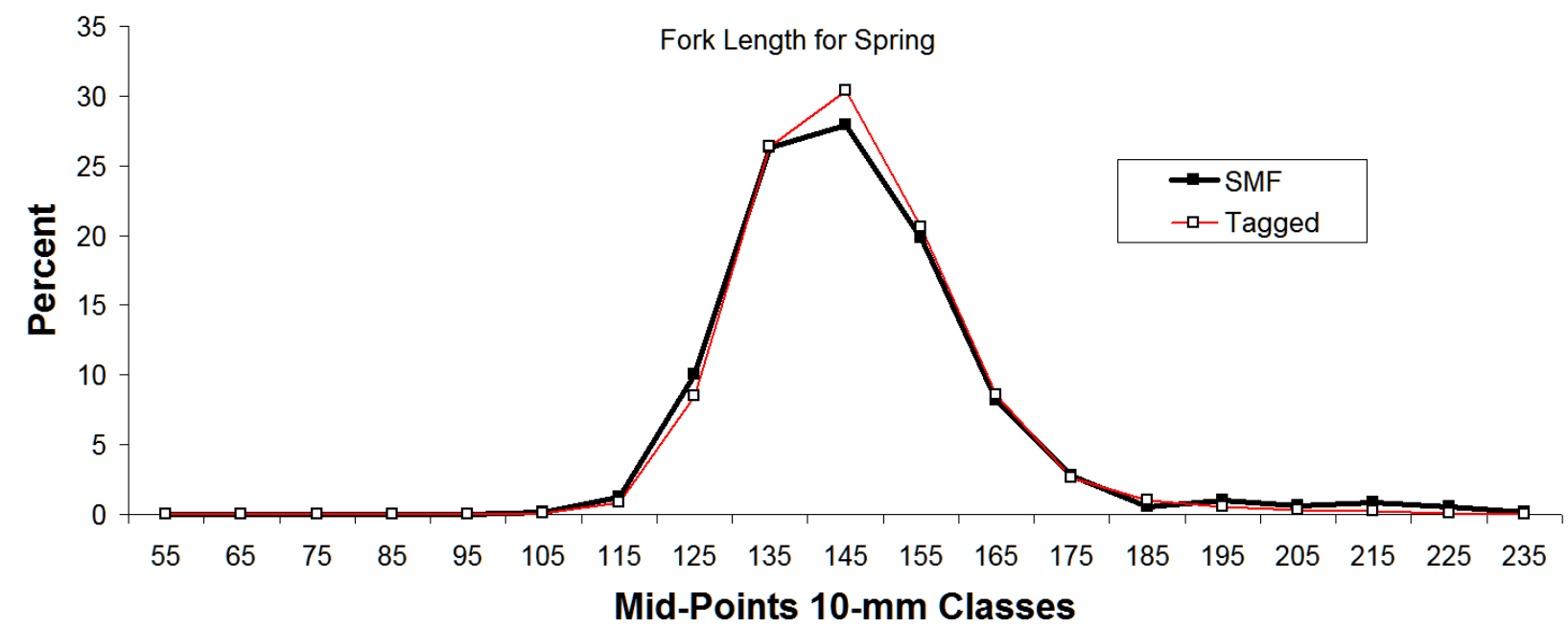

Figure 3.4. Length Frequency of Tagged and Untagged Run-of-River Yearling Chinook Salmon during Spring Tagging (5/16-6/05) at the JDA Smolt-Monitoring Facility in 2006 
The lower end of the distribution of length frequencies of 2,532 tagged subyearling Chinook salmon was truncated at $95 \mathrm{~mm}$ relative to the length frequency distribution of run-of-river subyearlings handled at the JDA SMF in summer (Figure 3.5). Some 95 to $100 \mathrm{~mm}$ subyearlings were tagged (2\%), but this was well below the $15 \%$ representation of this length class in the general population.

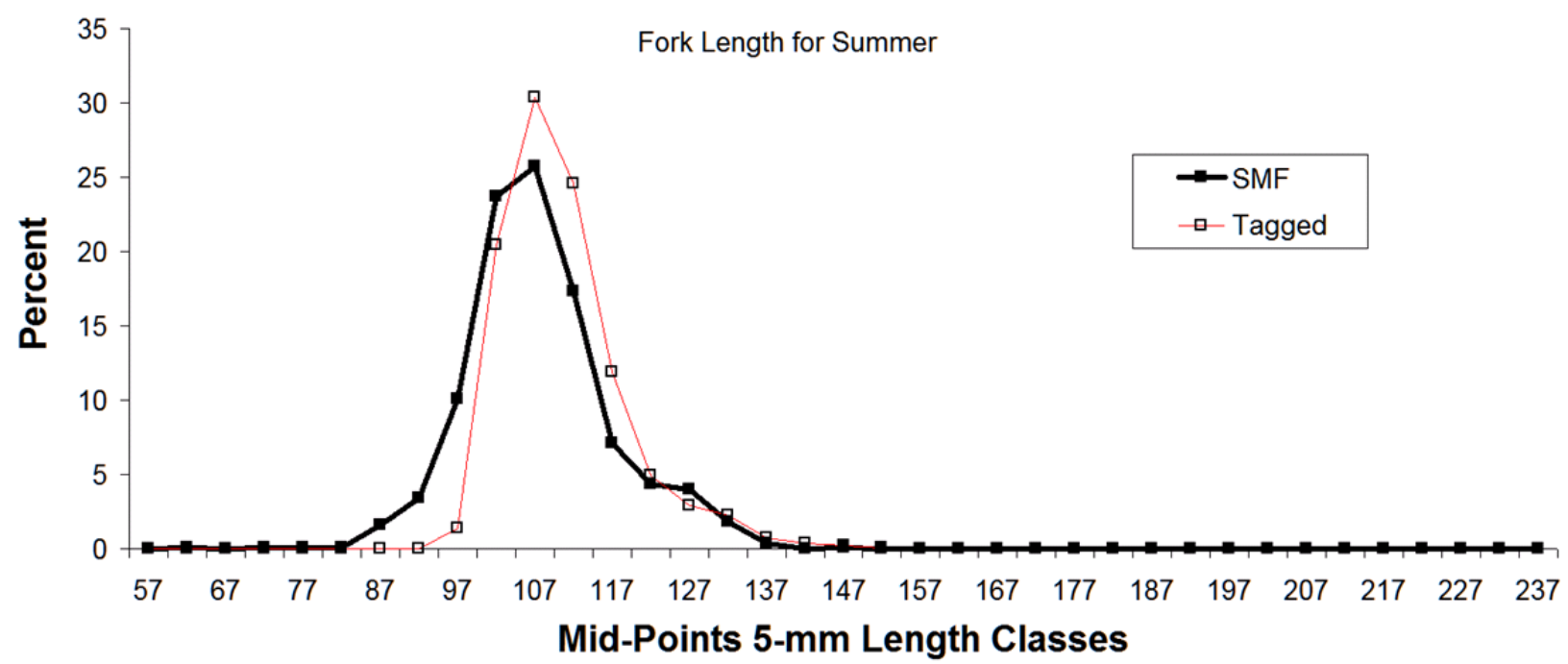

Figure 3.5. Length Frequency of Tagged and Untagged Sub-Yearling Chinook Salmon during Summer Tagging (6/13-7/13) at the JDA Smolt-Monitoring Facility in 2006

Additional information on fish, tag codes, release locations, release times, and dam operations can be found in Appendix A. Tables A1 and A2 include a summary of numbers and percentages of tagged fish released alive and dead (including numbers intentionally sacrificed) by date in spring and summer, respectively. Table A3 includes similar statistics by location and season. Tables A4 and A5 describe comma-separated variable (CSV) files for spring and summer that are on a CD that accompanies printed versions of this report. Those CSV files contain detailed data associated with every fish that was tagged and released at or below JDA including season, release date, release time, PIT tag code, acoustic tag code, acoustic tag activation date, fork length, weight, mortality status, and release location, as well as all dam operations at the time of release.

\subsection{Detection of Dead Fish}

We detected only one dead fish on survival arrays in 2006, out of releases of 23 at JDA, 46 at TDA, and 30 at BON. The single dead fish tag was detected on TDA survival arrays, but the pattern of movement within and upstream among arrays clearly indicated that this fish had been eaten by a predator. We detected two dead fish on the JDA egress array in spring, but that array was not used for survival calculations.

\subsection{Tag-Life Study}

A total of 74 tags that transmitted once every 10 seconds were sampled from tag lots used for yearling Chinook salmon on the Snake River and were continuously monitored until their failure to develop a taglife curve. The failure time data were fit to a logistic curve with the parameterization 


$$
S(t)=\left(1+e^{\frac{t-76.8028}{6.0149}}\right)^{-1}
$$

with standard errors of 1.1084 and 0.6346 for the numerator and denominator terms, respectively (Figure 3.6). This tag-life curve was used for the yearling Chinook salmon releases from LGR Tailrace.

For all yearlings released from JDA and below, tags transmitting once every 5 seconds were used. A separate tag-life curve was estimated from 100 5-second tags monitored until their failure. Their failure times were fit to a logistic curve with the parameterization

$$
S(t)=\left(1+e^{\frac{t-44.7226}{2.8940}}\right)^{-1}
$$

with standard errors of 0.4875 and 0.2485 , for the numerator and denominator terms, respectively (Figure 3.7; Appendix B, Figure B.3).

A tag-life survivorship curve was constructed from 99 10-second tags selected from those used to tag subyearling Chinook salmon smolts at Little Goose Dam (Figure 3.8), and there were indications that tags activated on July 15, 2006, had a different survival process (Figure 3.9) than did other tags used (Figure 3.10). Analysis of those 15 July tags shows an unusual survivorship function, with all 25 tags failing within a 2-day period (Figure 3.9).

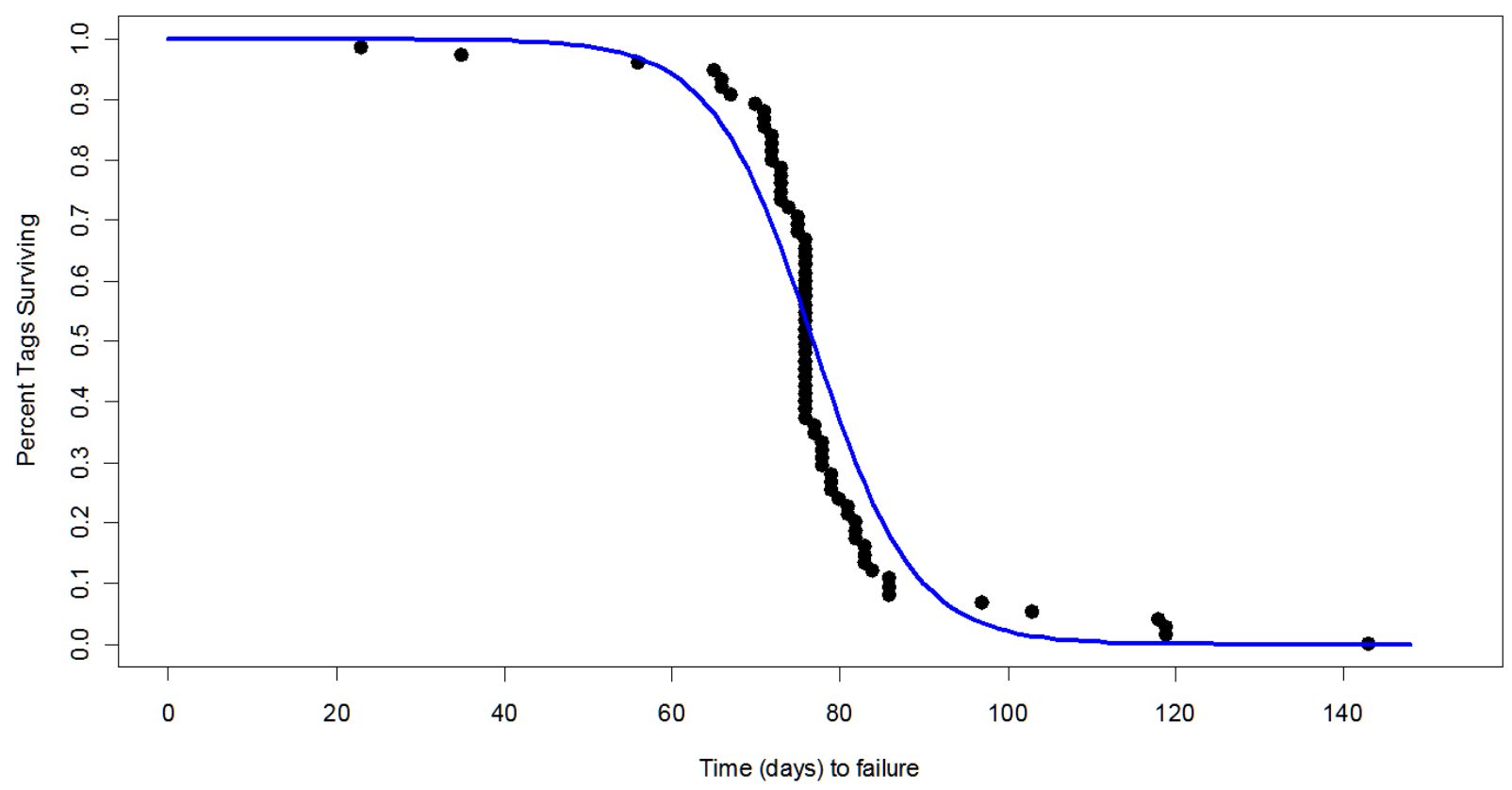

Figure 3.6. Estimated Time to Failure of Tags Transmitting Once Every 10 Seconds Like Those Implanted in Juvenile Chinook Salmon Released below LGR in Spring and below LGS in Summer 


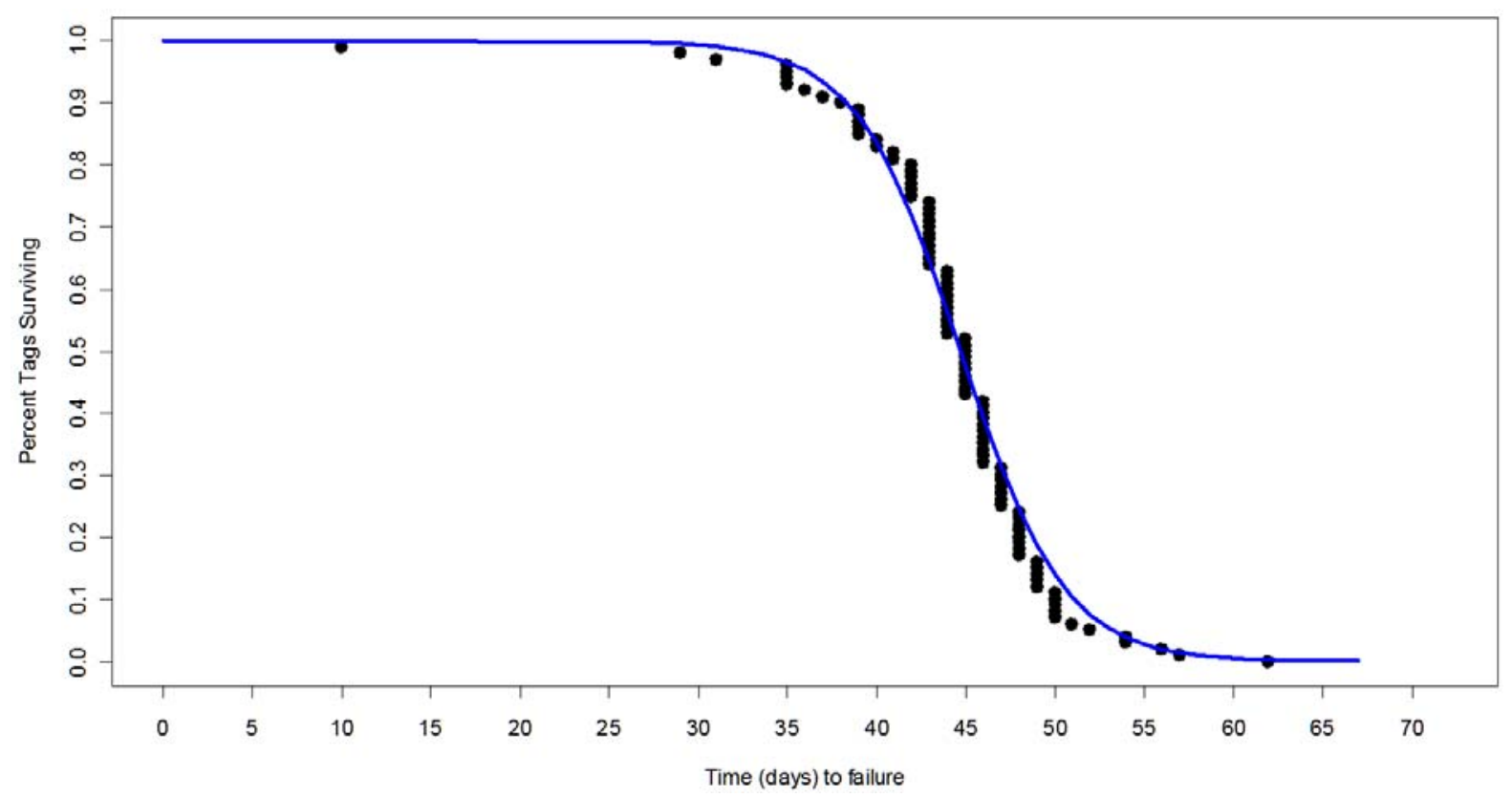

Figure 3.7. Estimated Time to Failure of Tags Transmitting Once Every 5 Seconds Like Those Implanted in Juvenile Chinook Salmon Released at JDA, TDA, and BON in Spring and Summer

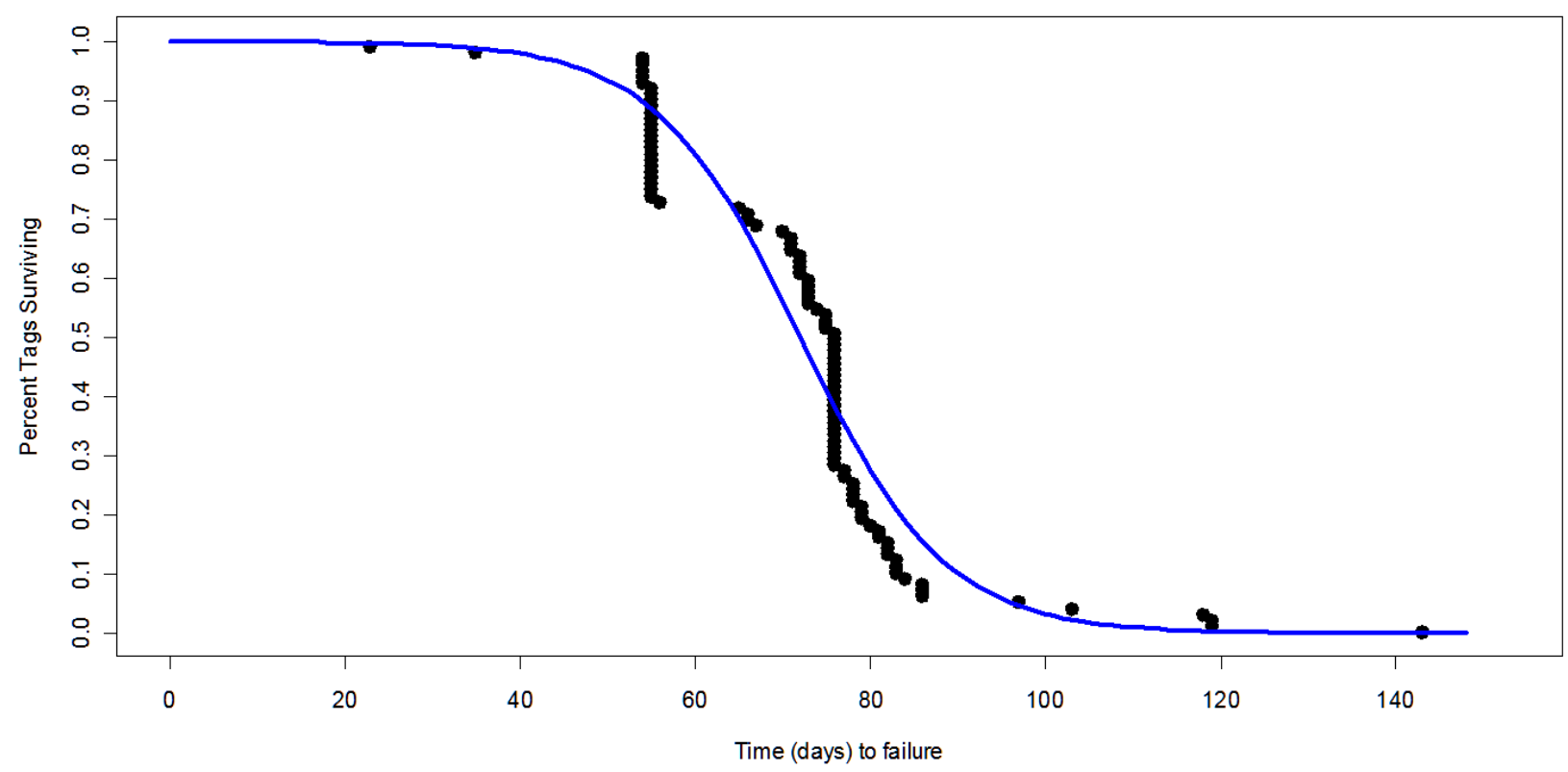

Figure 3.8. Estimated Time to Failure of Tags Transmitting Once every 10 Seconds Like Those Implanted in Chinook Salmon Released at LGR in Spring and LGS in Summer. The solid blue line is a curve fitted to the black points. 


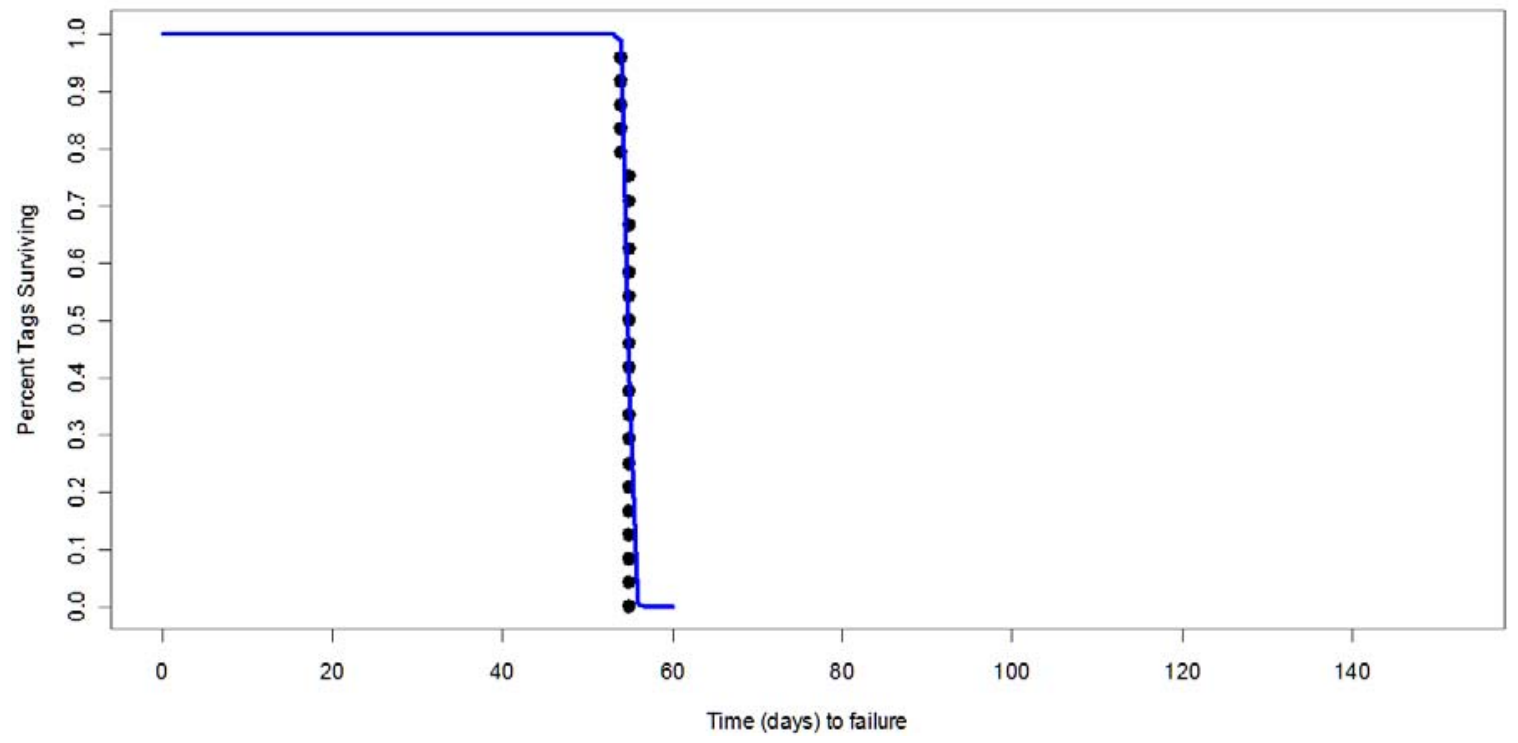

Figure 3.9. Estimated Time to Failure of 24 10-Second Tags Activated on July 15, 2006. The solid blue line is a curve fitted to the black points.

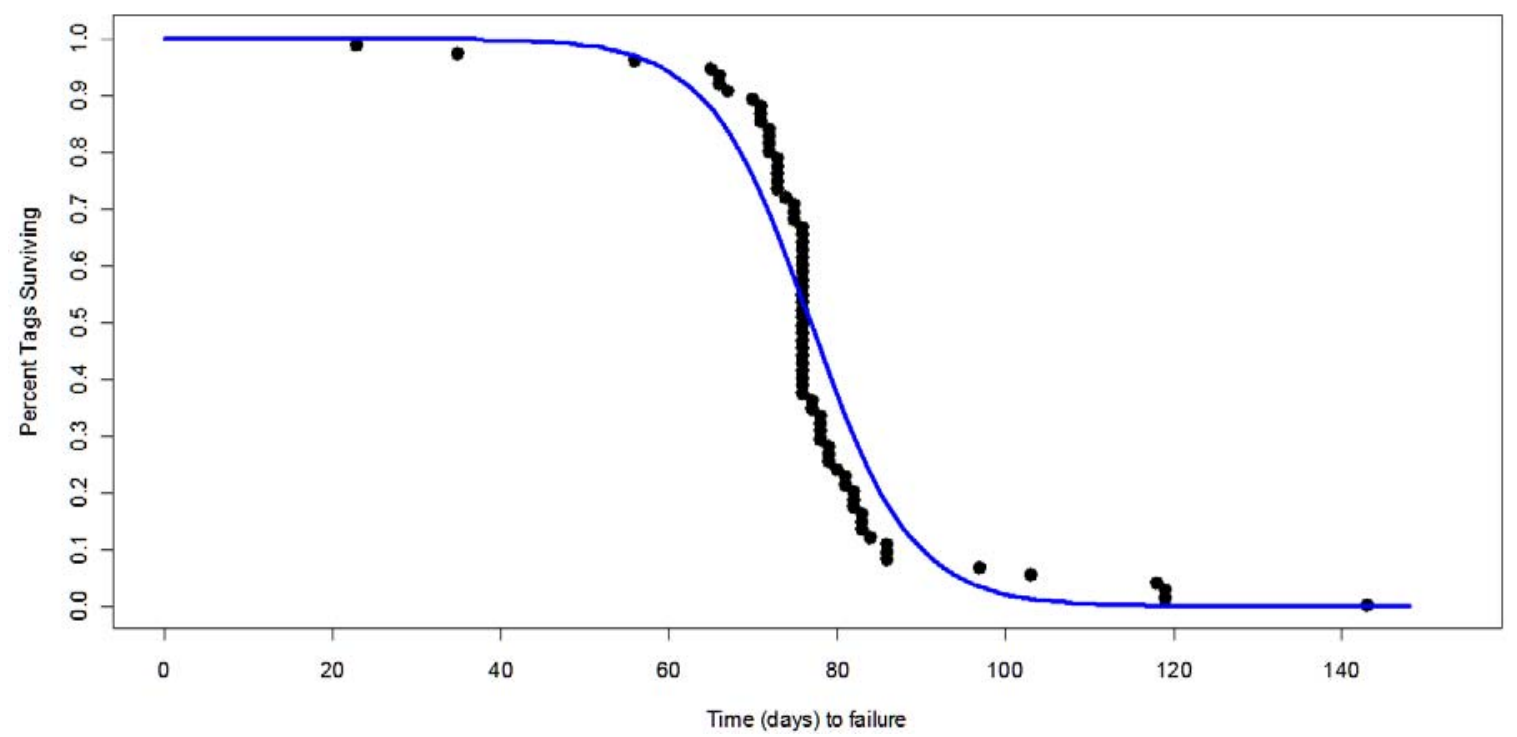

Figure 3.10. Estimated Tag Life of 10-Second Tags, Excluding Those Activated on July 15, 2006. The solid blue line is a curve fitted to the black points.

After the 24 tags that died prematurely were removed, a typical survivorship curve with relatively gradual loss of tag life was realized (Figure 3.10), but because fish tagged from different tag batches could not be differentiated, we used an overall survivorship curve based on all tags (Figure 3.8). The failure time data were fitted to a logistic curve with the parameterization

$$
S(t)=\left(1+e^{\frac{t-71.9645}{8.2595}}\right)^{-1},
$$

with standard errors of 1.4104 and 0.7075 for the numerator and denominator terms, respectively. The data did not have to be fit precisely because the arrival time for most tags was $>60$ days (Appendix D). 


\subsection{Detection and Survival of Yearling Chinook Salmon in Spring}

After presentation of tag-life study results and arrival times for yearling Chinook salmon, we present detection and survival results by release location or type.

\subsubsection{Tag-Life Study Correction}

Examination of the tag-life curve and arrival distributions of fish to downstream detection arrays (Appendix B) indicated that the vast majority of fish arrived before the time of first tag failure. In these cases, no tag-life correction was necessary. Only fish from the BON Tailrace (Figure B.5), the virtual release above BON (Figure B.7), and the TDA Tailrace release (Figure B.9) showed the potential need for tag-life correction. However, in all three cases, this was only for the last detection array and the expected probability of tag life was $\geq 0.999$.

\subsubsection{Lower Granite Releases}

For releases of yearling Chinook from LGR (Table 3.1), we used a single release-recapture model and detection data from the JDA primary (1J), TDA primary (1T), and TDA secondary (2T) arrays to estimate reach survival (Table 3.2). According to the Tag-Effects Study (Hockersmith et al. 2007), LGR releases were scheduled for 14 days partitioned over a 30-day period from 14 April through 15 May, but tag manufacturing and delivery problems permitted only two replicate releases on May 6 and 13, 2006. The replicate survival estimates were not significantly different $(\mathrm{P}>0.10)$. From release at the LGR Tailrace (rkm 696) to the JDA primary array at rkm 325.6, survival was estimated to be 0.487 ( $\widehat{\mathrm{SE}}=0.016$ ). Between the JDA primary array (RKM 325.6) and the TDA primary array (rkm 275.6), survival was estimated to be $0.877(\widehat{\mathrm{SE}}=0.017)$. Average detection probability at these two acoustic arrays was 0.896 and 0.770, respectively (Figure 3.11).

Table 3.1. Detection Histories for each Release Group from Lower Granite Dam. In the table heading, a 1 denotes detected and 0 not detected at the JDA primary array and the TDA primary and secondary arrays, respectively.

\begin{tabular}{|c|c|c|c|c|c|c|c|c|c|}
\hline \hline Release & $\mathbf{1} \mathbf{1} \mathbf{1}$ & $\mathbf{0} \mathbf{1} \mathbf{1}$ & $\mathbf{1} \mathbf{0} \mathbf{1}$ & $\mathbf{0} \mathbf{0} \mathbf{1}$ & $\mathbf{1} \mathbf{1} \mathbf{0}$ & $\mathbf{0} \mathbf{1} \mathbf{0}$ & $\mathbf{1} \mathbf{0} \mathbf{0}$ & $\mathbf{0} \mathbf{0} \mathbf{0}$ & Total \\
\hline $5 / 06$ & 75 & 7 & 14 & 4 & 3 & 0 & 17 & 118 & 238 \\
\hline $5 / 13$ & 209 & 23 & 67 & 9 & 9 & 1 & 40 & 400 & 758 \\
\hline Pooled & 284 & 30 & 81 & 13 & 12 & 1 & 57 & 518 & 996 \\
\hline
\end{tabular}

Table 3.2. Cormack-Jolly-Seber, Single-Release Estimates of Survival and Detection Probabilities for each Group of Fish Released from LGR Tailrace. The joint probability of survival from the TDA primary array to the secondary array and being detected at the secondary array $(\lambda)$ is reported in the last column. Standard errors are reported in parentheses.

\begin{tabular}{|c|c|c|c|c|c|}
\hline \multirow{2}{*}{$\begin{array}{l}\text { Day of } \\
\text { Release }\end{array}$} & \multicolumn{2}{|c|}{ Survival Probability } & \multicolumn{2}{|c|}{ Detection Probability } & \multirow{2}{*}{$\begin{array}{c}\text { Detection and } \\
\text { Survival }(\lambda) \text { to } 2 \mathrm{~T}\end{array}$} \\
\hline & to $1 \mathrm{~J}$ & $1 \mathrm{~J}$ to $1 \mathrm{~T}$ & $1 \mathrm{~J}$ & $1 T$ & \\
\hline $5 / 06$ & $0.513(0.033)$ & $0.849(0.035)$ & $0.893(0.030)$ & $0.820(0.038)$ & $0.965(0.020)$ \\
\hline $5 / 13$ & $0.478(0.018)$ & $0.886(0.019)$ & $0.896(0.017)$ & $0.753(0.025)$ & $0.959(0.013)$ \\
\hline Pooled & $0.487(0.016)$ & $0.877(0.017)$ & $0.896(0.015)$ & $0.770(0.021)$ & $0.960(0.011)$ \\
\hline
\end{tabular}




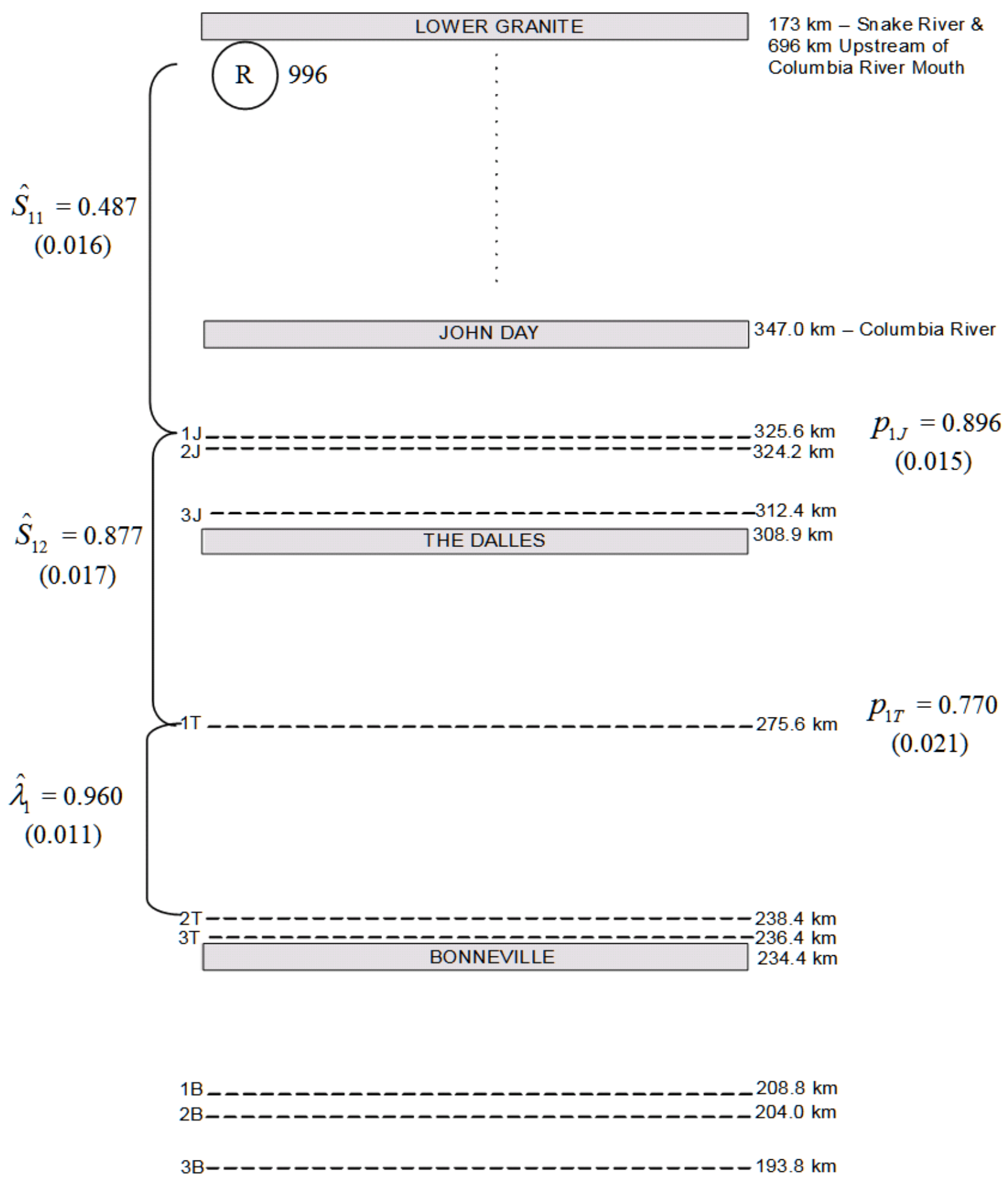

Figure 3.11. Summary of Results for the Single Release-Recapture (SR) Analysis of the LGR Release Groups of Yearling Chinook Salmon. Standard errors are reported in parentheses.

\subsubsection{John Day Dam Releases}

The three releases at Turbine Intake 9C, its Front Roll, and the JDA Tailrace provided the paired release-recapture data (Table 3.3) to estimate passage survival (Table 3.4) using downstream detection at the JDA primary array (rkm 325.6), TDA primary array (rkm 275.6), and TDA secondary array 
(rkm 238.4). Ratios of the release survival from the point of release to the TDA primary array were used in the paired release analysis. Detection probabilities and reach survivals below the JDA primary array were found to be homogeneous (Appendix C, Table C1), for the most part, for the paired releases, allowing survival for the paired releases to be estimated by either Model $M_{S_{1}}$ or $M_{S_{1}, p_{1}}$ (Table 3.5).

Table 3.3. Detection Histories for Each Release Group at JDA. In the table heading, a JDA a 1 denotes detected and 0 not detected at the JDA primary and TDA primary and secondary arrays, respectively.

\begin{tabular}{|c|c|c|c|c|c|c|c|c|c|}
\hline Release & 111 & 011 & 101 & 001 & 110 & 010 & 100 & 000 & Total \\
\hline \multicolumn{10}{|c|}{ John Day Front Roll } \\
\hline $5 / 16$ & 44 & 1 & 0 & 0 & 2 & 0 & 5 & 2 & 54 \\
\hline $5 / 19$ & 49 & 0 & 6 & 0 & 1 & 0 & 2 & 1 & 59 \\
\hline $5 / 21$ & 44 & 1 & 6 & 1 & 0 & 0 & 5 & 2 & 59 \\
\hline $5 / 23$ & 51 & 0 & 9 & 0 & 2 & 0 & 6 & 2 & 70 \\
\hline $5 / 25$ & 42 & 0 & 7 & 0 & 2 & 0 & 9 & 0 & 60 \\
\hline $5 / 27$ & 67 & 1 & 7 & 0 & 0 & 0 & 3 & 2 & 80 \\
\hline $6 / 01$ & 56 & 1 & 1 & 0 & 0 & 0 & 2 & 0 & 60 \\
\hline $6 / 03$ & 51 & 0 & 0 & 0 & 1 & 0 & 3 & 0 & 55 \\
\hline Pooled & 404 & 4 & 36 & 1 & 8 & 0 & 35 & 9 & 497 \\
\hline \multicolumn{10}{|c|}{ John Day Intake 9C } \\
\hline $5 / 16$ & 37 & 1 & 0 & 0 & 0 & 0 & 8 & 9 & 55 \\
\hline $5 / 19$ & 45 & 0 & 5 & 1 & 1 & 0 & 2 & 9 & 63 \\
\hline $5 / 21$ & 37 & 1 & 5 & 0 & 1 & 0 & 2 & 12 & 58 \\
\hline $5 / 23$ & 44 & 1 & 5 & 2 & 3 & 0 & 3 & 10 & 68 \\
\hline $5 / 25$ & 44 & 1 & 3 & 0 & 1 & 0 & 4 & 7 & 60 \\
\hline $5 / 27$ & 59 & 4 & 5 & 2 & 1 & 0 & 3 & 6 & 80 \\
\hline $6 / 01$ & 47 & 2 & 1 & 1 & 1 & 0 & 3 & 5 & 60 \\
\hline $6 / 03$ & 43 & 0 & 2 & 0 & 2 & 0 & 4 & 5 & 56 \\
\hline Pooled & 356 & 10 & 26 & 6 & 10 & 0 & 29 & 63 & 500 \\
\hline \multicolumn{10}{|c|}{ John Day Tailrace } \\
\hline $5 / 16$ & 46 & 0 & 0 & 0 & 0 & 0 & 6 & 2 & 54 \\
\hline $5 / 19$ & 48 & 0 & 9 & 0 & 2 & 0 & 0 & 1 & 60 \\
\hline $5 / 21$ & 46 & 0 & 6 & 0 & 2 & 0 & 6 & 0 & 60 \\
\hline $5 / 23$ & 48 & 3 & 4 & 3 & 1 & 0 & 7 & 4 & 70 \\
\hline $5 / 25$ & 33 & 1 & 3 & 0 & 0 & 0 & 2 & 2 & 41 \\
\hline $5 / 27$ & 66 & 2 & 4 & 0 & 1 & 0 & 3 & 1 & 77 \\
\hline $6 / 01$ & 74 & 0 & 0 & 0 & 1 & 0 & 2 & 2 & 79 \\
\hline $6 / 03$ & 37 & 1 & 0 & 0 & 0 & 0 & 1 & 1 & 40 \\
\hline Pooled & 398 & 7 & 26 & 3 & 7 & 0 & 27 & 13 & 481 \\
\hline
\end{tabular}


Table 3.4. Cormack-Jolly-Seber Single-Release Estimates of Survival and Detection Probabilities for each Group Released from JDA. The joint probability of survival from the TDA primary array to the secondary array and being detected at the secondary array $(\lambda)$ is reported in the last column. Standard errors are reported in parentheses.

\begin{tabular}{|c|c|c|c|c|c|}
\hline \multirow{2}{*}{$\begin{array}{c}\text { Day of } \\
\text { Release }\end{array}$} & \multicolumn{2}{|c|}{ Survival Probability } & \multicolumn{2}{|c|}{ Detection Probability } & \multirow{2}{*}{$\begin{array}{c}\text { Detection and } \\
\text { Survival }(\lambda) \text { to } 2 \mathbf{T}\end{array}$} \\
\hline & to $1 \mathrm{~J}$ & $1 \mathrm{~J}$ to $1 \mathrm{~T}$ & $1 \mathrm{~J}$ & $1 T$ & \\
\hline \multicolumn{6}{|c|}{ John Day Front Roll } \\
\hline $5 / 16$ & $0.965(0.026)$ & $0.902(0.042)$ & $0.979(0.021)$ & $1.000(<0.0001)$ & $0.957(0.029)$ \\
\hline $5 / 19$ & $0.983(0.017)$ & $0.968(0.024)$ & $1.000(<0.0001)$ & $0.891(0.042)$ & $0.980(0.020)$ \\
\hline $5 / 21$ & $0.970(0.024)$ & $0.909(0.039)$ & $0.962(0.027)$ & $0.865(0.047)$ & $1.000(<0.0001)$ \\
\hline $5 / 23$ & $0.971(0.020)$ & $0.917(0.035)$ & $1.000(<0.0001)$ & $0.850(0.046)$ & $0.962(0.026)$ \\
\hline $5 / 25$ & $1.000(<0.0001)$ & $0.856(0.047)$ & $1.000(<0.0001)$ & $0.857(0.050)$ & $0.955(0.031)$ \\
\hline $5 / 27$ & $0.976(0.018)$ & $0.961(0.022)$ & $0.987(0.013)$ & $0.907(0.034)$ & $1.000(<0.0001)$ \\
\hline $6 / 01$ & $1.001(0.001)$ & $0.966(0.024)$ & $0.983(0.017)$ & $0.983(0.017)$ & $1.000(<0.0001)$ \\
\hline $6 / 03$ & $1.000(<0.0001)$ & $0.946(0.031)$ & $1.000(<0.0001)$ & $1.000(<0.0001)$ & $0.981(0.019)$ \\
\hline Pooled & $0.983(0.006)$ & $0.929(0.012)$ & $0.989(0.005)$ & $0.917(0.013)$ & $0.981(0.007)$ \\
\hline \multicolumn{6}{|c|}{ John Day Intake 9C } \\
\hline $5 / 16$ & $0.840(0.050)$ & $0.822(0.057)$ & $0.974(0.026)$ & $1.0000(<0.0001)$ & $1.000(<0.0001)$ \\
\hline $5 / 19$ & $0.858(0.044)$ & $0.965(0.026)$ & $0.981(0.019)$ & $0.882(0.045)$ & $0.978(0.022)$ \\
\hline $5 / 21$ & $0.794(0.053)$ & $0.958(0.031)$ & $0.977(0.023)$ & $0.884(0.049)$ & $0.974(0.025)$ \\
\hline $5 / 23$ & $0.856(0.043)$ & $0.954(0.031)$ & $0.946(0.030)$ & $0.865(0.047)$ & $0.938(0.035)$ \\
\hline $5 / 25$ & $0.885(0.042)$ & $0.924(0.037)$ & $0.980(0.020)$ & $0.938(0.035)$ & $0.978(0.023)$ \\
\hline $5 / 27$ & $0.929(0.030)$ & $0.957(0.025)$ & $0.9160(0.033)$ & $0.900(0.036)$ & $0.984(0.016)$ \\
\hline $6 / 01$ & $0.920(0.036)$ & $0.943(0.032)$ & $0.942(0.032)$ & $0.961(0.027)$ & $0.980(0.020)$ \\
\hline $6 / 03$ & $0.911(0.038)$ & $0.923(0.038)$ & $1.000(<0.0001)$ & $0.956(0.031)$ & $0.956(0.031)$ \\
\hline Pooled & $0.8764(0.0149)$ & $0.9331(0.0124)$ & $0.9608(0.0096)$ & $0.9196(0.0136)$ & $0.9734(0.0083)$ \\
\hline \multicolumn{6}{|c|}{ John Day Tailrace } \\
\hline $5 / 16$ & $0.963(0.026)$ & $0.885(0.044)$ & $1.000(<0.0001)$ & $1.000(<0.0001)$ & $1.000(<0.0001)$ \\
\hline $5 / 19$ & $0.983(0.017)$ & $1.006(0.005)$ & $1.000(<0.0001)$ & $0.842(0.048)$ & $0.960(0.028)$ \\
\hline $5 / 21$ & $1.000(<0.0001)$ & $0.904(0.039)$ & $1.000(<0.0001)$ & $0.885(0.044)$ & $0.958(0.029)$ \\
\hline $5 / 23$ & $0.954(0.029)$ & $0.885(0.042)$ & $0.898(0.039)$ & $0.879(0.043)$ & $0.981(0.019)$ \\
\hline $5 / 25$ & $0.957(0.034)$ & $0.947(0.036)$ & $0.973(0.027)$ & $0.919(0.045)$ & $1.000(<0.0001)$ \\
\hline $5 / 27$ & $0.988(0.013)$ & $0.960(0.023)$ & $0.973(0.019)$ & $0.944(0.027)$ & $0.986(0.014)$ \\
\hline $6 / 01$ & $0.975(0.018)$ & $0.974(0.018)$ & $1.000(<0.0001)$ & $1.000(<0.0001)$ & $0.987(0.0132)$ \\
\hline $6 / 03$ & $0.976(0.025)$ & $0.974(0.026)$ & $0.974(0.026)$ & $1.000(<0.0001)$ & $1.000(<0.0001)$ \\
\hline Pooled & $0.974(0.007)$ & $0.942(0.011)$ & 0.977 (0.007) & $0.933(0.012)$ & $0.983(0.006)$ \\
\hline
\end{tabular}


Table 3.5. Modeled Estimates of Single-Release Survival and Detection Probabilities for each PairedRelease Group from John Day Dam. Estimates were from pooled data from both singlereleases when differences in single-release estimates did not differ significantly. The joint probability of survival from the TDA primary array to the secondary array and being detected at the secondary array $(\lambda)$ is reported in the last column. Standard errors are reported in parentheses.

\begin{tabular}{|c|c|c|c|c|c||}
\hline \multirow{2}{*}{$\begin{array}{c}\text { John Day } \\
\text { Release Site }\end{array}$} & \multicolumn{2}{|c|}{ Survival Probability } & \multicolumn{2}{|c|}{ Detection Probability } & $\begin{array}{c}\text { Detection and } \\
\text { Survival }(\lambda) \text { to 2T }\end{array}$ \\
\cline { 2 - 6 } & to $\mathbf{1 J}$ & $\mathbf{1 J}$ to $\mathbf{1 T}$ & $\mathbf{1 J}$ & $\mathbf{1 T}$ & $0.982(0.005)$ \\
\hline Front roll & $0.983(0.006)$ & $0.935(0.008)$ & $0.983(0.004)$ & $0.925(0.009)$ & \\
\hline Tailrace & $0.974(0.007)$ & & & & $0.978(0.005)$ \\
\hline Intake 9C & $0.876(0.015)$ & \multirow{2}{*}{$0.938(0.008)$} & $0.969(0.006)$ & $0.927(0.009)$ & \\
\hline Tailrace & $0.975(0.007)$ & & & & $0.977(0.005)$ \\
\hline Intake 9C & $0.876(0.015)$ & \multirow{2}{*}{$0.931(0.009)$} & $0.961(0.010)$ & $0.918(0.009)$ & \\
\hline Front roll & $0.983(0.006)$ & & $0.989(0.005)$ & & \\
\hline
\end{tabular}

Survival from the Front Roll to the JDA Tailrace was estimated to be $\hat{S}=1.009$ ( $\widehat{\mathrm{SE}}=0.010$ ). Survival through Turbine Intake 9C to the JDA Tailrace was estimated to be $\hat{S}=0.898$ ( $\widehat{\mathrm{SE}}=0.017$ ). From Turbine Intake 9C to the Front Roll, survival was estimated to be $\hat{S}=0.892$ ( $\widehat{\mathrm{SE}}=0.016$ ). Figure 3.12 summarizes the results of the three acoustic-tag releases at JDA.

A Z-test indicated that the single-release survival estimate for Intake-released yearlings was significantly lower than that for yearlings released in the Front Roll $(\mathrm{Z}=-6.385 ; \mathrm{P}<0.0001 ; \mathrm{n}=8)$, and it was significantly lower than that for yearlings released in the Tailrace $(Z=-5.843 ; P<0.0001 ; n=8)$. However, single release survival estimates from the Front Roll and Tailrace releases to the primary array did not differ significantly $(\mathrm{Z}=1.131<1.645$; $\mathrm{P}=0.129 ; \mathrm{n}=8)$. A paired-release survival estimate for yearlings passing through Intake $9 \mathrm{C}$ to the Tailrace was significantly lower than a paired-release estimate for yearlings released in the Front Roll and passing to the Tailrace $(\mathrm{Z}=-4.945 ; \mathrm{P}<0.0001 ; \mathrm{n}=8$ ).

\subsubsection{The Dalles and Bonneville Tailrace Releases}

Releases from the TDA Tailrace were performed from May 16- June 5, 2006 (Table 3.6). Survival from the tailrace release ( $\mathrm{rkm} 306)$ to the TDA primary array ( $\mathrm{rkm} 275.6)$ ranged from 0.959 ( $\widehat{\mathrm{SE}}=$ 0.018 ) to 1.001 ( $\widehat{\mathrm{SE}} 0.001$ ) with a pooled estimate across the season of 0.989 ( $\widehat{\mathrm{SE}}=0.003$ ). From the primary (rkm 275.6) to the secondary (rkm 238.4) array, survival ranged from 0.979 ( $\widehat{\mathrm{SE}}=0.015)$ to $1.004(\widehat{\mathrm{SE}}=0.004)$, with a pooled estimate across the season of $0.992(\widehat{\mathrm{SE}}=0.004)$ (Table 3.7). Joint survival through the BON reservoir is therefore estimated to be $0.989 \times 0.992=0.981(\widehat{\mathrm{SE}}=0.005)$. Results are summarized in Figure 3.13. 


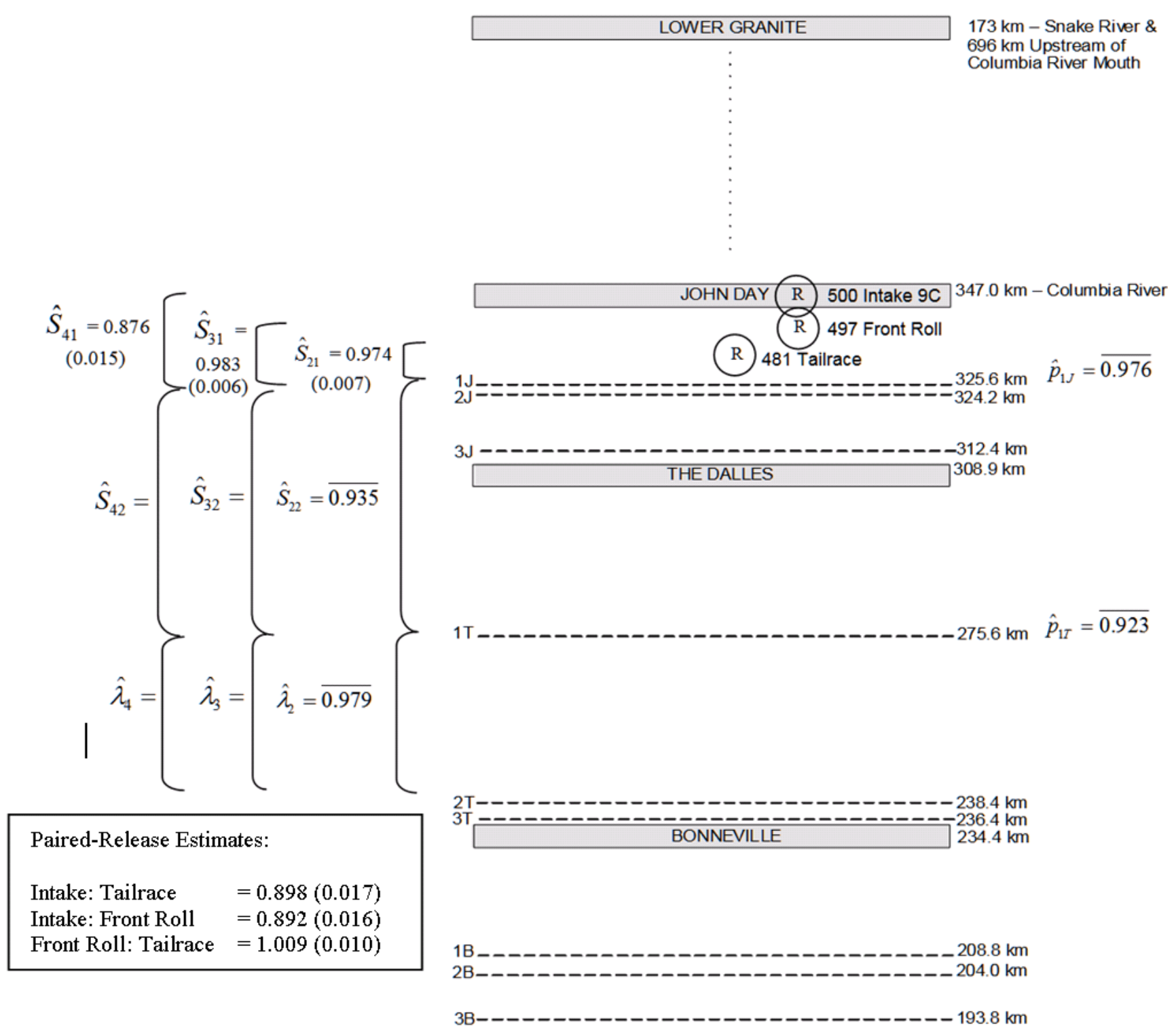

Figure 3.12. Summary of Results for the Single-Release and Paired-Release Analysis of the JDA Release Groups. Single-release estimates are adjacent to the figure and paired-release estimates are in the text box. 
Table 3.6. Detection Histories for each Release Group from the TDA Tailrace. In the table heading, a 1 denotes detected and 0 not detected at the TDA primary and secondary arrays, and the BON primary array, respectively.

\begin{tabular}{|c|c|c|c|c|c|c|c|c|c||}
\hline Release & $\mathbf{1} \mathbf{1} \mathbf{1}$ & $\mathbf{0} \mathbf{1} \mathbf{1}$ & $\mathbf{1} \mathbf{0} \mathbf{1}$ & $\mathbf{0} \mathbf{0} \mathbf{1}$ & $\mathbf{1} \mathbf{1} \mathbf{0}$ & $\mathbf{0} \mathbf{1} \mathbf{0}$ & $\mathbf{1} \mathbf{0} \mathbf{0}$ & $\mathbf{0} \mathbf{0} \mathbf{0}$ & Total \\
\hline $5 / 16$ & 72 & 0 & 0 & 0 & 22 & 0 & 1 & 1 & 96 \\
\hline $5 / 19$ & 77 & 0 & 1 & 0 & 36 & 2 & 3 & 1 & 120 \\
\hline $5 / 21$ & 68 & 4 & 0 & 0 & 41 & 1 & 1 & 5 & 120 \\
\hline $5 / 23$ & 50 & 1 & 0 & 0 & 35 & 2 & 0 & 2 & 90 \\
\hline $5 / 25$ & 19 & 0 & 0 & 0 & 27 & 1 & 1 & 0 & 48 \\
\hline $5 / 27$ & 33 & 3 & 0 & 0 & 43 & 4 & 1 & 1 & 85 \\
\hline $6 / 01$ & 36 & 1 & 0 & 0 & 29 & 1 & 0 & 0 & 67 \\
\hline $6 / 03$ & 93 & 1 & 1 & 0 & 58 & 0 & 0 & 0 & 153 \\
\hline $6 / 05$ & 94 & 2 & 1 & 0 & 97 & 1 & 3 & 1 & 199 \\
\hline Pooled & 542 & 12 & 3 & 0 & 388 & 12 & 10 & 11 & 978 \\
\hline
\end{tabular}

Table 3.7. Cormack-Jolly-Seber Single-Release Estimates of Survival and Detection Probabilities for each Group Released from the TDA Tailrace. The joint probability of survival from the TDA secondary array to the BON primary array and being detected at the BON primary array $(\lambda)$ is in the last column. Standard errors are in parentheses.

\begin{tabular}{|c|c|c|c|c|c||}
\hline \hline \multirow{2}{*}{$\begin{array}{c}\text { Day of } \\
\text { Release }\end{array}$} & \multicolumn{2}{|c|}{ Survival Probability } & \multicolumn{2}{c|}{ Detection Probability } & $\begin{array}{c}\text { Detection and } \\
\text { Survival }(\lambda) \text { to 1B }\end{array}$ \\
\hline $5 / 16$ & to 1T & $\mathbf{1 T}$ to $\mathbf{2 T}$ & $\mathbf{1 T}$ & $\mathbf{2 T}$ & \\
\hline $5 / 19$ & $0.99(0.010)$ & $0.99(0.011)$ & $1.000(<0.0001)$ & $1.000(<0.0001)$ & $0.766(0.044)$ \\
\hline $5 / 21$ & $0.992(0.008)$ & $0.979(0.015)$ & $0.983(0.012)$ & $0.987(0.013)$ & $0.670(0.044)$ \\
\hline $5 / 23$ & $0.978(0.016)$ & $0.991(0.009)$ & $0.956(0.019)$ & $1.000(<0.0001)$ & $0.632(0.045)$ \\
\hline $5 / 25$ & $1.001(0.001)$ & $0.979(0.021)$ & $0.979(0.021)$ & $1.000(<0.0001)$ & $0.404(0.072)$ \\
\hline $5 / 27$ & $0.989(0.012)$ & $0.987(0.013)$ & $0.916(0.031)$ & $1.000(<0.0001)$ & $0.434(0.054)$ \\
\hline $6 / 01$ & $1.000(<0.0001)$ & $1.000(<0.0001)$ & $0.970(0.021)$ & $1.000(<0.0001)$ & $0.552(0.061)$ \\
\hline $6 / 03$ & $1.000(<0.0001)$ & $1.004(0.004)$ & $0.994(0.007)$ & $0.990(0.011)$ & $0.618(0.039)$ \\
\hline $6 / 05$ & $0.995(0.005)$ & $0.990(0.010)$ & $0.985(0.009)$ & $0.990(0.010)$ & $0.495(0.036)$ \\
\hline Pooled & $0.989(0.003)$ & $0.992(0.004)$ & $0.975(0.005)$ & $0.995(0.003)$ & $0.581(0.016)$ \\
\hline
\end{tabular}



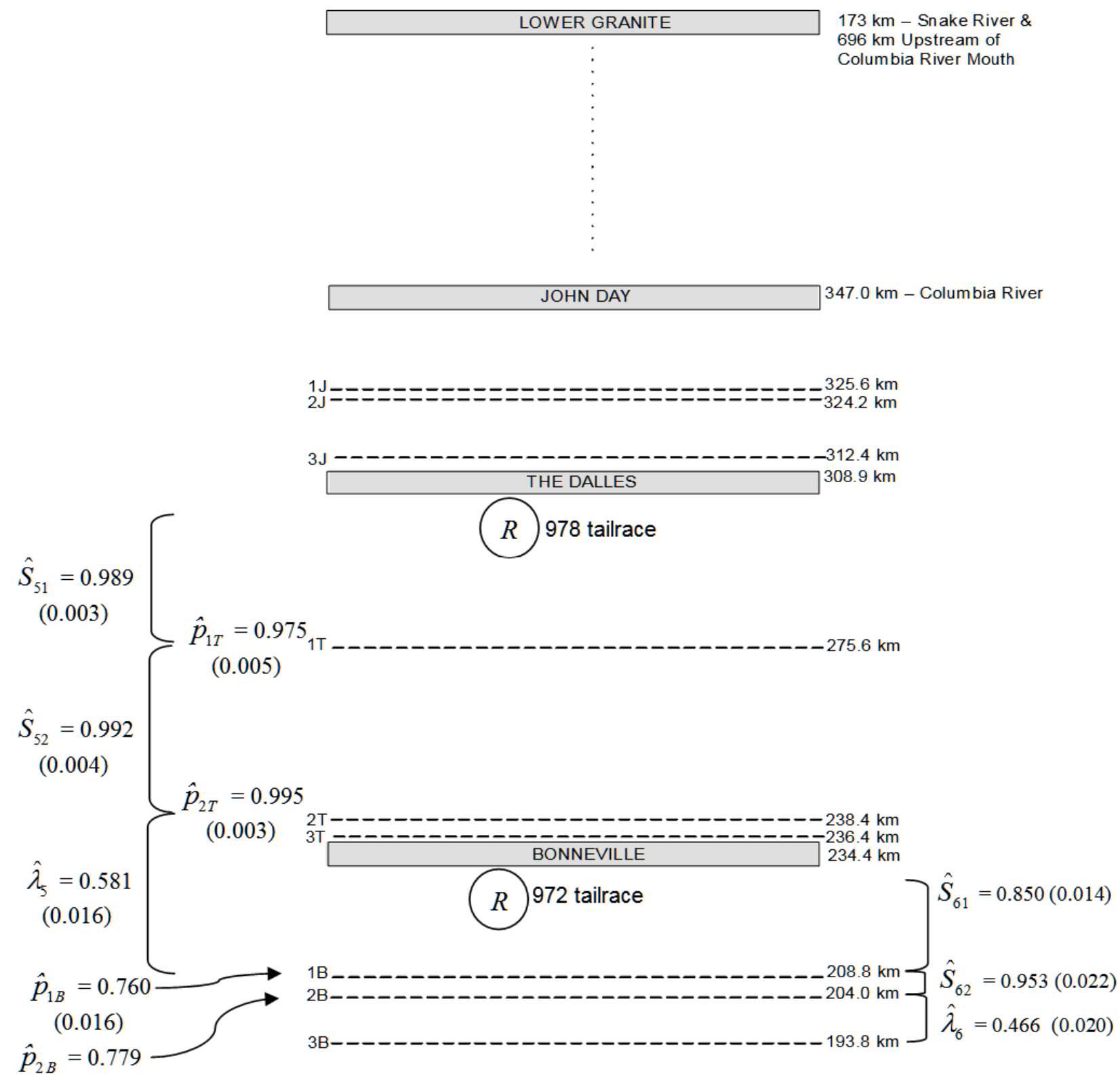

Figure 3.13. Summary of the Single-Release (SR) Analyses of TDA and BON Tailrace Releases

Four releases from BON Tailrace were performed from May 2 to 27, 2006 (Table 3.8) and detections were used to estimate detection probabilities and survivals in Table 3.9. From BON Tailrace to the BON primary array (rkm 208.8), survival ranged from $0.708(\widehat{\mathrm{SE}}=0.030)$ to 0.916 ( $\widehat{\mathrm{SE}}=0.034)$, with a pooled value of $0.850(\widehat{\mathrm{SE}}=0.014)$. Between the BON primary (rkm 208.8) and secondary (rkm 204.0) array, survival ranged from 0.887 ( $\widehat{\mathrm{SE}}=0.043)$ to $1.013(\widehat{\mathrm{SE}}=0.045)$, with a pooled estimated of $0.953(\widehat{\mathrm{SE}}=$ 0.0222). Figure 3.13 summarizes the observed detection and survival probabilities resulting from the single-release analyses of the TDA and BON Tailrace releases. 
Table 3.8. Detection Histories for each Release Group from the BON Tailrace. In the table heading, 1 denotes detected and 0 not detected at the BON primary, secondary, and tertiary arrays, respectively.

\begin{tabular}{|c|c|c|c|c|c|c|c|c|c|}
\hline Release & $\mathbf{1} \mathbf{1} \mathbf{1}$ & $\mathbf{0} \mathbf{1} \mathbf{1}$ & $\mathbf{1} \mathbf{0} \mathbf{1}$ & $\mathbf{0} \mathbf{0} \mathbf{1}$ & $\mathbf{1} \mathbf{1} \mathbf{0}$ & $\mathbf{0} \mathbf{1} \mathbf{0}$ & $\mathbf{1} \mathbf{0} \mathbf{0}$ & $\mathbf{0} \mathbf{0} \mathbf{0}$ & Total \\
\hline $5 / 02$ & 48 & 10 & 8 & 1 & 88 & 22 & 34 & 28 & 239 \\
\hline $5 / 11$ & 66 & 6 & 6 & 1 & 71 & 8 & 14 & 73 & 245 \\
\hline $5 / 19$ & 62 & 20 & 31 & 11 & 51 & 13 & 23 & 33 & 244 \\
\hline $5 / 27$ & 43 & 31 & 13 & 10 & 41 & 34 & 29 & 43 & 244 \\
\hline \hline Pooled & 219 & 67 & 58 & 23 & 251 & 77 & 100 & 177 & 972 \\
\hline
\end{tabular}

Table 3.9. Cormack-Jolly-Seber Single-Release Estimates of Survival and Detection Probabilities for each Group of Fish Released from the BON Tailrace. The joint probability of survival from the BON secondary array to the tertiary array and being detected at the tertiary array $(\lambda)$ is reported in the last column. Standard errors are reported in parentheses.

\begin{tabular}{|c|c|c|c|c|c||}
\hline \multirow{2}{*}{$\begin{array}{c}\text { Day of } \\
\text { Release }\end{array}$} & \multicolumn{2}{|c|}{ Survival Probability } & \multicolumn{2}{c|}{ Detection Probability } & $\begin{array}{c}\text { Detection and } \\
\text { Survival }(\lambda) \text { to 3B }\end{array}$ \\
\cline { 2 - 6 } & to 1B & 1B to 2B & 1B & 2B & \\
\hline $5 / 02$ & $0.915(0.023)$ & $0.887(0.043)$ & $0.814(0.030)$ & $0.866(0.042)$ & $0.345(0.037)$ \\
\hline $5 / 11$ & $0.708(0.030)$ & $0.955(0.030)$ & $0.905(0.023)$ & $0.911(0.032)$ & $0.477(0.041)$ \\
\hline $5 / 19$ & $0.894(0.024)$ & $1.013(0.045)$ & $0.766(0.031)$ & $0.661(0.043)$ & $0.562(0.041)$ \\
\hline $5 / 27$ & $0.916(0.034)$ & $0.874(0.050)$ & $0.564(0.038)$ & $0.763(0.043)$ & $0.497(0.041)$ \\
\hline Pooled & $0.850(0.014)$ & $0.953(0.022)$ & $0.760(0.016)$ & $0.779(0.022)$ & $0.466(0.020)$ \\
\hline \hline
\end{tabular}

\subsubsection{Virtual Releases from The Dalles and Bonneville Forebays}

Smolts known to have arrived at the JDA tertiary array (rkm 312.4) served as a virtual release of fish known to have gone through TDA (rkm 308.9). These fish were used to estimate reach survivals to rkm 275.6 and between rkm 275.6 and 238.4. Eight virtual release groups were formed from May 16 - June 3, 2006 (Table 3.10). In the first reach, survivals ranged from 0.885 ( $\widehat{\mathrm{SE}}=0.030$ ) to 0.982 ( $\widehat{\mathrm{SE}}=0.013$ ), with a pooled estimate of 0.947 ( $\widehat{\mathrm{SE}}=0.007$ ). In the second reach, replicate survival estimates ranged from $0.961(\widehat{\mathrm{SE}}=0.017)$ to $0.993(\widehat{\mathrm{SE}}=0.007)$, with a pooled estimate of $0.979(\widehat{\mathrm{SE}}=0.005)$ (Table 3.11). Survival through the joint reach from the forebay of TDA to the forebay of BON was estimated to be $0.947 \times 0.979=0.927(\widehat{\mathrm{SE}}=0.008)$. 
Table 3.10. Detection Histories for each Virtual Release Group through TDA. In the table heading, a 1 denotes detected and 0 not detected at the TDA primary and secondary arrays, and the BON primary array, respectively.

\begin{tabular}{|c|c|c|c|c|c|c|c|c|c|}
\hline Release & $\mathbf{1} \mathbf{1} \mathbf{1}$ & $\mathbf{0} \mathbf{1} \mathbf{1}$ & $\mathbf{1} \mathbf{0} \mathbf{1}$ & $\mathbf{0} \mathbf{0} \mathbf{1}$ & $\mathbf{1} \mathbf{1} \mathbf{0}$ & $\mathbf{0} \mathbf{1} \mathbf{0}$ & $\mathbf{1} \mathbf{0} \mathbf{0}$ & $\mathbf{0} \mathbf{0} \mathbf{0}$ & Total \\
\hline $5 / 16$ & 68 & 0 & 0 & 0 & 30 & 0 & 2 & 13 & 113 \\
\hline $5 / 19$ & 78 & 8 & 0 & 0 & 35 & 10 & 3 & 3 & 137 \\
\hline $5 / 21$ & 68 & 7 & 0 & 0 & 43 & 7 & 2 & 9 & 136 \\
\hline $5 / 23$ & 80 & 5 & 0 & 0 & 43 & 13 & 5 & 9 & 155 \\
\hline $5 / 25$ & 50 & 5 & 0 & 0 & 43 & 4 & 3 & 11 & 116 \\
\hline $5 / 27$ & 59 & 5 & 0 & 0 & 71 & 3 & 1 & 5 & 144 \\
\hline $6 / 01$ & 90 & 2 & 0 & 0 & 60 & 0 & 1 & 4 & 157 \\
\hline $6 / 03$ & 55 & 1 & 0 & 0 & 57 & 0 & 3 & 5 & 121 \\
\hline Pooled & 548 & 33 & 0 & 0 & 382 & 37 & 20 & 59 & 1079 \\
\hline
\end{tabular}

Table 3.11. Cormack-Jolly-Seber Single-Release Estimates of Survival and Detection Probabilities for each Virtual Release Group through TDA. The joint probability of survival from the TDA secondary array to the BON primary array and being detected at the BON primary array $(\lambda)$ is reported in the last column. Standard errors are reported in parentheses.

\begin{tabular}{|c|c|c|c|c|c||}
\hline \multirow{2}{*}{$\begin{array}{c}\text { Day of } \\
\text { Release }\end{array}$} & \multicolumn{2}{|c|}{ Survival Probability } & \multicolumn{2}{c|}{ Detection Probability } & $\begin{array}{c}\text { Detection and } \\
\text { Survival }(\lambda) \text { to } \\
\text { 1B }\end{array}$ \\
\hline $5 / 16$ & to 1T & 1T to 2T & $\mathbf{1 T}$ & $\mathbf{2 T}$ & \begin{tabular}{c} 
1T \\
\hline $5 / 19$
\end{tabular} \\
\hline $5 / 21$ & $0.985(0.030)$ & $0.980(0.014)$ & $1.000(<0.0001)$ & $1.000(<0.0001)$ & $0.694(0.047)$ \\
\hline $5 / 23$ & $0.936(0.021)$ & $0.982(0.012)$ & $0.888(0.028)$ & $1.000(<0.0001)$ & $0.600(0.044)$ \\
\hline $5 / 25$ & $0.947(0.019)$ & $0.961(0.017)$ & $0.872(0.028)$ & $1.000(<0.0001)$ & $0.603(0.041)$ \\
\hline $5 / 27$ & $0.966(0.015)$ & $0.992(0.008)$ & $0.942(0.020)$ & $1.000(<0.0001)$ & $0.464(0.043)$ \\
\hline $6 / 01$ & $0.975(0.013)$ & $0.993(0.007)$ & $0.987(0.009)$ & $1.000(<0.0001)$ & $0.605(0.040)$ \\
\hline $6 / 03$ & $0.959(0.018)$ & $0.974(0.015)$ & $0.991(0.009)$ & $1.000(<0.0001)$ & $0.496(0.047)$ \\
\hline Pooled & $0.947(0.007)$ & $0.979(0.005)$ & $0.930(0.008)$ & $1.000(<0.0001)$ & $0.581(0.016)$ \\
\hline \hline
\end{tabular}

Nine virtual releases were formed at the forebay of BON from May 14 through June 7, 2006 (Table 3.12). Survival from the BON forebay (rkm 236.4) to rkm 208.8 below BON ranged from 0.846 ( $\widehat{\mathrm{SE}}=0.037)$ to $0.975(\widehat{\mathrm{SE}}=0.051)$, with a pooled estimate of $0.919(\widehat{\mathrm{SE}}=0.014)$ (Table 3.13). Figure 3.14 summarizes the results of the single release-recapture analysis for the virtual releases from the TDA and BON forebays. 
Table 3.12. Detection History for each Virtual Release Group through BON. In the table heading, a 1 denotes detected and 0 not detected at BON primary, secondary, and tertiary arrays, respectively.

\begin{tabular}{|c|c|c|c|c|c|c|c|c|c|}
\hline Release & 1111 & 011 & 101 & 001 & 110 & 010 & 100 & 000 & Total \\
\hline \multicolumn{10}{|c|}{ Bonneville Dam } \\
\hline $5 / 14$ & 39 & 6 & 9 & 1 & 24 & 3 & 7 & 5 & 94 \\
\hline $5 / 17$ & 31 & 11 & 14 & 2 & 30 & 8 & 11 & 10 & 117 \\
\hline $5 / 19$ & 39 & 7 & 10 & 7 & 22 & 7 & 7 & 15 & 114 \\
\hline $5 / 21$ & 30 & 13 & 6 & 5 & 15 & 6 & 4 & 7 & 86 \\
\hline $5 / 23$ & 11 & 6 & 3 & 2 & 6 & 8 & 3 & 7 & 46 \\
\hline $5 / 25$ & 26 & 15 & 2 & 4 & 10 & 17 & 3 & 4 & 81 \\
\hline $5 / 30$ & 21 & 9 & 6 & 2 & 16 & 7 & 1 & 5 & 67 \\
\hline $6 / 01$ & 49 & 23 & 15 & 4 & 27 & 17 & 11 & 9 & 155 \\
\hline $6 / 03$ & 52 & 23 & 17 & 9 & 32 & 15 & 11 & 36 & 195 \\
\hline Pooled & 299 & 113 & 82 & 36 & 182 & 88 & 58 & 99 & 957 \\
\hline
\end{tabular}

Table 3.13. Cormack-Jolly-Seber Single-Release Estimates of Survival and Detection Probabilities for each Virtual Release Group through BON. The joint probability of survival from the BON secondary array to the tertiary array and being detected at the tertiary array $(\lambda)$ is reported in the last column. Standard errors are reported in parentheses.

\begin{tabular}{|c|c|c|c|c|c||}
\hline \multirow{2}{*}{$\begin{array}{c}\text { Day of } \\
\text { Release }\end{array}$} & \multicolumn{2}{|c|}{ Survival Probability } & \multicolumn{2}{c|}{ Detection Probability } & $\begin{array}{c}\text { Detection and } \\
\text { Survival }(\lambda) \text { to 3B }\end{array}$ \\
\cline { 2 - 6 } Bonneville Dam 1B & 1B to 2B & 1B & 2B & \\
\hline $5 / 14$ & $0.961(0.028)$ & $1.028(0.071)$ & $0.798(0.045)$ & $0.711(0.068)$ & $0.485(0.062)$ \\
\hline $5 / 17$ & $0.947(0.041)$ & $0.907(0.087)$ & $0.704(0.051)$ & $0.667(0.073)$ & $0.418(0.060)$ \\
\hline $5 / 19$ & $0.879(0.039)$ & $1.046(0.088)$ & $0.732(0.049)$ & $0.612(0.070)$ & $0.476(0.063)$ \\
\hline $5 / 21$ & $0.971(0.047)$ & $0.926(0.086)$ & $0.625(0.061)$ & $0.675(0.074)$ & $0.529(0.070)$ \\
\hline $5 / 23$ & $0.890(0.112)$ & $0.874(0.176)$ & $0.464(0.094)$ & $0.643(0.128)$ & $0.391(0.102)$ \\
\hline $5 / 25$ & $0.975(0.051)$ & $1.013(0.094)$ & $0.456(0.060)$ & $0.750(0.077)$ & $0.400(0.063)$ \\
\hline $5 / 30$ & $0.905(0.039)$ & $1.330(0.140)$ & $0.610(0.064)$ & $0.546(0.087)$ & $0.409(0.074)$ \\
\hline $6 / 01$ & $0.957(0.033)$ & $0.926(0.059)$ & $0.647(0.044)$ & $0.735(0.054)$ & $0.495(0.050)$ \\
\hline $6 / 03$ & $0.846(0.037)$ & $1.014(0.071)$ & $0.582(0.043)$ & $0.610(0.054)$ & $0.490(0.050)$ \\
\hline Pooled & $0.919(0.014)$ & $0.998(0.029)$ & $0.636(0.018)$ & $0.662(0.024)$ & $0.464(0.021)$ \\
\hline
\end{tabular}




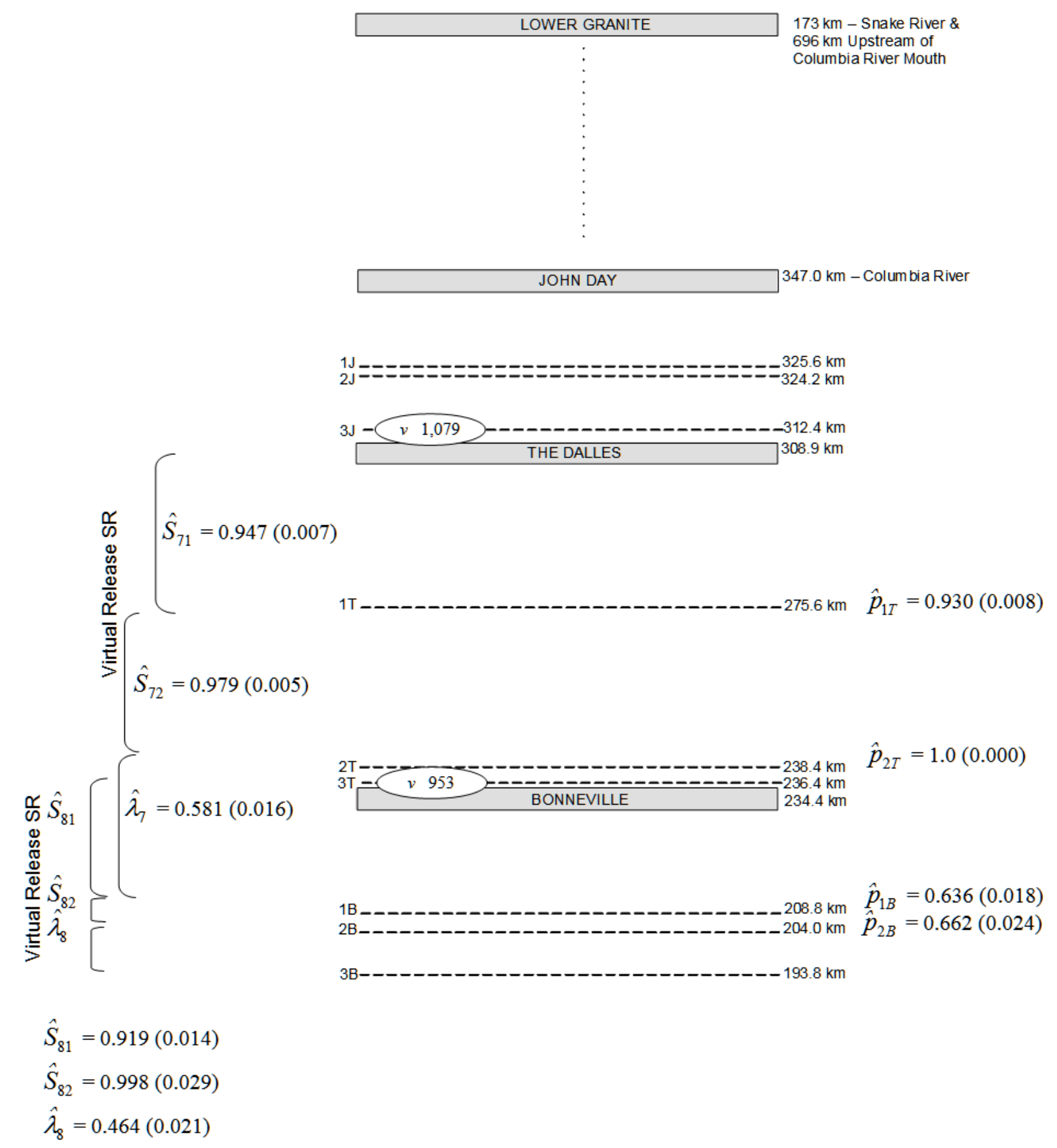

Figure 3.14. Summary of Single Release-Recapture Analyses of Virtual Releases of Yearling Chinook Salmon from the TDA and BON Forebays

\subsubsection{The Dalles and Bonneville Project Passage Survivals}

Tailrace releases from the JDA and the TDA Tailraces were used to estimate the TDA project passage survival using downstream detection histories at the TDA primary (rkm 275.6), TDA secondary (rkm 238.4), and BON primary (rkm 208.8) arrays (Table 3.14). Estimates of reach passage survival were based on the pooled release data from each tailrace (Table 3.15). Modeling of the paired-release data 
(Appendix C, Table C.2.; Table 3.16) found homogeneous capture and survival parameters after the TDA primary array (i.e., Model $\left.{ }_{S_{S_{1}, p_{i}}}\right)$. Project passage survival was $\hat{S}_{\text {Dalles }}=0.928(\widehat{\mathrm{SE}}=0.013)$.

Table 3.14. Detection History for the Pooled Release Groups Used to Estimate TDA Project Survival. In the table heading, 1 denotes detected and 0 not detected at the TDA primary and secondary arrays and the BON primary array, respectively.

\begin{tabular}{|c|c|c|c|c|c|c|c|c|c||}
\hline Release Site & $\mathbf{1} \mathbf{1} \mathbf{1}$ & $\mathbf{0} \mathbf{1} \mathbf{1}$ & $\mathbf{1} \mathbf{0} \mathbf{1}$ & $\mathbf{0} \mathbf{0} \mathbf{1}$ & $\mathbf{1} \mathbf{1} \mathbf{0}$ & $\mathbf{0} \mathbf{1} \mathbf{0}$ & $\mathbf{1} \mathbf{0} \mathbf{0}$ & $\mathbf{0} \mathbf{0} \mathbf{0}$ & Total \\
\hline John Day Tailrace & 232 & 12 & 0 & 0 & 173 & 17 & 7 & 40 & 481 \\
\hline The Dalles Tailrace & 542 & 12 & 3 & 0 & 388 & 12 & 10 & 11 & 978 \\
\hline
\end{tabular}

Table 3.15. Cormack-Jolly-Seber Single-Release Estimates of Survival and Detection Probabilities for the Pooled Release Groups Used to Estimate TDA Project Survival. The joint probability of survival from the TDA primary array to the secondary array and being detected at the secondary array $(\lambda)$ is reported in the last column. Standard errors are reported in parentheses.

\begin{tabular}{|c|c|c|c|c|c||}
\hline \multirow{2}{*}{ Release Site } & \multicolumn{2}{|c|}{ Survival Probability } & \multicolumn{2}{c|}{ Detection Probability } & \multicolumn{2}{c|}{\begin{tabular}{c} 
Detection and \\
\cline { 2 - 5 }
\end{tabular}} & to $\mathbf{1 T}$ & $\mathbf{1 T}$ to $\mathbf{2 T}$ & $\mathbf{1 T}$ & $\mathbf{2 T}$ & Survival $(\lambda)$ to 1B \\
\hline JDA Tailrace & $0.918(0.013)$ & $0.983(0.006)$ & $0.933(0.012)$ & $1.000(<0.0001)$ & $0.562(0.024)$ \\
\hline TDA Tailrace & $0.989(0.003)$ & $0.992(0.004)$ & $0.975(0.005)$ & $0.995(0.003)$ & $0.581(0.016)$ \\
\hline
\end{tabular}

Table 3.16. Modeled Single-Release Estimates of Survival and Detection Probabilities for JDA and TDA Tailrace Releases Used to Estimate TDA Project Passage Survival. Estimates were from pooled data from both single releases when differences in single-release estimates did not differ significantly. The joint probability of survival from the TDA secondary array to the BON primary array and being detected at the BON primary array $(\lambda)$ is reported in the last column. Standard errors are reported in parentheses.

\begin{tabular}{|c|c|c|c|c|c||}
\hline \multirow{2}{*}{$\begin{array}{c}\text { Tailrace } \\
\text { Release Site }\end{array}$} & \multicolumn{2}{|c|}{ Survival Probability } & \multicolumn{2}{|c|}{ Detection Probability } & $\begin{array}{c}\text { Detection and } \\
\text { Survival }(\lambda) \text { to 1B }\end{array}$ \\
\cline { 2 - 4 } & to 1T & 1T to $\mathbf{2 T}$ & $\mathbf{1 T}$ & $\mathbf{2 T}$ & \\
\hline JDA & $0.918(0.013)$ & \multirow{2}{*}{$0.989(0.003)$} & $0.934(0.012)$ & 0.996 & $0.575(0.013)$ \\
\cline { 2 - 2 } & & $0.975(0.005)$ & $(0.002)$ & \\
\hline TDA & $0.989(0.003)$ & &
\end{tabular}

Bonneville project passage survival was estimated from tailrace releases at TDA and BON dams and subsequent detection histories at BON primary (rkm 208.8), secondary (rkm 204.0), and tertiary (rkm 193.8) arrays (Table 3.17). Estimates of reach passage survival were based on the single-release data (Table 3.18). Figure 3.15 summarizes the results of the paired release-recapture analyses at the TDA and BON dams.

Table 3.17. Detection Histories for the Pooled Release Groups Used to Estimate BON Project Survival. In the table heading, a 1 denotes detected and 0 not detected at the BON primary, secondary, and tertiary arrays, respectively.

\begin{tabular}{|c|c|c|c|c|c|c|c|c|c||}
\hline Release Site & $\mathbf{1} \mathbf{1} \mathbf{1}$ & $\mathbf{0} \mathbf{1} \mathbf{1}$ & $\mathbf{1} \mathbf{0} \mathbf{1}$ & $\mathbf{0} \mathbf{0} \mathbf{1}$ & $\mathbf{1} \mathbf{1} \mathbf{0}$ & $\mathbf{0} \mathbf{1} \mathbf{0}$ & $\mathbf{1} \mathbf{0} \mathbf{0}$ & $\mathbf{0} \mathbf{0} \mathbf{0}$ & Total \\
\hline The Dalles Tailrace & 173 & 95 & 93 & 45 & 189 & 124 & 102 & 157 & 978 \\
\hline Bonneville Tailrace & 219 & 67 & 58 & 23 & 251 & 77 & 100 & 177 & 972 \\
\hline
\end{tabular}


Table 3.18. Cormack-Jolly-Seber Single-Release Estimates of Survival and Detection Probabilities for the Pooled Release Groups Used to Estimate BON Project Survival. The joint probability of survival from the BON primary array to the secondary array and being detected at the secondary array $(\lambda)$ is reported in the last column. Standard errors are in parentheses.

\begin{tabular}{|c|c|c|c|c|c|}
\hline & \multicolumn{2}{|c|}{ Survival Probability } & \multicolumn{2}{|c|}{ Detection Probability } & \multirow{2}{*}{$\begin{array}{c}\text { Detection and } \\
\text { Survival }(\lambda) \text { to } 1 \mathrm{~B}\end{array}$} \\
\hline Release Site & to $1 B$ & $1 B$ to $2 B$ & 1B & 2B & \\
\hline The Dalles Tailrace & $0.900(0.015)$ & $1.000(0.029)$ & $0.633(0.018)$ & $0.660(0.024)$ & $0.461(0.021)$ \\
\hline Bonneville Tailrace & $0.850(0.014)$ & $0.953(0.022)$ & $0.760(0.016)$ & $0.779(0.022)$ & $0.466(0.020)$ \\
\hline
\end{tabular}

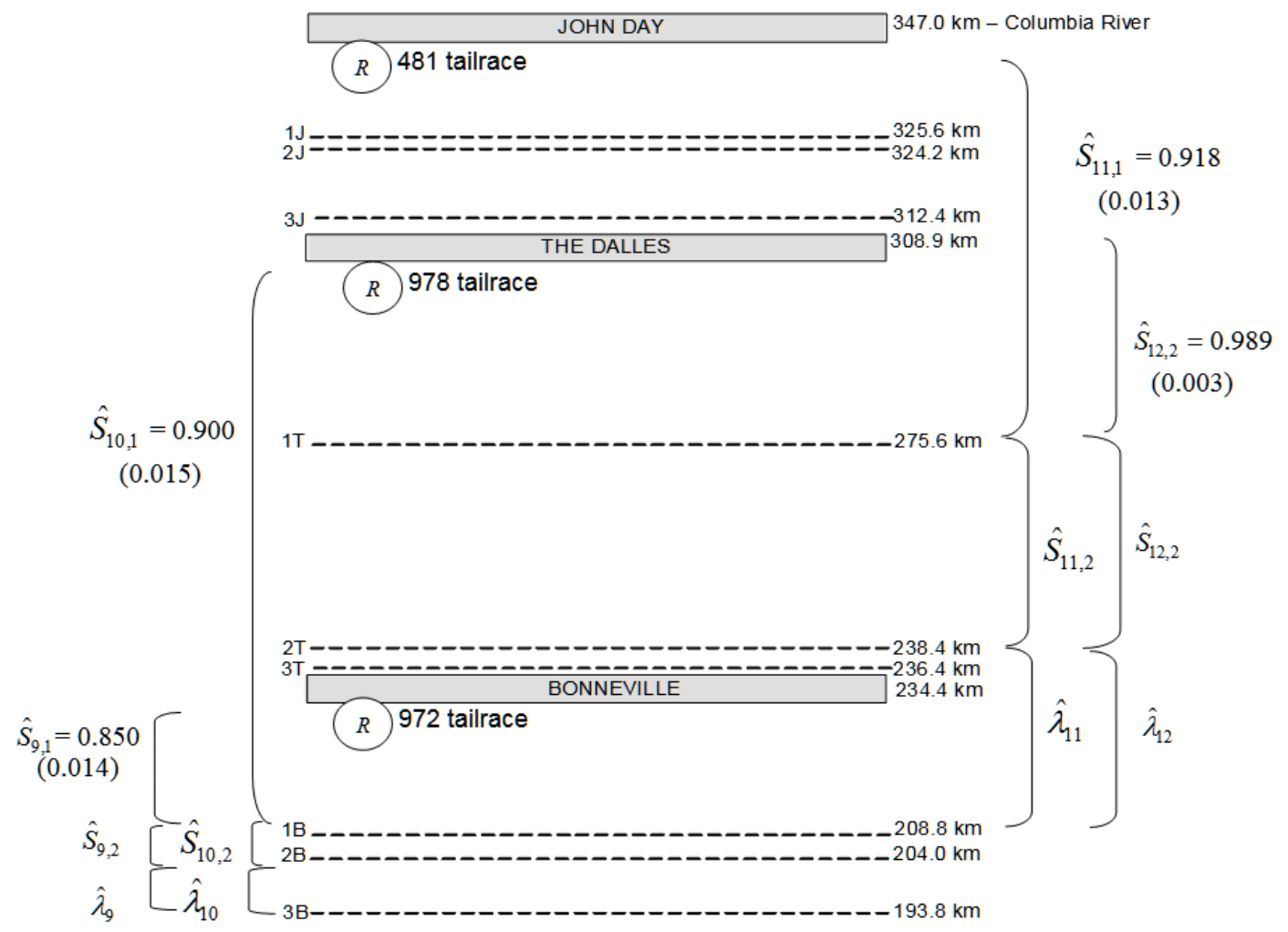

Estimate $\hat{S}_{\mathrm{TDA}}=0.928(0.013)$ and $\hat{S}_{\mathrm{BON}}=1.058(0.024)$.

Figure 3.15. Summary of the Paired-Release Studies to Estimate The Dalles and Bonneville Project Passage Survivals for Yearling Chinook Salmon Smolts. Single-release estimates are presented adjacent to the diagram, and the paired-release estimates are at the bottom. 
Modeling of the paired-release data (Appendix C, Table C.2; Table 3.19) found homogenous capture and survival parameters only in the last reach (i.e., Model $M_{\underline{S}_{1}, p_{1}, \underline{S}_{2}, \underline{p}_{2}}$ ). The project passage survival was estimated to be $\hat{S}_{\text {BоN }}=1.0583(\widehat{\mathrm{SE}}=0.0240)$.

Table 3.19. Modeled Single-Release Estimates of Survival and Detection Probabilities for TDA and BON Tailrace Releases Used to Estimate BON Project Passage Survival. The joint probability of survival from the BON primary array to the BON secondary array and being detected at BON tertiary array $(\lambda)$ is reported in the last column. Standard errors are reported in parentheses.

\begin{tabular}{|c|c|c|c|c|c||}
\hline \multirow{2}{*}{$\begin{array}{c}\text { Tailrace } \\
\text { Release Site }\end{array}$} & \multicolumn{2}{|c|}{ Survival Probability } & \multicolumn{2}{c|}{ Detection Probability } & $\begin{array}{c}\text { Detection and } \\
\text { Survival }(\lambda) \text { to 3B }\end{array}$ \\
\cline { 2 - 5 } & to 1B & 1B to 2B & 1B & 2B & \multirow{2}{*}{$0.464(0.014)$} \\
\hline TDA & $0.900(0.015)$ & $0.998(0.027)$ & $0.633(0.018)$ & $0.661(0.022)$ & \\
\hline BON & $0.850(0.014)$ & $0.954(0.021)$ & $0.760(0.016)$ & $0.779(0.021)$ & \\
\hline
\end{tabular}

\subsubsection{Tests of Assumptions}

\subsubsection{Assessment of Mixing}

For the paired release-recapture analysis, mixing of upstream and downstream releases is a good indicator of whether the paired releases shared similar downstream conditions. There were a few significant Chi-square tests for homogeneous arrival distributions $(\mathrm{P}<0.05)$ for all three JDA releases in spring (Appendix D, Figures D.1, D.2, and D.3), even though median arrival times per release day were within two hours of each other and 95\% confidence intervals on arrival times overlapped (Figure 3.16).

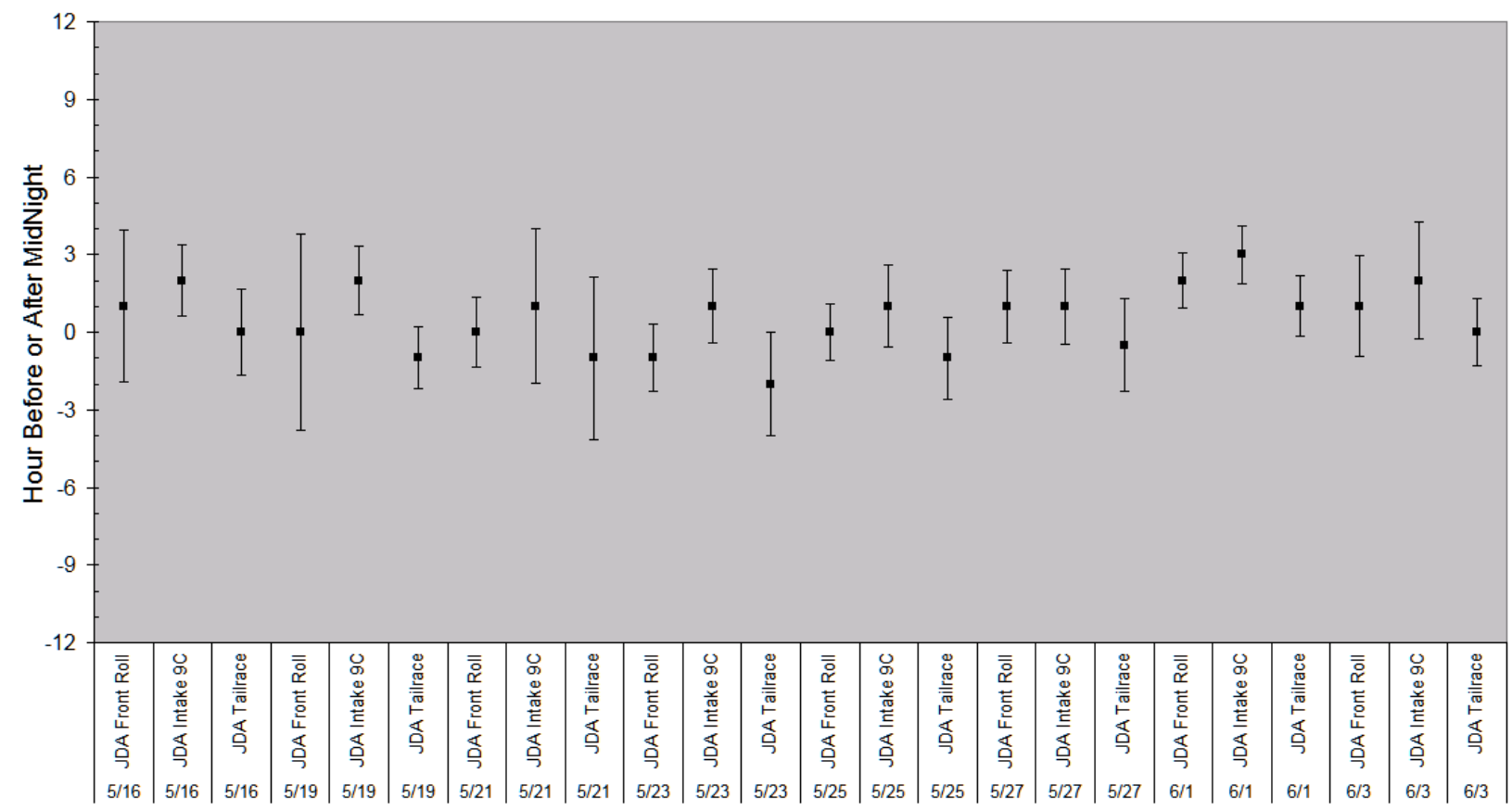

Release Location and Date

Figure 3.16. Plot of Median Hour of Arrival at Array 1J Below JDA Dam for Three Release Locations at JDA by Release Date. Vertical error bars represent $95 \%$ confidence intervals. 
The JDA and TDA Tailrace releases used in estimating the TDA project passage survival seemed to show systemic departures from mixing in late spring (Appendix D, Figure D.4), but the apparent departure was a function of differences in the size of release groups and not differences in rates of movement of the two groups. Adding estimates of the cumulative percent of fish released to one of the three figures in Appendix D, Figure D.4 clearly shows that the apparent deviation was driven by differences in the number of tagged fish in late spring treatment and reference-release groups (e.g., Figure 3.17). The figure also shows that treatment and reference fish usually were detected on the same days. Within days, the distribution of arrivals ranged over all hours of the day based upon detections of the slowest and fastest fish from each release group at Array 1T. The minimum arrival time for most release dates was 0000 hours and the maximum arrival time was 2300 hours. However, the range in mean arrival times at $1 \mathrm{~T}$ were different [1530 hours ( $\mathrm{SE}=4.6$ hours)] for JDA Tailrace releases versus 0430 hours (SE $=4.2$ hours), so most fish in treatment and reference release groups did not traverse the TDA Tailwater to Array $1 \mathrm{~T}$ at the same time of day.

There was an appreciable departure from pair-release model mixing assumptions associated with the point estimate of $\hat{S}_{\text {BON }}=1.058(\widehat{\mathrm{SE}}=0.0240)$. The TDA and BON Tailrace releases used in estimating BON project passage survival were very poorly mixed because there were only four "reference" releases below BON versus nine below TDA, and two of those BON releases occurred 5 to 14 days before the TDA releases began (Appendix D, Figure D.5). We ran the paired release model a second time after eliminating data acquired before May 16 from the BON releases and data acquired after May 27 from the TDA releases so that treatment fish and control fish were released during the same block of days. The resulting estimate $\hat{S}_{\text {BON }}=1.057(\widehat{\mathrm{SE}}=0.045)$ was essentially the same as that produced using all release data.

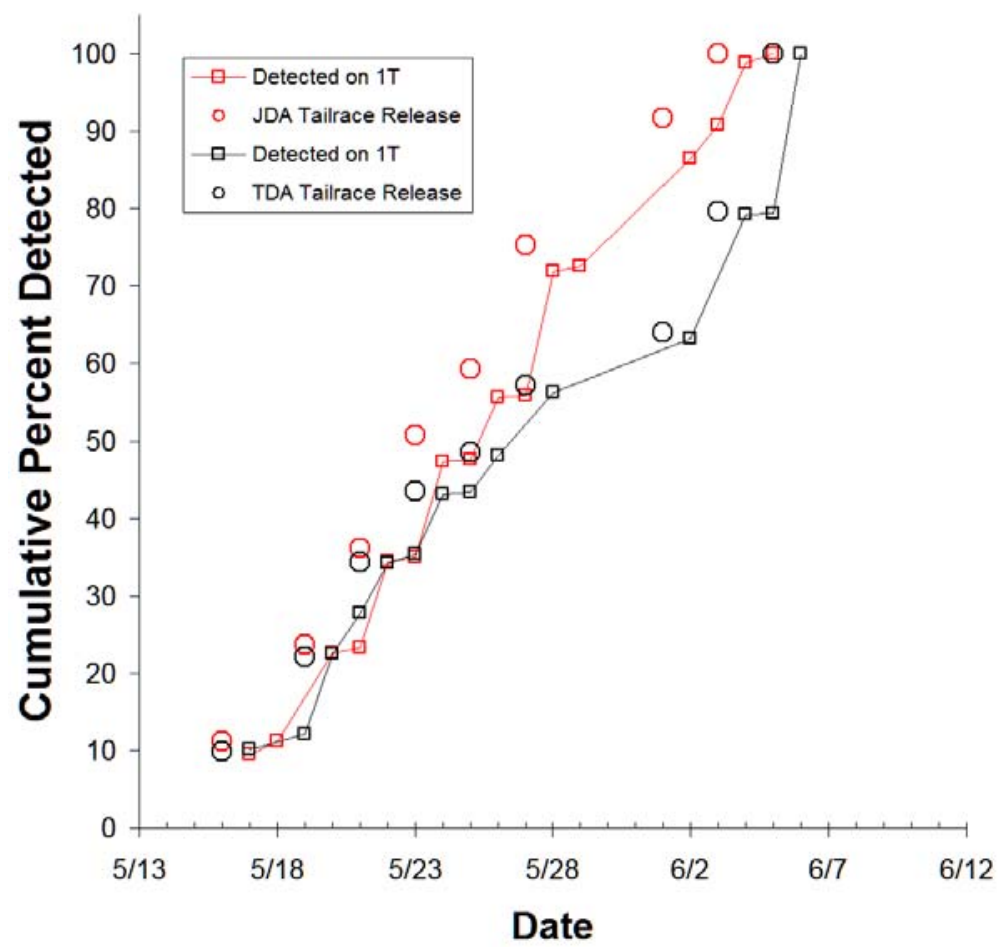

Figure 3.17. Cumulative Percent of Primary Array Detections of Treatment and Reference Fish Used to Make Paired-Release Estimates of TDA Project Survival in Spring 2006. 
Close inspection of time of detection data indicate that fish released in the TDA Tailrace had an average arrival time at Array 1B of 1320 hours ( $\widehat{\mathrm{SE}}=7.15$ hours) and those from the BON Tailrace releases had an average arrival of 1239 hours ( $\widehat{\mathrm{SE}}=10.4$ hours) during the first two releases and 0210 hours ( \pm 8 hours SE) during the second two releases. In summary, the first two reference releases preceded treatment releases by 5 to 14 days but had arrival hours that were similar to those of treatment fish, and the last two reference releases matched up well with days of treatment releases but not with hours of the day.

\subsubsection{Goodness-of-Fit}

Burnham et al.'s (1987) Tests 2 and 3 were performed to assess goodness-of-fit of the tagging data to the release-recapture models. Both tests assess whether the upstream detection history has an effect on downstream detections within a release group. Two of the three JDA releases had significant $(P<0.10)$ Test 2 results (Appendix D, Table D.1). No significant departures $(P>0.10)$ were observed for the JDA, TDA, or BON Tailrace releases (Appendix D, Tables D.2 and C3). None of the Burnham et al. (1987) Test 3 results were significant for any of the release groups tested (Appendix D, Tables D.4-D.6).

\subsubsection{Survival through Successive Reaches}

We made estimates of survival for yearling Chinook salmon from point of release to each successive array in our study area, except the last reach (Figure 3.18). We released tagged yearlings from four different locations (JDA turbine, JDA Front Roll, and JDA Tailrace, and TDA Tailrace); the tag-effects study released them in the LGR Tailrace and the estuary study released them in the BON Tailrace. Survival statistics in Figure 3.18 were calculated using a single release model and detections on the array of interest and on two successive arrays immediately downstream, except for Array 2B estimates, which were based upon detections on two arrays (2B and 3B).

\subsubsection{Bonneville Route-Specific Survival (Pooled Releases)}

We estimated detection probabilities and survival for yearling Chinook salmon based on the population of all tagged fish detected at specific sites while passing through BON, regardless of where the fish were originally released. Release sites that contributed fish to the detections included the LGR Tailrace, JDA Intake 9C, JDA Front Roll, JDA Tailrace, and TDA Tailrace. Even with pooling of data from all release sites, sample sizes were low and produced wide standard errors.

\subsubsection{Spillway, B2 JBS, and B2CC}

During spring, survival for three routes at BON was calculated. Each passage route had a specific collection type. Detection at the spillway was acoustic, based on an array of autonomous acoustic hydrophones in the forebay, while tagged fish at the B2CC and B2JBS were detected by PIT-tag detectors. Using data from the primary, secondary, and tertiary arrays below BON, pooled survival estimates were calculated for the B2CC and the B2JBS while a virtual estimate of survival was calculated for the spillway to increase the sample size (Table 3.20). 




Figure 3.18. Spring Survival Percentages for Tagged Fish from Release Location to each Survival Array except the Last. These survival statistics were calculated using a single release model. 
Table 3.20. Single-Release Survival and Detection Probabilities Based on Pooling of Releases from All Upstream Sites. Standard errors are in parentheses.

\begin{tabular}{|c|c|c|c|c|c|c|}
\hline \multirow[t]{2}{*}{$\begin{array}{l}\text { Detection } \\
\text { Site }\end{array}$} & \multirow{2}{*}{$\begin{array}{c}\begin{array}{c}\text { Survival } \\
\text { Probability }\end{array} \\
\text { To 1B }\end{array}$} & \multirow{2}{*}{$\begin{array}{c}\begin{array}{c}\text { Detection } \\
\text { Probability }\end{array} \\
\text { 1B to 2B } \\
\end{array}$} & \multicolumn{2}{|c|}{ Detection Probability } & \multirow{2}{*}{$\begin{array}{c}\begin{array}{c}\text { Detection } \\
\text { and } \\
\text { Survival }(\lambda)\end{array} \\
\text { to } 3 \mathrm{~B}\end{array}$} & \multirow{2}{*}{$\begin{array}{l}\text { Number } \\
\text { of Fish } \\
\text { (n) }\end{array}$} \\
\hline & & & 1B & 2B & & \\
\hline $\mathrm{B} 2 \mathrm{CC}$ & $0.946(0.051)$ & $0.966(0.096)$ & $0.610(0.064)$ & $0.669(0.042)$ & $0.533(0.074)$ & 78 \\
\hline B2JBS & $0.893(0.083)$ & $1.173(0.240)$ & $0.533(0.091)$ & $0.867(0.028)$ & $0.364(0.103)$ & 42 \\
\hline Spillway & $0.941(0.036)$ & $1.059(0.088)$ & $0.635(0.047)$ & $0.707(0.032)$ & $0.467(0.129)$ & 134 \\
\hline
\end{tabular}

We also divided single-release estimates to Array 1B in Table 3.20 by the pooled single-release estimate to Array 1B for the BON Tailrace release to obtain paired-release estimates of survival for each route. Each paired-release estimate exceeded 100\% $(111.2 \%$ [1/2 95\% CI = 98.9, 123.5] for the B2CC; $1.05 \%[1 / 295 \% \mathrm{CI}=85.5,124.4]$ for the B2JBS; and 110.6\% [1/2 95\% CI $=101.7,119.6]$ for the spillway).

\subsubsection{Spillway by Time of Day}

In spring, we also estimated BON spillway survival for day and night periods, although the exercise probably was not justified by the low numbers of tagged fish detected at the spillway (Table 3.21). Daytime was defined as from 0600 through 2100 hours each season, and the remaining hours of the day were assigned as nighttime hours. The detection array in the spillway forebay was not installed and functional until the last week of spring sampling because of delays in equipment availability. Survival estimates of 0.957 during the day and 0.875 at night differed by $8 \%$, and this difference was smaller than the standard error for the night estimate alone.

Table 3.21. Day and Night Estimates of Single-Release Survival and Detection Probabilities for Fish Detected in the Spillway Forebay, Regardless of Upstream Release Location. Standard errors are in parentheses.

\begin{tabular}{|c|c|c|c|c|c|c||}
\hline & $\begin{array}{c}\text { Survival } \\
\text { Probability }\end{array}$ & $\begin{array}{c}\text { Detection } \\
\text { Probability }\end{array}$ & \multicolumn{2}{|c|}{ Detection Probability } & $\begin{array}{c}\text { Detection and } \\
\text { Survival }(\lambda)\end{array}$ & $\begin{array}{c}\text { Number of } \\
\text { Fish (n) }\end{array}$ \\
\hline Time & To 1B & 1B to 2B & 1B & 2B & to 3B & \\
\hline Day & $0.957(0.038)$ & $1.038(0.095)$ & $0.651(0.052)$ & $0.653(0.040)$ & $0.418(0.060)$ & 106 \\
\hline Night & $0.875(0.088)$ & $1.137(0.214)$ & $0.571(0.108)$ & $0.828(0.047)$ & $0.467(0.129)$ & 28 \\
\hline
\end{tabular}

Division of these day and night estimates by the pooled estimate for the BON Tailrace release (85.0 \pm $1.40 \mathrm{SE}$ ) yields a paired release estimate of $112.5 \%$ [1/2 95\% CI $=103.1,122.0]$ for day and $102.9 \%$ [1/2 $95 \% \mathrm{CI}=82.3,123.4]$ for night. Confidence intervals overlap for single- and paired-release estimates.

\subsection{Detection and Survival of Subyearling Chinook Salmon in Summer}

\subsubsection{Tag-Life Study Correction}

Downstream arrival times on study arrays were sufficiently fast that tag-life corrections to the survival estimates were unnecessary. For subyearling Chinook salmon released below Little Goose Dam, 10-s tags were used with their own failure-time curve (see Section 3.3). Once again, examination of the 
tag-life curve and arrival distributions of fish to downstream detection arrays (Appendix E) indicated the vast majority of fish arrived before the time of first tag failure. In these cases, no tag-life correction was necessary. Only fish from the Bonneville tailrace (Appendix E, BON Tailrace (Figure E.5), the virtual release above Bonneville Dam (Appendix E, BON (Figure E.7), and the TDA Tailrace release (Appendix E, Figure E.9) showed the potential need for tag-life corrections. However, in all three cases, this was only for the last detection array and the expected probability of tag life was $\geq 0.999$.

\subsubsection{Little Goose Tailrace Releases}

Ten replicate releases from Little Goose Tailrace were performed between June 16 and July 18, 2006. Reach survivals were estimated from release to JDA primary array (1J) and between the JDA primary and the TDA primary arrays (1T). In both reaches, obvious seasonal trends in the perceived survival were noticed. In the first reach, perceived survivals ranged from a high of 0.484 ( $\widehat{\mathrm{SE}}=0.036$ ) for the June 16 release to a low of 0.016 ( $\widehat{\mathrm{SE}}=0.009$ ) for the July 10 release. None of the fish released on either July 14 or 18 were ever observed at a downriver detection site (Table 3.22). For the eight release groups with observed survival rates (Table 3.23), the arithmetic average was $\hat{\bar{S}}=0.196$ ( $\widehat{\mathrm{SE}}=0.056$ ). Survival and detection probabilities cannot be estimated for the July 14 and 18 releases because there were no downstream detections after release. Survival estimates between the JDA primary and the TDA primary arrays showed a similar monotonic decline, with values ranging from $0.848(\widehat{\mathrm{SE}}=0.037)$ to $0.645(\widehat{\mathrm{SE}}=$ 0.086). Average survival for the eight replicate releases with observed detections was $\hat{\bar{S}}=0.603(\widehat{\mathrm{SE}}=$ 0.104). Detection rates at all three JDA arrays (i.e., 1J, 1T, and 2T) exceeded 0.90 in all instances (Table 3.23). Figure 3.19 summarizes the results of the Little Goose Tailrace releases.

Table 3.22. Detection Histories for each Release Group at Little Goose Dam. In the table heading, a 1 denotes detected and 0 not detected on Arrays $1 \mathrm{~J}, 1 \mathrm{~T}$, and $2 \mathrm{~T}$, respectively.

\begin{tabular}{|c|c|c|c|c|c|c|c|c|c||}
\hline \hline Release & $\mathbf{1} \mathbf{1} \mathbf{1}$ & $\mathbf{0} \mathbf{1} \mathbf{1}$ & $\mathbf{1} \mathbf{0} \mathbf{1}$ & $\mathbf{0} \mathbf{0} \mathbf{1}$ & $\mathbf{1} \mathbf{1} \mathbf{0}$ & $\mathbf{0} \mathbf{1} \mathbf{0}$ & $\mathbf{1} \mathbf{0} \mathbf{0}$ & $\mathbf{0} 0 \mathbf{0}$ & Total \\
\hline $6 / 16$ & 76 & 2 & 0 & 0 & 2 & 0 & 14 & 101 & 195 \\
\hline $6 / 21$ & 62 & 2 & 1 & 0 & 2 & 0 & 15 & 113 & 195 \\
\hline $6 / 24$ & 46 & 5 & 0 & 0 & 1 & 0 & 6 & 137 & 195 \\
\hline $6 / 27$ & 41 & 4 & 1 & 0 & 3 & 0 & 12 & 134 & 195 \\
\hline $7 / 01$ & 18 & 2 & 0 & 0 & 2 & 0 & 11 & 162 & 195 \\
\hline $7 / 04$ & 14 & 0 & 0 & 0 & 1 & 0 & 8 & 172 & 195 \\
\hline $7 / 07$ & 15 & 1 & 0 & 0 & 1 & 0 & 6 & 171 & 194 \\
\hline $7 / 10$ & 2 & 0 & 0 & 0 & 0 & 0 & 1 & 189 & 192 \\
\hline $7 / 14$ & 0 & 0 & 0 & 0 & 0 & 0 & 0 & 198 & 198 \\
\hline $7 / 18$ & 0 & 0 & 0 & 0 & 0 & 0 & 0 & 195 & 195 \\
\hline Pooled & 274 & 16 & 2 & 0 & 12 & 0 & 73 & 1572 & 1949 \\
\hline \hline
\end{tabular}


Table 3.23. Cormack-Jolly-Seber Single-Release Estimates of Survival and Detection Probabilities for each Release Group of Subyearling Chinook Salmon Released from Little Goose Tailrace. The joint probability of survival from the TDA primary array to the secondary array and being detected at the secondary array $(\lambda)$ is in the last column. Standard errors are in parentheses.

\begin{tabular}{|c|c|c|c|c|c||}
\hline \multirow{2}{*}{$\begin{array}{c}\text { Day of } \\
\text { Release }\end{array}$} & \multicolumn{2}{|c|}{ Survival Probability } & \multicolumn{2}{c|}{ Detection Probability } & $\begin{array}{c}\text { Detection and } \\
\text { Survival }(\lambda) \text { to 2T }\end{array}$ \\
\cline { 2 - 5 } & to $\mathbf{1 J}$ & $\mathbf{1 J}$ to $\mathbf{1 T}$ & $\mathbf{1 J}$ & $\mathbf{1 T}$ & $0.975(0.018)$ \\
\hline $6 / 16$ & $0.484(0.036)$ & $0.848(0.037)$ & $0.975(0.018)$ & $1.000(<0.0001)$ & $0.970(0.021)$ \\
\hline $6 / 21$ & $0.423(0.036)$ & $0.813(0.044)$ & $0.970(0.021)$ & $0.985(0.015)$ & $0.981(0.019)$ \\
\hline $6 / 24$ & $0.301(0.033)$ & $0.887(0.044)$ & $0.904(0.041)$ & $1.000(<0.0001)$ & $0.938(0.035)$ \\
\hline $6 / 27$ & $0.318(0.034)$ & $0.791(0.054)$ & $0.918(0.039)$ & $0.978(0.022)$ & $0.909(0.061)$ \\
\hline $7 / 01$ & $0.175(0.028)$ & $0.645(0.086)$ & $0.909(0.061)$ & $1.000(<0.0001)$ & $0.901)$ \\
\hline $7 / 04$ & $0.118(0.023)$ & $0.652(0.099)$ & $1.000(<0.0001)$ & $1.000(<0.0001)$ & $0.933(0.064)$ \\
\hline $7 / 07$ & $0.121(0.0237)$ & $0.727(0.095)$ & $0.941(0.057)$ & $1.000(<0.0001)$ & $0.941(0.057)$ \\
\hline $7 / 10$ & $0.016(0.009)$ & $0.667(0.272)$ & $1.000(<0.0001)$ & $1.000(<0.0001)$ & $1.000(<0.0001)$ \\
\hline $7 / 14$ & $\mathrm{NA}$ & $\mathrm{NA}$ & $\mathrm{NA}$ & $\mathrm{NA}$ & $\mathrm{NA}$ \\
\hline $7 / 18$ & $\mathrm{NA}$ & $\mathrm{NA}$ & $\mathrm{NA}$ & $\mathrm{NA}$ & $\mathrm{NA}$ \\
\hline Pooled & & & $0.947(0.013)$ & $0.993(0.005)$ & $0.960(0.011)$ \\
\hline Arithmetic Avg. & $0.196(0.056)$ & $0.603(0.104)$ & & & \\
\hline \hline
\end{tabular}
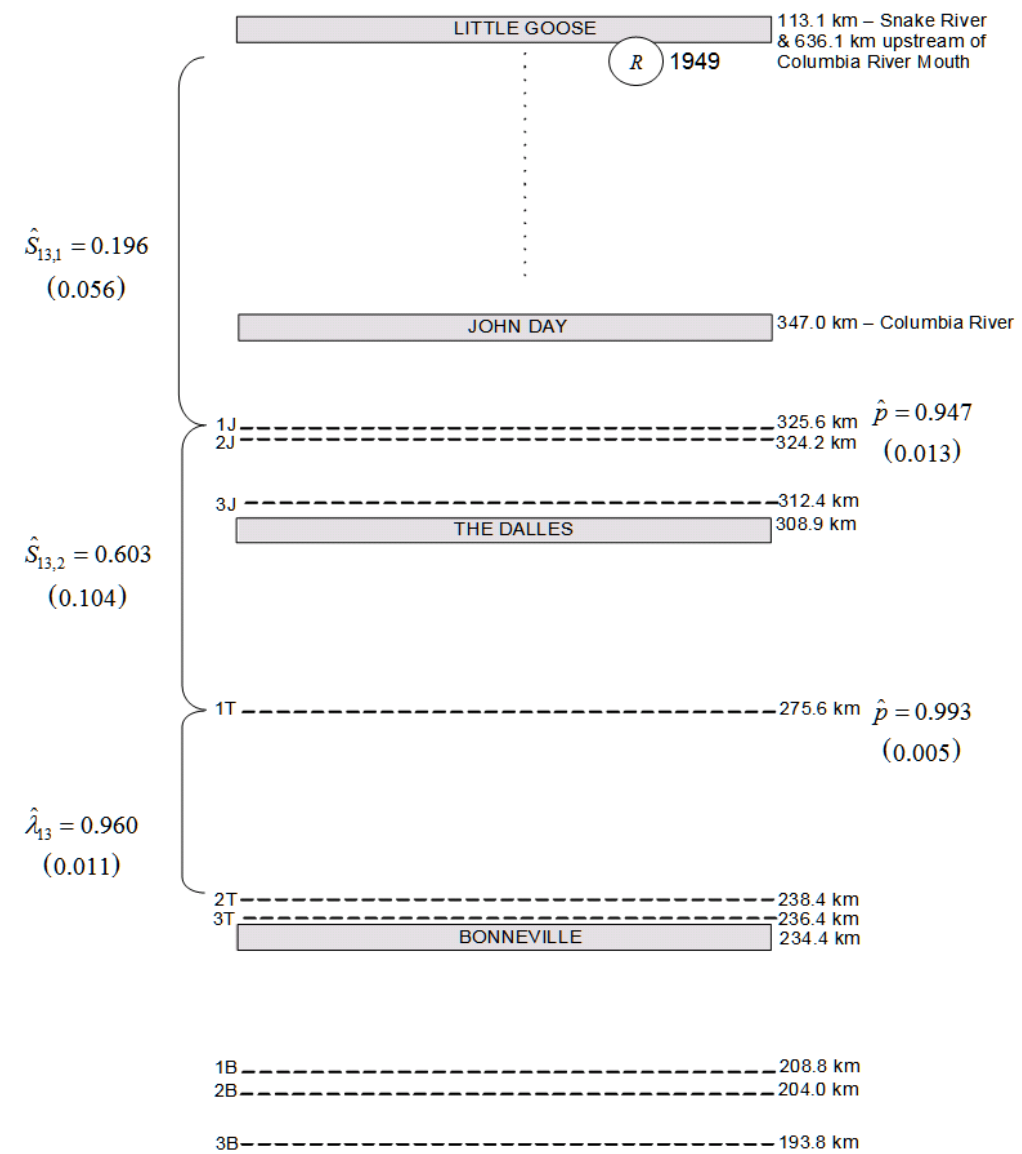

Figure 3.19. Summary of Single-Release Analysis of Reach Survival for Subyearling Chinook Salmon Smolts below Little Goose Dam 


\subsubsection{John Day Tailrace Releases}

Five replicate groups of fish were released from the JDA Tailrace between June 13 and 27, 2006 (Table 3.24) to estimate survival to the JDA primary array (1J) and between the JDA primary and the TDA primary arrays (1J-1T). No obvious seasonal trends in survival were observed, with pooled estimates of $\hat{S}=0.994(\widehat{\mathrm{SE}}=0.005)$ and $\hat{S}=0.828(\widehat{\mathrm{SE}}=0.0220)$ for the first and second reaches, respectively (Table 3.25). Detection probabilities at arrays $1 \mathrm{~J}$ and $1 \mathrm{~T}$ were in excess of 0.95 with pooled values ranging from $0.988-987$ to 0.996 . Figure 3.20 summarizes the results of the single-release analysis.

Table 3.24. Detection Histories for the JDA Tailrace Releases in Summer 2006. In the table heading, a 1 denotes detected and 0 not detected at the JDA primary and the TDA primary and secondary arrays, respectively.

\begin{tabular}{|c|c|c|c|c|c|c|c|c|c||}
\hline Release & $\mathbf{1} \mathbf{1} \mathbf{1}$ & $\mathbf{0} \mathbf{1} \mathbf{1}$ & $\mathbf{1} \mathbf{0} \mathbf{1}$ & $\mathbf{0} \mathbf{0} \mathbf{1}$ & $\mathbf{1} \mathbf{1} \mathbf{0}$ & $\mathbf{0} \mathbf{1} \mathbf{0}$ & $\mathbf{1} \mathbf{0} \mathbf{0}$ & $\mathbf{0} \mathbf{0} \mathbf{0}$ & Total \\
\hline $6 / 13$ & 41 & 0 & 1 & 0 & 0 & 0 & 8 & 0 & 50 \\
\hline $6 / 15$ & 42 & 0 & 0 & 0 & 0 & 0 & 7 & 1 & 50 \\
\hline $6 / 20$ & 45 & 0 & 0 & 0 & 1 & 0 & 4 & 0 & 50 \\
\hline $6 / 22$ & 37 & 1 & 2 & 0 & 1 & 0 & 8 & 0 & 49 \\
\hline $6 / 27$ & 75 & 0 & 0 & 0 & 0 & 0 & 24 & 1 & 100 \\
\hline Pooled & 240 & 1 & 3 & 0 & 2 & 0 & 51 & 2 & 299 \\
\hline
\end{tabular}

Table 3.25. Cormack-Jolly-Seber Single-Release Estimates of Survival and Detection Probabilities for the JDA Tailrace Releases in Summer. The joint probability of survival from the TDA primary array to the secondary array and being detected at the secondary array $(\lambda)$ is reported in the last column. Standard errors are reported in parentheses.

\begin{tabular}{|c|c|c|c|c|c|}
\hline \multirow{2}{*}{$\begin{array}{c}\text { Day of } \\
\text { Release }\end{array}$} & \multicolumn{2}{|c|}{ Survival Probability } & \multicolumn{2}{|c|}{ Detection Probability } & \multirow{2}{*}{$\begin{array}{l}\text { Detection and } \\
\text { Survival }(\lambda) \text { to } \\
2 \mathrm{~T}\end{array}$} \\
\hline & to $1 \mathrm{~J}$ & $1 \mathrm{~J}$ to $1 \mathrm{~T}$ & $1 \mathrm{~J}$ & 1T & \\
\hline $6 / 13$ & $1.000(<0.0001)$ & $0.840(0.052)$ & $1.000(<0.0001)$ & $0.976(0.024)$ & $1.000(<0.0001)$ \\
\hline $6 / 15$ & $0.980(0.020)$ & $0.857(0.050)$ & $1.000(<0.0001)$ & $1.000(<0.0001)$ & $1.000(<0.0001)$ \\
\hline $6 / 20$ & $1.000(<0.0001)$ & $0.920(0.038)$ & $1.000(<0.0001)$ & $1.000(<0.0001)$ & $0.978(0.022)$ \\
\hline $6 / 22$ & $1.004(0.004)$ & $0.834(0.054)$ & $0.976(0.024)$ & $0.950(0.035)$ & $0.974(0.025)$ \\
\hline $6 / 27$ & $0.990(0.010)$ & $0.758(0.043)$ & $1.000(<0.0001)$ & $1.000(<0.0001)$ & $1.000(<0.0001)$ \\
\hline Pooled & $0.994(0.005)$ & $0.828(0.022)$ & $0.996(0.004)$ & $0.988(0.007)$ & $0.992(0.006)$ \\
\hline Arithmetic Avg. & $0.995(0.004)$ & $0.862(0.0333)$ & & & \\
\hline
\end{tabular}




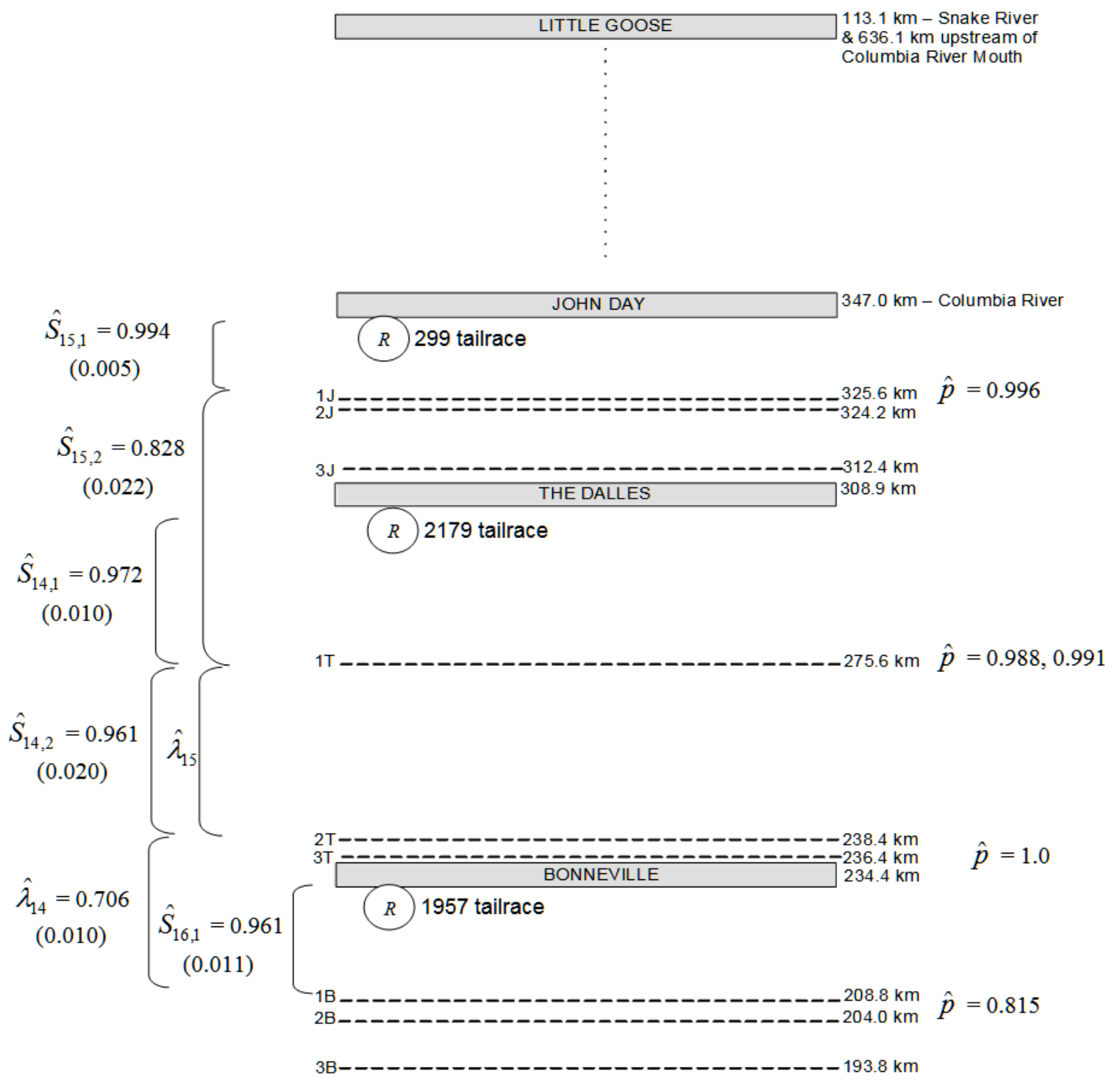

Figure 3.20. Release-Recapture Locations for the Single Releases Analyses of Reach Survival for Subyearling Chinook Salmon Smolts at JDA, TDA, and BON.

\subsubsection{The Dalles and Bonneville Tailrace Releases}

During summer 2006, ten replicate releases of subyearling Chinook salmon were performed between June 13 and July 13 at the TDA Tailrace (Table 3.26). Survival between release and the TDA primary array (T1) was estimated based on an arithmetic average to be $\hat{\bar{S}}=0.9716$ ( $\widehat{\mathrm{SE}}=0.0095$ ). There was a moderate decline in survival estimates over the course of the study from a high of 1.0 ( $\widehat{\mathrm{SE}}<0.0001$ ) to 0.9106 ( $\widehat{\mathrm{SE}}=0.0182$ ) (Table 3.27). Perceived survival between the TDA primary and secondary arrays also showed a seasonal decline, with an arithmetic average of $\hat{\bar{S}}=0.9611$ ( $\widehat{\mathrm{SE}}=0.0203$ ). Detection probabilities at arrays $1 \mathrm{~T}$ and $2 \mathrm{~T}$ exceeded 0.96 in all instances (Table 3.27). 
Table 3.26. Detection Histories for the TDA Tailrace Releases. In the table heading, a 1 denotes detected and 0 not detected at the TDA primary and secondary arrays and BON primary, respectively.

\begin{tabular}{|c|c|c|c|c|c|c|c|c|c||}
\hline Release & $\mathbf{1} \mathbf{1} \mathbf{1}$ & $\mathbf{0} \mathbf{1} \mathbf{1}$ & $\mathbf{1} \mathbf{0} \mathbf{1}$ & $\mathbf{0} \mathbf{0} \mathbf{1}$ & $\mathbf{1} \mathbf{1} \mathbf{0}$ & $\mathbf{0} \mathbf{1} \mathbf{0}$ & $\mathbf{1} \mathbf{0} \mathbf{0}$ & $\mathbf{0} \mathbf{0} \mathbf{0}$ & Total \\
\hline $6 / 13$ & 100 & 1 & 0 & 0 & 89 & 5 & 0 & 1 & 196 \\
\hline $6 / 15$ & 110 & 2 & 0 & 0 & 83 & 5 & 0 & 0 & 200 \\
\hline $6 / 20$ & 118 & 0 & 0 & 0 & 70 & 4 & 2 & 2 & 196 \\
\hline $6 / 22$ & 122 & 0 & 0 & 0 & 76 & 0 & 2 & 0 & 200 \\
\hline $6 / 27$ & 165 & 0 & 0 & 0 & 29 & 1 & 1 & 4 & 200 \\
\hline $6 / 28$ & 167 & 0 & 0 & 0 & 31 & 0 & 0 & 2 & 200 \\
\hline $7 / 01$ & 197 & 0 & 0 & 0 & 35 & 0 & 3 & 12 & 247 \\
\hline $7 / 07$ & 176 & 0 & 0 & 0 & 52 & 0 & 9 & 11 & 248 \\
\hline $7 / 11$ & 137 & 0 & 0 & 0 & 46 & 0 & 41 & 22 & 246 \\
\hline $7 / 13$ & 133 & 0 & 0 & 0 & 69 & 0 & 30 & 14 & 246 \\
\hline Pooled & 1425 & 3 & 0 & 0 & 580 & 15 & 88 & 68 & 2179 \\
\hline
\end{tabular}

Table 3.27. Cormack-Jolly-Seber Single-Release Estimates of Survival and Detection Probabilities for TDA Tailrace Release. The joint probability of survival from the TDA secondary array to the BON primary array and being detected at the primary array $(\lambda)$ is reported in the last column. Standard errors are reported in parentheses.

\begin{tabular}{|c|c|c|c|c|c|}
\hline \multirow{2}{*}{$\begin{array}{l}\text { Day of } \\
\text { Release }\end{array}$} & \multicolumn{2}{|c|}{ Survival Probability } & \multicolumn{2}{|c|}{ Detection Probability } & \multirow{2}{*}{$\begin{array}{c}\text { Detection and } \\
\text { Survival }(\lambda) \text { to } \\
\text { 1B }\end{array}$} \\
\hline & to $1 \mathrm{~T}$ & $1 \mathrm{~T}$ to $2 \mathrm{~T}$ & $1 T$ & $2 T$ & \\
\hline $6 / 13$ & $0.995(0.005)$ & $1.000(<0.0001)$ & $0.969(0.012)$ & $1.000(<0.0001)$ & $0.518(0.036)$ \\
\hline $6 / 15$ & $1.000(<0.0001)$ & $1.000(<0.0001)$ & $0.965(0.013)$ & $1.000(<0.0001)$ & $0.560(0.035)$ \\
\hline $6 / 20$ & $0.990(0.007)$ & $0.990(0.007)$ & $0.979(0.010)$ & $1.000(<0.0001)$ & $0.615(0.035)$ \\
\hline $6 / 22$ & $1.000(<0.0001)$ & $0.990(0.0070)$ & $1.000(<0.0001)$ & $1.000(<0.0001)$ & $0.616(0.035)$ \\
\hline $6 / 27$ & $0.980(0.010)$ & $0.995(0.005)$ & $0.995(0.005)$ & $1.000(<0.0001)$ & $0.846(0.026)$ \\
\hline $6 / 28$ & $0.990(0.007)$ & $1.000(<0.0001)$ & $1.000(<0.0001)$ & $1.000(<0.0001)$ & $0.843(0.026)$ \\
\hline $7 / 01$ & $0.951(0.014)$ & $0.987(0.007)$ & $1.000(<0.0001)$ & $1.000(<0.0001)$ & $0.849(0.024)$ \\
\hline $7 / 07$ & $0.956(0.013)$ & $0.962(0.012)$ & $1.000(<0.0001)$ & $1.000(<0.0001)$ & $0.772(0.028)$ \\
\hline $7 / 11$ & $0.911(0.018)$ & $0.817(0.026)$ & $1.000(<0.0001)$ & $1.000(<0.0001)$ & $0.749(0.032)$ \\
\hline $7 / 13$ & $0.943(0.015)$ & $0.871(0.022)$ & $1.000(<0.0001)$ & $1.000(<0.0001)$ & $0.658(0.033)$ \\
\hline Pooled & $0.969(0.004)$ & $0.958(0.004)$ & $0.991(0.002)$ & $1.000(<0.0001)$ & $0.706(0.010)$ \\
\hline Arithmetic Avg. & $0.972(0.010)$ & $0.961(0.020)$ & & & \\
\hline
\end{tabular}

Releases below BON were detected at the BON primary (1B) and secondary (2B) arrays (Table 3.28), providing perceived survival estimates only between the BON Tailrace and the first array (Table 3.29). Again, there is evidence of a seasonal decline in survival estimates, ranging from $1.003(\widehat{\mathrm{SE}}=0.052)$ to $0.914(\widehat{\mathrm{SE}}=0.018)$, with an arithmetic mean of $\hat{\bar{S}}=0.961(\widehat{\mathrm{SE}}=0.011)$. Detection probabilities at array 1B increased dramatically over the season, from 0.468 ( $\widehat{\mathrm{SE}}=0.040)$ to 0.970 ( $\widehat{\mathrm{SE}}=0.012$ ), with an arithmetic average of $0.815(\widehat{\mathrm{SE}}=0.065)$. 
Table 3.28. Detection Histories for BON Tailrace Releases. In the table heading, a 1 denotes detected and 0 not detected at BON primary and secondary arrays, respectively. BON tertiary array was not available for the entire study.

\begin{tabular}{|c|c|c|c|c|c||}
\hline Release & $\mathbf{1 ~ 1}$ & $\mathbf{0 ~ 1}$ & $\mathbf{1 0}$ & $\mathbf{0 ~ 0}$ & Total \\
\hline $6 / 17$ & 73 & 83 & 42 & 47 & 245 \\
\hline $6 / 22$ & 120 & 54 & 45 & 26 & 245 \\
\hline $6 / 27$ & 140 & 71 & 20 & 14 & 245 \\
\hline $7 / 02$ & 176 & 16 & 44 & 9 & 245 \\
\hline $7 / 07$ & 156 & 11 & 60 & 16 & 243 \\
\hline $7 / 12$ & 205 & 11 & 17 & 12 & 245 \\
\hline $7 / 17$ & 175 & 13 & 35 & 21 & 244 \\
\hline $7 / 22$ & 191 & 6 & 26 & 22 & 245 \\
\hline Pooled & 1236 & 265 & 289 & 167 & 1957 \\
\hline
\end{tabular}

Table 3.29. Cormack-Jolly-Seber Single-Release Estimates of Survival and Detection Probabilities for the Bonneville Tailrace release. The joint probability of survival from Bonneville primary array to secondary array and being detected at the secondary array $(\lambda)$ is reported in the last column. Standard errors are reported in parentheses. The BON tertiary array was not available all summer.

\begin{tabular}{|c|c|c|c|}
\hline \multirow{2}{*}{$\begin{array}{l}\text { Day of } \\
\text { Release }\end{array}$} & $\begin{array}{c}\text { Survival } \\
\text { Probability }\end{array}$ & Detection Probability & \multirow{2}{*}{$\begin{array}{c}\text { Detection and Survival }(\lambda) \\
\text { to } 2 \mathrm{~B}\end{array}$} \\
\hline & to $1 B$ & to $1 B$ & \\
\hline $6 / 17$ & $1.003(0.052)$ & $0.468(0.040)$ & $0.635(0.045)$ \\
\hline $6 / 22$ & $0.977(0.028)$ & $0.690(0.035)$ & $0.727(0.035)$ \\
\hline $6 / 27$ & $0.984(0.019)$ & $0.664(0.033)$ & $0.875(0.026)$ \\
\hline $7 / 02$ & $0.980(0.013)$ & $0.917(0.020)$ & $0.800(0.027)$ \\
\hline $7 / 07$ & $0.952(0.017)$ & $0.934(0.019)$ & $0.722(0.031)$ \\
\hline $7 / 12$ & $0.955(0.014)$ & $0.949(0.015)$ & $0.923(0.018)$ \\
\hline $7 / 17$ & $0.925(0.019)$ & $0.931(0.019)$ & $0.833(0.026)$ \\
\hline $7 / 22$ & $0.914(0.018)$ & $0.970(0.012)$ & $0.880(0.022)$ \\
\hline Pooled & $0.946(0.007)$ & $0.824(0.010)$ & $0.811(0.010)$ \\
\hline Arithmetic Avg. & $0.961(0.011)$ & $0.815(0.065)$ & \\
\hline
\end{tabular}

\subsubsection{Virtual Releases from The Dalles and Bonneville Forebays}

Virtual release groups were constructed using tagged fish known to have arrived at the JDA tertiary array (3J) just above TDA. These fish were used to generate detection histories (Table 3.30) to estimate survival through TDA and below (Table 3.31). Using the pooled data from five virtual releases June 1327, 2006, survival through TDA to primary array T1 was estimated to be 0.863 ( $\widehat{\mathrm{SE}}=0.021$ ). No obvious seasonal trends were observed (Table 3.31). Survival between the TDA primary (1T) and secondary (2T) arrays was estimated to be $0.991(\widehat{\mathrm{SE}}=0.006$ ). In all cases, detection probabilities at arrays $1 \mathrm{~T}$ and $2 \mathrm{~T}$ were $\geq 0.950$. 
Figure 3.21 summarizes the results of the analysis of The Dalles forebay virtual releases. Using tagged fish known to have arrived at the TDA tertiary array (3T), just above BON Dam, virtual release groups were constructed (Table 3.32) to estimate survival through BON Dam (Table 3.33). The BON tertiary array was not available for the entire summer. Survival through BON Dam to BON primary array (1B) was estimated to be $\hat{S}_{\text {BON }}=0.869$ ( $\widehat{\mathrm{SE}}=0.029$ ) using the pooled data. Detection probabilities at $1 \mathrm{~B}$ fluctuated over the course of the study, from a low of $0.583(\widehat{\mathrm{SE}}=0.044)$ to a high of $0.962(\widehat{\mathrm{SE}}=0.015)$, with an arithmetic average of $\hat{\bar{p}}=0.804$ ( $\widehat{\mathrm{SE}}=0.052$; Figure 3.21).

Table 3.30. Detection Histories for the TDA Virtual Releases at Array 3J. In the table heading, a 1 denotes detected and 0 not detected at the TDA primary and secondary arrays and BON primary, respectively.

\begin{tabular}{|c|c|c|c|c|c|c|c|c|c|}
\hline \hline Release & $\mathbf{1} \mathbf{1} \mathbf{1}$ & $\mathbf{0} \mathbf{1} \mathbf{1}$ & $\mathbf{1} \mathbf{0} \mathbf{1}$ & $\mathbf{0} \mathbf{0} \mathbf{1}$ & $\mathbf{1} \mathbf{1} \mathbf{0}$ & $\mathbf{0} \mathbf{1} \mathbf{0}$ & $\mathbf{1} \mathbf{0} \mathbf{0}$ & $\mathbf{0} \mathbf{0} \mathbf{0}$ & Total \\
\hline $6 / 13$ & 17 & 0 & 0 & 0 & 21 & 1 & 0 & 7 & 46 \\
\hline $6 / 15$ & 19 & 0 & 0 & 0 & 20 & 0 & 0 & 7 & 46 \\
\hline $6 / 20$ & 31 & 0 & 0 & 0 & 14 & 0 & 1 & 3 & 49 \\
\hline $6 / 22$ & 21 & 1 & 0 & 0 & 17 & 1 & 1 & 8 & 49 \\
\hline $6 / 27$ & 59 & 0 & 0 & 0 & 16 & 0 & 0 & 14 & 89 \\
\hline Pooled & 147 & 1 & 0 & 0 & 88 & 2 & 2 & 39 & 279 \\
\hline
\end{tabular}

Table 3.31. Cormack-Jolly-Seber Single-Release Estimates of Survival and Detection Probabilities for TDA Virtual Releases at Array 3J. The joint probability of survival from the TDA secondary array to BON primary array and being detected at the primary array $(\lambda)$ is reported in the last column. Standard errors are reported in parentheses.

\begin{tabular}{|c|c|c|c|c|c|}
\hline \multirow{2}{*}{$\begin{array}{c}\text { Day of } \\
\text { Release }\end{array}$} & \multicolumn{2}{|c|}{ Survival Probability } & \multicolumn{2}{c|}{ Detection Probability } & $\begin{array}{c}\text { Detection and } \\
\text { Survival }(\lambda) \text { to } \\
\text { 1B }\end{array}$ \\
\hline $6 / 13$ & $0.848(0.053)$ & $1.000(<0.0001)$ & $0.974(0.025)$ & $1.000(<0.0001)$ & $0.436(0.079)$ \\
\hline $6 / 15$ & $0.848(0.053)$ & $1.000(<0.0001)$ & $1.000(<0.0001)$ & $1.000(<0.0001)$ & $0.487(0.080)$ \\
\hline $6 / 20$ & $0.939(0.034)$ & $0.978(0.022)$ & $1.000(<0.0001)$ & $1.000(<0.0001)$ & $0.689(0.069)$ \\
\hline $6 / 22$ & $0.838(0.053)$ & $0.974(0.025)$ & $0.950(0.035)$ & $1.000(<0.0001)$ & $0.550(0.079)$ \\
\hline $6 / 27$ & $0.843(0.039)$ & $1.000(<0.0001)$ & $1.000(<0.0001)$ & $1.000(<0.0001)$ & $0.787(0.047)$ \\
\hline Pooled & $0.860(0.021)$ & $0.992(0.006)$ & $0.987(0.007)$ & $1.000(<0.0001)$ & $0.622(0.031)$ \\
\hline Arithmetic Avg. & $0.863(0.019)$ & $0.991(0.006)$ & & & \\
\hline
\end{tabular}


Table 3.32. Detection Histories in the BON Tailwater for the Virtual Releases above BON in Summer. In the table heading, a 1 denotes detected and 0 not detected at the BON primary and secondary arrays, respectively. The BON tertiary array was not available for the entire study.

\begin{tabular}{|c|c|c|c|c|c|}
\hline Release & $\mathbf{1 ~ 1}$ & $\mathbf{0 ~ 1}$ & $\mathbf{1 0}$ & $\mathbf{0 ~ 0}$ & Total \\
\hline $6 / 13$ & 74 & 53 & 27 & 41 & 195 \\
\hline $6 / 15$ & 88 & 46 & 24 & 42 & 200 \\
\hline $6 / 20$ & 71 & 40 & 47 & 34 & 192 \\
\hline $6 / 22$ & 58 & 40 & 64 & 36 & 198 \\
\hline $6 / 27$ & 111 & 12 & 54 & 18 & 195 \\
\hline $6 / 28$ & 117 & 11 & 50 & 20 & 198 \\
\hline $7 / 1$ & 153 & 6 & 44 & 29 & 232 \\
\hline $7 / 7$ & 113 & 11 & 63 & 41 & 228 \\
\hline $7 / 11$ & 127 & 5 & 10 & 41 & 183 \\
\hline $7 / 13$ & 101 & 9 & 32 & 59 & 201 \\
\hline Pooled & 1013 & 233 & 415 & 361 & 2022 \\
\hline \hline
\end{tabular}

Table 3.33. Cormack-Jolly-Seber Single-Release Estimates of Survival and Detection Probabilities for Virtual Releases above BON to the Primary Array in the Tailwater. The joint probability of survival from Bonneville primary array to secondary array and being detected at the secondary array $(\lambda)$ is reported in the last column. Standard errors are in parentheses.

\begin{tabular}{|c|c|c|c|}
\hline $\begin{array}{c}\text { Day of } \\
\text { Release }\end{array}$ & $\begin{array}{c}\text { Survival } \\
\text { Probability to 1B }\end{array}$ & $\begin{array}{c}\text { Detection Probability } \\
\text { to 1B }\end{array}$ & $\begin{array}{c}\text { Detection and Survival }(\lambda) \\
\text { to 2B }\end{array}$ \\
\hline $06 / 13$ & $0.889(0.041)$ & $0.583(0.044)$ & $0.733(0.044)$ \\
\hline $06 / 15$ & $0.853(0.035)$ & $0.657(0.041)$ & $0.786(0.039)$ \\
\hline $06 / 20$ & $0.961(0.045)$ & $0.640(0.046)$ & $0.602(0.045)$ \\
\hline $06 / 22$ & $1.041(0.062)$ & $0.592(0.050)$ & $0.475(0.045)$ \\
\hline $06 / 27$ & $0.938(0.024)$ & $0.902(0.027)$ & $0.673(0.037)$ \\
\hline $06 / 28$ & $0.923(0.023)$ & $0.914(0.025)$ & $0.701(0.035)$ \\
\hline $07 / 01$ & $0.882(0.022)$ & $0.962(0.015)$ & $0.777(0.030)$ \\
\hline $07 / 07$ & $0.847(0.028)$ & $0.911(0.026)$ & $0.642(0.036)$ \\
\hline $07 / 11$ & $0.778(0.031)$ & $0.962(0.017)$ & $0.927(0.022)$ \\
\hline $07 / 13$ & $0.721(0.033)$ & $0.918(0.026)$ & $0.759(0.037)$ \\
\hline Pooled & $0.869(0.010)$ & $0.813(0.011)$ & $0.709(0.012)$ \\
\hline Arithmetic Avg. & $0.883(0.029)$ & $0.804(0.052)$ & $0.707(0.038)$ \\
\hline
\end{tabular}



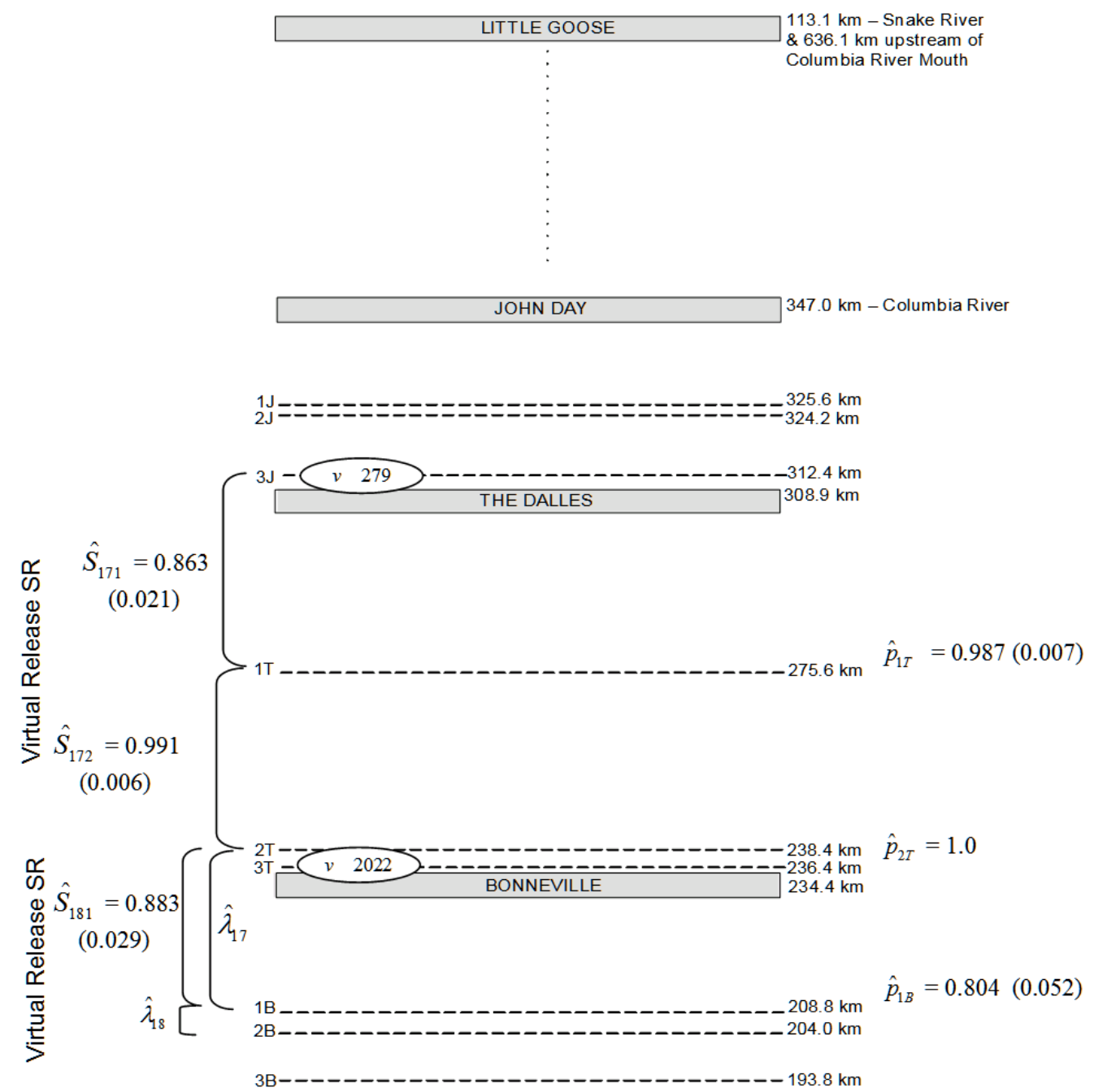

Figure 3.21. Summary of Single Release-Recapture Analysis of Virtual Releases of Subyearling Chinook Salmon from the TDA and BON Forebays

\subsubsection{The Dalles and Bonneville Project Passage Survivals}

Using the releases from the JDA and TDA tailraces, paired release recapture data (Table 3.34) were analyzed to estimate project passage survival at TDA, as summarized in Figure 3.22. The survival estimate through the TDA project was calculated using the reach survival estimates (Table 3.35) from each location. The most parsimonious model describing the paired release was the full CJS model (Table 3.35, Appendix F). The TDA project passage survival was estimated to be $\hat{S}_{\mathrm{TDA}}=0.849$ $(\widehat{\mathrm{SE}}=0.023)$.

Table 3.34. Detection Histories for the Pooled Release Groups Used to Estimate TDA Project Survival. In the table heading, a 1 denotes detected and 0 not detected at the TDA primary and secondary arrays, and the BON primary array, respectively.

\begin{tabular}{|c|c|c|c|c|c|c|c|c|c||}
\hline Release Site & $\mathbf{1} \mathbf{1} \mathbf{1}$ & $\mathbf{0} \mathbf{1} \mathbf{1}$ & $\mathbf{1} \mathbf{0} \mathbf{1}$ & $\mathbf{0} \mathbf{0} \mathbf{1}$ & $\mathbf{1} \mathbf{1} \mathbf{0}$ & $\mathbf{0} \mathbf{1} \mathbf{0}$ & $\mathbf{1} \mathbf{0} \mathbf{0}$ & $\mathbf{0} \mathbf{0} \mathbf{0}$ & Total \\
\hline JDA Tailrace & 151 & 1 & 0 & 0 & 90 & 2 & 2 & 53 & 299 \\
\hline TDA Tailrace & 1425 & 3 & 0 & 0 & 580 & 15 & 88 & 68 & 2179 \\
\hline
\end{tabular}




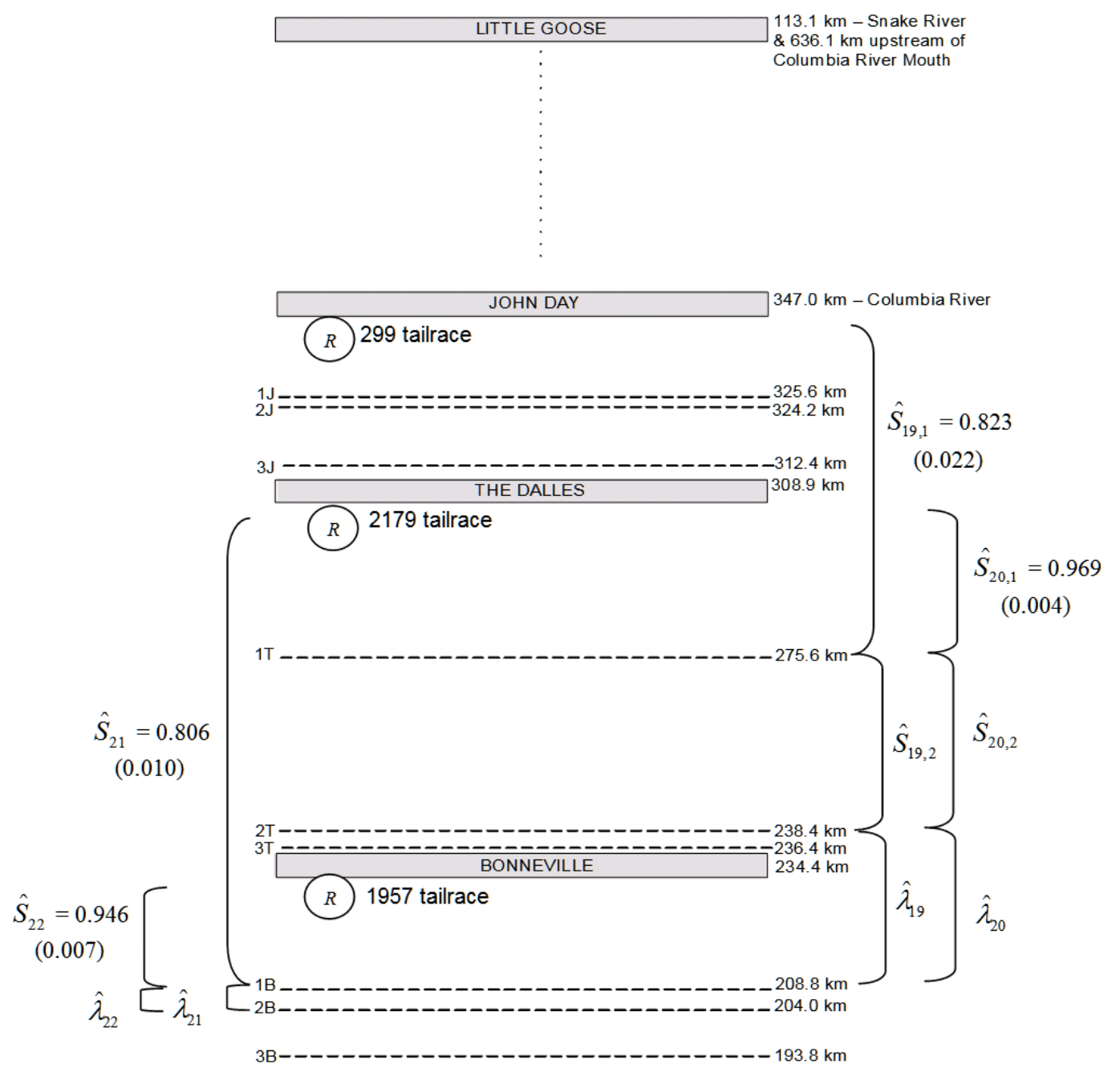

Estimate $\hat{S}_{\text {TDA }}=0.849(0.023)$ and $\hat{S}_{\text {BoN }}=0.852(0.013)$.

Figure 3.22. Summary of Single-Release Estimates of Survival that were Paired to Estimate TDA and BON Project Passage Survivals for Subyearling Chinook Salmon Smolts. Single-release estimates are adjacent to the diagram and the paired-release estimates are presented at the bottom of the diagram.

Table 3.35. Cormack-Jolly-Seber Estimates of Survival and Detection Probabilities for the Pooled Release Groups Used to Estimate TDA Project Survival. The joint probability of survival from the TDA primary array to the secondary array and being detected at the secondary array $(\lambda)$ is reported in the last column. Standard errors are reported in parentheses.

\begin{tabular}{|c|c|c|c|c|c|}
\hline \multirow{2}{*}{ Release Site } & \multicolumn{2}{|c|}{ Survival Probability } & \multicolumn{2}{|c|}{ Detection Probability } & \multirow{2}{*}{$\begin{array}{l}\text { Detection and } \\
\text { Survival }(\lambda) \text { to } 1 \mathrm{~B}\end{array}$} \\
\hline & to $1 \mathrm{~T}$ & $1 \mathrm{~T}$ to $2 \mathrm{~T}$ & $1 T$ & $2 T$ & \\
\hline JDA Tailrace & $0.823(0.022)$ & $0.992(0.006)$ & $0.988(0.007)$ & $1.000(<0.0001)$ & $0.623(0.031)$ \\
\hline TDA Tailrace & $0.969(0.004)$ & $0.958(0.004)$ & $0.991(0.002)$ & $1.000(<0.0001)$ & $0.706(0.010)$ \\
\hline
\end{tabular}

The Dalles and BON Tailrace releases (Figure 3.22) were used to generate capture histories (Table 3.36) to estimate BON project passage survival. The individual release locations generated reach survivals (Table 3.37) that were then modeled to find the best parsimonious description of the data. In 
this case, the project passage survival estimate was $\hat{S}_{\text {BON }}=0.852(\widehat{\mathrm{SE}}=0.013)$ based upon the fully parameterized model $M_{S_{1}, p_{1}, \lambda}$ (Appendix F), which best described the data.

Table 3.36. Detection Histories for the Pooled Release Groups Used to Estimate BON Project Survival. In the table heading, a 1 denotes detected and 0 not detected at BON primary and secondary arrays, respectively. The BON tertiary array was not available for the entire study.

\begin{tabular}{||c|c|c|c|c|c||}
\hline Release Site & $\mathbf{1 ~ 1}$ & $\mathbf{0 ~ 1}$ & $\mathbf{1 0}$ & $\mathbf{0 ~ 0}$ & Total \\
\hline TDA Tailrace & 1013 & 233 & 415 & 518 & 2179 \\
\hline BON Tailrace & 1236 & 265 & 289 & 167 & 1957 \\
\hline
\end{tabular}

Table 3.37. Cormack-Jolly-Seber Single-Release Estimates of Survival and Detection Probabilities for the Pooled Release Groups Used to Estimate BON Project Survival. The joint probability of survival from the BON primary array to the secondary array and being detected at the secondary array $(\lambda)$ is reported in the last column. Standard errors are reported in parentheses. This is also the most appropriate paired-release model. BON tertiary array was not available for the entire study.

\begin{tabular}{||c|c|c|c|}
\hline \multirow{2}{*}{ Release Site } & Survival Probability & Detection Probability & $\begin{array}{c}\text { Detection and } \\
\text { Survival }(\lambda) \text { to 2B }\end{array}$ \\
\cline { 2 - 3 } & to 1B & 1B & $0.709(0.012)$ \\
\hline TDA Tailrace & $0.806(0.010)$ & $0.813(0.011)$ & $0.811(0.010)$ \\
\hline BON Tailrace & $0.946(0.007)$ & $0.824(0.010)$ & \multicolumn{2}{|c|}{} \\
\hline
\end{tabular}

\subsubsection{Tests of Assumptions}

\subsubsection{Assignment of Mixing}

The JDA and TDA Tailrace releases used to estimate project survival at TDA again showed significant $(P<0.001)$ and apparently appreciable departures from mixing (Appendix G, Figure G.1) primarily because releases after 6/27 in the TDA Tailrace had no treatment counterparts (Figure 3.23). For the period of mostly concurrent paired releases, divergence in the two lines could be explained by differences in the numbers of fish released at each location and not by differences in arrival date, because travel times to Array 1T were very consistent (Figure 3.23). We reran the paired release survival estimate using data acquired during the period of concurrent releases, and the resulting survival estimates [0.830 $(\widehat{\mathrm{SE}}=0.022)]$ did not differ significantly from the estimate based upon all acquired data $[0.852(\widehat{\mathrm{SE}}=$ 0.013)]. Within days, for same-day releases, the average minimum, mean, and maximum detection hours for JDA Tailraces releases on 1T were 2.8, 15.1, and 21.8 hours compared with 0.8, 10.6, and 23.0 hours for TDA releases. In short, the slowest and fastest fish from either release group could show up at Array $1 \mathrm{~T}$ almost any time of day, but on average, there was about a four-hour difference in the average arrival hour in summer.

Comparison of the TDA and BON Tailrace releases used to estimate project survival at BON indicated that all but two reference releases and one treatment release at the end of summer occurred on concurrent dates (Appendix G, Figure G.2). We reran the paired release survival estimate using only data acquired during the period of concurrent releases and the resulting survival estimates $[0.837(\widehat{\mathrm{SE}}=$ 0.015)] did not differ significantly from the estimate based upon all of the acquired data $[0.849$ ( $\widehat{\mathrm{SE}}=$ 0.0230)]. Close inspection revealed that BON releases usually were detected on the same day as 
treatment-released fish because travel times were quite consistent (Figure 3.24). In addition, within days fish from both release locations were detected at Array 1B at about the same time of day in summer. The average arrival hour at Array 1B for the TDA Tailrace releases was 1040 ( $\widehat{\mathrm{SE}}=6$ hours), and for BON releases, it was 0913 ( $\widehat{\mathrm{SE}}=2.2$ hours). Therefore, fish in summer releases from TDA and BON Tailraces should have been well mixed as they traversed the BON Tailwater at about the same time of day.

\subsubsection{Goodness of Fit}

Burnham et al. (1987) Tests 2 and 3 were performed on the JDA and TDA Tailrace releases (Appendix G, Tables G.1 and G.2). Test 2 could not be performed because of the high recapture probabilities at 2T. One of the Test 3's was significant at $P<0.0001$, indicating capture history to 2T had an effect on detection at the 1B array.

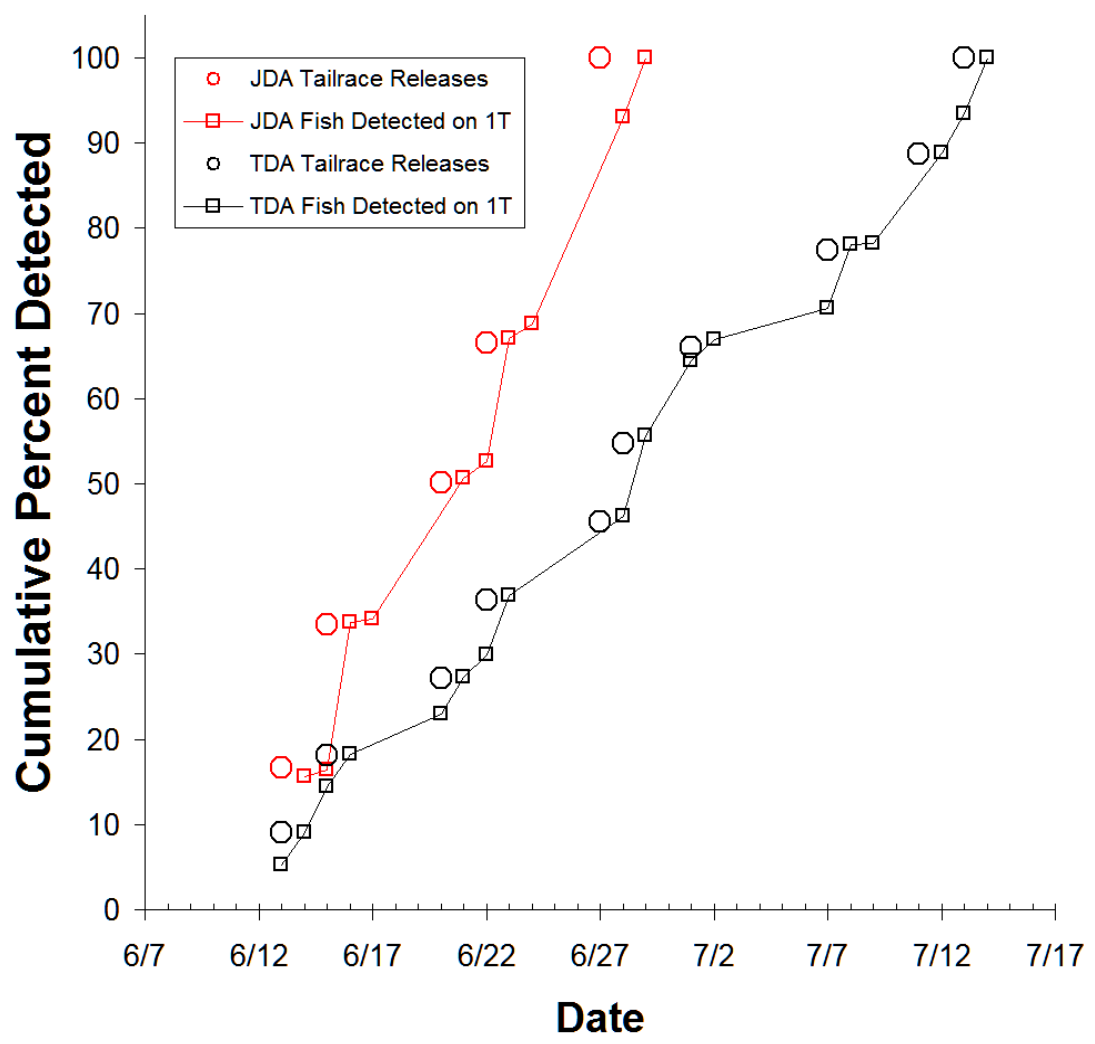

Figure 3.23. Plot of Dates of Release and Detections on Array 1T for Tagged Fish Released in the JDA Tailrace and TDA Tailrace 


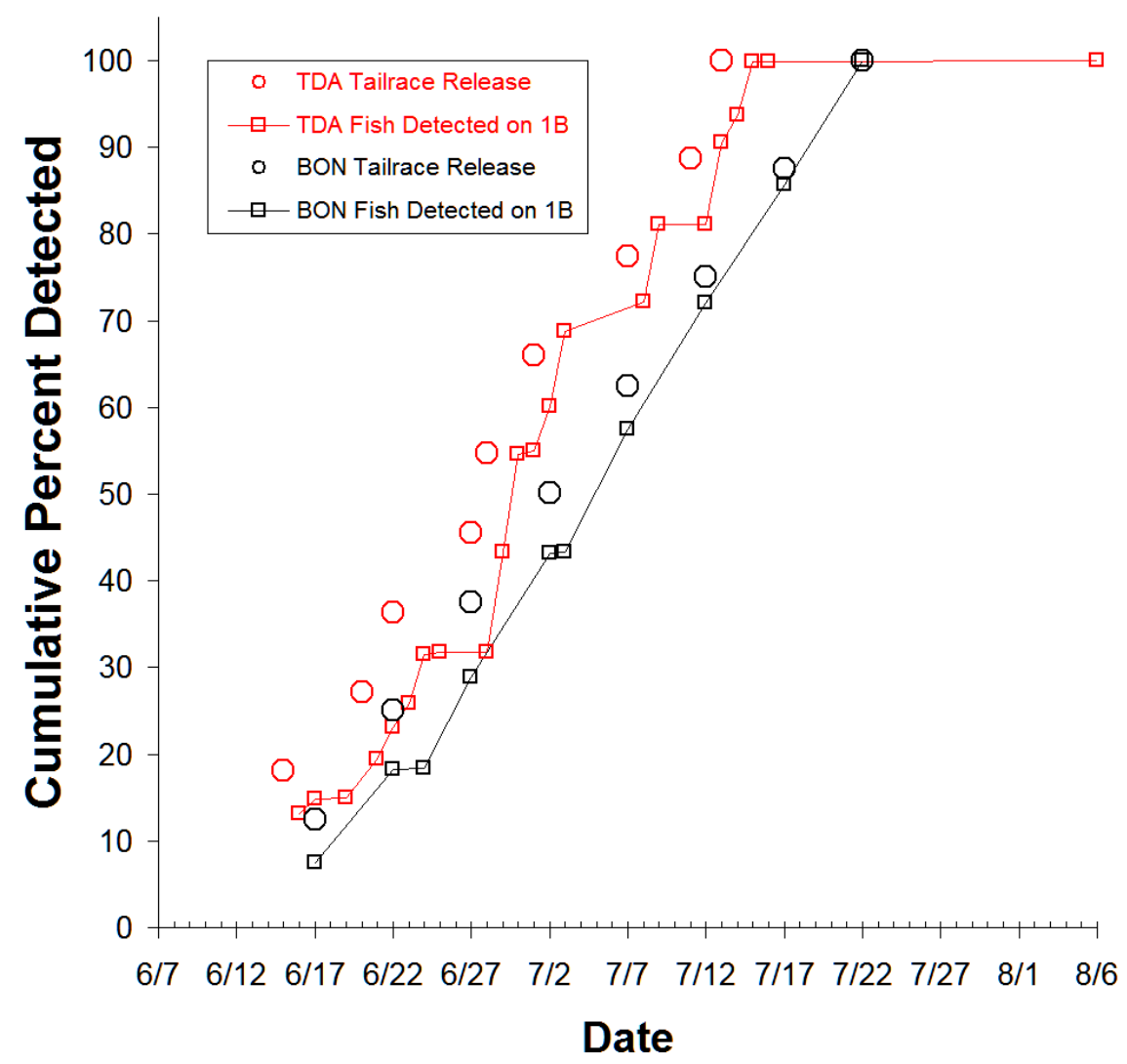

Figure 3.24. Plot of Dates of Release and Detections on Array 1B for Tagged Fish Released in the TDA Tailrace and BON Tailrace

\subsubsection{Survival through Successive Reaches}

We made estimates of survival for subyearling Chinook salmon from the point of release to each successive array in our study area, except the last reach (Figure 3.25). We released subyearlings in the JDA and TDA Tailraces, and the Lower Monumental and Columbia River Estuary studies released subyearlings into the Little Goose and BON Tailraces. Survival statistics were calculated using a single release model and detections for the array of interest two successive arrays immediately downstream, except for Array 1B estimates, which were based upon detections on two arrays. What is not indicated in the figure is the length of each reach, which was highly variable (see Figure 3.22). Obviously, the fish from the Little Goose Tailrace release had the farthest to travel to reach the first survival array at $1 \mathrm{~J}$.

\subsubsection{Bonneville Route-Specific Survival (Pooled Releases)}

We estimated detection probabilities and survival for subyearling Chinook salmon based on the population of all tagged fish detected at three sites while passing through BON, regardless of where the fish were originally released. Release sites that contributed fish to the detections included the LGR Tailrace, JDA Intake 9C, JDA Front Roll, JDA Tailrace, and TDA Tailrace. The pooled release groups included fish from the LGS Tailrace, the JDA Tailrace, and the TDA Tailrace. 


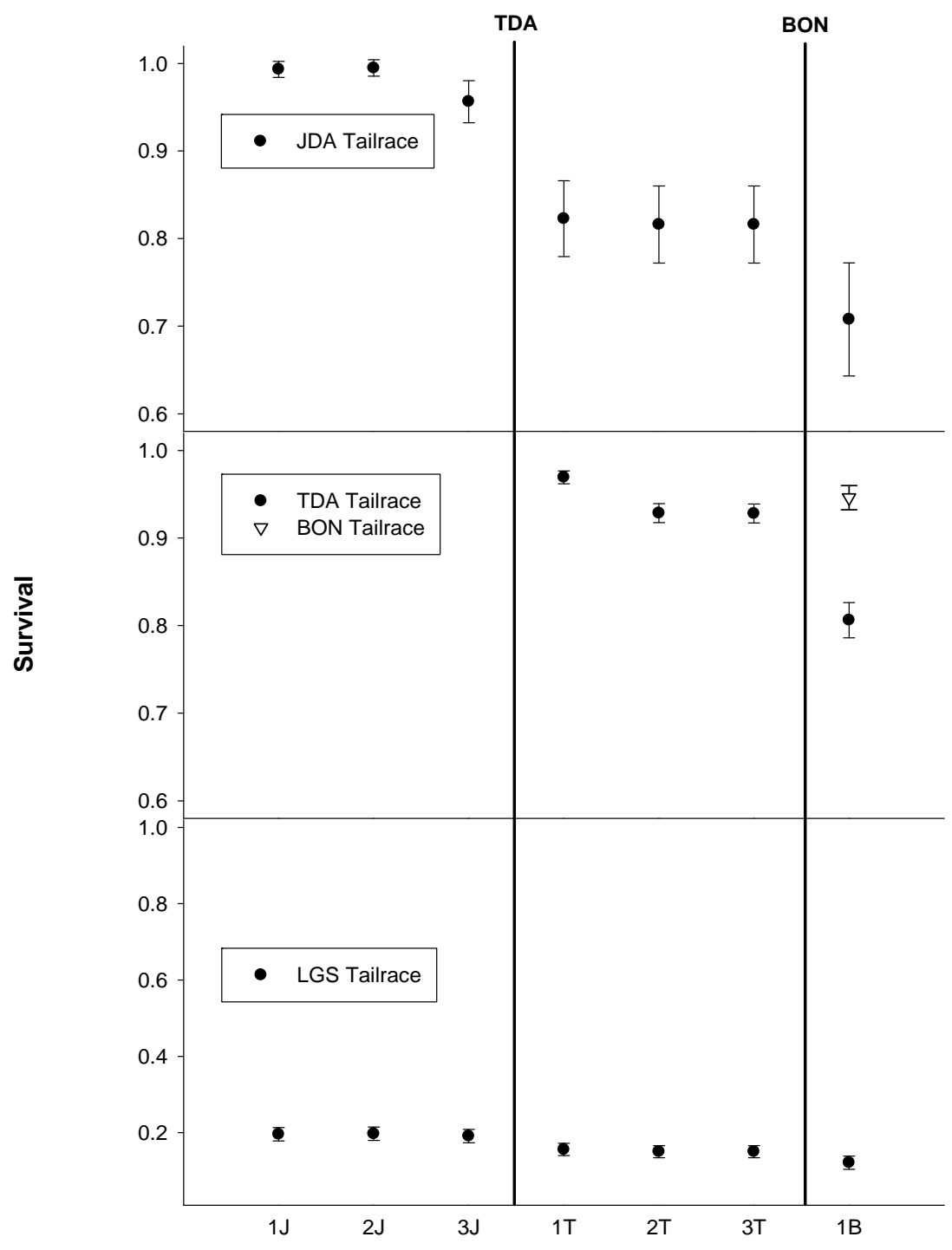

Array

Figure 3.25. Summer Survival for Subyearling Chinook Salmon from Release Location to Each Successive Array, Except the Last. Vertical bars are 95\% confidence intervals.

\subsubsection{Spillway, B2 JBS, and B2CC}

During summer, we estimated survival of fish passing several routes through BON. Tagged fish were detected by an array of autonomous acoustic hydrophones and dam-mounted hydrophones in the spillway forebay and by PIT tag detectors at the B2CC and the B2 JBS. Using data from the primary and secondary arrays below BON, pooled survival estimates and detection probabilities were calculated for each route (Table 3.38). The survival estimate for fish passing the B2CC was highest (95.2\%), followed by the estimate for B2 JBS-passed fish (90.7\%), and then by the estimate for spillway-passed fish (85.8\%). Based upon non-overlap of 95\% confidence limits calculated from standard errors listed in Table 3.38 (i.e., 95\% CI $=\widehat{S E} \times 1.96$ ), estimates for the B2CC and the spillway could be significantly different, but the B2CC did not differ from the B2 JBS estimate and the B2 JBS estimate did not differ from the spillway estimate. 
Table 3.38. Single-Release Survival and Detection Probabilities for Subyearling Chinook Salmon based on Pooled Releases from All Upstream Sites for Specific Passage Routes. Standard errors are in parentheses.

\begin{tabular}{|c|c|c|c|c|}
\hline \multirow{2}{*}{$\begin{array}{l}\text { Route of } \\
\text { Passage }\end{array}$} & $\begin{array}{c}\text { Survival } \\
\text { Probability }\end{array}$ & $\begin{array}{c}\text { Detection } \\
\text { Probability }\end{array}$ & $\begin{array}{c}\text { Detection and } \\
\text { Survival }(\lambda) \text { to }\end{array}$ & $\begin{array}{c}\text { Number Detected } \\
\text { by }\end{array}$ \\
\cline { 2 - 5 } & To 1B & 1B & 2B & Route \\
\hline B2CC & $0.952(0.031)$ & $0.877(0.041)$ & $0.750(0.050)$ & 91 \\
\hline B2 JBS & $0.907(0.031)$ & $0.823(0.036)$ & $0.660(0.040)$ & 189 \\
\hline Spillway & $0.858(0.017)$ & $0.822(0.019)$ & $0.808(0.033)$ & 706 \\
\hline
\end{tabular}

We also calculated paired release estimates for the three passage routes in summer by dividing the single-release estimates in Table 3.38 by the pooled estimate for the BON Tailrace release in summer $(0.946 \pm 0.007$ SE). Paired-release estimates \pm standard errors were as follows: B2CC Survival $=100.6 \%$ [1/2 95\% CI = 94.0, 107.2]; B2 JBS Survival = 95.9\% [1/2 95\% CI = 89.3, 102.4]; and B2 Spillway Survival $=90.6 \%$ [1/2 95\% CI = 86.9, 94.4]. The 95\% confidence intervals had a lot of overlap for the B2CC and B2JBS and for the B2 JBS and spillway, but only slight overlap for the B2CC and spillway.

\subsubsection{Spillway Survival by Spill Condition}

In summer, when more tagged fish were detected passing the spillway, we calculated spillway survival for three periods that had different diel spill regimes (Figure 3.26). The first regime was 24-hour spill to the gas cap (94 to $149 \mathrm{kcfs}$ from June 14 through June 25); the second regime was 24-hour low spill ranging from 63 to 83 kcfs (June 26 through July 5); the third regime was 75 kcfs day spill and spill to the gas cap at night after July 6. The detection array in the spillway forebay was operational for the entire summer season and consisted of five cabled nodes on piers and four autonomous nodes in the forebay. Both of these arrays were used to establish the population of tagged fish for detection and survival calculations.



Figure 3.26. Spill Pattern during Summer 2006 
After July 6, survival estimates for day (80\%) and night (76\%) did not differ significantly (Table 3.39), even though spill levels clearly were different (Figure 3.26). Therefore, we calculated a pooled survival estimate for fish passing the spillway during the day or night after July 6 and compared that estimate with estimates for the two other spill conditions (Table 3.40). Survival during the 24-hour gas cap condition was significantly higher than survival during the Biop-spill treatment (75 kcfs day; gas cap night), but the former condition occurred early in summer and the latter in late summer. There was a significant decline in survival of subyearling fish from LGS passing from Array $1 \mathrm{~J}$ to 1T, TDA Tailrace subyearlings passing through the TDA Tailwater, TDA Tailrace fish passing through all routes through BON Project, and all subyearlings in the BON virtual releases (Figure 3.27).

Table 3.39. Single-Release Survival and Detection Probabilities for Subyearling Chinook Salmon Passing the BON Spillway after July 5 during the Day and Night Periods based on Pooled Releases from All Upstream Sites. Standard errors are in parentheses.

\begin{tabular}{|c|c|c|c|c||}
\hline \hline & Survival Probability & Detection Probability & $\begin{array}{c}\text { Detection and } \\
\text { Survival }(\lambda) \text { to }\end{array}$ & $\begin{array}{c}\text { Number Detected } \\
\text { by }\end{array}$ \\
\hline \hline Time & To 1B & 1B & 2B & Condition \\
\hline Day & $0.800(0.034)$ & $0.860(0.034)$ & $0.653(0.040)$ & 205 \\
\hline Night & $0.758(0.047)$ & $0.982(0.018)$ & $0.828(0.047)$ & 86 \\
\hline
\end{tabular}

Table 3.40. Single-Release Survival and Detection Probabilities for Subyearling Chinook Salmon Passing the BON Spillway and Released in the Bonneville Tailrace during Three Periods with Different Spill Conditions. The estimates were based on spillway-detected fish regardless of release location upstream or date unless a BON Tailrace release is indicated. Standard errors are in parentheses.

\begin{tabular}{||l|c|c|c|c||}
\hline \multicolumn{1}{|c|}{ Spill-passed during Condition } & $\begin{array}{c}\text { Survival } \\
\text { Probability }\end{array}$ & $\begin{array}{c}\text { Detection } \\
\text { Probability }\end{array}$ & $\begin{array}{c}\text { Detection and } \\
\text { Survival }(\lambda) \text { to }\end{array}$ & $\begin{array}{c}\text { Number } \\
\text { Detected } \\
\text { by } \\
\text { Condition }\end{array}$ \\
\cline { 2 - 5 } & To 1B & 1B & 2B & 193 \\
\hline 24 h gas cap spill & $0.960(0.038)$ & $0.670(0.042)$ & $0.669(0.042)$ & 490 \\
\hline $\begin{array}{l}\text { BON Tailrace release during 24 h gas cap } \\
\text { spill }\end{array}$ & $0.990(0.040)$ & $0.579(0.038)$ & $0.681(0.040)$ & 222 \\
\hline Spill-passed during 24 h low spill & $0.878(0.027)$ & $0.867(0.028)$ & $0.734(0.034)$ & 490 \\
\hline BON Tailrace release during 24 h low spill & $0.982(0.016)$ & $0.790(0.026)$ & $0.838(0.027)$ & 291 \\
\hline $\begin{array}{l}\text { Spill-passed during 75 kcfs day and gas-cap } \\
\text { night spill }\end{array}$ & $0.782(0.027)$ & $0.901(0.024)$ & $0.707(0.032)$ & 977 \\
\hline $\begin{array}{l}\text { BON Tailrace during 75 kcfs day and gas-cap } \\
\text { night spill }\end{array}$ & $0.936(0.017)$ & $0.946(0.016)$ & $0.840(0.024)$ & 9 \\
\hline
\end{tabular}

After dividing the single-release estimates for spilled fish by single-release estimates for the BON Tailrace releases for the same time periods (Table 3.40), we obtained the following paired-release survival estimates and $1 \frac{1}{2}$ 95\% CIs (in parentheses after the survival estimate) for each spill condition:

$\underline{\text { Condition }}$

$24 \mathrm{~h}$ gas cap spill

24 h low spill

75 kcfs day and gas cap night spill
Survival

$0.970(0.863,1.076)$

0.894 (0.834, 0.954)

$0.836(0.773,0.899)$ 


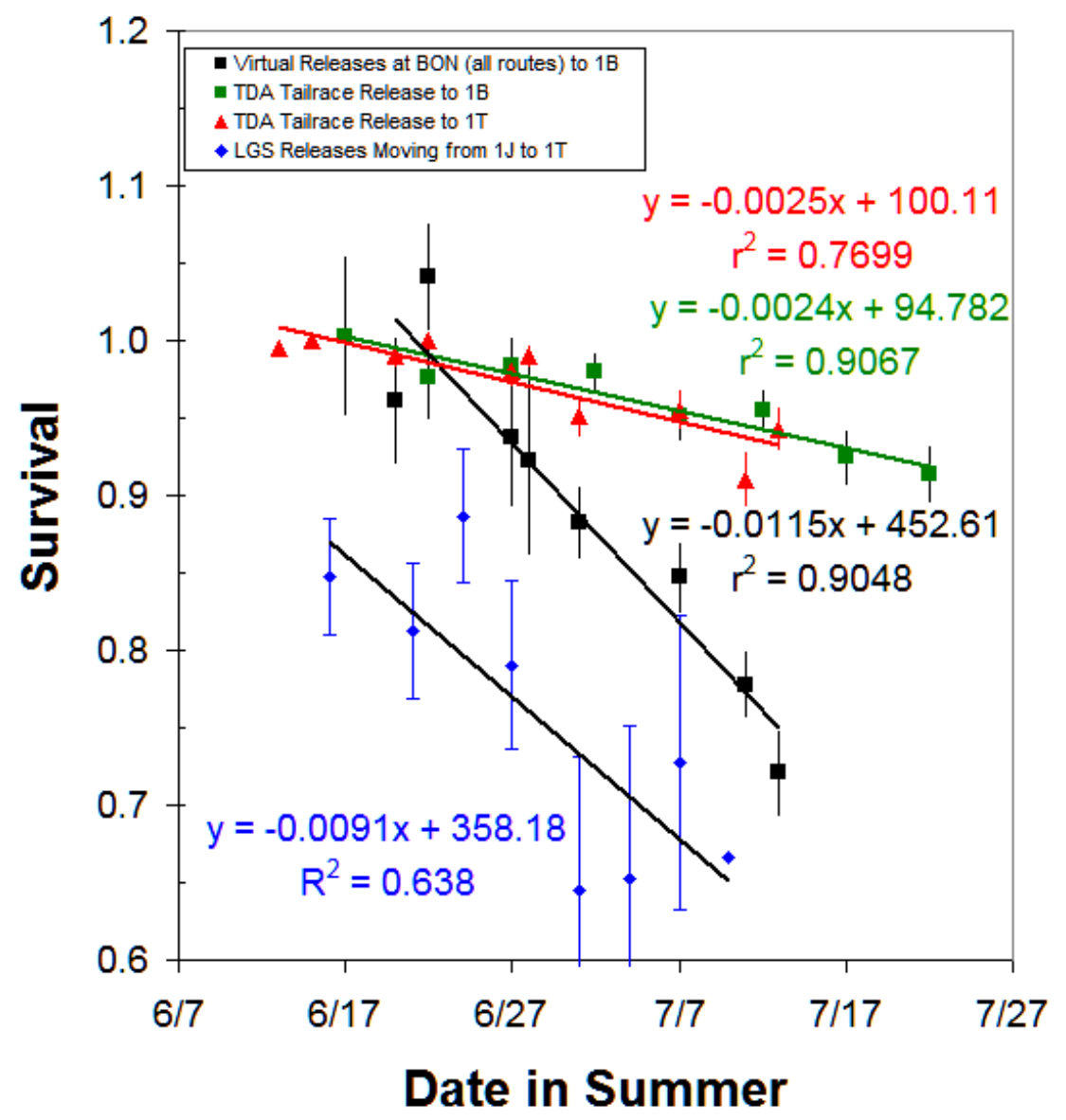

Figure 3.27. Trends in Survival during Summer 2006

\subsection{Comparison of Estimates Using Preferred Versus As-Planned Arrays}

In this section, we compare survival estimates calculated from detection data using different choices for secondary or tertiary arrays. Given the number of arrays deployed, there were choices for the arrays to be used as secondary or tertiary arrays in calculations for arrays upstream of Array 2B in the BON Tailwater. The most independent primary, secondary, and tertiary arrays based upon long intervening river reaches were considered to be "preferred arrays," and estimates from those arrays were compared with estimates from "as planned" arrays deployed in the same pool as the primary array. Survival and detection probability estimates based on the two approaches did not differ significantly in spring (Table 3.41 and Table 3.42) or summer (Table 3.43 and Table 3.44). A full list of detection frequencies and associated detection and survival estimates for as-planned arrays are presented in Appendix H. 
Table 3.41. Uncorrected Cormack-Jolly-Seber Estimates of Survival Probabilities Calculated from Preferred and As-Planned Arrays in Spring. Standard errors (SE) in parenthesis that allow survival to overlap between the two estimate types were not considered to differ significantly. Differences in estimates are flagged with an * in the last column (Diff = difference).

\begin{tabular}{|c|c|c|c|c|c|c|c|}
\hline Releases & Reach & Model & $\begin{array}{l}\text { Preferred } \\
\text { Arrays }\end{array}$ & $\begin{array}{l}\text { Survival } \\
\text { Estimates }\end{array}$ & $\begin{array}{c}\text { As } \\
\text { Planned } \\
\text { Arrays }\end{array}$ & $\begin{array}{l}\text { Survival } \\
\text { Estimates }\end{array}$ & Diff \\
\hline LGR TR & LGR TR to $1 \mathrm{~J}$ & $S$ & $1 \mathrm{~J}, 1 \mathrm{~T}, 2 \mathrm{~T}$ & $0.487(0.016)$ & $1 \mathrm{~J}, 2 \mathrm{~J}, 3 \mathrm{~J}$ & $0.481(0.016)$ & \\
\hline $9 \mathrm{C}$ & $9 \mathrm{C}$ to $1 \mathrm{~J}$ & $\mathrm{~S}$ & $1 \mathrm{~J}, 1 \mathrm{~T}, 2 \mathrm{~T}$ & $0.876(0.015)$ & $1 \mathrm{~J}, 2 \mathrm{~J}, 3 \mathrm{~J}$ & $0.863(0.015)$ & \\
\hline JDA FR & FR to $1 \mathrm{~J}$ & $S$ & $1 \mathrm{~J}, 1 \mathrm{~T}, 2 \mathrm{~T}$ & $0.983(0.006)$ & 1J, 2J, 3J & $0.980(0.006)$ & \\
\hline JDA TR & TR to $1 \mathrm{~J}$ & $S$ & $1 \mathrm{~J}, 1 \mathrm{~T}, 2 \mathrm{~T}$ & $0.974(0.007)$ & $1 \mathrm{~J}, 2 \mathrm{~J}, 3 \mathrm{~J}$ & $0.967(0.008)$ & \\
\hline JDA FR \& JDA TR & FR - TR & $\mathrm{P}$ & $1 \mathrm{~J}, 1 \mathrm{~T}, 2 \mathrm{~T}$ & 1.009 (0.019) & $1 \mathrm{~J}, 2 \mathrm{~J}, 3 \mathrm{~J}$ & $1.014(0.021)$ & \\
\hline JDA 9C \& JDA TR & 9C - TR & $\mathrm{P}$ & $1 \mathrm{~J}, 1 \mathrm{~T}, 2 \mathrm{~T}$ & $0.898(0.033)$ & $1 \mathrm{~J}, 2 \mathrm{~J}, 3 \mathrm{~J}$ & $0.892(0.035)$ & \\
\hline JDA 9C \& JDA FR & 9C - FR & $\mathrm{P}$ & $1 \mathrm{~J}, 1 \mathrm{~T}, 2 \mathrm{~T}$ & $0.892(0.032)$ & $1 \mathrm{~J}, 2 \mathrm{~J}, 3 \mathrm{~J}$ & $0.880(0.033)$ & \\
\hline TDA TR & TR to $1 \mathrm{~T}$ & $\mathrm{~S}$ & $1 \mathrm{~T}, 2 \mathrm{~T}, 1 \mathrm{~B}$ & $0.989(0.003)$ & $1 \mathrm{~T}, 2 \mathrm{~T}, 3 \mathrm{~T}$ & $0.989(0.003)$ & \\
\hline TDA TR & $1 \mathrm{~T}$ to $2 \mathrm{~T}$ & $\mathrm{~S}$ & $2 \mathrm{~T}, 1 \mathrm{~B}$ & $0.992(0.004)$ & $2 \mathrm{~T}, 3 \mathrm{~T}$ & $0.993(0.003)$ & \\
\hline JDA TR \& TDA TR & JDA to $1 \mathrm{~T}$ & $\mathrm{P}$ & $1 \mathrm{~T}, 2 \mathrm{~T}, 1 \mathrm{~B}$ & $0.928(0.013)$ & $1 \mathrm{~T}, 2 \mathrm{~T}, 3 \mathrm{~T}$ & $0.928(0.013)$ & \\
\hline Virtual TDA & $3 \mathrm{~J}$ to $1 \mathrm{~T}$ & VS & $1 \mathrm{~T}, 2 \mathrm{~T}, 1 \mathrm{~B}$ & $0.947(0.007)$ & $1 \mathrm{~T}, 2 \mathrm{~T}, 3 \mathrm{~T}$ & $0.954(0.011)$ & \\
\hline Virtual TDA & $1 \mathrm{~T}$ to $2 \mathrm{~T}$ & VS & $2 \mathrm{~T}, 1 \mathrm{~B}$ & $0.979(0.005)$ & $2 \mathrm{~T}, 3 \mathrm{~T}$ & $0.988(0.006)$ & \\
\hline
\end{tabular}

Table 3.42. Uncorrected Cormack-Jolly-Seber Estimates of Detection Probabilities Calculated from Preferred and As-Planned Arrays in Spring. Standard errors (SE) in parenthesis that allow survival to overlap between the two estimate types were not considered to differ significantly. Differences in estimates are flagged with an * in the last column (Diff = difference).

\begin{tabular}{|c|c|c|c|c|c|c|c|}
\hline Releases & Reach & Model & $\begin{array}{l}\text { Preferred } \\
\text { Arrays }\end{array}$ & $\begin{array}{l}\text { Detection } \\
\text { Probability } \\
\text { Estimates }\end{array}$ & $\begin{array}{c}\text { As } \\
\text { Planned } \\
\text { Arrays }\end{array}$ & $\begin{array}{l}\text { Detection } \\
\text { Probability } \\
\text { Estimates }\end{array}$ & Diff \\
\hline LGR TR & LGR TR to $1 \mathrm{~J}$ & $\mathrm{~S}$ & $1 \mathrm{~J}, 1 \mathrm{~T}, 2 \mathrm{~T}$ & $0.896(0.015)$ & $1 \mathrm{~J}, 2 \mathrm{~J}, 3 \mathrm{~J}$ & $0.907(0.014)$ & \\
\hline $9 \mathrm{C}$ & $9 \mathrm{C}$ to $1 \mathrm{~J}$ & $\mathrm{~S}$ & $1 \mathrm{~J}, 1 \mathrm{~T}, 2 \mathrm{~T}$ & $0.961(0.010)$ & $1 \mathrm{~J}, 2 \mathrm{~J}, 3 \mathrm{~J}$ & $0.976(0.008)$ & \\
\hline $9 \mathrm{C}$ & $9 \mathrm{C}$ to $1 \mathrm{~J}$ & $\mathrm{~S}$ & $1 \mathrm{~J}, 1 \mathrm{~T}, 2 \mathrm{~T}$ & $0.989(0.005)$ & 1J, 2J, 3J & $0.991(0.004)$ & \\
\hline JDA FR & FR to $1 \mathrm{~J}$ & $\mathrm{~S}$ & $1 \mathrm{~J}, 1 \mathrm{~T}, 2 \mathrm{~T}$ & $0.977(0.007)$ & $1 \mathrm{~J}, 2 \mathrm{~J}, 3 \mathrm{~J}$ & $0.985(0.006)$ & \\
\hline JDA TR & TR & $S$ & $1 \mathrm{~J}, 1 \mathrm{~T}, 2 \mathrm{~T}$ & $0.983(0.004)$ & 1J, 2J, 3J & $0.988(0.004)$ & \\
\hline JDA FR \& JDA TR & FR - TR & $\mathrm{P}$ & $1 \mathrm{~J}, 1 \mathrm{~T}, 2 \mathrm{~T}$ & $0.969(0.006)$ & 1J, 2J, 3J & $0.981(0.005)$ & \\
\hline JDA 9C \& JDA TR & 9C - TR & $\mathrm{P}$ & $1 \mathrm{~J}, 1 \mathrm{~T}, 2 \mathrm{~T}$ & $\begin{array}{l}0.961(0.010) \\
0.989(0.005)\end{array}$ & 1J, 2J, 3J & $\begin{array}{l}0.976(0.008) \\
0.991(0.004)\end{array}$ & \\
\hline TDA TR & 9C - FR & $\mathrm{P}$ & $1 \mathrm{~T}, 2 \mathrm{~T}$ & $0.975(0.005)$ & 1J, 2J, 3J & $0.975(0.005)$ & \\
\hline TDA TR & TR to $1 \mathrm{~T}$ & $\mathrm{~S}$ & $2 \mathrm{~T}, 1 \mathrm{~B}$ & $0.995(0.003)$ & $2 \mathrm{~T}, 3 \mathrm{~T}$ & $0.994(0.003)$ & \\
\hline TDA TR & $1 \mathrm{~T}$ to $2 \mathrm{~T}$ & S & $2 \mathrm{~T}, 1 \mathrm{~B}$ & $\begin{array}{l}0.934(0.012) \\
0.975(0.005)\end{array}$ & $2 \mathrm{~T}, 3 \mathrm{~T}$ & $0.933(0.0036)$ & \\
\hline JDA TR \& TDA & $3 \mathrm{~J}$ to $1 \mathrm{~T}$ & $\mathrm{P}$ & $1 \mathrm{~T}, 2 \mathrm{~T}, 1 \mathrm{~B}$ & $0.930(0.008)$ & $1 \mathrm{~T}, 2 \mathrm{~T}, 3 \mathrm{~T}$ & $0.936(0.013)$ & \\
\hline Virtual TDA & $3 \mathrm{~J}$ to $1 \mathrm{~T}$ & VS & $2 \mathrm{~T}, 1 \mathrm{~B}$ & $0.9300(0.008)$ & $2 \mathrm{~T}, 3 \mathrm{~T}$ & $0.9363(0.0139)$ & \\
\hline Virtual TDA & $1 \mathrm{~T}$ to $2 \mathrm{~T}$ & VS & $2 \mathrm{~T}, 1 \mathrm{~B}$ & $1.000(<0.0001)$ & $2 \mathrm{~T}, 3 \mathrm{~T}$ & $1.000(<0.0001)$ & \\
\hline
\end{tabular}


Table 3.43. Uncorrected Cormack-Jolly-Seber Estimates of Survival Probabilities Calculated from Preferred and As-Planned Arrays in Summer. Standard errors (SE) in parenthesis that allow survival to overlap between the two estimate types were not considered to differ significantly. Differences in estimates are flagged with an * in the last column (Diff = difference).

\begin{tabular}{|c|c|c|c|c|c|c|c|}
\hline Releases & Reach & Model & $\begin{array}{c}\text { Preferred } \\
\text { Arrays }\end{array}$ & $\begin{array}{c}\text { Survival } \\
\text { Estimates }\end{array}$ & $\begin{array}{c}\text { As } \\
\text { Planned } \\
\text { Arrays }\end{array}$ & $\begin{array}{c}\text { Survival } \\
\text { Estimates }\end{array}$ & Diff \\
\hline LGS TR & LGS TR to $1 \mathrm{~J}$ & $S$ & $1 \mathrm{~J}, 1 \mathrm{~T}, 2 \mathrm{~T}$ & $0.196(0.056)$ & $1 \mathrm{~J}, 2 \mathrm{~J}, 3 \mathrm{~J}$ & $0.196(0.009)$ & \\
\hline JDA TR & TR to $1 \mathrm{~J}$ & $S$ & $1 \mathrm{~J}, 1 \mathrm{~T}, 2 \mathrm{~T}$ & $0.994(0.005)$ & $1 \mathrm{~J}, 2 \mathrm{~J}, 3 \mathrm{~J}$ & $0.993(0.005)$ & \\
\hline TDA TR & TR to $1 \mathrm{~T}$ & $S$ & $1 \mathrm{~T}, 2 \mathrm{~T}, 1 \mathrm{~B}$ & $0.969(0.004)$ & $1 \mathrm{~T}, 2 \mathrm{~T}, 3 \mathrm{~T}$ & $0.969(0.004)$ & \\
\hline TDA TR & $1 \mathrm{~T}$ to $2 \mathrm{~T}$ & $S$ & $2 \mathrm{~T}, 1 \mathrm{~B}$ & $0.958(0.004)$ & $2 \mathrm{~T}, 3 \mathrm{~T}$ & $0.958(0.004)$ & \\
\hline JDA TR \& TDA TR & JDA to $1 \mathrm{~T}$ & $\mathrm{P}$ & $1 \mathrm{~T}, 2 \mathrm{~T}, 1 \mathrm{~B}$ & $0.849(0.023)$ & $1 \mathrm{~T}, 2 \mathrm{~T}, 3 \mathrm{~T}$ & $0.849(0.023)$ & \\
\hline Virtual TDA & $3 \mathrm{~J}$ to $1 \mathrm{~T}$ & VS & $1 \mathrm{~T}, 2 \mathrm{~T}, 1 \mathrm{~B}$ & $0.860(0.021)$ & $1 \mathrm{~T}, 2 \mathrm{~T}, 3 \mathrm{~T}$ & $0.860(0.021)$ & \\
\hline Virtual TDA & $1 \mathrm{~T}$ to $2 \mathrm{~T}$ & VS & $2 \mathrm{~T}, 1 \mathrm{~B}$ & $0.992(0.006)$ & $2 \mathrm{~T}, 3 \mathrm{~T}$ & $0.992(0.006)$ & \\
\hline
\end{tabular}

Table 3.44. Uncorrected Cormack-Jolly-Seber Estimates of Detection Probabilities Calculated from Preferred and As-Planned Arrays in Summer. Standard errors (SE) in parenthesis that allow survival to overlap between the two estimate types were not considered to differ significantly. Differences in estimates are flagged with an * in the last column (Diff = difference).

\begin{tabular}{|l|c|c|c|c|c|c|c|}
\hline \multicolumn{1}{|c|}{ Releases } & Reach & Model & $\begin{array}{c}\text { Preferred } \\
\text { Arrays }\end{array}$ & $\begin{array}{c}\text { Detection } \\
\text { Probability } \\
\text { Estimates }\end{array}$ & $\begin{array}{c}\text { As } \\
\text { Planned } \\
\text { Arrays }\end{array}$ & $\begin{array}{c}\text { Detection } \\
\text { Probability } \\
\text { Estimates }\end{array}$ & Diff \\
\hline LGS TR & LGS TR to $1 \mathrm{~J}$ & $\mathrm{~S}$ & $1 \mathrm{~J}, 1 \mathrm{~T}, 2 \mathrm{~T}$ & $0.947(0.013)$ & $1 \mathrm{~J}, 2 \mathrm{~J}, 3 \mathrm{~J}$ & $0.945(0.012)$ & \\
\hline JDA TR & TR to $1 \mathrm{~J}$ & $\mathrm{~S}$ & $1 \mathrm{~J}, 1 \mathrm{~T}, 2 \mathrm{~T}$ & $0.996(0.004)$ & $1 \mathrm{~J}, 2 \mathrm{~J}, 3 \mathrm{~J}$ & $0.997(0.003)$ & \\
\hline TDA TR & TR to $1 \mathrm{~T}$ & $\mathrm{~S}$ & $1 \mathrm{~T}, 2 \mathrm{~T}, 1 \mathrm{~B}$ & $0.991(0.002)$ & $1 \mathrm{~T}, 2 \mathrm{~T}, 3 \mathrm{~T}$ & $0.991(0.002)$ & \\
\hline TDA TR & $1 \mathrm{~T}$ to $2 \mathrm{~T}$ & $\mathrm{~S}$ & $2 \mathrm{~T}, 1 \mathrm{~B}$ & $1.000(<0.0001)$ & $2 \mathrm{~T}, 3 \mathrm{~T}$ & $\begin{array}{c}1.000 \\
(<0.0001)\end{array}$ & \\
\hline JDA TR \& TDA TR & JDA to $1 \mathrm{~T}$ & $\mathrm{P}$ & $1 \mathrm{~T}, 2 \mathrm{~T}, 1 \mathrm{~B}$ & $\begin{array}{c}0.988(0.007) \\
0.991(0.002)\end{array}$ & $1 \mathrm{~T}, 2 \mathrm{~T}, 3 \mathrm{~T}$ & $\begin{array}{c}0.988(0.007) \\
0.991(0.002)\end{array}$ & \\
\hline Virtual TDA & $3 \mathrm{~J}$ to $1 \mathrm{~T}$ & VS & $1 \mathrm{~T}, 2 \mathrm{~T}, 1 \mathrm{~B}$ & $0.987(0.007)$ & $1 \mathrm{~T}, 2 \mathrm{~T}, 3 \mathrm{~T}$ & $0.987(0.007)$ & \\
\hline Virtual TDA & $1 \mathrm{~T}$ to $2 \mathrm{~T}$ & VS & $2 \mathrm{~T}, 1 \mathrm{~B}$ & $1.000(<0.0001)$ & $2 \mathrm{~T}, 3 \mathrm{~T}$ & $\begin{array}{c}1.000 \\
(<0.0001)\end{array}$ & \\
\hline
\end{tabular}

* TR - Tailrace; S - Single Release; FR - Front roll; P - Paired Release; 9C - Turbine Intake 9C; VS - Virtual Single Release; LGS - Little Goose Dam.

\subsection{Travel Time and Rate}

\subsubsection{Spring}

Yearling Chinook salmon smolts from six different release locations were detected on 11 arrays of acoustic nodes deployed below JDA, TDA, and BON. Four of these release locations were for this study and two were for other studies. For simplicity, we present statistics on travel time and rate of passage through dam projects. 


\subsubsection{LGR Releases}

Yearling Chinook salmon smolts were also released from the LGR Tailrace as part of the Tag Effects project and we used the time of release and time of detection at Array $1 \mathrm{~J}$ to estimate the median travel time, rate, and distance from LGR through JDA to the first survival array (1J; Table 3.45). Median travel time from LGR was 8.9 days to Array 1J, 9.5 days to Array 1T, and 10.2 days to Array 1B. This was much shorter than the expected 55-day tag life for these $10 \mathrm{~s}$ tags.

Table 3.45. Median Hours, Rate, and Distance of Travel from LGR Tailrace Release to Primary Arrays Below Each Project in Spring. Values after the \pm signs are one-half 95\% confidence limits.

\begin{tabular}{|c|c|c|c|c|}
\hline Array & Time (hours) & Rate $\mathbf{( m / s )}$ & $\mathbf{n}$ & Distance $(\mathbf{k m})$ \\
\hline $1 \mathrm{~J}$ & $212.6 \pm 4.6$ & $0.48 \pm 0.01$ & 434 & 369.4 \\
\hline $1 \mathrm{~T}$ & $228.6 \pm 5.6$ & $0.51 \pm 0.01$ & 327 & 419.4 \\
\hline $1 \mathrm{~B}$ & $245.8 \pm 9.2$ & $0.55 \pm 0.03$ & 152 & 486.2 \\
\hline
\end{tabular}

\subsubsection{JDA Releases}

Fish released into the tailrace arrived at the egress array faster than turbine-passed and front roll fish because they moved faster and had less distance to travel (Table 3.46). Front-roll fish also traveled faster than turbine-released fish to the egress array, although the distance traveled was only $110 \mathrm{~m}$ shorter than for turbine-released fish. The median rate of travel of LGR-released fish from Array 3T through TDA Dam to Array $1 \mathrm{~T}$ was significantly faster than the rate for JDA turbine, front roll, and tailrace fish (Table 3.47).

Table 3.46. Median Hours, Rate, and Distance of Travel from Release Site at JDA to the JDA Egress Array in Spring. Values after the \pm signs are one-half $95 \%$ confidence limits.

\begin{tabular}{||c|c|c|c|c||}
\hline Release Site & Time (hours) & Rate (m/s) & $\mathbf{n}$ & Distance (km) \\
\hline JDA Intake 9C & $1.3 \pm 0.1$ & $1.7 \pm 0.02$ & 421 & 7.75 \\
\hline JDA Front Roll & $1.2 \pm 0.02$ & $1.8 \pm 0.02$ & 444 & 7.64 \\
\hline JDA Tailrace & $0.8 \pm 0.2$ & $1.9 \pm 0.1$ & 460 & 5.14 \\
\hline
\end{tabular}

Table 3.47. Median Hours, Rate, and Distance of Travel from Array $3 \mathrm{~J}$ to Array $1 T$ through the TDA Project in Spring. Values after the \pm signs are one-half 95\% confidence limits.

\begin{tabular}{|c|c|c|c|c||}
\hline Release Site & Time (hours) & Rate $\mathbf{( m / s )}$ & $\mathbf{n}$ & Distance $(\mathbf{k m})$ \\
\hline LGR Tailrace & $10.2 \pm 1.7$ & $1.0 \pm 0.03$ & 175 & 36.75 \\
\hline JDA Intake 9C & $12.8 \pm 0.4$ & $0.8 \pm 0.02$ & 241 & 36.75 \\
\hline JDA Front Roll & $12.2 \pm 4.3$ & $0.8 \pm 0.02$ & 299 & 36.75 \\
\hline JDA Tailrace & $12.3 \pm 0.4$ & $0.8 \pm 0.02$ & 301 & 36.75 \\
\hline
\end{tabular}




\subsubsection{TDA Releases}

We estimated travel time and rate for three parts of the passage journey through BON. First, we estimated the travel statistics for the entire trip from Array 3T above BON forebays and Boat Rock down to Array 1B in the tailwater (Table 3.48). Fish from LGR moved faster and took less time than other releases. Second, we estimated travel statistics for the first leg of the trip from Array 3T above Boat Rock to the point of detection for the three routes of passage. Times and rates were similar for spillway and B2CC-passed fish (mean time $=0.4$ hours), but there was an obvious delay until detection of fish passing through the JBS (mean time $=4.9$ hours; Table 3.49). Third, we estimated statistics from the point of passage detection down to Array $1 \mathrm{~B}$, and in most cases, travel time estimates did not differ based upon overlapping 95\% CIs (mean $=7.7$ hours; Table 3.50). The median rate of travel for LGR releases was lower than that of other releases passing through the B2CC and B2 JBS, although overlapping 95\% CIs suggest that differences were not significant.

Table 3.48. Median Hours, Rate, and Distance of Travel through BON (from Array $3 T$ to $1 B$ ) in Spring. Values after the \pm signs are one-half $95 \%$ confidence limits.

\begin{tabular}{|c|c|c|c|c||}
\hline Release Site & Time (hours) & Rate (m/s) & $\mathbf{n}$ & Distance (km) \\
\hline LGR Tailrace & $5.9 \pm 0.5$ & $1.3 \pm 0.05$ & 122 & 27.6 \\
\hline JDA Intake 9C & $6.7 \pm 1.5$ & $1.2 \pm 0.04$ & 225 & 27.6 \\
\hline JDA Front Roll & $6.7 \pm 1.4$ & $1.1 \pm 0.04$ & 251 & 27.6 \\
\hline JDA Tailrace & $6.5 \pm 0.7$ & $1.29 \pm 0.04$ & 243 & 27.6 \\
\hline TDA Tailrace & $7.0 \pm 1.3$ & $1.1 \pm 0.02$ & 557 & 27.6 \\
\hline
\end{tabular}

Table 3.49. Spring Median Hours, Rate, and Distance of Travel from Array $3 T$ Immediately above Boat Rock and BON Forebays to Specific Routes of Passage in Spring. Values after the \pm signs are one-half $95 \%$ confidence limits.

\begin{tabular}{|c|c|c|c|c|c||}
\hline Release Site & Route & Time (hours) & Rate (m/s) & $\mathbf{n}$ & $\begin{array}{c}\text { Distance } \\
(\mathbf{k m})\end{array}$ \\
\hline JDA Intake 9C & Array 3T to Spillway & $0.4 \pm 0.1$ & $0.8 \pm 0.18$ & 10 & 1.2 \\
\hline JDA Front Roll & Array 3T to Spillway & $0.4 \pm 0.1$ & $0.8 \pm 0.12$ & 25 & 1.2 \\
\hline JDA Tailrace & Array 3T to Spillway & $0.4 \pm 0.1$ & $0.8 \pm 0.13$ & 21 & 1.2 \\
\hline TDA Tailrace & Array 3T to Spillway & $0.4 \pm 0.1$ & $0.8 \pm 0.08$ & 75 & 1.2 \\
\hline LGR Tailrace & Array 3T to B2CC & $0.3 \pm 0.1$ & $1.2 \pm 0.21$ & 19 & 1.5 \\
\hline JDA Intake 9C & Array 3T to B2CC & $0.3 \pm 0.1$ & $1.1 \pm 0.16$ & 7 & 1.5 \\
\hline JDA Front Roll & Array 3T to B2CC & $0.3 \pm 0.04$ & $1.1 \pm 0.13$ & 8 & 1.5 \\
\hline JDA Tailrace & Array 3T to B2CC & $0.3 \pm 0.1$ & $1.2 \pm 0.13$ & 13 & 1.5 \\
\hline TDA Tailrace & Array 3T to B2CC & $0.4 \pm 0.1$ & $0.8 \pm 0.16$ & 28 & 1.5 \\
\hline LGR Tailrace & Array 3T to B2 JBS & $4.6 \pm 2.1$ & $0.1 \pm 0.06$ & 23 & 3.6 \\
\hline JDA Intake 9C & Array 3T to B2 JBS & $5.7 \pm 2.4$ & $0.1 \pm 0.05$ & 31 & 3.6 \\
\hline JDA Front Roll & Array 3T to B2 JBS & $7.1 \pm 4.6$ & $0.1 \pm 0.05$ & 26 & 3.6 \\
\hline JDA Tailrace & Array 3T to B2 JBS & $4.7 \pm 3.7$ & $0.1 \pm 0.06$ & 22 & 3.6 \\
\hline TDA Tailrace & Array 3T to B2 JBS & $2.7 \pm 1.5$ & $0.12 \pm 0.03$ & 61 & 3.6 \\
\hline
\end{tabular}


Table 3.50. Median Hours, Rate, and Distance of Travel from Detection at Specific Routes to Array 1B below BON in Spring. Values after the \pm signs are one-half $95 \%$ confidence limits.

\begin{tabular}{||c|c|c|c|r|c||}
\hline Release Site & Route & Time (hours) & Rate (m/s) & \multicolumn{1}{|c||}{} & Distance (km) \\
\hline JDA Intake 9C & Spillway to 1B & $6.2 \pm 2.2$ & $1.2 \pm 0.28$ & 6 & 26.4 \\
\hline JDA Front Roll & Spillway to 1B & $7.1 \pm 2.0$ & $1.0 \pm 0.15$ & 12 & 26.4 \\
\hline JDA Tailrace & Spillway to 1B & $7.2 \pm 1.6$ & $1.1 \pm 0.15$ & 14 & 26.4 \\
\hline TDA Tailrace & Spillway to 1B & $6.6 \pm 4.9$ & $1.1 \pm 0.08$ & 46 & 26.4 \\
\hline LGR Tailrace & B2CC to 1B & $7.7 \pm 0.2$ & $1.0 \pm 0.03$ & 7 & 26.2 \\
\hline JDA Intake 9C & B2CC to 1B & $8.2 \pm 3.7$ & $0.9 \pm 0.25$ & 5 & 26.2 \\
\hline JDA Front Roll & B2CC to 1B & $7.8 \pm 1.7$ & $0.9 \pm 0.14$ & 5 & 26.2 \\
\hline JDA Tailrace & B2CC to 1B & $10.1 \pm 3.2$ & $0.7 \pm 0.15$ & 8 & 26.2 \\
\hline TDA Tailrace & B2CC to 1B & $8.4 \pm 0.8$ & $0.9 \pm 0.06$ & 19 & 26.2 \\
\hline LGR Tailrace & B2JBS to 1B & $7.1 \pm 0.4$ & $1.0 \pm 0.05$ & 9 & 24.0 \\
\hline JDA Intake 9C & B2JBS to 1B & $7.5 \pm 0.4$ & $1.0 \pm 0.04$ & 31 & 24.0 \\
\hline JDA Front Roll & B2JBS to 1B & $8.5 \pm 2.3$ & $0.9 \pm 0.12$ & 12 & 24.0 \\
\hline JDA Tailrace & B2JBS to 1B & $7.5 \pm 0.5$ & $1.0 \pm 0.06$ & 12 & 24.0 \\
\hline TDA Tailrace & B2JBS to 1B & $8.1 \pm 0.3$ & $0.9 \pm 0.03$ & 36 & 24.0 \\
\hline
\end{tabular}

\subsubsection{BON Releases}

As smolts released in the SMF outfall passed downstream, they were detected on all BON arrays so we could calculate travel time and rate for fish traversing each reach below the BON Tailrace (Table 3.51). Based on median travel times from the tailrace, fish took about 7.8 hours to reach Array $1 \mathrm{~B}$, another 1.4 hours to reach Array 2B, and another 2.2 hours to reach Array 3B. The rate of travel was fastest for the long uppermost reach and decreased for each successive reach downstream.

Table 3.51. Median Hours, Rate, and Distance of Travel from the BON Tailrace to Array 1B, from Array $1 \mathrm{~B}$ to $2 \mathrm{~B}$, and from Array $2 \mathrm{~B}$ to $3 \mathrm{~B}$ in Spring. Values after the \pm signs are one-half $95 \%$ confidence limits.

\begin{tabular}{|c|c|c|c|c||}
\hline Array & Time (hours) & Rate $\mathbf{( m / s )}$ & $\mathbf{n}$ & Distance (km) \\
\hline 1B & $7.8 \pm 0.7$ & $0.9 \pm 0.02$ & 628 & 24.0 \\
\hline 2B & $1.4 \pm 0.3$ & $0.9 \pm 0.03$ & 470 & 4.8 \\
\hline 3B & $2.2 \pm 0.6$ & $1.3 \pm 0.04$ & 286 & 10.2 \\
\hline
\end{tabular}

\subsubsection{Pooled Releases}

Using all arrays throughout the projects, total cumulative travel time was then measured and results are as follows (Figure 3.28). 


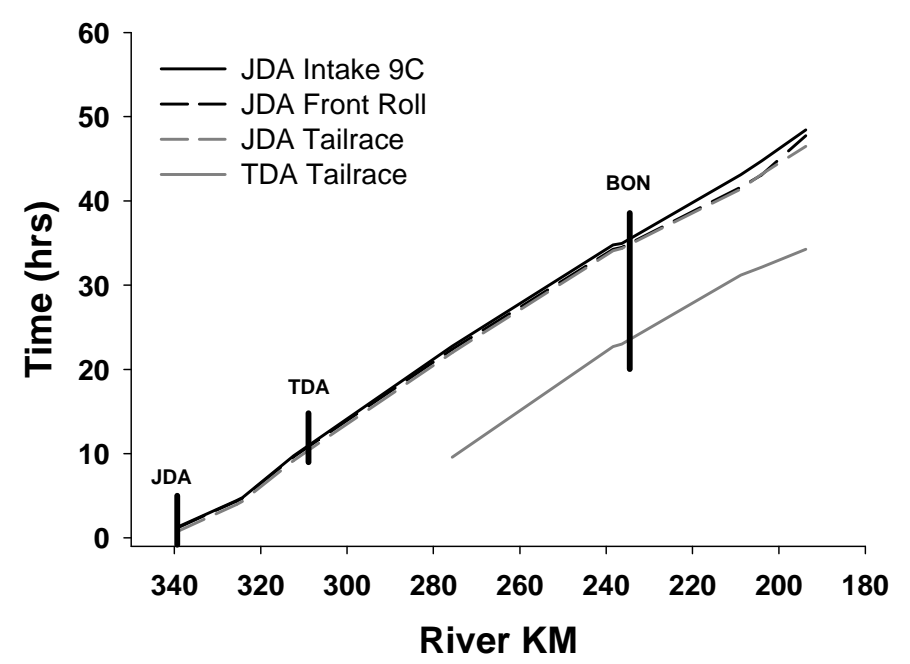

Figure 3.28. Median Time of Travel from Release Point through the Last Array in Spring 2006

\subsubsection{Summer}

\subsubsection{LGS Releases}

Subyearling Chinook salmon released in the LGS Tailrace as part of the Lower Monumental acoustic telemetry study had a median travel time of about 8.92 days to Array 1J, 9.92 days to Array 1T, and 11.2 days to Array 1B (Table 3.52). Rates of travel did not differ among the three reaches based on overlapping 95\% CIs.

Table 3.52. Median Hours, Rate, and Distance of Travel from LGS Tailrace Release to Primary Arrays Below Three Projects in Summer. Values after the \pm signs are one-half $95 \%$ confidence limits.

\begin{tabular}{|c|c|c|c|c|}
\hline To Array & Time (hours) & Rate (m/s) & $\mathbf{n}$ & Distance (km) \\
\hline $1 \mathrm{~J}$ & $213.8 \pm 10.1$ & $0.4 \pm 0.01$ & 361 & 303.4 \\
\hline 1T & $238.0 \pm 10.7$ & $0.4 \pm 0.01$ & 302 & 353.4 \\
\hline 1B & $268.9 \pm 10.7$ & $0.4 \pm 0.03$ & 149 & 429.2 \\
\hline
\end{tabular}

\subsubsection{JDA Releases}

The median travel time of JDA Tailrace-released fish to Array $1 \mathrm{~J}$ was only 4.7 hours, and the speed of fish traveling from the JDA Tailrace to Array $1 \mathrm{~J}$ was faster than that of fish moving from Array $3 \mathrm{~J}$ above TDA downstream to Array 1T in the TDA Tailwater (Table 3.53 and Table 3.54).

Table 3.53. Median Hours, Rate, and Distance of Travel from the JDA Tailrace Release Site to Array $1 \mathrm{~J}$ in Summer. Values after the \pm signs are one-half $95 \%$ confidence limits.

\begin{tabular}{|c|c|c|c|c|}
\hline Release Site & Time (hours) & Rate $\mathbf{( m / s )}$ & $\mathbf{n}$ & Distance $\mathbf{( k m )}$ \\
\hline JDA Tailrace & $4.7 \pm 0.2$ & $1.1 \pm 0.02$ & 296 & 18.8 \\
\hline
\end{tabular}


Table 3.54. Median Hours, Rate, and Distance of Travel from Array 3J through TDA to Array $1 T$ in Summer. Values after the \pm signs are one-half $95 \%$ confidence limits.

\begin{tabular}{||c|c|c|c|c||}
\hline \hline Release Site & Time (hours) & Rate $\mathbf{( m / s )}$ & $\mathbf{n}$ & Distance $(\mathbf{k m})$ \\
\hline LGS Tailrace & $13.2 \pm 0.8$ & $0.8 \pm 0.02$ & 286 & 36.8 \\
\hline JDA Tailrace & $14.4 \pm 1.7$ & $0.7 \pm 0.02$ & 232 & 36.8 \\
\hline
\end{tabular}

\subsubsection{TDA Releases}

We estimated travel time and rate for three parts of the passage journey through BON. First, we estimated the travel statistics for the entire trip from Array 3T above BON forebays and Boat Rock down to Array 1B in the tailwater for each of three summer releases (Table 3.55). Based upon overlap of 95\% CIs, there were no differences in median travel times to Array 1B (7.8-8.6 hours), but rates may have been higher for LGS fish than for TDA fish. Second, we estimated travel statistics for the first leg of the trip from Array $3 \mathrm{~T}$ above Boat Rock to the point of detection for three routes of passage. Times and rates were similar for spillway- and B2CC-passed fish (0.3-0.6 hours; mean $=0.5$ hours), but travel rates were significantly slower $(0.09 \mathrm{~m} / \mathrm{s})$ and travel times longer (4.3 hours) for fish passing the B2 JBS than for fish passing the spillway or B2CC (Table 3.56). Third, we estimated statistics from the point of passage detection down to Array 1B, and spillway-passed fish usually reached Array 1B in less time than fish passing the B2CC or B2 JBS (Table 3.57). Rates of travel for spillway fish usually were higher than for fish passed through the B2CC and B2 JBS, although LGS fish passing through the latter routes were just as fast based upon overlapping 95\% CIs.

Table 3.55. Summer Median Time and Rate of Travel through BON (TDA3 to BON1). Values after the \pm signs are one-half $95 \%$ confidence limits.

\begin{tabular}{|c|c|c|c|c|}
\hline Release Site & Time (hours) & Rate $\mathbf{( m / s )}$ & \multicolumn{1}{|c|}{$\mathbf{n}$} & Distance $(\mathbf{k m})$ \\
\hline LGS Tailrace & $7.8 \pm 0.9$ & $1.0 \pm 0.04$ & 143 & 27.6 \\
\hline JDA Tailrace & $8.1 \pm 0.5$ & $0.9 \pm 0.04$ & 156 & 27.6 \\
\hline TDA Tailrace & $8.6 \pm 0.8$ & $0.9 \pm 0.01$ & 1,428 & 27.6 \\
\hline
\end{tabular}

Table 3.56. Summer Median Time and Rate of Travel to Specific Routes at BON. Values after the \pm signs are one-half $95 \%$ confidence limits.

\begin{tabular}{||c|c|c|c|r|c||}
\hline Release Site & Route & Time (hours) & Rate $\mathbf{( m / s )}$ & \multicolumn{1}{|c||}{} & Distance (km) \\
\hline LGS Tailrace & $\begin{array}{c}\text { Array 3T to } \\
\text { Spillway }\end{array}$ & $0.6 \pm 0.3$ & $0.5 \pm 0.18$ & 86 & 1.2 \\
\hline JDA Tailrace & $\begin{array}{c}\text { Array 3T to } \\
\text { Spillway }\end{array}$ & $0.6 \pm 0.1$ & $0.6 \pm 0.09$ & 46 & 1.2 \\
\hline TDA Tailrace & $\begin{array}{c}\text { Array 3T to } \\
\text { Spillway }\end{array}$ & $0.6 \pm 0.1$ & $0.5 \pm 0.08$ & 574 & 1.2 \\
\hline LGS Tailrace & Array 3T to B2CC & $0.4 \pm 0.1$ & $0.8 \pm 0.17$ & 16 & 1.5 \\
\hline JDA Tailrace & Array 3T to B2CC & $0.3 \pm 0.1$ & $1.1 \pm 0.30$ & 3 & 1.5 \\
\hline TDA Tailrace & Array 3T to B2CC & $0.5 \pm 0.3$ & $0.7 \pm 0.09$ & 72 & 1.5 \\
\hline LGS Tailrace & $\begin{array}{c}\text { Array 3T to B2 } \\
\text { JBS }\end{array}$ & $6.5 \pm 9.2$ & $0.1 \pm 0.06$ & 12 & 3.6 \\
\hline JDA Tailrace & $\begin{array}{c}\text { Array 3T to B2 } \\
\text { JBS }\end{array}$ & $3.5 \pm 2.7$ & $0.1 \pm 0.04$ & 31 & 3.6 \\
\hline TDA Tailrace & $\begin{array}{c}\text { Array 3T to B2 } \\
\text { JBS }\end{array}$ & $2.9 \pm 1.0$ & $0.1 \pm 0.02$ & 146 & 3.6 \\
\hline
\end{tabular}


Table 3.57. Summer Median Time and Rate of Travel through Specific Routes at Bonneville Dam Downstream to Array 1B. Values after the \pm signs are one-half $95 \%$ confidence limits.

\begin{tabular}{|c|c|c|c|r|c|}
\hline \hline Release Site & Route & Time (hours) & Rate (m/s) & \multicolumn{1}{c|}{$\mathbf{~}$} & Distance (km) \\
\hline LGS Tailrace & Spillway to 1B & $7.4 \pm 0.7$ & $1.0 \pm 0.08$ & 44 & 26.4 \\
\hline JDA Tailrace & Spillway to 1B & $7.2 \pm 0.4$ & $1.0 \pm 0.05$ & 31 & 26.4 \\
\hline TDA Tailrace & Spillway to 1B & $7.7 \pm 2.8$ & $1.0 \pm 0.02$ & 423 & 26.4 \\
\hline LGS Tailrace & B2CC to 1B & $8.5 \pm 0.7$ & $0.9 \pm 0.08$ & 9 & 26.2 \\
\hline JDA Tailrace & B2CC to 1B & $9.5 \pm 1.1$ & $0.8 \pm 0.09$ & 2 & 26.2 \\
\hline TDA Tailrace & B2CC to 1B & $9.6 \pm 0.4$ & $0.8 \pm 0.03$ & 63 & 26.2 \\
\hline LGS Tailrace & B2JBS to 1B & $7.8 \pm 0.6$ & $0.9 \pm 0.07$ & 6 & 24.0 \\
\hline JDA Tailrace & B2JBS to 1B & $8.6 \pm 0.8$ & $0.9 \pm 0.05$ & 21 & 24.0 \\
\hline TDA Tailrace & B2JBS to 1B & $9.2 \pm 0.3$ & $0.8 \pm 0.03$ & 114 & 24.0 \\
\hline BON Tailrace & B2JBS to 1B & $8.4 \pm 0.1$ & $0.8 \pm 0.01$ & 1,236 & 24.0 \\
\hline \hline
\end{tabular}

\subsubsection{BON Releases}

Travel times for subyearling Chinook salmon tagged and released through the BON SMF outfall pipe to Arrays 1B and from Array $1 \mathrm{~B}$ to $2 \mathrm{~B}$ are presented in Table 3.58. It took these fish about 8.4 hours to reach Array 1B, and this was very similar to the time it took for B2 JBS-detected fish to reach the same array (see Table 3.56). The rate of travel to Array 1B was similar to rates for fish passing through the B2CC, but slower than spillway-passed fish. The rate of travel from Array 1B to Array 2B was slower than the rate of travel from the tailrace to Array 1B.

Table 3.58. Travel Time for Subyearlings from the BON Smolt Monitoring Facility to Array $1 \mathrm{~B}$ and from 1B to $2 B$. Values after the \pm signs are one-half $95 \%$ confidence limits.

\begin{tabular}{|c|c|c|c||}
\hline Time (hours) & Rate $\mathbf{( m / s )}$ & $\mathbf{n}$ & Distance $\mathbf{( k m )}$ \\
\hline $8.4 \pm 0.1$ & $0.8 \pm 0.01$ & 1,525 & 24.0 \\
\hline $1.5 \pm 0.1$ & $0.9 \pm 0.01$ & 1,236 & 4.8 \\
\hline
\end{tabular}

\subsubsection{Pooled Releases}

Using array detection data, we plotted cumulative travel time for fish released from all projects in summer and calculated a combined travel time by river mile (Figure 3.29). 


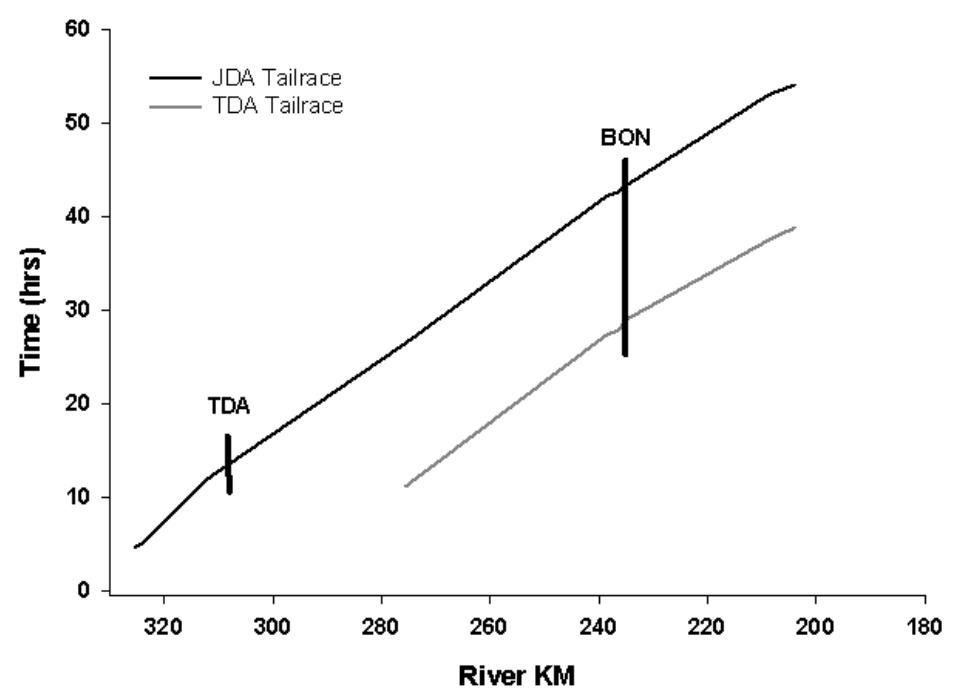

Figure 3.29. Median Time of Travel through All Reaches

\subsection{Using Time of Travel to Lag Paired Releases in Future Studies}

We estimated the lag time needed between upstream and downstream paired releases to maximize mixing of treatment and control fish in future studies. We calculated mean travel times from point and time of release from JDA, TDA, and BON to the primary array downstream of each dam, regressed those estimates on Columbia River discharge from each dam, and used the regression equations to predict a mean travel time as a function of discharge for all pairs of release locations (e.g., Figure 3.30 for spring and Figure 3.31 for summer). When regression slopes did not differ from zero, we used an average travel time over the range of river discharge. We subtracted predicted travel times for the downstream release from that of the upstream release at various river discharges to obtain an equation describing the required time lag as a function of river discharge. The equations can be used to calculate required lag times from expected river discharge. For JDA releases at the Turbine Intake and Front Roll, the lag time was short (12 to 17 minutes) and increased with discharge, but the order of releases was different for discharges below and above 345,000 cfs (Figure 3.32). Lag times ranged from 3 to 36 minutes for releases from the turbine and tailrace and from 18 to 26 minutes for releases from the front roll and the tailrace, but they consistently increased with increasing discharge (Figure 3.32). Lag times consistently decreased as river discharge increased for paired releases over greater distances such as the JDA and TDA Tailrace releases (Figure 3.33) and for TDA and BON Tailrace releases (Figure 3.34). 

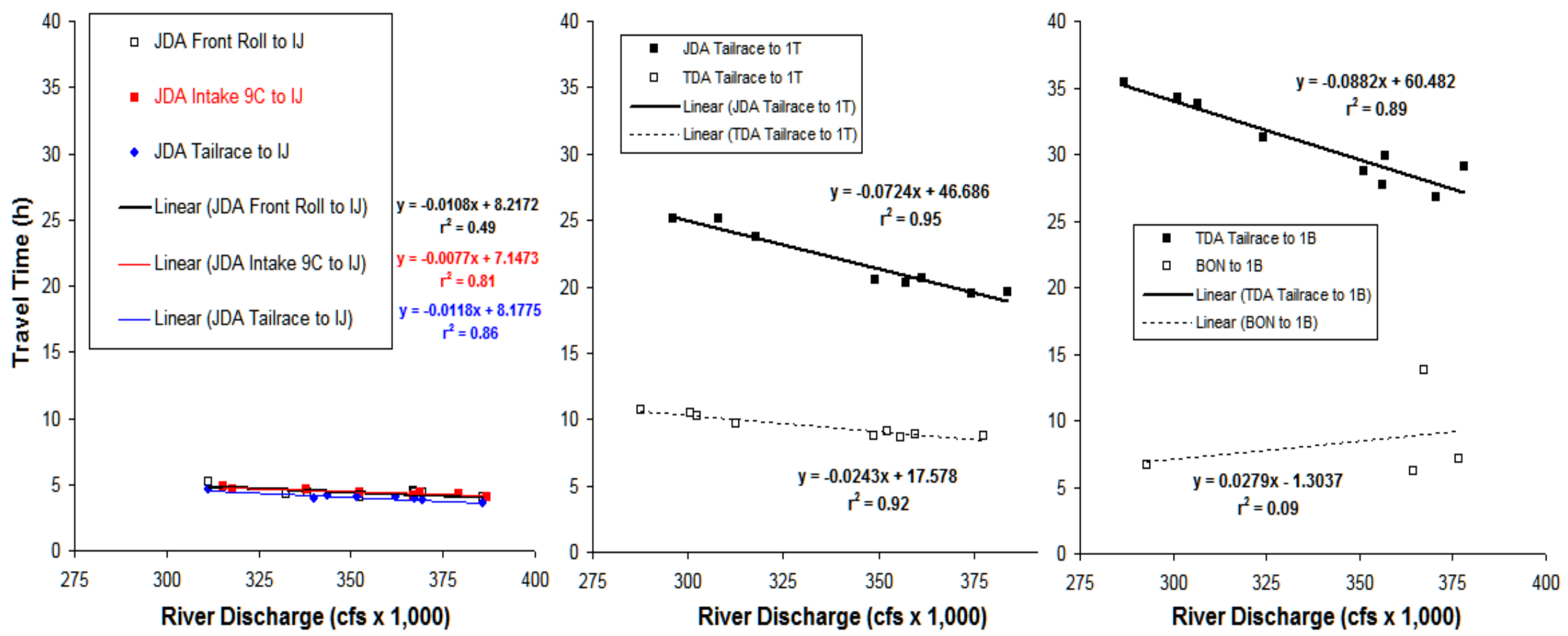

Figure 3.30. Median Travel Time as a Function of River Discharge for JDA Releases to Array 1J (Left), JDA and TDA Tailrace Releases to Array $1 T$ (Center), and TDA and BON Tailrace Releases to Array 1B (Right) in Spring 

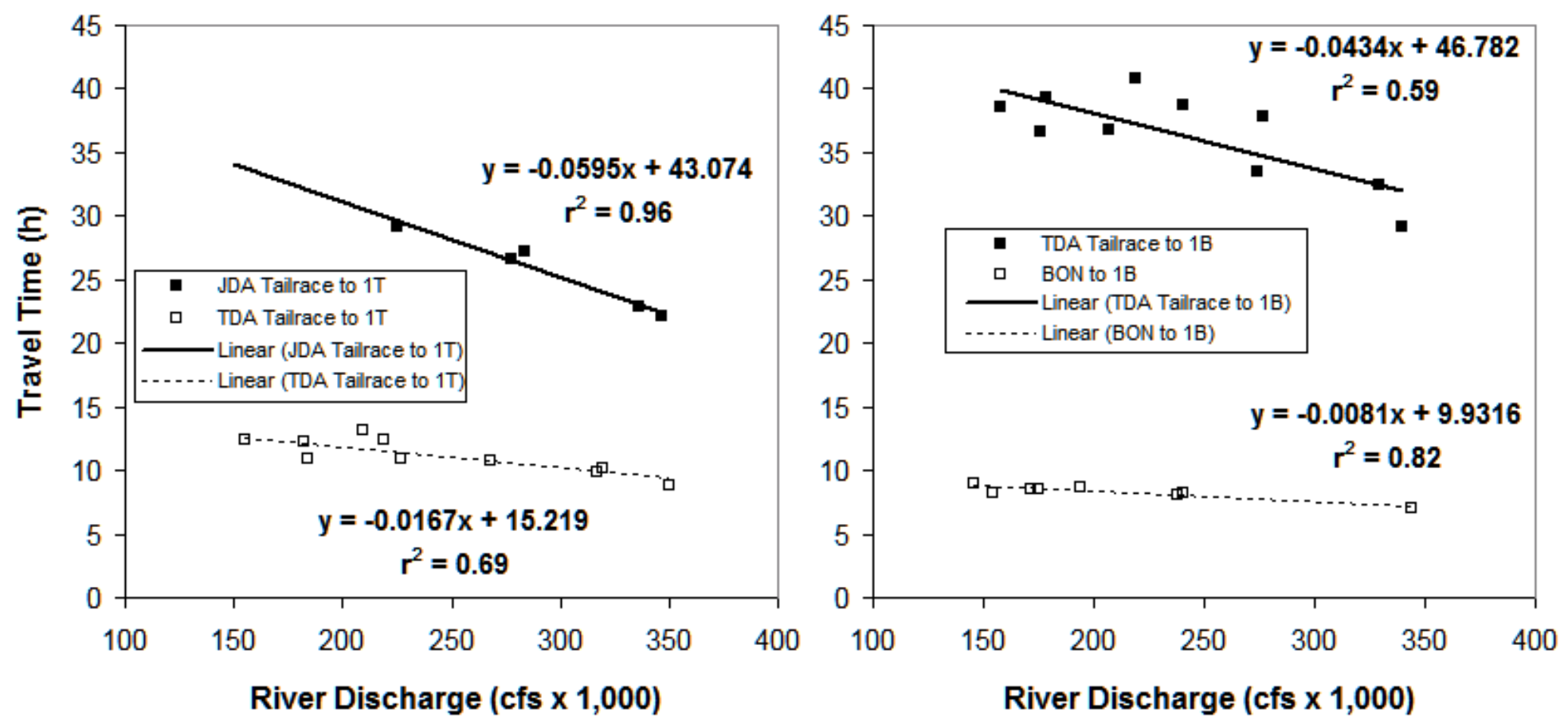

Figure 3.31. Median Travel Time as a Function of River Discharge for JDA and TDA Tailrace Releases to Array 1T (Left), and TDA and BON Tailrace Releases to Array 1B (Right) in Summer 

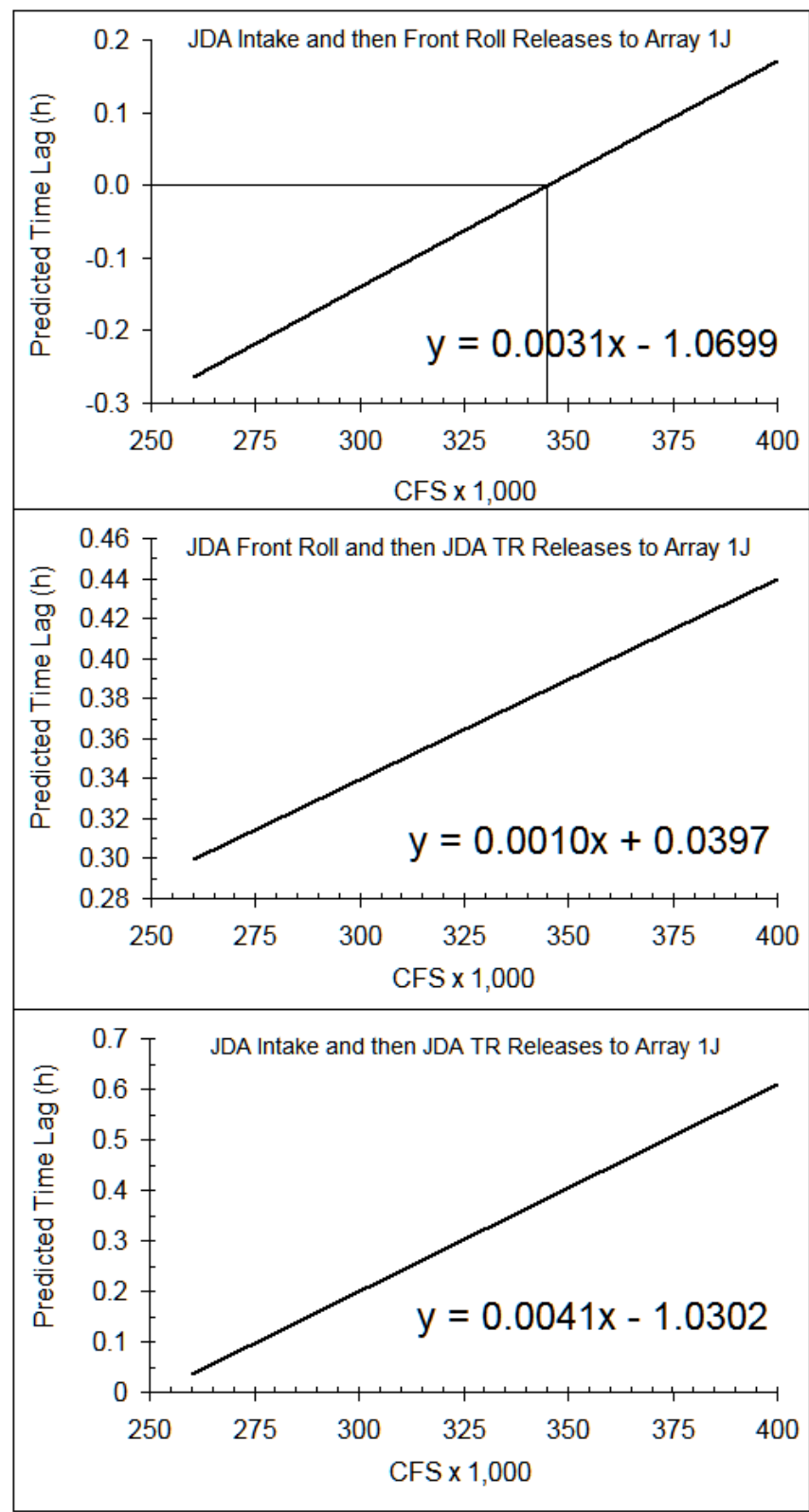

Figure 3.32. Lag Time Required Between Pairs of Releases of Yearling Chinook Salmon from JDA as a Function of River Discharge in Spring 


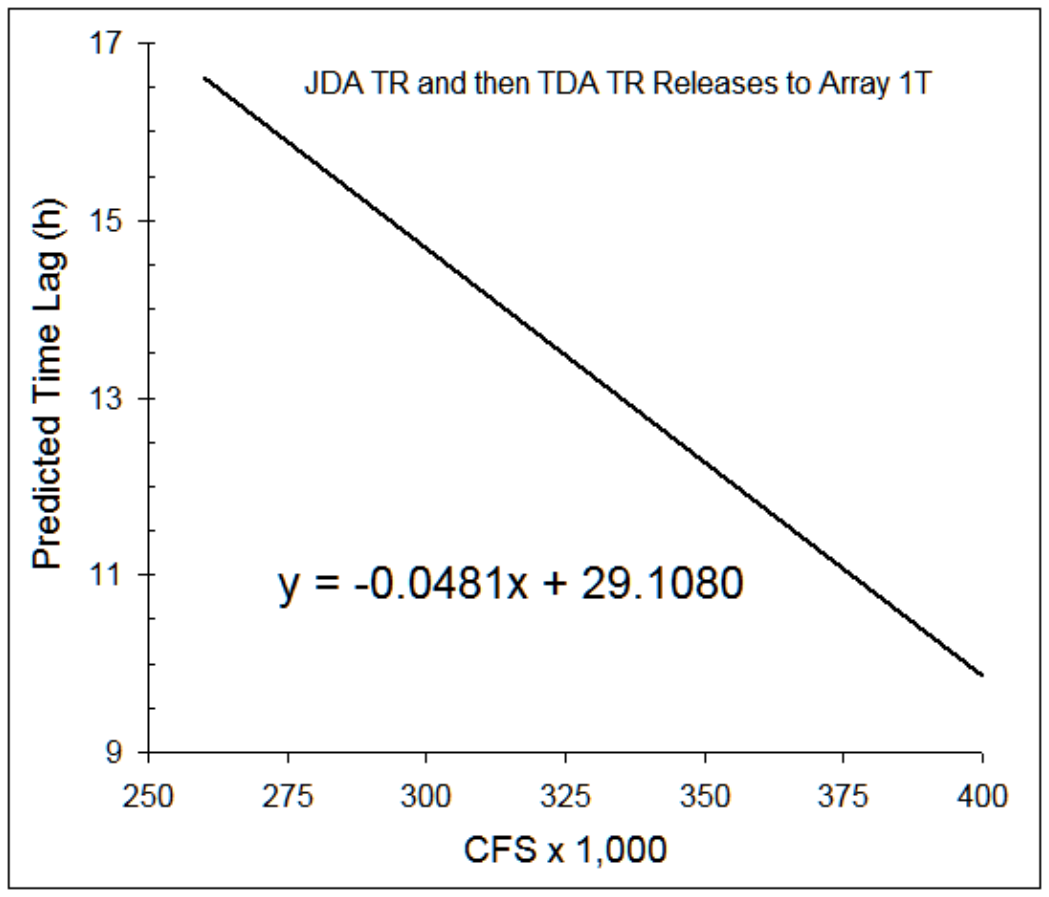

Figure 3.33. Lag Time Required Between Paired Releases of Yearling Chinook Salmon from JDA and TDA Tailrace (TR) as a Function of River Discharge in Spring

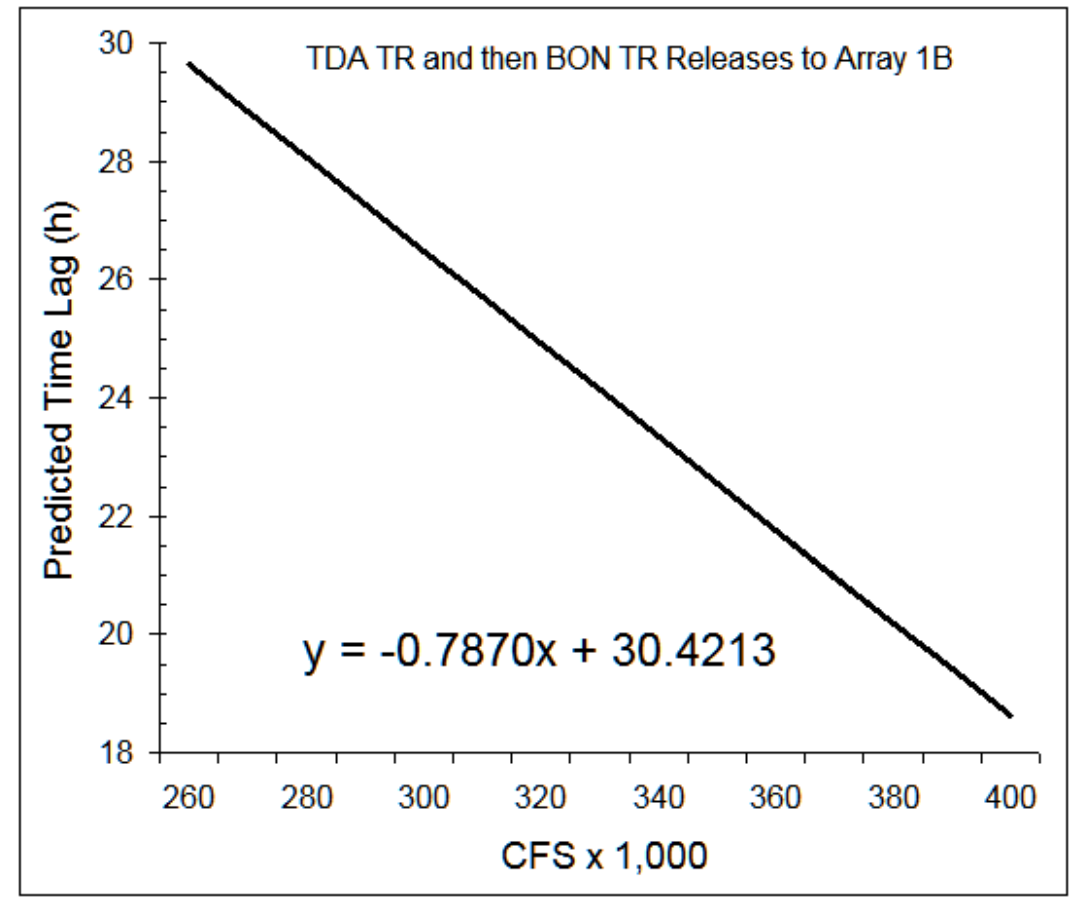

Figure 3.34. Lag Time Required Between Paired Releases of Yearling Chinook Salmon from TDA and BON Tailrace (TR) as a Function of River Discharge in Spring.

Lower river discharges were observed in summer than in spring, so relations describing lag times between paired releases from JDA and TDA (Figure 3.35) and from TDA and BON (Figure 3.36) in summer were different from those in spring (Figures 3.33 and 3.34 above). 


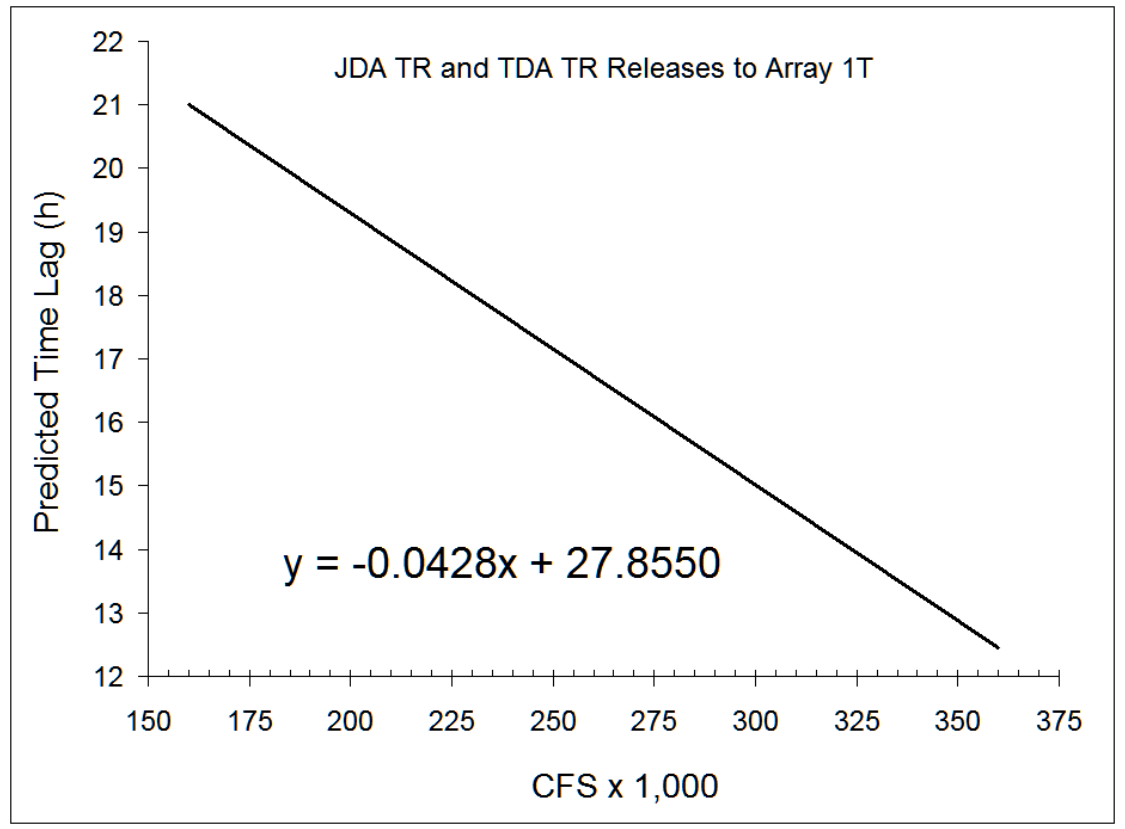

Figure 3.35. Lag Time Required Between Paired Releases of Subyearling Chinook Salmon from JDA and TDA Tailrace (TR) as a Function of River Discharge in Summer

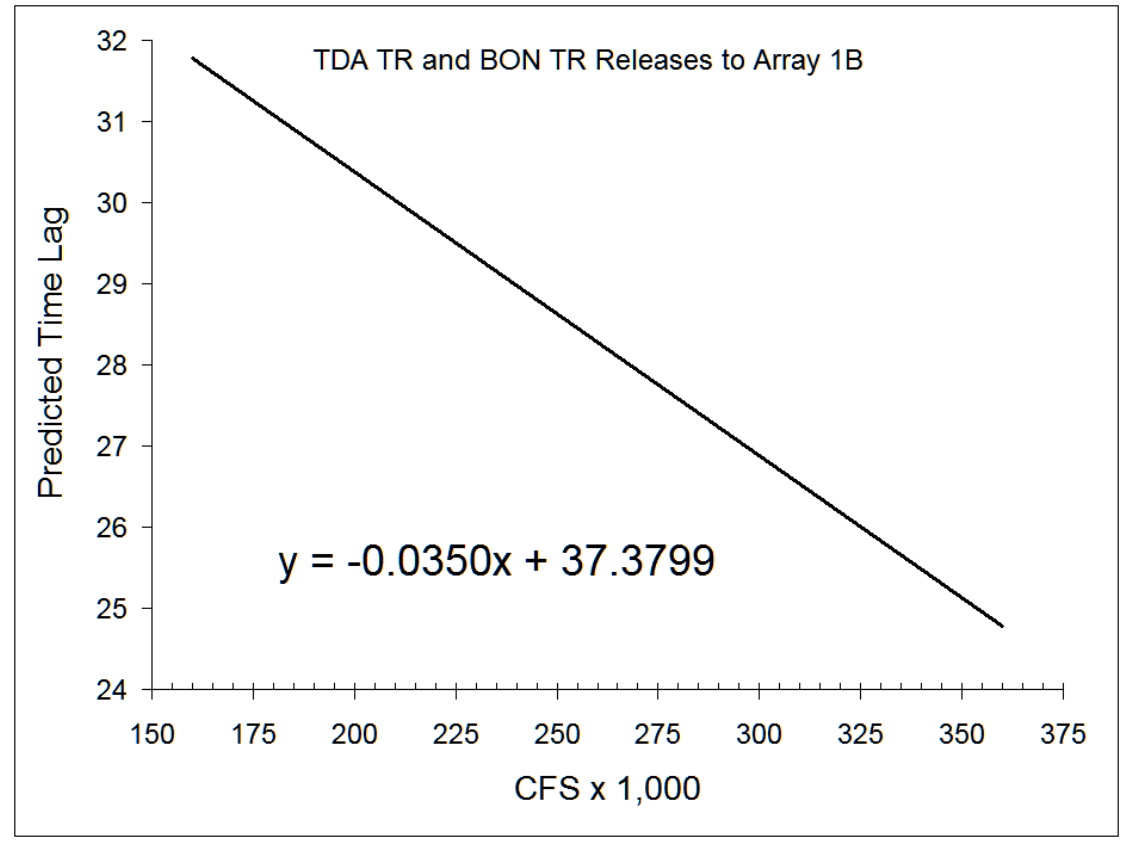

Figure 3.36. Lag Time Required Between Paired Releases of Subyearling Chinook Salmon from TDA and BON Tailrace (TR) as a Function of River Discharge in Summer

\subsection{Diel Distribution}

Fish arrived at BON during all hours of the day, although most fish from the JDA releases arrived at the BON forebay from 0000 to 1200 hours (Figure 3.37), whereas most fish from TDA releases arrived between 1000 and 2300 hours (Figure 3.38). This was true even when we examined the data by week 
within seasons. Between the two releases, the diel distribution of arrivals cover all hours relatively uniformly.

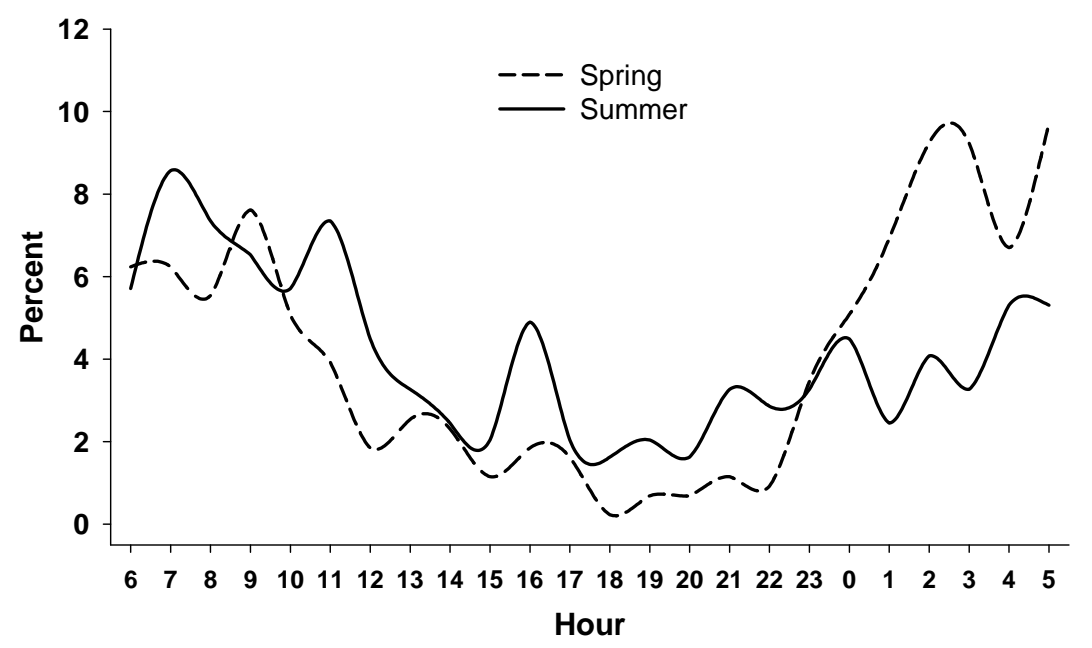

Figure 3.37. Diel Distribution of Tagged Fish Arriving at TDA3 (1.4 rkm above BON spillway) for Spring and Summer from the JDA Tailrace Release

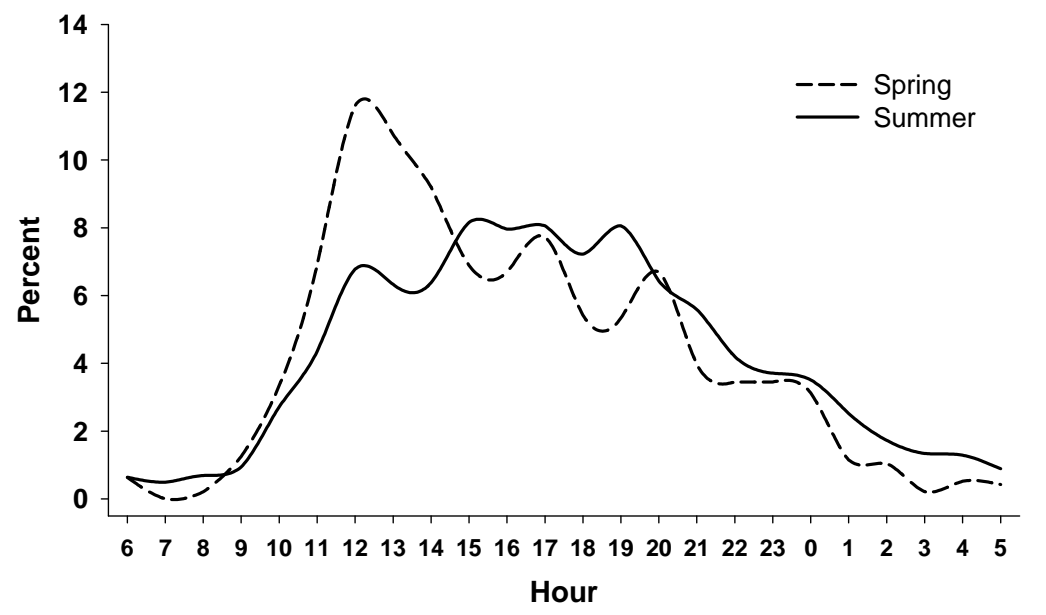

Figure 3.38. Diel Distribution of Tagged Fish Arriving at TDA3 (1.4 rkm above BON Spillway) in Spring and Summer, from the TDA Tailrace Release.

\subsection{Cross Channel Distribution}

Detections of tagged fish on downstream arrays were compiled to examine the distribution of passage through study cross sections where arrays were located (Figure 3.39). The cross-channel detection distributions show the percent of code detections weighted by the number of days each node was deployed and functional. Columns of plots from left to right are for the first, second, and third array in each tailwater including the JDA Tailwater (top row), TDA Tailwater (middle row), and BON Tailwater (bottom row). Spring and summer lateral distributions usually were similar, and there was no evidence of 
a shift of migrants to near-shore nodes in summer. There appeared to be a skew in the lateral distributions toward the Oregon shore at Array $1 \mathrm{~T}$ and perhaps toward the Washington shore at Array 3B, but other complete distributions appeared to be detected most frequently on mid-river nodes $(1 \mathrm{~J}, 1 \mathrm{~B}, 2 \mathrm{~T}, 2 \mathrm{~B}$, and 3T). Nodes most likely to detect fish passing behind islands on the BON primary (Node 1 downstream of the Sand Island side channel) and BON secondary (Node 4 downstream of the Miller Island side channel) had the lowest detection percentages each season. However, Node 4 at the upstream entrance to Camas Slough behind Lady Island had among the highest percent detection each season on Array 3B.

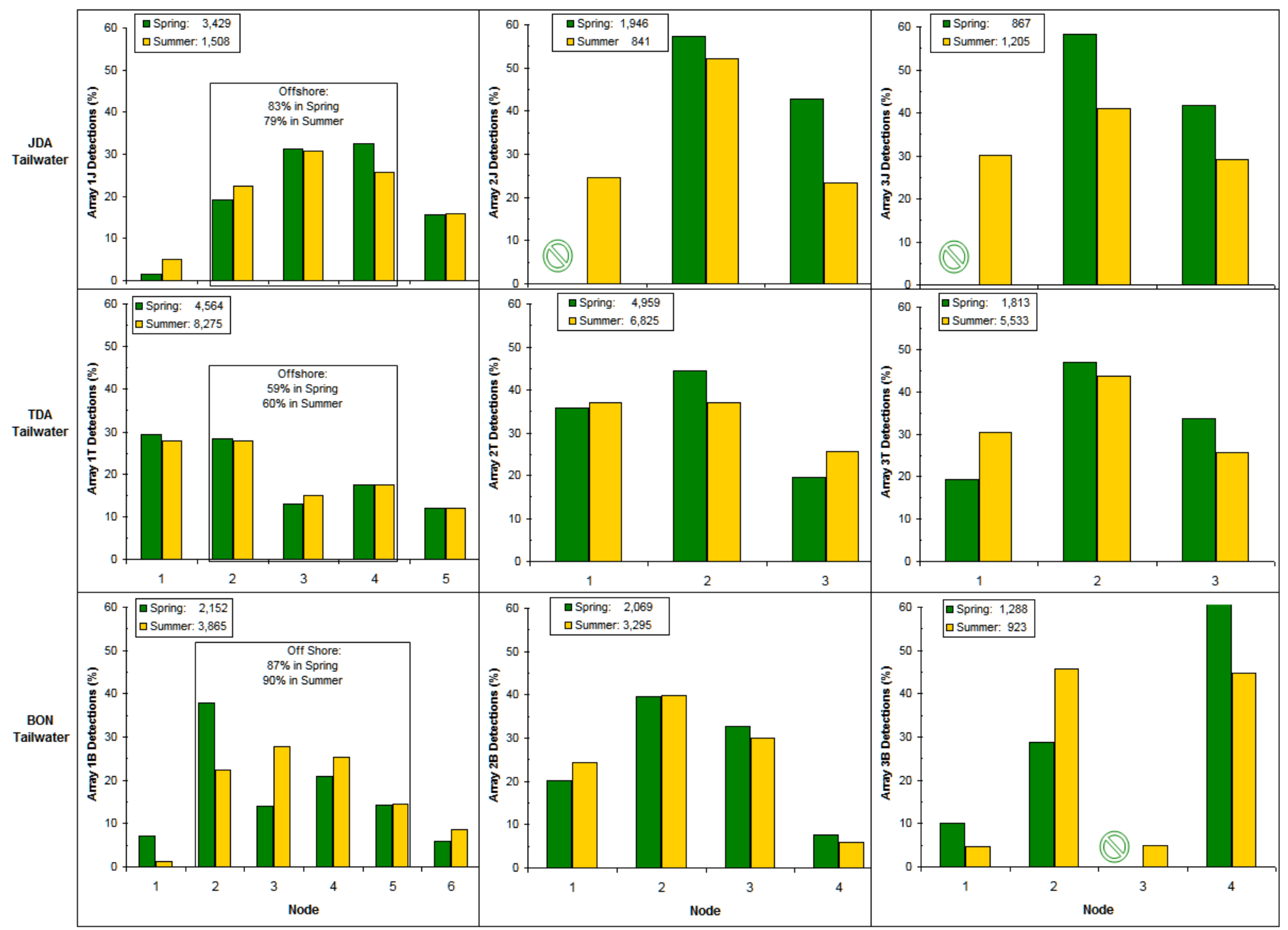

Figure 3.39. Cross Channel Distribution of Detections at Each Survival Array in the JDA Tailwater (top row), TDA Tailwater (middle row), and BON Tailwater (bottom row). Autonomous nodes detecting tags are numbered consecutively and represent locations from the Oregon to the Washington Shore. Each bar represents the percent of detections by node adjusted for the number of days each node was deployed or functional.

During the last week of spring and all of summer, the BON spillway was outfitted with five fixed hydrophones attached to piers between spill bays 1 and 2, 5 and 6, 9 and 10,13 and 14, and 17 and 18, and there were four autonomous nodes deployed in the spillway forebay within $150 \mathrm{ft}$ of the structure. 
We examined the distribution of detections on the nine nodes and made a crude histogram of detections relative to the length of the spillway (Figure 3.40). The distribution includes multiple detections and does not provide information about where tagged fish passed the spillway.

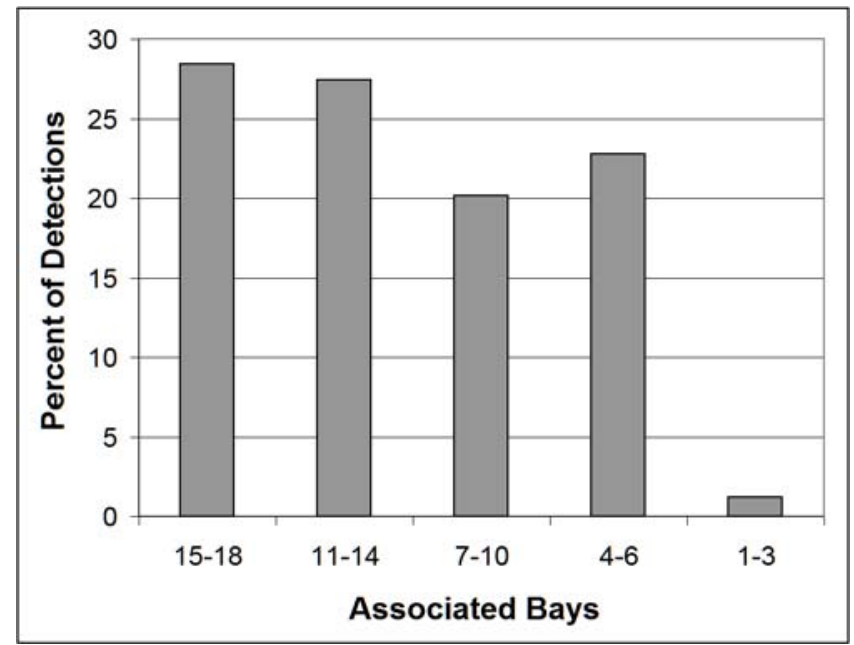

Figure 3.40. Distribution of Detections at the BON Spillway

\subsection{Physical Factors Affecting Array Detection Probabilities}

In order of significance, array detection probabilities were negatively correlated with river width, mean offshore distance to first nodes on either side of the river, and mean inter-node distance, and they were positively correlated with node density, and mean depth (Table 3.59). Inter-node spacing was calculated as sampled river width divided by the mean number of functional nodes, and the latter was weighted by the time that each node was functional. In short, high inter-node distances were realized not planned. There were no significant correlations of detection probabilities with the mean number of nodes nor with the standard deviation in depth. Plots of these relations are shown in Figure 3.41. 
Table 3.59. Input Data, Simple Statistics, and Pearson Correlation Statistics for Physical Variables Affecting Detection Probabilities in 2006.

\begin{tabular}{|l|l|r|r|r|r|r|r|r|r||}
\hline \multicolumn{1}{|c|}{ SEASON } & ARRAY & $\begin{array}{c}\text { Mean } \\
\text { Depth }\end{array}$ & $\begin{array}{c}\text { SE } \\
\text { Depth } \\
\mathbf{( m )}\end{array}$ & $\begin{array}{c}\text { River } \\
\text { Width } \\
\mathbf{( K m})\end{array}$ & $\begin{array}{c}\text { Mean } \\
\text { Number } \\
\text { of } \\
\text { Nodes }\end{array}$ & $\begin{array}{c}\text { Node } \\
\text { Density } \\
\text { (Nodes } \\
\text { IKm) }\end{array}$ & $\begin{array}{c}\text { Inter- } \\
\text { Node } \\
\text { Distance } \\
(\mathbf{m})\end{array}$ & $\begin{array}{c}\text { Mean } \\
\text { Offshore } \\
\text { Distance } \\
\mathbf{( m )}\end{array}$ & $\begin{array}{c}\text { Mean } \\
\text { Detection } \\
\text { Probability }\end{array}$ \\
\hline Spring & 1J & 16.2 & 3.7 & 0.7 & 5.00 & 7.02 & 142 & 71 & 0.9660 \\
\hline Spring & 2J & 13.9 & 3.4 & 0.7 & 2.00 & 2.83 & 354 & 125 & 0.9755 \\
\hline Spring & JJ & 20.1 & 4.9 & 0.6 & 2.00 & 3.15 & 317 & 100 & 0.8174 \\
\hline Spring & 1T & 16.7 & 12.8 & 0.5 & 4.00 & 7.72 & 130 & 65 & 0.9083 \\
\hline Spring & 2T & 18.2 & 4.6 & 0.3 & 2.80 & 9.33 & 107 & 54 & 0.9929 \\
\hline Spring & 3T & 18.3 & 1.8 & 0.3 & 2.40 & 7.27 & 138 & 69 & 0.9710 \\
\hline Spring & 1B & 8.6 & 4.8 & 1.2 & 5.67 & 4.91 & 204 & 102 & 0.6346 \\
\hline Spring & 2B & 13.5 & 6.1 & 1.1 & 4.00 & 3.61 & 277 & 139 & 0.7110 \\
\hline Spring & 3B & 13.3 & 3.6 & 1.0 & 2.67 & 2.58 & 388 & 194 & 0.4370 \\
\hline Summer & 1J & 14.6 & 3.7 & 0.7 & 4.81 & 6.76 & 148 & 74 & 0.8880 \\
\hline Summer & 2J & 12.4 & 3.4 & 0.7 & 2.88 & 4.07 & 245 & 60 & 1.0000 \\
\hline Summer & 3J & 18.6 & 4.9 & 0.6 & 2.88 & 4.54 & 220 & 48 & 0.9849 \\
\hline Summer & 1T & 16.2 & 11.6 & 0.5 & 4.88 & 9.42 & 106 & 53 & 0.9766 \\
\hline Summer & 2T & 16.7 & 4.6 & 0.3 & 3.00 & 10.00 & 100 & 50 & 1.0000 \\
\hline Summer & 3T & 16.8 & 1.8 & 0.3 & 2.25 & 6.82 & 147 & 73 & 1.0000 \\
\hline Summer & 1B & 7.4 & 4.3 & 1.2 & 5.75 & 4.98 & 201 & 100 & 0.7832 \\
\hline Summer & 2B & 11.9 & 6.1 & 1.1 & 2.31 & 2.09 & 479 & 240 & 0.7394 \\
\hline
\end{tabular}

\begin{tabular}{||c|c|c||c|c||l|l|l||}
\hline \hline \multicolumn{7}{||c||}{ Simple Statistics } \\
\hline \hline Variable & N & Mean & SE & Sum & Minimum & Maximum & \multicolumn{1}{||}{ Label } \\
\hline \hline DP & 17 & 0.8698 & 0.1617 & 14.7859 & 0.4370 & 1.0000 & Mean Detection Probability \\
\hline \hline X_Z_m & 17 & 14.91749 & 3.47727 & 253.59726 & 7.37482 & 20.14716 & Mean Depth (m) \\
\hline \hline STD_Z_m & 17 & 5.06257 & 2.94266 & 86.06369 & 1.78588 & 12.76355 & SE Depth (m) \\
\hline Width_km & 17 & 0.70371 & 0.30904 & 11.96300 & 0.30000 & 1.15500 & River Width (Km) \\
\hline \hline X_Nodes & 17 & 3.48841 & 1.29949 & 59.30300 & 2.00000 & 5.75000 & Mean Number of Nodes \\
\hline \hline Nodes_Km & 17 & 5.71176 & 2.53953 & 97.10000 & 2.09000 & 10.00000 & Node Density (Nodes / Km) \\
\hline Space_m & 17 & 217.75000 & 111.39770 & 3702 & 100.00000 & 479.03000 & Inter-node Distance (m) \\
\hline Offshore_m & 17 & 95.11588 & 53.32725 & 1617 & 48.46000 & 239.52000 & Mean Offshore Distance (m) \\
\hline \hline
\end{tabular}




\begin{tabular}{||c|l|l||l|l|l||l|l|}
\hline \hline \multicolumn{7}{|c|}{ Pearson Correlation Coefficients; N = 17; Prob > |r| under H0: Rho=0 } \\
\hline $\begin{array}{c}\text { Variable } \\
\text { Coef. }\end{array}$ & Width_km & Offshore_m & Space_m & Nodes_Km & X_Z_m & X_Nodes & STD_Z_m \\
P & -0.78041 & -0.74197 & -0.58771 & 0.58124 & 0.52399 & -0.17649 & 0.00485 \\
& 0.0002 & 0.0006 & 0.0131 & 0.0144 & 0.0309 & 0.4980 & 0.9853 \\
\hline \hline
\end{tabular}
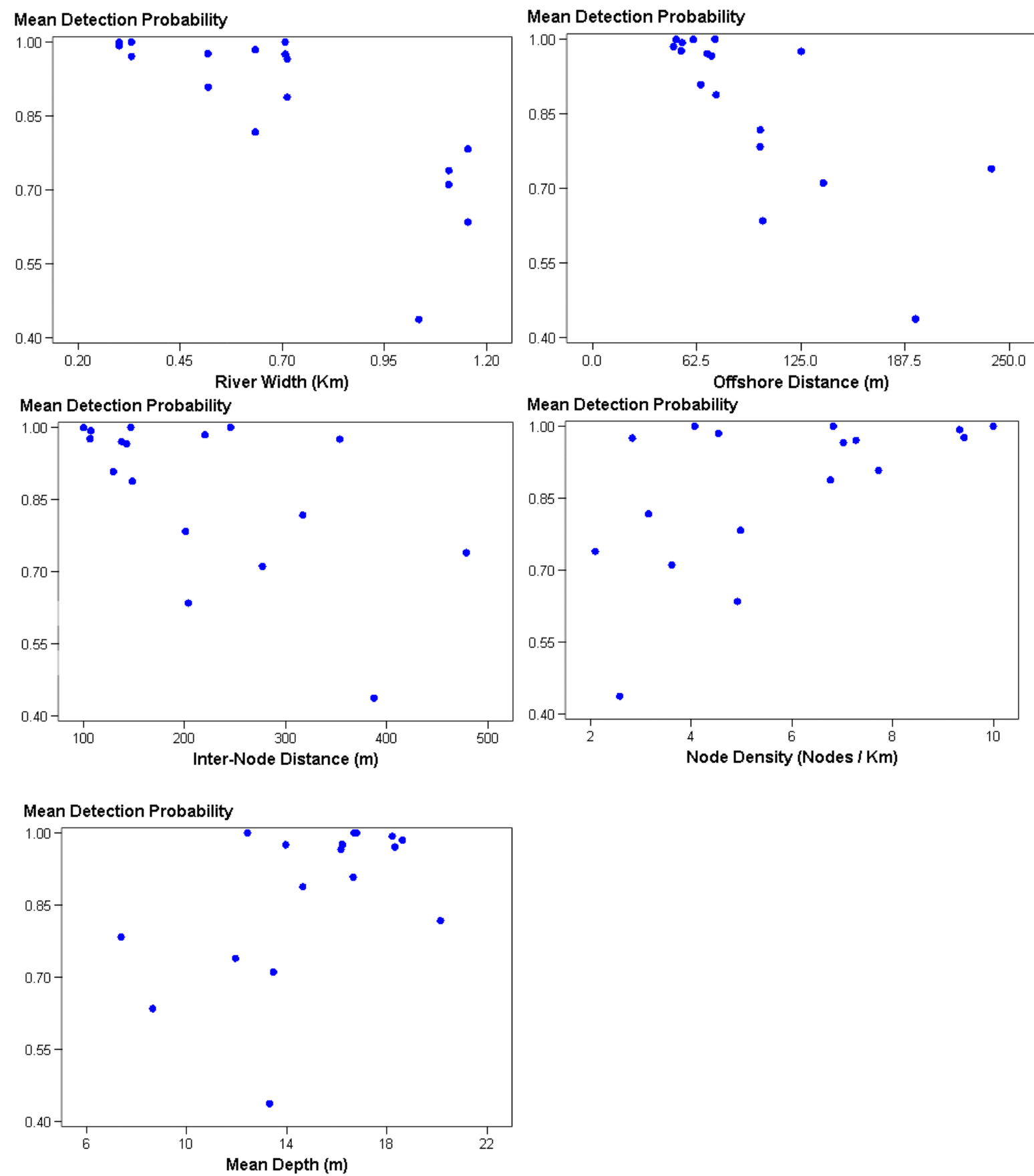

Figure 3.41. Scatter Plot of Mean Detection Probability as a Function of Physical Factors that Affect Array Performance 
Arrays in the JDA and TDA Tailwaters had a higher percentage of simultaneous detections on multiple nodes than did arrays in the BON Tailwater, where single-node detections predominated (Figure 3.42). The percent of multiple-node detections was higher than that of single-node detections on arrays $1 \mathrm{~J}, 3 \mathrm{~J}, 1 \mathrm{~T}, 2 \mathrm{~T}$, and $3 \mathrm{~T}$. About $30 \%$ of detections on Array $2 \mathrm{~J}$ were on two or more nodes. Over $80 \%$ of detections on BON arrays were on a single node (Figure 3.42).

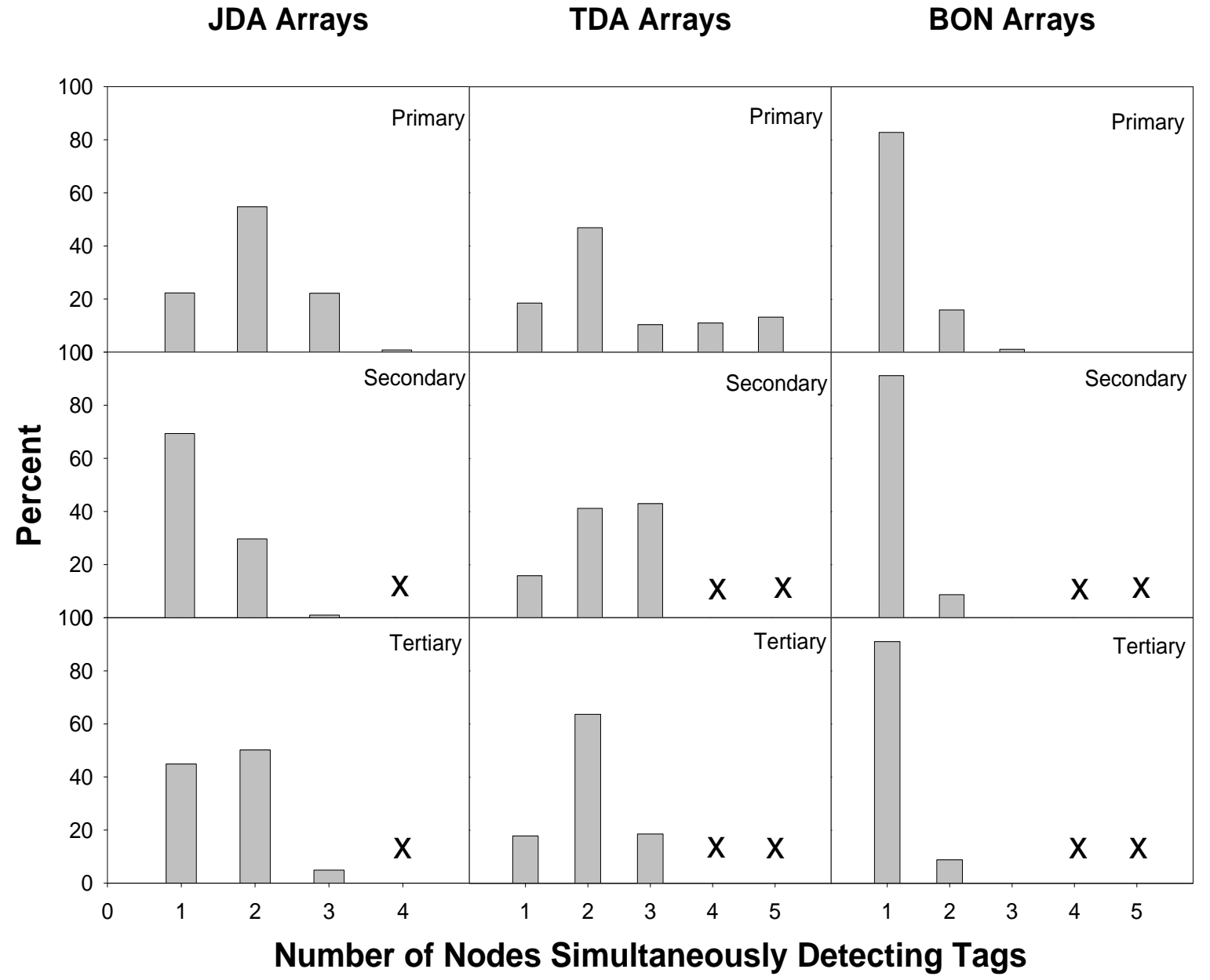

Figure 3.42. Percent of Single and Multiple-Node Detections on Survival Arrays in Spring and Summer 2006. An X indicates that no node was deployed, whereas a non-X position lacking a vertical bar indicates no detections on that many nodes.

\subsection{Node Gaps}

Some autonomous nodes malfunctioned, which resulted in gaps in detection fields within arrays in spring (Figure 3.43) and summer (Figure 3.44). In most cases, only one node in any given array was out at a time. In designing deployments, we spaced nodes closely enough in most arrays to provide some overlap in fields of detection, and this is reflected in the high percentage of multiple-node detections on many arrays in Figure 3.42. In summer, we had to take nodes from the tertiary array below BON Dam to supply other arrays upstream with adequate numbers of nodes. 


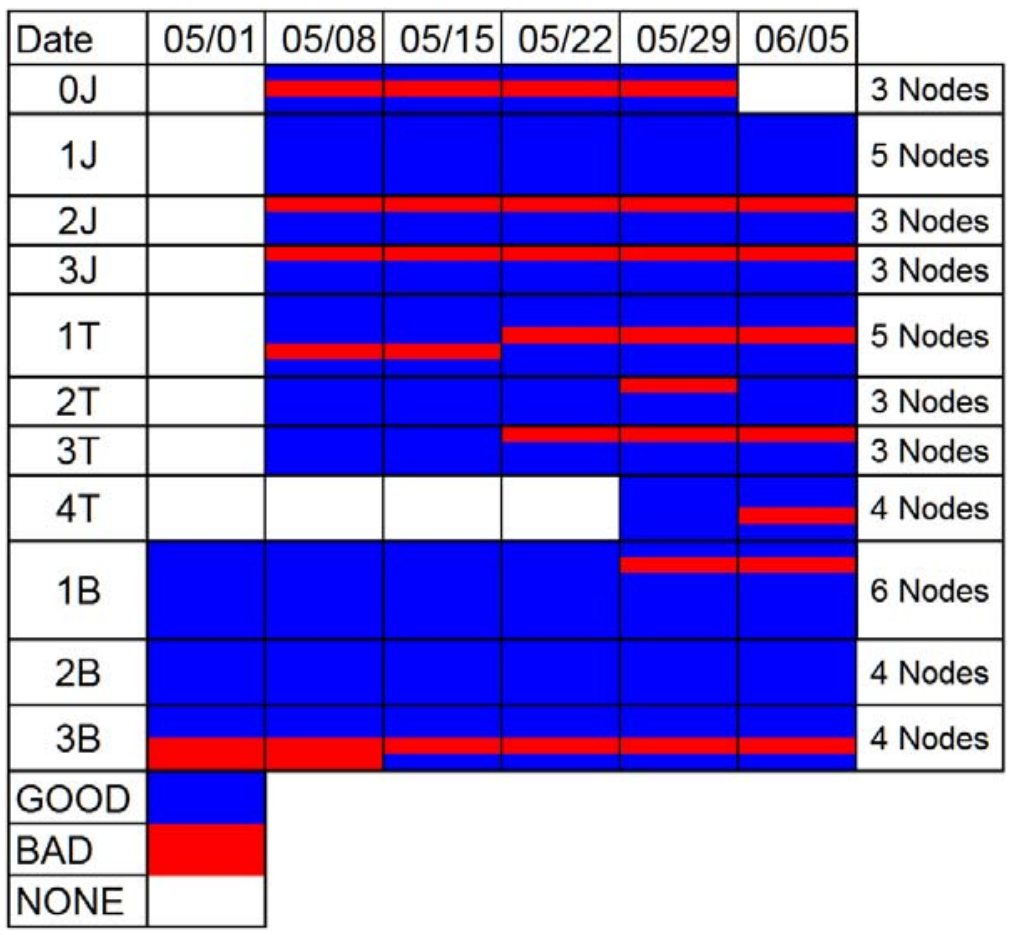

Figure 3.43. Spring Node Gap Chart for All Arrays. Blue Indicates Data Collected, Red Indicates missing data resulting from a malfunctioning or missing node.

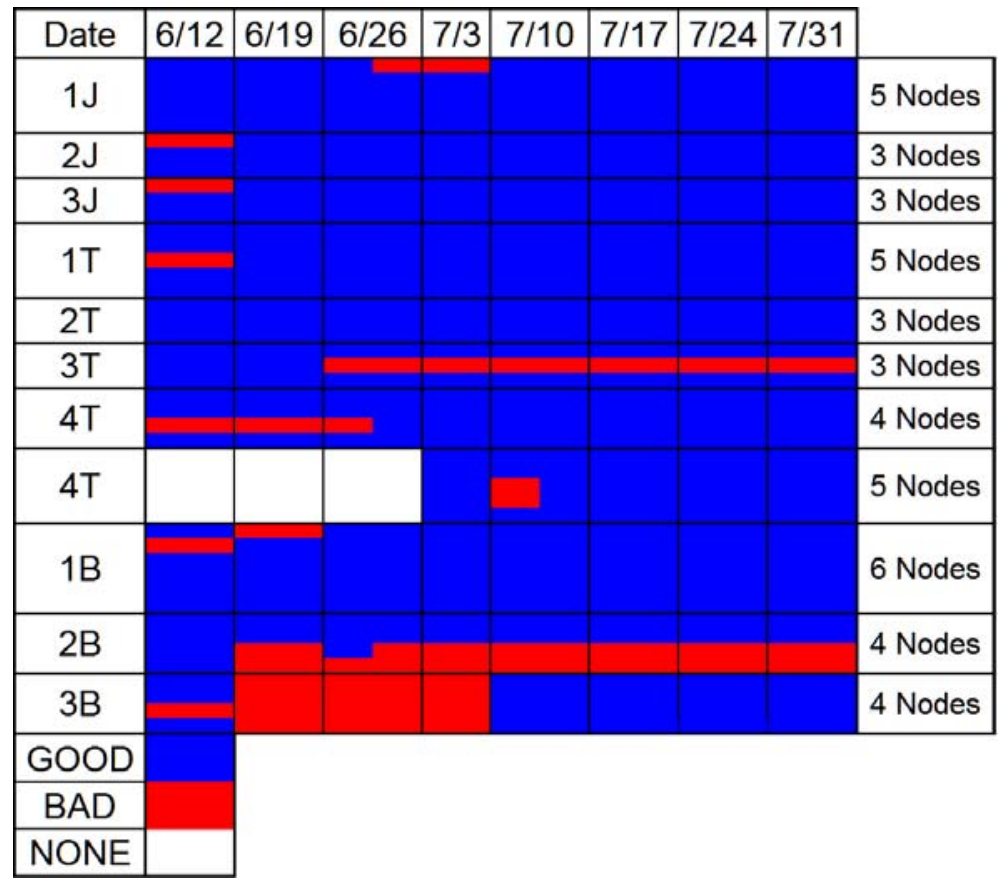

Figure 3.44. Summer Data Gap Chart for all Arrays. Blue indicates data collected, red indicates a data gap. 


\subsection{Survival and Dam Operations, Rate of Travel, Water Temperature}

We calculated and examined correlations of survival probabilities with rate of travel ( $\mathrm{m} / \mathrm{s})$, total project discharge, and forebay water temperature $\left({ }^{\circ} \mathrm{C}\right)$ for each release location in spring and summer. In spring, survival probabilities were positively correlated with rate of travel $(\mathrm{m} / \mathrm{s})$ for all JDA releases and inversely correlated with water temperature for the tailwater release (Table 3.60). No other significant correlations were found.

Table 3.60. Pearson's Correlations on Survival Probabilities with Rate of Tagged Fish Travel, Forebay Water Temperature $\left({ }^{\circ} \mathrm{C}\right)$, and Discharge (kcfs) by JDA and TDA Release Locations for Spring 2006

\begin{tabular}{|c|c|c|c|c|c|c|}
\hline \multirow{2}{*}{ Variable } & \multirow{2}{*}{ With } & \multicolumn{2}{|l|}{ BY } & \multicolumn{2}{|c|}{ Correlation } & \multirow{2}{*}{$\mathbf{N}$} \\
\hline & & Release & Array & Correlation & Prob $>|r|$ & \\
\hline \multirow{4}{*}{ Survival Prob. } & \multirow{4}{*}{ Rate $(\mathrm{m} / \mathrm{s})$ of travel } & JDA Front Roll & \multirow{4}{*}{ All } & 0.4927 & $<0.0001$ & 64 \\
\hline & & JDA Intake 9C & & 0.4528 & 0.0002 & 64 \\
\hline & & JDA Tailrace & & 0.4958 & $<0.0001$ & 64 \\
\hline & & TDA Tailrace & & -0.1607 & 0.2917 & 45 \\
\hline \multirow{4}{*}{ Survival Prob. } & \multirow{4}{*}{ Temperature $\left({ }^{\circ} \mathrm{C}\right)$} & JDA Front Roll & \multirow{4}{*}{ All } & -0.1592 & 0.2089 & 64 \\
\hline & & JDA Intake 9C & & 0.0502 & 0.6938 & 64 \\
\hline & & JDA Tailrace & & -0.0710 & 0.5771 & 64 \\
\hline & & TDA Tailrace & & -0.3349 & 0.0245 & 45 \\
\hline \multirow{4}{*}{ Survival Prob. } & \multirow{4}{*}{ Discharge (kcfs) } & JDA Front Roll & \multirow{4}{*}{ All } & -0.0258 & 0.8394 & 64 \\
\hline & & JDA Intake 9C & & 0.2101 & 0.0957 & 64 \\
\hline & & JDA Tailrace & & -0.0106 & 0.9339 & 64 \\
\hline & & TDA Tailrace & & -0.2542 & 0.0920 & 45 \\
\hline
\end{tabular}

In summer, survival was inversely correlated with water temperature for releases in the JDA Tailrace ( $\mathrm{P}=0.18$; at $\alpha=0.20)$ and TDA Tailrace $(\mathrm{P}<0.0001)$, and it was positively correlated with river discharge (releases in the JDA Tailrace at $\alpha=0.10$ and in TDA Tailrace at $\alpha=0.01$ ) and rate of travel, at least for JDA Tailrace releases. There was no significant correlation of survival with rate of travel for fish in the TDA Tailrace (Table 3.61).

Table 3.61. Pearson's Correlations on Survival Probabilities with Rate of Tagged Fish Travel, Forebay Water Temperature $\left({ }^{\circ} \mathrm{C}\right)$, and Discharge (kcfs) by JDA and TDA Release Locations for Summer 2006

\begin{tabular}{|c|c|c|c|c|c|c|}
\hline \multirow{2}{*}{ Variable } & \multirow{2}{*}{ With } & \multicolumn{2}{|l|}{ By } & \multicolumn{2}{|c|}{ Correlation } & \multirow{2}{*}{$\mathbf{N}$} \\
\hline & & Release & Array & Correlation & Prob $>|r|$ & \\
\hline \multirow{2}{*}{ Survival Prob. } & \multirow{2}{*}{ Rate $(\mathrm{m} / \mathrm{s})$ of travel } & JDA Tailrace & \multirow{2}{*}{ All } & 0.7048 & $<0.0001$ & 35 \\
\hline & & TDA Tailrace & & 0.0486 & 0.7657 & 40 \\
\hline \multirow{2}{*}{ Survival Prob. } & \multirow{2}{*}{ Temperature $\left({ }^{\circ} \mathrm{C}\right)$} & JDA Tailrace & \multirow{2}{*}{ All } & -0.2336 & 0.1769 & 35 \\
\hline & & TDA Tailrace & & -0.6739 & $<0.0001$ & 40 \\
\hline \multirow{2}{*}{ Survival Prob. } & \multirow{2}{*}{ Discharge (kcfs) } & JDA Tailrace & \multirow{2}{*}{ All } & 0.3318 & 0.0515 & 35 \\
\hline & & TDA Tailrace & & 0.4353 & 0.0050 & 40 \\
\hline
\end{tabular}




\subsection{Required Sample Sizes}

We ran the Model SampleSize v1.3 using detection and survival statistics estimated in this study to calculate one-half $95 \%$ confidence intervals (CIs) as a function of the total number of tags that might be released in a future study. Lookup-tables to find an estimate of the pooled sample size required to achieve a desired level of precision are presented for yearling Chinook salmon in spring for single-release models (Appendix I) and paired release models (Appendix J). Similar tables are presented for subyearling Chinook salmon in summer for single-release models (Appendix K) and paired-release models (Appendix L).

Most of the precision estimates were very similar to the precision obtained in the study. However, the predicted 95\% CI for the summer paired release model based on releases of 2,200 subyearlings from the TDA Tailrace and the BON Tailrace (0.0312) was slightly higher than the observed estimate (0.0247) based upon releases of 2,179 fish from the TDA Tailrace and 1,957 fish from the BON Tailrace. This tendency for predicted precision being slightly higher than observed precision also was observed for other paired release data (Figure 3.45), and it results from slightly conservative variance estimators in the SAMPLESIZE program.

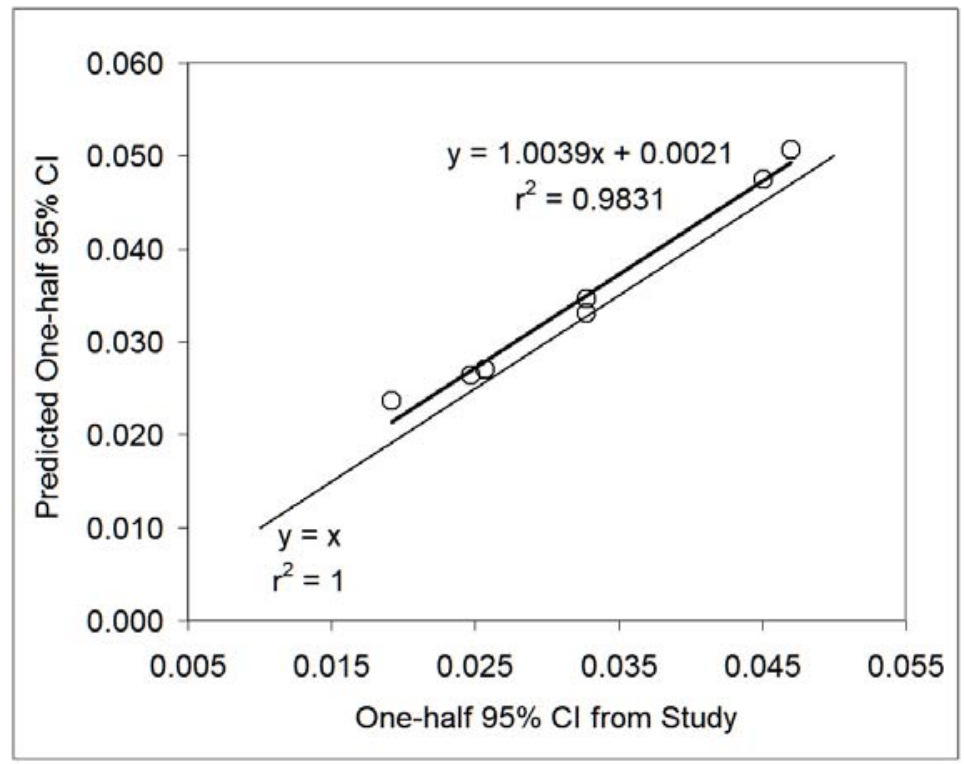

Figure 3.45. Regression of Predicted One-half 95\% Confidence Intervals on Observed Estimates in the 2006 Study. The light line shows a 1:1 relationship of comparison to the fitted line.

\subsection{Detection History Data for Every Acoustic Tag}

Detection history data for every tag released in the 2006 study are presented in Appendix M. 


\subsection{Discussion}

\subsection{Environmental Conditions}

Above-average river discharge during the spring release period precluded successful deployment of a release hose to the downstream side of the JDA Front Roll and forced us to deliver most releases to the site by boat. Days with the highest discharge forced us to release front roll fish near the JBS outfall about $100 \mathrm{~m}$ downstream of the front roll. We also had to abandon tag-line rigging of autonomous nodes. In our first round of deployments in spring, autonomous nodes were rigged with $250 \mathrm{ft}$ of tag line to allow retrieval of anchors as well as nodes and acoustic-release mechanisms. With tag-line deployments, the node and acoustic release pop to the surface briefly after the release is triggered but submerge again very quickly in high flow. We had intended to retrieve and download data weekly, but wound up leaving the first round of nodes deployed for almost a month (the expected battery life) to avoid damaging nodes with the boat during high-speed retrievals. After retrieving the first round of nodes, which included frequent prolonged dragging for many nodes re-submerged by high flow, we abandoned tag-line deployments and sacrificed anchors for the rest of the study.

\subsubsection{Project Discharge and Temperature}

Water temperatures were 1 to $2{ }^{\circ} \mathrm{C}$ higher than the average of the preceding 10 years during the first $60 \%$ of spring releases and during the last $50 \%$ of summer releases. Water temperatures did not reach 20 $21^{\circ} \mathrm{C}$ until the last couple of releases in summer, and most of those fish made it through the study area within a week. Observed water temperatures were below critical levels for juvenile Chinook salmon (Brett 1952), but higher water temperatures may increase susceptibility to disease (Tiffan et al. 2000) and may be an additional stressor on young Chinook salmon, particularly those that are not well fed (Cobleigh 2003).

\subsubsection{Run Timing and Smolt Species Composition}

The spring tagging season ran from May 13 to June 6, 2006, and encompassed the peak of the targeted yearling Chinook salmon run, which ran from May 20 to June 1, 2006. This collection period also encompassed peaks in the spring steelhead, sockeye, and coho runs at JDA, which required us to handle many non-target fish to obtain spring tagging quotas. Collection was in conjunction with normal collection at the JDA SMF to reduce the amount of by-catch and handling of in-stream migrants. In spring, the sockeye run was much larger than in 2005. It made up almost $10 \%$ of the entire spring salmonid run (DART Website), which probably can be attributed to increased spill from Dworshak Reservoir.

The summer tagging season ran from June 11 to July 11, 2006, and, as in spring, encompassed the peak of the migration of the targeted subyearling Chinook salmon run, which occurred around July 1. Sampling had to be increased at the JDA SMF to ensure that adequate numbers of clipped subyearlings from hatcheries were collected for tagging. Over the course of the summer tagging season, only $14 \%$ of collected subyearlings were clipped; large numbers of unclipped fish had to be processed to find the required numbers of clipped individuals. 


\subsubsection{Length Frequency}

A 95-mm minimum length limitation on tagging did not restrict the lengths of fish that could be tagged in the spring, and the length frequencies of tagged and untagged yearling Chinook salmon in the JBS samples were very similar. Only two yearling Chinook salmon smolts were measured that were smaller than the 95-mm size requirement.

The 95-mm minimum length limitation clearly excluded most subyearlings less than $100 \mathrm{~mm}$ in the summer sample (Figure 3.5); tagging would need to include 80 to $100 \mathrm{~mm}$ subyearlings to be fully representative of the population passing through the SMF at JDA in summer. The 95-mm minimum tagging length effectively eliminated about $23 \%$ of the run-of-river sub-yearlings from the sample because they were too small. Tagging subyearlings $80 \mathrm{~mm}$ long will require further miniaturization of tags and reduction in tag weight, according to results of a 2006 tag-effects study (Hockersmith et al. 2007).

Collection of fish exclusively from the JDA SMF also could limit inference about survival to the population of bypassed fish, which may or may not be representative of the entire run migrating seaward. According to previous route-specific survival studies, about $28.7 \%$ to $35.1 \%$ of yearling Chinook salmon pass JDA through the SMF (Counihan et al. 2006a, 2006b). In 2003, only $12.9 \%$ to $21.3 \%$ of subyearling Chinook salmon passed the JDA Project through the JDA SMF. The summer length limitations for tagging further restricts known inference to the larger subyearlings in the SMF samples. Length-related detection biases associated with acoustic telemetry have not yet been documented like those for PIT detection systems (Zabel et al. 2005), although this bias could not be large, if it exists at all, because detection probabilities like those observed for releases down to primary arrays in the JDA and TDA tailwaters usually were very high. For example, detection probabilities were $96.1 \%$ to $98.9 \%$ for JDAreleased fish and $97.5 \%$ for TDA Tailrace releases in spring, and $99.2 \%$ for TDA Tailrace fish in summer).

\subsection{Tag-Life Study}

The tag-life study verified that most tags lasted about as long as expected. All 10-s tags sampled from lots of tags implanted in Snake River fish lasted at least 57 days relative to an expected 55 days, and all 5-s tags exceeded the expected 30-day life by about 5 days.

Future tag-life studies need to be strategically performed so any corrections for tag failure can be properly applied. Recommendations include the following:

1. Systematically sample tags as they are activated for survival studies.

2. Record tag lot number as well as tag codes when fish are tagged, so that specific tag-life corrections can be made in the case of tag-manufacturing problems.

3. Record date and time to the nearest minute that each tag is activated for the tag-life study or JSATS survival studies. This could be accomplished by using a data-logging device when tag activations are verified with a hydrophone. The date and time settings are critical and should be checked regularly.

\subsection{Detection Probabilities and Required Sample Sizes}

Results obtained in spring and summer 2006 accomplished the study goals. Our primary goals were to estimate detection and survival probabilities for JSATS acoustic telemetry equipment in the lower Columbia River to assess the feasibility of using JSATS and to provide a basis for estimating required 
sample sizes to achieve desired precision in future studies. The importance of multi-node detections within the upstream arrays (Figure 3.42) is illustrated by high detection probabilities for Columbia River releases in the JDA and TDA tailwaters, in contrast to lower detection probabilities observed at arrays in the BON Tailwater (Table 4.1). The high detection probabilities in the JDA and TDA tailwaters were achieved in spite of a number of gaps in node arrays (Figures 3.41 and 3.42). One reason for the low detectability in the BON Tailwater resulted from equipment problems, including the loss of nodes to fishermen and commercial boat traffic. However, some of it is undoubtedly related to the relatively shallow bathymetry and extensive sand bars, which limit the range of sound propagation.

Table 4.1. Means and Standard Errors of Mean Detection Probabilities for Columbia River Releases of Chinook Salmon in Spring and Summer 2006. These estimates were calculated from pooled detection estimates.

\begin{tabular}{||c|c|c|c|c|c|}
\hline Statistic & To 1J & To 1T & To 2T & To 1B & To 2B \\
\hline \multicolumn{7}{|c|}{ Spring } \\
\hline Mean & 96.2 & 91.3 & 99.7 & 67.6 & 72.5 \\
\hline SE of Mean & 3.1 & 5.3 & 0.3 & 5.9 & 5.9 \\
\hline \multicolumn{7}{|c|}{ Summer } \\
\hline Mean & 97.2 & 99.0 & 100.0 & 80.2 & N/A \\
\hline SE of Mean & 2.4 & 0.2 & 0.0 & 11.4 & N/A \\
\hline
\end{tabular}

We could not compare detection probabilities for the primary and secondary arrays in this study with estimates in previous radio telemetry studies because those statistics were not reported, although they were mentioned. Capture history data presented in radio telemetry reports were not sufficient to calculate detection probabilities for individual arrays, so we compared the probability of fish being detected on any one of the downstream survival arrays in spring (Table 4.2) and summer (Table 4.3). This probability includes survival and detection probabilities inasmuch as tagged fish might miss detection because they died or because they passed through all three arrays undetected but alive.

According to results in Tables 4.2 and 4.3, the 2006 JSATS arrays usually performed as well as or better than radio telemetry arrays in the JDA and TDA tailwaters and usually underperformed radio arrays in the BON Tailwater. Acoustic arrays in the upstream pools likely perform better than arrays in the BON Tailwater because transects tend to be deeper, and there were few shallow bars and islands upstream to impede underwater sound transmission. Aerial radio antennas may perform better in the shallower BON Tailwater than in the upstream pools because tagged fish are less likely to evade detection by passing deep. Our comparison assumes that survival was similar among years and that most of the differences in detection probabilities were due to detectability. Given among-year variability in survival, this assumption may not be true, although we limited comparison to years with similar project configurations at TDA and BON. Regardless, most of the probabilities of detection on at least one of all survival arrays exceeded $80 \%$ for each method, which should be sufficient to provide confidence in survival estimates.

Deploying additional nodes below BON, where P1 detection probabilities averaged $67.6 \%$ in spring and $80.2 \%$ in summer, has the potential to significantly increase detectability and to reduce the need for large numbers of tags for future studies employing paired-release models. Sample-size tables for BON in Appendix I (Tables I.15 - I.18 for spring) and Appendix K (Tables K.9 - K.14 for summer) indicate that high precision can be obtained for single-release models with existing sampling effort and a reasonable number of tags in either season. However, tables for paired-release models in spring (Appendix J, 
Table J.3) and especially summer (Appendix L, Table L.2) indicate that buying a lot more tags will not improve precision significantly. The density of detection nodes will have to be increased to achieve a $2 \%$ one-half 95\% CI on paired-release survival estimates with a reasonable number of tags.

Table 4.2. Probability of Tagged Yearling Chinook Salmon Being Detected on at Least One of Three Arrays Downstream by JSATS Receivers in 2006 or by Radio Telemetry Receivers in Prior Studies in Spring

\begin{tabular}{|c|c|c|c|c|c|c|}
\hline Dam & \begin{tabular}{|c|} 
Acoustic \\
Telemetry \\
Release in 2006
\end{tabular} & $\begin{array}{c}\text { Probability of } \\
\text { Detection on } \\
\text { All } \\
\text { Downstream } \\
\text { Acoustic } \\
\text { Arrays (2006) } \\
\end{array}$ & $\begin{array}{c}\text { Probability of } \\
\text { Detection on } \\
\text { All } \\
\text { Downstream } \\
\text { Radio Arrays } \\
\end{array}$ & $\begin{array}{c}\text { Difference } \\
\text { Acoustic } \\
\text { Minus } \\
\text { Radio } \\
\text { Estimate } \\
\end{array}$ & $\begin{array}{c}\text { Radio } \\
\text { Telemetry } \\
\text { Study Year } \\
\end{array}$ & $\begin{array}{c}\text { Radio Telemetry Study Release, } \\
\text { Treatment, or Condition } \\
\end{array}$ \\
\hline JDA & Turbine I9C & 0.874 & 0.764 & 0.110 & 2002 & Powerhouse $=$ Turbine + JBS \\
\hline JDA & Turbine I9C & 0.874 & 0.804 & 0.070 & 2003 & Turbines \\
\hline JDA & Tailrace Control & 0.973 & 0.956 & 0.017 & 2002 & Tailrace Control \\
\hline JDA & Tailrace Control & 0.973 & 0.971 & 0.002 & 2003 & Tailrace Control \\
\hline TDA & JDA Tailrace & 0.917 & 0.844 & 0.072 & 2004 & JDA Tailrace \\
\hline TDA & JDA Tailrace & 0.917 & 0.881 & 0.036 & 2005 & JDA Tailrace \\
\hline TDA & TDA Control & 0.989 & 0.975 & 0.014 & 2004 & TDA Control \\
\hline TDA & TDA Control & 0.989 & 0.987 & 0.001 & 2005 & TDA Control \\
\hline $\mathrm{BON}$ & TDA Tailrace & 0.839 & 0.846 & -0.006 & 2004 & TDA Tailrace; 56 kcfs day / gas cap night \\
\hline $\mathrm{BON}$ & TDA Tailrace & 0.839 & 0.903 & -0.063 & 2005 & TDA Tailrace; 75 kcfs day / gas cap night \\
\hline $\mathrm{BON}$ & BON Tailrace & 0.818 & 0.958 & -0.140 & 2004 & $\begin{array}{l}\text { BON Tailrace; } 56 \text { kcfs day / gas cap } \\
\text { night }\end{array}$ \\
\hline $\mathrm{BON}$ & BON Tailrace & 0.818 & 0.971 & -0.154 & 2005 & $\begin{array}{l}\text { BON Tailrace; } 75 \text { kcfs day / gas cap } \\
\text { night }\end{array}$ \\
\hline
\end{tabular}

Table 4.3. Probability of Tagged Subyearling Chinook Salmon Being Detected on at Least One of the Downstream Survival Arrays by JSATS Receivers in 2006 or by Radio Telemetry Receivers in Prior Studies in Summer. There were only two acoustic survival arrays below BON in 2006, whereas there were three survival arrays below TDA in acoustic and radio telemetry studies.

\begin{tabular}{|c|c|c|c|c|c|c|}
\hline Dam & $\begin{array}{c}\text { Acoustic } \\
\text { Telemetry } \\
\text { Release in } \\
2006\end{array}$ & $\begin{array}{c}\text { Probability of } \\
\text { Detection on All } \\
\text { Downstream } \\
\text { Acoustic Arrays } \\
(2006) \\
\end{array}$ & $\begin{array}{c}\text { Probability of } \\
\text { Detection on } \\
\text { All } \\
\text { Downstream } \\
\text { Radio Arrays } \\
\end{array}$ & \begin{tabular}{|c|} 
Difference \\
Acoustic \\
Minus \\
Radio \\
Estimate \\
\end{tabular} & \begin{tabular}{|c|} 
Radio \\
Telemetry \\
Study \\
Year \\
\end{tabular} & $\begin{array}{c}\text { Radio Telemetry Study Release, Treatment, } \\
\text { or Condition }\end{array}$ \\
\hline JDA & JDA Tailrace & 0.993 & 0.993 & 0.955 & 2002 & JDA Tailrace Control \\
\hline JDA & JDA Tailrace & 0.993 & 0.993 & 0.988 & 2003 & JDA Tailrace Control \\
\hline TDA & JDA Tailrace & 0.823 & 0.662 & 0.161 & 2004 & JDA Tailrace; TDA Treatment \\
\hline TDA & JDA Tailrace & 0.823 & 0.825 & -0.002 & 2005 & JDA Tailrace; TDA Treatment \\
\hline TDA & TDA Tailrace & 0.969 & 0.954 & 0.015 & 2004 & TDA Tailrace Control \\
\hline TDA & TDA Tailrace & 0.969 & 0.968 & 0.001 & 2005 & TDA Tailrace Control \\
\hline $\mathrm{BON}$ & TDA Tailrace & 0.762 & 0.802 & -0.040 & 2005 & TDA Tailrace; 75 kcfs day/gas cap night \\
\hline BON & BON Control & 0.915 & 0.960 & -0.046 & 2005 & BON Tailrace Control \\
\hline
\end{tabular}


The tradeoff between buying tags and buying autonomous nodes can easily be calculated and compared to find an optimum balance between detectability and sample size. For example, in 2006, one fully rigged node and acoustic release mechanism cost about as much as 67 acoustic tags. In Appendix L, Table L.2, it is clear that doubling the number of tags from 2,500 to 5,000 only reduces the one-half $95 \%$ CI from 0.0304 to 0.0271 , but that amount of money could more than double node density in downstream arrays. We estimate that adding just two nodes to each array and deploying three arrays in summer would provide a $90 \%$ detection probability for BON Tailwater arrays and, everything else being equal, would achieve the same precision with just 1,800 tags. If there is room for improvement in detectability, then increasing detectability probably is more cost effective than buying tags up to some detection saturation point.

The choice of array locations and spacing between arrays can provide savings for future studies seeking to evaluate survival at multiple projects. We deployed nine survival arrays (three per tailwater) to thoroughly assess detection and survival probabilities in three tailwaters, but our results indicate that all survival estimates could have been obtained with just six arrays. Those arrays would include:

1. One in the JDA Tailwater located near the TDA forebay serving as both a primary survival array and as a TDA forebay array.

2. Two in the TDA Tailwater (2006 arrays $1 \mathrm{~T}$ and $3 \mathrm{~T}$ ), where $1 \mathrm{~T}$ would serve as a secondary for JDA releases or as a primary for TDA virtual and Tailrace releases, and 2T located near the BON forebay would serve as a tertiary array for JDA releases, a secondary array for TDA virtual and tailrace releases, and a forebay array for constructing BON virtual releases.

3. Three in the BON Tailwater.

We compared survival estimates calculated from detections on "as planned" arrays in each tailwater with estimates based on detection on "preferred arrays" in Chapter 3, Section 3.6, and found no significant differences in any estimates (Tables 3.41 through 3.44). Therefore, we recommend that future studies maximize return on investment by using the arrays described above when multiple projects are being studied. Had we known that the use of the preferred arrays would yield similar results to the "as planned" arrays, we could have saved deployment and servicing of two arrays and six autonomous nodes in the JDA Tailwater, and one array and three autonomous nodes in the TDA Tailwater without detriment. Some of these nine nodes could have been used as spares, which would have eliminated our need to cannibalize the BON tertiary array in summer to keep upstream arrays populated, and the rest would have been available for other studies. However, our results also indicate that if a single study is planned, survival arrays can be located in one tailwater and can be relatively close together without detriment, as long as detections cannot be made simultaneously on two successive arrays. However, spreading out three arrays within a pool will provide greater inference about survival in the first two river reaches. There may be other considerations of consequence, including increased servicing of widely dispersed arrays. Nevertheless, these are tradeoffs worth considering when planning future studies.

The primary array clearly needs to be far enough downstream so that the probability of detecting dead fish is near zero, and so that time is allowed for injuries associated with dam passage to result in death. We did not detect dead fish on any array in this study, so apparently the primary arrays were located far enough downstream to avoid detecting dead fish. In spring, survival to the primary, secondary, and tertiary arrays in each tailwater did not differ significantly (see Figure 3.18); therefore, locating the primary in any of the three locations would not have made a significant difference. However, in summer, the survival to Array 3J was significantly lower than it was to Arrays $1 \mathrm{~J}$ and $2 \mathrm{~J}$, and survival to Array $2 \mathrm{~T}$ and 3T was significantly lower than it was to Array 1T (Figure 3.25). Consequently, locating a primary 
JDA array near the TDA forebay (where Array 3J was in this study) or the primary TDA array just above the BON forebay (where 3T was located in this study) would have provided a significantly lower singlerelease survival estimate than we observed with primaries located further upstream. The reduced survival for the most downstream arrays in the JDA and TDA tailwaters in summer may have resulted from the realization of mortality of injured fish or just from fish having to travel through a longer reach. On the chance that the cause was delayed mortality, it might be prudent to locate primary arrays as far downstream as possible. Paired release models will remove the tailwater effect in either case.

\subsection{Detection and Survival of Yearling Chinook Salmon in Spring}

\subsubsection{Tag-Life Study Correction}

No tag-life correction was needed or used for the 2006 yearling Chinook survival studies. The only releases with tags potentially needing corrections were those at the last array below BON and even then the expected probability of tag life exceeded 99.9\% (Appendix B). In these circumstances, the tag-life correction of the reach survival estimates would be inconsequential. It would not change the point estimate and would only slightly inflate the variance of detection and survival estimates.

\subsubsection{Lower Granite Release Group}

A pooled survival estimate of $48.7 \%$ for these yearlings that traveled through five dams over $370 \mathrm{~km}$ down to Array $1 \mathrm{~J}$ equates to an average loss of about $10.2 \%$ per dam and tailwater, and this is within the range of previous observations for the lower Columbia River. The Lower Granite fish traveled $370 \mathrm{~km}$ and passed five dams to reach Array 1J. These two release groups were the first groups of active tagged fish released on the Snake River and detected on the Columbia River. Within this study, we observed dam and tailwater mortalities of $12.4 \%$ for fish released into the JDA turbine, $5.3 \%$ for virtual releases through TDA, and $8.2 \%$ for virtual releases through BON. High spillway passage at TDA may account for 95\% survival there. From 2002 through 2005, the TDA spillway passed about 76\% of yearling Chinook salmon (Johnson et al. 2007), and survival of yearling Chinook salmon there was reported to be 90.6\% in 2004 (Counihan et al. 2006a) and 94\% in 2005 (Counihan et al. 2006b).

\subsubsection{John Day Dam Releases}

Paired releases at JDA provided reasonably precise estimates of survival for yearlings passing through a turbine to the front roll (89.2\% with a 3.2\% one half $95 \% \mathrm{CI}$ ) and through the turbine to the tailrace (89.8\% with a 3.3\% one half $95 \% \mathrm{CI}$ ). Survival of yearling Chinook salmon to the primary array after release in Turbine Intake 9C was significantly lower than that of yearlings released in the downstream front roll or tailrace according to a Z-test. A paired-release survival estimate for yearlings passing through Intake 9C to the tailrace was significantly lower than a paired-release estimate for yearlings released in the front roll and traveling to the tailrace $(\mathrm{Z}=-4.945 ; \mathrm{P}<0.0001 ; \mathrm{n}=8)$. Our estimates of $89 \%$ to $90 \%$ are $5.8 \%$ to $9.3 \%$ higher than some previous route-specific survival estimates including 83.2\% in 2002 (Counihan 2006d) and 80.7\% during the night in 2003 (Counihan et al. 2006e), but our estimates were comparable to an estimate of 89.1\% during the day in 2003 (Counihan et al. 2006e). Estimates of survival through turbines may vary depending upon the exact geometry associated with operations under different flow regimes. With very high river discharge in 2006, it is possible that turbines were run to maximize discharge, and such a fully open runner-blade geometry is known to reduce injury and mortality associated with blade strike (Ploskey and Carlson 2004). 
There were Burnham Test 2 violations of independence assumptions for the primary and secondary arrays for two of the three releases, but it is difficult to understand the mechanism involved since fish were merely detected as they passed the primary array and were not delayed or handled in any way. As noted by Counihan et al. (2006d), the utility of these tests to discern whether independence assumptions have been met is limited by the high capture probabilities. This was true for radio telemetry, and it likely is true for JSATS acoustic telemetry in the JDA and TDA tailwaters. Since detection arrays span the entire river channel, the possibility that this assumption could be violated if downstream detections were influenced by upstream passage routes is minimized, and the lack of handling following initial release of fish also minimizes the risk that upstream detections affect survival (Skalski 1999). However, there may simply be an association relating to unequal detectability and paths of fish or (perhaps more likely) fish may be moving in groups or in clusters relating to local environmental conditions that lead to violation of the independence assumption of Chi-square tests. Small p-values very easily arise when there is nonindependence. This needs to be investigated further for non-independence may lead to the model standard errors being too small.

The JDA and TDA releases in spring were used to estimate pool and dam survival for TDA. Our spring estimate of $92.8 \%(95 \% \mathrm{CI}=90.2,95.4 \%)$ was $1 \%$ to $2 \%$ higher than a 2004 estimate and the same as a 2005 estimate based upon radio telemetry studies for two years with similar spill configurations to those used in 2006. Radio telemetry studies estimated project survival at $86.6 \%$ (95\% CI $=84.3$, 88.9\%) for 2004 (Counihan et al. 2006a) and at 89.2\% (95\% CI = 86.4, 92.0\%) in 2005 (Counihan et al. 2006b). Most fish pass through the spillway at TDA, and spillway survival ran 94\% to 95\% with an average $95 \%$ CI that bracketed our project survival estimates according to PIT tag studies conducted in 1999 and 2000 (Dawley et al. 2000; Absolon et al. 2002).

\subsubsection{The Dalles and Bonneville Tailrace Releases}

Tailrace releases below TDA were used as controls for TDA project survival estimates, and tailrace releases below BON were used as controls for BON project survival estimates; as such they can be compared to radio telemetry survival estimates for spillway control releases in 2004 and 2005. Our survival estimate for the TDA control release to Array $1 \mathrm{~T}$ was $98.9 \%(95 \% \mathrm{CI}=98.3,99.6)$; this did not differ from mean radio telemetry estimates of 95.7\% (95\% CI $=92.4,99.1)$ in 2004 (Counihan et al. 2006a). We could not find a reported survival estimate for control fish released in the TDA Tailrace in 2005, but the reported $\lambda$ of all arrays was $98.7 \%$ (Counihan et al. 2006b).

Our survival estimate for BON Tailrace control releases to Array 1B near Rooster Rock State Park was $85.1 \%$ (95\% CI $=82.4,87.7)$, and this was significantly lower than radio telemetry estimates of 94.4\% (95\% CI = 91.3, 97.6) in spring 2004 (for a control release below the B2 JBS outfall - Counihan et al. 2006f) and of about 97.1\% in spring 2005 (Counihan et al. 2006g).

\subsubsection{Virtual Releases from The Dalles and Bonneville Forebays}

Acoustic and radio dam-survival estimates are not exactly comparable because the former were based on single release models and the latter on paired-release models. However these estimates were the only ones available for comparison, given problems with paired-release models for TDA and BON, as described in Results Section 3.4.7 and discussed in Section 4.4.6 below. Our TDA virtual release estimate of dam and tailwater survival of $94.7 \%(95 \% \mathrm{CI}=93.4,96.1)$ for the reach from the TDA forebay to Array 1T near Hood River was slightly higher than the radio telemetry dam estimate of 90.6\% $(95 \% \mathrm{CI}=89.0,92.2)$ for 2004 and did not differ from the 2005 dam survival estimate of $93.3 \%$ (95\% CI $=94.4,96.8)$. 
Our BON virtual release estimate of dam and tailwater survival of 91.9\% (95\% CI =89.1, 94.7) did not differ from the radio telemetry dam-survival estimate of 95.1\% (95\% CI = 93.7, 96.6) for 2004 based on overlapping 95\% CIs but was slightly lower than the 2005 estimate of $96.6 \%(95 \% \mathrm{CI}=95.2,98.0)$. Of course our estimate was based on a single-release model and theirs was based on a paired release model and that would account for the observed difference. Tailwater mortality is included in the singlerelease models but not in the paired release models.

\subsubsection{The Dalles and Bonneville Project Passage Survivals}

Project passage survival for TDA using JDA Tailrace releases as treatment fish and TDA Tailrace fish as control fish was $92.8 \%(95 \% \mathrm{CI}=90.3,95.4)$. This estimate was $6.2 \%$ higher than a TDA Project survival estimate of $86.6 \%(95 \% \mathrm{CI}=84.3,88.9)$ for 2004 by Counihan et al. (2006a) and similar to a TDA Project estimate of 89.2\% (95\% CI = 86.4, 92.0) for 2005 (Counihan et al. 2006b).

The Dalles and BON releases were used to estimate BON Project survival, and our initial estimate of 1.0583 (95\% CI $=1.01126,1.10534)$ was high. It was based on the ratio of a single-release estimate for TDA Tailrace fish of $90.0 \%$ (95\% CI $=87.2,92.9)$ and a pooled control release (BON Tailrace) estimate of $85.04 \%$. Even if we drop one very low control release estimate of 70.8\% (Table 3.9) and recalculate an average control release estimate of $90.9 \%(95 \% \mathrm{CI}=88.8,92.9)$ from the three remaining control estimates, we obtain a revised paired-release project estimate of $99.0 \%$, which still seems high.

The estimates of survival are too low for tailrace-released fish or the estimates of survival for the treatment fish are too high, and the former possibility seems most likely. Survival of radio-tagged control releases below the B2 JBS outfall was 94.7\% $(95 \%$ CI = 91.3, 97.6) in 2004 and a joint probability of detection and survival on at least one of three arrays was $97.1 \%$ in 2005; this suggests that survival of acoustically tagged control fish may have been low in 2006. In addition and within the same year, routespecific estimates for yearlings passing through the B2CC and spillway were $94.6 \%$ and $94.1 \%$, respectively; these estimates were higher than the $90.9 \%$ estimate for the last two control releases and certainly higher than the four-release control estimate of $85 \%$. If we took an average of those estimates (94.4\%) as a tailrace survival estimate, we would have generated a paired-release estimate of Project survival of $95.4 \%(95 \% \mathrm{CI}=89.3,101.5)$ for spring 2006 . This is very similar to single-release estimates for fish passing the B2CC and the spillway in spring.

Given poor mixing of treatment and control releases in the paired release model for BON, it might be best to assume $100 \%$ control release survival and use the single release estimate of $90.9 \%$ (95\% CI $=88.8$, 92.9) for project survival (pool and dam). In 2004, a radio telemetry estimate of BON project survival was 90.8\% (95\% CI = 88.1, 93.7\%) during spill to the gas cap at night (Counihan et al. 2006f), which is the condition that prevailed most of spring 2006. In 2005, project survival by radio telemetry was estimated at $92.9 \%(95 \% \mathrm{CI}=91.0,94.9)$ for a $75 \mathrm{kcfs}$ day and gas-cap-night spill condition. These radio telemetry estimates probably do not differ significantly from our single-release survival estimate of $90 \%$ (95\% CI =87.2, 92.9), based on overlapping 95\% CIs.

\subsubsection{Tests of Assumptions}

There were no significant trends in detection probabilities or survival through time in spring, so we were able to pool estimates for the season.

Some homogeneity tests were significant because of Chi square test sensitivity to large sample sizes, but we know that treatment and control fish mixed and experienced similar tailwater conditions relative to time of day because median arrival times were within 2 hours of each other and 95\% confidence intervals overlapped (Figure 3.16). Differences in arrival times $<2$ hours are not biologically significant, although 
they can be statistically significant. The paired release model for JDA Turbine, Front Roll, and Tailrace releases was the only one designed before the 2006 study began.

There were significant departures from mixing for pairings of JDA Tailrace and TDA Tailrace Releases and for pairings of TDA and BON Tailrace releases, primarily because these pairings were made post hoc without benefit of planning to synchronize timing. Research at the three projects was originally conceived and proposed as separate pilot studies, and post-hoc pairings were our way of trying to get the most from available data. Nevertheless, data from the next reach downstream of the reach from TDA to Array 1T (i.e., from $1 \mathrm{~T}$ to $2 \mathrm{~T}$ ) suggest that survival processes were stable regardless of differences in the time of passage. Survival and detection estimates for the $1 \mathrm{~T}$ to $2 \mathrm{~T}$ reach did not differ significantly for JDA and TDA Tailrace releases, and neither had significant temporal trends in spring. In addition, high river flow throughout spring 2006 resulted in a consistency of discharge among days and among hours that may not occur in an average or low-flow year, and this likely contributed to stability in survival processes. Similarly, survival estimates for TDA and BON Tailrace releases from Array 1B to 2B did not differ from each other and had no seasonal trend, which again suggests that survival processes were stable for the two release groups.

Clearly, inter-dam travel times need to be used to stagger upstream-downstream release times for better prospects of mixing in future studies. The violation of model mixing assumptions for JDA and TDA Tailrace pairs and for TDA and BON Tailrace pairs leaves ample room for improvement. We used time of travel data as a function of river discharge each season (Figures 3.29 and 3.30) to develop equations for predicting appropriate lag times between upstream and downstream releases as a function of river discharge. In the future, researchers can use equations in Figures 3.31 through 3.35 as a starting place to predict appropriate lag times from forecasts of river discharge. Data on travel times from years with a lower range of discharge also should be consulted to increase the appropriateness of lag estimates for normal to low water years. River discharge was higher than average throughout spring and the first half of summer.

Survival models assume that upstream and downstream detections did not affect estimates of detection or survival, and we applied Burnham et al. (1987) Test 2 and Test 3 to evaluate that assumption. Two out of the three JDA releases had significant $(\mathrm{P}<0.10)$ Burnham et al. (1987) Test 2 results (Appendix D, Table D.1), but none of the tests was significant for the JDA, TDA, or BON Tailrace releases (Appendix D, Tables D.2 and D.3). None of the Burnham et al. (1987) Test 3 results were significant for any of the release groups tested (Appendix D, Tables D.4-D.6). This was not surprising because there was no physical mechanism like recapture or re-handling associated with detections to affect downstream detection performance. Counihan et al. (2002a) noted that the utility of these tests seemed to be affected by high capture probabilities at radio telemetry arrays, and if true, that would also be the case for tests on pooled data in this study. For the Intake 9C release, pooled data had a highly significant Test $2(\mathrm{P}=0.0001)$, but the Chi square test statistic was only significant in one of six tests (16.7\%) that could be calculated (83.3\% were not significant). The other release with a significant Test 2 for pooled releases was the JDA Tailrace where only three of eight releases could be calculated of those, two were not significant and one was significant.

It is no longer clear that the Burnham et al. (1987) test of goodness-of-fit is ever relevant to radio- or acoustic-tag studies where recaptures are not physical. The high detection rates and lack of mechanism for model violations appear to make the violations artifacts of previous technologies. Other possible explanations for violations of assumptions are only reasonable if the explanations are plausible. There is no evidence that water depth or schooling are affecting hydroacoustic-detection histories. 


\subsubsection{Survival through Successive Reaches}

In spring, a plot of survival from point of release to each array but the last in the study area indicated that most losses occurred in reaches with dams rather than in reaches between dams (Figures 3.17 and 3.24). Cumulative survival plots are a good way to summarize single-release model results. Betweendam reach survivals from JDA to TDA and TDA to BON were among the highest observed in this study. Smolts released from the LGR Tailrace had the lowest survival of all released smolts with a survival rate of $37 \%$ but only because these fish had to pass through five dams before reaching the primary array at JDA and a total of seven dams by the time they left the last array below BON with a survival rate of 37\%. However, the average dam and tailwater survival to Array $1 \mathrm{~J} \mathrm{(10.2 \% )} \mathrm{was} \mathrm{similar} \mathrm{to} \mathrm{estimates} \mathrm{observed}$ for other releases in this study and in previous survival studies on the lower river, as mentioned in Section 4.4.2 above. Only $68 \%$ of fish released in the JDA turbine intake survived to reach the BON secondary array. The other two JDA releases had survivals ranging from $70 \%$ to $75 \%$ by the time the smolts reached the final arrays. The TDA Tailrace-released smolts had the highest survival rates in spring, with $90 \%$ reaching the BON secondary array. The BON Tailrace-released smolts had a lower survival rate of $81 \%$ at the BON secondary array for unknown reasons. This result was surprising since fish released below BON did not have to travel through any dams. However, all smolts released below BON were released through the BON JBS. Early in the season, large numbers of predatory birds were observed sitting on the outfall tubes of the JBS actively feeding on smolts exiting the JBS. Steps were taken to remedy this by releasing tagged smolts at night when predatory birds were not actively feeding.

\subsubsection{Bonneville Route-Specific Survival (Pooled Releases)}

Regrouping fish as they passed through the BON spillway, B2 JBS, and B2CC regardless of release location was the only way to obtain enough detections to make these route-specific survival estimates and even then sample sizes were low.

\subsubsection{Spillway, B2 JBS, and B2CC}

We could not distinguish between survival rates of yearlings passing the B2CC, B2 JBS, and spillway because of low precision of estimates associated with small sample sizes. The estimate for the B2 JBS of 89.3\% (95\% CI =73.0, 105.6) did not differ from estimates for the B2CC of 94.6\% (95\% CI =84.6, 104.6) or from the spillway estimate of $94.1 \%$ (95\% CI $=87.1,101.1)$, according to overlapping $95 \%$ CIs. The highest survival estimates for the B2CC and spillway did not differ from the BON project estimate of $89 \%$, for the same reason.

We compared acoustic telemetry estimates with radio telemetry estimates reported by Counihan et al. $2006 \mathrm{f}$ and 2006g and found no significant differences, mostly due to poor precision in our estimates, which were based upon low numbers of detected fish (42-134). Spill was lower in spring 2004 and 2005 than it was in spring 2006, but radio telemetry survival estimates of 91.0\% (95\% CI = 88.8, 93.2) in 2004 and of $93.0 \%(95 \% \mathrm{CI}=91.2,94.7)$ in 2005 did not differ significantly from our estimate for the spillway or from each other. If we divide the 2006 single-release model estimate for the B2 JBS (89.3\%) by $90.5 \%$, which is the average survival for the last two BON Tailrace releases that were concurrent with our releases, we get a paired-release point estimate of $98.7 \%$. This paired-release estimate is between the 97\% estimate for 2004 and the $100 \%$ estimate for 2005 based on radio telemetry. Radio telemetry studies in 2004 and 2005 produced paired release survival estimates of 102\% each year, and that would not differ significantly from either our single release estimate of $94.6 \%(95 \% \mathrm{CI}=84.6,104.6)$ or a paired release estimate of $104.5 \%$. 


\subsubsection{Spillway by Time of Day}

Spillway survival during the daytime hours (96\%) did seem to be slightly higher than a nighttime estimate of $88 \%$, but completely overlapping 95\% CIs indicate that this difference probably was not significant. Spill was consistently high (to gas cap) $24 \mathrm{~h}$ per day, so diel shifts in spill would not have been a major driving factor in spring 2006. This was not the case in 2004 or 2005 when radio telemetry studies were conducted and river flow was low enough to provide day and night differences in spill.

\subsection{Detection and Survival of Subyearling Chinook Salmon in Summer}

\subsubsection{Tag-Life Study Correction}

As in spring, no tag-life correction was needed or used for the summer survival study of subyearling Chinook salmon because examination of the tag-life curve and arrival distributions of fish to downstream detection arrays (Appendix E) indicated that the vast majority of fish arrived before the time of first tag failure. Only three releases show any need for tag-life correction, and these had tag-life probabilities > 99.9\%, which made a correction inconsequential because it would only inflate the variance and would not change point estimates.

\subsubsection{Little Goose Tailrace Releases}

A significant decline in survival estimates during summer suggests that many fall subyearling Chinook salmon stopped migrating or died before reaching the beginning of our study area below JDA. The possibility of residualization in upstream areas is supported by results of the Lower Monumental Fall Chinook Behavioral Study (Cook et al. 2007). Throughout that study period, $44 \%(\mathrm{~N}=852)$ of the study fish did not pass downstream of Lower Monumental Reservoir even though detection probabilities of seven acoustic arrays downstream of the LGS Tailrace were unchanged throughout the season. The majority ( $\mathrm{N}=647 ; 76 \%$ ) of the fish that ceased downstream migration did so in the stratified portion of the reservoir and upstream of Lower Monumental Dam, and most of the fish that stopped in the isothermal zone were never detected at any of the acoustic telemetry arrays $(\mathrm{N}=170 ; 20 \%$ of the fish that did not emigrate from the reservoir). Researchers attribute the loss of these fish to predation near the release site because this was supported by mobile tracking data. Regardless of residualization, if most fish were ultimately lost, then the apparent downward trend in survival may be real.

Because of the reduction in apparent survival, data from replicate releases should not be pooled, but analyzed separately to properly characterize the between-release variability (Figure 4.1). Interestingly, the difference in survival between successive primary arrays in our study area also decreased significantly, indicating that residualization or mortality continued within our study area.

\subsubsection{John Day Tailrace Releases}

Releases from the JDA Tailrace in summer were designed to establish single-release detection and survival probabilities and, for the limited time that releases were made (five releases between June 16 and June 27), that was accomplished. Detection and survival estimates to Array $1 \mathrm{~J}$ were consistently high, ranging from $98 \%$ to $100 \%$. We could not find comparable estimates in radio telemetry reports, so we made an estimate for the reach from the JDA Tailrace to Array 3J, which is similar to the pool estimates for the 2004 and 2005 TDA survival studies (Counihan et al. 2006a and b). The TDA "pool” estimate for this study was $95.7 \%$ (95\% CI =93.3, 98.1), and this was slightly higher than a summer 2004 estimate of 91.1\% (95\% CI =89.6, 92.7) based upon releases through July 21 of that year (Counihan et al. 2006a). However, it was very similar to a summer 2005 estimate of $94.7 \%$ (95\% CI =93.6, 95.9). Our last 
survival estimate for subyearlings traveling from JDA to Array 3J near the TDA forebay was the lowest in summer 2006 at 89.0\% (95\% CI =82.9, 95.2), and it did not differ from either JDA Tailwater estimates by radio telemetry.

We had originally planned for 10 releases lasting until July 13, but releases were stopped on June 27 to increase the size of releases below TDA when the spill pattern was to shift to a Bi-op pattern of about 75,000 cfs day spill and gas-cap spill at night. Curtailing releases likely prevented us from detecting a trend of decreasing survival for these releases in summer, something that we did observe for LGS, TDA, and BON releases, which ran until mid July (Figure 3.27).
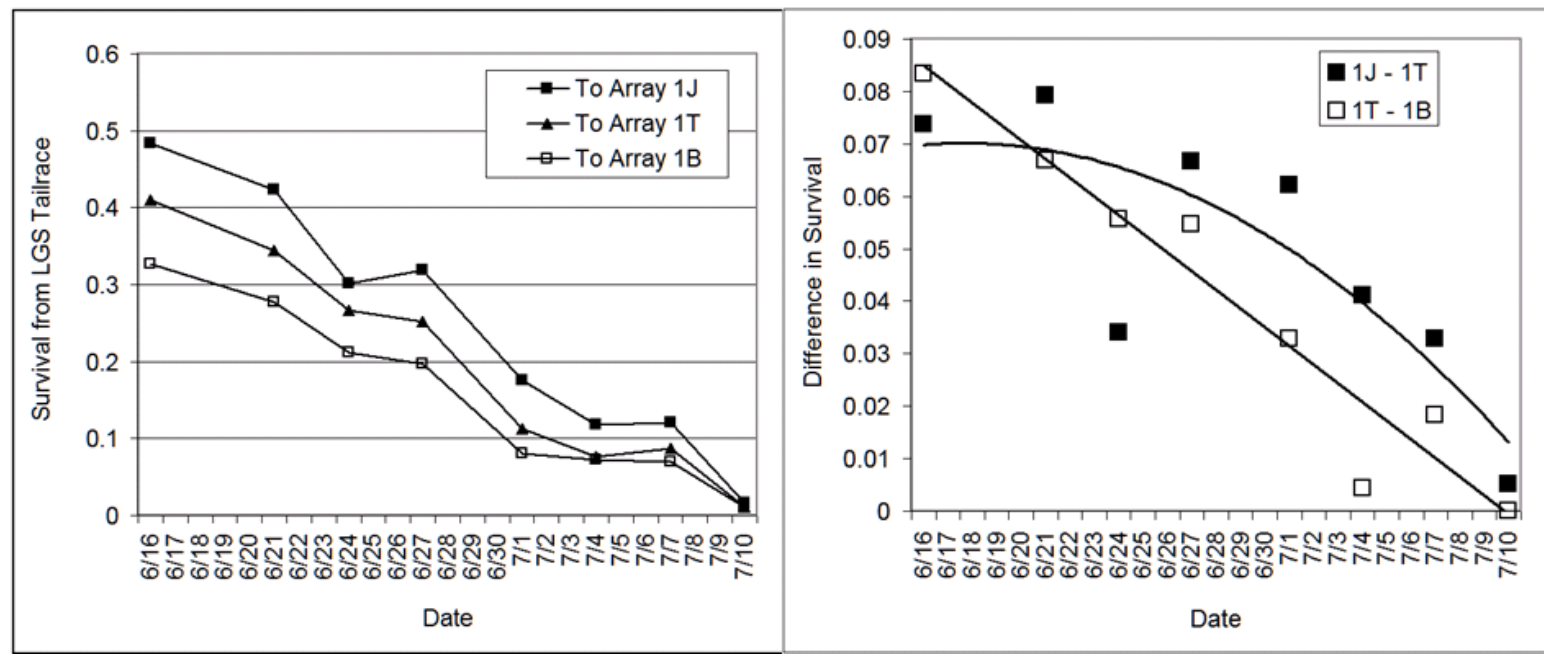

Figure 4.1. Apparent Survival of Subyearling Chinook Salmon Released from Lower Goose Tailrace in Summer Down to Primary Arrays in the JDA, TDA, and BON Tailwaters (Left) and Differences in Survival Between Successive Primary Arrays (Right).

\subsubsection{The Dalles and Bonneville Tailrace Releases}

Survival of TDA Tailrace releases of subyearlings in the BON pool declined moderately as summer progressed, a fact that could be hidden by summer pooled and arithmetic mean estimates of $97 \%$ in Table 3.27. We calculated estimates for TDA Tailrace fish down to Array 3T in the BON forebay and found that apparent survival declined significantly during summer so that an average estimate would depend upon the length of the summer release season (Figure 4.2). The last release was on July 13 in 2006, July 20 in 2004, and July 17 in 2005.

Subyearlings released from the BON Tailrace in 2006 also exhibited a trend of apparently decreasing survival during summer (Figure 4.3), although this trend was not as pronounced as it was for the BON pool upstream. We could not find survival estimates for controls released into the BON Tailrace in 2004 and 2005 radio telemetry reports (Counihan et al. 2006f and g), but combined probabilities of those fish surviving and being detected on at least one of three arrays was $94.7 \%$ to $94.8 \%$ in 2004 and $95 \%$ in 2005. Survival probabilities should have been slightly higher than those combined probabilities, and this would put them within the range of survival estimates depicted for 2006 (Figure 4.3). 


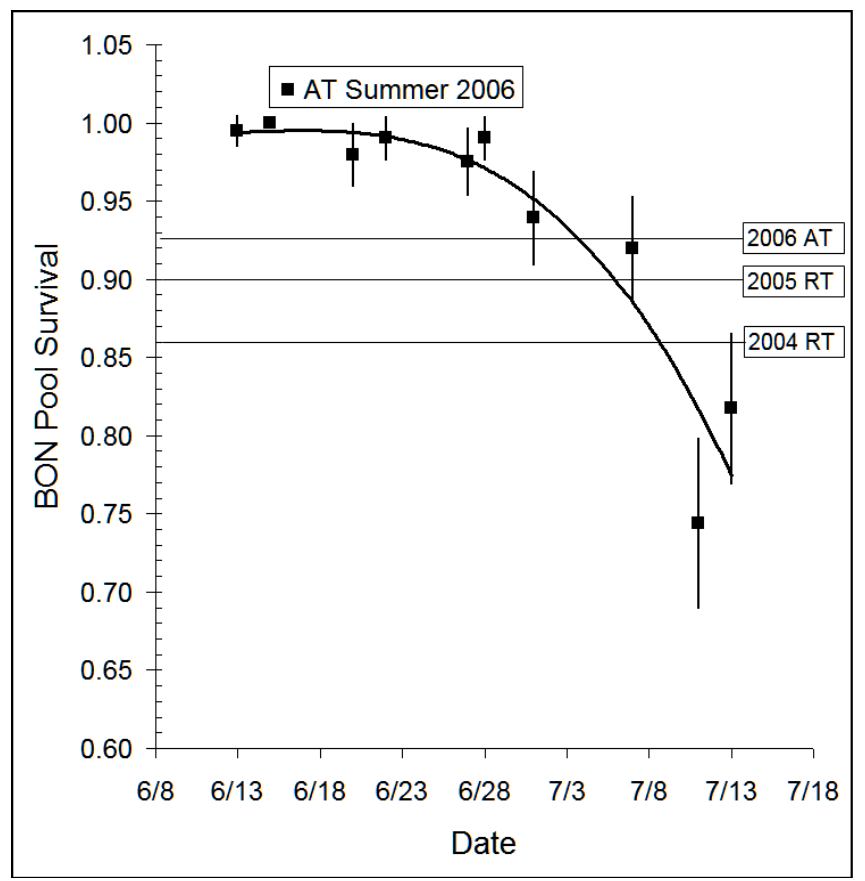

Figure 4.2. Apparent Survival of Subyearling Chinook Salmon Released from the TDA Tailrace in Summer Down to Array 3T just above BON. Vertical bars are $95 \%$ Cls. Horizontal lines show means for this study (2006 AT) and for the 2004 and 2005 radio telemetry (RT) studies (after Counihan et al. 2006a and b).

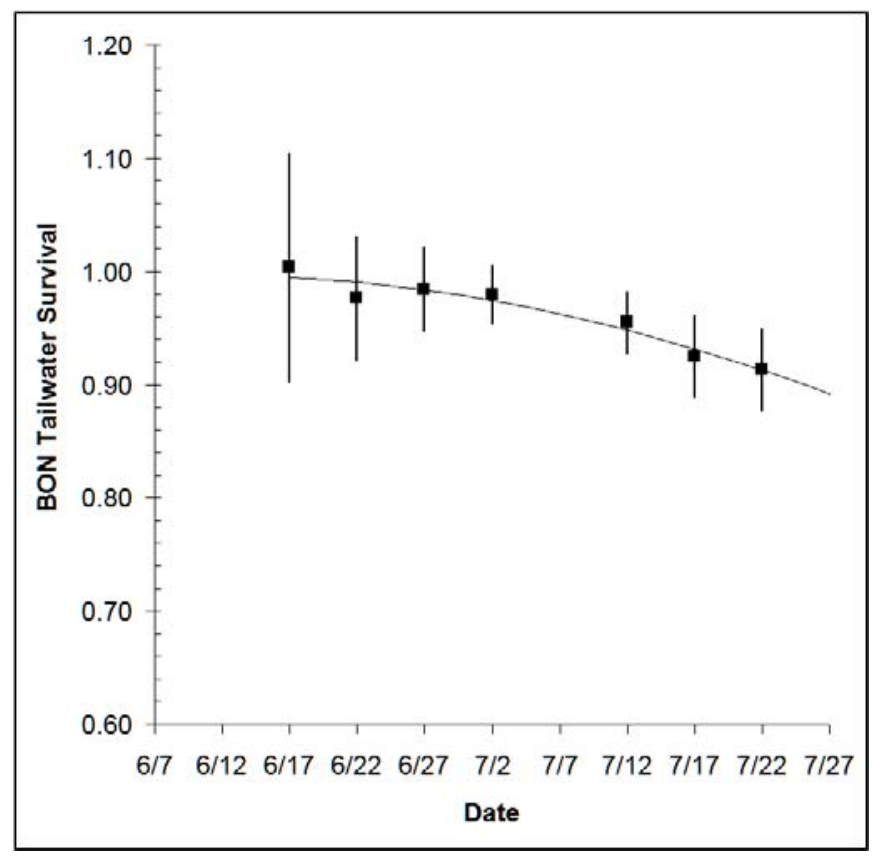

Figure 4.3. Apparent Survival of Subyearling Chinook Salmon Released from the BON Tailrace in Summer Down to Array 1B. Vertical bars are $95 \%$ Cls. 


\subsubsection{Virtual Release from The Dalles and Bonneville Forebays}

Releases into the JDA Tailrace ended on June 27, and therefore trends in virtual survival estimates for TDA did not exhibit an apparent summer decline as observed elsewhere. Subyearlings clearly suffered significant losses in passing TDA as the summer estimate was $86.3 \%$ (95\% CI $=82.3,90.4)$. If we divide this estimate by $97 \%$ (a TDA control release estimate) we get a paired-release estimate of $89.0 \%$ (95\% CI $=84.5$, 93.5), which is slightly higher than a TDA Dam survival estimate of $81.7 \%(95 \% \mathrm{CI}=79.5,83.9)$ in 2004 (Counihan et al. 2006a) and similar to an estimate of 90.0\% (95\% CI = 88.1, 91.8) in 2005 (Counihan et al. 2006b).

Virtual survival estimates for BON in summer declined significantly after June 22, 2006 (Figure 4.4) and therefore the estimates cannot be pooled or averaged without obscuring important trends in apparent survival (residualization or survival). Point estimates of BON survival based on paired-release radio telemetry estimates in 2004 and 2005 are illustrated as lines in Figure 4.4, and both point estimates fall within the range of JSATS estimates for summer 2006.

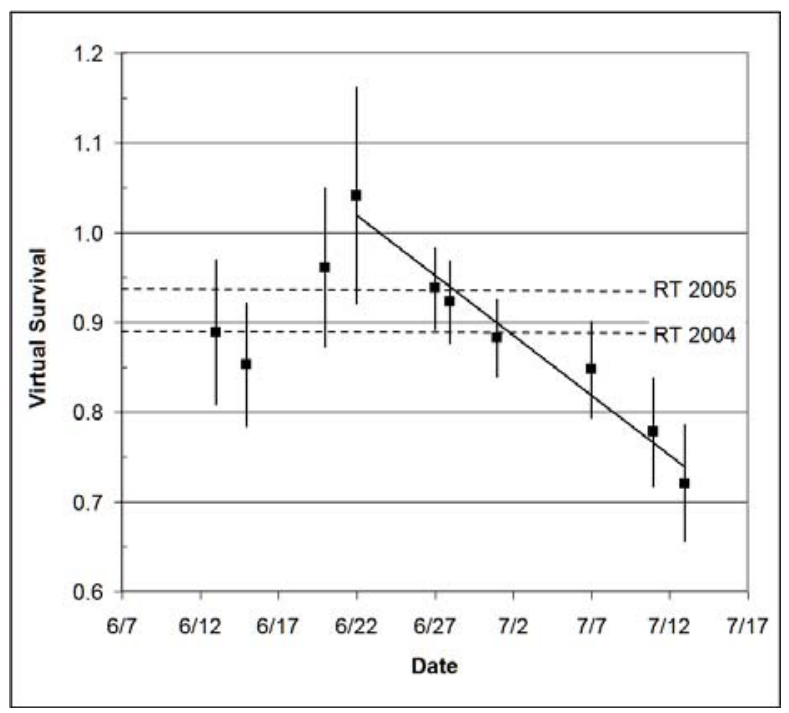

Figure 4.4. Apparent Survival of Subyearling Chinook Salmon Regrouped at Array 3T above BON. Vertical bars are $95 \%$ Cls. Horizontal lines show means for the 2004 and 2005 radio telemetry (RT) studies (after Counihan et al. $2006 f$ and g).

\subsubsection{The Dalles and Bonneville Project Passage Survivals}

\subsubsection{The Dalles Project}

We compared our project survival estimates based upon concurrent treatment and control releases, which ended before the decline in survival began in 2006, and compared them with project survival estimates reported by Counihan et al. 2006a and 2006b. Our estimates for the TDA project for summer 2006 of 82.9\% (95\% CI =78.6, 87.2) based on all releases and of 85.2\% (95\% CI =82.8, 87.7) based on concurrent releases were higher than the radio telemetry estimate of $69.4 \%(95 \% \mathrm{CI}=66.7,72.0)$ for 2004 (Counihan et al. 2006a) but similar to an estimate of 85.2\% (95\% CI $=82.4,88.0)$ for 2005 (Counihan et al. 2006b).

There was ample opportunity for seasonal survival trends to have made the 2004 radio-telemetry estimate lower than our estimate and that of the 2005 radio-telemetry study. Our JDA releases ended 
prematurely on June 27 before a seasonal decline in survival, whereas the 2005 study released fish there through July 17, and the 2004 study, with the lowest point estimate of project survival, released fish through July 28. Spill-bay survival estimates from Counihan et al. (2006a, Appendix 8) show a clear trend of decreasing survival after about July 12 and this trend would reduce the point estimate for TDA project survival to something lower than observed in 2005 and 2006 (Figure 4.5). We could not recalculate the 2004 point estimate for project survival for a shorter season because survival estimates were not reported for individual releases. However, in Counihan et al. (2006a, Figure 11) shows a seasonal decline in dam survival based upon eight-day increments that suggests that shortening the 2004 release season by eight days would have increased the 2004 point estimate at least $10 \%$.

\subsubsection{Bonneville Project}

Our 2006 survival estimate for JSATS-tagged fish of 83.7\% (95\% CI $=80.8$, 86.7) based on concurrent releases below TDA and BON was higher than the 2004 project survival estimate for radiotagged fish $(76.8 \%$; 95\% CI $=74.7,78.8)$ but very close to the 2005 radio telemetry estimate of $84.4 \%$. The 2004 study started releasing fish on June 20 and ended on July 20, which was about a week later than our summer schedule, and, given trends in summer survival in 2004 (Figure 4.5), may account for differences between our BON project estimate for 2006 and the radio-telemetry estimate in 2004.

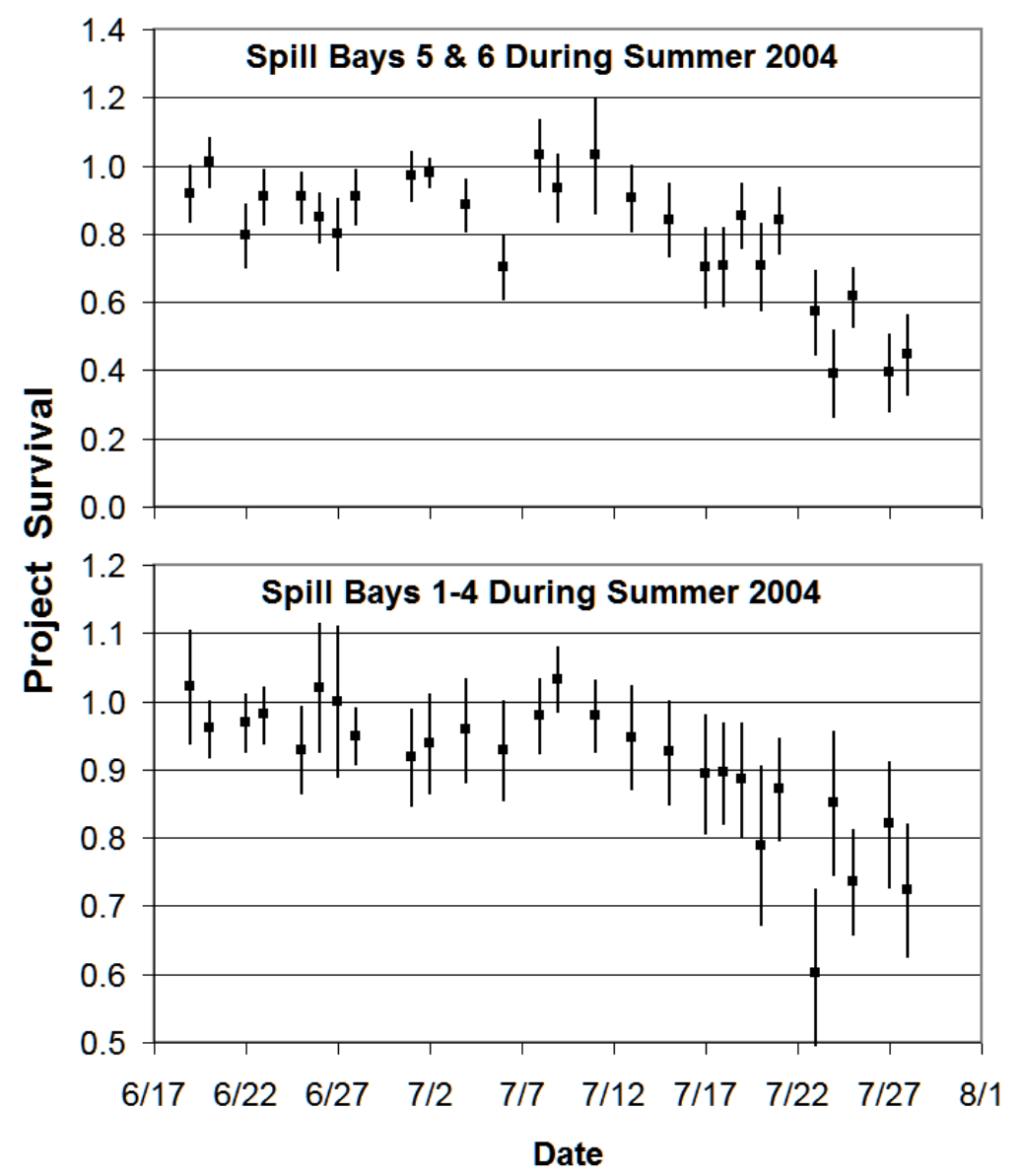

Figure 4.5. Apparent Survival of Subyearling Chinook Salmon Released above TDA Spill Bays in Summer 2004. Vertical bars are standard errors. Data were from Appendix 8 in Counihan et al. 2006a). 


\subsubsection{Tests of Assumptions}

Mixing violations for post-hoc pairings of JDA and TDA releases may not have been as detrimental as goodness-of-fit-tests indicated, although we acknowledge that mixing could be improved. The JDA and TDA tailrace releases used to estimate project survival at TDA showed significant $(P<0.001)$ departures from mixing in summer, primarily because releases after June 27 in the TDA Tailrace had no treatment counterparts. These mixing violations raised concerns about interpreting paired-release project survival models for TDA, so we recomputed estimates using only data acquired during the period of concurrent releases, and the resulting survival estimate of $82.9 \%(95 \% \mathrm{CI}=78.6,87.2)$ did not differ significantly from the estimate based on all releases $(85.2 \%$; 95\% CI $=82.8,87.7)$. Hourly time-of-arrival data indicated that the slowest and fastest fish from the JDA or TDA groups could arrive any hour of the day, but there was a clear 4-h difference in mean arrival time that may have affected survival conditions. Post hoc paired-release estimates were our attempt to extract as much information as possible from the JDA and TDA releases. Future studies could use the regression equation (Figure 3.35) to calculate a lag between upstream and downstream release times to assure mixing of treatment and control fish in the common tailwater reach below TDA. Travel times from other years should be considered as well because 2006 was a high-water year.

The BON Project survival estimate of $83.7 \%$ for concurrent releases is considered reliable because subyearlings from the TDA and BON Tailraces traversed the BON Tailwater at about the same time of day, even though all release data indicated significant differences in arrival distributions. However, the point estimate is not particularly meaningful given the significant decrease in survival during summer. Mixing violations resulted primarily from non-concurrent releases of two control groups and one treatment group, but even after we dropped those releases, the revised survival estimate of $83.7 \%$ (95\% $\mathrm{CI}=80.8$, 86.7) did not differ from the original estimate of $84.9 \%(95 \% \mathrm{CI}=80.4,89.5)$. For the concurrent releases, time of arrival data indicated that the average arrival hour at Array 1B for TDA Tailrace releases was 1040 hours $(\widehat{\mathrm{SE}}=6$ hours), and for BON releases, it was 0913 hours $(\widehat{\mathrm{SE}}=2.2$ hours).

None of the calculable Burnham et al. (1987) Test 2 results were significant, and only one Test 3 result was significant. It indicated that the capture history to Array 2T had an effect on detection at Array 1B. There is no physical mechanism for such an effect, but very high detection probabilities on upstream arrays (Pool estimate $=99.1 \%$ to $100 \%$, see Table 3.27 ) relative to a lower probability of $81.5 \%$ for Array 1B may have produced a false-positive result. When we ran the Test 3 on 10 individual releases, only one was significant, out of the four that were calculable. With high detection probabilities, the utility of these tests may be questionable.

\subsubsection{Survival through Successive Reaches}

Survival estimates for summer, as in spring, were estimated from release location to the final array and showed that the most significant decreases were in reaches that included passage through a dam (TDA or BON; Figure 3.25). Mortality for non-dam reaches usually was $<5 \%$. The decline in survival of JDA-released subyearlings in the reach including TDA was three times greater than that observed in spring for yearlings. The TDA release showed similar results for passage through BON with a $13 \%$ decrease in survival from TDA3 to BON1. This decline was double that experienced by yearlings in spring.

Possible reasons for a steeper decline in survival in summer include lower flows, higher water temperatures and associated increases in thermal and disease stress, smaller fish size in general and 
relative to tag size, and residualization of subyearlings in the TDA Tailwater. The fact that losses for non-dam reaches are much lower than for reaches with dams suggests that residualization is not a dominant factor causing losses in the lower river. Smaller size and lower energy reserves likely make subyearlings more susceptible to death than yearlings. For fish of the lengths that we tagged in summer (>95 mm), the tag-effects study showed minimal tagging mortality, although it was higher than that observed for yearlings (Rich Brown, PNNL, Personal Communication).

\subsubsection{Bonneville Route-Specific Survival (Pooled Releases)}

\subsubsection{Spillway, B2 JBS, and B2CC}

There were few surprises in the point estimates of survival for the B2CC, B2 JBS, and spillway in summer. Survival at the spillway decreased almost $15 \%$ in summer relative to a $5 \%$ drop in spring, but the summer estimates for the B2CC and B2 JBS did not differ from spring estimates. Based upon nonoverlap of 95\% confidence intervals, the B2CC estimate of $95.24 \%$ (95\% CI $=89.09,101.4)$ could be significantly different from a $85.77 \%(95 \% \mathrm{CI}=82.48$, 89.07) estimate for the spillway, but the B2CC estimate did not differ from the B2 JBS estimate of $90.7 \%(95 \%$ CI $=84.6,96.8)$ and the B2 JBS estimate did not differ from that of the spillway, mostly because of poor precision associated with a small number of detected fish (91 at the B2CC, 189 at the B2 JBS, and 706 at the spillway).

\subsubsection{Spillway Survival by Condition}

Our comparison of subyearling survival during three different spill conditions in summer was confounded by an independent decline in survival as summer progressed and the chronological order of three successive spill conditions. The earliest spill condition through June 25 happened to be 24-h spill to the gas cap, and it had the highest survival $(96.0 \%$; 95\% CI = 88.7, 103.4). The next condition was 24-h $\leq 80,000$ cfs spill, which occurred from June 26 through about July 5. It was associated with a lower, although not significantly lower, survival estimate $(87.8 \%$; 95\% CI $=82.6,93.0)$ than the first 24-h high spill condition. The third spill condition was Bi-op spill of 75,000 cfs during the day and spill to the gas cap at night. It lasted through the end of the summer releases and not surprisingly was associated with a significantly lower survival of $78.3 \%(95 \% \mathrm{CI}=73.1,83.5)$ that probably would have occurred regardless of the spill treatment.

There are several comparisons of results that reinforce our conclusion that survival trends for BON spillway-passed subyearlings were not related to spill condition but to date within summer. First, survival estimates for the 24-h gas-cap spill condition and the 24-h low-spill condition did not differ significantly, probably because both occurred before a summer decline in survival was obvious. Second, survival estimates associated with 75,000 cfs spill during the day and gas-cap spill at night did not differ significantly and were low (75.82-79.99\%) because they occurred in mid to late summer when survival was low. In short, subyearlings that migrate in early summer had better survival than those migrating in later summer, regardless of spill condition at BON.

If there is a desire to test different spill conditions in summer, the confounding effect of decreasing survival through time must be considered and eliminated from the experimental design. We recommend confining tests of spill conditions to early summer periods or late summer periods to avoid confounding results. 


\subsection{Comparison of Estimates Using Preferred vs. As-Planned Arrays}

In spring and summer, there were no differences in survival statistics calculated from "preferred" and "as planned” arrays, either because estimates were identical (7 of 17 in spring and 8 of 10 in summer) or because pairs of estimates had overlapping standard deviations. Therefore, future studies should maximize return on investment by using the arrays described at the end of Section 4.3 above whenever multiple projects are being studied.

\subsection{Travel Time and Rate}

Travel times and rates were primarily a function of river discharge, particularly when discharge was above 250,000 cfs (Figure 4.6), as it was in spring and early summer. Relations between travel time and discharge were much weaker when river discharge was $<250,000 \mathrm{cfs}$, a level that first appeared after June 26 and continued throughout summer 2006. This period coincided with declining survival estimates associated with increased mortality or residualization of subyearlings. Travel times were slower in summer than they were in spring, particularly at downstream locations (Figure 4.7). On average, subyearlings released at JDA took 10 hours longer than yearlings to make it from the first array below JDA to the last array below BON. For TDA Tailrace releases, subyearlings took an average of 5 hours longer than yearlings to reach the last array below BON.

Travel times were useful for identifying delays at dams when specific routes could be identified. Median egress times for yearlings released at three locations at JDA were shortest for tailrace-released fish $(0.8 \mathrm{~h})$ because they had the shortest distance to travel, longer for fish released into the Turbine 9 front roll (1.2 h), and longest for fish released into the Turbine Intake 9c (1.3 h) turbine. Egress times did not differ between turbine- and front-roll releases. Egress times were significantly and inversely correlated with river discharge, so that egress time was about one hour longer for fish released at minimum discharge (311,000 cfs) than it was for fish released at maximum discharge (387,000 cfs).

The time it took fish to traverse the BON forebay until they were detected passing the dam was much longer for fish using the B2 JBS than for other routes, probably because of holding delays in gatewell slots. Passage times were 4.5 to 21.6 times longer for B2 JBS-passed fish than for fish passing the B2CC or spillway. Delays are not desirable in late summer when survival estimates appear to decline significantly over time.

\subsection{Using Time of Travel to Lag Paired Releases in Future Studies}

Travel times were useful for deriving predictors of lag times between paired releases as a function of discharge (Figures 3.30 through 3.35) for future studies. We recommend the use of those equations for determining appropriate lag times to assure mixing in a common downstream reach. 


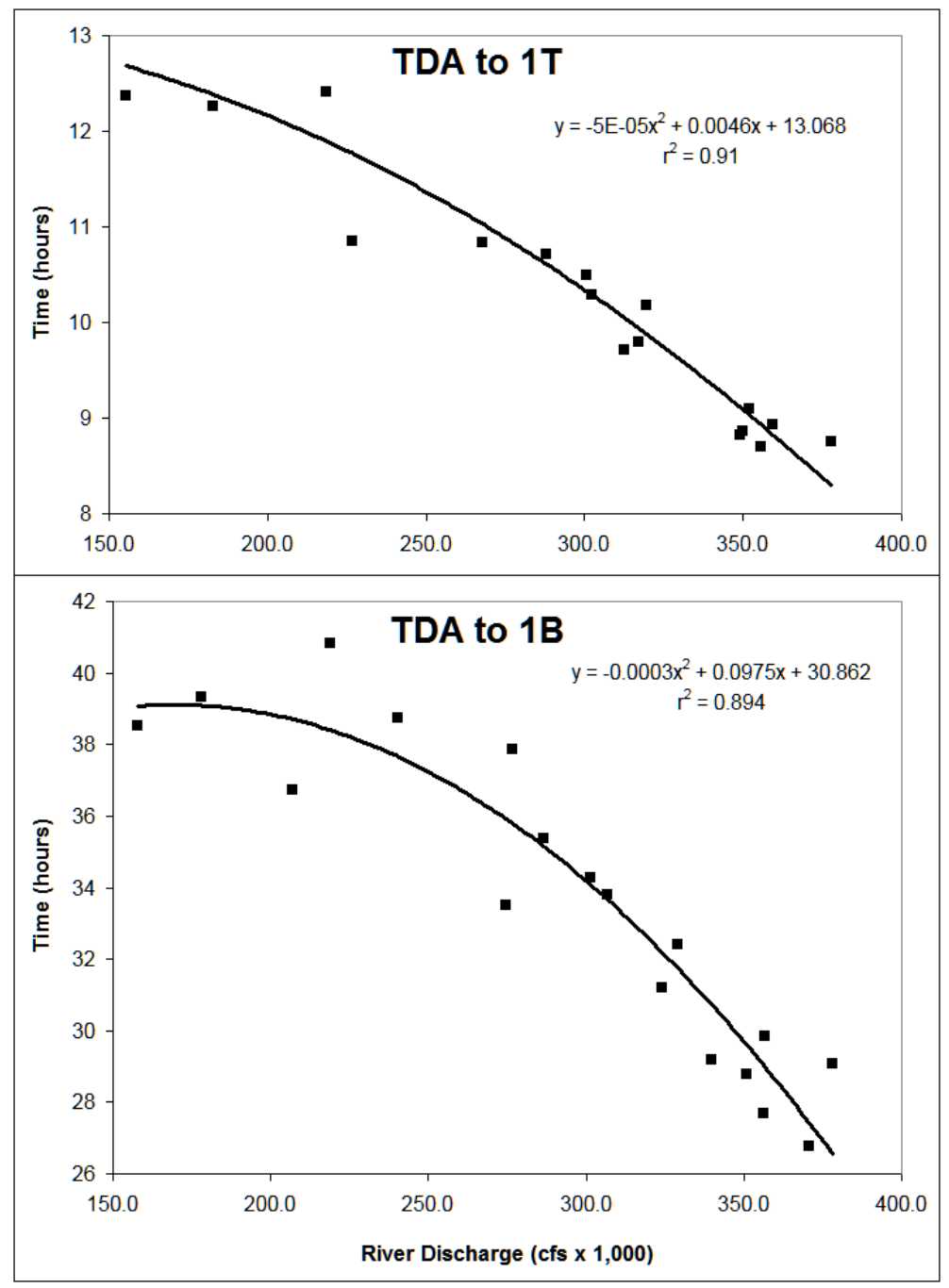

Figure 4.6. Travel Time as a Function of River Discharge for the River Reach from TDA to Array $1 T$ near Hood River and from TDA to Array 1B near Rooster Rock State Park below BON

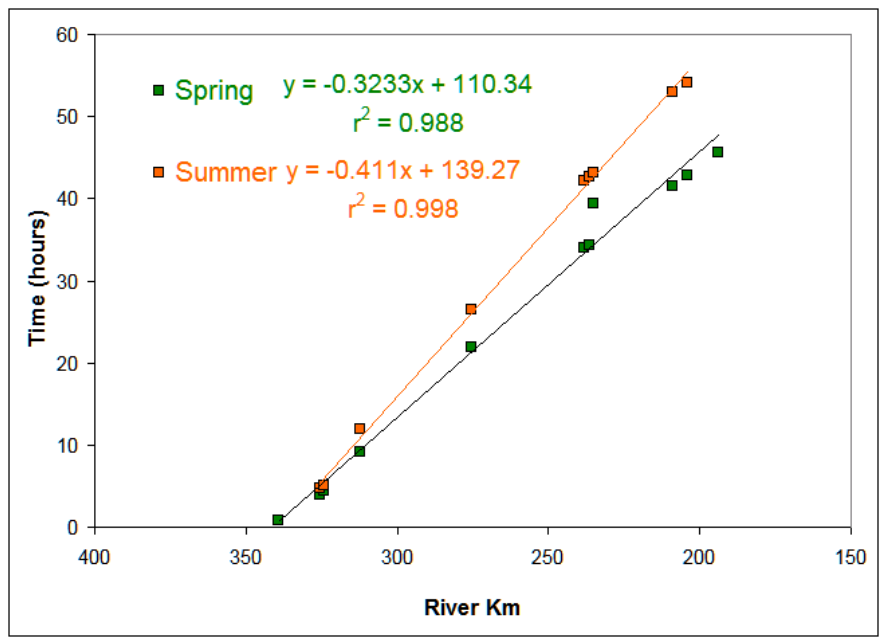

Figure 4.7. Travel Time in Spring and Summer as a Function of River Kilometer 


\subsection{Diel Distribution}

Fish regrouped at Array 3T in the BON forebay from all upstream releases and passed the dam at all hours of the day, because diel distributions of arrival from TDA and JDA Tailrace release locations complimented one another. Most TDA Tailrace-released fish arrived during hours when arrivals from the JDA Tailrace releases were low (compare Figures 3.36 and 3.37). This serendipitous and broad representation of hours would not have occurred if we had carefully lagged JDA and TDA Tailrace releases to maximize mixing in those releases in the TDA Tailwater. Arrival and passage times may have an effect on survival of fish passing BON, but we may not have detected it because most daytime-passed fish arrived from TDA Tailrace releases while most night-passed fish arrived from further upstream at JDA. When time of arrival is related to release location and most fish from day and night periods have different passage histories, diel effects on survival could be confounded.

\subsection{Cross Channel Distribution}

One of the advantages of acoustic telemetry is that cross-channel distributions can be compiled to learn more about how juvenile salmonids migrate through river channel cross sections. Radio telemetry can detect passing fish but usually does not provide distribution data without a special effort like that described by Hansel et al. (2005 and 2007) to sample approach patterns in the TDA forebay.

A majority of fish were detected away from shore each season, and there was little evidence that subyearlings preferred to migrate near shore instead of in the middle of the river in summer (Figure 3.39). Only two of nine lateral distribution plots showed any skew toward shore in summer. The most reliable evidence came from primary arrays in each tailwater (1J, 1T, and 1B) because they each had five or six autonomous nodes. Distribution data from arrays with three nodes were less informative because it was possible that some detections on the center node could have come from tagged fish passing on either side of the river if the tag was simultaneously detected on two nodes. Simultaneous detection was common for arrays in the JDA and TDA tailwaters but was rare on the three arrays in the BON Tailwater.

We worried a lot about tagged fish migrating around islands and avoiding detection in the BON Tailwater, but the percentage of detections on nodes sampling side channels was low in two of three locations. Those nodes with low detection percentages included Node 1 on Array 1B, which was on a shallow flat downstream of the Sand Island side channel, and Node 4 on Array 2B, which was located downstream of a Washington side channel created by Miller Island. High detection percentages on Node 4 of Array 3B located at the upstream opening to Camas Slough formed by Lady Island made it the only exception. The Camas Slough entrance is located on an outside bend across from the mouth of the Sandy River and was not far from the navigation channel, but clearly this site must be monitored for an array to be successful at Lady Island. In contrast, Node 4 below the Reed Island side channel was on an inside bend. Node 1 below the Sand Island side channel was over a large shallow mud flat on the south shore of a straight stretch of river.

The four autonomous nodes and five fixed nodes were deployed at the BON spillway for the last week of spring and all of the summer monitoring season, and these receivers showed a skew in the percent of detections toward the south end of the spillway (Figure 3.40). Only 1\% of all tags detected at the spillway were detected on the most northern receivers. The distribution of detections suggests passage locations but does not provide unequivocal evidence. A southerly skew in observed acoustic detections is consistent with the distribution of juvenile salmonid passage at the BON spillway based upon previous studies (Ploskey et al. 2006). 


\subsection{Physical Factors Affecting Array Detection Probabilities}

We examined the frequency of detections on one or more nodes within each array to assess receiver coverage and to help explain observed detection probabilities of arrays described previously. Obviously, simultaneous detections on two or more nodes indicates that detection fields overlapped, and this situation is highly preferred over a predominance of detections on a single node. Arrays with very high detection probabilities had a majority of detections on 2 to 5 nodes, and this was the case for five of nine arrays (1J, 3J, 1T, 2T, and 3T). About 70\% of detections at Array 2J were on single nodes, but only two nodes were functional in spring. Detection probabilities for JDA-released fish on Array 2J averaged 88\% in spring and $96.8 \%$ in summer when three nodes were functional. The percent of multiple-node detections on this array for 2006 would have been higher than 30\% had three nodes been functional each season.

The BON Tailwater arrays, which had the lowest detection probabilities (mean $=67.6 \%$ in spring and $80.2 \%$ in summer), received $80 \%$ or more detections on a single node (Figure 3.42 ). Array $1 \mathrm{~B}$ had $16 \%$ multiple node detections, showing that contributing factors of node density and bathymetry played a role in the poor performance of this array. The maximum depth of Array $1 \mathrm{~B}$ was $50 \mathrm{ft}$ and distance across the river was around 1,100 ft.; therefore, spacing of nodes was much greater than at Array 1T. Array $2 \mathrm{~B}$ and 3B performed similarly in spring with only $9 \%$ detections on multiple nodes. Both of these arrays had three nodes covering a 650-m transect across the river and a backwater node separate from the main transect. Array 2B had a node that was on the north side of Reed Island to detect tagged fish exiting the side channel and Array 3B had a node out the mouth of the Washougal River to detect tagged fish entering the Camas Slough. Separate nodes for sampling side channels would not allow for simultaneous detections on the side channel node and other nodes in the main channel, but multiple node detections should have occurred on the other three nodes.

The 2006 single- and multi-node detection results indicate that the best location for an array is at a cross section that is deep and narrow and the worst location is one with extensive shallows, uneven bathymetry, and islands that limit sound propagation and maximize multi-path signals. Primary factors affecting array performance include the shape (depth and width) of the river cross section and node density. In 2006, multiple detections were more common at upstream locations that tended to be deeper and narrower than locations below BON, where finding narrow cross sections without bars, islands, and side channels was difficult.

Examination of scatter plots of detection probability regressed on physical variables provided some useful recommendations for deploying acoustic receivers. The ultimate measure of array performance is detection probability, but it is not always clear what physical factors affect detection probabilities. Our examination of correlations of observed average detection probabilities with several physical factors (Table 3.59; Figure 3.41) led us to recommend the following to provide a reasonable chance of achieving detection probabilities $>80 \%$ in future studies.

1. Arrays should be located at the narrowest and deepest (mean depth $>14 \mathrm{~m}$ ) cross sections available, after allowing enough travel distance to avoid detecting dead fish on an array. There was a significant negative correlation between detection probability and river width and a positive correlation between the probability and mean depth.

2. We recommend deploying enough autonomous nodes to keep inter-nodal distances $<150 \mathrm{~m}$, so that node densities are at least six per km of river width.

3. Offshore distances to the first node on either side of the river should not exceed $100 \mathrm{~m}$. 
Limiting offshore distances to $50 \mathrm{~m}$ and inter-node distances to $100 \mathrm{~m}$ (i.e., node density $\approx 10 / \mathrm{km}$ ) would provide completely overlapping coverage so that the loss of any single node would not diminish detection probability. The loss of two adjacent nodes would only leave a small breach in coverage. An example approaching such a deployment was Array $1 \mathrm{~T}$ in the TDA Tailwater. This array had $82 \%$ of detections occurring on multiple nodes because the width of the river at this array location was only 500 $\mathrm{m}$ and five nodes were deployed there, so that the inter-node spacing with five nodes was $100 \mathrm{~m}$. The offshore distance was about $100 \mathrm{~m}$, which is double the $50 \mathrm{~m}$ recommended for overlapping coverage. The depth of the river in this location ranged from $35 \mathrm{ft}$ to $120 \mathrm{ft}$. TDA2 and TDA3 performed similarly in that around $80 \%$ of detections were multiple node detections.

\subsection{Data Gaps}

We tried to deploy nodes with overlapping coverage to minimize impacts of node failure or loss but did so without benefit of an extensive data set on range of detection. In short, we used node densities and inter-nodal distances based upon experience with detections on previous estuary arrays, and we were limited by the number of nodes available in 2006. Each year and season can have very different factors that result in malfunction, loss, or damage.

In spring, there were multiple factors that resulted in data loss. First, higher-than-average spring flows caused an increase in the amount of debris in the water to collide with and damage fragile hydrophones or snag rigging and drag entire assemblies downstream. Second, high water in spring 2006 delayed recovery of many of the first round of deployments for about three weeks because we used tagline canisters. In the initial deployment, tagline canisters were used to allow recovery of anchors and reduce costs; however, the combination of taglines, high pool elevations, and high flow caused serious recovery problems. Depending upon river depth, nodes rigged with tag-line canisters and $250 \mathrm{ft}$ of line surfaced for only 10-40 seconds after acoustic triggering of the release mechanism before submerging again. Dragging for re-submerged nodes was a very time consuming and potentially dangerous process. Also, with the limited amount of time nodes were at the surface, nodes could be damaged during a speedy approach by the recovery boat. If not dragged up, nodes were suspended below the surface and vulnerable to commercial vessels. This second problem was solved in late spring with the removal of all taglines and switching to disposable anchors.

The version of nodes deployed in 2006 provided no indication of whether they were acquiring data when sealed and ready for deployment. The 2007 version will have light emitting diodes to provide that indication, which will be a great improvement. We recommend having future nodes transmit a coded signal every 15-30 seconds to remotely indicate the node's status to researchers in a nearby boat. The codes might include the status of batteries, data-storage space, and data acquisition. With this capability, researchers could visit the nodes twice a week, once to check on performance without having to retrieve each node, and a second time, to download data.

The number of data gaps was lower in summer than in spring, but new problems arose. As water levels started to decline, especially below BON, one node was hit by a boat and destroyed, and two other nodes had to be removed due to low water levels. We had more problems with commercial fisherman snagging nodes, damaging node tips, and dragging nodes downstream. Talking with commercial fisherman and ultimately moving two arrays slightly helped decrease the probability of data loss, but it did not resolve the problem. The insufficiency of spare nodes became apparent in early summer when four nodes from various parts of the river went out and no spare nodes were available to replace them. Therefore, we removed the BON tertiary array and those nodes were used to fill holes in other arrays. 
After 3 weeks, we were able to borrow enough spare nodes from the Estuary Survival Study to redeploy the BON tertiary array, but by then half of the summer season was over. Until node losses can be accurately forecasted, we recommend that researchers plan to have one spare node for every four that will be deployed.

\subsection{Survival and Dam Operations, Rate of Travel, Water Temperature}

Significant positive correlations of survival probabilities with travel rates of some releases in spring and with travel rate and discharge in summer make sense based upon some published information (Raymond 1964; Sims and Ossiander 1981; Cada 1997). Most researchers agree that there may be a weak positive correlation between travel rate and survival, although variability is high and sometimes correlations are not significant (e.g., Bickford and Skalski 2000). We were reassured by significant positive correlations of survival with rate of travel for all three JDA releases in spring and for the JDA Tailrace release of subyearlings in summer. Explained variation ranged from $21 \%$ to $50 \%$. However, we were puzzled why the same correlations were not observed for TDA Tailrace releases in spring or summer. It also is strange that discharge, which is a strong correlate with travel time (Zabel and Anderson 1997), was not also consistently correlated with survival whenever we found significant correlations of survival with travel rate.

The strong decline in survival of subyearlings in summer would make correlations with discharge and temperature very likely, but it is not indicative of cause and effect. During the first half of summer, discharge was above the last 10-year average and temperature was about average, but during the second half of summer, the opposite was true (discharge was well below average and forebay temperatures were above average - see Figure 3.1). Loss of fish to residualization (reverse smoltification) in summer could produce spurious correlations of apparent survival with discharge and water temperatures, simply because there is a usually a downward trend in discharge and an upward trend in water temperature at that time. Sorting out cause and effect would require more information than is available from this study. One might accept that forebay water temperature could have a negative impact on survival in summer, as observed for both JDA and TDA releases, but it is more difficult to imagine a temperature effect in spring, as observed for TDA Tailrace releases.

\subsection{Required Sample Sizes}

We used detection and survival estimates from this study to estimate one-half $95 \%$ CIs as a function of sample size for all reported releases and model designs and tabulated those results so that readers could look up required sample sizes needed to obtain a desired 95\% CI, assuming similar detection and survival estimates to those observed in 2006. These tables should be useful for conducting power analyses for future studies that have a specific study design in mind. There is a one-to-one correspondence between the release-recapture study design, the desired level of precision, and the required sample size to achieve that precision, and calculations can only be performed within the context of a specific study design and a specified level of precision.

In addition to the relation between precision and sample size, performance of survival arrays and resulting detection probabilities have a significant impact on precision, and this relationship should not be ignored when estimating the number of tags needed for future studies. We have discussed in some detail the tradeoff between tagging more fish and deploying more nodes in Section 4.3 above. Our recommendation is to make certain that arrays are populated fully or even overpopulated with receivers to ensure high detection probabilities before buying more tags to increase precision, because tags will be 
more costly than receivers until detection probabilities exceed about 0.7 (Figure 4.8). Above a $70 \%$ detection probability, researchers will see little improvement in precision from increasing detection probabilities alone, unless survival also increases. See Section 4.11 above for a discussion of array performance and recommendations on populating arrays to ensure adequate detection probabilities.

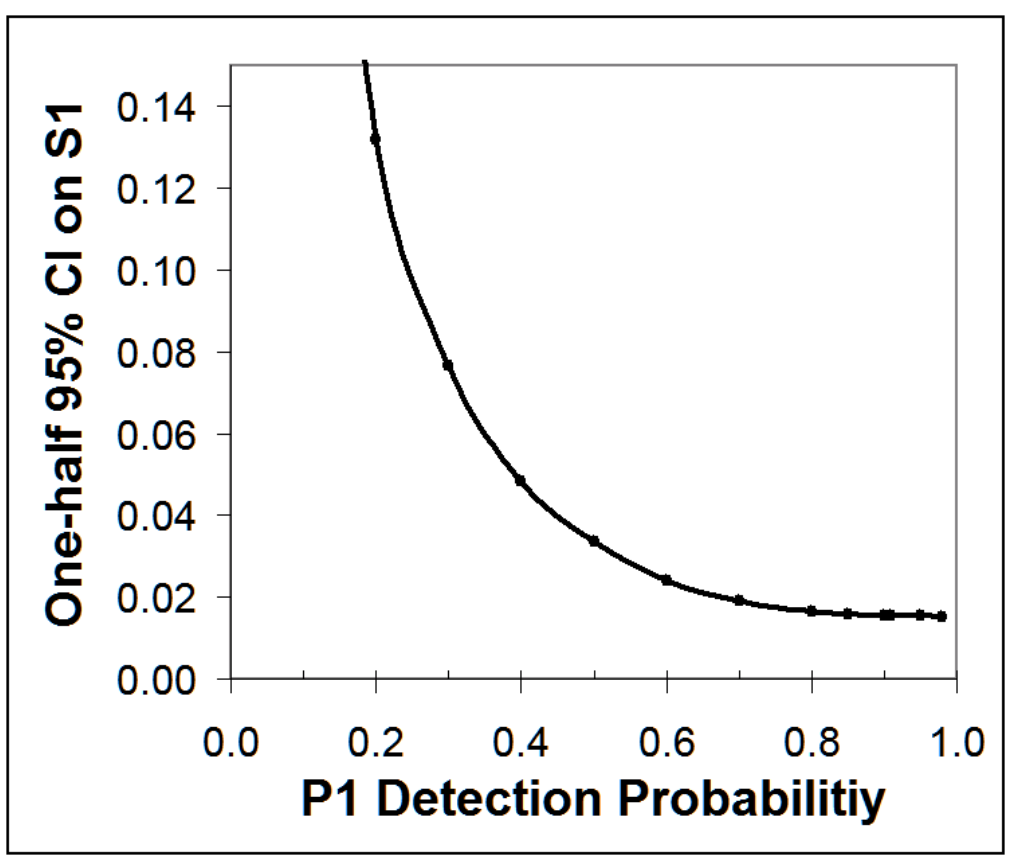

Figure 4.8. One-half $95 \% \mathrm{Cl}$ on Survival to a Primary Array (S1) as a Function of the Detection Probability to the Same Array $(\mathrm{P} 1)$. The relation assumes $\mathrm{R} 0=1,500 ; \mathrm{S} 1=0.9 ; \mathrm{S} 2=0.97$; $\mathrm{P} 2=\mathrm{P} 1$; and $\mathrm{S}^{*} \mathrm{P}=\mathrm{P} 2{ }^{*} \mathrm{~S} 2$, where $\mathrm{R} 0$ is the number of fish tagged and released; $\mathrm{S} 1$ is survival to Array $1 ; \mathrm{S} 2$ is survival to Array $2, \mathrm{P} 2$ is detection probability to Array 2 , and $\mathrm{S}^{\star} \mathrm{P}$ is the product of survival and detection to Array 3. 


\subsection{Recommendations}

1. We recommend placing additional emphasis on finding smaller yearlings to fully represent these length classes in the sample of tagged fish. We suspect that they tend to be under-represented because they are less visible to collectors. Checking length frequencies of SMF and tagged fish as the season progresses would help.

2. We had several recommendations for future tag-life studies and tag activations:

a. Systematically sample tags as they are activated for survival studies.

b. Record tag lot number as well as tag codes when fish are tagged, so that specific tag-life corrections can be made in the case of tag-manufacturing problems.

c. Record date and time to the nearest minute that each tag is activated for the tag-life study or JSATS survival studies. This could be accomplished by using a data-logging device when tag activations are verified with a hydrophone. The date and time settings are critical and should be checked regularly.

3. In years when funding is tight and survival is being studied at JDA, TDA, and BON, savings can be obtained by deploying one array above JDA, one below JDA, two below TDA, and three below BON. A JDA forebay array would serve to estimate survival to JDA and could allow for a virtual release for JDA. A single JDA Tailwater array located near the TDA forebay would serve as a primary survival array and as a TDA forebay array for forming a virtual release for TDA. The two arrays below TDA would be located near the Bingen Marina to split the long TDA tailwater into two long segments, and the second array near the BON forebay would serve as a secondary array and to provide a virtual release for BON.

4. If there is a desire to test different spill conditions in summer, the confounding effect of decreasing survival through time must be considered and eliminated from the experimental design. We recommend confining tests of spill conditions to early summer periods or late summer periods to avoid a confounding effect.

5. We recommend that lag times between the upstream and downstream releases of a pair be reevaluated for future studies based upon anticipated river discharge. The equations derived in this study for estimating an appropriate lag time to ensure adequate mixing in a common downstream reach of paired releases often were related to river discharge and represent a good starting place. However, consideration of travel-time data from other years with lower river discharge should increase the robustness of estimates.

6. Our examination of correlations of observed average detection probabilities with several physical factors (Figure 3.40) led us to recommend the following to provide a reasonable chance of achieving detection probabilities $>80 \%$ in future studies.

a. Arrays should be located at the narrowest and deepest (mean depth $>14 \mathrm{~m}$ ) cross sections available, after allowing enough travel distance to avoid detecting dead fish on an array. There was a significant negative correlation between detection probability and river width and a positive correlation between the probability and mean depth.

b. We recommend deploying enough autonomous nodes to keep inter-nodal distances $<150$ $\mathrm{m}$, so that node densities are at least six per $\mathrm{km}$ of river width.

c. Offshore distances to the first node on either side of the river should not exceed $100 \mathrm{~m}$. 
7. We recommend making certain that arrays are populated fully or even overpopulated with receivers to ensure high detection probabilities before buying more tags to increase precision. The latter approach will usually be more costly than the former until detection probabilities are high.

8. We recommend having future nodes transmit a coded signal every 15-30 seconds to remotely indicate the node's status to researchers in a nearby boat. The codes might include the status of batteries, data-storage space, and data acquisition. With this capability, researchers could visit the nodes twice a week, once to check on performance without having to retrieve each node, and a second time to download data. A more sophisticated setup might include an underwater hydrophone cabled to a radio- or satellite-uplink buoy so that coded acoustic signals from all nodes could be transmitted to a real-time monitoring web site on the Internet.

9. Until node losses can be accurately forecasted, we recommend that researchers plan to have one spare node for every four that will be deployed. 


\subsection{References}

Absolon, R. F., E. M. Dawley, B. P. Sandford, J. W. Ferguson, and D. A. Bregeon. 2002. Relative Survival of Juvenile Salmon Passing through the Spillway of The Dalles Dam, 1997-2000. Report of Research by the Northwest Fisheries Science Center, National Marine Fisheries Service for the U. S. Army Corps of Engineer, Portland District, Portland, Oregon.

Bickford, S. H. and J. R. Skalski. 2000. "Reanalysis and interpretation of 25 years of Snake-Columbia River juvenile salmonid survival studies.” North American Journal of Fisheries Management. 20:53-68.

Brett, J.R. 1952. “Temperature Tolerance in Young Pacific Salmon, Genus Oncorhynchus.” Journal of the Fisheries Research Board of Canada. 9: 265-323.

Burnham, K.P., D.R Anderson, G.C. White, C. Brownie, and K.H. Pollock. 1987. "Design and analysis methods for fish survival estimates based on release-recapture." American Fisheries Society Monograph No. 5.

Cada, G. F., M.D. Deacon, S.V. Mitz, and M.S. Bevelhimer. 1997. Effects of water velocity on the survival of downstream-migrating juvenile salmon and steelhead: A review with emphasis on the Columbia River Basin. Reviews in Fisheries Science 5(2):131-183.

Cash, K.M., D.M. Faber, T.W. Hatton, E.C. Jones, R.J. Magie, N.M. Swyers, R.K. Burns, M.D. Sholtis, S.A. Zimmerman, J.S. Hughes, T.L. Gilbride, N.S. Adams, and D.W. Rondorf. 2005. Threedimensional behavior and passage of juvenile Salmonids at The Dalles Dam, 2004. Final Report by U.S. Geological Survey and Pacific Northwest National Laboratory to the U.S. Army Corps of Engineers, Portland, Oregon.

Cobleigh, M. M. 2003. Stress, Growth and Survival of Juvenile Chinook Salmon. MS Thesis, University of Washington, Seattle, Washington.

Conover, W. J. 1980. Practical Nonparametric Statistics. Wiley \& Sons, New York.

Cook CB, GA McMichael, JA Vucelick, B Dibrani, EE Hockersmith, CA Duberstein, ID Welch, BJ Bellgraph, CA McKinstry, P Titzler, RR Kirkham, and MD Bleich. 2007. Lower Monumental Reservoir Juvenile Fall Chinook Salmon Behavior Studies . PNWD-3800, Battelle-Pacific Northwest Division, Richland, Washington.

Counihan, T.D., J.H. Petersen, N.S. Adams, R.S. Shively, and H.C. Hansel. 2002a. Feasibility of Extracting Survival Information from Radio-Telemetry Studies at the John Day Dam, 1999. Annual Report prepared by the U.S. Geological Survey, Cook, Washington, for the U.S. Army Corps of Engineers, Portland District, Portland, Oregon.

Counihan, T. D., J. H. Petersen, and K. J. Felton. 2002b. Survival Estimates of Migrant Juvenile Salmonids in the Columbia River from John Day Dam through Bonneville Dam using RadioTelemetry, 2000. Annual report prepared by the U.S. Geological Survey, Cook, Washington, for the U.S. Army Corps of Engineers, Portland, Oregon. 
Counihan, T.D., G.S. Holmberg, and J.H. Petersen. 2003. Survival Estimates of Migrant Juvenile Salmonids through Bonneville Dam Using Radio-Telemetry, 2002. Annual Report prepared by the U.S. Geological Survey, Cook, Washington, for the U.S. Army Corps of Engineers, Portland District, Portland, Oregon.

Counihan, T.D., A.L. Puls, C.E. Walker, J.M. Hardiman, and G.S. Holmberg. 2006a. Survival Estimates of Migrant Juvenile Salmonids through The Dalles Dam Using Radiotelemetry, 2004. Final Report of Research prepared by the U.S. Geological Survey, Cook, Washington, for the U.S. Army Corps of Engineers, Portland, Oregon.

Counihan, T.D., A.L. Puls, C.E. Walker, J.M. Hardiman, and G.S. Holmberg. 2006b. Survival Estimates of Migrant Juvenile Salmonids through The Dalles Dam Using Radiotelemetry, 2005. Final Report of Research prepared by the U.S. Geological Survey, Cook, Washington, for the U.S. Army Corps of Engineers, Portland, Oregon.

Counihan, T.D., G.S. Holmberg, C.E. Walker, and J.M. Hardiman. 2006c. Survival Estimates of Migrant Juvenile Salmonids through The Dalles Dam using Radiotelemetry, 2002. Final Report of Research prepared by the U.S. Geological Survey, Cook, Washington, for the U.S. Army Corps of Engineers, Portland, Oregon.

Counihan, T. D., G. S. Holmberg, and J. H. Peterson. 2006d. Survival Estimates of Migrant Juvenile Salmonids in the Columbia River through John Day Dam using Radio Telemetry, 2002. Annual Report by the U.S. Geological Survey, Columbia River Research Laboratory, Cook, Washington, for the U.S. Army Engineer District, Portland, Oregon.

Counihan, T. D., G. S. Holmberg, C. E. Walker, and J. M. Hardiman. 2006e. Survival Estimates of Migrant Juvenile Salmonids in the Columbia River through John Day Dam using RadioTelemetry, 2003. Annual Report by the U.S. Geological Survey, Columbia River Research Laboratory, Cook, Washington, for the U.S. Army Engineer District, Portland, Oregon.

Counihan, T. D., J. Hardiman, C. Walker, A. Puls, and G. Holmberg. 2006f. Survival Estimates of Migrant Juvenile Salmonids through Bonneville Dam using Radio Telemetry, 2004. Annual Report by the U.S. Geological Survey, Columbia River Research Laboratory, Cook, Washington, for the U.S. Army Engineer District, Portland, Oregon.

Counihan, T. D., J. Hardiman, C. Walker, A. Puls, and G. Holmberg. 2006g. Survival Estimates of Migrant Juvenile Salmonids through Bonneville Dam using Radio Telemetry, 2005. Annual Report by the U.S. Geological Survey, Columbia River Research Laboratory, Cook, Washington, for the U.S. Army Engineer District, Portland, Oregon.

Efron, B., and R. J. Tibshirani. 1993. An Introduction to the Bootstrap. Chapman \& Hall, New York.

Faber, D.M., M.A. Weiland, R.A. Moursund, and T.J. Carlson. 2001. Evaluation of the Fish Passage Effectiveness of the Bonneville I Prototype Surface Collector using Three-Dimensional Ultrasonic Fish Tracking, PNNL-13526, Prepared for U.S. Army Corps of Engineer District, Portland, Oregon by Pacific Northwest National Laboratory, Richland, Washington.

Dawley, E.M., L.G. Gilbreath, R.F. Absolon, B.P. Sandford, and J.W. Ferguson. 2000. Relative Survival of Juvenile Salmon Passing through the Spillway and the Ice and Trash Sluiceway of The Dalles Dam, 1998. Report of Research by the Northwest Fisheries Science Center, National Marine Fisheries Service for the U.S. Army Engineer District, Portland, Oregon. 
Efron, B., and R. J. Tibshirani. 1993. An Introduction to the Bootstrap. Chapman \& Hall, New York.

Hansel, H.C., J.W. Beeman, S.D. Juhnke, P.V. Haner, and L.L. Dingmon. 2005. Estimates of Fish-, Spilland Sluiceway Efficiencies of Radio-Tagged Juvenile Chinook Salmon during Spring and Summer at The Dalles Dam in 2004. Annual Report of Research to the U.S. Army Corps of Engineers, Portland District, Portland, Oregon.

Hansel, H. C. , S. D. Juhnke, P. V. Haner, L.L. Dingmon, and J. W. Beeman. 2007. Estimates of Fish-, Spill-, and Sluiceway-Passage Efficiencies of Radio-Tagged Juvenile Chinook Salmon during Spring and Summer at The Dalles Dam in 2005. Draft final report of research. Prepared by the U.S. Geological Survey for the U.S. Corps of Engineers, Portland, Oregon.

Hockersmith, E. E., R. S. Brown, and T. L. Liedtke. 2007. Comparative Performance of Acoustic-tagged and PIT-tagged Juvenile Salmonids. Draft Report prepared for the U.S. Army Corps of Engineer District, Portland, Oregon, USA.

Johnson, G. E., J. Beeman, I. Duran, and A. Puls. 2007. Synthesis of Juvenile Salmonid Passage Studies at The Dalles Dam, Volume II, 2001-2005. Draft Technical Report by the Pacific Northwest National Laboratory, Richland, Washington, for the U.S. Army Corps of Engineers District, Portland, Oregon.

McComas, R. L., J. W. Ferguson, S. G. Smith, G. A. McMichael, and T. J. Carlson. 2004. A study to estimate salmonid survival through the Columbia River Estuary using acoustic tags. Abstract in the 2004 Anadromous Fish Evaluation Program, U. S. Army Corps of Engineer District, Portland, Oregon.

McComas, R. L., J. W. Feguson, S. G. Smith, G. A. McMichael, T. J. Carlson, J. A. Vucelick, and K. D. Ham. 2005. A study to estimate salmonid survival through the Columbia River Estuary using Acoustic Tags.2005. Abstract in the 2005 Anadromous Fish Evaluation Program, U. S. Army Corps of Engineer District, Portland, Oregon, USA.

McComas, R. L., L. Gilbreath, Eric Hockersmith, and S. G. Smith, G. A. McMichael, T. J. Carlson, J. A. Vucelick, and K. D. Ham. 2006. A study to estimate salmonid survival through the Columbia River Estuary using Acoustic Tags, 2006. Abstract in the 2006 Anadromous Fish Evaluation Program, U. S. Army Corps of Engineer District, Portland, Oregon, USA.

Ploskey, G. R. and T. J. Carlson. 2004. Comparison of Blade-Strike Modeling Results with Empirical Data. Technical Report PNNL-14603 to the U. S. Department of Energy Hydropower Program.

Ploskey, G. R., G. E. Johnson, A. E. Giorgi, R. L. Johnson, J. R. Stevenson, Synthesis of Biological Research on Juvenile Fish Passage and Survival at Bonneville Dam through 2005. Draft Technical Report by the Pacific Northwest National Laboratory, Richland, Washington, for the U.S. Army Corps of Engineers, Portland District, Portland, Oregon.

Peven, C., A. Giorgi, J. Skalski, M. Langeslay, A. Grassell, S.G. Smith, T. Counihan, R. Perry, and S. Bickford. 2005. Guidelines and Recommended Protocols for Conducting, Analyzing, and Reporting Juvenile Salmonid Survival Studies in the Columbia River Basin. Published electronically; available in PDF electronic format from chuckp@chelanpud.org. 
Raymond, H. L. 1964. Effects of Dams on the Upstream Migration Rates and Timing of Columbia River Salmonids. Report for Fish Passage Research Program of the Bureau of Commercial Fisheries, Northwest Fisheries Science Center, Seattle, Washington.

Robson, D. S., and H. A. Regier. 1964. "Sample size in Petersen mark-recapture experiments." Transactions of the American Fisheries Society 93:215-226.

Seber, G. A. F. 1982. The Estimation of Animal Abundance. MacMillan, New York.

Sims, C. W., and F. Ossiander. 1981. Migrations of Juvenile Chinook Salmon and Steelhead in the Snake River, from 1973 to 1979, a Research Summary. Report prepared by the National Marine Fisheries Service for the U.S. Army Corps of Engineers, Portland, Oregon.

Skalski, J. R., R. L. Townsend, T. W. Steig, J. W. Horchik, G. W. Tritt, and A. Grassell. 2003a. Estimation of Rock Island Project Passage Survival of Yearling Chinook Salmon Smolts in 2003 Using Acoustic and PIT-Tag Release-Recapture Methods. Report prepared by the University of Washington, School of Aquatic and Fishery Sciences, for the Public Utility District No. 1 of Chelan County, Wenatchee, Washington.

Skalski, J. R., R. L. Townsend, T. W. Steig, J. W. Horchik, G. W. Tritt, and R. D. McDonald. 2003 b. Estimation of Survival of Yearling Chinook Salmon Smolts at the Rock Island Dam, Pool, and Project in 2002 Using Acoustic and PIT-Tag Release-Recapture Methods. Report prepared by the University of Washington, School of Aquatic and Fishery Sciences, for the Public Utility District No. 1 of Chelan County, Wenatchee, Washington.

Skalski, J. R., S. G. Smith, R. N. Iwamoto, J. G. Williams, and A. Hoffmann. 1998. "Use of PIT-tags to estimate survival of migrating juvenile salmonids in the Snake and Columbia Rivers." Canadian Journal of Fisheries and Aquatic Sciences 55:1484-1493.

Skalski, J.R. 1999. Statistical Methods to Extract Survival Information from the John Day and The Dalles Dams Radiotag Studies. Report prepared by the University of Washington, School of Aquatic and Fishery Sciences, for the U.S. Army Corps of Engineers, Portland, Oregon.

Tiffan, K.F., D.W. Rondorf, and P.G. Wagner. 2000. "Physiological development and migratory behavior of subyearling chinook salmon in the Columbia river." North American Journal of Fisheries Management 20: 28-40.

Townsend, R. L., J. R. Skalski, P. Dillingham, and T. W. Steig. 2006. "Correcting bias in survival estimation resulting from tag failure in acoustic and radiotelemetry studies." Journal of Agricultural Biology and Environmental Statistics (in press).

Zabel, R.W. and J.J. Anderson. 1997. A Model of the Travel Time of Migrating Juvenile Salmon, with an Application to Snake River Spring Chinook Salmon. North American Journal of Fisheries Management 17(1): 93-100.

Zabel, R. W., T. W. Wagner, J. L. Congleton, S. C. Smith, and L. C. Williams. 2005. Survival and selection of migrating salmon from capture-recapture models with individual traits. Ecological Applications 15(4): 1427-1439. 


\section{Appendix A}

\section{Tables of All Fish Tagging and Release Data}


Acoustic Telemetry Studies of Juvenile Chinook Salmon Survival at the Lower Columbia Projects in 2006 
Table A.1. Summary of Tagging Numbers and Statistics by Release Location, and Release Date in Spring

\begin{tabular}{|c|c|c|c|c|c|c|c|c|}
\hline \begin{tabular}{|l} 
Release \\
Location
\end{tabular} & $\begin{array}{l}\text { Release } \\
\text { Date }\end{array}$ & $\begin{array}{l}\text { Number } \\
\text { Released }\end{array}$ & $\begin{array}{l}\text { Number } \\
\text { Surviving } \\
\text { Tagging }\end{array}$ & $\begin{array}{l}\text { Percent } \\
\text { Alive }\end{array}$ & $\begin{array}{l}\text { Number } \\
\text { Dead }\end{array}$ & $\begin{array}{l}\text { Percent } \\
\text { Dead }\end{array}$ & $\begin{array}{l}\text { Number } \\
\text { Sacrificed }\end{array}$ & $\begin{array}{l}\text { Percent } \\
\text { Sacrificed }\end{array}$ \\
\hline JDA Front Roll & 05/16/06 & 55 & 54 & 98.2 & 1 & 1.8 & 0 & 0 \\
\hline JDA Front Roll & 05/19/06 & 60 & 59 & 98.3 & 1 & 1.7 & 0 & 0 \\
\hline JDA Front Roll & 05/21/06 & 60 & 59 & 98.3 & 1 & 1.7 & 0 & 0 \\
\hline JDA Front Roll & 05/23/06 & 70 & 70 & 100 & 0 & 0 & 0 & 0 \\
\hline JDA Front Roll & $05 / 25 / 06$ & 60 & 60 & 100 & 0 & 0 & 0 & 0 \\
\hline JDA Front Roll & 05/27/06 & 80 & 80 & 100 & 0 & 0 & 0 & 0 \\
\hline JDA Front Roll & 06/01/06 & 60 & 60 & 100 & 0 & 0 & 0 & 0 \\
\hline JDA Front Roll & 06/03/06 & 55 & 55 & 100 & 0 & 0 & 0 & 0 \\
\hline JDA Intake 9C & 05/16/06 & 55 & 55 & 100 & 0 & 0 & 0 & 0 \\
\hline JDA Intake 9C & 05/19/06 & 63 & 63 & 100 & 0 & 0 & 0 & 0 \\
\hline JDA Intake 9C & 05/21/06 & 58 & 58 & 100 & 0 & 0 & 0 & 0 \\
\hline JDA Intake 9C & 05/23/06 & 68 & 68 & 100 & 0 & 0 & 0 & 0 \\
\hline JDA Intake 9C & $05 / 25 / 06$ & 60 & 60 & 100 & 0 & 0 & 0 & 0 \\
\hline JDA Intake 9C & 05/27/06 & 80 & 80 & 100 & 0 & 0 & 0 & 0 \\
\hline JDA Intake 9C & 06/01/06 & 60 & 60 & 100 & 0 & 0 & 0 & 0 \\
\hline JDA Intake 9C & 06/03/06 & 56 & 56 & 100 & 0 & 0 & 0 & 0 \\
\hline JDA Tailrace & 05/16/06 & 55 & 54 & 98.2 & 1 & 1.8 & 0 & 0 \\
\hline JDA Tailrace & 05/19/06 & 60 & 60 & 100 & 0 & 0 & 0 & 0 \\
\hline JDA Tailrace & 05/21/06 & 60 & 60 & 100 & 0 & 0 & 0 & 0 \\
\hline JDA Tailrace & 05/23/06 & 70 & 70 & 100 & 0 & 0 & 0 & 0 \\
\hline JDA Tailrace & 05/25/06 & 42 & 41 & 97.6 & 0 & 0 & 1 & 2.4 \\
\hline JDA Tailrace & 05/27/06 & 79 & 77 & 97.5 & 1 & 1.3 & 1 & 1.3 \\
\hline JDA Tailrace & 06/01/06 & 80 & 79 & 98.8 & 1 & 1.3 & 0 & 0 \\
\hline JDA Tailrace & 06/03/06 & 54 & 40 & 74.1 & 2 & 3.7 & 12 & 22.2 \\
\hline TDA Tailrace & 05/16/06 & 97 & 96 & 99 & 1 & 1 & 0 & 0 \\
\hline TDA Tailrace & 05/19/06 & 120 & 120 & 100 & 0 & 0 & 0 & 0 \\
\hline TDA Tailrace & 05/21/06 & 120 & 120 & 100 & 0 & 0 & 0 & 0 \\
\hline TDA Tailrace & $05 / 23 / 06$ & 90 & 90 & 100 & 0 & 0 & 0 & 0 \\
\hline TDA Tailrace & $05 / 25 / 06$ & 50 & 48 & 96 & 0 & 0 & 2 & 4 \\
\hline TDA Tailrace & 05/27/06 & 89 & 85 & 95.5 & 4 & 4.5 & 0 & 0 \\
\hline TDA Tailrace & 06/01/06 & 67 & 67 & 100 & 0 & 0 & 0 & 0 \\
\hline TDA Tailrace & 06/03/06 & 153 & 153 & 100 & 0 & 0 & 0 & 0 \\
\hline TDA Tailrace & 06/05/06 & 215 & 199 & 92.6 & 2 & 0.9 & 13 & 6 \\
\hline Average & & & & & & 0.597 & & \\
\hline
\end{tabular}


Table A.2. Summary of Tagging Numbers and Statistics by Release Location, and Release Date in Summer

\begin{tabular}{|c|c|c|c|c|c|c|c|c|}
\hline $\begin{array}{l}\text { Release } \\
\text { Location } \\
\end{array}$ & $\begin{array}{l}\text { Release } \\
\text { Date } \\
\end{array}$ & $\begin{array}{l}\text { Number } \\
\text { Released } \\
\end{array}$ & $\begin{array}{l}\text { Number } \\
\text { Surviving } \\
\text { Tagging } \\
\end{array}$ & $\begin{array}{l}\text { Percent } \\
\text { Alive } \\
\end{array}$ & $\begin{array}{l}\text { Number } \\
\text { Dead } \\
\end{array}$ & $\begin{array}{l}\text { Percent } \\
\text { Dead } \\
\end{array}$ & $\begin{array}{l}\text { Number } \\
\text { Sacrificed } \\
\end{array}$ & $\begin{array}{l}\text { Percent } \\
\text { Sacrificed } \\
\end{array}$ \\
\hline BON B2CC & Summer & 17 & 0 & 0 & 0 & 0 & 17 & 100 \\
\hline BON B2CC & Summer & 7 & 0 & 0 & 0 & 0 & 7 & 100 \\
\hline BON B2CC & Summer & 6 & 0 & 0 & 0 & 0 & 6 & 100 \\
\hline JDA Tailrace & 6/13/2006 & 50 & 50 & 100 & 0 & 0 & 0 & 0 \\
\hline JDA Tailrace & $6 / 15 / 2006$ & 50 & 50 & 100 & 0 & 0 & 0 & 0 \\
\hline JDA Tailrace & $6 / 20 / 2006$ & 50 & 50 & 100 & 0 & 0 & 0 & 0 \\
\hline JDA Tailrace & 6/22/2006 & 50 & 49 & 98 & 1 & 2 & 0 & 0 \\
\hline JDA Tailrace & 6/27/2006 & 100 & 100 & 100 & 0 & 0 & 0 & 0 \\
\hline TDA Tailrace & 6/13/2006 & 200 & 196 & 98 & 4 & 2 & 0 & 0 \\
\hline TDA Tailrace & 6/15/2006 & 200 & 200 & 100 & 0 & 0 & 0 & 0 \\
\hline TDA Tailrace & $6 / 20 / 2006$ & 200 & 196 & 98 & 4 & 2 & 0 & 0 \\
\hline TDA Tailrace & $6 / 22 / 2006$ & 200 & 200 & 100 & 0 & 0 & 0 & 0 \\
\hline TDA Tailrace & $6 / 27 / 2006$ & 200 & 200 & 100 & 0 & 0 & 0 & 0 \\
\hline TDA Tailrace & $6 / 28 / 2006$ & 200 & 200 & 100 & 0 & 0 & 0 & 0 \\
\hline TDA Tailrace & $7 / 1 / 2006$ & 250 & 245 & 98 & 3 & 1.2 & 0 & 0 \\
\hline TDA Tailrace & 7/7/2006 & 250 & 248 & 99.2 & 2 & 0.8 & 0 & 0 \\
\hline TDA Tailrace & 7/11/2006 & 250 & 246 & 98.4 & 4 & 1.6 & 0 & 0 \\
\hline TDA Tailrace & 7/13/2006 & 252 & 246 & 97.6 & 6 & 2.4 & 0 & 0 \\
\hline Average & & & & & & 0.667 & & \\
\hline
\end{tabular}


Acoustic Telemetry Studies of Juvenile Chinook Salmon Survival at the Lower Columbia Projects in 2006

Table A.3. Summary of Tagging Numbers and Statistics by Release Location, and Release Date in Summer

\begin{tabular}{||lllllllll||}
\hline \hline $\begin{array}{l}\text { Release } \\
\text { Location }\end{array}$ & Season & $\begin{array}{l}\text { Number } \\
\text { Released }\end{array}$ & $\begin{array}{l}\text { Number } \\
\text { Alive }\end{array}$ & $\begin{array}{l}\text { Percent } \\
\text { Alive }\end{array}$ & $\begin{array}{l}\text { Number } \\
\text { Dead }\end{array}$ & $\begin{array}{l}\text { Percent } \\
\text { Dead }\end{array}$ & $\begin{array}{l}\text { Number } \\
\text { Sacrificed }\end{array}$ & $\begin{array}{l}\text { Percent } \\
\text { Sacrificed }\end{array}$ \\
\hline \hline JDA Front Roll & Spring & 500 & 497 & 99.4 & 3 & 0.6 & 0 & 0.0 \\
JDA Intake 9C & Spring & 500 & 500 & 100.0 & 0 & 0.0 & 0 & 0.0 \\
JDA Tailrace & Spring & 500 & 481 & 96.2 & 5 & 1.0 & 14 & 2.8 \\
TDA Tailrace & Spring & 1,001 & 978 & 97.7 & 7 & 0.7 & 15 & 1.5 \\
BON B2CC & Summer & 30 & 0 & 0.0 & 0 & 0.0 & 30 & 100.0 \\
JDA Tailrace & Summer & 300 & 299 & 99.7 & 1 & 0.3 & 0 & 0.0 \\
TDA Tailrace & Summer & 2,202 & 2,177 & 98.9 & 23 & 1.0 & 0 & 0.0 \\
\hline
\end{tabular}


Acoustic Telemetry Studies of Juvenile Chinook Salmon Survival at the Lower Columbia Projects in 2006

Table A.4. List of Appendix A CSV Files on an Accompanying Compact Disc*. Variables in the CSV files are defined in Table A.5 below.

\begin{tabular}{||cl||}
\hline \hline File & \multicolumn{1}{c||}{ Description } \\
\hline \hline Appendix A - Spring Codes.CSV & $\begin{array}{l}\text { PIT and Acoustic Tag Codes Released in Spring 2006 by Date, Time, and Location } \\
\text { followed by dam operations data }\end{array}$ \\
Appendix A - Summer Codes.CSV & $\begin{array}{l}\text { PIT and Acoustic Tag Codes Released in Summer } 2006 \text { by Date, Time and Location } \\
\text { followed by dam operations data }\end{array}$ \\
\hline *A compact disc accompanying the report has two files: Appendix A - Spring Codes.CSV and Appendix a - Summer Codes.CSV.
\end{tabular}


Table A.5. Definitions of Variables in Headings of Appendix A CSV Files on the Accompanying Compact Disc.

\begin{tabular}{|c|c|}
\hline Variable & Definition \\
\hline SEASON & Fish Released season Spring/Summer \\
\hline ReleaseDate & Fish released date \\
\hline ReleaseTime & Fish released time \\
\hline TagCode & PIT tag code \\
\hline AcousticTagCode & Acoustic Tag Code \\
\hline ActivationDate & Acoustic Tag Activated date \\
\hline ForkLength & Fish length \\
\hline Weight & Fish weight \\
\hline Mortality & MORT/NO MORT \\
\hline ReleaseLoc & Fish Release Location \\
\hline FB & Forebay Elevation, ft above mean sea level \\
\hline TW & Tailwater Elevation, $\mathrm{ft}$ above mean sea level \\
\hline N_Units & Number of operating turbines \\
\hline PH1_Q & Powerhouse 1 Discharge (cfs x 1,000 ) \\
\hline PH2_Q & Powerhouse 2 Discharge (cfs x 1,000) \\
\hline Spill_Q & Spillway Discharge (cfs x 1,000) \\
\hline Total_Q & Total Project Discharge (cfs x 1,000 ) \\
\hline $\mathrm{T} 1$ & Turbine 1 Discharge (cfs x 1,000) \\
\hline $\mathrm{T} 2$ & Turbine 2 Discharge (cfs x 1,000) \\
\hline T3 & Turbine 3 Discharge (cfs x 1,000) \\
\hline $\mathrm{T} 4$ & Turbine 4 Discharge (cfs x 1,000) \\
\hline T5 & Turbine 5 Discharge (cfs x 1,000 ) \\
\hline T6 & Turbine 6 Discharge (cfs x 1,000) \\
\hline $\mathrm{T} 7$ & Turbine 7 Discharge (cfs x 1,000 ) \\
\hline $\mathrm{T} 8$ & Turbine 8 Discharge (cfs x 1,000) \\
\hline T9 & Turbine 9 Discharge (cfs x 1,000) \\
\hline $\mathrm{T} 10$ & Turbine 10 Discharge (cfs x 1,000) \\
\hline $\mathrm{T} 11$ & Turbine 11 Discharge (cfs x 1,000) \\
\hline $\mathrm{T} 12$ & Turbine 12 Discharge (cfs x 1,000) \\
\hline $\mathrm{T} 13$ & Turbine 13 Discharge (cfs x 1,000) \\
\hline $\mathrm{T} 14$ & Turbine 14 Discharge (cfs x 1,000) \\
\hline $\mathrm{T} 15$ & Turbine 15 Discharge (cfs x 1,000) \\
\hline $\mathrm{T} 16$ & Turbine 16 Discharge (cfs x 1,000) \\
\hline $\mathrm{T} 17$ & Turbine 17 Discharge (cfs x 1,000) \\
\hline $\mathrm{T} 18$ & Turbine 18 Discharge (cfs x 1,000) \\
\hline T19 & Turbine 19 Discharge (cfs x 1,000) \\
\hline $\mathrm{T} 20$ & Turbine 20 Discharge (cfs x 1,000) \\
\hline $\mathrm{T} 21$ & Turbine 21 Discharge (cfs x 1,000) \\
\hline $\mathrm{T} 22$ & Turbine 22 Discharge (cfs x 1,000) \\
\hline S1 & Spill Bay 1 \\
\hline S2 & Spill Bay 2 \\
\hline S3 & Spill Bay 3 \\
\hline S4 & Spill Bay 4 \\
\hline S5 & Spill Bay 5 \\
\hline S6 & Spill Bay 6 \\
\hline S7 & Spill Bay 7 \\
\hline
\end{tabular}




\begin{tabular}{||ll||}
\hline Variable & Definition \\
\hline \hline S8 & Spill Bay 8 \\
S9 & Spill Bay 9 \\
S10 & Spill Bay 10 \\
S11 & Spill Bay 11 \\
S12 & Spill Bay 12 \\
S13 & Spill Bay 13 \\
S14 & Spill Bay 14 \\
S15 & Spill Bay 15 \\
S16 & Spill Bay 16 \\
S17 & Spill Bay 17 \\
S18 & Spill Bay 18 \\
S19 & Spill Bay 19 \\
S20 & Spill Bay 20 \\
S21 & Spill Bay 21 \\
S22 & Spill Bay 22 \\
S23 & Spill Bay 23 \\
\hline
\end{tabular}




\section{Appendix B}

\section{Yearling Chinook Salmon Tag-Life Analysis Including Fitted Survivorship Curve and Arrival Time vs. Tag Survivorship Plots}


Acoustic Telemetry Studies of Juvenile Chinook Salmon Survival at the Lower Columbia Projects in 2006 


\section{Appendix B}

\section{Yearling Chinook Salmon Tag-Life Analysis Including Fitted Survivorship Curve and Arrival Time vs. Tag Survivorship Plots}

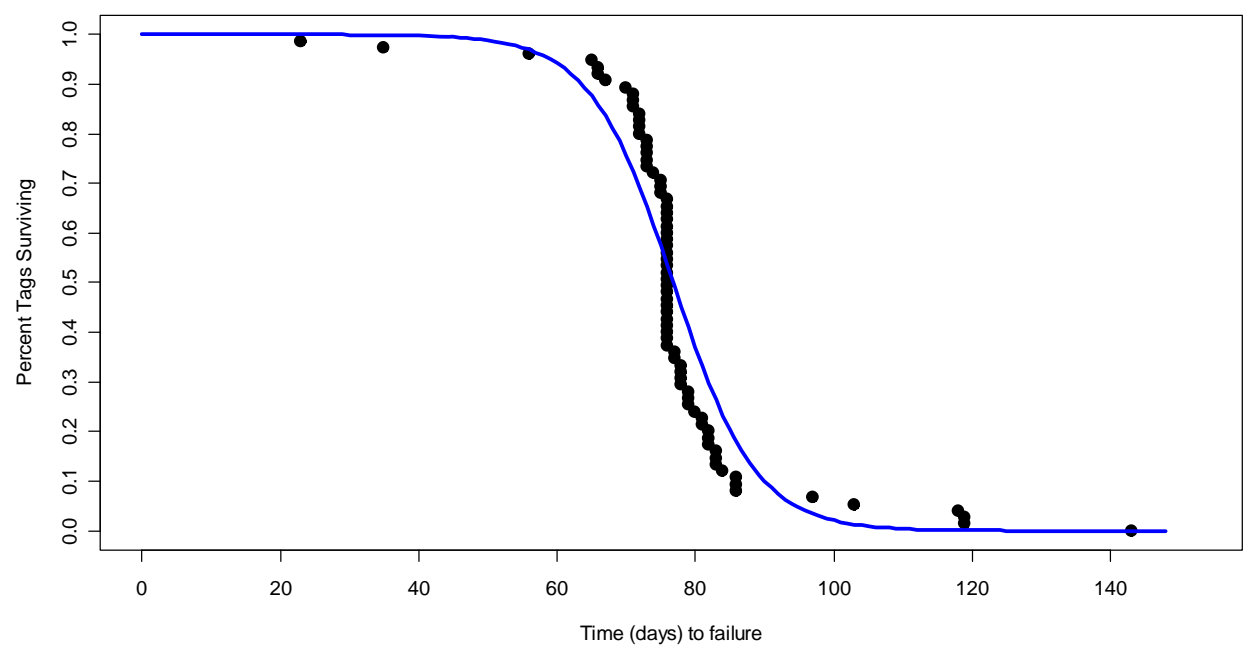

Figure B.1. Estimated Time to Failure for the 10-s Tags Used for Yearling Chinook salmon Released from Lower Granite Dam

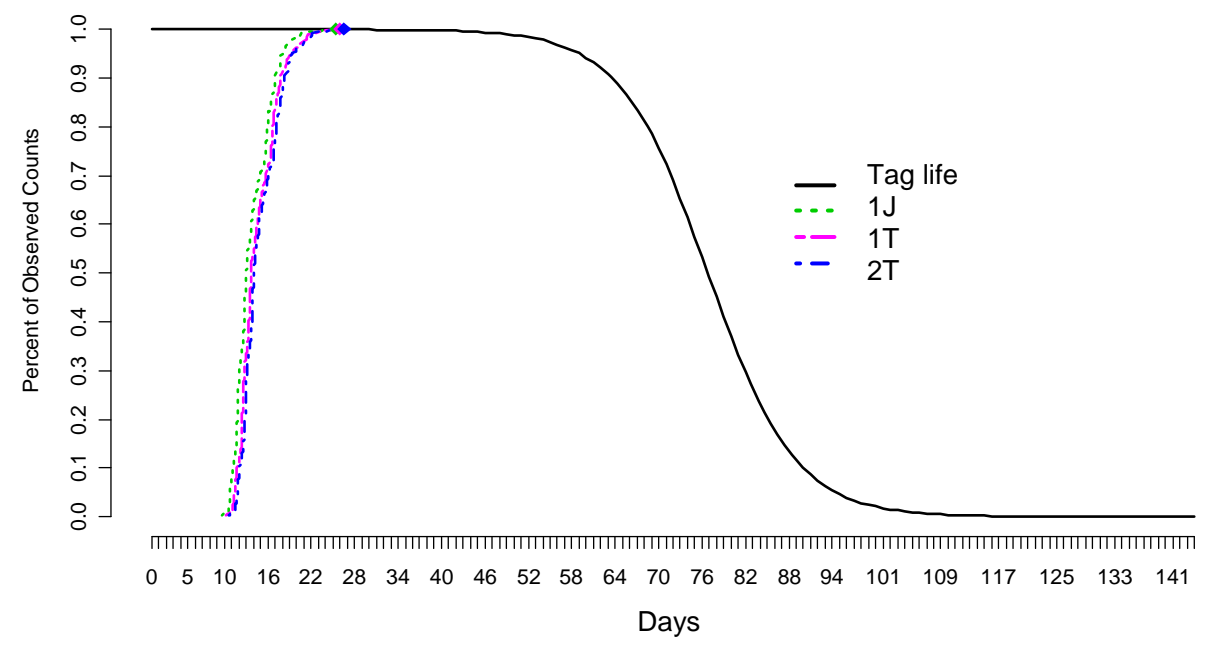

Figure B.2. Cumulative Arrival Time for Releases from John Day Dam to Detection Arrays $1 \mathrm{~J}$, 1T, and 2T Versus Tag Life 


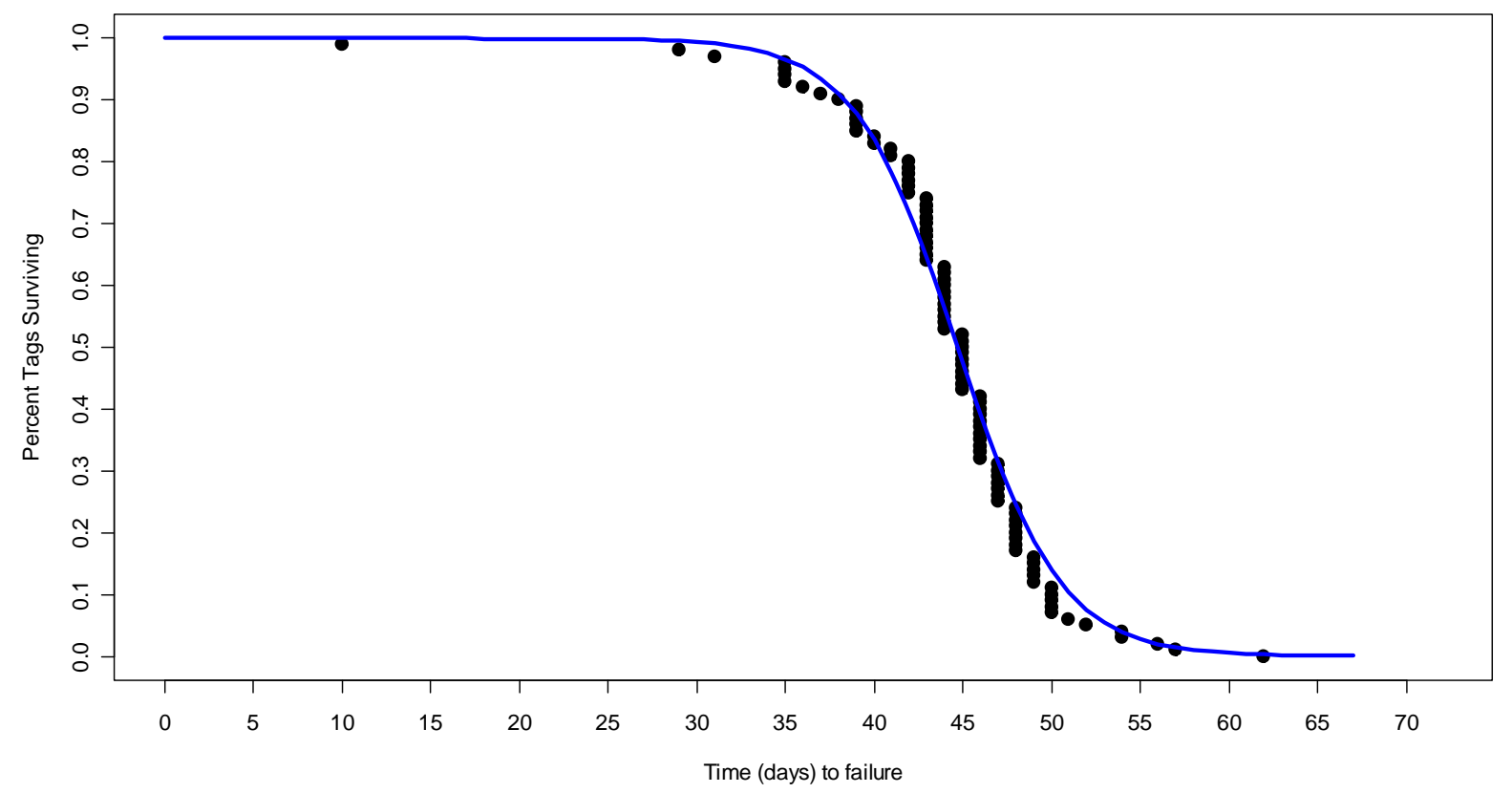

Figure B.3. Estimated Time to Failure for 5-s Tags Used for spring and summer Chinook salmon released from John Day Dam, below Dalles Dam, and below Bonneville Dam. 
a. Front Roll

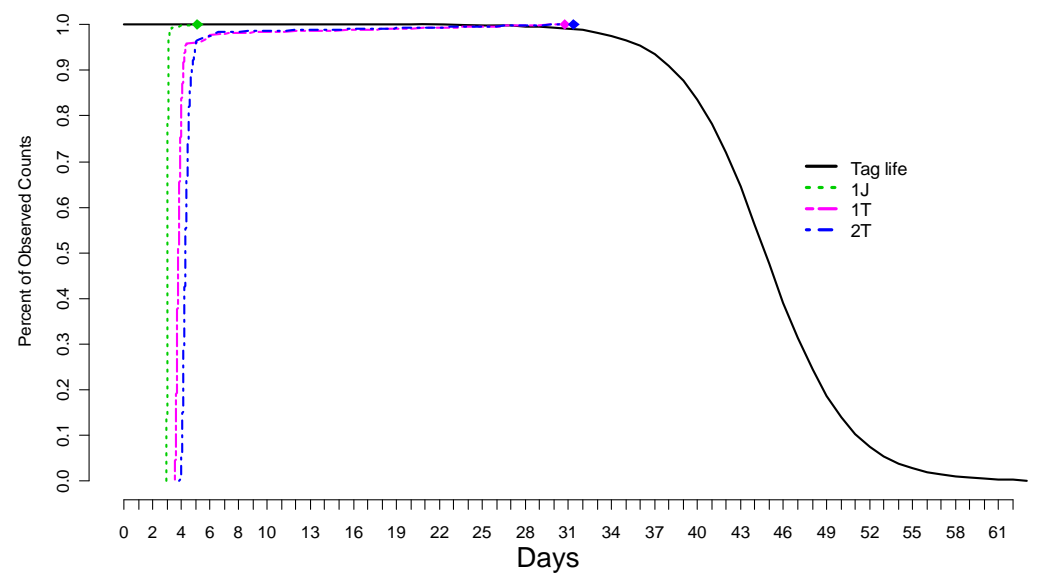

b. Turbine Intake

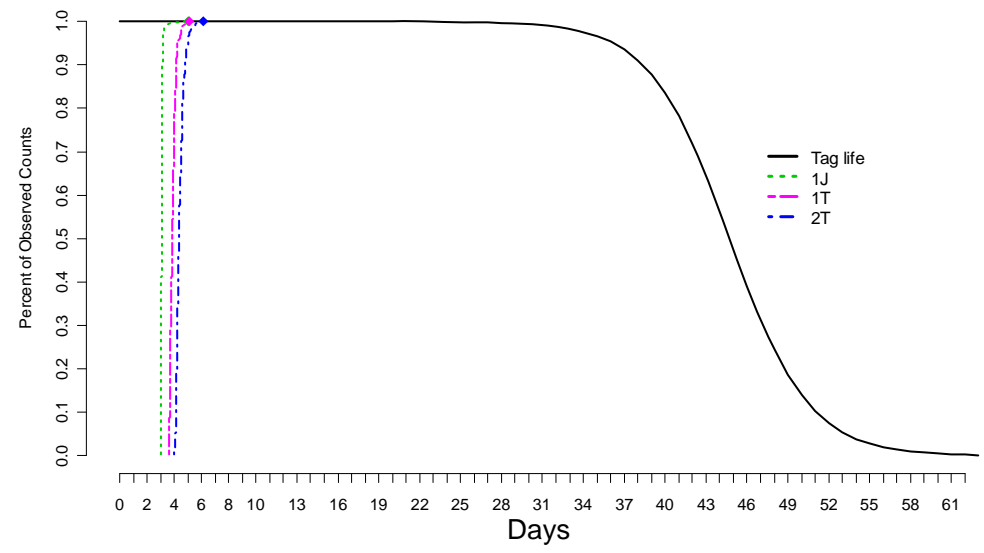

c. Tailrace

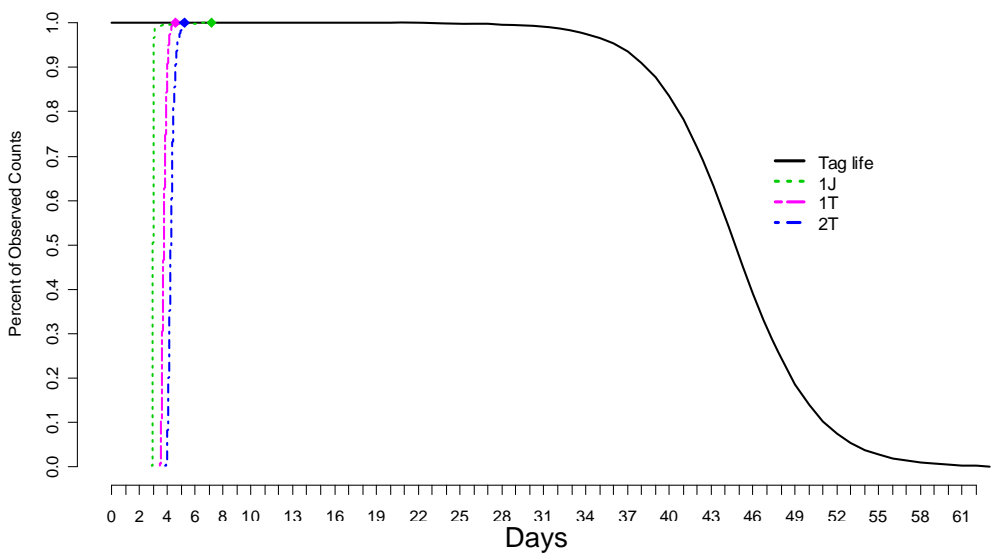

Figure B.4. Cumulative Arrival Time for Releases from John Day Dam to Detection Arrays $1 \mathrm{~J}$, 1T, and 2T Versus Tag Life 


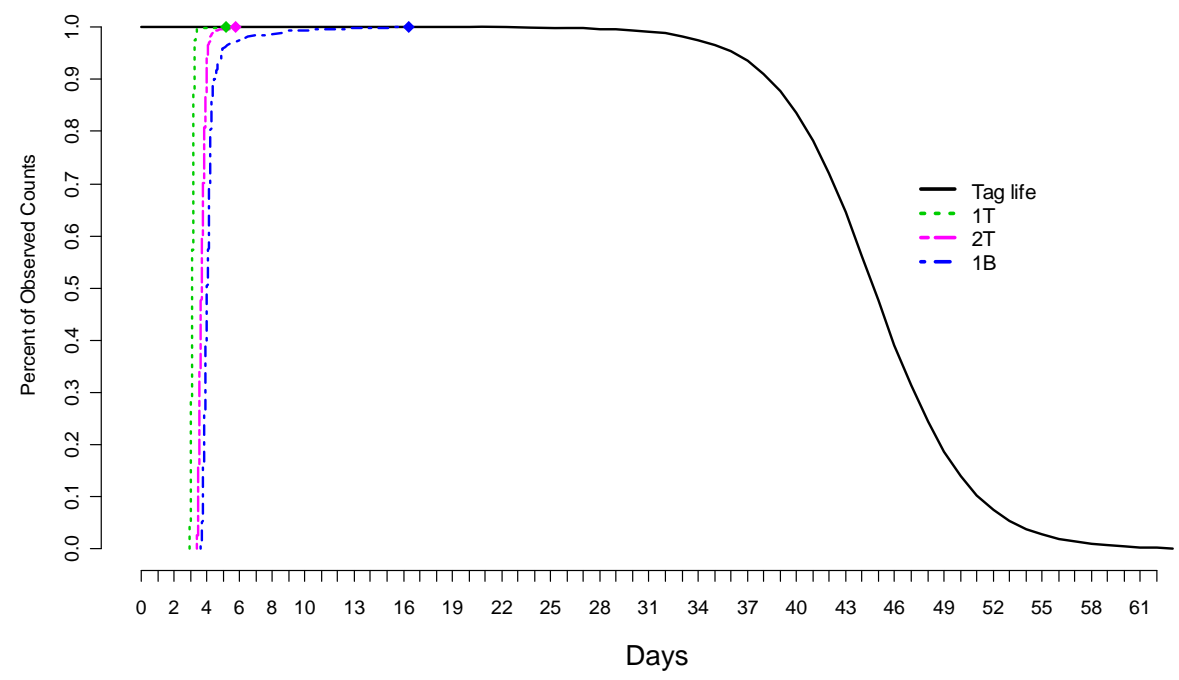

Figure B.5. Cumulative Arrival Time for Releases from The Dalles Tailrace to Detection Arrays 1T, 2T, and 1B Versus Tag Life



Figure B.6. Cumulative Arrival Time from Bonneville Tailrace to Detection Arrays 1B, 2B, and 3B Versus Tag Life 


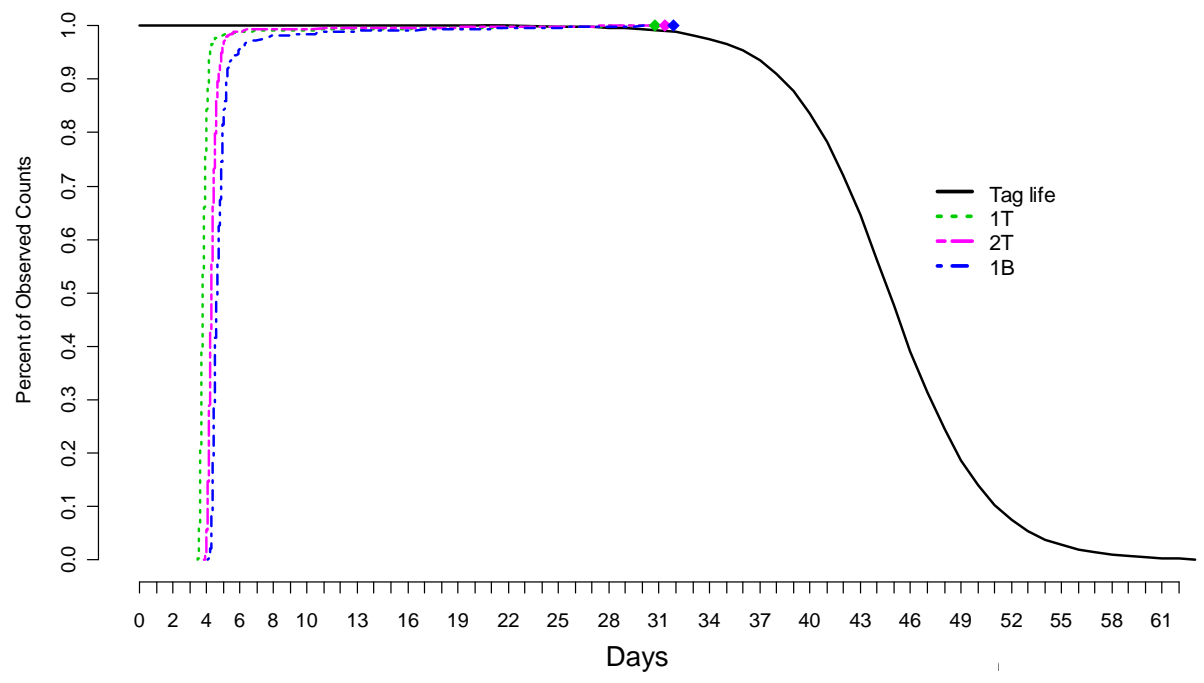

Figure B.7. Cumulative Arrival Time for the Virtual Release Above The Dalles Dam to Downstream Detection Arrays 1T, 2T, and 1B Versus Tag Life

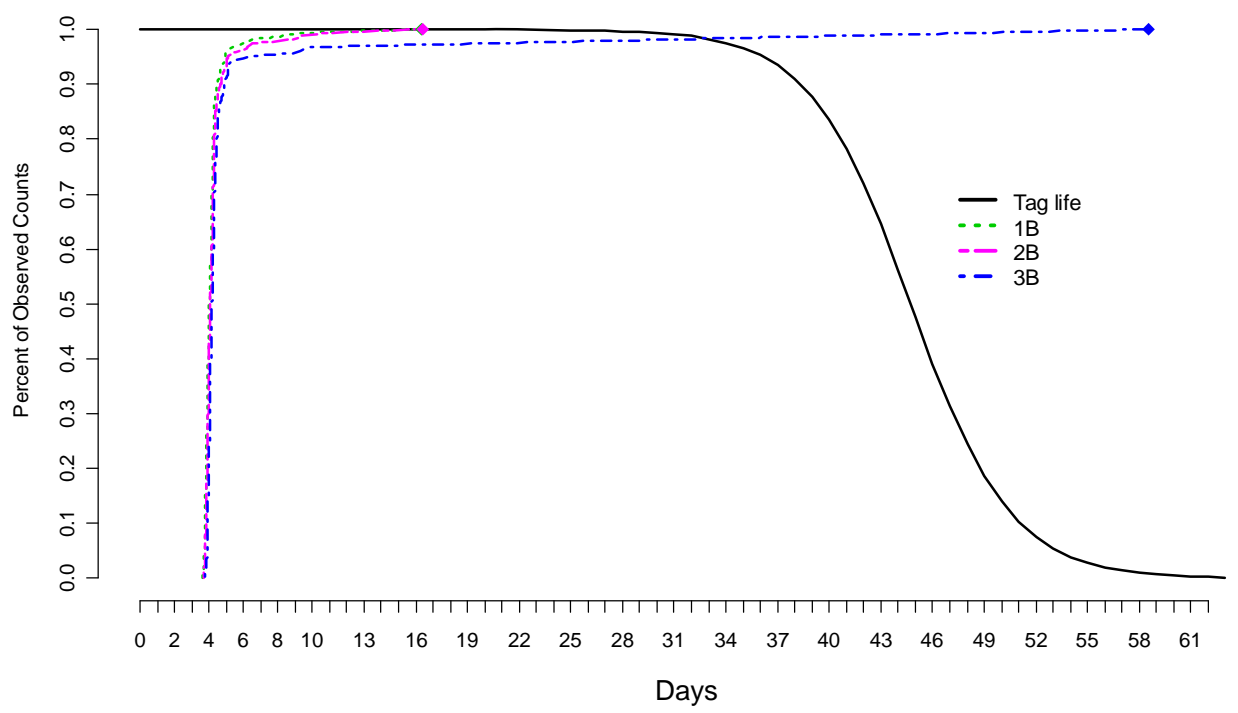

Figure B.8. Cumulative Time for the Virtual Release Above Bonneville Dam to Downstream Detection Arrays 1B, 2B, and 3B Versus Tag Life 


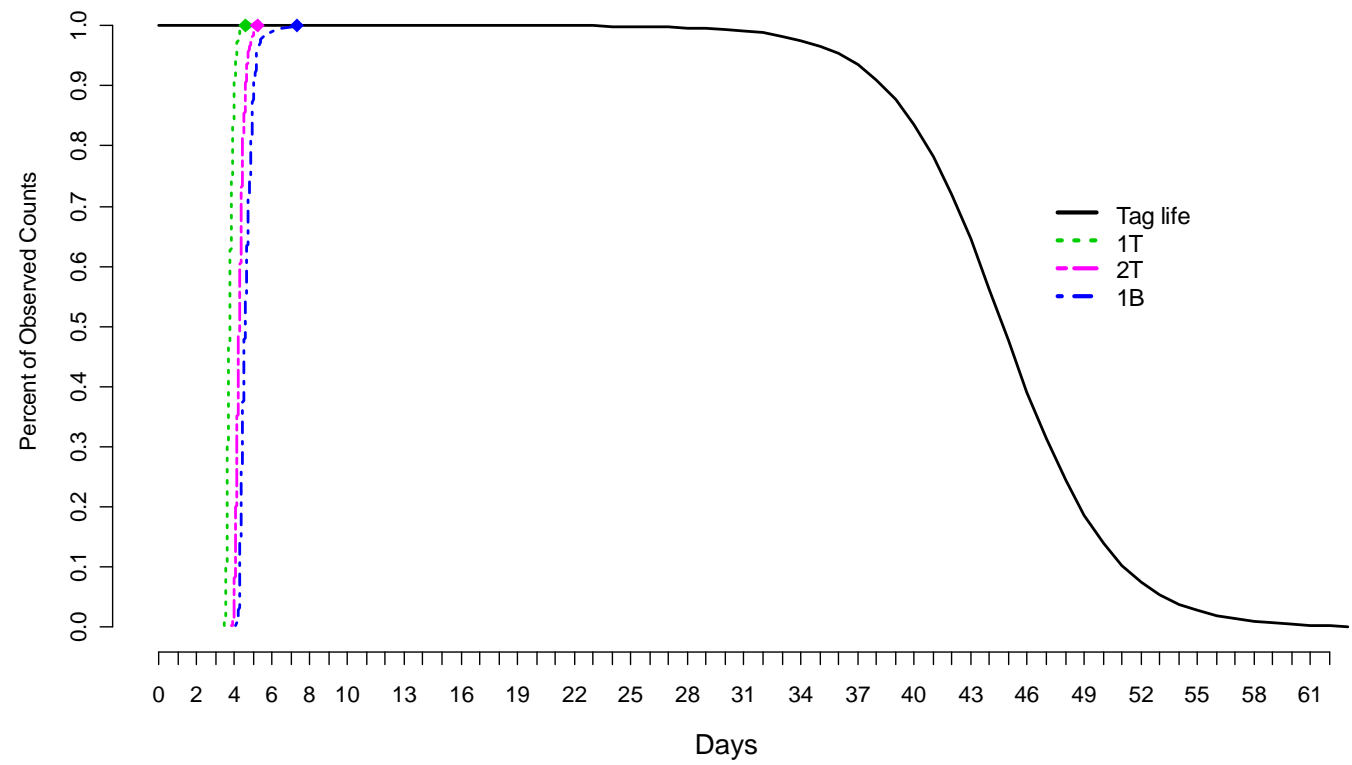

Figure B.9. Cumulative Arrival Time for Releases from John Day Tailrace to Downstream Detection Arrays 1T, 2T, and 1B Versus Tag Life

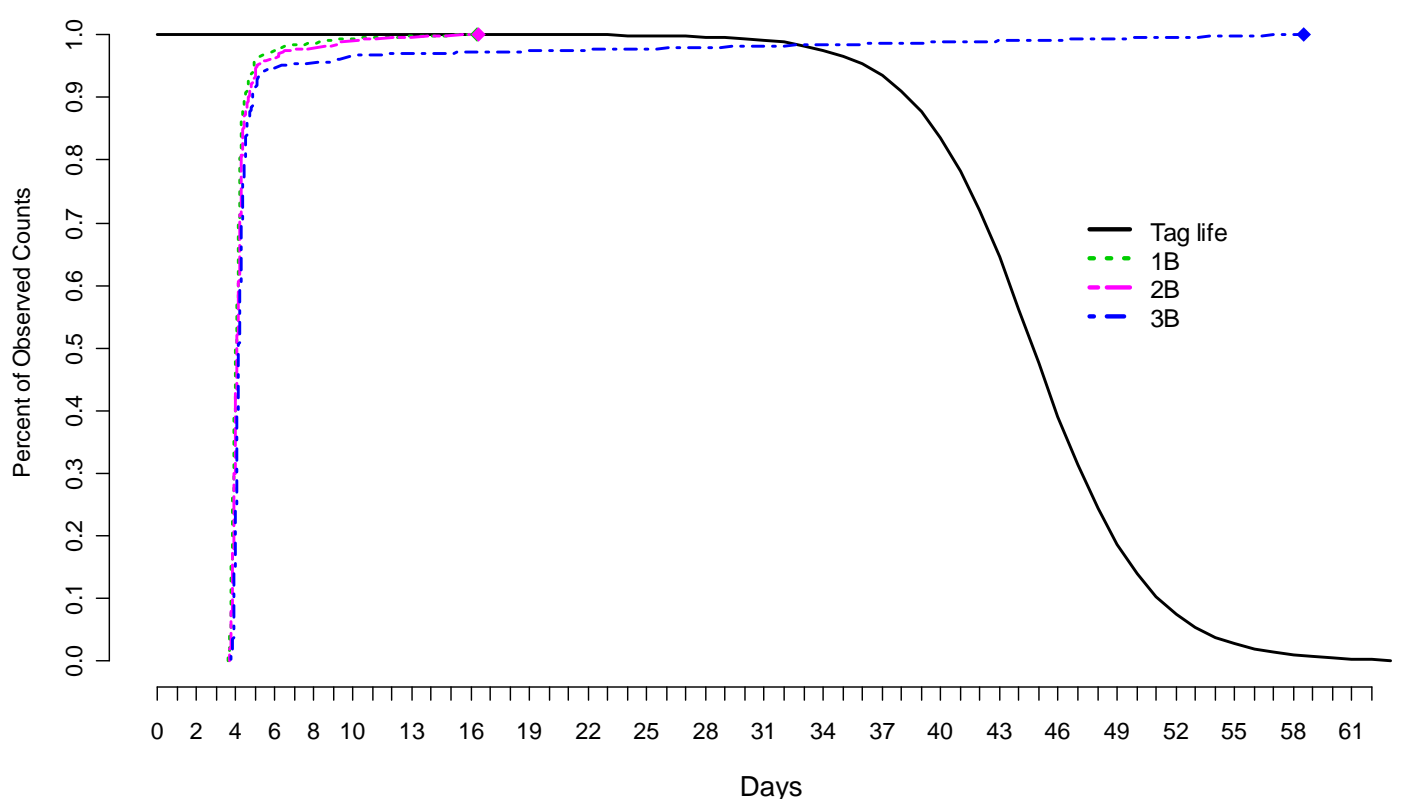

Figure B.10. Cumulative Arrival Time for Releases from The Dalles Tailrace to Downstream Detection Arrays 1B, 2B, and 3B Versus Tag Life 


\section{Appendix C}

Forward-Sequential Model Selection Results for AcousticTag Release Pairs in the 2006 Acoustic-Tag Survival Studies through John Day, The Dalles, and Bonneville Projects for Yearling Chinook Salmon 
Acoustic Telemetry Studies of Juvenile Chinook Salmon Survival at the Lower Columbia Projects in 2006 


\section{Appendix C}

\section{Forward-Sequential Model Selection Results for Acoustic- Tag Release Pairs in the 2006 Acoustic-Tag Survival Studies through John Day, The Dalles, and Bonneville Projects for Yearling Chinook Salmon}

Table C.1. Forward-Sequential Model Selection Results for John Day Dam Release Pairs for AcousticTelemetry Studies ${ }^{1}$

a. Acoustic-tagged Chinook salmon smolts, John Day front roll and tailrace releases.

\begin{tabular}{|c|c|c|c|}
\hline Hypothesis & $\chi^{2}$ & df & P-value \\
\hline$p_{1} \mid \underset{\sim 1}{S}, \underset{\sim}{S}, \underset{\sim}{p_{2}} \underset{\sim}{\lambda}$ & 1.8667 & 1 & 0.1719 \\
\hline$M_{S_{1}}$ vs CJS & 3.5333 & 4 & 0.4728 \\
\hline \multicolumn{4}{|l|}{ Conclude Model: $M_{S_{1}}$} \\
\hline \multicolumn{4}{|c|}{ b. Acoustic-tagged Chinook salmon smolts, John Day intake 9C and tailrace releases. } \\
\hline$p_{1} \mid{\underset{\sim}{1}}_{1}, \underset{\sim}{S_{2}}, \underset{\sim}{p_{2}, \underset{\sim}{\lambda}}$ & 1.9630 & 1 & 0.1612 \\
\hline$M_{S_{1}}$ vs CJS & 3.6257 & 4 & 0.4590 \\
\hline \multicolumn{4}{|l|}{ Conclude Model: $M_{S_{1}}$} \\
\hline \multicolumn{4}{|c|}{ c. Acoustic-tagged Chinook salmon smolts, John Day intake 9C and front roll releases } \\
\hline$p_{1} \mid \underset{\sim 1}{S_{1}}, \underset{\sim}{S_{2}}, \underset{\sim}{\underset{\sim}{p}, \underset{\sim}{\lambda}}$ & 7.4426 & 1 & 0.0064 \\
\hline$S_{2} \mid \underset{\sim 1}{S_{1}}, \underset{\sim}{p_{1}}, \underset{\sim}{p_{2}} \underset{\sim}{\lambda}$ & 0.0569 & 4 & 0.8115 \\
\hline$M_{S_{1}, p_{1}}$ vs CJS & 0.5564 & 3 & 0.9063 \\
\hline Conclude Model: $M_{\underline{S}_{1}, p_{1}}$ & & & \\
\hline
\end{tabular}

1 Note: Model fit to the data are indicated by a " " when the parameters were treated as a vector (i.e., different between releases within a pair). The notation indicates which parameter was tested for homogeneity, given (i.e., “|”) the specification of the other model parameters. 
Table C.2. Forward-Sequential Model Selection Results for The Dalles Project Release Pairs for Acoustic-Tagged Studies. Acoustic-tagged Chinook salmon smolts released from John Day and The Dalles Dam tailraces.

\begin{tabular}{|rccc||}
\hline Hypothesis & $\chi^{2}$ & df & P-value \\
\hline \hline$p_{1} \mid{\underset{\sim}{\sim}}_{\sim}, \underset{\sim}{S_{2}}, \underset{\sim}{p_{2}, \underset{\sim}{\lambda}}$ & 13.0480 & 1 & 0.0003 \\
$S_{2} \mid{\underset{\sim}{S}}_{\sim}, \underset{\sim}{p_{1}}, \underset{\sim}{p_{2}, \underset{\sim}{\lambda}}$ & 1.6251 & 1 & 0.2024 \\
$M_{\mathcal{S}_{1}, p_{1}}$ vs CJS & 3.5583 & 3 & 0.3133 \\
Conclude Model: $M_{S_{1}, p_{1}}$ & & & \\
\hline \hline
\end{tabular}

Table C.3. Forward-Sequential Model Selection Results for Bonneville Project Release Pairs for Acoustic-Tagged Studies. Acoustic-tagged Chinook salmon smolts released from The Dalles and Bonneville Dam tailraces.

\begin{tabular}{|c|c|c|c|}
\hline Hypothesis & $\chi^{2}$ & df & P-value \\
\hline$p_{1} \mid{\underset{\sim}{1}}_{1}, \underset{\sim}{S_{2}}, \underset{\sim}{p_{2}}, \underset{\sim}{\lambda}$ & 27.4017 & 1 & $<0.0001$ \\
\hline$S_{2} \mid{\underset{\sim}{1}}_{1}, \underset{\sim}{p_{1}}, \underset{\sim}{p_{2}}, \underset{\sim}{\lambda}$ & 1.6764 & 1 & 0.1954 \\
\hline$M_{S_{1}, p_{1}}$ vs CJS & 16.7258 & 3 & 0.0008 \\
\hline$p_{2} \mid \underset{\sim 1}{S_{1}}, \underset{\sim}{p_{1}}, \underset{\sim}{S_{2}}, \underset{\sim}{\lambda}$ & 13.6243 & 1 & 0.0002 \\
\hline$\lambda \mid{\underset{\sim}{S}}_{1}, \underset{\sim}{p_{1}}, \underset{\sim}{S_{2}}, \underset{\sim}{p_{2}}$ vs CJS & 0.0246 & 1 & 0.8754 \\
\hline
\end{tabular}




\section{Appendix D}

\section{Tests of Mixing and Goodness-of-Fit for Yearling Chinook Salmon Release Groups}


Acoustic Telemetry Studies of Juvenile Chinook Salmon Survival at the Lower Columbia Projects in 2006 


\section{Appendix D}

\section{Tests of Mixing and Goodness-of-Fit for Yearling Chinook Salmon Release Groups}


Figure D.1. Cumulative Arrival Distributions of the John Day Front Roll and Tailrace Releases to Detection Arrays $1 \mathrm{~J}, 1 \mathrm{~T}$, and $2 \mathrm{~T}$ 

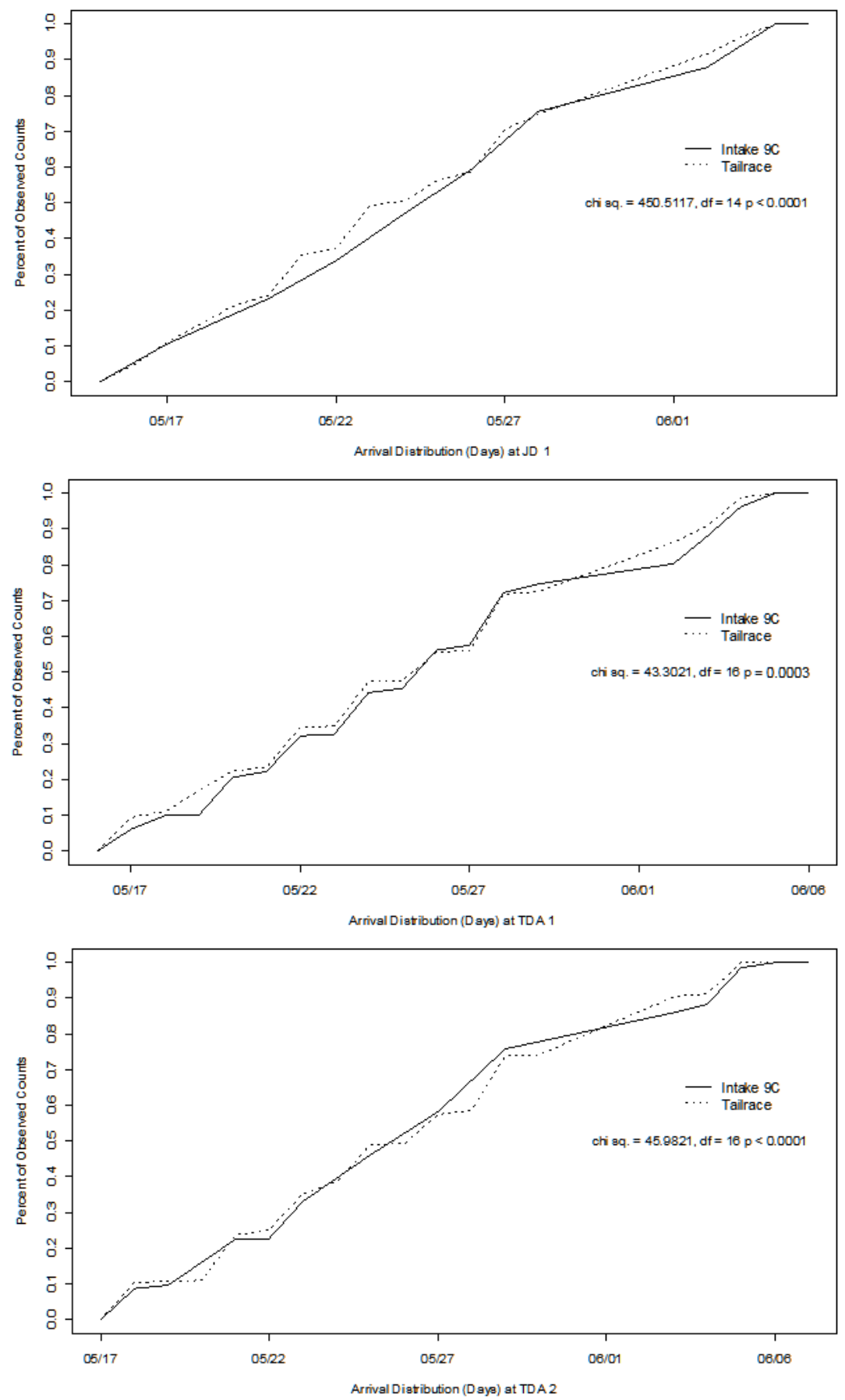

Figure D.2. Cumulative arrival distributions of John Day turbine intake $9 \mathrm{C}$ and tailrace releases to detection arrays $1 \mathrm{~J}, 1 \mathrm{~T}$, and $2 \mathrm{~T}$ 

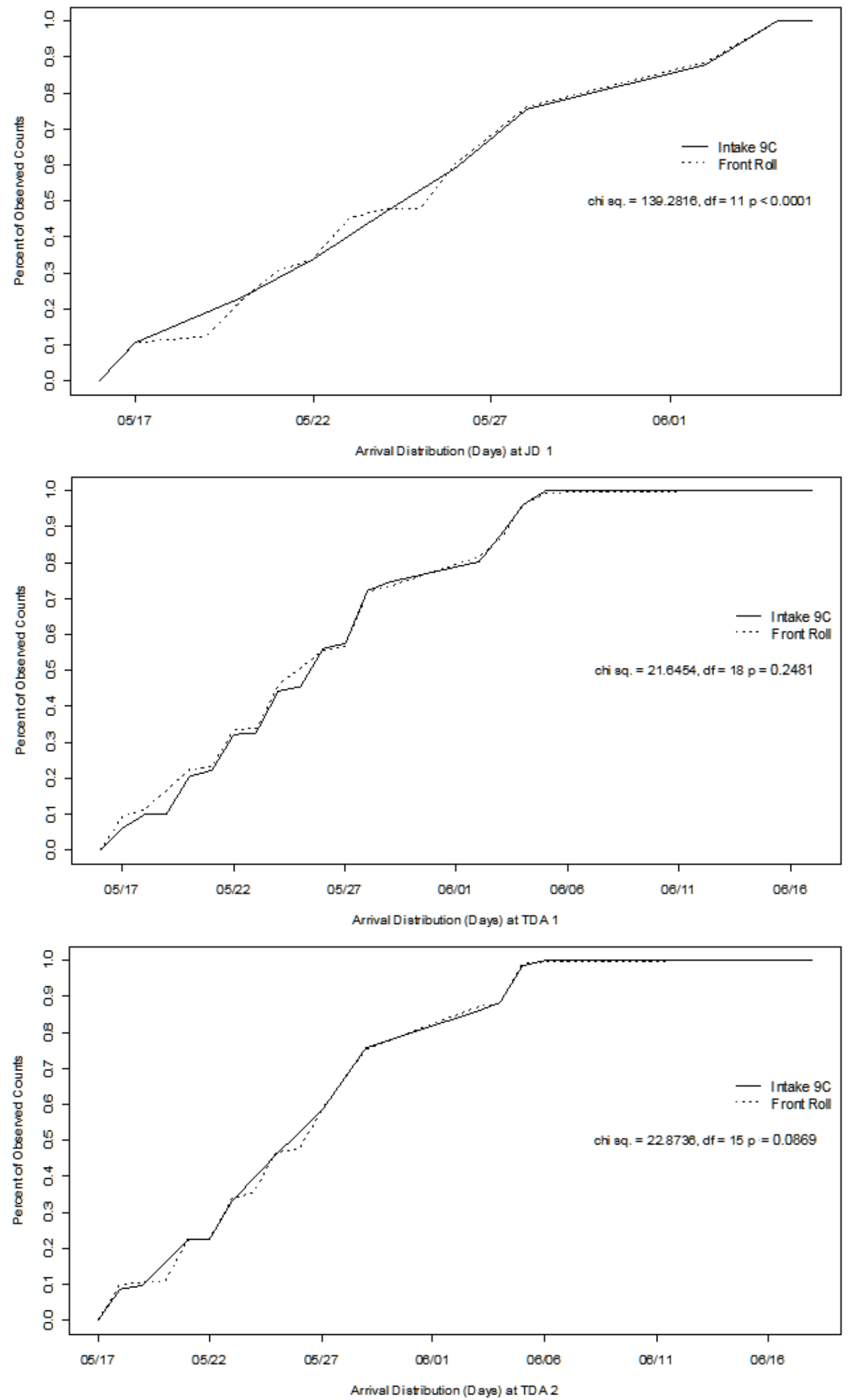

Figure D.3. Cumulative Arrival Distributions for the John Day Turbine Intake and Front Roll Releases to Detection Arrays $1 \mathrm{~J}, 1 \mathrm{~T}$, and $2 \mathrm{~T}$ 

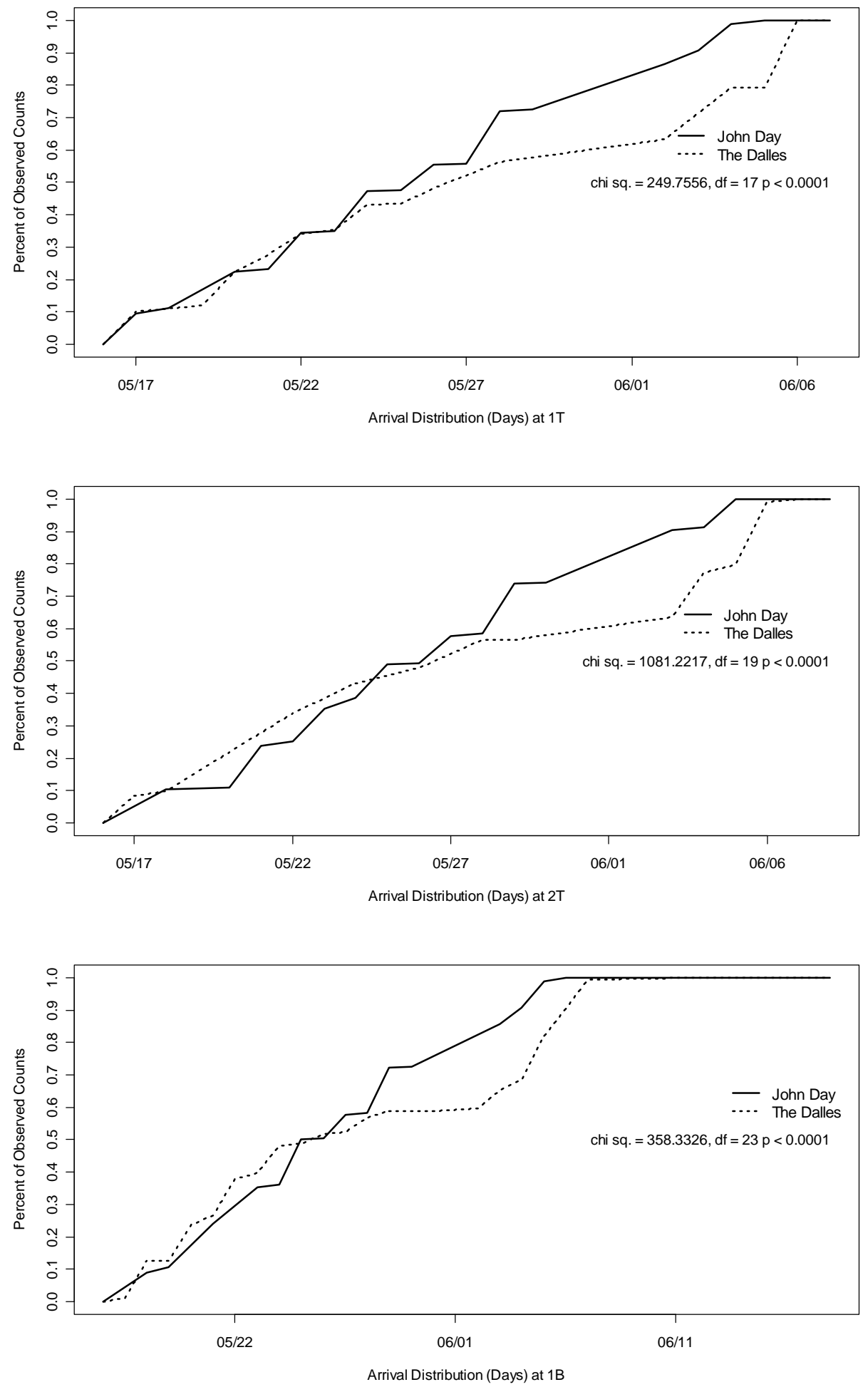

Figure D.4. Cumulative Arrival Distributions for John Day and The Dalles Tailrace Releases to Detection Arrays $1 \mathrm{~T}, 2 \mathrm{~T}$, and $1 \mathrm{~B}$ 

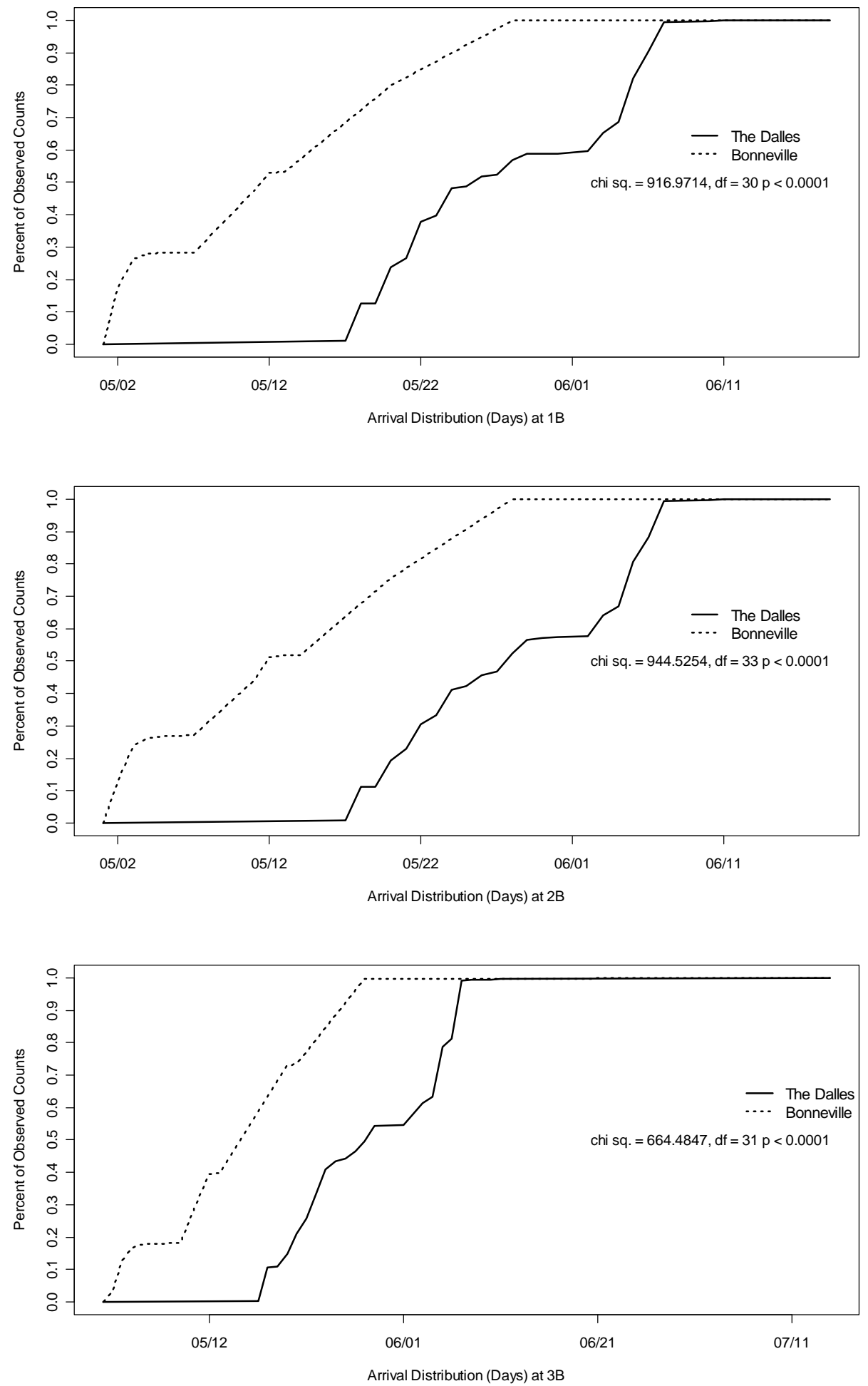

Figure D.5. Cumulative arrival distributions for The Dalles and Bonneville tailrace releases to detection arrays $1 \mathrm{~B}, 2 \mathrm{~B}$, and $3 \mathrm{~B}$ 
Table D.1. Burnham Test 2.2 for John Day Dam single releases. This procedure tests the assumption of whether detections at John Day primary array affect downstream survival and/or detection

\begin{tabular}{||lcccc||}
\hline \multicolumn{1}{|c}{ Release Site } & \multicolumn{2}{c}{ Test 2.2 } & $\chi_{1}^{2}$ & P-value \\
\hline \hline & \multicolumn{2}{c}{ Detection Site } & & \\
JD Front Roll & $4 \mathrm{~T}$ & $2 \mathrm{~T}$ & & \\
1J array & 412 & 36 & 0.0226 & 0.8804 \\
JD Intake 9C & 10 & 6 & & \\
1J array & 366 & 26 & 16.2186 & 0.0001 \\
& & & & \\
JD Tailrace & 7 & 3 & & \\
1J array & 405 & 26 & 5.6534 & 0.0174 \\
\hline \hline
\end{tabular}

Table D.2. Burnham Test 2.2 for The Dalles Project single releases. This procedure tests the assumption of whether detections at The Dalles primary array affect downstream survival and/or detection.

\begin{tabular}{||lcccc||}
\hline \multicolumn{1}{|c}{ Release Site } & \multicolumn{2}{c}{ Test 2.2 } & $\chi_{1}^{2}$ & $\boldsymbol{P}$-value \\
\hline \hline & \multicolumn{2}{c}{ Detection Site } & & \\
& $2 \mathrm{~T}$ & $1 \mathrm{~B}$ & & \\
John Day tailrace & 29 & 0 & & \\
1T array & 405 & 0 & NA & NA \\
& & & & \\
The Dalles tailrace & 24 & 0 & & \\
1T array & 930 & 3 & 2.4676 & 0.1162 \\
\hline
\end{tabular}

Table D.3. Burnham Test 2.2 for Bonneville Project single releases. This procedure tests the assumption of whether detections at Bonneville primary array affect downstream survival and/or detection

\begin{tabular}{|c|c|c|c|c|}
\hline Release Site & \multicolumn{2}{|c|}{ Test 2.2} & $\chi_{1}^{2}$ & $P$-value \\
\hline \multicolumn{5}{|c|}{ Detection Site } \\
\hline & $2 B$ & 3B & & \\
\hline The Dalles tailrace & 219 & 45 & & \\
\hline B1 array & 362 & 93 & 1.0317 & 0.3098 \\
\hline Bonneville tailrace & 144 & 23 & & \\
\hline B1 array & 470 & 58 & 0.7059 & 0.4008 \\
\hline
\end{tabular}


Table D.4. Burnham et al. (1987) Test 3.1 John Day release groups. This procedure tests whether detection at John Day primary array affect downstream detection histories

\begin{tabular}{|lccccc||}
\hline $\begin{array}{c}\text { Release } \\
\text { Group }\end{array}$ & $\begin{array}{c}\text { Capture History at } \\
\text { 2T }\end{array}$ & $\begin{array}{c}\text { Capture History to } \\
\text { 1T }\end{array}$ & $\chi_{1}^{2}$ & P-value \\
\hline \hline & & 101 & 111 & & \\
Front Roll & 1 & 4 & 404 & & \\
& 0 & 0 & 8 & 2.3956 & 0.1217 \\
Intake 9C & 1 & 10 & 356 & & \\
& 0 & 0 & 10 & 0.2174 & 0.6411 \\
Tailrace & 1 & 7 & 398 & & \\
& 0 & 0 & 7 & 1.2635 & 0.2610 \\
\hline
\end{tabular}

Table D.5. Burnham et al. (1987) Test 3.1 The Dalles Project release groups. This procedure tests whether detection at The Dalles primary array affect downstream detection histories.

\begin{tabular}{|c|c|c|c|c|c|}
\hline \multirow[t]{2}{*}{$\begin{array}{l}\text { Release } \\
\text { Group }\end{array}$} & \multirow[t]{2}{*}{$\begin{array}{c}\text { Capture History at } \\
\text { 1B }\end{array}$} & \multicolumn{2}{|c|}{$\begin{array}{c}\text { Capture History to } \\
2 \mathrm{~T}\end{array}$} & \multirow[t]{2}{*}{$\chi_{1}^{2}$} & \multirow[t]{2}{*}{$P$-value } \\
\hline & & 101 & 111 & & \\
\hline \multirow[t]{2}{*}{ John Day } & 1 & 12 & 232 & & \\
\hline & 0 & 17 & 173 & 2.1726 & 0.1405 \\
\hline \multirow[t]{2}{*}{ The Dalles } & 1 & 12 & 542 & & \\
\hline & 0 & 12 & 388 & 0.3625 & 0.5471 \\
\hline
\end{tabular}

Table D.6. Burnham et al. (1987) Test 3.1 Bonneville Project release groups. This procedure tests whether detection at the Bonneville primary array affect downstream detection histories.

\begin{tabular}{|cccccc||}
\hline $\begin{array}{c}\text { Release } \\
\text { Group }\end{array}$ & $\begin{array}{c}\text { Capture History at } \\
\text { 3B }\end{array}$ & \multicolumn{2}{c|}{$\begin{array}{c}\text { Capture History to } \\
\text { 2B }\end{array}$} & $\chi_{1}^{2}$ & P-value \\
\hline \hline \multirow{5}{*}{ John Day } & & 101 & 111 & & \\
The Dalles & 1 & 95 & 173 & & \\
& 0 & 124 & 189 & 0.8983 & 0.3432 \\
& 1 & 67 & 219 & & \\
\hline
\end{tabular}


Acoustic Telemetry Studies of Juvenile Chinook Salmon Survival at the Lower Columbia Projects in 2006 


\section{Appendix E}

\section{Tag-Life Survivorship Curve and Comparisons of Arrival Distributions Versus Tag Life for Subyearling Chinook Salmon}


Acoustic Telemetry Studies of Juvenile Chinook Salmon Survival at the Lower Columbia Projects in 2006 


\section{Appendix E}

\section{Tag-Life Survivorship Curve and Comparisons of Arrival} Distributions Versus Tag Life for Subyearling Chinook Salmon

a. Estimated tag life using all 99 10-s tags.

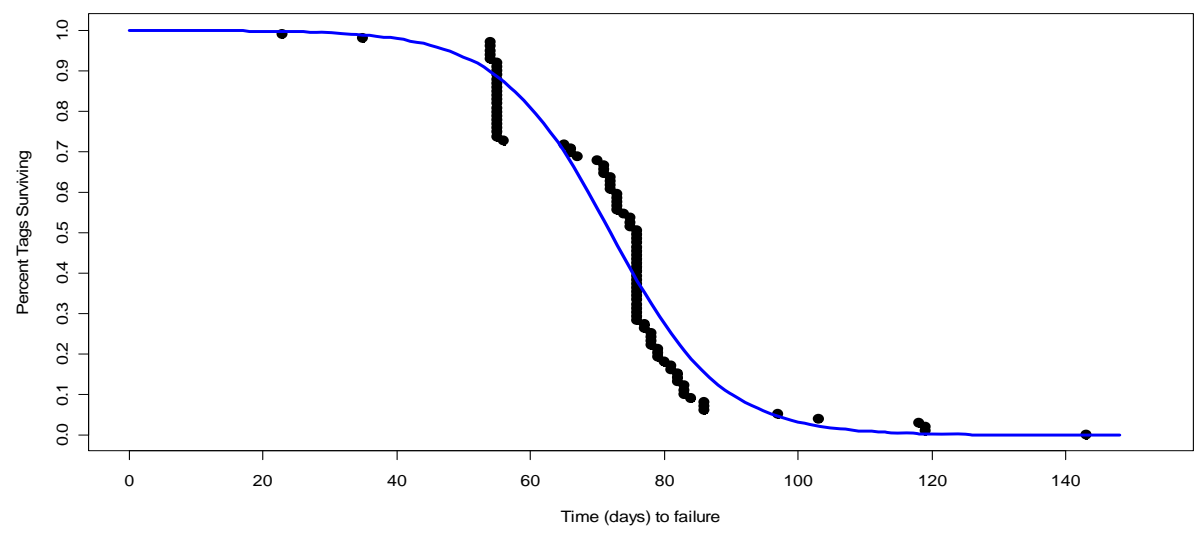

b. Estimated tag life without the 24 10-s tags activated on July 152006

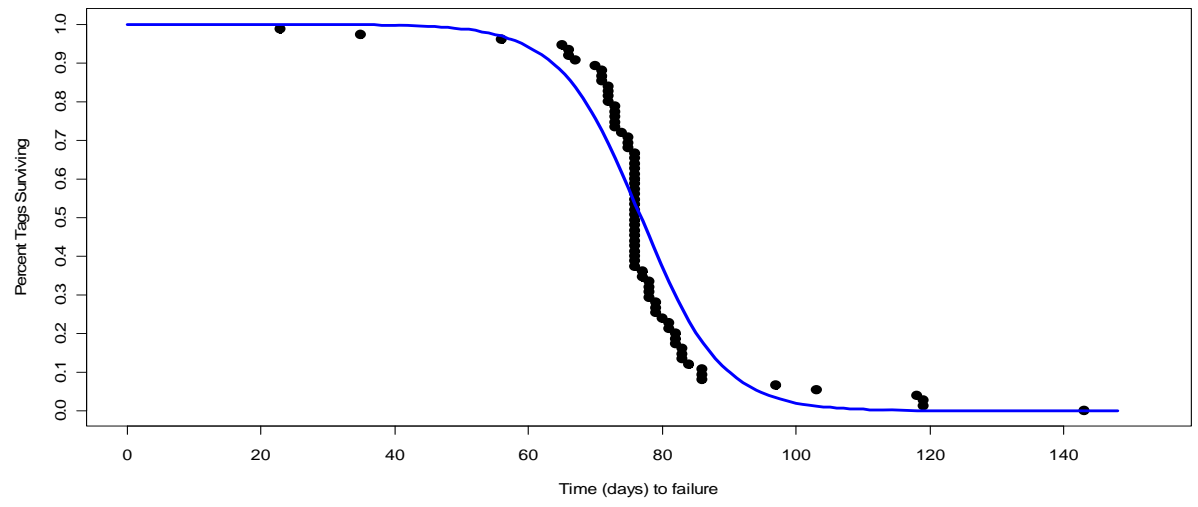

c. Estimated tag life of the 24 10-s tags activated on July 152006

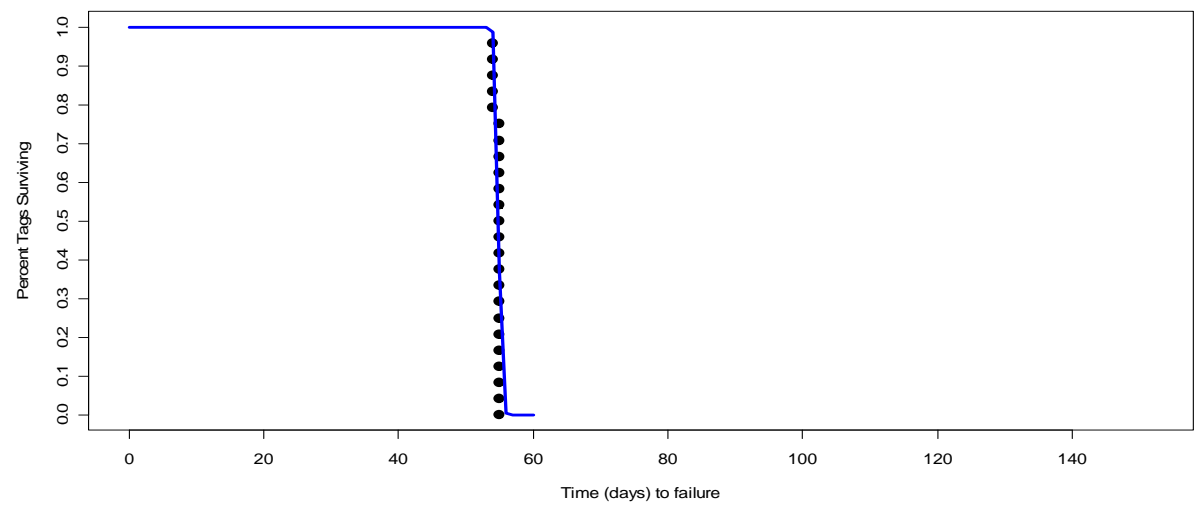

Figure E.1. Estimated Time to Failure for 10-s Tags for Summer Chinook Salmon 


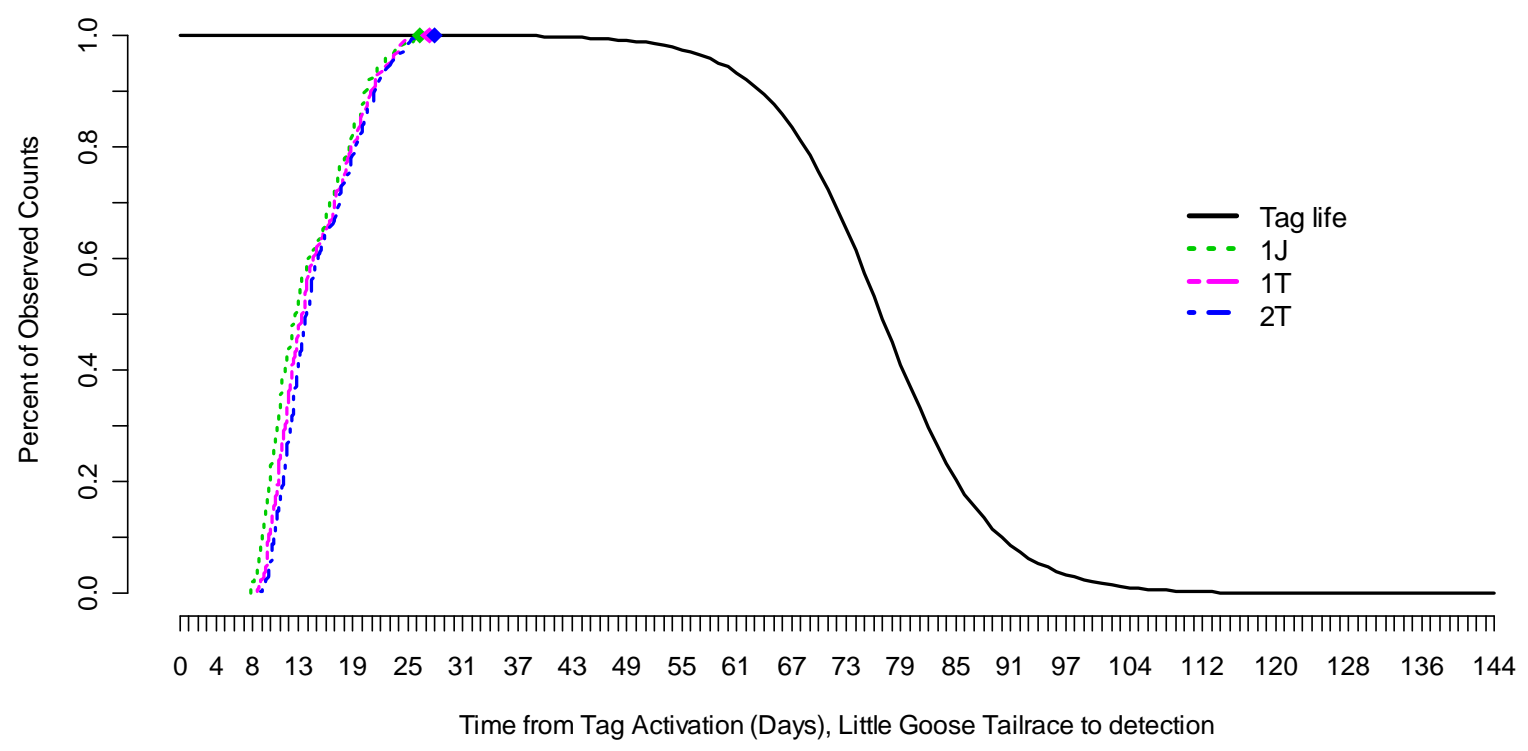

Figure E.2. Cumulative Time, from Time of Activation to Detection from the Little Goose Dam

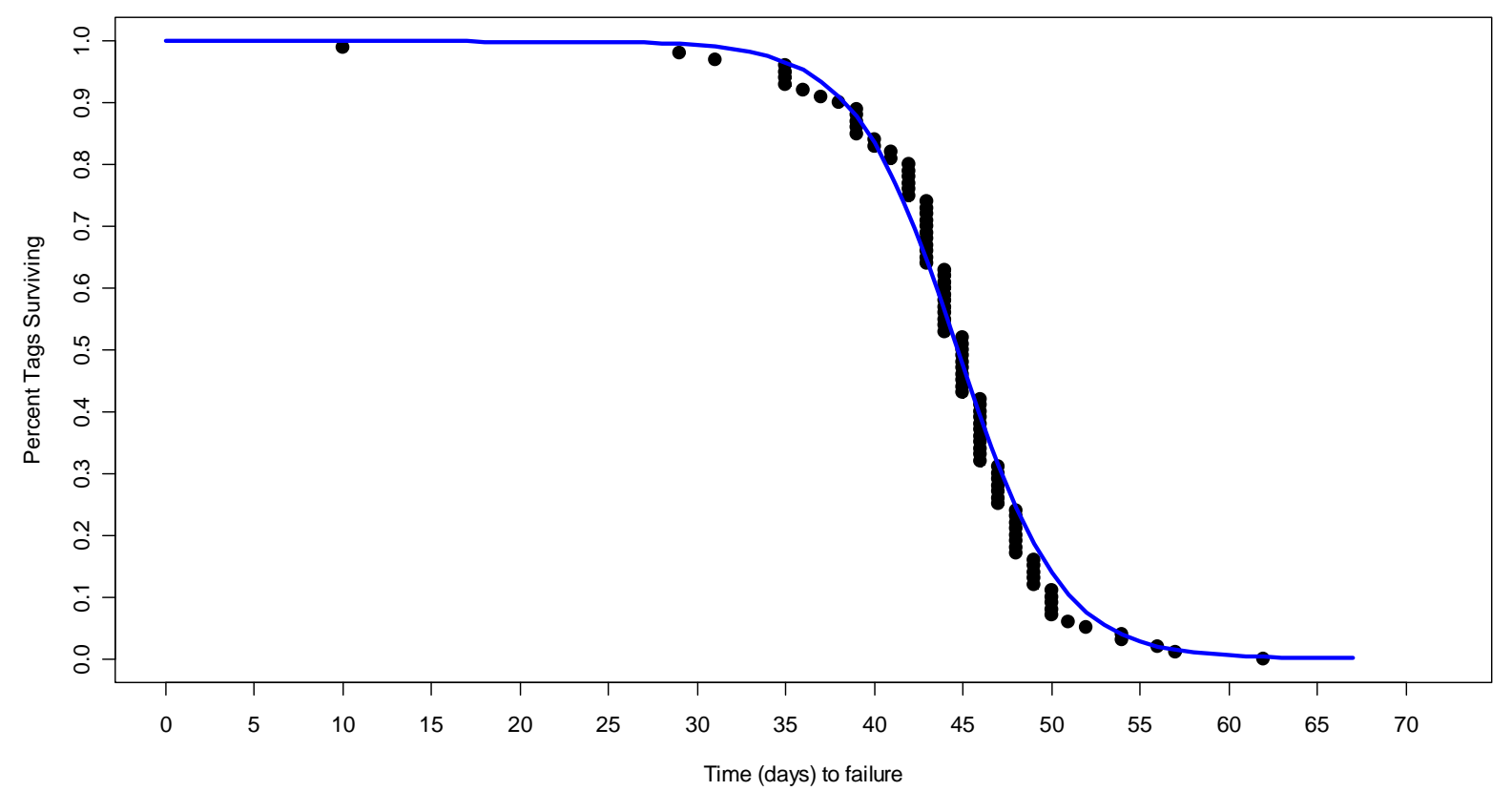

Figure E.3. Estimated Time to Failure for 5-s Tags for Spring and Summer Chinook Salmon Released from John Day Dam and Downstream. 


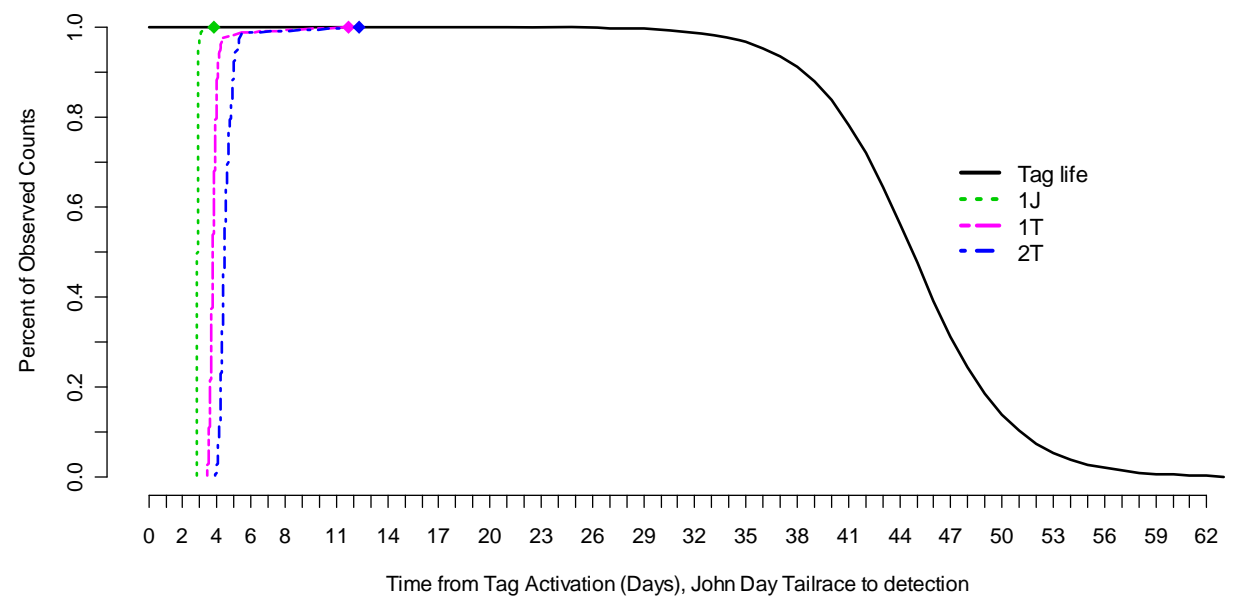

Figure E.4. Cumulative Time, from Time of Activation to Detection, from John Day Dam

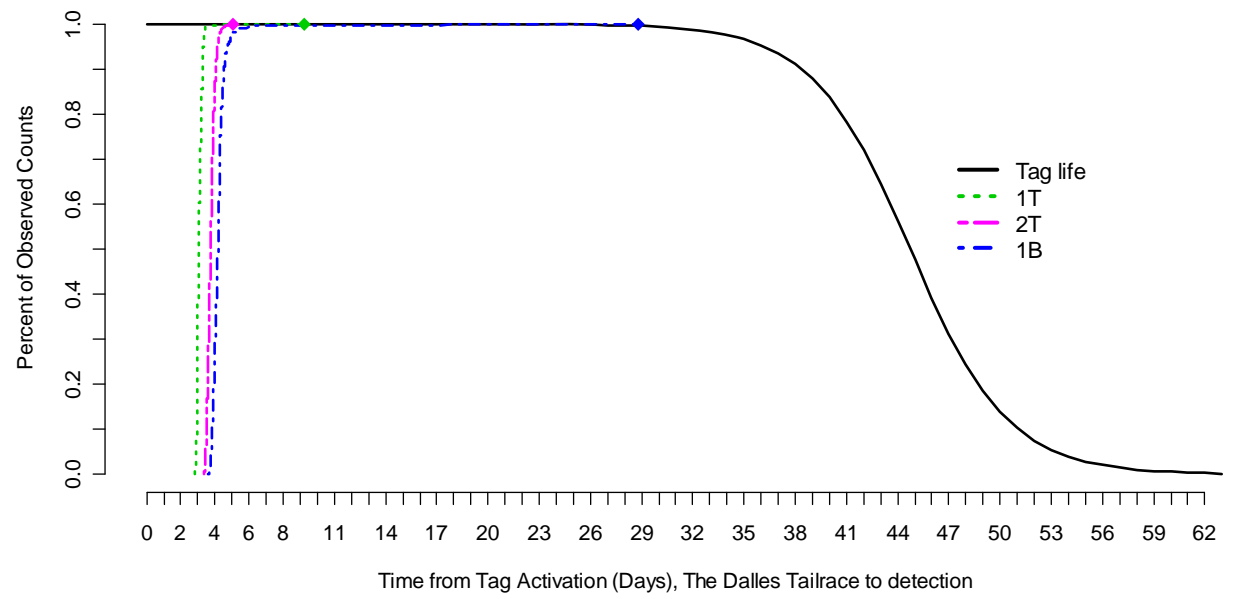

Figure E.5. Cumulative Time, from Time of Activation to Detection, from the Dalles Dam 


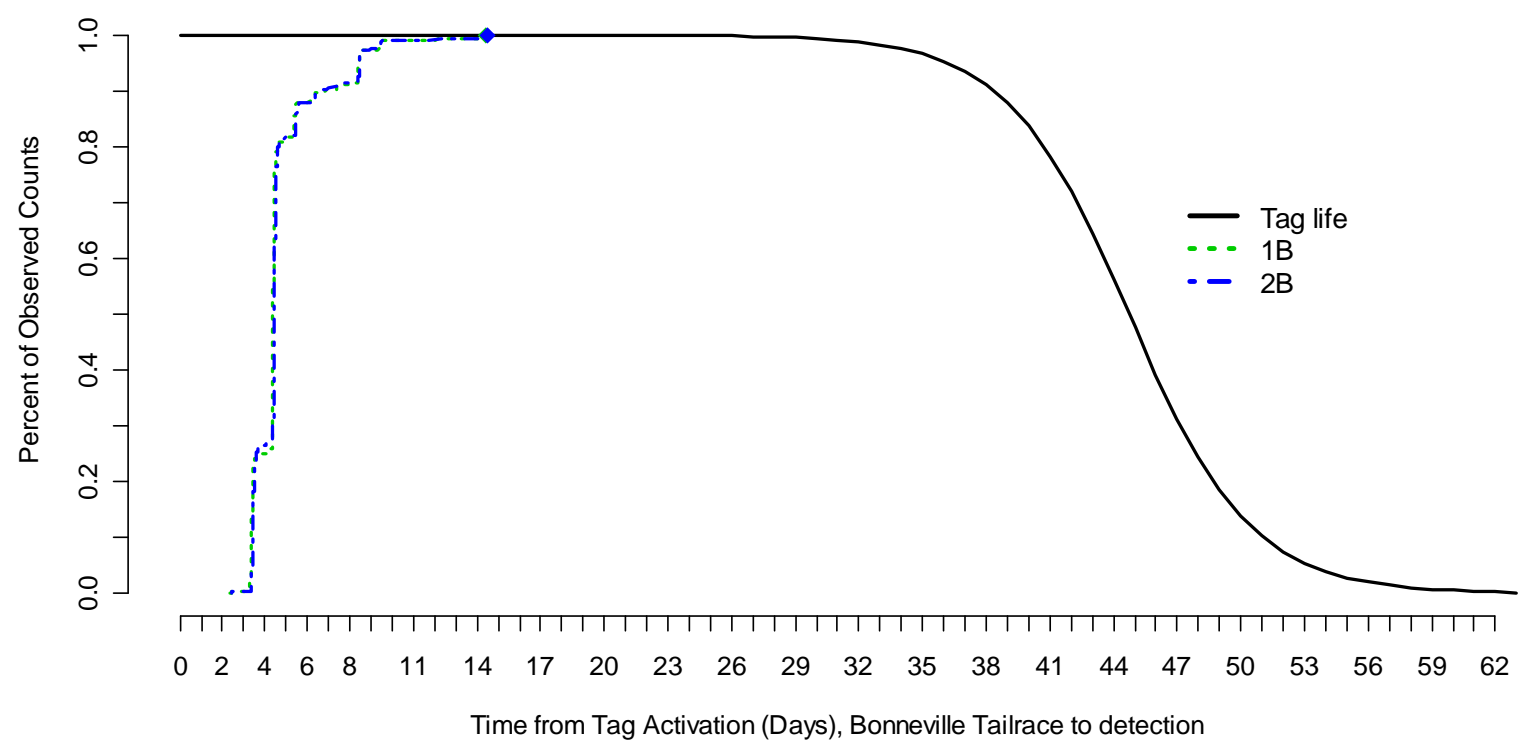

Figure E.6. Cumulative Time, from Time of Activation to Detection, from Bonneville Dam. The 3B Array was Not Operative during the Entire Study



Figure E.7. Cumulative Time, from Time of Activation to Detection, from the Virtual Release above The Dalles Dam 


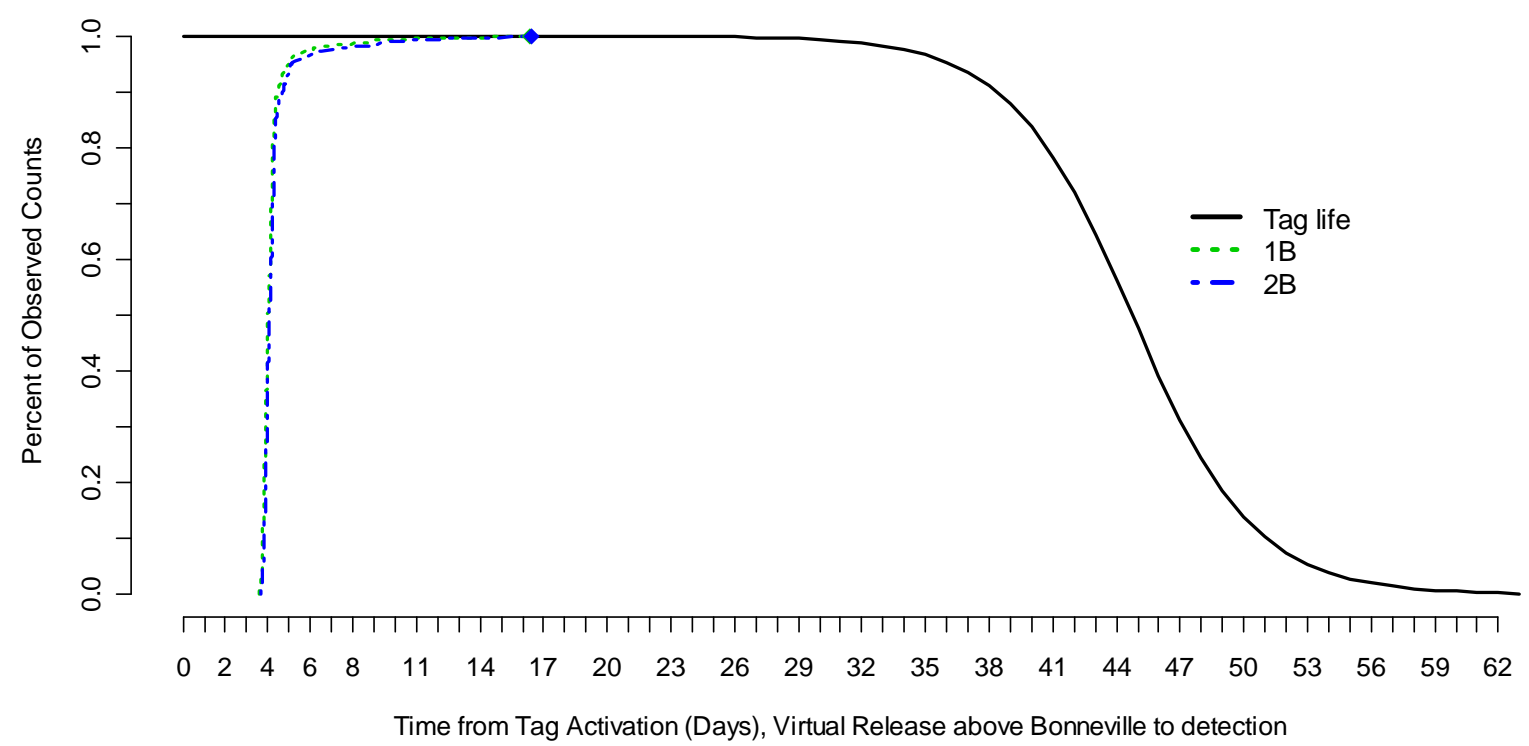

Figure E.8. Cumulative Time, from Time of Activation to Detection, from the Virtual Release above Bonneville Dam

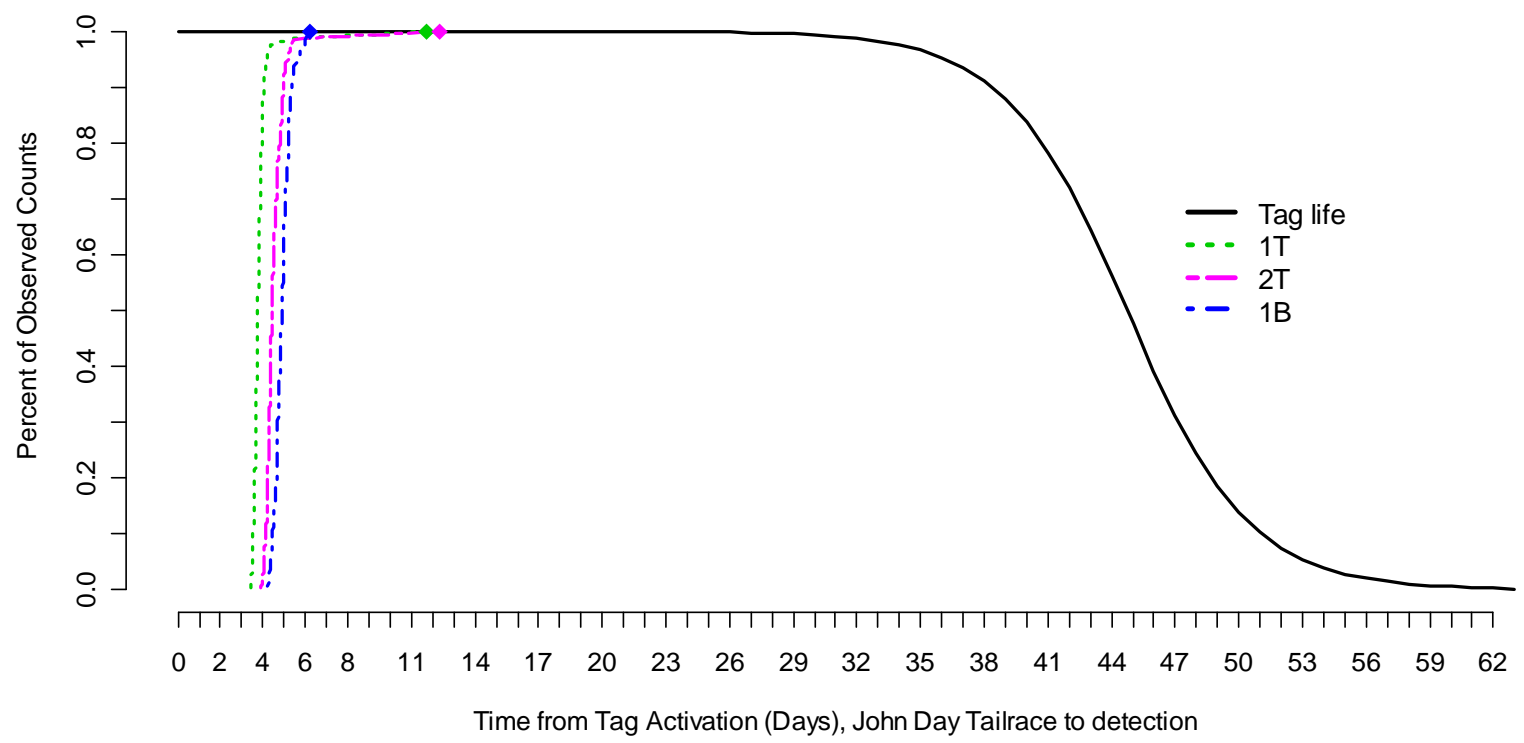

Figure E.9. Cumulative Time, from Time of Activation to Detection, from John Day Tailrace for The Dalles Project Survival 


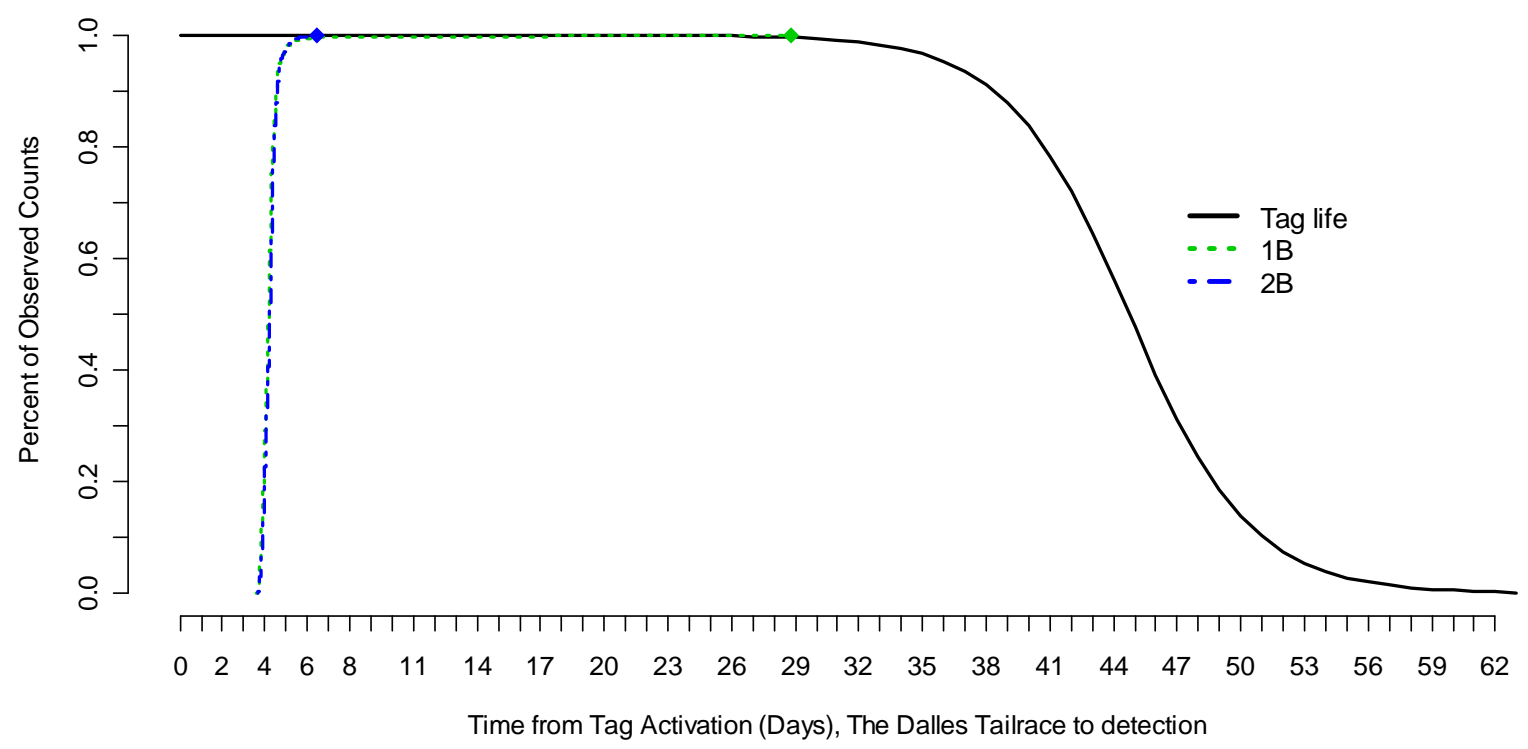

Figure E.10. Cumulative Time, from Time of Activation to Detection, from The Dalles Tailrace for Bonneville Project Survival 


\section{Appendix F}

Forward-Sequential Model Selection Results for AcousticTag Release Pairs in 2006 Acoustic-Tag Survival Studies through John Day, The Dalles, and Bonneville Projects for Subyearling Chinook Salmon 
Acoustic Telemetry Studies of Juvenile Chinook Salmon Survival at the Lower Columbia Projects in 2006 


\section{Appendix F}

\section{Forward-Sequential Model Selection Results for Acoustic- Tag Release Pairs in 2006 Acoustic-Tag Survival Studies through John Day, The Dalles, and Bonneville Projects for Subyearling Chinook Salmon}

Table F.1. Forward-Sequential Model Selection Results for The Dalles Project Release Pairs for Acoustic-Tag Studies. Acoustic-tagged subyearling smolts released from John Day and The Dalles Dam tailraces. ${ }^{1}$ The detection probability $\left(p_{2}\right)$ at The Dalles secondary array $(2 \mathrm{~T})$ was set to $100 \%$ for both release groups

\begin{tabular}{|c|c|c|c|}
\hline Hypothesis & $\chi^{2}$ & df & P-value \\
\hline$p_{1} \mid{\underset{\sim}{1}}_{1}, \underset{\sim}{S_{2}}, p_{2} \underset{\sim}{\lambda}$ & 0.2514 & 1 & 0.6161 \\
\hline$M_{S_{1}}$ vs. CJS & 16.6102 & 3 & 0.0008 \\
\hline$S_{2} \mid S_{\sim}, \underset{\sim}{p_{1}}, p_{2, \underset{\sim}{\lambda}}^{\lambda}$ & 9.4594 & 1 & 0.0021 \\
\hline$\lambda \mid{\underset{\sim}{S}}_{1}, \underset{\sim}{p_{1}}, \underset{\sim}{S_{2}}, p_{2}$ & 6.8456 & 1 & 0.0089 \\
\hline Conclude Model: CJS & & & \\
\hline
\end{tabular}

1 Note: Model fit to the data were indicated by a “ " when the parameters were treated as a vector (i.e. different between releases within a pair). The notation indicates which parameter was tested for homogeneity given (i.e. “| ”) the specification of the other model parameters. 
Acoustic Telemetry Studies of Juvenile Chinook Salmon Survival at the Lower Columbia Projects in 2006

Table F.2. Forward-Sequential Model Selection Results for Bonneville Project Release Pairs for Acoustic-Tag Studies. Acoustic-tagged Chinook smolts released from The Dalles and Bonneville Dam tailraces

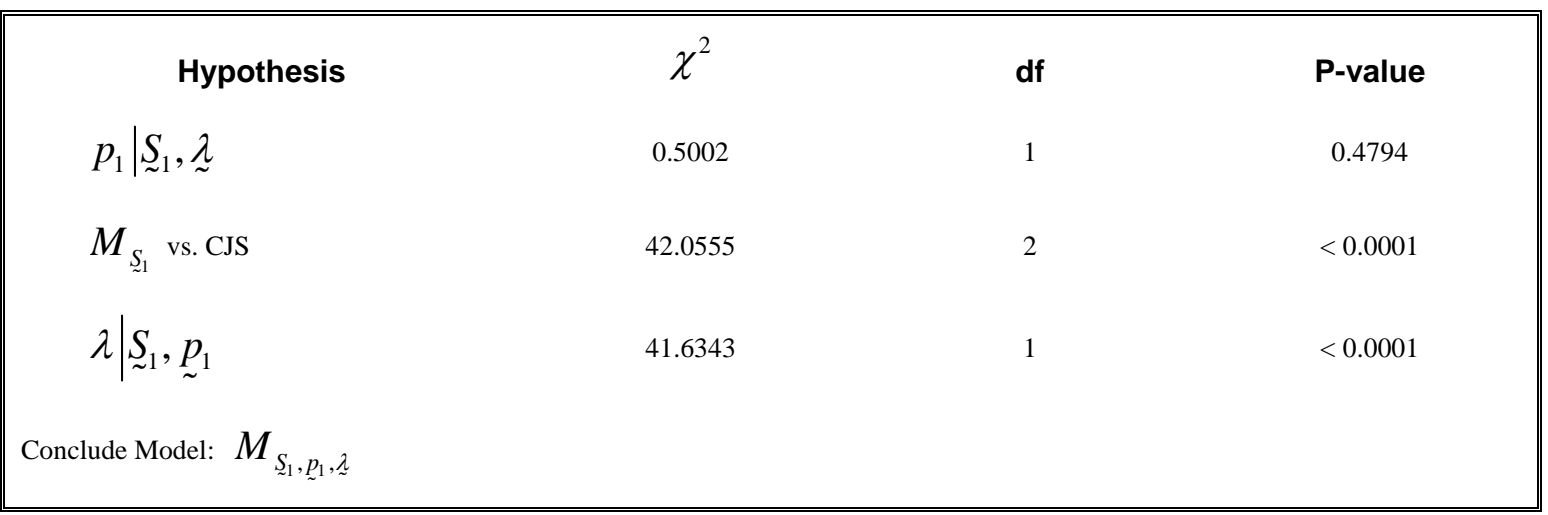




\section{Appendix G}

Tests of Mixing and Goodness of Fit for Subyearling Chinook Salmon Release Groups 
Acoustic Telemetry Studies of Juvenile Chinook Salmon Survival at the Lower Columbia Projects in 2006 


\section{Appendix G}

\section{Tests of Mixing and Goodness of Fit for Subyearling Chinook Salmon Release Groups}
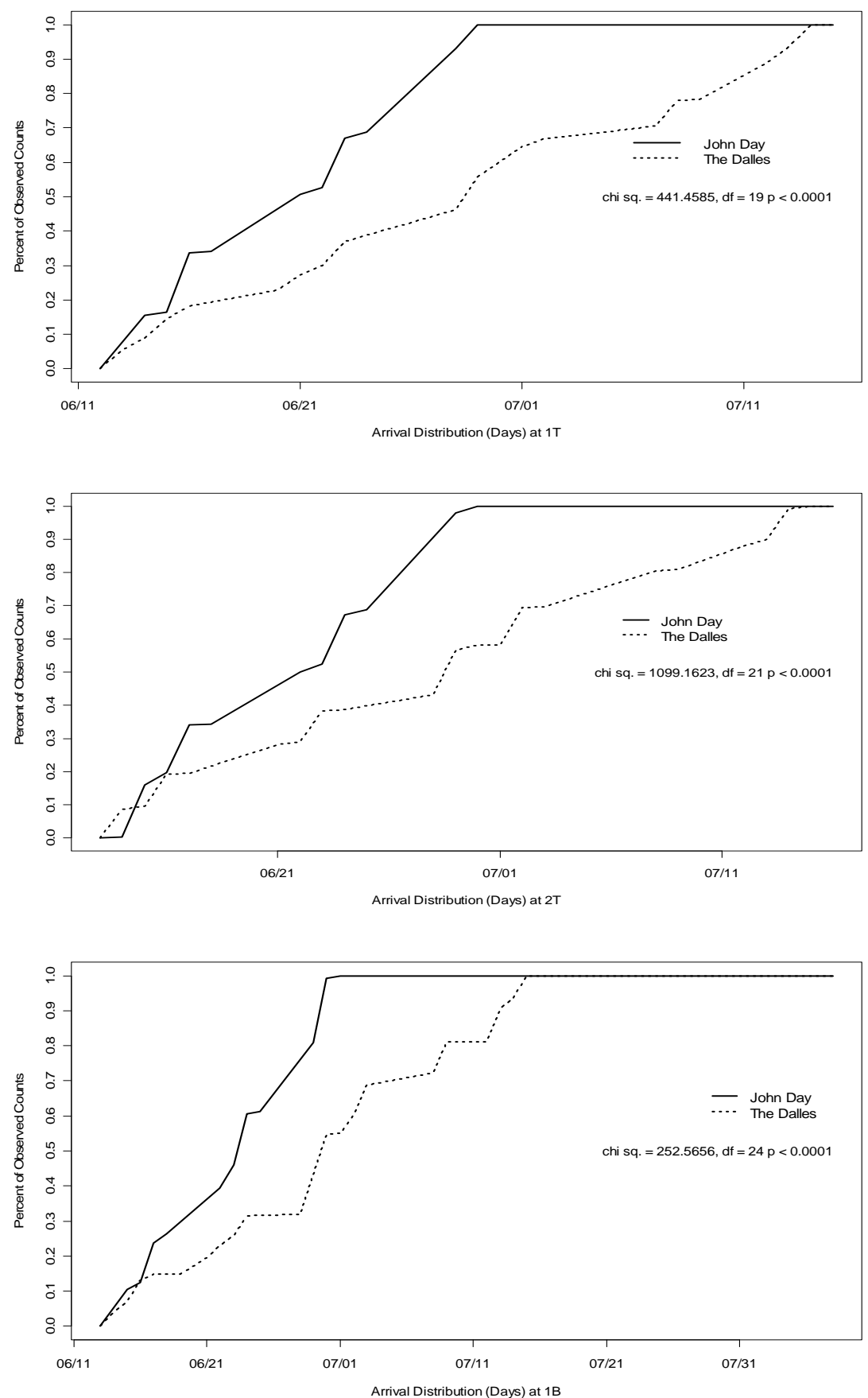

Figure G.1. Estimated Cumulative Arrival Distributions to Detection Arrays, John Day Dam and The Dalles Dam Tailrace Releases 

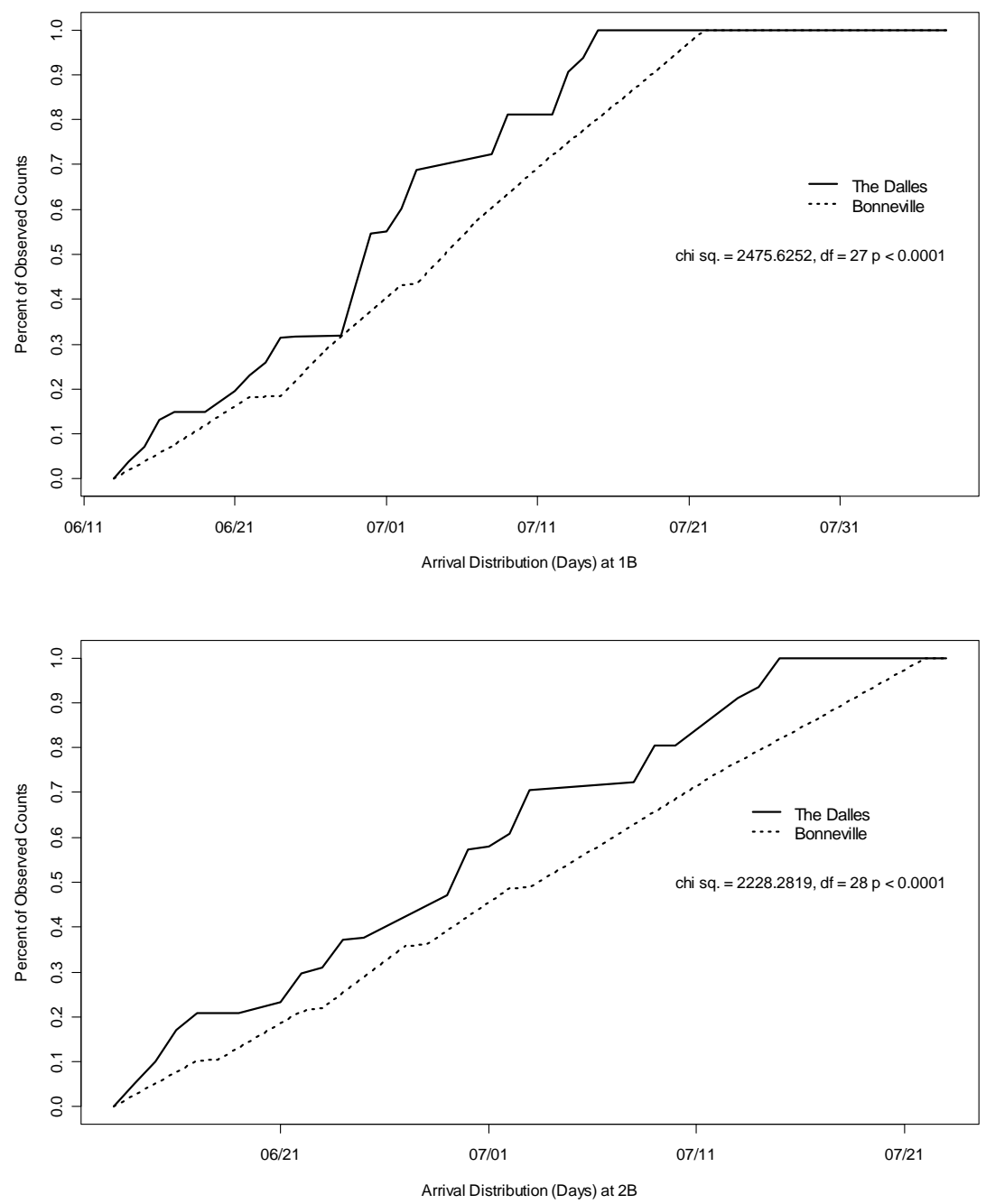

Figure G.2. Estimated Cumulative Arrival Distributions to Detection Arrays, The Dalles Dam and Bonneville Tailrace Releases 
Table G.1. Burnham Test 1.T2 and 1.T3 for The Dalles Project Paired Releases. The $m_{1}$ are the number of fish detected at that array, $z_{1}$ are the number of fish not detected at that array, but detected downstream

\begin{tabular}{|c|c|c|c|c|c|c|c|c|c|c|}
\hline \multirow{3}{*}{ Release Pair } & \multicolumn{6}{|c|}{ The Dalles 1 Array } & \multicolumn{4}{|c|}{ The Dalles 2 Array } \\
\hline & & \multicolumn{2}{|c|}{ Release } & \multirow[t]{2}{*}{$\chi_{1}^{2}$} & \multirow[t]{2}{*}{ P-value } & & \multicolumn{2}{|c|}{ Release } & \multirow[t]{2}{*}{$\chi_{1}^{2}$} & \multirow[t]{2}{*}{$P$-value } \\
\hline & History & J.Day & TDA & & & History & J.Day & TDA & & \\
\hline John Day \& & $m_{.1}$ & 243 & 2093 & & & $m_{.1}$ & 244 & 2023 & & \\
\hline The Dalles & $Z_{.1}$ & 3 & 18 & 0.0488 & 0.8251 & $Z_{.1}$ & 0 & 0 & NA & NA \\
\hline
\end{tabular}

Table G.2. Burnham Test 1.T2 for Bonneville Project Paired Releases. The $m_{1}$ are the number of fish detected at that array, $z_{1}$ are the number of fish not detected at that array, but detected downstream

\begin{tabular}{|c|c|c|c|c|c|}
\hline \multirow{3}{*}{ Release Pair } & & \multicolumn{4}{|c|}{ Bonneville 1 Array } \\
\hline & & \multicolumn{2}{|c|}{ Release } & \multirow[t]{2}{*}{$\chi_{1}^{2}$} & \multirow[t]{2}{*}{$P$-value } \\
\hline & History & TDA & Bonn. & & \\
\hline The Dalles \& & $m_{.1}$ & 1428 & 1525 & & \\
\hline Bonneville & $Z_{.1}$ & 233 & 265 & 0.3604 & 0.5483 \\
\hline
\end{tabular}


Table G.3. Burnham Test 2.2 for The Dalles Project Single Releases. This procedure tests the assumption of whether detections at The Dalles primary array affect downstream survival and/or detection

\begin{tabular}{||lcccc||}
\hline \multicolumn{1}{|c}{ Release Site } & \multicolumn{2}{c}{ Test 2.2 } & $\chi_{1}^{2}$ & $\boldsymbol{P}$-value \\
\hline \hline & \multicolumn{2}{c}{ Detection Site } & & \\
& $2 \mathrm{~T}$ & $1 \mathrm{~B}$ & & \\
John Day tailrace & 3 & 0 & & NA \\
TDA 1 array & 241 & 0 & NA & \\
The Dalles tailrace & 18 & 0 & & NA \\
TDA 1 array & 2005 & 0 & NA & \\
& & & & \\
\hline
\end{tabular}

Table G.4. Burnham et al. (1987) Test 3.1 The Dalles Project Release Groups. This procedure tests whether detection at The Dalles primary array affect downstream detection histories

\begin{tabular}{|c|c|c|c|c|c|}
\hline \multirow[t]{2}{*}{ Release Group } & \multirow[t]{2}{*}{$\begin{array}{c}\text { Capture History at } \\
\text { 1B }\end{array}$} & \multicolumn{2}{|c|}{$\begin{array}{l}\text { Capture History to } \\
\text { 2T }\end{array}$} & \multirow[t]{2}{*}{$\chi_{1}^{2}$} & \multirow[t]{2}{*}{$P$-value } \\
\hline & & 101 & 111 & & \\
\hline \multirow[t]{2}{*}{ John Day } & 1 & 1 & 151 & & \\
\hline & 0 & 2 & 90 & 0.1955 & 0.6584 \\
\hline \multirow[t]{2}{*}{ The Dalles } & 1 & 3 & 1425 & & \\
\hline & 0 & 15 & 580 & 22.8816 & $<0.0001$ \\
\hline
\end{tabular}




\section{Appendix $\mathrm{H}$}

Tables of Detection Frequencies and Estimates of Detection and Survival for As-Planned Arrays 
Acoustic Telemetry Studies of Juvenile Chinook Salmon Survival at the Lower Columbia Projects in 2006 


\section{Appendix $\mathrm{H}$}

\section{Tables of Detection Frequencies and Estimates of Detection and Survival for As-Planned Arrays}

Table H.1. Spring Detection History

\begin{tabular}{|c|c|c|c|c|c|c|c|c|c|c|c|}
\hline \multirow[t]{2}{*}{ Season } & \multirow{2}{*}{$\begin{array}{c}\text { Release } \\
\text { Type }\end{array}$} & \multirow{2}{*}{$\begin{array}{l}\text { Release } \\
\text { Location }\end{array}$} & \multicolumn{9}{|c|}{ Detection History } \\
\hline & & & & & & $\underline{\text { Det }}$ & d at $1 \mathrm{~J}$ & & & & \\
\hline \multirow[t]{5}{*}{ Spring } & Single & LGR Tailrace & 111 & 011 & 101 & 001 & 110 & 010 & 100 & 000 & Total \\
\hline & & 6-May & 60 & 3 & 23 & 5 & 18 & 0 & 8 & 121 & 238 \\
\hline & & 13-May & 175 & 10 & 75 & 22 & 56 & 2 & 19 & 399 & 758 \\
\hline & & Pooled & 235 & 13 & 98 & 27 & 74 & 2 & 27 & 520 & 996 \\
\hline & & & \multicolumn{9}{|c|}{ Detected at 1T 2T 3T } \\
\hline \multirow[t]{5}{*}{ Spring } & Single & LGR Tailrace & 111 & 011 & 101 & 001 & 110 & 010 & 100 & 000 & Total \\
\hline & & 6-May & 77 & 14 & 2 & 0 & 5 & 4 & 1 & 135 & 238 \\
\hline & & 13-May & 216 & 65 & 3 & 6 & 16 & 11 & 7 & 434 & 758 \\
\hline & & Pooled & 293 & 79 & 5 & 6 & 21 & 15 & 8 & 569 & 996 \\
\hline & & & \multicolumn{9}{|c|}{ Detected at 1B 2B 3B } \\
\hline \multirow[t]{5}{*}{ Spring } & Single & LGR Tailrace & 111 & 011 & 101 & 001 & 110 & 010 & 100 & 000 & Total \\
\hline & & 6-May & 3 & 4 & 5 & 10 & 7 & 13 & 22 & 174 & 238 \\
\hline & & 13-May & 9 & 11 & 16 & 21 & 35 & 56 & 55 & 555 & 758 \\
\hline & & Pooled & 12 & 15 & 21 & 31 & 42 & 69 & 77 & 729 & 996 \\
\hline & & & \multicolumn{9}{|c|}{$\underline{\text { Detected at } 1 \mathrm{~J} 2 \mathrm{~J} 3 \mathrm{~J}}$} \\
\hline Spring & Single & $\begin{array}{c}\text { JDA Front } \\
\text { Roll } \\
\end{array}$ & 111 & 011 & 101 & 001 & 110 & 010 & 100 & 000 & Total \\
\hline \multirow{20}{*}{ Spring } & & 16-May & 30 & 0 & 11 & 1 & 4 & 0 & 6 & 2 & 54 \\
\hline & & 19-May & 42 & 0 & 6 & 0 & 8 & 0 & 2 & 1 & 59 \\
\hline & & 21-May & 49 & 1 & 2 & 1 & 2 & 0 & 2 & 2 & 59 \\
\hline & & 23-May & 42 & 0 & 11 & 0 & 13 & 0 & 2 & 2 & 70 \\
\hline & & 25-May & 45 & 0 & 1 & 0 & 12 & 0 & 2 & 0 & 60 \\
\hline & & 27-May & 38 & 0 & 6 & 0 & 28 & 0 & 5 & 3 & 80 \\
\hline & & 1-Jun & 49 & 0 & 3 & 1 & 5 & 0 & 2 & 0 & 60 \\
\hline & & 3-Jun & 43 & 0 & 2 & 0 & 10 & 0 & 0 & 0 & 55 \\
\hline & & Pooled & 338 & 1 & 42 & 3 & 82 & 0 & 21 & 10 & 497 \\
\hline & & & \multicolumn{9}{|c|}{ Detected at $1 \mathrm{~J} 2 \mathrm{~J} 3 \mathrm{~J}$} \\
\hline & Single & JDA Intake 9C & 111 & 011 & 101 & 001 & 110 & 010 & 100 & 000 & Total \\
\hline & & 16-May & 28 & 0 & 5 & 1 & 10 & 0 & 2 & 9 & 55 \\
\hline & & 19-May & 30 & 0 & 6 & 0 & 14 & 0 & 3 & 10 & 63 \\
\hline & & 21-May & 30 & 0 & 2 & 1 & 12 & 0 & 1 & 12 & 58 \\
\hline & & 23-May & 39 & 0 & 3 & 1 & 12 & 0 & 1 & 12 & 68 \\
\hline & & 25-May & 34 & 0 & 7 & 0 & 11 & 0 & 0 & 8 & 60 \\
\hline & & 27-May & 39 & 2 & 2 & 1 & 22 & 2 & 5 & 7 & 80 \\
\hline & & 1-Jun & 35 & 0 & 4 & 2 & 10 & 0 & 3 & 6 & 60 \\
\hline & & 3-Jun & 37 & 0 & 3 & 0 & 10 & 0 & 1 & 5 & 56 \\
\hline & & Pooled & 272 & 2 & 32 & 6 & 101 & 2 & 16 & 69 & 500 \\
\hline
\end{tabular}




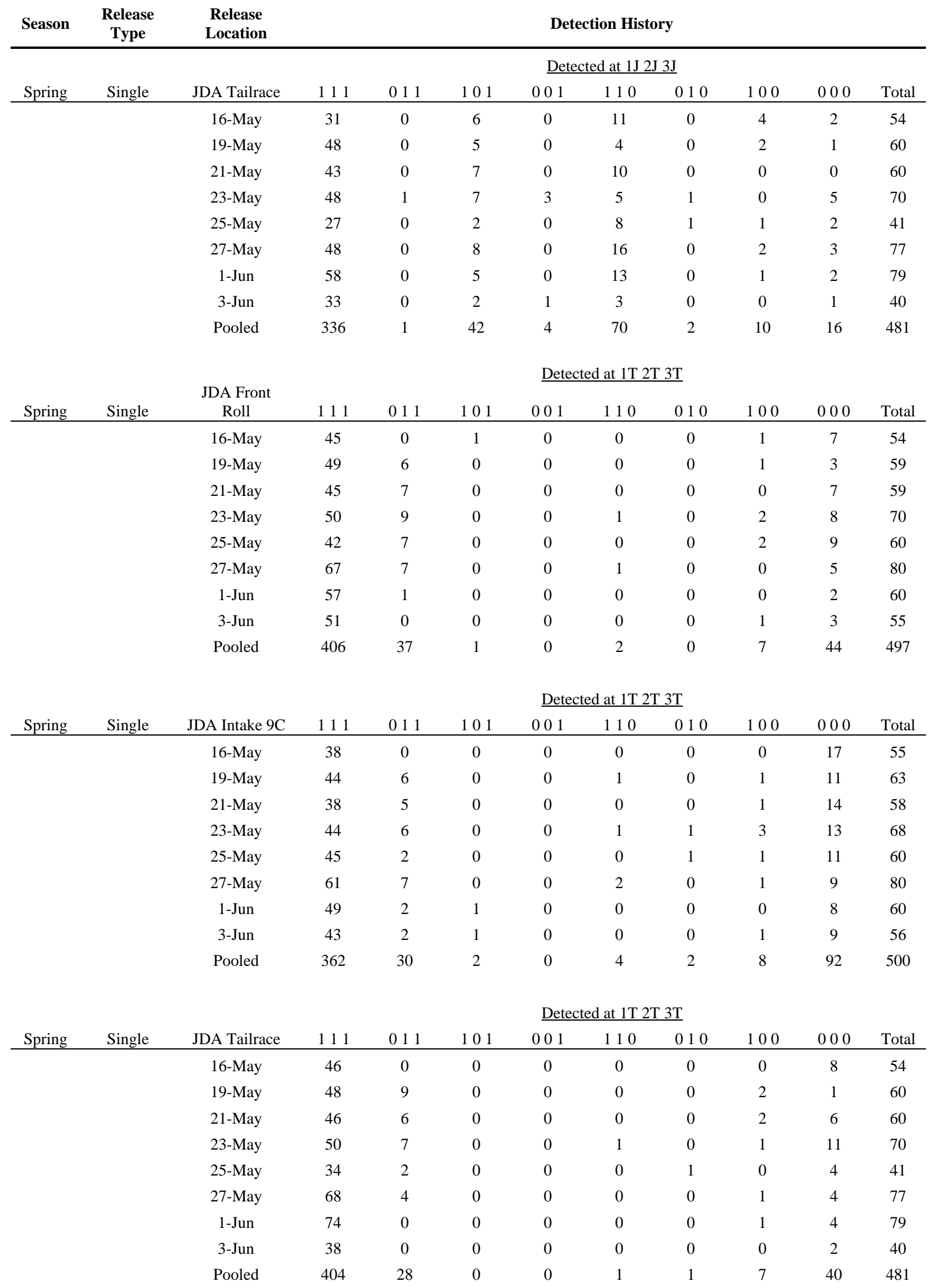




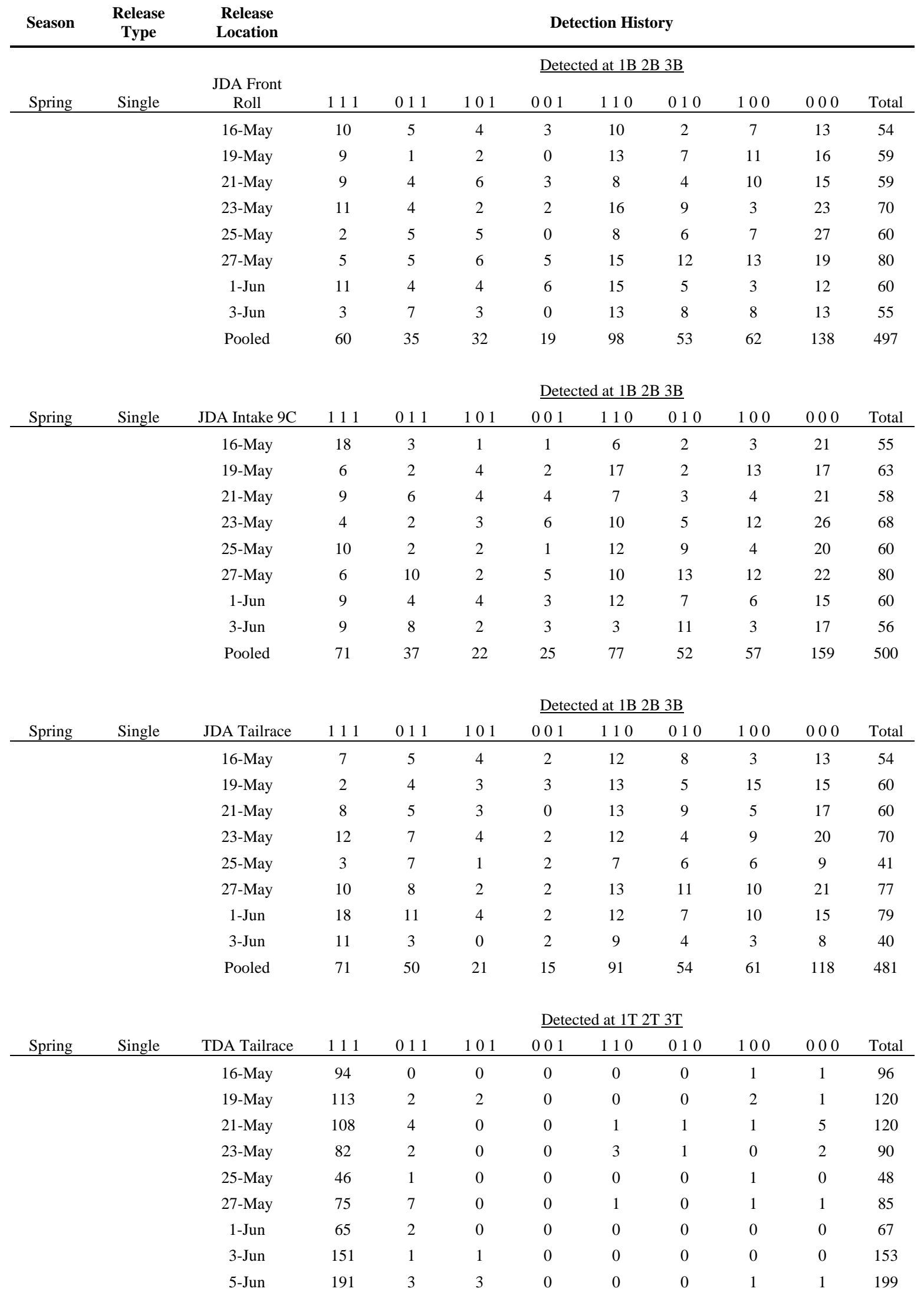




\begin{tabular}{|c|c|c|c|c|c|c|c|c|c|c|c|}
\hline \multirow[b]{2}{*}{ Season } & \multirow[b]{2}{*}{$\begin{array}{c}\text { Release } \\
\text { Type }\end{array}$} & Pooled & 925 & 22 & 6 & 0 & 5 & 2 & 7 & 11 & 978 \\
\hline & & $\begin{array}{l}\text { Release } \\
\text { Location }\end{array}$ & \multicolumn{9}{|c|}{ Detection History } \\
\hline \multirow[b]{2}{*}{ Spring } & \multirow[b]{2}{*}{ Single } & \multirow[b]{2}{*}{ TDA Tailrace } & \multicolumn{9}{|c|}{ Detected at 1B 2B 3B } \\
\hline & & & 111 & 011 & 101 & 001 & 110 & 010 & 100 & 000 & Total \\
\hline & & 16-May & 26 & 6 & 10 & 3 & 27 & 7 & 9 & 8 & 96 \\
\hline & & 19-May & 18 & 10 & 12 & 2 & 27 & 12 & 21 & 18 & 120 \\
\hline & & 21-May & 23 & 7 & 14 & 6 & 23 & 10 & 12 & 25 & 120 \\
\hline & & 23-May & 19 & 8 & 8 & 5 & 13 & 13 & 11 & 13 & 90 \\
\hline & & 25-May & 5 & 4 & 3 & 2 & 5 & 10 & 6 & 13 & 48 \\
\hline & & 27-May & 14 & 10 & 4 & 4 & 13 & 24 & 5 & 11 & 85 \\
\hline & & 1-Jun & 10 & 8 & 9 & 6 & 17 & 9 & 1 & 7 & 67 \\
\hline & & 3-Jun & 31 & 19 & 13 & 5 & 32 & 17 & 19 & 17 & 153 \\
\hline & & 5-Jun & 27 & 23 & 20 & 12 & 32 & 22 & 18 & 45 & 199 \\
\hline & & Pooled & 173 & 95 & 93 & 45 & 189 & 124 & 102 & 157 & 978 \\
\hline
\end{tabular}

\begin{tabular}{ccccccccccccc}
\multicolumn{10}{c}{ Detected at 1B 2B 3B } \\
\hline Spring & Single & BON Tailrace & 111 & 011 & 101 & 001 & 110 & 010 & 100 & 000 & Total \\
\hline & 2-May & 48 & 10 & 8 & 1 & 88 & 22 & 34 & 28 & 239 \\
& 11-May & 66 & 6 & 6 & 1 & 71 & 8 & 14 & 73 & 245 \\
& 19-May & 62 & 20 & 31 & 11 & 51 & 13 & 23 & 33 & 244 \\
& 27-May & 43 & 31 & 13 & 10 & 41 & 34 & 29 & 43 & 244 \\
& Pooled & 219 & 67 & 58 & 23 & 251 & 77 & 100 & 177 & 972
\end{tabular}

\begin{tabular}{cccccccccccc} 
& \multicolumn{1}{c}{ Detected at 1B 2B 3B } \\
Spring & Single & BON B2CC & 111 & 011 & 101 & 001 & 110 & 010 & 100 & 000 & Total \\
\hline & Pooled & 14 & 10 & 9 & 5 & 13 & 8 & 9 & 10 & 78
\end{tabular}

\begin{tabular}{cccccccccccc} 
& \multicolumn{1}{c}{ Detected at 1B 2B 3B } \\
Spring & Single & BON B2JBS & 111 & 011 & 101 & 001 & 110 & 010 & 100 & 000 & Total \\
\hline & Pooled & 5 & 3 & 4 & 4 & 7 & 7 & 4 & 8 & 42
\end{tabular}

\begin{tabular}{cccccccccccc} 
& \multicolumn{1}{c}{ Detected at 1B 2B 3B } \\
Spring & Single & BON Spillway & 111 & 011 & 101 & 001 & 110 & 010 & 100 & 000 & Total \\
\hline & Pooled & 19 & 16 & 16 & 6 & 31 & 16 & 14 & 16 & 134
\end{tabular}

\begin{tabular}{ccccccccccccc} 
& \multicolumn{9}{c}{ Detected at 1T 2T 3T } \\
Spring Virtual & JDA & 111 & 011 & 101 & 001 & 110 & 010 & 100 & 000 & Total \\
\hline & 16-May & 35 & 0 & 0 & 0 & 0 & 0 & 0 & 2 & 37 \\
& 19-May & 42 & 9 & 0 & 0 & 0 & 0 & 2 & 0 & 53 \\
& 21-May & 39 & 5 & 0 & 0 & 0 & 0 & 1 & 5 & 50 \\
& 23-May & 46 & 6 & 0 & 0 & 1 & 0 & 1 & 5 & 59 \\
& 25-May & 25 & 2 & 0 & 0 & 0 & 0 & 0 & 2 & 29 \\
& 27-May & 53 & 1 & 0 & 0 & 0 & 0 & 0 & 2 & 56 \\
& 1-Jun & 62 & 0 & 0 & 0 & 0 & 0 & 0 & 1 & 63 \\
& 3-Jun & 35 & 0 & 0 & 0 & 0 & 0 & 0 & 1 & 36 \\
& Pooled & 337 & 23 & 0 & 0 & 1 & 0 & 4 & 18 & 383
\end{tabular}




\begin{tabular}{|c|c|c|c|c|c|c|c|c|c|c|c|}
\hline Season & $\begin{array}{c}\text { Release } \\
\text { Type }\end{array}$ & $\begin{array}{l}\text { Release } \\
\text { Location }\end{array}$ & \multicolumn{9}{|c|}{ Detection History } \\
\hline \multirow[b]{2}{*}{ Spring } & \multirow[b]{2}{*}{ Virtual } & \multirow[b]{2}{*}{ TDA } & \multicolumn{9}{|c|}{ Detected at 1B 2B 3B } \\
\hline & & & 111 & 011 & 101 & 001 & 110 & 010 & 100 & 000 & Total \\
\hline & & 16-May & 26 & 6 & 10 & 3 & 27 & 7 & 9 & 6 & 94 \\
\hline & & 19-May & 18 & 10 & 12 & 2 & 27 & 12 & 21 & 15 & 117 \\
\hline & & 21-May & 23 & 7 & 14 & 5 & 23 & 10 & 12 & 18 & 112 \\
\hline & & 23-May & 19 & 8 & 8 & 5 & 13 & 11 & 11 & 9 & 84 \\
\hline & & 25-May & 5 & 4 & 3 & 2 & 5 & 10 & 6 & 12 & 47 \\
\hline & & 27-May & 14 & 10 & 4 & 4 & 13 & 23 & 5 & 9 & 82 \\
\hline & & 1-Jun & 10 & 8 & 9 & 6 & 17 & 9 & 1 & 7 & 67 \\
\hline & & 3-Jun & 31 & 19 & 13 & 5 & 32 & 17 & 19 & 17 & 153 \\
\hline & & 5-Jun & 27 & 23 & 20 & 12 & 32 & 22 & 18 & 43 & 197 \\
\hline & & Pooled & 173 & 95 & 93 & 44 & 189 & 121 & 102 & 136 & 953 \\
\hline & & & & & & $\underline{\text { Dete }}$ & $\mathrm{d}$ at $1 \mathrm{~T}$ & & & & \\
\hline \multirow[t]{3}{*}{ Spring } & Virtual & JDA & 111 & 011 & 101 & 001 & 110 & 010 & 100 & 000 & Total \\
\hline & & Pooled & 1212 & 120 & 5 & 2 & 15 & 6 & 22 & 104 & 1486 \\
\hline & & & \multicolumn{9}{|c|}{ Detected at 1B 2B 3B } \\
\hline \multirow[t]{3}{*}{ Spring } & Virtual & TDA & 111 & 011 & 101 & 001 & 110 & 010 & 100 & 000 & Total \\
\hline & & Pooled & 407 & 235 & 189 & 128 & 500 & 325 & 339 & 500 & 2623 \\
\hline & & & \multicolumn{9}{|c|}{ Detected at 1T 2T 3T } \\
\hline \multirow[t]{4}{*}{ Spring } & Paired & TDA Dam & 111 & 011 & 101 & 001 & 110 & 010 & 100 & 000 & Total \\
\hline & & JDA Tailrace & 404 & 28 & 0 & 0 & 1 & 1 & 7 & 40 & 481 \\
\hline & & TDA Tailrace & 925 & 22 & 6 & 0 & 5 & 2 & 7 & 11 & 978 \\
\hline & & & \multicolumn{9}{|c|}{ Detected at 1B 2B 3B } \\
\hline \multirow[t]{3}{*}{ Spring } & Paired & BON Dam & 111 & 011 & 101 & 001 & 110 & 010 & 100 & 000 & Total \\
\hline & & TDA Tailrace & 173 & 95 & 93 & 45 & 189 & 124 & 102 & 157 & 978 \\
\hline & & BON Tailrace & 219 & 67 & 58 & 23 & 251 & 77 & 100 & 177 & 972 \\
\hline
\end{tabular}


Table H.2. Spring Detection and Survival Probabilities

\begin{tabular}{|c|c|c|c|c|c|c|c|c|c|c|c|c|}
\hline \multirow{2}{*}{$\begin{array}{l}\text { Season } \\
\text { Spring }\end{array}$} & \multirow{2}{*}{$\begin{array}{c}\begin{array}{c}\text { Release } \\
\text { Type }\end{array} \\
\text { Single } \\
\end{array}$} & \multirow{2}{*}{$\begin{array}{l}\text { Release Site } \\
\text { LGR Release } \\
\end{array}$} & \multicolumn{4}{|c|}{ Survival Probability } & \multicolumn{4}{|c|}{ Detection Probability } & \multicolumn{2}{|c|}{ Detection and Survival } \\
\hline & & & to $1 \mathrm{~J}$ & $95 \% \mathrm{CL}$ & $1 \mathrm{~J}$ to $2 \mathrm{~J}$ & $95 \% \mathrm{CL}$ & $1 \mathrm{~J}$ & $95 \%$ CL & $2 \mathrm{~J}$ & $95 \% \mathrm{CL}$ & $\lambda$ to $3 \mathrm{~J}$ & $95 \% \mathrm{CL}$ \\
\hline \multirow[b]{4}{*}{ Spring } & \multirow[b]{4}{*}{ Single } & $5 / 6$ & 0.4943 & 0.0639 & 0.9946 & 0.0670 & 0.9266 & 0.0490 & 0.6923 & 0.0949 & 0.7778 & 0.0906 \\
\hline & & $5 / 13$ & 0.4764 & 0.0359 & 1.0258 & 0.0398 & 0.9000 & 0.0319 & 0.6560 & 0.0555 & 0.7613 & 0.0535 \\
\hline & & Pooled & 0.4807 & 0.0312 & 1.0178 & 0.0343 & 0.9065 & 0.0269 & 0.6649 & 0.0478 & 0.7654 & 0.0461 \\
\hline & & LGR Release & to $1 \mathrm{~T}$ & $95 \% \mathrm{CL}$ & $1 \mathrm{~T}$ to $2 \mathrm{~T}$ & $95 \% \mathrm{CL}$ & $1 \mathrm{~T}$ & $95 \%$ CL & $2 \mathrm{~T}$ & $95 \% \mathrm{CL}$ & $\lambda$ to $3 \mathrm{~T}$ & $95 \% \mathrm{CL}$ \\
\hline \multirow[b]{4}{*}{ Spring } & \multirow[b]{4}{*}{ Single } & $5 / 6$ & 0.4337 & 0.0631 & 0.9902 & 0.0231 & 0.8235 & 0.0739 & 0.9785 & 0.0294 & 0.9100 & 0.0561 \\
\hline & & $5 / 13$ & 0.4307 & 0.0355 & 0.9737 & 0.0214 & 0.7413 & 0.0482 & 0.9690 & 0.0200 & 0.9123 & 0.0316 \\
\hline & & Pooled & 0.4312 & 0.0310 & 0.9780 & 0.0169 & 0.7613 & 0.0408 & 0.9713 & 0.0167 & 0.9118 & 0.0274 \\
\hline & & LGR Release & to $1 \mathrm{~B}$ & $95 \% \mathrm{CL}$ & $1 \mathrm{~B}$ to $2 \mathrm{~B}$ & $95 \% \mathrm{CL}$ & $1 \mathrm{~B}$ & $95 \% \mathrm{CL}$ & $2 B$ & $95 \% \mathrm{CL}$ & $\lambda$ to $3 \mathrm{~B}$ & $95 \% \mathrm{CL}$ \\
\hline \multirow[b]{4}{*}{ Spring } & \multirow[b]{4}{*}{ Single } & $5 / 6$ & 0.4353 & 0.1501 & 0.8191 & 0.5071 & 0.3571 & 0.1448 & 0.3182 & 0.1946 & 0.2593 & 0.0561 \\
\hline & & $5 / 13$ & 0.3742 & 0.0612 & 1.1152 & 0.3847 & 0.4054 & 0.0792 & 0.3509 & 0.1239 & 0.1802 & 0.0316 \\
\hline & & Pooled & 0.3866 & 0.0570 & 1.0486 & 0.3156 & 0.3947 & 0.0696 & 0.3418 & 0.1047 & 0.1957 & 0.0274 \\
\hline & & JDA Front Roll & to $1 \mathrm{~J}$ & 95\% CL & $1 \mathrm{~J}$ to $2 \mathrm{~J}$ & 95\% CL & $1 \mathrm{~J}$ & 95\% CL & $2 \mathrm{~J}$ & $95 \%$ CL & $\lambda$ to $3 \mathrm{~J}$ & 95\% CL \\
\hline \multirow{19}{*}{ Spring } & \multirow{19}{*}{ Single } & $5 / 16$ & 0.9654 & 0.0508 & 0.9130 & 0.0980 & 0.9783 & 0.0421 & 0.7143 & 0.1366 & 0.8824 & 0.1084 \\
\hline & & $5 / 19$ & 0.9831 & 0.0329 & 0.9852 & 0.0523 & 1.0000 & 0.0000 & 0.8750 & 0.0935 & 0.8400 & 0.1015 \\
\hline & & $5 / 21$ & 0.9674 & 0.0463 & 0.9657 & 0.0498 & 0.9636 & 0.0494 & 0.9434 & 0.0621 & 0.9615 & 0.0523 \\
\hline & & $5 / 23$ & 0.9714 & 0.0390 & 1.0207 & 0.0590 & 1.0000 & 0.0000 & 0.7925 & 0.1092 & 0.7636 & 0.1123 \\
\hline & & $5 / 25$ & 1.0000 & 0.0000 & 0.9711 & 0.0465 & 1.0000 & 0.0000 & 0.9783 & 0.0421 & 0.7895 & 0.1058 \\
\hline & & $5 / 27$ & 0.9625 & 0.0416 & 0.9925 & 0.0784 & 1.0000 & 0.0000 & 0.8636 & 0.1013 & 0.5758 & 0.1192 \\
\hline & & $6 / 1$ & 1.0006 & 0.0014 & 0.9729 & 0.0474 & 0.9828 & 0.0335 & 0.9245 & 0.0711 & 0.9074 & 0.0772 \\
\hline & & $6 / 3$ & 1.0000 & 0.0000 & 1.0085 & 0.0129 & 1.0000 & 0.0000 & 0.9556 & 0.0602 & 0.8113 & 0.1053 \\
\hline & & Pooled & 0.9802 & 0.0123 & 0.9789 & 0.0204 & 0.9914 & 0.0084 & 0.8828 & 0.0321 & 0.8052 & 0.0378 \\
\hline & & JDA Intake 9C & to $1 \mathrm{~J}$ & $95 \% \mathrm{CL}$ & $1 \mathrm{~J}$ to $2 \mathrm{~J}$ & 95\% CL & $1 \mathrm{~J}$ & $95 \% \mathrm{CL}$ & $2 \mathrm{~J}$ & $95 \% \mathrm{CL}$ & $\lambda$ to $3 \mathrm{~J}$ & $95 \% \mathrm{CL}$ \\
\hline & & $5 / 16$ & 0.8372 & 0.0978 & 1.0021 & 0.0794 & 0.9773 & 0.0441 & 0.8235 & 0.1282 & 0.7368 & 0.1399 \\
\hline & & $5 / 19$ & 0.8413 & 0.0902 & 0.9962 & 0.0837 & 1.0000 & 0.0000 & 0.8333 & 0.1217 & 0.6818 & 0.1376 \\
\hline & & $5 / 21$ & 0.7935 & 0.1043 & 1.0039 & 0.0555 & 0.9778 & 0.0431 & 0.9091 & 0.0000 & 0.7143 & 0.1366 \\
\hline & & $5 / 23$ & 0.8238 & 0.0906 & 1.0038 & 0.0439 & 0.9818 & 0.0353 & 0.9070 & 0.0868 & 0.7647 & 0.1164 \\
\hline & & $5 / 25$ & 0.8667 & 0.0860 & 1.0436 & 0.0421 & 1.0000 & 0.0000 & 0.8293 & 0.1152 & 0.7556 & 0.1256 \\
\hline & & $5 / 27$ & 0.9175 & 0.0625 & 0.9504 & 0.0700 & 0.9265 & 0.0621 & 0.9318 & 0.0745 & 0.6308 & 0.1174 \\
\hline & & $6 / 1$ & 0.9020 & 0.0762 & 0.9740 & 0.0731 & 0.9608 & 0.0533 & 0.8537 & 0.1082 & 0.7778 & 0.1215 \\
\hline & & $6 / 3$ & 0.9107 & 0.0747 & 0.9963 & 0.0439 & 1.0000 & 0.0000 & 0.9250 & 0.0815 & 0.7872 & 0.1170 \\
\hline & & Pooled & 0.8628 & 0.0302 & 0.9951 & 0.0227 & 0.9759 & 0.0147 & 0.8782 & 0.0363 & 0.7268 & 0.0449 \\
\hline
\end{tabular}




\begin{tabular}{|c|c|c|c|c|c|c|c|c|c|c|c|c|}
\hline \multirow{2}{*}{$\begin{array}{l}\text { Season } \\
\text { Spring }\end{array}$} & \multirow{2}{*}{$\begin{array}{c}\begin{array}{c}\text { Release } \\
\text { Type }\end{array} \\
\text { Single } \\
\end{array}$} & \multirow{2}{*}{$\begin{array}{l}\text { Release Site } \\
\text { JDA Tailrace } \\
\end{array}$} & \multicolumn{4}{|c|}{ Survival Probability } & \multicolumn{4}{|c|}{ Detection Probability } & \multicolumn{2}{|c|}{ Detection and Survival } \\
\hline & & & to $1 \mathrm{~J}$ & $95 \%$ CL & $1 \mathrm{~J}$ to $2 \mathrm{~J}$ & $95 \% \mathrm{CL}$ & $1 \mathrm{~J}$ & $95 \% \mathrm{CL}$ & $2 \mathrm{~J}$ & $95 \% \mathrm{CL}$ & $\lambda$ to $3 \mathrm{~J}$ & $95 \% \mathrm{CL}$ \\
\hline \multirow[b]{10}{*}{ Spring } & & $5 / 16$ & 0.9630 & 0.0504 & 0.9640 & 0.0862 & 1.0000 & 0.0000 & 0.8378 & 0.1188 & 0.7381 & 0.1329 \\
\hline & & $5 / 19$ & 0.9833 & 0.0323 & 0.9732 & 0.0474 & 1.0000 & 0.0000 & 0.9057 & 0.0788 & 0.9231 & 0.0725 \\
\hline & & $5 / 21$ & 1.0000 & 0.0000 & 1.0271 & 0.0267 & 1.0000 & 0.0000 & 0.8600 & 0.0962 & 0.8113 & 0.1053 \\
\hline & & $5 / 23$ & 0.9286 & 0.0604 & 1.0188 & 0.0192 & 0.9231 & 0.0649 & 0.8305 & 0.0956 & 0.8909 & 0.0823 \\
\hline & & $5 / 25$ & 0.9519 & 0.0661 & 0.9908 & 0.0582 & 0.9737 & 0.0510 & 0.9310 & 0.0923 & 0.7500 & 0.1415 \\
\hline & & $5 / 27$ & 0.9610 & 0.0433 & 1.0090 & 0.0494 & 1.0000 & 0.0000 & 0.8571 & 0.0917 & 0.7500 & 0.1060 \\
\hline & & $6 / 1$ & 0.9747 & 0.0347 & 1.0016 & 0.0298 & 1.0000 & 0.0000 & 0.9206 & 0.0668 & 0.8169 & 0.0900 \\
\hline & & $6 / 3$ & 0.9750 & 0.0484 & 1.0070 & 0.0112 & 0.9744 & 0.0496 & 0.9167 & 0.0904 & 0.9167 & 0.0904 \\
\hline & & Pooled & 0.9671 & 0.0161 & 0.9993 & 0.0159 & 0.9846 & 0.0114 & 0.8799 & 0.0325 & 0.8240 & 0.0368 \\
\hline & Single & JDA Front Roll & to $1 \mathrm{~T}$ & $95 \%$ CL & $1 \mathrm{~T}$ to $2 \mathrm{~T}$ & $95 \% \mathrm{CL}$ & $1 \mathrm{~T}$ & $95 \%$ CL & $2 \mathrm{~T}$ & $95 \% \mathrm{CL}$ & $\lambda$ to $3 \mathrm{~T}$ & $95 \%$ CL \\
\hline \multirow{19}{*}{ Spring } & & $5 / 16$ & 0.8704 & 0.0896 & 0.9787 & 0.0412 & 1.0000 & 0.0000 & 0.9783 & 0.0421 & 1.0000 & 0.0000 \\
\hline & & $5 / 19$ & 0.9512 & 0.0564 & 0.9800 & 0.0388 & 0.8909 & 0.0823 & 1.0000 & 0.0000 & 1.0000 & 0.0000 \\
\hline & & $5 / 21$ & 0.8814 & 0.0825 & 1.0000 & 0.0000 & 0.8654 & 0.0927 & 1.0000 & 0.0000 & 1.0000 & 0.0000 \\
\hline & & $5 / 23$ & 0.8908 & 0.0753 & 0.9623 & 0.0514 & 0.8500 & 0.0904 & 1.0000 & 0.0000 & 0.9833 & 0.0323 \\
\hline & & $5 / 25$ & 0.8556 & 0.0913 & 0.9545 & 0.0615 & 0.8571 & 0.0980 & 1.0000 & 0.0000 & 1.0000 & 0.0000 \\
\hline & & $5 / 27$ & 0.9375 & 0.0531 & 1.0000 & 0.0000 & 0.9067 & 0.0659 & 1.0000 & 0.0000 & 0.9867 & 0.0259 \\
\hline & & $6 / 1$ & 0.9667 & 0.0455 & 1.0000 & 0.0000 & 0.9828 & 0.0335 & 1.0000 & 0.0000 & 1.0000 & 0.0000 \\
\hline & & $6 / 3$ & 0.9455 & 0.0600 & 0.9808 & 0.0372 & 1.0000 & 0.0000 & 1.0000 & 0.0000 & 1.0000 & 0.0000 \\
\hline & & Pooled & 0.9127 & 0.0251 & 0.9832 & 0.0123 & 0.9170 & 0.0257 & 0.9977 & 0.0043 & 0.9955 & 0.0063 \\
\hline & Single & JDA Intake 9C & to $1 \mathrm{~T}$ & 95\% CL & $1 \mathrm{~T}$ to $2 \mathrm{~T}$ & $95 \%$ CL & $1 \mathrm{~T}$ & $95 \%$ CL & $2 \mathrm{~T}$ & $95 \%$ CL & $\lambda$ to $3 \mathrm{~T}$ & $95 \%$ CL \\
\hline & & $5 / 16$ & 0.6909 & 0.1221 & 1.0000 & 0.0000 & 1.0000 & 0.0000 & 1.0000 & 0.0000 & 1.0000 & 0.0000 \\
\hline & & $5 / 19$ & 0.8275 & 0.0941 & 0.9783 & 0.0421 & 0.8824 & 0.0884 & 1.0000 & 0.0000 & 0.9804 & 0.0380 \\
\hline & & $5 / 21$ & 0.7609 & 0.1105 & 0.9744 & 0.0496 & 0.8837 & 0.0958 & 1.0000 & 0.0000 & 1.0000 & 0.0000 \\
\hline & & $5 / 23$ & 0.8157 & 0.0947 & 0.9375 & 0.0684 & 0.8654 & 0.0927 & 1.0000 & 0.0000 & 0.9615 & 0.0523 \\
\hline & & $5 / 25$ & 0.8178 & 0.0980 & 0.9783 & 0.0421 & 0.9375 & 0.0684 & 1.0000 & 0.0000 & 0.9792 & 0.0404 \\
\hline & & $5 / 27$ & 0.8889 & 0.0694 & 0.9844 & 0.0304 & 0.9000 & 0.0704 & 1.0000 & 0.0000 & 0.9714 & 0.0390 \\
\hline & & $6 / 1$ & 0.8667 & 0.0860 & 1.0000 & 0.0000 & 0.9615 & 0.0523 & 0.9808 & 0.0372 & 1.0000 & 0.0000 \\
\hline & & $6 / 3$ & 0.8401 & 0.0962 & 0.9778 & 0.0431 & 0.9565 & 0.0590 & 0.9783 & 0.0421 & 1.0000 & 0.0000 \\
\hline & & Pooled & 0.8174 & 0.0341 & 0.9788 & 0.0145 & 0.9200 & 0.0267 & 0.9949 & 0.0071 & 0.9849 & 0.0120 \\
\hline
\end{tabular}




\begin{tabular}{|c|c|c|c|c|c|c|c|c|c|c|c|c|}
\hline \multirow{2}{*}{$\begin{array}{l}\text { Season } \\
\text { Spring } \\
\end{array}$} & \multirow{2}{*}{$\begin{array}{c}\begin{array}{c}\text { Release } \\
\text { Type }\end{array} \\
\text { Single } \\
\end{array}$} & \multirow{2}{*}{$\begin{array}{l}\text { Release Site } \\
\text { JDA Tailrace }\end{array}$} & \multicolumn{4}{|c|}{ Survival Probability } & \multicolumn{4}{|c|}{ Detection Probability } & \multicolumn{2}{|c|}{ Detection and Survival } \\
\hline & & & to $1 \mathrm{~T}$ & $95 \%$ CL & $1 \mathrm{~T}$ to $2 \mathrm{~T}$ & $95 \%$ CL & $1 \mathrm{~T}$ & 95\% CL & $2 \mathrm{~T}$ & 95\% CL & $\lambda$ to $3 \mathrm{~T}$ & $95 \%$ CL \\
\hline \multirow[b]{10}{*}{ Spring } & \multirow[b]{10}{*}{ Single } & $5 / 16$ & 0.8519 & 0.0947 & 1.0000 & 0.0000 & 1.0000 & 0.0000 & 1.0000 & 0.0000 & 1.0000 & 0.0000 \\
\hline & & $5 / 19$ & 0.9896 & 0.0339 & 0.9600 & 0.0543 & 0.8421 & 0.0947 & 1.0000 & 0.0000 & 1.0000 & 0.0000 \\
\hline & & $5 / 21$ & 0.9043 & 0.0766 & 0.9583 & 0.0564 & 0.8846 & 0.0868 & 1.0000 & 0.0000 & 1.0000 & 0.0000 \\
\hline & & $5 / 23$ & 0.8448 & 0.0857 & 0.9808 & 0.0372 & 0.8793 & 0.0839 & 1.0000 & 0.0000 & 0.9828 & 0.0335 \\
\hline & & $5 / 25$ & 0.9024 & 0.0907 & 1.0000 & 0.0000 & 0.9189 & 0.0880 & 1.0000 & 0.0000 & 0.9730 & 0.0523 \\
\hline & & $5 / 27$ & 0.9488 & 0.0496 & 0.9855 & 0.0282 & 0.9444 & 0.0529 & 1.0000 & 0.0000 & 1.0000 & 0.0000 \\
\hline & & $6 / 1$ & 0.9494 & 0.0484 & 0.9867 & 0.0259 & 1.0000 & 0.0000 & 1.0000 & 0.0000 & 1.0000 & 0.0000 \\
\hline & & $6 / 3$ & 0.9500 & 0.0676 & 1.0000 & 0.0000 & 1.0000 & 0.0000 & 1.0000 & 0.0000 & 1.0000 & 0.0000 \\
\hline & & Pooled & 0.9179 & 0.0247 & 0.9830 & 0.0125 & 0.9332 & 0.0235 & 1.0000 & 0.0000 & 0.9954 & 0.0065 \\
\hline & & JDA Front Roll & to $1 \mathrm{~B}$ & 95\% CL & $1 \mathrm{~B}$ to $2 \mathrm{~B}$ & $95 \% \mathrm{CL}$ & $1 \mathrm{~B}$ & $95 \% \mathrm{CL}$ & $2 \mathrm{~B}$ & $95 \% \mathrm{CL}$ & $\lambda$ to $3 \mathrm{~B}$ & $95 \% \mathrm{CL}$ \\
\hline \multirow{19}{*}{ Spring } & \multirow{19}{*}{ Single } & $5 / 16$ & 0.8133 & 0.1335 & 0.9017 & 0.2140 & 0.7059 & 0.1531 & 0.6818 & 0.1946 & 0.5556 & 0.1874 \\
\hline & & $5 / 19$ & 0.7910 & 0.1364 & 0.7714 & 0.2178 & 0.7500 & 0.1499 & 0.8333 & 0.2109 & 0.3333 & 0.1688 \\
\hline & & $5 / 21$ & 0.8268 & 0.1433 & 0.8673 & 0.2550 & 0.6765 & 0.1572 & 0.5909 & 0.2054 & 0.5200 & 0.1958 \\
\hline & & $5 / 23$ & 0.6936 & 0.1170 & 1.0436 & 0.1942 & 0.6591 & 0.1401 & 0.7895 & 0.1833 & 0.3750 & 0.1499 \\
\hline & & $5 / 25$ & 0.6356 & 0.1695 & 0.9441 & 0.4145 & 0.5769 & 0.1899 & 0.5833 & 0.2789 & 0.3333 & 0.2017 \\
\hline & & $5 / 27$ & 0.9000 & 0.1503 & 1.0792 & 0.4390 & 0.5417 & 0.1409 & 0.4762 & 0.2136 & 0.2703 & 0.1431 \\
\hline & & $6 / 1$ & 0.8250 & 0.1090 & 1.1785 & 0.2652 & 0.6667 & 0.1378 & 0.6000 & 0.1921 & 0.4286 & 0.1639 \\
\hline & & $6 / 3$ & 0.8785 & 0.1668 & 0.8341 & 0.2668 & 0.5588 & 0.1670 & 0.7692 & 0.2291 & 0.3226 & 0.1646 \\
\hline & & Pooled & 0.7926 & 0.0490 & 0.9598 & 0.1002 & 0.6397 & 0.0547 & 0.6507 & 0.0774 & 0.3862 & 0.0608 \\
\hline & & JDA Intake 9C & to $1 \mathrm{~B}$ & 95\% CL & $1 \mathrm{~B}$ to $2 \mathrm{~B}$ & $95 \% \mathrm{CL}$ & $1 \mathrm{~B}$ & $95 \% \mathrm{CL}$ & $2 \mathrm{~B}$ & $95 \% \mathrm{CL}$ & $\lambda$ to $3 \mathrm{~B}$ & $95 \% \mathrm{CL}$ \\
\hline & & $5 / 16$ & 0.6313 & 0.1323 & 0.9148 & 0.1223 & 0.8065 & 0.1392 & 0.9130 & 0.1152 & 0.7241 & 0.1627 \\
\hline & & $5 / 19$ & 0.7760 & 0.1252 & 0.9665 & 0.3816 & 0.8182 & 0.1315 & 0.5714 & 0.2593 & 0.2963 & 0.1723 \\
\hline & & $5 / 21$ & 0.6828 & 0.1423 & 0.9680 & 0.2195 & 0.6061 & 0.1668 & 0.6522 & 0.1946 & 0.6000 & 0.1921 \\
\hline & & $5 / 23$ & 0.7526 & 0.1829 & 1.0259 & 0.5739 & 0.5667 & 0.1774 & 0.4000 & 0.2479 & 0.2857 & 0.1933 \\
\hline & & $5 / 25$ & 0.7000 & 0.1311 & 0.9821 & 0.2197 & 0.6667 & 0.1541 & 0.8000 & 0.2025 & 0.3636 & 0.1641 \\
\hline & & $5 / 27$ & 0.9583 & 0.2229 & 0.7312 & 0.2464 & 0.3913 & 0.1411 & 0.6957 & 0.1880 & 0.4103 & 0.1544 \\
\hline & & $6 / 1$ & 0.8060 & 0.1301 & 1.0180 & 0.2707 & 0.6410 & 0.1505 & 0.6500 & 0.2091 & 0.4063 & 0.1701 \\
\hline & & $6 / 3$ & 0.7806 & 0.1725 & 0.9177 & 0.2260 & 0.3889 & 0.1592 & 0.7727 & 0.1750 & 0.5484 & 0.1752 \\
\hline & & Pooled & 0.7584 & 0.0521 & 0.8969 & 0.0866 & 0.5986 & 0.0570 & 0.6968 & 0.0723 & 0.4557 & 0.0635 \\
\hline
\end{tabular}




\begin{tabular}{|c|c|c|c|c|c|c|c|c|c|c|c|c|}
\hline \multirow{2}{*}{$\begin{array}{l}\text { Season } \\
\text { Spring } \\
\end{array}$} & \multirow{2}{*}{$\begin{array}{c}\begin{array}{c}\text { Release } \\
\text { Type }\end{array} \\
\text { Single } \\
\end{array}$} & \multirow{2}{*}{$\begin{array}{c}\text { Release Site } \\
\text { JDA Tailrace } \\
\end{array}$} & \multicolumn{4}{|c|}{ Survival Probability } & \multicolumn{4}{|c|}{ Detection Probability } & \multicolumn{2}{|c|}{ Detection and Survival } \\
\hline & & & to $1 \mathrm{~B}$ & 95\% CL & $1 \mathrm{~B}$ to $2 \mathrm{~B}$ & 95\% CL & $1 \mathrm{~B}$ & $95 \% \mathrm{CL}$ & $2 \mathrm{~B}$ & $95 \%$ CL & $\lambda$ to $3 \mathrm{~B}$ & $95 \% \mathrm{CL}$ \\
\hline \multirow[b]{10}{*}{ Spring } & \multirow[b]{10}{*}{ Single } & $5 / 16$ & 0.7955 & 0.1280 & 1.1174 & 0.2846 & 0.6053 & 0.1554 & 0.6667 & 0.2178 & 0.3750 & 0.1678 \\
\hline & & $5 / 19$ & 0.9167 & 0.1936 & 0.8727 & 0.4692 & 0.6000 & 0.1752 & 0.5000 & 0.2828 & 0.2500 & 0.1733 \\
\hline & & $5 / 21$ & 0.7653 & 0.1321 & 0.9382 & 0.2109 & 0.6316 & 0.1535 & 0.8125 & 0.1913 & 0.3714 & 0.1601 \\
\hline & & $5 / 23$ & 0.7740 & 0.1262 & 0.8500 & 0.1809 & 0.6829 & 0.1425 & 0.7600 & 0.1674 & 0.5429 & 0.1650 \\
\hline & & $5 / 25$ & 0.9800 & 0.2648 & 0.7441 & 0.2920 & 0.4231 & 0.1899 & 0.7692 & 0.2291 & 0.4348 & 0.2027 \\
\hline & & $5 / 27$ & 0.8364 & 0.1445 & 0.7971 & 0.1909 & 0.5435 & 0.1439 & 0.8182 & 0.1611 & 0.4286 & 0.1497 \\
\hline & & $6 / 1$ & 0.8846 & 0.1113 & 0.8290 & 0.1433 & 0.6296 & 0.1288 & 0.8286 & 0.1249 & 0.6042 & 0.1384 \\
\hline & & $6 / 3$ & 0.8338 & 0.1368 & 0.9253 & 0.1695 & 0.6897 & 0.1684 & 0.8750 & 0.1621 & 0.5185 & 0.1886 \\
\hline & & Pooled & 0.8371 & 0.0504 & 0.8571 & 0.0749 & 0.6060 & 0.0551 & 0.7707 & 0.0659 & 0.4549 & 0.0598 \\
\hline & & TDA Tailrace & to $1 \mathrm{~T}$ & 95\% CL & $1 \mathrm{~T}$ to $2 \mathrm{~T}$ & 95\% CL & $1 \mathrm{~T}$ & $95 \% \mathrm{CL}$ & $2 \mathrm{~T}$ & $95 \%$ CL & $\lambda$ to $3 \mathrm{~T}$ & $95 \% \mathrm{CL}$ \\
\hline \multirow{21}{*}{ Spring } & \multirow{21}{*}{ Single } & $5 / 16$ & 0.9896 & 0.0204 & 0.9895 & 0.0206 & 1.0000 & 0.0000 & 1.0000 & 0.0000 & 1.0000 & 0.0000 \\
\hline & & $5 / 19$ & 0.9920 & 0.0163 & 0.9829 & 0.0235 & 0.9829 & 0.0235 & 0.9829 & 0.0235 & 1.0000 & 0.0000 \\
\hline & & $5 / 21$ & 0.9587 & 0.0359 & 0.9909 & 0.0176 & 0.9561 & 0.0376 & 1.0000 & 0.0000 & 0.9825 & 0.0241 \\
\hline & & $5 / 23$ & 0.9778 & 0.0304 & 1.0000 & 0.0000 & 0.9659 & 0.0378 & 1.0000 & 0.0000 & 0.9545 & 0.0435 \\
\hline & & $5 / 25$ & 1.0005 & 0.0012 & 0.9787 & 0.0412 & 0.9787 & 0.0412 & 1.0000 & 0.0000 & 1.0000 & 0.0000 \\
\hline & & $5 / 27$ & 0.9892 & 0.0229 & 0.9872 & 0.0249 & 0.9277 & 0.0557 & 1.0000 & 0.0000 & 0.9880 & 0.0235 \\
\hline & & $6 / 1$ & 1.0000 & 0.0000 & 1.0000 & 0.0000 & 0.9701 & 0.0408 & 1.0000 & 0.0000 & 1.0000 & 0.0000 \\
\hline & & $6 / 3$ & 1.0000 & 0.0000 & 1.0000 & 0.0000 & 0.9935 & 0.0127 & 0.9935 & 0.0127 & 1.0000 & 0.0000 \\
\hline & & $6 / 5$ & 0.9951 & 0.0098 & 0.9949 & 0.0100 & 0.9848 & 0.0171 & 0.9848 & 0.0171 & 1.0000 & 0.0000 \\
\hline & & Pooled & 0.9889 & 0.0067 & 0.9926 & 0.0055 & 0.9760 & 0.0096 & 0.9937 & 0.0051 & 0.9927 & 0.0055 \\
\hline & & TDA Tailrace & to $1 \mathrm{~B}$ & $95 \%$ CL & $1 \mathrm{~B}$ to $2 \mathrm{~B}$ & 95\% CL & $1 \mathrm{~B}$ & $95 \%$ CL & $2 \mathrm{~B}$ & $95 \%$ CL & $\lambda$ to $3 \mathrm{~B}$ & $95 \% \mathrm{CL}$ \\
\hline & & $5 / 16$ & 0.9405 & 0.0600 & 1.0280 & 0.1390 & 0.7975 & 0.0886 & 0.7111 & 0.1325 & 0.4848 & 0.1205 \\
\hline & & $5 / 19$ & 0.9237 & 0.0827 & 0.9067 & 0.1709 & 0.7037 & 0.0994 & 0.6667 & 0.1425 & 0.4179 & 0.1182 \\
\hline & & $5 / 21$ & 0.8300 & 0.0809 & 1.0542 & 0.1758 & 0.7229 & 0.0962 & 0.6000 & 0.1358 & 0.4762 & 0.1233 \\
\hline & & $5 / 23$ & 0.9350 & 0.0986 & 0.9331 & 0.1723 & 0.6061 & 0.1178 & 0.6750 & 0.1452 & 0.5094 & 0.1347 \\
\hline & & $5 / 25$ & 0.8830 & 0.2201 & 0.8808 & 0.3512 & 0.4483 & 0.1809 & 0.6429 & 0.2511 & 0.3750 & 0.1936 \\
\hline & & $5 / 27$ & 0.9427 & 0.1043 & 1.0150 & 0.1844 & 0.4493 & 0.1174 & 0.7500 & 0.1499 & 0.3934 & 0.1225 \\
\hline & & $6 / 1$ & 0.9051 & 0.0764 & 1.3303 & 0.2750 & 0.6102 & 0.1245 & 0.5455 & 0.1699 & 0.4091 & 0.1452 \\
\hline & & $6 / 3$ & 0.9559 & 0.0655 & 0.9206 & 0.1160 & 0.6496 & 0.0864 & 0.7353 & 0.1049 & 0.5051 & 0.0984 \\
\hline & & $6 / 5$ & 0.8391 & 0.0725 & 1.0214 & 0.1403 & 0.5809 & 0.0829 & 0.6098 & 0.1056 & 0.4808 & 0.0960 \\
\hline & & Pooled & 0.9000 & 0.0286 & 1.0000 & 0.0564 & 0.6328 & 0.0353 & 0.6601 & 0.0461 & 0.4613 & 0.0406 \\
\hline
\end{tabular}




\begin{tabular}{|c|c|c|c|c|c|c|c|c|c|c|c|c|}
\hline \multirow{2}{*}{$\begin{array}{l}\text { Season } \\
\text { Spring } \\
\end{array}$} & \multirow{2}{*}{$\begin{array}{c}\begin{array}{c}\text { Release } \\
\text { Type }\end{array} \\
\text { Single } \\
\end{array}$} & \multirow{2}{*}{$\begin{array}{c}\text { Release Site } \\
\text { BON Tailrace } \\
\end{array}$} & \multicolumn{4}{|c|}{ Survival Probability } & \multicolumn{4}{|c|}{ Detection Probability } & \multicolumn{2}{|c|}{ Detection and Survival } \\
\hline & & & to $1 \mathrm{~B}$ & $95 \% \mathrm{CL}$ & $1 \mathrm{~B}$ to $2 \mathrm{~B}$ & 95\% CL & $1 \mathrm{~B}$ & $95 \% \mathrm{CL}$ & $2 \mathrm{~B}$ & $95 \% \mathrm{CL}$ & $\lambda$ to $3 \mathrm{~B}$ & $95 \% \mathrm{CL}$ \\
\hline \multirow{7}{*}{ Spring } & & $5 / 2$ & 0.9154 & 0.0451 & 0.8870 & 0.0843 & 0.8136 & 0.0574 & 0.8657 & 0.0817 & 0.3452 & 0.0719 \\
\hline & & $5 / 11$ & 0.7080 & 0.0580 & 0.9551 & 0.0584 & 0.9051 & 0.0457 & 0.9114 & 0.0627 & 0.4768 & 0.0796 \\
\hline & & $5 / 19$ & 0.8936 & 0.0466 & 1.0126 & 0.0882 & 0.7660 & 0.0606 & 0.6613 & 0.0833 & 0.5616 & 0.0806 \\
\hline & & $5 / 27$ & 0.9157 & 0.0674 & 0.8742 & 0.0984 & 0.5640 & 0.0741 & 0.7629 & 0.0847 & 0.4966 & 0.0804 \\
\hline & & Pooled & 0.8504 & 0.0265 & 0.9531 & 0.0435 & 0.7597 & 0.0318 & 0.7793 & 0.0423 & 0.4658 & 0.0394 \\
\hline & Single & BON B2CC & to $1 \mathrm{~B}$ & $95 \% \mathrm{CL}$ & $1 \mathrm{~B}$ to $2 \mathrm{~B}$ & 95\% CL & $1 \mathrm{~B}$ & $95 \% \mathrm{CL}$ & $2 \mathrm{~B}$ & $95 \% \mathrm{CL}$ & $\lambda$ to $3 \mathrm{~B}$ & $95 \%$ CL \\
\hline & & Pooled & 0.9455 & 0.1000 & 0.9661 & 0.1876 & 0.6102 & 0.1245 & 0.6316 & 0.1535 & 0.5333 & 0.1458 \\
\hline \multirow[t]{2}{*}{ Spring } & Single & BON B2JBS & to $1 \mathrm{~B}$ & $95 \% \mathrm{CL}$ & $1 \mathrm{~B}$ to $2 \mathrm{~B}$ & 95\% CL & $1 \mathrm{~B}$ & $95 \% \mathrm{CL}$ & $2 \mathrm{~B}$ & $95 \% \mathrm{CL}$ & $\lambda$ to $3 \mathrm{~B}$ & $95 \% \mathrm{CL}$ \\
\hline & & Pooled & 0.8929 & 0.1631 & 1.1733 & 0.4694 & 0.5333 & 0.1786 & 0.5000 & 0.2450 & 0.3636 & 0.2011 \\
\hline \multirow[t]{2}{*}{ Spring } & Single & BON Spillway & to $1 \mathrm{~B}$ & $95 \%$ CL & $1 \mathrm{~B}$ to $2 \mathrm{~B}$ & 95\% CL & $1 \mathrm{~B}$ & $95 \% \mathrm{CL}$ & $2 \mathrm{~B}$ & $95 \% \mathrm{CL}$ & $\lambda$ to $3 \mathrm{~B}$ & 95\% CL \\
\hline & & Pooled & 0.9408 & 0.0700 & 1.0594 & 0.1717 & 0.6346 & 0.0925 & 0.6140 & 0.1264 & 0.4268 & 0.1070 \\
\hline \multirow[t]{10}{*}{ Spring } & Virtual & JDA & to $1 \mathrm{~T}$ & $95 \%$ CL & $1 \mathrm{~T}$ to $2 \mathrm{~T}$ & 95\% CL & $1 \mathrm{~T}$ & 95\% CL & $2 \mathrm{~T}$ & $95 \% \mathrm{CL}$ & $\lambda$ to $3 \mathrm{~T}$ & 95\% CL \\
\hline & & $5 / 16$ & 0.9459 & 0.0729 & 1.0000 & 0.0000 & 1.0000 & 0.0000 & 1.0000 & 0.0000 & 1.0000 & 0.0000 \\
\hline & & $5 / 19$ & 1.0081 & 0.0123 & 0.9545 & 0.0615 & 0.8235 & 0.1047 & 1.0000 & 0.0000 & 1.0000 & 0.0000 \\
\hline & & $5 / 21$ & 0.9026 & 0.0835 & 0.9750 & 0.0484 & 0.8864 & 0.0937 & 1.0000 & 0.0000 & 1.0000 & 0.0000 \\
\hline & & $5 / 23$ & 0.9174 & 0.0713 & 0.9792 & 0.0404 & 0.8868 & 0.0853 & 1.0000 & 0.0000 & 0.9811 & 0.0367 \\
\hline & & $5 / 25$ & 0.9310 & 0.0923 & 1.0000 & 0.0000 & 0.9259 & 0.0988 & 1.0000 & 0.0000 & 1.0000 & 0.0000 \\
\hline & & $5 / 27$ & 0.9643 & 0.0486 & 1.0000 & 0.0000 & 0.9815 & 0.0359 & 1.0000 & 0.0000 & 1.0000 & 0.0000 \\
\hline & & $6 / 1$ & 0.9841 & 0.0308 & 1.0000 & 0.0000 & 1.0000 & 0.0000 & 1.0000 & 0.0000 & 1.0000 & 0.0000 \\
\hline & & $6 / 3$ & 0.9722 & 0.0537 & 1.0000 & 0.0000 & 1.0000 & 0.0000 & 1.0000 & 0.0000 & 1.0000 & 0.0000 \\
\hline & & Pooled & 0.9537 & 0.0212 & 0.9883 & 0.0114 & 0.9363 & 0.0253 & 1.0000 & 0.0000 & 0.9972 & 0.0055 \\
\hline \multirow[t]{11}{*}{ Spring } & Virtual & TDA & to $1 \mathrm{~B}$ & 95\% CL & $1 \mathrm{~B}$ to $2 \mathrm{~B}$ & 95\% CL & $1 \mathrm{~B}$ & 95\% CL & $2 \mathrm{~B}$ & $95 \%$ CL & $\lambda$ to $3 \mathrm{~B}$ & 95\% CL \\
\hline & & $5 / 16$ & 0.9605 & 0.0545 & 1.0280 & 0.1390 & 0.7975 & 0.0886 & 0.7111 & 0.1325 & 0.4848 & 0.1205 \\
\hline & & $5 / 19$ & 0.9474 & 0.0804 & 0.9067 & 0.1709 & 0.7037 & 0.0994 & 0.6667 & 0.1425 & 0.4179 & 0.1182 \\
\hline & & $5 / 21$ & 0.8786 & 0.0766 & 1.0457 & 0.1723 & 0.7317 & 0.0958 & 0.6122 & 0.1364 & 0.4762 & 0.1233 \\
\hline & & $5 / 23$ & 0.9714 & 0.0927 & 0.9259 & 0.1690 & 0.6250 & 0.1186 & 0.6750 & 0.1452 & 0.5294 & 0.1370 \\
\hline & & $5 / 25$ & 0.9018 & 0.2217 & 0.8808 & 0.3512 & 0.4483 & 0.1809 & 0.6429 & 0.2511 & 0.3750 & 0.1936 \\
\hline & & $5 / 27$ & 0.9630 & 0.1017 & 1.0131 & 0.1833 & 0.4559 & 0.1184 & 0.7500 & 0.1499 & 0.4000 & 0.1239 \\
\hline & & $6 / 1$ & 0.9051 & 0.0764 & 1.3303 & 0.2750 & 0.6102 & 0.1245 & 0.5455 & 0.1699 & 0.4091 & 0.1452 \\
\hline & & $6 / 3$ & 0.9559 & 0.0655 & 0.9206 & 0.1160 & 0.6496 & 0.0864 & 0.7353 & 0.1049 & 0.5051 & 0.0984 \\
\hline & & $6 / 5$ & 0.8477 & 0.0723 & 1.0214 & 0.1403 & 0.5809 & 0.0829 & 0.6098 & 0.1056 & 0.4808 & 0.0960 \\
\hline & & Pooled & 0.9185 & 0.0278 & 0.9979 & 0.0563 & 0.6364 & 0.0353 & 0.6617 & 0.0461 & 0.4637 & 0.0406 \\
\hline
\end{tabular}




\begin{tabular}{|c|c|c|c|c|c|c|c|c|c|c|c|c|}
\hline \multirow{2}{*}{$\begin{array}{c}\text { Season } \\
\text { Spring }\end{array}$} & \multirow{2}{*}{$\begin{array}{c}\begin{array}{c}\text { Release } \\
\text { Type }\end{array} \\
\text { Virtual } \\
\end{array}$} & \multirow{2}{*}{$\begin{array}{c}\text { Release Site } \\
\text { JDA } \\
\end{array}$} & \multicolumn{4}{|c|}{ Survival Probability } & \multicolumn{4}{|c|}{ Detection Probability } & \multicolumn{2}{|c|}{ Detection and Survival } \\
\hline & & & to $1 \mathrm{~T}$ & $95 \%$ CL & $1 \mathrm{~T}$ to $2 \mathrm{~T}$ & 95\% CL & $1 \mathrm{~T}$ & 95\% CL & $2 \mathrm{~T}$ & $95 \% \mathrm{CL}$ & $\lambda$ to $3 \mathrm{~T}$ & $95 \% \mathrm{CL}$ \\
\hline \multirow{3}{*}{ Spring } & & Pooled & 0.9316 & 0.0129 & 0.9825 & 0.0073 & 0.9059 & 0.0155 & 0.9948 & 0.0039 & 0.9845 & 0.0067 \\
\hline & Virtual & TDA & to $1 \mathrm{~B}$ & $95 \% \mathrm{CL}$ & $1 \mathrm{~B}$ to $2 \mathrm{~B}$ & $95 \% \mathrm{CL}$ & $1 \mathrm{~B}$ & $95 \% \mathrm{CL}$ & $2 \mathrm{~B}$ & $95 \% \mathrm{CL}$ & $\lambda$ to $3 \mathrm{~B}$ & $95 \%$ CL \\
\hline & & Pooled & 0.8905 & 0.0200 & 0.9382 & 0.0368 & 0.6143 & 0.0225 & 0.6694 & 0.0298 & 0.4376 & 0.0255 \\
\hline \multirow[t]{3}{*}{ Spring } & Paired & & to $1 \mathrm{~J}$ & $95 \% \mathrm{CL}$ & $1 \mathrm{~J}$ to $2 \mathrm{~J}$ & $95 \% \mathrm{CL}$ & $1 \mathrm{~J}$ & $95 \%$ CL & $2 \mathrm{~J}$ & $95 \% \mathrm{CL}$ & $\lambda$ to $3 \mathrm{~J}$ & $95 \%$ CL \\
\hline & & JDA Front Roll & 0.9803 & 0.0123 & 0.9888 & 0.0129 & 0.9881 & 0.0071 & 0.8814 & 0.0229 & 0.8145 & 0.0265 \\
\hline & & JDA Tailrace & 0.9671 & 0.0161 & & & & & & & & \\
\hline \multirow[t]{3}{*}{ Spring } & Paired & & to $1 \mathrm{~J}$ & 95\% CL & $1 \mathrm{~J}$ to $2 \mathrm{~J}$ & 95\% CL & $1 \mathrm{~J}$ & 95\% CL & $2 \mathrm{~J}$ & $95 \% \mathrm{CL}$ & $\lambda$ to $3 \mathrm{~J}$ & $95 \% \mathrm{CL}$ \\
\hline & & JDA Intake 9C & 0.8626 & 0.0302 & 0.9978 & 0.0131 & 0.9805 & 0.0092 & 0.8786 & 0.0241 & 0.7251 & 0.0435 \\
\hline & & JDA Tailrace & 0.9672 & 0.0161 & & & & & & & 0.8250 & 0.0361 \\
\hline \multirow[t]{3}{*}{ Spring } & Paired & & to $1 \mathrm{~J}$ & $95 \% \mathrm{CL}$ & $1 \mathrm{~J}$ to $2 \mathrm{~J}$ & $95 \% \mathrm{CL}$ & $1 \mathrm{~J}$ & 95\% CL & $2 \mathrm{~J}$ & $95 \% \mathrm{CL}$ & $\lambda$ to $3 \mathrm{~J}$ & $95 \%$ CL \\
\hline & & JDA Intake 9C & 0.8626 & 0.0302 & 0.9853 & 0.0149 & 0.9841 & 0.0082 & 0.8816 & 0.0239 & 0.7322 & 0.0431 \\
\hline & & JDA Front Roll & 0.9803 & 0.0123 & & & & & & & 0.8016 & 0.0378 \\
\hline \multirow[t]{3}{*}{ Spring } & Paired & & to $1 \mathrm{~T}$ & $95 \%$ CL & $1 \mathrm{~T}$ to $2 \mathrm{~T}$ & 95\% CL & $1 \mathrm{~T}$ & 95\% CL & $2 \mathrm{~T}$ & $95 \%$ CL & $\lambda$ to $3 \mathrm{~T}$ & $95 \%$ CL \\
\hline & & JDA Tailrace & 0.9175 & 0.0247 & 0.9830 & 0.0125 & 0.9332 & 0.0120 & 1.0000 & 0.0000 & 0.9954 & 0.0065 \\
\hline & & TDA Tailrace & 0.9890 & 0.0067 & 0.9926 & 0.0055 & 0.9750 & 0.0050 & 0.9937 & 0.0051 & 0.9927 & 0.0055 \\
\hline \multirow[t]{3}{*}{ Spring } & Paired & & to $1 \mathrm{~B}$ & $95 \%$ CL & $1 \mathrm{~B}$ to $2 \mathrm{~B}$ & $95 \%$ CL & $1 \mathrm{~B}$ & $95 \%$ CL & $2 \mathrm{~B}$ & $95 \% \mathrm{CL}$ & $\lambda$ to $3 \mathrm{~B}$ & $95 \%$ CL \\
\hline & & TDA Tailrace & 0.9000 & 0.0286 & 1.0000 & 0.0564 & 0.6328 & 0.0353 & 0.6601 & 0.0461 & 0.4613 & 0.0406 \\
\hline & & BON Tailrace & 0.8504 & 0.0265 & 0.9531 & 0.0435 & 0.7597 & 0.0318 & 0.7793 & 0.0423 & 0.4658 & 0.0394 \\
\hline \multirow[t]{7}{*}{ Spring } & Paired & & $\hat{S}(\widehat{s . e .})$ & 95\% CL & & & & & & & & \\
\hline & & $\begin{array}{l}\text { JDA Front Roll } \\
\text { to Tailrace }\end{array}$ & 1.0136 & 0.0414 & & & & & & & & \\
\hline & & $\begin{array}{c}\text { JDA Intake 9C to } \\
\text { Tailrace }\end{array}$ & 0.8919 & 0.0676 & & & & & & & & \\
\hline & & JDA Intake 9C to & & & & & & & & & & \\
\hline & & Front Roll & 0.8798 & 0.0641 & & & & & & & & \\
\hline & & TDA Project & 0.9277 & 0.0504 & & & & & & & & \\
\hline & & BON Project & 1.0583 & 0.0923 & & & & & & & & \\
\hline
\end{tabular}


Table H.3. Summer Detection History

Season Release Type Release Location

Detection Histories

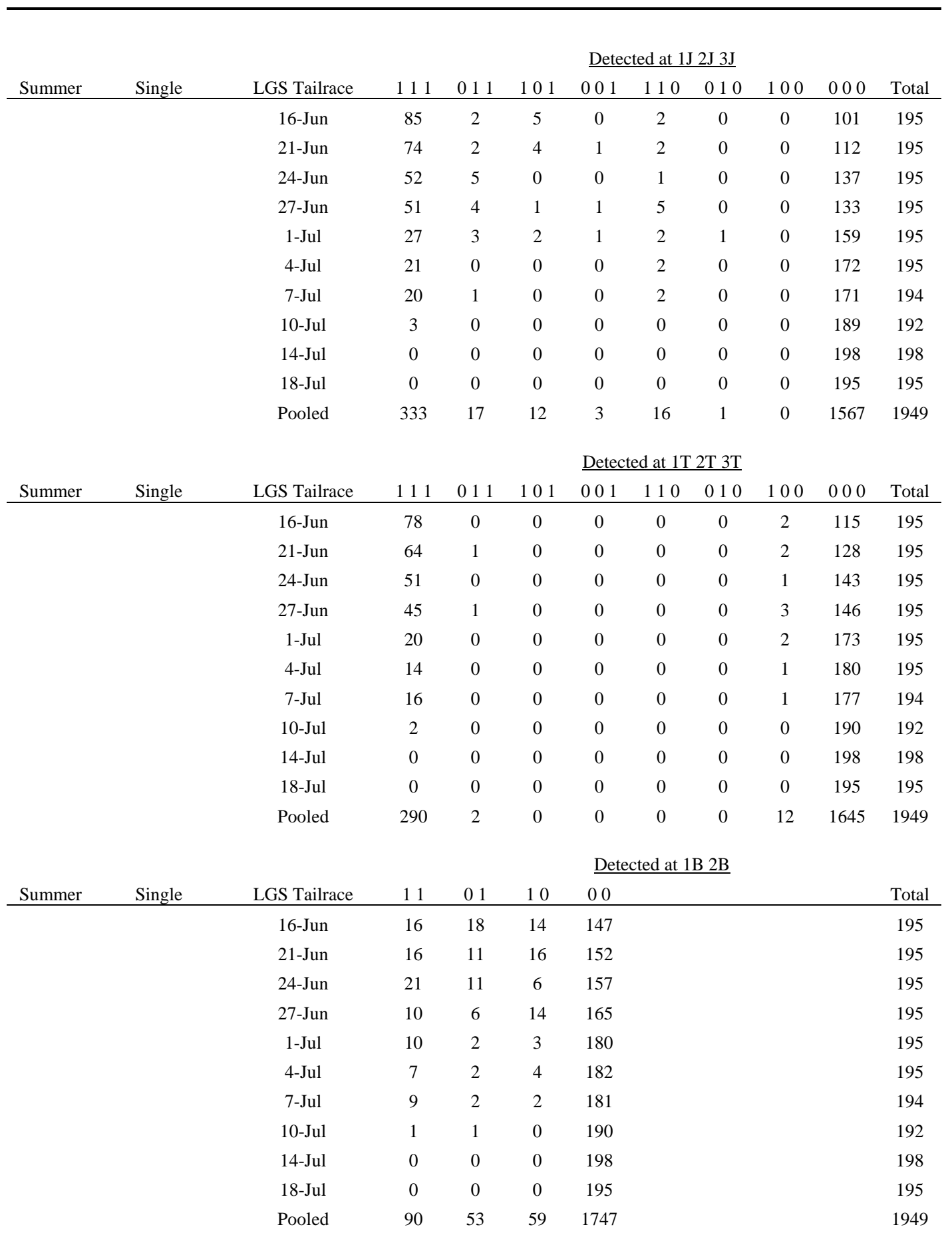




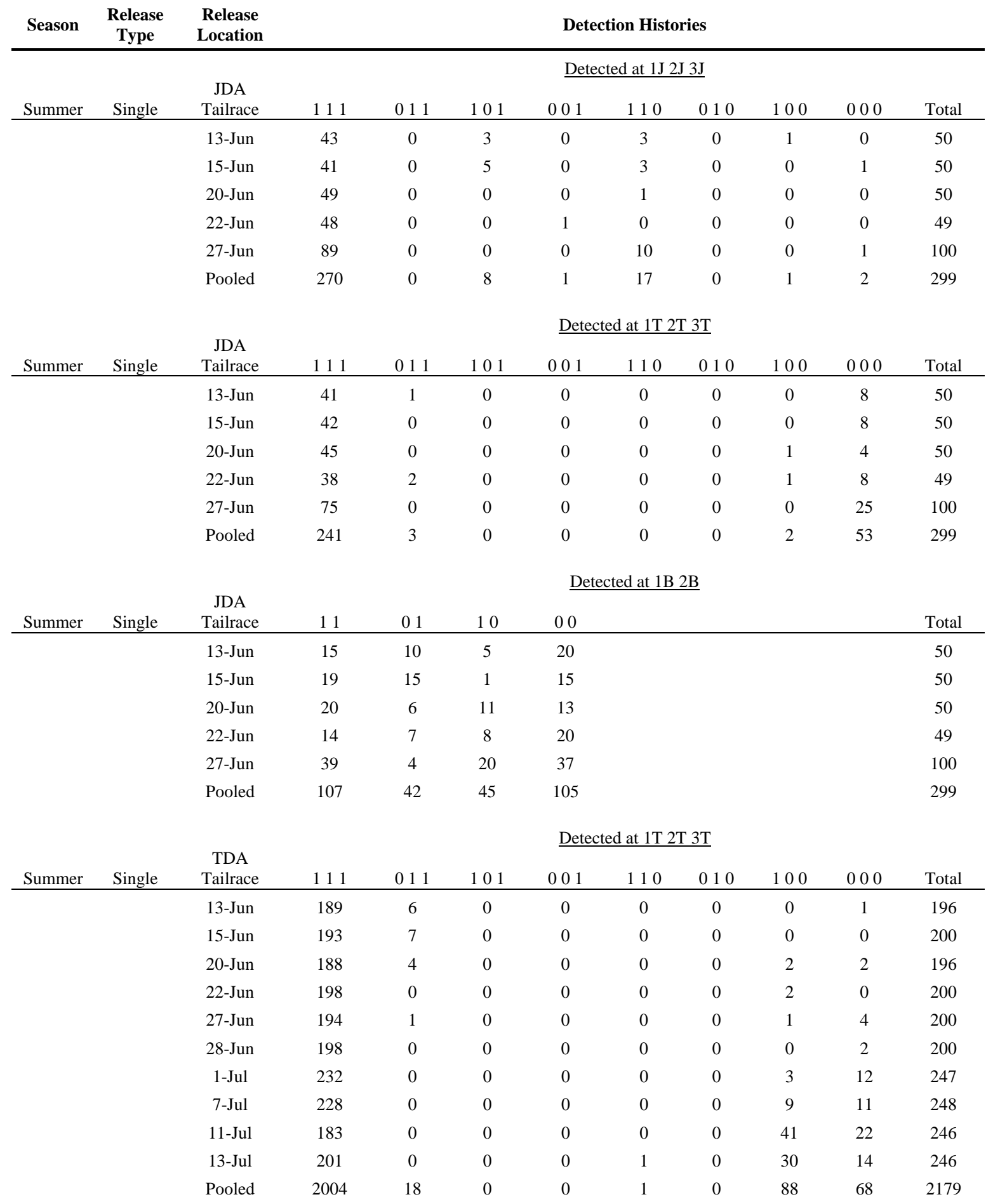




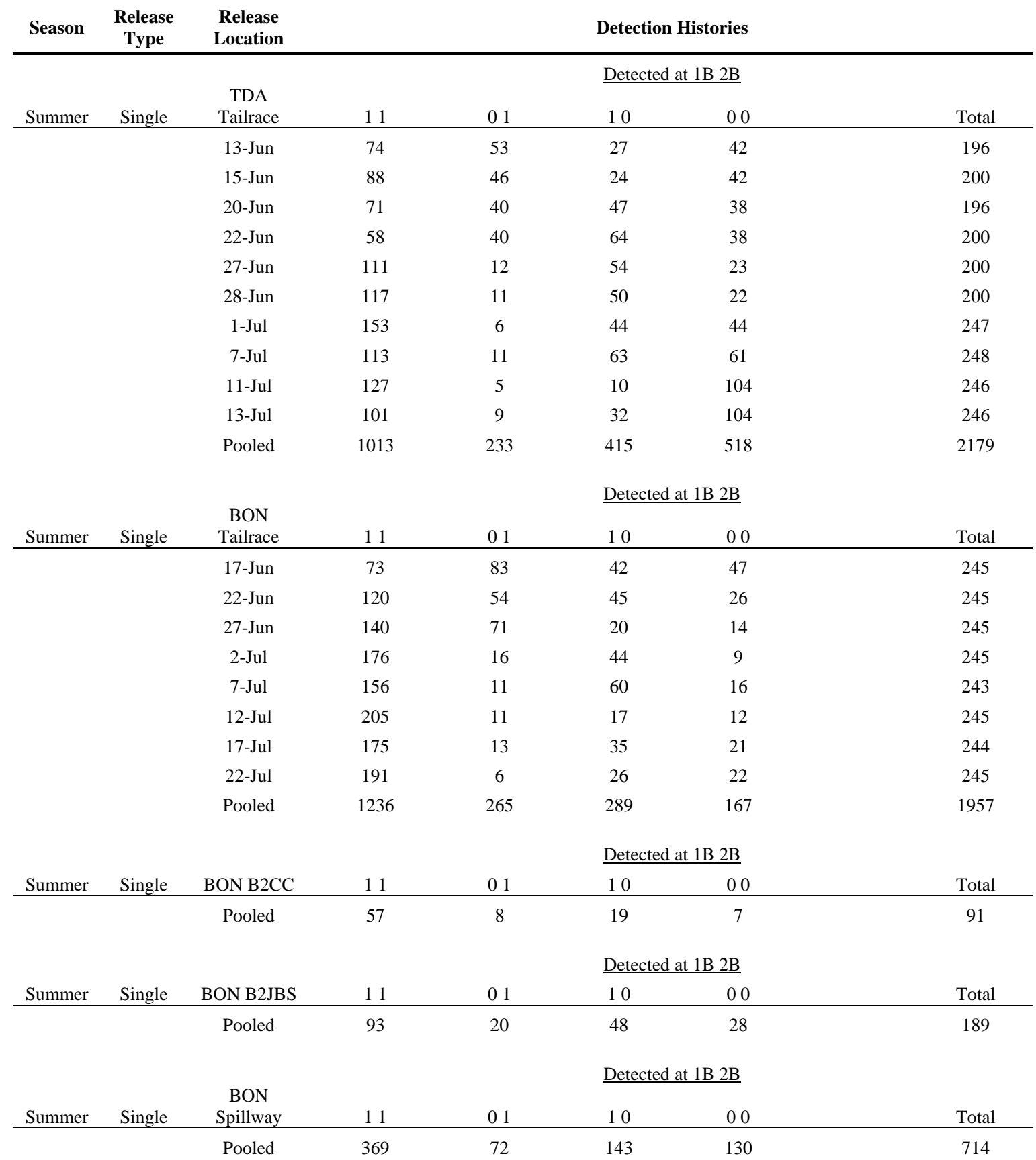




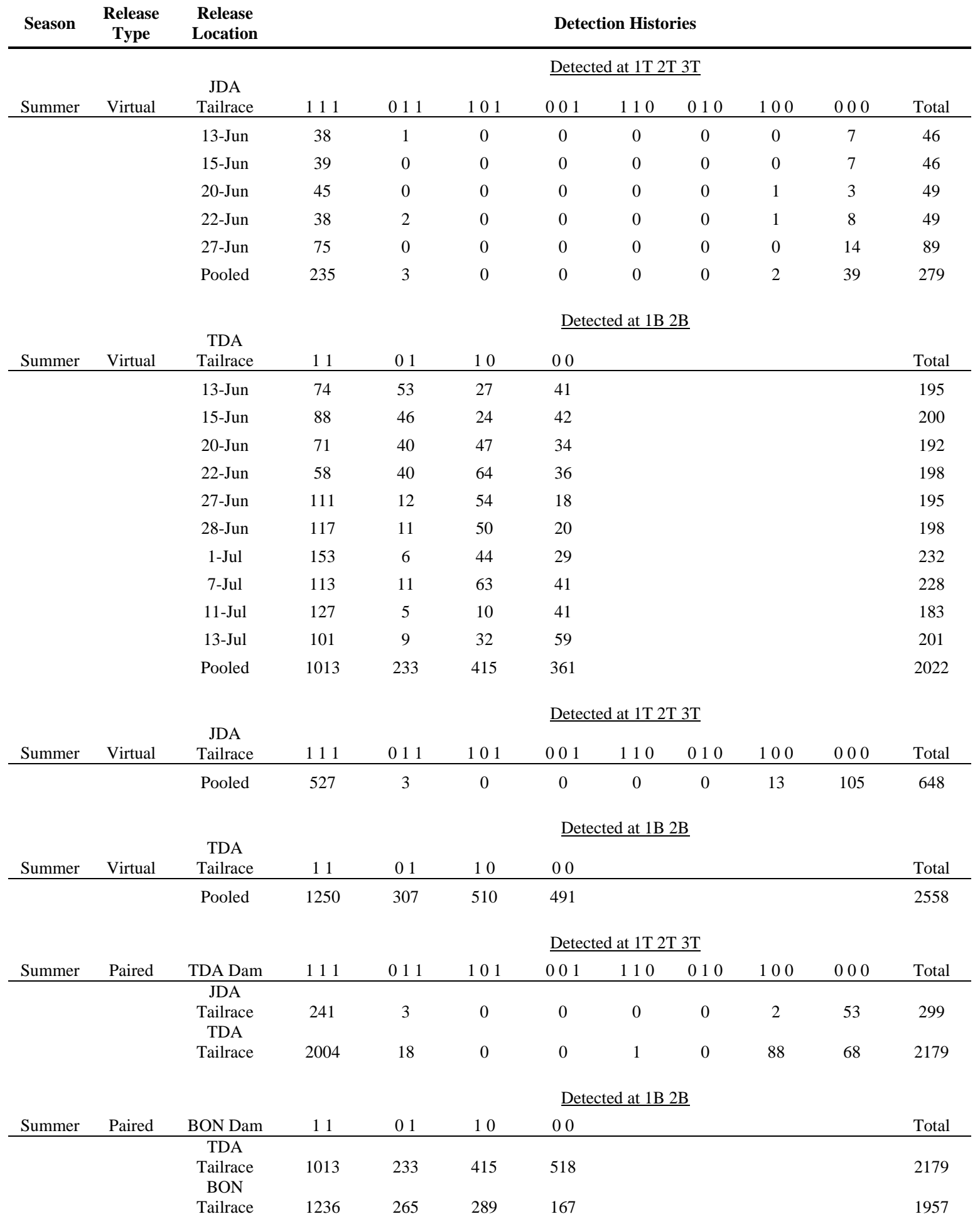


Table H.4. Summer Detection and Survival Probabilities

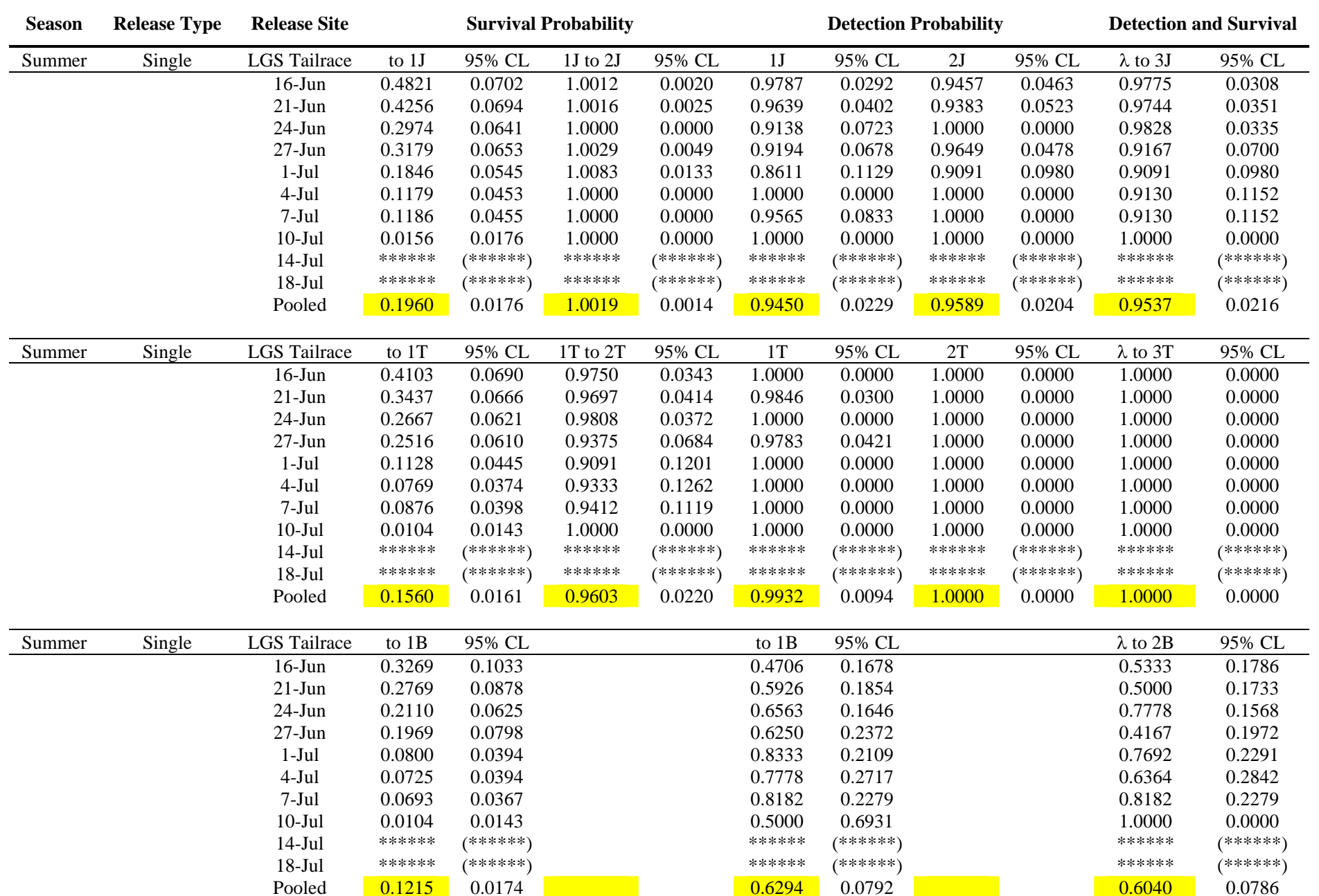




\begin{tabular}{|c|c|c|c|c|c|c|c|c|c|c|c|c|}
\hline \multirow{2}{*}{$\frac{\text { Season }}{\text { Summer }}$} & \multirow{2}{*}{$\begin{array}{c}\text { Release Type } \\
\text { Single }\end{array}$} & \multirow{2}{*}{$\begin{array}{c}\text { Release Site } \\
\text { JDA Tailrace }\end{array}$} & \multicolumn{4}{|c|}{ Survival Probability } & \multicolumn{4}{|c|}{ Detection Probability } & \multicolumn{2}{|c|}{ Detection and Survival } \\
\hline & & & to $1 \mathrm{~J}$ & $95 \% \mathrm{CL}$ & $1 \mathrm{~J}$ to $2 \mathrm{~J}$ & $95 \%$ CL & $1 \mathrm{~J}$ & $95 \%$ CL & $2 \mathrm{~J}$ & $95 \% \mathrm{CL}$ & $\lambda$ to $3 \mathrm{~J}$ & $95 \%$ CL \\
\hline & & 13-Jun & 1.0000 & 0.0000 & 0.9842 & 0.0396 & 1.0000 & 0.0000 & 0.9348 & 0.0713 & 0.9348 & 0.0713 \\
\hline & & 15-Jun & 0.9800 & 0.0388 & 1.0075 & 0.0108 & 1.0000 & 0.0000 & 0.8913 & 0.0900 & 0.9318 & 0.0745 \\
\hline & & 20-Jun & 1.0000 & 0.0000 & 1.0000 & 0.0000 & 1.0000 & 0.0000 & 1.0000 & 0.0000 & 0.9800 & 0.0388 \\
\hline & & 22-Jun & 1.0000 & 0.0000 & 1.0000 & 0.0000 & 0.9796 & 0.0396 & 0.9796 & 0.0396 & 1.0000 & 0.0000 \\
\hline & & 27-Jun & 0.9900 & 0.0194 & 1.0000 & 0.0000 & 1.0000 & 0.0000 & 1.0000 & 0.0000 & 0.8990 & 0.0594 \\
\hline & & Pooled & 0.9933 & 0.0092 & 0.9985 & 0.0069 & 0.9966 & 0.0067 & 0.9677 & 0.0208 & 0.9408 & 0.0272 \\
\hline \multirow[t]{7}{*}{ Summer } & Single & JDA Tailrace & to $1 \mathrm{~T}$ & $95 \% \mathrm{CL}$ & $1 \mathrm{~T}$ to $2 \mathrm{~T}$ & 95\% CL & $1 \mathrm{~T}$ & $95 \%$ CL & $2 \mathrm{~T}$ & $95 \%$ CL & $\lambda$ to $3 \mathrm{~T}$ & 95\% CL \\
\hline & & 13-Jun & 0.8400 & 0.1015 & 1.0000 & 0.0000 & 0.9762 & 0.0461 & 1.0000 & 0.0000 & 1.0000 & 0.0000 \\
\hline & & 15-Jun & 0.8400 & 0.1015 & 1.0000 & 0.0000 & 1.0000 & 0.0000 & 1.0000 & 0.0000 & 1.0000 & 0.0000 \\
\hline & & 20-Jun & 0.9200 & 0.0753 & 0.9783 & 0.0421 & 1.0000 & 0.0000 & 1.0000 & 0.0000 & 1.0000 & 0.0000 \\
\hline & & 22-Jun & 0.8378 & 0.1037 & 0.9744 & 0.0496 & 0.9500 & 0.0676 & 1.0000 & 0.0000 & 1.0000 & 0.0000 \\
\hline & & 27-Jun & 0.7500 & 0.0849 & 1.0000 & 0.0000 & 1.0000 & 0.0000 & 1.0000 & 0.0000 & 1.0000 & 0.0000 \\
\hline & & Pooled & 0.8228 & 0.0433 & 0.9918 & 0.0114 & 0.9877 & 0.0139 & 1.0000 & 0.0000 & 1.0000 & 0.0000 \\
\hline \multirow[t]{7}{*}{ Summer } & Single & JDA Tailrace & to $1 \mathrm{~B}$ & 95\% CL & & & to $1 \mathrm{~B}$ & $95 \%$ CL & & & $\lambda$ to $2 \mathrm{~B}$ & $95 \% \mathrm{CL}$ \\
\hline & & 13-Jun & 0.6667 & 0.1688 & & & 0.6000 & 0.1921 & & & 0.7500 & 0.1897 \\
\hline & & 15-Jun & 0.7158 & 0.1339 & & & 0.5588 & 0.1670 & & & 0.9500 & 0.0955 \\
\hline & & 20-Jun & 0.8060 & 0.1492 & & & 0.7692 & 0.1619 & & & 0.6452 & 0.1684 \\
\hline & & 22-Jun & 0.6735 & 0.1797 & & & 0.6667 & 0.2017 & & & 0.6364 & 0.2011 \\
\hline & & 27-Jun & 0.6505 & 0.1002 & & & 0.9070 & 0.0868 & & & 0.6610 & 0.1207 \\
\hline & & Pooled & 0.7079 & 0.0645 & & & 0.7181 & 0.0723 & & & 0.7039 & 0.0725 \\
\hline \multirow[t]{12}{*}{ Summer } & Single & TDA Tailrace & to $1 \mathrm{~T}$ & $95 \%$ CL & $1 \mathrm{~T}$ to $2 \mathrm{~T}$ & $95 \%$ CL & $1 \mathrm{~T}$ & $95 \%$ CL & $2 \mathrm{~T}$ & $95 \%$ CL & $\lambda$ to $3 \mathrm{~T}$ & $95 \%$ CL \\
\hline & & 13-Jun & 0.9949 & 0.0100 & 1.0000 & 0.0000 & 0.9692 & 0.0243 & 1.0000 & 0.0000 & 1.0000 & 0.0000 \\
\hline & & 15-Jun & 1.0000 & 0.0000 & 1.0000 & 0.0000 & 0.9650 & 0.0255 & 1.0000 & 0.0000 & 1.0000 & 0.0000 \\
\hline & & 20-Jun & 0.9900 & 0.0141 & 0.9895 & 0.0145 & 0.9792 & 0.0202 & 1.0000 & 0.0000 & 1.0000 & 0.0000 \\
\hline & & 22-Jun & 1.0000 & 0.0000 & 0.9900 & 0.0137 & 1.0000 & 0.0000 & 1.0000 & 0.0000 & 1.0000 & 0.0000 \\
\hline & & 27-Jun & 0.9800 & 0.0194 & 0.9949 & 0.0100 & 0.9949 & 0.0100 & 1.0000 & 0.0000 & 1.0000 & 0.0000 \\
\hline & & 28-Jun & 0.9900 & 0.0137 & 1.0000 & 0.0000 & 1.0000 & 0.0000 & 1.0000 & 0.0000 & 1.0000 & 0.0000 \\
\hline & & 1-Jul & 0.9514 & 0.0269 & 0.9872 & 0.0143 & 1.0000 & 0.0000 & 1.0000 & 0.0000 & 1.0000 & 0.0000 \\
\hline & & 7-Jul & 0.9556 & 0.0257 & 0.9620 & 0.0243 & 1.0000 & 0.0000 & 1.0000 & 0.0000 & 1.0000 & 0.0000 \\
\hline & & 11-Jul & 0.9106 & 0.0357 & 0.8170 & 0.0506 & 1.0000 & 0.0000 & 1.0000 & 0.0000 & 1.0000 & 0.0000 \\
\hline & & 13-Jul & 0.9431 & 0.0290 & 0.8707 & 0.0431 & 1.0000 & 0.0000 & 1.0000 & 0.0000 & 0.9950 & 0.0096 \\
\hline & & Pooled & 0.9692 & 0.0073 & 0.9580 & 0.0086 & 0.9911 & 0.0041 & 1.0000 & 0.0000 & 0.9995 & 0.0010 \\
\hline
\end{tabular}




\begin{tabular}{|c|c|c|c|c|c|c|c|c|}
\hline \multirow{2}{*}{$\begin{array}{l}\text { Season } \\
\text { Summer } \\
\end{array}$} & \multirow{2}{*}{$\begin{array}{c}\begin{array}{c}\text { Release } \\
\text { Type }\end{array} \\
\text { Single } \\
\end{array}$} & \multirow{2}{*}{$\begin{array}{l}\text { Release Site } \\
\text { TDA Tailrace } \\
\end{array}$} & \multicolumn{2}{|c|}{ Survival Probability } & \multicolumn{2}{|c|}{ Detection Probability } & \multicolumn{2}{|c|}{ Detection and Survival } \\
\hline & & & to $1 \mathrm{~B}$ & 95\% CL & to $1 \mathrm{~B}$ & $95 \%$ CL & $\lambda$ to $2 \mathrm{~B}$ & $95 \%$ CL \\
\hline & & 13-Jun & 0.8844 & 0.0808 & 0.5827 & 0.0858 & 0.7327 & 0.0862 \\
\hline & & 15-Jun & 0.8527 & 0.0690 & 0.6567 & 0.0804 & 0.7857 & 0.0760 \\
\hline & & 20-Jun & 0.9412 & 0.0892 & 0.6396 & 0.0894 & 0.6017 & 0.0884 \\
\hline & & 22-Jun & 1.0307 & 0.1201 & 0.5918 & 0.0972 & 0.4754 & 0.0886 \\
\hline & & 27-Jun & 0.9142 & 0.0494 & 0.9024 & 0.0525 & 0.6727 & 0.0715 \\
\hline & & 28-Jun & 0.9135 & 0.0472 & 0.9141 & 0.0486 & 0.7006 & 0.0694 \\
\hline & & 1-Jul & 0.8288 & 0.0484 & 0.9623 & 0.0296 & 0.7766 & 0.0582 \\
\hline & & 7-Jul & 0.7788 & 0.0576 & 0.9113 & 0.0500 & 0.6420 & 0.0708 \\
\hline & & 11-Jul & 0.5788 & 0.0619 & 0.9621 & 0.0325 & 0.9270 & 0.0435 \\
\hline & & 13-Jul & 0.5888 & 0.0635 & 0.9182 & 0.0512 & 0.7594 & 0.0727 \\
\hline & & Pooled & 0.8061 & 0.0202 & 0.8130 & 0.0216 & 0.7094 & 0.0235 \\
\hline \multirow[t]{10}{*}{ Summer } & Single & BON Tailrace & to $1 \mathrm{~B}$ & $95 \% \mathrm{CL}$ & to $1 \mathrm{~B}$ & $95 \% \mathrm{CL}$ & $\lambda$ to $2 \mathrm{~B}$ & $95 \% \mathrm{CL}$ \\
\hline & & 17-Jun & 1.0031 & 0.1011 & 0.4679 & 0.0782 & 0.6348 & 0.0880 \\
\hline & & 22-Jun & 0.9765 & 0.0543 & 0.6897 & 0.0688 & 0.7273 & 0.0680 \\
\hline & & 27-Jun & 0.9843 & 0.0368 & 0.6635 & 0.0637 & 0.8750 & 0.0512 \\
\hline & & 2-Jul & 0.9796 & 0.0257 & 0.9167 & 0.0390 & 0.8000 & 0.0529 \\
\hline & & 7-Jul & 0.9516 & 0.0337 & 0.9341 & 0.0376 & 0.7222 & 0.0598 \\
\hline & & 12-Jul & 0.9547 & 0.0272 & 0.9491 & 0.0294 & 0.9234 & 0.0349 \\
\hline & & 17-Jul & 0.9246 & 0.0363 & 0.9309 & 0.0363 & 0.8333 & 0.0504 \\
\hline & & 22-Jul & 0.9135 & 0.0361 & 0.9695 & 0.0239 & 0.8802 & 0.0431 \\
\hline & & Pooled & 0.9463 & 0.0139 & 0.8235 & 0.0192 & 0.8105 & 0.0196 \\
\hline \multirow[t]{2}{*}{ Summer } & Single & BON B2CC & to $1 \mathrm{~B}$ & $95 \% \mathrm{CL}$ & to $1 \mathrm{~B}$ & $95 \% \mathrm{CL}$ & $\lambda$ to $2 \mathrm{~B}$ & $95 \% \mathrm{CL}$ \\
\hline & & Pooled & 0.9524 & 0.0615 & 0.8769 & 0.0798 & 0.7500 & 0.0974 \\
\hline \multirow[t]{2}{*}{ Summer } & Single & BON B2JBS & to $1 \mathrm{~B}$ & 95\% CL & to $1 \mathrm{~B}$ & $95 \%$ CL & $\lambda$ to $2 \mathrm{~B}$ & $95 \% \mathrm{CL}$ \\
\hline & & Pooled & 0.9065 & 0.0613 & 0.8230 & 0.0704 & 0.6596 & 0.0782 \\
\hline \multirow[t]{2}{*}{ Summer } & Single & BON Spillway & to $1 \mathrm{~B}$ & 95\% CL & to $1 \mathrm{~B}$ & $95 \%$ CL & $\lambda$ to $2 \mathrm{~B}$ & 95\% CL \\
\hline & & Pooled & 0.8570 & 0.0318 & 0.8367 & 0.0345 & 0.7207 & 0.0388 \\
\hline
\end{tabular}




\begin{tabular}{|c|c|c|c|c|c|c|c|c|c|c|c|c|}
\hline \multirow{2}{*}{$\begin{array}{l}\text { Season } \\
\text { Summer }\end{array}$} & \multirow{2}{*}{$\begin{array}{c}\text { Release Type } \\
\text { Virtual } \\
\end{array}$} & \multirow{2}{*}{$\begin{array}{l}\text { Release Site } \\
\text { JDA Tailrace } \\
\end{array}$} & \multicolumn{4}{|c|}{ Survival Probability } & \multicolumn{4}{|c|}{ Detection Probability } & \multicolumn{2}{|c|}{ Detection and Survival } \\
\hline & & & to $1 \mathrm{~T}$ & $95 \%$ CL & $1 \mathrm{~T}$ to $2 \mathrm{~T}$ & $95 \%$ CL & $1 \mathrm{~T}$ & 95\% CL & $2 \mathrm{~T}$ & $95 \%$ CL & $\lambda$ to $3 \mathrm{~T}$ & $95 \%$ CL \\
\hline & & 13-Jun & 0.8478 & 0.1039 & 1.0000 & 0.0000 & 0.9744 & 0.0496 & 1.0000 & 0.0000 & 1.0000 & 0.0000 \\
\hline & & 15-Jun & 0.8478 & 0.1039 & 1.0000 & 0.0000 & 1.0000 & 0.0000 & 1.0000 & 0.0000 & 1.0000 & 0.0000 \\
\hline & & 20-Jun & 0.9388 & 0.0670 & 0.9783 & 0.0421 & 1.0000 & 0.0000 & 1.0000 & 0.0000 & 1.0000 & 0.0000 \\
\hline & & 22-Jun & 0.8378 & 0.1037 & 0.9744 & 0.0496 & 0.9500 & 0.0676 & 1.0000 & 0.0000 & 1.0000 & 0.0000 \\
\hline & & 27-Jun & 0.8427 & 0.0757 & 1.0000 & 0.0000 & 1.0000 & 0.0000 & 1.0000 & 0.0000 & 1.0000 & 0.0000 \\
\hline & & Pooled & 0.8603 & 0.0408 & 0.9916 & 0.0116 & 0.9874 & 0.0141 & 1.0000 & 0.0000 & 1.0000 & 0.0000 \\
\hline \multirow[t]{12}{*}{ Summer } & Virtual & TDA Tailrace & to $1 \mathrm{~B}$ & $95 \% \mathrm{CL}$ & & & to $1 \mathrm{~B}$ & $95 \% \mathrm{CL}$ & & & $\lambda$ to $2 \mathrm{~B}$ & $95 \% \mathrm{CL}$ \\
\hline & & 13-Jun & 0.8889 & 0.0808 & & & 0.5827 & 0.0858 & & & 0.7327 & 0.0862 \\
\hline & & 15-Jun & 0.8527 & 0.0690 & & & 0.6567 & 0.0804 & & & 0.7857 & 0.0760 \\
\hline & & 20-Jun & 0.9608 & 0.0890 & & & 0.6396 & 0.0894 & & & 0.6017 & 0.0884 \\
\hline & & 22-Jun & 1.0411 & 0.1205 & & & 0.5918 & 0.0972 & & & 0.4754 & 0.0886 \\
\hline & & 27-Jun & 0.9376 & 0.0461 & & & 0.9024 & 0.0525 & & & 0.6727 & 0.0715 \\
\hline & & 28-Jun & 0.9227 & 0.0459 & & & 0.9141 & 0.0486 & & & 0.7006 & 0.0694 \\
\hline & & 1-Jul & 0.8824 & 0.0433 & & & 0.9623 & 0.0296 & & & 0.7766 & 0.0582 \\
\hline & & 7-Jul & 0.8471 & 0.0543 & & & 0.9113 & 0.0500 & & & 0.6420 & 0.0708 \\
\hline & & 11-Jul & 0.7781 & 0.0606 & & & 0.9621 & 0.0325 & & & 0.9270 & 0.0435 \\
\hline & & 13-Jul & 0.7207 & 0.0651 & & & 0.9182 & 0.0512 & & & 0.7594 & 0.0727 \\
\hline & & Pooled & 0.8687 & 0.0192 & & & 0.8130 & 0.0216 & & & 0.7094 & 0.0235 \\
\hline \multirow[t]{2}{*}{ Summer } & Virtual & JDA Tailrace & to $1 \mathrm{~T}$ & $95 \% \mathrm{CL}$ & $1 \mathrm{~T}$ to $2 \mathrm{~T}$ & 95\% CL & $1 \mathrm{~T}$ & 95\% CL & $2 \mathrm{~T}$ & $95 \% \mathrm{CL}$ & $\lambda$ to $3 \mathrm{~T}$ & $95 \% \mathrm{CL}$ \\
\hline & & Pooled & 0.8381 & 0.0284 & 0.9759 & 0.0129 & 0.9943 & 0.0065 & 1.0000 & 0.0000 & 1.0000 & 0.0000 \\
\hline \multirow{2}{*}{ Summer } & Virtual & TDA Tailrace & to $1 \mathrm{~B}$ & $95 \%$ CL & & & to $1 \mathrm{~B}$ & $95 \%$ CL & & & $\lambda$ to $2 B$ & $95 \%$ CL \\
\hline & & Pooled & 0.8570 & 0.0176 & & & 0.8028 & 0.0198 & & & 0.7102 & 0.0212 \\
\hline \multirow[t]{3}{*}{ Summer } & Paired & TDA Dam & to $1 \mathrm{~T}$ & $95 \% \mathrm{CL}$ & $1 \mathrm{~T}$ to $2 \mathrm{~T}$ & 95\% CL & $1 \mathrm{~T}$ & 95\% CL & $2 \mathrm{~T}$ & 95\% CL & $\lambda$ to $3 \mathrm{~T}$ & 95\% CL \\
\hline & & JDA Tailrace & 0.8228 & 0.0433 & 0.9918 & 0.0114 & 0.9877 & 0.0139 & 1.0000 & 0.0000 & 1.0000 & 0.0000 \\
\hline & & TDA Tailrace & 0.9692 & 0.0073 & 0.9580 & 0.0086 & 0.9911 & 0.0041 & 1.0000 & 0.0000 & 0.9995 & 0.0010 \\
\hline \multirow[t]{3}{*}{ Summer } & Paired & BON Dam & to $1 \mathrm{~B}$ & $95 \% \mathrm{CL}$ & & & to $1 \mathrm{~B}$ & 95\% CL & & & $\lambda$ to $2 \mathrm{~B}$ & $95 \%$ CL \\
\hline & & TDA Tailrace & 0.8044 & 0.0196 & & & 0.8187 & 0.0150 & & & 0.7108 & 0.0231 \\
\hline & & BON Tailrace & 0.9474 & 0.0139 & & & 0.8187 & 0.0150 & & & 0.8096 & 0.0196 \\
\hline \multirow[t]{3}{*}{ Summer } & Paired & & $\hat{S}(\widehat{s . e .})$ & $95 \%$ CL & & & & & & & & \\
\hline & & TDA Project & 0.8489 & 0.0884 & & & & & & & & \\
\hline & & BON Project & 0.8491 & 0.0472 & & & & & & & & \\
\hline
\end{tabular}


Acoustic Telemetry Studies of Juvenile Chinook Salmon Survival at the Lower Columbia Projects in 2006 


\section{Appendix I}

Model Estimates of One-Half 95\% Confidence Intervals on Detection and Survival Statistics for Yearling Chinook Salmon Based on Single-Release Survival Models for Spring 2006 
Acoustic Telemetry Studies of Juvenile Chinook Salmon Survival at the Lower Columbia Projects in 2006 


\section{Appendix I}

\section{Model Estimates of One-Half 95\% Confidence Intervals on Detection and Survival Statistics for Yearling Chinook Salmon Based on Single-Release Survival Models for Spring 2006}

All predicted estimates of 95\% confidence intervals (CI) are based upon spring 2006 estimates of survival and detection probabilities, and sample-size estimates associated with a one-half $95 \%$ CIs of $2 \%, 3 \%, 4 \%$, and $5 \%$ on primary array survival (S1) are highlighted when listed.

Table I.1. Predictions of One-half $95 \%$ Confidence Intervals $(\mathrm{Cl})$ on Survival of Fish Traveling from the Lower Granite Tailrace to Array 1J (S1) and from Array 1J to Array 1T (S2), on Associated Detection Probabilities P1 and P2, and on the Joint Probability $(\lambda)$ as a Function of Possible Total Numbers that Could be Released.

\begin{tabular}{|c|c|c|c|c|c|}
\hline $\begin{array}{l}\text { Release } \\
\text { Number }\end{array}$ & $\begin{array}{l}\text { One half } \\
95 \% \mathrm{Cl} \\
\text { on S1 } \\
\end{array}$ & $\begin{array}{l}\text { One-half } \\
95 \% \mathrm{Cl} \\
\text { on S2 }\end{array}$ & $\begin{array}{l}\text { One-half } \\
95 \% \mathrm{Cl} \\
\text { on P1 }\end{array}$ & $\begin{array}{l}\text { One-half } \\
95 \% \mathrm{Cl} \\
\text { on } \mathrm{P} 2 \\
\end{array}$ & $\begin{array}{l}\text { One-half } \\
95 \% \mathrm{Cl} \\
\text { on Lamda }\end{array}$ \\
\hline 300 & 0.056918 & 0.062406 & 0.049059 & 0.087279 & 0.084064 \\
\hline 400 & 0.049294 & 0.054037 & 0.042493 & 0.075597 & 0.072814 \\
\hline 500 & 0.044080 & 0.048334 & 0.038004 & 0.067620 & 0.065131 \\
\hline 600 & 0.040239 & 0.044120 & 0.034692 & 0.061720 & 0.059447 \\
\hline 700 & 0.037260 & 0.040846 & 0.032124 & 0.057134 & 0.055037 \\
\hline 800 & 0.034849 & 0.038220 & 0.030047 & 0.053449 & 0.051489 \\
\hline 900 & 0.032850 & 0.036025 & 0.028322 & 0.050392 & 0.048549 \\
\hline 1000 & 0.031164 & 0.034182 & 0.026872 & 0.047804 & 0.046040 \\
\hline 1100 & 0.029714 & 0.032595 & 0.025617 & 0.045590 & 0.043904 \\
\hline 1200 & 0.028459 & 0.031203 & 0.024539 & 0.043649 & 0.042042 \\
\hline 1300 & 0.027342 & 0.029988 & 0.023579 & 0.041924 & 0.040396 \\
\hline 1400 & 0.026342 & 0.028890 & 0.022716 & 0.040415 & 0.038926 \\
\hline 1500 & 0.025460 & 0.027910 & 0.021952 & 0.039043 & 0.037593 \\
\hline 1600 & 0.024637 & 0.027028 & 0.021246 & 0.037789 & 0.036397 \\
\hline 1700 & 0.023912 & 0.026225 & 0.020619 & 0.036672 & 0.035319 \\
\hline 1800 & 0.023226 & 0.025480 & 0.020031 & 0.035633 & 0.034320 \\
\hline 1900 & 0.022618 & 0.024794 & 0.019502 & 0.034692 & 0.033398 \\
\hline 2000 & 0.022050 & 0.024167 & 0.019012 & 0.033810 & 0.032556 \\
\hline 2100 & 0.021501 & 0.023579 & 0.018542 & 0.032987 & 0.031772 \\
\hline 2200 & 0.021011 & 0.023050 & 0.018110 & 0.032242 & 0.031046 \\
\hline 2300 & 0.020560 & 0.022540 & 0.017718 & 0.031517 & 0.030360 \\
\hline 2400 & 0.020129 & 0.022070 & 0.017346 & 0.030870 & 0.029733 \\
\hline 2500 & 0.019718 & 0.021619 & 0.016993 & 0.030243 & 0.029126 \\
\hline 2600 & 0.019326 & 0.021207 & 0.016660 & 0.029655 & 0.028557 \\
\hline 2700 & 0.018973 & 0.020796 & 0.016346 & 0.029086 & 0.028028 \\
\hline 2800 & 0.018620 & 0.020423 & 0.016052 & 0.028577 & 0.027518 \\
\hline 3000 & 0.017993 & 0.019737 & 0.015523 & 0.027597 & 0.026578 \\
\hline
\end{tabular}


Table I.2. Predictions of One-half 95\% Confidence Intervals (Cl) on Survival of Fish Traveling from the Lower Granite Tailrace to Array 1T (S1) and from Array 1T to Array 1B (S2), on Associated Detection Probabilities P1 and P2, and on the Joint Probability $(\lambda)$ as a Function of Possible Total Numbers that Could be Released.

\begin{tabular}{|c|c|c|c|c|c|}
\hline $\begin{array}{l}\text { Release } \\
\text { Number }\end{array}$ & $\begin{array}{l}\text { One half } \\
95 \% \mathrm{Cl} \\
\text { on S1 }\end{array}$ & $\begin{array}{l}\text { One-half } \\
95 \% \mathrm{Cl} \\
\text { on S2 }\end{array}$ & $\begin{array}{l}\text { One-half } \\
95 \% \mathrm{Cl} \\
\text { on P1 }\end{array}$ & $\begin{array}{l}\text { One-half } \\
95 \% \mathrm{Cl} \\
\text { on P2 }\end{array}$ & $\begin{array}{l}\text { One-half } \\
95 \% \mathrm{Cl} \\
\text { on Lamda }\end{array}$ \\
\hline 300 & 0.056428 & 0.030752 & 0.074382 & 0.030478 & 0.050137 \\
\hline 400 & 0.048863 & 0.026636 & 0.064406 & 0.026382 & 0.043414 \\
\hline 500 & 0.043708 & 0.023814 & 0.057604 & 0.023598 & 0.038847 \\
\hline 600 & 0.039906 & 0.021736 & 0.052587 & 0.021540 & 0.035456 \\
\hline 700 & 0.036946 & 0.020129 & 0.048686 & 0.019953 & 0.032830 \\
\hline 800 & 0.034555 & 0.018836 & 0.045550 & 0.018659 & 0.030713 \\
\hline 900 & 0.032575 & 0.017758 & 0.042944 & 0.017601 & 0.028949 \\
\hline 1000 & 0.030909 & 0.016836 & 0.040729 & 0.016680 & 0.027460 \\
\hline 1100 & 0.029478 & 0.016052 & 0.038847 & 0.015915 & 0.026186 \\
\hline 1200 & 0.028204 & 0.015366 & 0.037181 & 0.015229 & 0.025068 \\
\hline 1300 & 0.027107 & 0.014778 & 0.035731 & 0.014641 & 0.024088 \\
\hline 1400 & 0.026127 & 0.014230 & 0.034437 & 0.014112 & 0.023206 \\
\hline 1500 & 0.025245 & 0.013759 & 0.033261 & 0.013622 & 0.022422 \\
\hline 1600 & 0.024441 & 0.013308 & 0.032203 & 0.013191 & 0.021717 \\
\hline 1700 & 0.023696 & 0.012916 & 0.031242 & 0.012799 & 0.021070 \\
\hline 1800 & 0.023030 & 0.012544 & 0.030360 & 0.012446 & 0.020462 \\
\hline 1900 & 0.022422 & 0.012211 & 0.029557 & 0.012113 & 0.019933 \\
\hline 2000 & 0.021854 & 0.011917 & 0.028812 & 0.011799 & 0.019424 \\
\hline 2100 & 0.021325 & 0.011623 & 0.028106 & 0.011525 & 0.018953 \\
\hline 2200 & 0.020835 & 0.011348 & 0.027460 & 0.011250 & 0.018522 \\
\hline 2300 & 0.020384 & 0.011113 & 0.026872 & 0.010996 & 0.018110 \\
\hline 2400 & 0.019953 & 0.010878 & 0.026303 & 0.010780 & 0.017718 \\
\hline 2500 & 0.019541 & 0.010643 & 0.025774 & 0.010564 & 0.017366 \\
\hline 2600 & 0.019169 & 0.010447 & 0.025264 & 0.010349 & 0.017032 \\
\hline 2700 & 0.018816 & 0.010251 & 0.024794 & 0.010153 & 0.016719 \\
\hline 2800 & 0.018463 & 0.010055 & 0.024343 & 0.009976 & 0.016405 \\
\hline 3000 & 0.017836 & 0.009722 & 0.023520 & 0.009643 & 0.015856 \\
\hline
\end{tabular}


Table I.3. Predictions of One-half $95 \%$ Confidence Intervals $(\mathrm{Cl})$ on Survival of Fish Traveling from the Lower Granite Tailrace to Array 1B (S1) and from Array 1B to Array 2B (S2), on Associated Detection Probabilities P1 and P2, and on the Joint Probability $(\lambda)$ as a Function of Possible Total Numbers that Could be Released.

\begin{tabular}{|c|c|c|c|c|c|}
\hline $\begin{array}{l}\text { Release } \\
\text { Number }\end{array}$ & $\begin{array}{l}\text { One half } \\
95 \% \mathrm{Cl} \\
\text { on S1 }\end{array}$ & $\begin{array}{l}\text { One-half } \\
95 \% \mathrm{Cl} \\
\text { on S2 }\end{array}$ & $\begin{array}{l}\text { One-half } \\
95 \% \mathrm{Cl} \\
\text { on P1 }\end{array}$ & $\begin{array}{l}\text { One-half } \\
95 \% \mathrm{Cl} \\
\text { on P2 }\end{array}$ & $\begin{array}{l}\text { One-half } \\
95 \% \mathrm{Cl} \\
\text { on Lamda }\end{array}$ \\
\hline 300 & 0.104060 & 0.574910 & 0.126640 & 0.190550 & 0.120600 \\
\hline 400 & 0.090120 & 0.497880 & 0.109660 & 0.165030 & 0.104450 \\
\hline 500 & 0.080610 & 0.445350 & 0.098100 & 0.147610 & 0.093430 \\
\hline 600 & 0.073580 & 0.406520 & 0.089530 & 0.134750 & 0.085280 \\
\hline 700 & 0.068130 & 0.376400 & 0.082910 & 0.124750 & 0.078970 \\
\hline 800 & 0.063720 & 0.352060 & 0.077540 & 0.116700 & 0.073850 \\
\hline 900 & 0.060070 & 0.331930 & 0.073110 & 0.110010 & 0.069640 \\
\hline 1000 & 0.057000 & 0.314910 & 0.069360 & 0.104390 & 0.066070 \\
\hline 1100 & 0.054350 & 0.300270 & 0.066130 & 0.099530 & 0.062990 \\
\hline 1200 & 0.052040 & 0.287450 & 0.063310 & 0.095280 & 0.060310 \\
\hline 1300 & 0.050000 & 0.276160 & 0.060840 & 0.091530 & 0.057940 \\
\hline 1400 & 0.048180 & 0.266150 & 0.058620 & 0.088220 & 0.055840 \\
\hline 1500 & 0.046530 & 0.257090 & 0.056620 & 0.085220 & 0.053940 \\
\hline 1600 & 0.045060 & 0.248940 & 0.054840 & 0.082520 & 0.052210 \\
\hline 1700 & 0.043710 & 0.241530 & 0.053190 & 0.080070 & 0.050670 \\
\hline 1800 & 0.042490 & 0.234710 & 0.051700 & 0.077790 & 0.049240 \\
\hline 1900 & 0.041360 & 0.228440 & 0.050310 & 0.075710 & 0.047920 \\
\hline 2000 & 0.040300 & 0.222680 & 0.049040 & 0.073810 & 0.046710 \\
\hline 2100 & 0.039340 & 0.217340 & 0.047860 & 0.072030 & 0.045590 \\
\hline 2200 & 0.038440 & 0.212330 & 0.046770 & 0.070380 & 0.044550 \\
\hline 2300 & 0.037590 & 0.207660 & 0.045730 & 0.068840 & 0.043570 \\
\hline 2400 & 0.036790 & 0.203250 & 0.044770 & 0.067370 & 0.042650 \\
\hline 2500 & 0.036040 & 0.199180 & 0.043860 & 0.066010 & 0.041790 \\
\hline 2600 & 0.035360 & 0.195270 & 0.043020 & 0.064720 & 0.040960 \\
\hline 2700 & 0.034690 & 0.191630 & 0.042220 & 0.063520 & 0.040200 \\
\hline 2800 & 0.034060 & 0.188200 & 0.041450 & 0.062390 & 0.039470 \\
\hline 2900 & 0.033480 & 0.184910 & 0.040730 & 0.061290 & 0.038790 \\
\hline 3000 & 0.032910 & 0.181790 & 0.040040 & 0.060250 & 0.038140 \\
\hline 3100 & 0.032380 & 0.178850 & 0.039400 & 0.059290 & 0.037510 \\
\hline 3200 & 0.031870 & 0.176030 & 0.038770 & 0.058350 & 0.036930 \\
\hline 3300 & 0.031380 & 0.173340 & 0.038180 & 0.057450 & 0.036360 \\
\hline 3400 & 0.030910 & 0.170790 & 0.037610 & 0.056600 & 0.035830 \\
\hline 3500 & 0.030460 & 0.168310 & 0.037080 & 0.055780 & 0.035300 \\
\hline 3600 & 0.030050 & 0.165970 & 0.036550 & 0.055020 & 0.034810 \\
\hline 3700 & 0.029640 & 0.163720 & 0.036060 & 0.054270 & 0.034340 \\
\hline 3800 & 0.029240 & 0.161540 & 0.035570 & 0.053550 & 0.033890 \\
\hline 3900 & 0.028870 & 0.159470 & 0.035120 & 0.052860 & 0.033460 \\
\hline 4000 & 0.028500 & 0.157450 & 0.034670 & 0.052190 & 0.033030 \\
\hline 4100 & 0.028150 & 0.155510 & 0.034260 & 0.051550 & 0.032610 \\
\hline 4200 & 0.027810 & 0.153680 & 0.033850 & 0.050940 & 0.032240 \\
\hline 4300 & 0.027480 & 0.151880 & 0.033460 & 0.050330 & 0.031870 \\
\hline 4400 & 0.027170 & 0.150140 & 0.033070 & 0.049760 & 0.031500 \\
\hline 4500 & 0.026870 & 0.148430 & 0.032690 & 0.049200 & 0.031140 \\
\hline 4600 & 0.026580 & 0.146820 & 0.032340 & 0.048670 & 0.030810 \\
\hline 4700 & 0.026280 & 0.145260 & 0.031990 & 0.048140 & 0.030480 \\
\hline 4800 & 0.026010 & 0.143730 & 0.031650 & 0.047650 & 0.030140 \\
\hline 5000 & 0.025500 & 0.140830 & 0.031030 & 0.046690 & 0.029540 \\
\hline
\end{tabular}


Table I.4. Predictions of One-half $95 \%$ Confidence Intervals (Cl) on Survival of Fish Traveling from the JDA Front Roll to Array 1J (S1) and from Array 1J to Array 1T (S2), on Associated Detection Probabilities P1 and P2, and on the Joint Probability $(\lambda)$ as a Function of Possible Total Numbers that Could be Released.

\begin{tabular}{|c|c|c|c|c|c|}
\hline $\begin{array}{l}\text { Release } \\
\text { Number }\end{array}$ & $\begin{array}{l}\text { One half } \\
95 \% \mathrm{Cl} \\
\text { on S1 } \\
\end{array}$ & $\begin{array}{l}\text { One-half } \\
95 \% \mathrm{Cl} \\
\text { on S2 }\end{array}$ & $\begin{array}{l}\text { One-half } \\
95 \% \mathrm{Cl} \\
\text { on P1 }\end{array}$ & $\begin{array}{l}\text { One-half } \\
95 \% \mathrm{Cl} \\
\text { on P2 }\end{array}$ & $\begin{array}{l}\text { One-half } \\
95 \% \mathrm{Cl} \\
\text { on Lamda }\end{array}$ \\
\hline 300 & 0.015915 & 0.026186 & 0.010800 & 0.041415 & 0.048686 \\
\hline 400 & 0.013779 & 0.022677 & 0.009349 & 0.035868 & 0.042179 \\
\hline 500 & 0.012328 & 0.020286 & 0.008350 & 0.032085 & 0.037710 \\
\hline 600 & 0.011250 & 0.018522 & 0.007624 & 0.029282 & 0.034437 \\
\hline 700 & 0.010427 & 0.017150 & 0.007056 & 0.027107 & 0.031870 \\
\hline 800 & 0.009741 & 0.016033 & 0.006605 & 0.025362 & 0.029812 \\
\hline 900 & 0.009192 & 0.015112 & 0.006233 & 0.023912 & 0.028106 \\
\hline 1000 & 0.008722 & 0.014347 & 0.005919 & 0.022677 & 0.026676 \\
\hline 1100 & 0.008310 & 0.013681 & 0.005645 & 0.021619 & 0.025421 \\
\hline 1200 & 0.007958 & 0.013093 & 0.005390 & 0.020698 & 0.024343 \\
\hline 1300 & 0.007644 & 0.012583 & 0.005174 & 0.019894 & 0.023383 \\
\hline 1400 & 0.007370 & 0.012113 & 0.004998 & 0.019169 & 0.022540 \\
\hline 1500 & 0.007115 & 0.011701 & 0.004822 & 0.018522 & 0.021776 \\
\hline 1600 & 0.006899 & 0.011329 & 0.004665 & 0.017934 & 0.021090 \\
\hline 1700 & 0.006684 & 0.010996 & 0.004528 & 0.017405 & 0.020462 \\
\hline 1800 & 0.006507 & 0.010682 & 0.004410 & 0.016915 & 0.019874 \\
\hline 1900 & 0.006331 & 0.010408 & 0.004292 & 0.016464 & 0.019345 \\
\hline 2000 & 0.006174 & 0.010133 & 0.004175 & 0.016033 & 0.018855 \\
\hline 2100 & 0.006017 & 0.009898 & 0.004077 & 0.015660 & 0.018404 \\
\hline 2200 & 0.005880 & 0.009663 & 0.003979 & 0.015288 & 0.017973 \\
\hline 2300 & 0.005743 & 0.009447 & 0.003900 & 0.014955 & 0.017581 \\
\hline 2400 & 0.005625 & 0.009251 & 0.003822 & 0.014641 & 0.017209 \\
\hline 2500 & 0.005508 & 0.009075 & 0.003744 & 0.014347 & 0.016876 \\
\hline 2600 & 0.005410 & 0.008898 & 0.003665 & 0.014073 & 0.016542 \\
\hline 2700 & 0.005312 & 0.008722 & 0.003606 & 0.013798 & 0.016229 \\
\hline 2800 & 0.005214 & 0.008565 & 0.003528 & 0.013563 & 0.015935 \\
\hline 3000 & 0.005037 & 0.008271 & 0.003410 & 0.013093 & 0.015406 \\
\hline
\end{tabular}


Table I.5. Predictions of One-half $95 \%$ Confidence Intervals $(\mathrm{Cl})$ on Survival of Fish Traveling from the JDA Intake to Array $1 \mathrm{~J}$ (S1) and from Array $1 \mathrm{~J}$ to Array 1T (S2), on Associated Detection Probabilities P1 and P2, and on the Joint Probability $(\lambda)$ as a Function of Possible Total Numbers that Could be Released.

\begin{tabular}{|c|c|c|c|c|c|}
\hline $\begin{array}{l}\text { Release } \\
\text { Number }\end{array}$ & $\begin{array}{l}\text { One half } \\
95 \% \mathrm{Cl} \\
\text { on S1 }\end{array}$ & $\begin{array}{l}\text { One-half } \\
95 \% \mathrm{CI} \\
\text { on S2 }\end{array}$ & $\begin{array}{l}\text { One-half } \\
95 \% \mathrm{Cl} \\
\text { on P1 }\end{array}$ & $\begin{array}{l}\text { One-half } \\
95 \% \mathrm{Cl} \\
\text { on P2 }\end{array}$ & $\begin{array}{l}\text { One-half } \\
95 \% \mathrm{Cl} \\
\text { on Lamda }\end{array}$ \\
\hline 300 & 0.039063 & 0.029263 & 0.019051 & 0.046844 & 0.058075 \\
\hline 400 & 0.033830 & 0.025343 & 0.016503 & 0.040572 & 0.050294 \\
\hline 500 & 0.030262 & 0.022677 & 0.014759 & 0.036299 & 0.044982 \\
\hline 600 & 0.027636 & 0.020698 & 0.013465 & 0.033124 & 0.041062 \\
\hline 700 & 0.025578 & 0.019169 & 0.012466 & 0.030674 & 0.038024 \\
\hline 800 & 0.023932 & 0.017914 & 0.011662 & 0.028694 & 0.035554 \\
\hline 900 & 0.022560 & 0.016895 & 0.010996 & 0.027048 & 0.033536 \\
\hline 1000 & 0.021403 & 0.016033 & 0.010427 & 0.025656 & 0.031811 \\
\hline 1100 & 0.020404 & 0.015288 & 0.009957 & 0.024461 & 0.030321 \\
\hline 1200 & 0.019541 & 0.014641 & 0.009526 & 0.023422 & 0.029028 \\
\hline 1300 & 0.018777 & 0.014053 & 0.009153 & 0.022501 & 0.027891 \\
\hline 1400 & 0.018091 & 0.013544 & 0.008820 & 0.021697 & 0.026891 \\
\hline 1500 & 0.017483 & 0.013093 & 0.008526 & 0.020952 & 0.025970 \\
\hline 1600 & 0.016915 & 0.012681 & 0.008252 & 0.020286 & 0.025147 \\
\hline 1700 & 0.016405 & 0.012289 & 0.007997 & 0.019678 & 0.024402 \\
\hline 1800 & 0.015954 & 0.011956 & 0.007781 & 0.019130 & 0.023716 \\
\hline 1900 & 0.015523 & 0.011623 & 0.007566 & 0.018620 & 0.023069 \\
\hline 2000 & 0.015131 & 0.011329 & 0.007370 & 0.018150 & 0.022481 \\
\hline 2100 & 0.014759 & 0.011054 & 0.007193 & 0.017699 & 0.021952 \\
\hline 2200 & 0.014426 & 0.010800 & 0.007036 & 0.017307 & 0.021442 \\
\hline 2300 & 0.014112 & 0.010564 & 0.006880 & 0.016915 & 0.020972 \\
\hline 2400 & 0.013818 & 0.010349 & 0.006742 & 0.016562 & 0.020541 \\
\hline 2500 & 0.013544 & 0.010133 & 0.006605 & 0.016229 & 0.020110 \\
\hline 2600 & 0.013269 & 0.009937 & 0.006468 & 0.015915 & 0.019718 \\
\hline 2700 & 0.013014 & 0.009761 & 0.006350 & 0.015621 & 0.019365 \\
\hline 2800 & 0.012799 & 0.009584 & 0.006233 & 0.015327 & 0.019012 \\
\hline 3000 & 0.012348 & 0.009251 & 0.006017 & 0.014818 & 0.018365 \\
\hline
\end{tabular}


Table I.6. Predictions of One-half $95 \%$ Confidence Intervals $(\mathrm{Cl})$ on Survival of Fish Traveling from the JDA Tailrace to Array $1 \mathrm{~J}$ (S1) and from Array $1 \mathrm{~J}$ to Array 1T (S2), on Associated Detection Probabilities P1 and P2, and on the Joint Probability $(\lambda)$ as a Function of Possible Total Numbers that Could be Released.

\begin{tabular}{|c|c|c|c|c|c|}
\hline $\begin{array}{l}\text { Release } \\
\text { Number }\end{array}$ & $\begin{array}{l}\text { One half } \\
95 \% \mathrm{Cl} \\
\text { on S1 } \\
\end{array}$ & $\begin{array}{l}\text { One-half } \\
95 \% \mathrm{Cl} \\
\text { on S2 } \\
\end{array}$ & $\begin{array}{l}\text { One-half } \\
95 \% \mathrm{Cl} \\
\text { on P1 }\end{array}$ & $\begin{array}{l}\text { One-half } \\
95 \% \mathrm{Cl} \\
\text { on } \mathrm{P2} \\
\end{array}$ & $\begin{array}{l}\text { One-half } \\
95 \% \mathrm{Cl} \\
\text { on Lamda }\end{array}$ \\
\hline 300 & 0.020286 & 0.019992 & 0.014328 & 0.041219 & 0.046726 \\
\hline 400 & 0.017581 & 0.017307 & 0.012407 & 0.035692 & 0.040474 \\
\hline 500 & 0.015719 & 0.015484 & 0.011094 & 0.031928 & 0.036201 \\
\hline 600 & 0.014347 & 0.014132 & 0.010133 & 0.029145 & 0.033046 \\
\hline 700 & 0.013289 & 0.013093 & 0.009388 & 0.026989 & 0.030596 \\
\hline 800 & 0.012426 & 0.012250 & 0.008781 & 0.025245 & 0.028616 \\
\hline 900 & 0.011721 & 0.011544 & 0.008271 & 0.023794 & 0.026989 \\
\hline 1000 & 0.011113 & 0.010956 & 0.007840 & 0.022579 & 0.025598 \\
\hline 1100 & 0.010604 & 0.010447 & 0.007487 & 0.021521 & 0.024402 \\
\hline 1200 & 0.010153 & 0.009996 & 0.007154 & 0.020619 & 0.023363 \\
\hline 1300 & 0.009741 & 0.009604 & 0.006880 & 0.019796 & 0.022442 \\
\hline 1400 & 0.009388 & 0.009251 & 0.006625 & 0.019090 & 0.021638 \\
\hline 1500 & 0.009075 & 0.008938 & 0.006409 & 0.018444 & 0.020894 \\
\hline 1600 & 0.008781 & 0.008663 & 0.006213 & 0.017856 & 0.020227 \\
\hline 1700 & 0.008526 & 0.008389 & 0.006017 & 0.017326 & 0.019639 \\
\hline 1800 & 0.008291 & 0.008154 & 0.005841 & 0.016836 & 0.019071 \\
\hline 1900 & 0.008056 & 0.007938 & 0.005684 & 0.016386 & 0.018561 \\
\hline 2000 & 0.007860 & 0.007742 & 0.005547 & 0.015974 & 0.018091 \\
\hline 2100 & 0.007664 & 0.007546 & 0.005410 & 0.015582 & 0.017660 \\
\hline 2200 & 0.007487 & 0.007389 & 0.005292 & 0.015229 & 0.017248 \\
\hline 2300 & 0.007330 & 0.007213 & 0.005174 & 0.014896 & 0.016876 \\
\hline 2400 & 0.007174 & 0.007076 & 0.005057 & 0.014582 & 0.016523 \\
\hline 2500 & 0.007036 & 0.006919 & 0.004959 & 0.014288 & 0.016190 \\
\hline 2600 & 0.006899 & 0.006782 & 0.004861 & 0.013994 & 0.015876 \\
\hline 2700 & 0.006762 & 0.006664 & 0.004782 & 0.013740 & 0.015582 \\
\hline 2800 & 0.006644 & 0.006546 & 0.004684 & 0.013485 & 0.015288 \\
\hline 3000 & 0.006409 & 0.006331 & 0.004528 & 0.013034 & 0.014778 \\
\hline
\end{tabular}


Table I.7. Predictions of One-half 95\% Confidence Intervals $(\mathrm{Cl})$ on Survival of Fish Traveling from the JDA Front Roll to Array 1T (S1) and from Array 1T to Array 1B (S2), on Associated Detection Probabilities P1 and P2, and on the Joint Probability $(\lambda)$ as a Function of Possible Total Numbers that Could be Released.

\begin{tabular}{|c|c|c|c|c|c|}
\hline $\begin{array}{l}\text { Release } \\
\text { Number }\end{array}$ & $\begin{array}{l}\text { One half } \\
95 \% \mathrm{Cl} \\
\text { on S1 }\end{array}$ & $\begin{array}{l}\text { One-half } \\
95 \% \mathrm{Cl} \\
\text { on S2 }\end{array}$ & $\begin{array}{l}\text { One-half } \\
95 \% \mathrm{Cl} \\
\text { on P1 }\end{array}$ & $\begin{array}{l}\text { One-half } \\
95 \% \mathrm{Cl} \\
\text { on P2 }\end{array}$ & $\begin{array}{l}\text { One-half } \\
95 \% \mathrm{Cl} \\
\text { on Lamda }\end{array}$ \\
\hline 300 & 0.032222 & 0.015896 & 0.032948 & 0.005743 & 0.007997 \\
\hline 400 & 0.027910 & 0.013779 & 0.028538 & 0.004959 & 0.006938 \\
\hline 500 & 0.024970 & 0.012309 & 0.025519 & 0.004449 & 0.006194 \\
\hline 600 & 0.022795 & 0.011250 & 0.023304 & 0.004057 & 0.005664 \\
\hline 700 & 0.021090 & 0.010408 & 0.021580 & 0.003763 & 0.005233 \\
\hline 800 & 0.019737 & 0.009741 & 0.020188 & 0.003508 & 0.004900 \\
\hline 900 & 0.018600 & 0.009173 & 0.019032 & 0.003312 & 0.004626 \\
\hline 1000 & 0.017660 & 0.008702 & 0.018052 & 0.003136 & 0.004390 \\
\hline 1100 & 0.016836 & 0.008310 & 0.017209 & 0.002999 & 0.004175 \\
\hline 1200 & 0.016111 & 0.007958 & 0.016484 & 0.002862 & 0.003998 \\
\hline 1300 & 0.015484 & 0.007644 & 0.015837 & 0.002764 & 0.003842 \\
\hline 1400 & 0.014916 & 0.007370 & 0.015249 & 0.002646 & 0.003704 \\
\hline 1500 & 0.014406 & 0.007115 & 0.014739 & 0.002568 & 0.003587 \\
\hline 1600 & 0.013955 & 0.006880 & 0.014269 & 0.002489 & 0.003469 \\
\hline 1700 & 0.013544 & 0.006684 & 0.013838 & 0.002411 & 0.003371 \\
\hline 1800 & 0.013152 & 0.006488 & 0.013446 & 0.002332 & 0.003273 \\
\hline 1900 & 0.012799 & 0.006311 & 0.013093 & 0.002274 & 0.003175 \\
\hline 2000 & 0.012485 & 0.006154 & 0.012760 & 0.002215 & 0.003097 \\
\hline 2100 & 0.012172 & 0.006017 & 0.012466 & 0.002176 & 0.003018 \\
\hline 2200 & 0.011897 & 0.005880 & 0.012172 & 0.002117 & 0.002960 \\
\hline 2300 & 0.011642 & 0.005743 & 0.011897 & 0.002078 & 0.002881 \\
\hline 2400 & 0.011388 & 0.005625 & 0.011642 & 0.002019 & 0.002822 \\
\hline 2500 & 0.011172 & 0.005508 & 0.011407 & 0.001980 & 0.002764 \\
\hline 2600 & 0.010937 & 0.005410 & 0.011192 & 0.001940 & 0.002724 \\
\hline 2700 & 0.010741 & 0.005292 & 0.010976 & 0.001921 & 0.002666 \\
\hline 2800 & 0.010545 & 0.005214 & 0.010780 & 0.001882 & 0.002626 \\
\hline 3000 & 0.010192 & 0.005037 & 0.010427 & 0.001823 & 0.002528 \\
\hline
\end{tabular}


Table I.8. Predictions of One-half $95 \%$ Confidence Intervals (Cl) on Survival of Fish Traveling from the JDA Intake to Array 1T (S1) and from Array 1T to Array 1B (S2), on Associated Detection Probabilities P1 and P2, and on the Joint Probability $(\lambda)$ as a Function of Possible Total Numbers that Could be Released.

\begin{tabular}{|c|c|c|c|c|c|}
\hline $\begin{array}{l}\text { Release } \\
\text { Number }\end{array}$ & $\begin{array}{l}\text { One half } \\
95 \% \mathrm{Cl} \\
\text { on S1 } \\
\end{array}$ & $\begin{array}{l}\text { One-half } \\
95 \% \mathrm{Cl} \\
\text { on S2 }\end{array}$ & $\begin{array}{l}\text { One-half } \\
95 \% \mathrm{Cl} \\
\text { on P1 }\end{array}$ & $\begin{array}{l}\text { One-half } \\
95 \% \mathrm{Cl} \\
\text { on P2 }\end{array}$ & $\begin{array}{l}\text { One-half } \\
95 \% \mathrm{Cl} \\
\text { on Lamda }\end{array}$ \\
\hline 300 & 0.043943 & 0.018836 & 0.034320 & 0.009075 & 0.015464 \\
\hline 400 & 0.038063 & 0.016307 & 0.029733 & 0.007860 & 0.013387 \\
\hline 500 & 0.034045 & 0.014582 & 0.026578 & 0.007036 & 0.011976 \\
\hline 600 & 0.031066 & 0.013308 & 0.024265 & 0.006429 & 0.010937 \\
\hline 700 & 0.028773 & 0.012328 & 0.022462 & 0.005939 & 0.010133 \\
\hline 800 & 0.026911 & 0.011525 & 0.021011 & 0.005566 & 0.009467 \\
\hline 900 & 0.025362 & 0.010878 & 0.019816 & 0.005233 & 0.008938 \\
\hline 1000 & 0.024069 & 0.010310 & 0.018796 & 0.004978 & 0.008467 \\
\hline 1100 & 0.022952 & 0.009839 & 0.017934 & 0.004743 & 0.008075 \\
\hline 1200 & 0.021972 & 0.009408 & 0.017170 & 0.004547 & 0.007742 \\
\hline 1300 & 0.021109 & 0.009055 & 0.016484 & 0.004371 & 0.007428 \\
\hline 1400 & 0.020345 & 0.008722 & 0.015896 & 0.004194 & 0.007154 \\
\hline 1500 & 0.019659 & 0.008428 & 0.015347 & 0.004057 & 0.006919 \\
\hline 1600 & 0.019032 & 0.008154 & 0.014857 & 0.003940 & 0.006703 \\
\hline 1700 & 0.018463 & 0.007918 & 0.014426 & 0.003822 & 0.006507 \\
\hline 1800 & 0.017934 & 0.007683 & 0.014014 & 0.003704 & 0.006311 \\
\hline 1900 & 0.017464 & 0.007487 & 0.013642 & 0.003606 & 0.006154 \\
\hline 2000 & 0.017013 & 0.007291 & 0.013289 & 0.003508 & 0.005998 \\
\hline 2100 & 0.016601 & 0.007115 & 0.012975 & 0.003430 & 0.005841 \\
\hline 2200 & 0.016229 & 0.006958 & 0.012681 & 0.003352 & 0.005704 \\
\hline 2300 & 0.015876 & 0.006801 & 0.012387 & 0.003273 & 0.005586 \\
\hline 2400 & 0.015543 & 0.006664 & 0.012132 & 0.003214 & 0.005468 \\
\hline 2500 & 0.015229 & 0.006527 & 0.011897 & 0.003136 & 0.005351 \\
\hline 2600 & 0.014935 & 0.006390 & 0.011662 & 0.003077 & 0.005253 \\
\hline 2700 & 0.014641 & 0.006272 & 0.011446 & 0.003018 & 0.005155 \\
\hline 2800 & 0.014386 & 0.006174 & 0.011231 & 0.002979 & 0.005057 \\
\hline 3000 & 0.013896 & 0.005958 & 0.010858 & 0.002881 & 0.004900 \\
\hline
\end{tabular}


Table 1.9. Predictions of One-half $95 \%$ Confidence Intervals $(\mathrm{Cl})$ on Survival of Fish Traveling from the JDA Tailrace to Array 1T (S1) and from Array 1T to Array 1B (S2), on Associated Detection Probabilities $\mathrm{P} 1$ and $\mathrm{P} 2$, and on the Joint Probability $(\lambda)$ as a Function of Possible Total Numbers that Could be Released.

\begin{tabular}{|c|c|c|c|c|c|}
\hline $\begin{array}{l}\text { Release } \\
\text { Number }\end{array}$ & $\begin{array}{l}\text { One half } \\
95 \% \mathrm{Cl} \\
\text { on S1 }\end{array}$ & $\begin{array}{l}\text { One-half } \\
95 \% \mathrm{CI} \\
\text { on S2 }\end{array}$ & $\begin{array}{l}\text { One-half } \\
95 \% \mathrm{Cl} \\
\text { on P1 }\end{array}$ & $\begin{array}{l}\text { One-half } \\
95 \% \mathrm{Cl} \\
\text { on P2 }\end{array}$ & $\begin{array}{l}\text { One-half } \\
95 \% \mathrm{Cl} \\
\text { on Lamda }\end{array}$ \\
\hline 300 & 0.031301 & 0.015817 & 0.029753 & 0.119400 & 0.008075 \\
\hline 400 & 0.027107 & 0.013700 & 0.025754 & 0.103410 & 0.006997 \\
\hline 500 & 0.024245 & 0.012250 & 0.023030 & 0.092490 & 0.006252 \\
\hline 600 & 0.022128 & 0.011192 & 0.021031 & 0.084440 & 0.005704 \\
\hline 700 & 0.020482 & 0.010349 & 0.019463 & 0.078160 & 0.005292 \\
\hline 800 & 0.019169 & 0.009682 & 0.018208 & 0.073130 & 0.004939 \\
\hline 900 & 0.018071 & 0.009134 & 0.017170 & 0.068930 & 0.004665 \\
\hline 1000 & 0.017150 & 0.008663 & 0.016288 & 0.065410 & 0.004430 \\
\hline 1100 & 0.016346 & 0.008252 & 0.015543 & 0.062350 & 0.004214 \\
\hline 1200 & 0.015641 & 0.007899 & 0.014876 & 0.059700 & 0.004038 \\
\hline 1300 & 0.015033 & 0.007605 & 0.014288 & 0.057370 & 0.003881 \\
\hline 1400 & 0.014484 & 0.007330 & 0.013759 & 0.055270 & 0.003744 \\
\hline 1500 & 0.013994 & 0.007076 & 0.013308 & 0.053390 & 0.003606 \\
\hline 1600 & 0.013544 & 0.006840 & 0.012877 & 0.051700 & 0.003508 \\
\hline 1700 & 0.013152 & 0.006644 & 0.012485 & 0.050160 & 0.003391 \\
\hline 1800 & 0.012779 & 0.006448 & 0.012152 & 0.048750 & 0.003293 \\
\hline 1900 & 0.012446 & 0.006292 & 0.011819 & 0.047450 & 0.003214 \\
\hline 2000 & 0.012113 & 0.006135 & 0.011525 & 0.046240 & 0.003136 \\
\hline 2100 & 0.011838 & 0.005978 & 0.011250 & 0.045140 & 0.003058 \\
\hline 2200 & 0.011564 & 0.005841 & 0.010976 & 0.044100 & 0.002979 \\
\hline 2300 & 0.011309 & 0.005704 & 0.010741 & 0.043120 & 0.002920 \\
\hline 2400 & 0.011074 & 0.005586 & 0.010525 & 0.042220 & 0.002862 \\
\hline 2500 & 0.010839 & 0.005488 & 0.010310 & 0.041360 & 0.002803 \\
\hline 2600 & 0.010623 & 0.005370 & 0.010094 & 0.040550 & 0.002744 \\
\hline 2700 & 0.010427 & 0.005272 & 0.009918 & 0.039810 & 0.002685 \\
\hline 2800 & 0.010251 & 0.005174 & 0.009741 & 0.039080 & 0.002646 \\
\hline 3000 & 0.009898 & 0.004998 & 0.009408 & 0.037750 & 0.002548 \\
\hline
\end{tabular}


Table I.10. Predictions of One-half 95\% Confidence Intervals $(\mathrm{Cl})$ on Survival of Fish Traveling from the JDA Front Roll to Array 1B (S1) and from Array 1B to Array 2B (S2), on Associated Detection Probabilities P1 and P2, and on the Joint Probability $(\lambda)$ as a Function of Possible Total Numbers that Could be Released.

\begin{tabular}{|c|c|c|c|c|c|}
\hline $\begin{array}{l}\text { Release } \\
\text { Number }\end{array}$ & $\begin{array}{l}\text { One half } \\
95 \% \mathrm{Cl} \\
\text { on S1 }\end{array}$ & $\begin{array}{l}\text { One-half } \\
95 \% \mathrm{Cl} \\
\text { on S2 }\end{array}$ & $\begin{array}{l}\text { One-half } \\
95 \% \mathrm{Cl} \\
\text { on P1 }\end{array}$ & $\begin{array}{l}\text { One-half } \\
95 \% \mathrm{Cl} \\
\text { on P2 }\end{array}$ & $\begin{array}{l}\text { One-half } \\
95 \% \mathrm{Cl} \\
\text { on Lamda }\end{array}$ \\
\hline 300 & 0.063014 & 0.128790 & 0.070266 & 0.099529 & 0.078302 \\
\hline 400 & 0.054566 & 0.111540 & 0.060858 & 0.086201 & 0.067816 \\
\hline 500 & 0.048804 & 0.099760 & 0.054429 & 0.077106 & 0.060662 \\
\hline 600 & 0.044551 & 0.091060 & 0.049686 & 0.070384 & 0.055370 \\
\hline 700 & 0.041238 & 0.084320 & 0.046001 & 0.065150 & 0.051274 \\
\hline 800 & 0.038592 & 0.078870 & 0.043042 & 0.060956 & 0.047961 \\
\hline 900 & 0.036378 & 0.074360 & 0.040572 & 0.057467 & 0.045217 \\
\hline 1000 & 0.034516 & 0.070540 & 0.038494 & 0.054508 & 0.042885 \\
\hline 1100 & 0.032908 & 0.067270 & 0.036691 & 0.051979 & 0.040886 \\
\hline 1200 & 0.031497 & 0.064410 & 0.035143 & 0.049764 & 0.039161 \\
\hline 1300 & 0.030262 & 0.061880 & 0.033751 & 0.047804 & 0.037612 \\
\hline 1400 & 0.029165 & 0.059620 & 0.032536 & 0.046080 & 0.036240 \\
\hline 1500 & 0.028185 & 0.057600 & 0.031419 & 0.044512 & 0.035025 \\
\hline 1600 & 0.027283 & 0.055760 & 0.030439 & 0.043100 & 0.033908 \\
\hline 1700 & 0.026460 & 0.054100 & 0.029518 & 0.041807 & 0.032889 \\
\hline 1800 & 0.025715 & 0.052590 & 0.028694 & 0.040631 & 0.031968 \\
\hline 1900 & 0.025029 & 0.051180 & 0.027930 & 0.039553 & 0.031125 \\
\hline 2000 & 0.024402 & 0.049880 & 0.027224 & 0.038553 & 0.030321 \\
\hline 2100 & 0.023814 & 0.048690 & 0.026558 & 0.037612 & 0.029596 \\
\hline 2200 & 0.023265 & 0.047570 & 0.025950 & 0.036750 & 0.028910 \\
\hline 2300 & 0.022756 & 0.046510 & 0.025382 & 0.035946 & 0.028283 \\
\hline 2400 & 0.022285 & 0.045530 & 0.024853 & 0.035182 & 0.027695 \\
\hline 2500 & 0.021834 & 0.044610 & 0.024343 & 0.034476 & 0.027126 \\
\hline 2600 & 0.021403 & 0.043750 & 0.023873 & 0.033810 & 0.026597 \\
\hline 2700 & 0.021011 & 0.042920 & 0.023422 & 0.033183 & 0.026107 \\
\hline 2800 & 0.020619 & 0.042160 & 0.023010 & 0.032575 & 0.025637 \\
\hline 3000 & 0.019933 & 0.040730 & 0.022226 & 0.031478 & 0.024755 \\
\hline
\end{tabular}


Table I.11. Predictions of One-half 95\% Confidence Intervals $(\mathrm{Cl})$ on Survival of Fish Traveling from the JDA Intake to Array 1B (S1) and from Array 1B to Array 2B (S2), on Associated Detection Probabilities P1 and P2, and on the Joint Probability $(\lambda)$ as a Function of Possible Total Numbers that Could be Released.

\begin{tabular}{|c|c|c|c|c|c|}
\hline $\begin{array}{l}\text { Release } \\
\text { Number }\end{array}$ & $\begin{array}{l}\text { One half } \\
95 \% \mathrm{Cl} \\
\text { on S1 }\end{array}$ & $\begin{array}{l}\text { One-half } \\
95 \% \mathrm{Cl} \\
\text { on } \mathrm{S} 2\end{array}$ & $\begin{array}{l}\text { One-half } \\
95 \% \mathrm{Cl} \\
\text { on P1 }\end{array}$ & $\begin{array}{l}\text { One-half } \\
95 \% \mathrm{Cl} \\
\text { on P2 }\end{array}$ & $\begin{array}{l}\text { One-half } \\
95 \% \mathrm{Cl} \\
\text { on Lamda }\end{array}$ \\
\hline 300 & 0.067306 & 0.111740 & 0.073598 & 0.093414 & 0.081869 \\
\hline 400 & 0.058290 & 0.096770 & 0.063739 & 0.080909 & 0.070893 \\
\hline 500 & 0.052136 & 0.086550 & 0.057016 & 0.072363 & 0.063406 \\
\hline 600 & 0.047589 & 0.079010 & 0.052038 & 0.066052 & 0.057879 \\
\hline 700 & 0.044061 & 0.073150 & 0.048177 & 0.061152 & 0.053586 \\
\hline 800 & 0.041219 & 0.068420 & 0.045080 & 0.057212 & 0.050137 \\
\hline 900 & 0.038867 & 0.064520 & 0.042493 & 0.053939 & 0.047256 \\
\hline 1000 & 0.036868 & 0.061210 & 0.040317 & 0.051176 & 0.044845 \\
\hline 1100 & 0.035143 & 0.058350 & 0.038436 & 0.048784 & 0.042748 \\
\hline 1200 & 0.033653 & 0.055880 & 0.036809 & 0.046707 & 0.040925 \\
\hline 1300 & 0.032340 & 0.053680 & 0.035358 & 0.044884 & 0.039318 \\
\hline 1400 & 0.031164 & 0.051720 & 0.034065 & 0.043238 & 0.037887 \\
\hline 1500 & 0.030106 & 0.049980 & 0.032908 & 0.041787 & 0.036613 \\
\hline 1600 & 0.029145 & 0.048390 & 0.031870 & 0.040454 & 0.035456 \\
\hline 1700 & 0.028283 & 0.046940 & 0.030929 & 0.039239 & 0.034398 \\
\hline 1800 & 0.027479 & 0.045610 & 0.030047 & 0.038142 & 0.033418 \\
\hline 1900 & 0.026754 & 0.044390 & 0.029243 & 0.037122 & 0.032536 \\
\hline 2000 & 0.026068 & 0.043280 & 0.028498 & 0.036182 & 0.031713 \\
\hline 2100 & 0.025441 & 0.042240 & 0.027812 & 0.035319 & 0.030948 \\
\hline 2200 & 0.024853 & 0.041260 & 0.027185 & 0.034496 & 0.030223 \\
\hline 2300 & 0.024304 & 0.040360 & 0.026578 & 0.033732 & 0.029557 \\
\hline 2400 & 0.023794 & 0.039510 & 0.026029 & 0.033026 & 0.028949 \\
\hline 2500 & 0.023324 & 0.038710 & 0.025500 & 0.032360 & 0.028361 \\
\hline 2600 & 0.022854 & 0.037970 & 0.025010 & 0.031732 & 0.027812 \\
\hline 2700 & 0.022442 & 0.037240 & 0.024539 & 0.031144 & 0.027283 \\
\hline 2800 & 0.022030 & 0.036570 & 0.024088 & 0.030576 & 0.026793 \\
\hline 3000 & 0.021286 & 0.035340 & 0.023285 & 0.029537 & 0.025892 \\
\hline
\end{tabular}


Table I.12. Predictions of One-half 95\% Confidence Intervals $(\mathrm{Cl})$ on Survival of Fish Traveling from the JDA Tailrace to Array 1B (S1) and from Array 1B to Array 2B (S2), on Associated Detection Probabilities P1 and P2, and on the Joint Probability $(\lambda)$ as a Function of Possible Total Numbers that Could be Released.

\begin{tabular}{|c|c|c|c|c|c|}
\hline $\begin{array}{l}\text { Release } \\
\text { Number }\end{array}$ & $\begin{array}{l}\text { One half } \\
95 \% \mathrm{Cl} \\
\text { on S1 }\end{array}$ & $\begin{array}{l}\text { One-half } \\
95 \% \mathrm{Cl} \\
\text { on S2 }\end{array}$ & $\begin{array}{l}\text { One-half } \\
95 \% \mathrm{Cl} \\
\text { on P1 }\end{array}$ & $\begin{array}{l}\text { One-half } \\
95 \% \mathrm{Cl} \\
\text { on P2 }\end{array}$ & $\begin{array}{l}\text { One-half } \\
95 \% \mathrm{Cl} \\
\text { on Lamda }\end{array}$ \\
\hline 300 & 0.063798 & 0.094786 & 0.069796 & 0.083261 & 0.075774 \\
\hline 400 & 0.055252 & 0.082085 & 0.060446 & 0.072108 & 0.065621 \\
\hline 500 & 0.049412 & 0.073422 & 0.054057 & 0.064504 & 0.058702 \\
\hline 600 & 0.045100 & 0.067012 & 0.049353 & 0.058878 & 0.053586 \\
\hline 700 & 0.041768 & 0.062054 & 0.045688 & 0.054508 & 0.049608 \\
\hline 800 & 0.039063 & 0.058036 & 0.042728 & 0.050999 & 0.046413 \\
\hline 900 & 0.036828 & 0.054723 & 0.040298 & 0.048079 & 0.043747 \\
\hline 1000 & 0.034947 & 0.051920 & 0.038220 & 0.045609 & 0.041513 \\
\hline 1100 & 0.033320 & 0.049490 & 0.036436 & 0.043492 & 0.039572 \\
\hline 1200 & 0.031889 & 0.047393 & 0.034888 & 0.041630 & 0.037887 \\
\hline 1300 & 0.030654 & 0.045531 & 0.033516 & 0.040004 & 0.036397 \\
\hline 1400 & 0.029537 & 0.043884 & 0.032301 & 0.038553 & 0.035084 \\
\hline 1500 & 0.028538 & 0.042395 & 0.031203 & 0.037240 & 0.033888 \\
\hline 1600 & 0.027616 & 0.041042 & 0.030223 & 0.036064 & 0.032810 \\
\hline 1700 & 0.026793 & 0.039808 & 0.029322 & 0.034986 & 0.031830 \\
\hline 1800 & 0.026048 & 0.038690 & 0.028498 & 0.033986 & 0.030929 \\
\hline 1900 & 0.025343 & 0.037671 & 0.027734 & 0.033085 & 0.030106 \\
\hline 2000 & 0.024716 & 0.036711 & 0.027028 & 0.032242 & 0.029341 \\
\hline 2100 & 0.024108 & 0.035829 & 0.026382 & 0.031478 & 0.028636 \\
\hline 2200 & 0.023559 & 0.035006 & 0.025774 & 0.030752 & 0.027989 \\
\hline 2300 & 0.023030 & 0.034241 & 0.025206 & 0.030066 & 0.027362 \\
\hline 2400 & 0.022560 & 0.033516 & 0.024676 & 0.029439 & 0.026793 \\
\hline 2500 & 0.022089 & 0.032830 & 0.024167 & 0.028851 & 0.026244 \\
\hline 2600 & 0.021678 & 0.032203 & 0.023696 & 0.028283 & 0.025735 \\
\hline 2700 & 0.021266 & 0.031595 & 0.023265 & 0.027754 & 0.025264 \\
\hline 2800 & 0.020874 & 0.031027 & 0.022834 & 0.027264 & 0.024814 \\
\hline 3000 & 0.020168 & 0.029968 & 0.022070 & 0.026323 & 0.023971 \\
\hline
\end{tabular}


Table I.13. Predictions of One-half 95\% Confidence Intervals $(\mathrm{Cl})$ on Survival of Fish Traveling from the TDA Tailrace to Array 1T (S1) and from Array 1T to Array 1B (S2), on Associated Detection Probabilities P1 and P2, and on the Joint Probability $(\lambda)$ as a Function of Possible Total Numbers that Could be Released.

\begin{tabular}{|c|c|c|c|c|c|}
\hline $\begin{array}{l}\text { Release } \\
\text { Number }\end{array}$ & $\begin{array}{l}\text { One half } \\
95 \% \mathrm{Cl} \\
\text { on } \mathrm{S} 1\end{array}$ & $\begin{array}{l}\text { One-half } \\
95 \% \mathrm{Cl} \\
\text { on } \mathrm{S} 2\end{array}$ & $\begin{array}{l}\text { One-half } \\
95 \% \mathrm{Cl} \\
\text { on P1 }\end{array}$ & $\begin{array}{l}\text { One-half } \\
95 \% \mathrm{Cl} \\
\text { on P2 }\end{array}$ & $\begin{array}{l}\text { One-half } \\
95 \% \mathrm{Cl} \\
\text { on Lamda }\end{array}$ \\
\hline 300 & 0.011956 & 0.009898 & 0.017483 & 0.009075 & 0.009761 \\
\hline 400 & 0.010349 & 0.008585 & 0.015131 & 0.007860 & 0.008448 \\
\hline 500 & 0.009251 & 0.007664 & 0.013544 & 0.007017 & 0.007546 \\
\hline 600 & 0.008448 & 0.006997 & 0.012368 & 0.006409 & 0.006899 \\
\hline 700 & 0.007820 & 0.006488 & 0.011446 & 0.005939 & 0.006390 \\
\hline 800 & 0.007311 & 0.006056 & 0.010702 & 0.005547 & 0.005978 \\
\hline 900 & 0.006899 & 0.005723 & 0.010094 & 0.005233 & 0.005625 \\
\hline 1000 & 0.006546 & 0.005429 & 0.009584 & 0.004959 & 0.005351 \\
\hline 1100 & 0.006252 & 0.005174 & 0.009134 & 0.004743 & 0.005096 \\
\hline 1200 & 0.005978 & 0.004959 & 0.008742 & 0.004528 & 0.004880 \\
\hline 1300 & 0.005743 & 0.004763 & 0.008389 & 0.004351 & 0.004684 \\
\hline 1400 & 0.005527 & 0.004586 & 0.008095 & 0.004194 & 0.004508 \\
\hline 1500 & 0.005351 & 0.004430 & 0.007820 & 0.004057 & 0.004371 \\
\hline 1600 & 0.005174 & 0.004292 & 0.007566 & 0.003920 & 0.004214 \\
\hline 1700 & 0.005018 & 0.004155 & 0.007350 & 0.003802 & 0.004096 \\
\hline 1800 & 0.004880 & 0.004038 & 0.007134 & 0.003704 & 0.003979 \\
\hline 1900 & 0.004743 & 0.003940 & 0.006938 & 0.003606 & 0.003881 \\
\hline 2000 & 0.004626 & 0.003842 & 0.006762 & 0.003508 & 0.003783 \\
\hline 2100 & 0.004528 & 0.003744 & 0.006605 & 0.003430 & 0.003685 \\
\hline 2200 & 0.004410 & 0.003665 & 0.006448 & 0.003352 & 0.003606 \\
\hline 2300 & 0.004312 & 0.003567 & 0.006311 & 0.003273 & 0.003528 \\
\hline 2400 & 0.004234 & 0.003508 & 0.006174 & 0.003214 & 0.003450 \\
\hline 2500 & 0.004136 & 0.003430 & 0.006056 & 0.003136 & 0.003371 \\
\hline 2600 & 0.004057 & 0.003371 & 0.005939 & 0.003077 & 0.003312 \\
\hline 2700 & 0.003979 & 0.003293 & 0.005821 & 0.003018 & 0.003254 \\
\hline 2800 & 0.003920 & 0.003234 & 0.005723 & 0.002960 & 0.003195 \\
\hline 3000 & 0.003783 & 0.003136 & 0.005527 & 0.002862 & 0.003077 \\
\hline
\end{tabular}


Table I.14. Predictions of One-half 95\% Confidence Intervals $(\mathrm{Cl})$ on Survival of Fish Traveling from the TDA Tailrace to Array 1B (S1) and from Array 1B to Array 2B (S2), on Associated Detection Probabilities $\mathrm{P} 1$ and $\mathrm{P} 2$, and on the Joint Probability $(\lambda)$ as a Function of Possible Total Numbers that Could be Released.

\begin{tabular}{|c|c|c|c|c|c|}
\hline $\begin{array}{l}\text { Release } \\
\text { Number }\end{array}$ & $\begin{array}{l}\text { One half } \\
95 \% \mathrm{Cl} \\
\text { on } \mathrm{S} 1\end{array}$ & $\begin{array}{l}\text { One-half } \\
95 \% \mathrm{Cl} \\
\text { on } \mathrm{S} 2\end{array}$ & $\begin{array}{l}\text { One-half } \\
95 \% \mathrm{Cl} \\
\text { on P1 }\end{array}$ & $\begin{array}{l}\text { One-half } \\
95 \% \mathrm{Cl} \\
\text { on P2 }\end{array}$ & $\begin{array}{l}\text { One-half } \\
95 \% \mathrm{Cl} \\
\text { on Lamda }\end{array}$ \\
\hline 300 & 0.051489 & 0.102020 & 0.063622 & 0.083182 & 0.073186 \\
\hline 400 & 0.044590 & 0.088340 & 0.055096 & 0.072050 & 0.063386 \\
\hline 500 & 0.039886 & 0.079030 & 0.049274 & 0.064445 & 0.056683 \\
\hline 600 & 0.036417 & 0.072130 & 0.044982 & 0.058820 & 0.051744 \\
\hline 700 & 0.033712 & 0.066780 & 0.041650 & 0.054468 & 0.047902 \\
\hline 800 & 0.031536 & 0.062470 & 0.038965 & 0.050940 & 0.044825 \\
\hline 900 & 0.029733 & 0.058900 & 0.036730 & 0.048020 & 0.042258 \\
\hline 1000 & 0.028204 & 0.055880 & 0.034849 & 0.045570 & 0.040082 \\
\hline 1100 & 0.026891 & 0.053270 & 0.033222 & 0.043453 & 0.038220 \\
\hline 1200 & 0.025754 & 0.051000 & 0.031811 & 0.041591 & 0.036593 \\
\hline 1300 & 0.024735 & 0.049000 & 0.030556 & 0.039964 & 0.035162 \\
\hline 1400 & 0.023834 & 0.047220 & 0.029459 & 0.038514 & 0.033888 \\
\hline 1500 & 0.023030 & 0.045630 & 0.028459 & 0.037201 & 0.032732 \\
\hline 1600 & 0.022305 & 0.044180 & 0.027538 & 0.036025 & 0.031693 \\
\hline 1700 & 0.021638 & 0.042850 & 0.026734 & 0.034947 & 0.030752 \\
\hline 1800 & 0.021031 & 0.041650 & 0.025970 & 0.033967 & 0.029870 \\
\hline 1900 & 0.020462 & 0.040530 & 0.025284 & 0.033065 & 0.029086 \\
\hline 2000 & 0.019933 & 0.039510 & 0.024637 & 0.032222 & 0.028342 \\
\hline 2100 & 0.019463 & 0.038550 & 0.024049 & 0.031438 & 0.027656 \\
\hline 2200 & 0.019012 & 0.037670 & 0.023500 & 0.030713 & 0.027028 \\
\hline 2300 & 0.018600 & 0.036850 & 0.022971 & 0.030047 & 0.026440 \\
\hline 2400 & 0.018208 & 0.036060 & 0.022501 & 0.029420 & 0.025872 \\
\hline 2500 & 0.017836 & 0.035340 & 0.022030 & 0.028812 & 0.025362 \\
\hline 2600 & 0.017483 & 0.034650 & 0.021619 & 0.028263 & 0.024853 \\
\hline 2700 & 0.017170 & 0.034010 & 0.021207 & 0.027734 & 0.024402 \\
\hline 2800 & 0.016856 & 0.033400 & 0.020815 & 0.027224 & 0.023951 \\
\hline 3000 & 0.016288 & 0.032260 & 0.020110 & 0.026303 & 0.023148 \\
\hline
\end{tabular}


Table I.15. Predictions of One-half 95\% Confidence Intervals $(\mathrm{Cl})$ on Survival of Fish Traveling from the BON Tailrace to Array 1B (S1) and from Array 1B to Array 2B (S2), on Associated Detection Probabilities P1 and P2, and on the Joint Probability $(\lambda)$ as a Function of Possible Total Numbers that Could be Released.

\begin{tabular}{|c|c|c|c|c|c|}
\hline $\begin{array}{l}\text { Release } \\
\text { Number }\end{array}$ & $\begin{array}{l}\text { One half } \\
95 \% \mathrm{Cl} \\
\text { on S1 }\end{array}$ & $\begin{array}{l}\text { One-half } \\
95 \% \mathrm{Cl} \\
\text { on } \mathrm{S} 2\end{array}$ & $\begin{array}{l}\text { One-half } \\
95 \% \mathrm{Cl} \\
\text { on P1 }\end{array}$ & $\begin{array}{l}\text { One-half } \\
95 \% \mathrm{Cl} \\
\text { on P2 }\end{array}$ & $\begin{array}{l}\text { One-half } \\
95 \% \mathrm{Cl} \\
\text { on Lamda }\end{array}$ \\
\hline 300 & 0.047765 & 0.078439 & 0.057173 & 0.076381 & 0.071030 \\
\hline 400 & 0.041376 & 0.067934 & 0.049529 & 0.066150 & 0.061505 \\
\hline 500 & 0.037005 & 0.060760 & 0.044296 & 0.059153 & 0.055017 \\
\hline 600 & 0.033771 & 0.055468 & 0.040435 & 0.053998 & 0.050215 \\
\hline 700 & 0.031262 & 0.051352 & 0.037436 & 0.050000 & 0.046491 \\
\hline 800 & 0.029243 & 0.048040 & 0.035025 & 0.046766 & 0.043492 \\
\hline 900 & 0.027577 & 0.045296 & 0.033006 & 0.044100 & 0.041003 \\
\hline 1000 & 0.026166 & 0.042963 & 0.031321 & 0.041826 & 0.038906 \\
\hline 1100 & 0.024951 & 0.040964 & 0.029870 & 0.039886 & 0.037083 \\
\hline 1200 & 0.023892 & 0.039220 & 0.028596 & 0.038181 & 0.035515 \\
\hline 1300 & 0.022952 & 0.037691 & 0.027460 & 0.036691 & 0.034124 \\
\hline 1400 & 0.022109 & 0.036319 & 0.026460 & 0.035358 & 0.032869 \\
\hline 1500 & 0.021364 & 0.035084 & 0.025578 & 0.034163 & 0.031772 \\
\hline 1600 & 0.020678 & 0.033967 & 0.024755 & 0.033065 & 0.030752 \\
\hline 1700 & 0.020070 & 0.032948 & 0.024030 & 0.032085 & 0.029831 \\
\hline 1800 & 0.019502 & 0.032026 & 0.023344 & 0.031184 & 0.028988 \\
\hline 1900 & 0.018973 & 0.031164 & 0.022716 & 0.030341 & 0.028224 \\
\hline 2000 & 0.018502 & 0.030380 & 0.022148 & 0.029576 & 0.027499 \\
\hline 2100 & 0.018052 & 0.029655 & 0.021619 & 0.028871 & 0.026852 \\
\hline 2200 & 0.017640 & 0.028969 & 0.021109 & 0.028204 & 0.026225 \\
\hline 2300 & 0.017248 & 0.028342 & 0.020658 & 0.027577 & 0.025656 \\
\hline 2400 & 0.016895 & 0.027734 & 0.020208 & 0.027009 & 0.025108 \\
\hline 2500 & 0.016542 & 0.027166 & 0.019816 & 0.026460 & 0.024598 \\
\hline 2600 & 0.016229 & 0.026656 & 0.019424 & 0.025950 & 0.024128 \\
\hline 2700 & 0.015915 & 0.026146 & 0.019051 & 0.025460 & 0.023677 \\
\hline 2800 & 0.015641 & 0.025676 & 0.018718 & 0.025010 & 0.023246 \\
\hline 3000 & 0.015112 & 0.024814 & 0.018091 & 0.024147 & 0.022462 \\
\hline
\end{tabular}


Table I.16. Predictions of One-half $95 \%$ Confidence Intervals $(\mathrm{Cl})$ on Survival of Fish Traveling from the BON B2CC to Array 1B (S1) and from Array 1B to Array 2B (S2), on Associated Detection Probabilities P1 and P2, and on the Joint Probability $(\lambda)$ as a Function of Possible Total Numbers that Could be Released.

\begin{tabular}{|c|c|c|c|c|c|}
\hline $\begin{array}{l}\text { Release } \\
\text { Number }\end{array}$ & $\begin{array}{l}\text { One half } \\
95 \% \mathrm{Cl} \\
\text { on S1 } \\
\end{array}$ & $\begin{array}{l}\text { One-half } \\
95 \% \mathrm{Cl} \\
\text { on S2 }\end{array}$ & $\begin{array}{l}\text { One-half } \\
95 \% \mathrm{Cl} \\
\text { on P1 }\end{array}$ & $\begin{array}{l}\text { One-half } \\
95 \% \mathrm{Cl} \\
\text { on P2 }\end{array}$ & $\begin{array}{l}\text { One-half } \\
95 \% \mathrm{Cl} \\
\text { on Lamda }\end{array}$ \\
\hline 300 & 0.050921 & 0.095609 & 0.063465 & 0.078204 & 0.074323 \\
\hline 400 & 0.044100 & 0.082790 & 0.054958 & 0.067738 & 0.064366 \\
\hline 500 & 0.039455 & 0.074049 & 0.049157 & 0.060584 & 0.057565 \\
\hline 600 & 0.036005 & 0.067600 & 0.044864 & 0.055292 & 0.052548 \\
\hline 700 & 0.033340 & 0.062583 & 0.041552 & 0.051195 & 0.048667 \\
\hline 800 & 0.031184 & 0.058545 & 0.038867 & 0.047883 & 0.045511 \\
\hline 900 & 0.029400 & 0.055194 & 0.036632 & 0.045158 & 0.042904 \\
\hline 1000 & 0.027891 & 0.052371 & 0.034751 & 0.042846 & 0.040709 \\
\hline 1100 & 0.026597 & 0.049921 & 0.033144 & 0.040846 & 0.038808 \\
\hline 1200 & 0.025460 & 0.047804 & 0.031732 & 0.039102 & 0.037162 \\
\hline 1300 & 0.024461 & 0.045923 & 0.030478 & 0.037573 & 0.035711 \\
\hline 1400 & 0.023579 & 0.044257 & 0.029380 & 0.036201 & 0.034398 \\
\hline 1500 & 0.022775 & 0.042767 & 0.028381 & 0.034966 & 0.033242 \\
\hline 1600 & 0.022050 & 0.041395 & 0.027479 & 0.033869 & 0.032183 \\
\hline 1700 & 0.021384 & 0.040160 & 0.026656 & 0.032850 & 0.031223 \\
\hline 1800 & 0.020796 & 0.039024 & 0.025911 & 0.031928 & 0.030341 \\
\hline 1900 & 0.020227 & 0.037985 & 0.025206 & 0.031086 & 0.029537 \\
\hline 2000 & 0.019718 & 0.037024 & 0.024578 & 0.030282 & 0.028792 \\
\hline 2100 & 0.019247 & 0.036142 & 0.023990 & 0.029557 & 0.028087 \\
\hline 2200 & 0.018796 & 0.035300 & 0.023442 & 0.028871 & 0.027440 \\
\hline 2300 & 0.018385 & 0.034535 & 0.022912 & 0.028244 & 0.026852 \\
\hline 2400 & 0.018012 & 0.033810 & 0.022442 & 0.027656 & 0.026284 \\
\hline 2500 & 0.017640 & 0.033124 & 0.021991 & 0.027087 & 0.025754 \\
\hline 2600 & 0.017307 & 0.032477 & 0.021560 & 0.026558 & 0.025245 \\
\hline 2700 & 0.016974 & 0.031870 & 0.021148 & 0.026068 & 0.024774 \\
\hline 2800 & 0.016660 & 0.031301 & 0.020776 & 0.025598 & 0.024324 \\
\hline 3000 & 0.016111 & 0.030243 & 0.020070 & 0.024735 & 0.023500 \\
\hline
\end{tabular}


Table I.17. Predictions of One-half $95 \%$ Confidence Intervals $(\mathrm{Cl})$ on Survival of Fish Traveling from the B2 JBS to Array 1B (S1) and from Array 1B to Array 2B (S2), on Associated Detection Probabilities P1 and P2, and on the Joint Probability $(\lambda)$ as a Function of Possible Total Numbers that Could be Released.

\begin{tabular}{|c|c|c|c|c|c|}
\hline $\begin{array}{l}\text { Release } \\
\text { Number }\end{array}$ & $\begin{array}{l}\text { One half } \\
95 \% \mathrm{Cl} \\
\text { on S1 } \\
\end{array}$ & $\begin{array}{l}\text { One-half } \\
95 \% \mathrm{Cl} \\
\text { on S2 }\end{array}$ & $\begin{array}{l}\text { One-half } \\
95 \% \mathrm{Cl} \\
\text { on P1 }\end{array}$ & $\begin{array}{l}\text { One-half } \\
95 \% \mathrm{Cl} \\
\text { on P2 }\end{array}$ & $\begin{array}{l}\text { One-half } \\
95 \% \mathrm{Cl} \\
\text { on Lamda }\end{array}$ \\
\hline 300 & 0.061054 & 0.175660 & 0.066797 & 0.091669 & 0.075205 \\
\hline 400 & 0.052861 & 0.152120 & 0.057840 & 0.079400 & 0.065131 \\
\hline 500 & 0.047295 & 0.136060 & 0.051744 & 0.071011 & 0.058251 \\
\hline 600 & 0.043159 & 0.124210 & 0.047236 & 0.064817 & 0.053175 \\
\hline 700 & 0.039964 & 0.114990 & 0.043728 & 0.060015 & 0.049235 \\
\hline 800 & 0.037377 & 0.107560 & 0.040905 & 0.056134 & 0.046060 \\
\hline 900 & 0.035241 & 0.101410 & 0.038573 & 0.052920 & 0.043434 \\
\hline 1000 & 0.033438 & 0.096220 & 0.036593 & 0.050215 & 0.041199 \\
\hline 1100 & 0.031889 & 0.091730 & 0.034888 & 0.047883 & 0.039278 \\
\hline 1200 & 0.030517 & 0.087830 & 0.033398 & 0.045844 & 0.037612 \\
\hline 1300 & 0.029322 & 0.084380 & 0.032085 & 0.044041 & 0.036123 \\
\hline 1400 & 0.028263 & 0.081320 & 0.030929 & 0.042434 & 0.034810 \\
\hline 1500 & 0.027303 & 0.078560 & 0.029870 & 0.041003 & 0.033634 \\
\hline 1600 & 0.026440 & 0.076070 & 0.028930 & 0.039690 & 0.032575 \\
\hline 1700 & 0.025637 & 0.073790 & 0.028067 & 0.038514 & 0.031595 \\
\hline 1800 & 0.024931 & 0.071720 & 0.027264 & 0.037436 & 0.030713 \\
\hline 1900 & 0.024265 & 0.069800 & 0.026538 & 0.036436 & 0.029890 \\
\hline 2000 & 0.023638 & 0.068030 & 0.025872 & 0.035515 & 0.029126 \\
\hline 2100 & 0.023069 & 0.066390 & 0.025245 & 0.034653 & 0.028420 \\
\hline 2200 & 0.022540 & 0.064860 & 0.024676 & 0.033849 & 0.027773 \\
\hline 2300 & 0.022050 & 0.063450 & 0.024128 & 0.033104 & 0.027166 \\
\hline 2400 & 0.021580 & 0.062110 & 0.023618 & 0.032418 & 0.026597 \\
\hline 2500 & 0.021148 & 0.060860 & 0.023148 & 0.031752 & 0.026048 \\
\hline 2600 & 0.020737 & 0.059660 & 0.022697 & 0.031144 & 0.025539 \\
\hline 2700 & 0.020345 & 0.058550 & 0.022266 & 0.030556 & 0.025068 \\
\hline 2800 & 0.019992 & 0.057510 & 0.021874 & 0.030008 & 0.024618 \\
\hline 3000 & 0.019306 & 0.055550 & 0.021129 & 0.028988 & 0.023775 \\
\hline
\end{tabular}


Table I.18. Predictions of One-half 95\% Confidence Intervals $(\mathrm{Cl})$ on Survival of Fish Traveling from the BON Spillway to Array 1B (S1) and from Array 1B to Array 2B (S2), on Associated Detection Probabilities P1 and P2, and on the Joint Probability $(\lambda)$ as a Function of Possible Total Numbers that Could be Released.

\begin{tabular}{|c|c|c|c|c|c|}
\hline $\begin{array}{l}\text { Release } \\
\text { Number }\end{array}$ & $\begin{array}{l}\text { One half } \\
95 \% \mathrm{Cl} \\
\text { on S1 } \\
\end{array}$ & $\begin{array}{l}\text { One-half } \\
95 \% \mathrm{Cl} \\
\text { on S2 } \\
\end{array}$ & $\begin{array}{l}\text { One-half } \\
95 \% \mathrm{Cl} \\
\text { on P1 }\end{array}$ & $\begin{array}{l}\text { One-half } \\
95 \% \mathrm{Cl} \\
\text { on } \mathrm{P2} \\
\end{array}$ & $\begin{array}{l}\text { One-half } \\
95 \% \mathrm{Cl} \\
\text { on Lamda }\end{array}$ \\
\hline 300 & 0.046746 & 0.114820 & 0.061858 & 0.084456 & 0.071540 \\
\hline 400 & 0.040474 & 0.099430 & 0.053567 & 0.073147 & 0.061956 \\
\hline 500 & 0.036201 & 0.088940 & 0.047902 & 0.065425 & 0.055429 \\
\hline 600 & 0.033046 & 0.081180 & 0.043728 & 0.059721 & 0.050588 \\
\hline 700 & 0.030596 & 0.075170 & 0.040494 & 0.055292 & 0.046844 \\
\hline 800 & 0.028616 & 0.070310 & 0.037867 & 0.051724 & 0.043806 \\
\hline 900 & 0.026989 & 0.066290 & 0.035711 & 0.048765 & 0.041317 \\
\hline 1000 & 0.025598 & 0.062900 & 0.033869 & 0.046256 & 0.039180 \\
\hline 1100 & 0.024402 & 0.059960 & 0.032301 & 0.044120 & 0.037358 \\
\hline 1200 & 0.023363 & 0.057410 & 0.030929 & 0.042238 & 0.035770 \\
\hline 1300 & 0.022462 & 0.055150 & 0.029714 & 0.040572 & 0.034378 \\
\hline 1400 & 0.021638 & 0.053160 & 0.028636 & 0.039102 & 0.033124 \\
\hline 1500 & 0.020894 & 0.051350 & 0.027656 & 0.037769 & 0.032007 \\
\hline 1600 & 0.020247 & 0.049730 & 0.026774 & 0.036574 & 0.030988 \\
\hline 1700 & 0.019639 & 0.048240 & 0.025990 & 0.035476 & 0.030047 \\
\hline 1800 & 0.019090 & 0.046880 & 0.025245 & 0.034476 & 0.029204 \\
\hline 1900 & 0.018581 & 0.045630 & 0.024578 & 0.033555 & 0.028440 \\
\hline 2000 & 0.018110 & 0.044470 & 0.023951 & 0.032712 & 0.027714 \\
\hline 2100 & 0.017660 & 0.043390 & 0.023383 & 0.031928 & 0.027048 \\
\hline 2200 & 0.017268 & 0.042390 & 0.022834 & 0.031184 & 0.026421 \\
\hline 2300 & 0.016876 & 0.041470 & 0.022344 & 0.030498 & 0.025833 \\
\hline 2400 & 0.016523 & 0.040590 & 0.021874 & 0.029870 & 0.025304 \\
\hline 2500 & 0.016190 & 0.039770 & 0.021423 & 0.029263 & 0.024794 \\
\hline 2600 & 0.015876 & 0.039000 & 0.021011 & 0.028694 & 0.024304 \\
\hline 2700 & 0.015582 & 0.038280 & 0.020619 & 0.028146 & 0.023853 \\
\hline 2800 & 0.015308 & 0.037590 & 0.020247 & 0.027656 & 0.023422 \\
\hline 3000 & 0.014778 & 0.036320 & 0.019561 & 0.026715 & 0.022618 \\
\hline
\end{tabular}




\section{Appendix J}

Model Estimates of One-Half 95\% Confidence Intervals on Detection and Survival Statistics for Yearling Chinook Salmon Based on Paired-Release Survival Models for Spring 2006 
Acoustic Telemetry Studies of Juvenile Chinook Salmon Survival at the Lower Columbia Projects in 2006 


\section{Appendix J}

\section{Model Estimates of One-Half 95\% Confidence Intervals on Detection and Survival Statistics for Yearling Chinook Salmon Based on Paired-Release Survival Models for Spring 2006}

All predicted estimates of 95\% confidence intervals (CI) are based upon spring 2006 estimates of survival and detection probabilities, and sample-size estimates associated with a one-half $95 \%$ CIs of about $2 \%$, $3 \%, 4 \%$, and $5 \%$ on the primary-array survival of treatment fish (S1 in the third column) are highlighted when listed.

Table J.1. Predictions of One-half 95\% Confidence Intervals (Cl) on Survivals of Control and Treatment Fish Traveling to Array $1 \mathrm{~J}$ (S1) and from Array 1J to Array 1T (S2), on Associated Detection Probabilities P1 and P2, and on the Joint Probabilities $(\lambda)$ as a Function of Possible Total Numbers that Could be Released. Release locations include a turbine (treatment) and the front roll (controls) to assess turbine survival.

\begin{tabular}{|c|c|c|c|c|c|c|c|c|c|c|}
\hline $\begin{array}{l}\text { Release } \\
\text { Number }\end{array}$ & $\begin{array}{c}\begin{array}{c}\text { One } \\
\text { half }\end{array} \\
95 \% \mathrm{Cl} \\
\text { on } \\
\text { Control } \\
\mathrm{S} 1 \\
\end{array}$ & $\begin{array}{c}\text { One half } \\
95 \% \mathrm{Cl} \\
\text { on } \\
\text { Treatment } \\
\text { S1 } \\
\end{array}$ & $\begin{array}{c}\begin{array}{c}\text { One } \\
\text { half }\end{array} \\
95 \% \mathrm{Cl} \\
\text { on } \\
\text { Control } \\
\mathrm{S} 2 \\
\end{array}$ & $\begin{array}{c}\text { One half } \\
95 \% \mathrm{Cl} \\
\text { on } \\
\text { Treatment } \\
\text { S2 } \\
\end{array}$ & $\begin{array}{c}\begin{array}{c}\text { One } \\
\text { half }\end{array} \\
95 \% \mathrm{Cl} \\
\text { on } \\
\text { Control } \\
\text { P1 } \\
\end{array}$ & $\begin{array}{c}\text { One half } \\
95 \% \mathrm{Cl} \\
\text { on } \\
\text { Treatment } \\
\text { P1 } \\
\end{array}$ & $\begin{array}{c}\begin{array}{c}\text { One } \\
\text { half }\end{array} \\
95 \% \mathrm{Cl} \\
\text { on } \\
\text { Control } \\
\text { P2 } \\
\end{array}$ & $\begin{array}{c}\text { One half } \\
95 \% \mathrm{Cl} \\
\text { on } \\
\text { Treatment } \\
\text { P2 } \\
\end{array}$ & $\begin{array}{c}\begin{array}{c}\text { One } \\
\text { half }\end{array} \\
95 \% \mathrm{Cl} \\
\text { on } \\
\text { Control } \\
\text { Lamda } \\
\end{array}$ & $\begin{array}{c}\text { One half } \\
95 \% \mathrm{Cl} \\
\text { on } \\
\text { Treatment } \\
\text { Lamda } \\
\end{array}$ \\
\hline 300 & 0.016033 & 0.044139 & 0.028832 & 0.031046 & 0.014641 & 0.015758 & 0.043473 & 0.046805 & 0.054312 & 0.058467 \\
\hline 400 & 0.013877 & 0.038220 & 0.024970 & 0.026891 & 0.012681 & 0.013642 & 0.037652 & 0.040533 & 0.047020 & 0.050627 \\
\hline 500 & 0.012426 & 0.034182 & 0.022324 & 0.024049 & 0.011329 & 0.012211 & 0.033673 & 0.036260 & 0.042062 & 0.045296 \\
\hline 600 & 0.011329 & 0.031203 & 0.020384 & 0.021952 & 0.010349 & 0.011152 & 0.030733 & 0.033104 & 0.038396 & 0.041336 \\
\hline 700 & 0.010506 & 0.028890 & 0.018875 & 0.020325 & 0.009584 & 0.010310 & 0.028459 & 0.030635 & 0.035554 & 0.038279 \\
\hline 800 & 0.009820 & 0.027028 & 0.017660 & 0.019012 & 0.008957 & 0.009643 & 0.026617 & 0.028655 & 0.033261 & 0.035809 \\
\hline 900 & 0.009251 & 0.025480 & 0.016640 & 0.017914 & 0.008448 & 0.009094 & 0.025108 & 0.027028 & 0.031360 & 0.033751 \\
\hline 1000 & 0.008781 & 0.024167 & 0.015798 & 0.017013 & 0.008016 & 0.008624 & 0.023814 & 0.025637 & 0.029733 & 0.032026 \\
\hline 1100 & 0.008369 & 0.023050 & 0.015053 & 0.016209 & 0.007644 & 0.008232 & 0.022697 & 0.024441 & 0.028361 & 0.030537 \\
\hline 1200 & 0.008016 & 0.022070 & 0.014426 & 0.015523 & 0.007311 & 0.007879 & 0.021736 & 0.023402 & 0.027146 & 0.029243 \\
\hline 1300 & 0.007703 & 0.021207 & 0.013857 & 0.014916 & 0.007036 & 0.007566 & 0.020894 & 0.022481 & 0.026088 & 0.028087 \\
\hline 1400 & 0.007428 & 0.020423 & 0.013348 & 0.014367 & 0.006782 & 0.007291 & 0.020129 & 0.021678 & 0.025127 & 0.027068 \\
\hline 1500 & 0.007174 & 0.019737 & 0.012897 & 0.013877 & 0.006546 & 0.007056 & 0.019443 & 0.020933 & 0.024284 & 0.026146 \\
\hline 1600 & 0.006938 & 0.019110 & 0.012485 & 0.013446 & 0.006331 & 0.006821 & 0.018816 & 0.020266 & 0.023520 & 0.025323 \\
\hline 1700 & 0.006742 & 0.018542 & 0.012113 & 0.013034 & 0.006154 & 0.006625 & 0.018267 & 0.019659 & 0.022814 & 0.024559 \\
\hline 1800 & 0.006546 & 0.018012 & 0.011780 & 0.012681 & 0.005978 & 0.006429 & 0.017758 & 0.019110 & 0.022168 & 0.023873 \\
\hline 1900 & 0.006370 & 0.017542 & 0.011466 & 0.012328 & 0.005821 & 0.006252 & 0.017268 & 0.018600 & 0.021580 & 0.023226 \\
\hline 2000 & 0.006213 & 0.017091 & 0.011172 & 0.012015 & 0.005664 & 0.006096 & 0.016836 & 0.018130 & 0.021031 & 0.022638 \\
\hline 2100 & 0.006056 & 0.016680 & 0.010898 & 0.011740 & 0.005527 & 0.005958 & 0.016425 & 0.017699 & 0.020521 & 0.022089 \\
\hline 2200 & 0.005919 & 0.016288 & 0.010643 & 0.011466 & 0.005410 & 0.005821 & 0.016052 & 0.017287 & 0.020051 & 0.021599 \\
\hline 2300 & 0.005782 & 0.015935 & 0.010408 & 0.011211 & 0.005292 & 0.005684 & 0.015700 & 0.016915 & 0.019620 & 0.021109 \\
\hline 2400 & 0.005664 & 0.015602 & 0.010192 & 0.010976 & 0.005174 & 0.005566 & 0.015366 & 0.016542 & 0.019208 & 0.020678 \\
\hline 2500 & 0.005547 & 0.015288 & 0.009996 & 0.010760 & 0.005076 & 0.005468 & 0.015053 & 0.016209 & 0.018816 & 0.020247 \\
\hline 2600 & 0.005449 & 0.014994 & 0.009800 & 0.010545 & 0.004978 & 0.005351 & 0.014759 & 0.015896 & 0.018444 & 0.019855 \\
\hline 2700 & 0.005351 & 0.014720 & 0.009604 & 0.010349 & 0.004880 & 0.005253 & 0.014484 & 0.015602 & 0.018110 & 0.019482 \\
\hline 2800 & 0.005253 & 0.014445 & 0.009447 & 0.010153 & 0.004782 & 0.005155 & 0.014230 & 0.015327 & 0.017777 & 0.019130 \\
\hline 2900 & 0.005155 & 0.014190 & 0.009271 & 0.009976 & 0.004704 & 0.005076 & 0.013975 & 0.015053 & 0.017464 & 0.018796 \\
\hline 3000 & 0.005076 & 0.013955 & 0.009114 & 0.009820 & 0.004626 & 0.004978 & 0.013740 & 0.014798 & 0.017170 & 0.018483 \\
\hline
\end{tabular}


Table J.2. Predictions of One-half 95\% Confidence Intervals $(\mathrm{Cl})$ on Survivals of Control and Treatment Fish Traveling to Array 1T (S1) and from Array 1T to Array 2T (S2), on Associated Detection Probabilities $\mathrm{P} 1$ and $\mathrm{P} 2$, and on the Joint Probabilities $(\lambda)$ as a Function of Possible Total Numbers that Could be Released. Release locations include the JDA Tailrace (treatment) and TDA Tailrace (controls) to assess TDA survival.

\begin{tabular}{|c|c|c|c|c|c|c|c|c|c|c|}
\hline $\begin{array}{l}\text { Release } \\
\text { Number }\end{array}$ & $\begin{array}{c}\text { One } \\
\text { half } \\
95 \% \mathrm{Cl} \\
\text { on } \\
\text { Control } \\
\text { S1 } \\
\end{array}$ & $\begin{array}{l}\text { One half } \\
95 \% \mathrm{Cl} \\
\text { on } \\
\text { Treatment } \\
\text { S1 }\end{array}$ & $\begin{array}{c}\text { One } \\
\text { half } \\
95 \% \mathrm{Cl} \\
\text { on } \\
\text { Control } \\
\text { S2 } \\
\end{array}$ & $\begin{array}{c}\text { One half } \\
95 \% \mathrm{Cl} \\
\text { on } \\
\text { Treatment } \\
\text { S2 }\end{array}$ & $\begin{array}{c}\text { One } \\
\text { half } \\
95 \% \mathrm{Cl} \\
\text { on } \\
\text { Control } \\
\text { P1 }\end{array}$ & $\begin{array}{l}\text { One half } \\
95 \% \mathrm{Cl} \\
\text { on } \\
\text { Treatment } \\
\text { P1 }\end{array}$ & $\begin{array}{c}\text { One } \\
\text { half } \\
95 \% \mathrm{Cl} \\
\text { on } \\
\text { Control } \\
\text { P2 }\end{array}$ & $\begin{array}{c}\text { One half } \\
95 \% \mathrm{Cl} \\
\text { on } \\
\text { Treatment } \\
\text { P2 }\end{array}$ & $\begin{array}{c}\text { One } \\
\text { half } \\
95 \% \mathrm{Cl} \\
\text { on } \\
\text { Control } \\
\text { Lamda } \\
\end{array}$ & $\begin{array}{c}\text { One half } \\
95 \% \mathrm{Cl} \\
\text { on } \\
\text { Treatment } \\
\text { Lamda }\end{array}$ \\
\hline 300 & 0.012446 & 0.042101 & 0.015249 & 0.016425 & 0.028655 & 0.030850 & 0.009114 & 0.009820 & 0.009800 & 0.010545 \\
\hline 400 & 0.010780 & 0.036456 & 0.013210 & 0.014210 & 0.024814 & 0.026715 & 0.007899 & 0.008506 & 0.008487 & 0.009134 \\
\hline 500 & 0.009643 & 0.032614 & 0.011819 & 0.012720 & 0.022187 & 0.023892 & 0.007056 & 0.007605 & 0.007585 & 0.008173 \\
\hline 600 & 0.008800 & 0.029772 & 0.010780 & 0.011603 & 0.020266 & 0.021815 & 0.006448 & 0.006938 & 0.006938 & 0.007468 \\
\hline 700 & 0.008154 & 0.027558 & 0.009976 & 0.010741 & 0.018757 & 0.020208 & 0.005958 & 0.006429 & 0.006409 & 0.006899 \\
\hline 800 & 0.007624 & 0.025774 & 0.009330 & 0.010055 & 0.017542 & 0.018894 & 0.005586 & 0.006017 & 0.005998 & 0.006468 \\
\hline 900 & 0.007193 & 0.024304 & 0.008800 & 0.009486 & 0.016542 & 0.017816 & 0.005253 & 0.005664 & 0.005664 & 0.006096 \\
\hline 1000 & 0.006821 & 0.023050 & 0.008350 & 0.008996 & 0.015700 & 0.016895 & 0.004998 & 0.005370 & 0.005370 & 0.005782 \\
\hline 1100 & 0.006507 & 0.021991 & 0.007958 & 0.008565 & 0.014974 & 0.016111 & 0.004763 & 0.005116 & 0.005116 & 0.005508 \\
\hline 1200 & 0.006233 & 0.021050 & 0.007624 & 0.008212 & 0.014328 & 0.015425 & 0.004567 & 0.004900 & 0.004900 & 0.005272 \\
\hline 1300 & 0.005978 & 0.020227 & 0.007330 & 0.007879 & 0.013759 & 0.014818 & 0.004371 & 0.004724 & 0.004704 & 0.005076 \\
\hline 1400 & 0.005762 & 0.019482 & 0.007056 & 0.007605 & 0.013269 & 0.014288 & 0.004214 & 0.004547 & 0.004528 & 0.004880 \\
\hline 1500 & 0.005566 & 0.018836 & 0.006821 & 0.007350 & 0.012818 & 0.013798 & 0.004077 & 0.004390 & 0.004390 & 0.004724 \\
\hline 1600 & 0.005390 & 0.018228 & 0.006605 & 0.007115 & 0.012407 & 0.013367 & 0.003940 & 0.004253 & 0.004253 & 0.004567 \\
\hline 1700 & 0.005233 & 0.017679 & 0.006409 & 0.006899 & 0.012034 & 0.012956 & 0.003822 & 0.004116 & 0.004116 & 0.004430 \\
\hline 1800 & 0.005076 & 0.017189 & 0.006233 & 0.006703 & 0.011701 & 0.012603 & 0.003724 & 0.003998 & 0.003998 & 0.004312 \\
\hline 1900 & 0.004939 & 0.016738 & 0.006056 & 0.006527 & 0.011388 & 0.012270 & 0.003626 & 0.003900 & 0.003900 & 0.004194 \\
\hline 2000 & 0.004822 & 0.016307 & 0.005900 & 0.006350 & 0.011094 & 0.011956 & 0.003528 & 0.003802 & 0.003802 & 0.004096 \\
\hline 2100 & 0.004704 & 0.015915 & 0.005762 & 0.006213 & 0.010839 & 0.011662 & 0.003450 & 0.003704 & 0.003704 & 0.003979 \\
\hline 2200 & 0.004606 & 0.015543 & 0.005625 & 0.006056 & 0.010584 & 0.011388 & 0.003371 & 0.003626 & 0.003626 & 0.003900 \\
\hline 2300 & 0.004488 & 0.015210 & 0.005508 & 0.005939 & 0.010349 & 0.011152 & 0.003293 & 0.003548 & 0.003548 & 0.003802 \\
\hline 2400 & 0.004410 & 0.014876 & 0.005390 & 0.005802 & 0.010133 & 0.010917 & 0.003214 & 0.003469 & 0.003469 & 0.003724 \\
\hline 2500 & 0.004312 & 0.014582 & 0.005272 & 0.005684 & 0.009918 & 0.010682 & 0.003156 & 0.003391 & 0.003391 & 0.003665 \\
\hline 2600 & 0.004234 & 0.014308 & 0.005174 & 0.005586 & 0.009741 & 0.010486 & 0.003097 & 0.003332 & 0.003332 & 0.003587 \\
\hline 2700 & 0.004155 & 0.014034 & 0.005076 & 0.005468 & 0.009545 & 0.010290 & 0.003038 & 0.003273 & 0.003273 & 0.003508 \\
\hline 2800 & 0.004077 & 0.013779 & 0.004998 & 0.005370 & 0.009388 & 0.010094 & 0.002979 & 0.003214 & 0.003214 & 0.003450 \\
\hline 2900 & 0.003998 & 0.013544 & 0.004900 & 0.005272 & 0.009212 & 0.009918 & 0.002940 & 0.003156 & 0.003156 & 0.003391 \\
\hline 3000 & 0.003940 & 0.013308 & 0.004822 & 0.005194 & 0.009055 & 0.009761 & 0.002881 & 0.003097 & 0.003097 & 0.003332 \\
\hline 3100 & 0.003881 & 0.013093 & 0.004743 & 0.005116 & 0.008918 & 0.009604 & 0.002842 & 0.003058 & 0.003058 & 0.003273 \\
\hline 3200 & 0.003822 & 0.012897 & 0.004665 & 0.005018 & 0.008781 & 0.009447 & 0.002783 & 0.002999 & 0.002999 & 0.003234 \\
\hline 3300 & 0.003763 & 0.012701 & 0.004606 & 0.004959 & 0.008644 & 0.009310 & 0.002744 & 0.002960 & 0.002960 & 0.003175 \\
\hline 3400 & 0.003704 & 0.012505 & 0.004528 & 0.004880 & 0.008506 & 0.009173 & 0.002705 & 0.002920 & 0.002920 & 0.003136 \\
\hline 3500 & 0.003646 & 0.012328 & 0.004469 & 0.004802 & 0.008389 & 0.009036 & 0.002666 & 0.002881 & 0.002862 & 0.003097 \\
\hline 3600 & 0.003587 & 0.012152 & 0.004410 & 0.004743 & 0.008271 & 0.008898 & 0.002626 & 0.002842 & 0.002822 & 0.003038 \\
\hline 3700 & 0.003548 & 0.011995 & 0.004351 & 0.004684 & 0.008154 & 0.008781 & 0.002587 & 0.002803 & 0.002783 & 0.002999 \\
\hline 3800 & 0.003489 & 0.011838 & 0.004292 & 0.004606 & 0.008056 & 0.008663 & 0.002568 & 0.002764 & 0.002744 & 0.002960 \\
\hline 3900 & 0.003450 & 0.011682 & 0.004234 & 0.004547 & 0.007938 & 0.008565 & 0.002528 & 0.002724 & 0.002724 & 0.002920 \\
\hline 4000 & 0.003410 & 0.011525 & 0.004175 & 0.004488 & 0.007840 & 0.008448 & 0.002489 & 0.002685 & 0.002685 & 0.002881 \\
\hline 4100 & 0.003371 & 0.011388 & 0.004116 & 0.004449 & 0.007742 & 0.008350 & 0.002470 & 0.002646 & 0.002646 & 0.002862 \\
\hline 4200 & 0.003332 & 0.011250 & 0.004077 & 0.004390 & 0.007664 & 0.008252 & 0.002430 & 0.002626 & 0.002626 & 0.002822 \\
\hline 4300 & 0.003293 & 0.011113 & 0.004018 & 0.004332 & 0.007566 & 0.008154 & 0.002411 & 0.002587 & 0.002587 & 0.002783 \\
\hline 4400 & 0.003254 & 0.010996 & 0.003979 & 0.004292 & 0.007487 & 0.008056 & 0.002372 & 0.002568 & 0.002568 & 0.002764 \\
\hline 4500 & 0.003214 & 0.010878 & 0.003940 & 0.004234 & 0.007389 & 0.007958 & 0.002352 & 0.002528 & 0.002528 & 0.002724 \\
\hline 4600 & 0.003175 & 0.010760 & 0.003900 & 0.004194 & 0.007311 & 0.007879 & 0.002332 & 0.002509 & 0.002509 & 0.002685 \\
\hline 4700 & 0.003136 & 0.010643 & 0.003861 & 0.004155 & 0.007232 & 0.007801 & 0.002293 & 0.002470 & 0.002470 & 0.002666 \\
\hline 4800 & 0.003116 & 0.010525 & 0.003802 & 0.004096 & 0.007174 & 0.007722 & 0.002274 & 0.002450 & 0.002450 & 0.002646 \\
\hline 5000 & 0.003058 & 0.010310 & 0.003744 & 0.004018 & 0.007017 & 0.007566 & 0.002234 & 0.002411 & 0.002391 & 0.002587 \\
\hline
\end{tabular}


Table J.3. Predictions of One-half 95\% Confidence Intervals $(\mathrm{Cl})$ on Survivals of Control and Treatment Fish Traveling to Array 1B (S1) and from Array 1B to Array 2B (S2), on Associated Detection Probabilities $P 1$ and $P 2$, and on the Joint Probabilities $(\lambda)$ as a Function of Possible Total Numbers that Could be Released. Release locations include the TDA Tailrace (treatment) and BON Tailrace (controls) to assess BON survival.

\begin{tabular}{|c|c|c|c|c|c|c|c|c|c|c|}
\hline $\begin{array}{l}\text { Release } \\
\text { Number }\end{array}$ & $\begin{array}{c}\text { One } \\
\text { half } \\
95 \% \mathrm{Cl} \\
\text { on } \\
\text { Control } \\
\text { S1 } \\
\end{array}$ & $\begin{array}{c}\text { One half } \\
95 \% \mathrm{Cl} \\
\text { on } \\
\text { Treatment } \\
\text { S1 }\end{array}$ & $\begin{array}{c}\text { One } \\
\text { half } \\
95 \% \mathrm{Cl} \\
\text { on } \\
\text { Control } \\
\text { S2 } \\
\end{array}$ & $\begin{array}{l}\text { One half } \\
95 \% \mathrm{Cl} \\
\text { on } \\
\text { Treatment } \\
\text { S2 }\end{array}$ & $\begin{array}{c}\text { One } \\
\text { half } \\
95 \% \mathrm{Cl} \\
\text { on } \\
\text { Control } \\
\text { P1 } \\
\end{array}$ & $\begin{array}{l}\text { One half } \\
95 \% \mathrm{Cl} \\
\text { on } \\
\text { Treatment } \\
\text { P1 }\end{array}$ & $\begin{array}{c}\text { One } \\
\text { half } \\
95 \% \mathrm{Cl} \\
\text { on } \\
\text { Control } \\
\text { P2 } \\
\end{array}$ & $\begin{array}{l}\text { One half } \\
95 \% \mathrm{Cl} \\
\text { on } \\
\text { Treatment } \\
\text { P2 }\end{array}$ & $\begin{array}{c}\text { One } \\
\text { half } \\
95 \% \mathrm{Cl} \\
\text { on } \\
\text { Control } \\
\text { Lamda } \\
\end{array}$ & $\begin{array}{c}\text { One half } \\
95 \% \mathrm{Cl} \\
\text { on } \\
\text { Treatment } \\
\text { Lamda }\end{array}$ \\
\hline 300 & 0.058526 & $\begin{array}{c}0.096197 \\
\end{array}$ & "0.107530 & "0.113330 & "0.067032 & "0.070658 & 0.087651 & "0.092394 & $\begin{array}{c}0.077126 \\
\end{array}$ & 0.081301 \\
\hline 400 & 0.050686 & 0.083300 & 0.093120 & 0.098160 & 0.058055 & 0.061191 & 0.075911 & 0.080027 & 0.066797 & 0.070403 \\
\hline 500 & 0.045335 & 0.074519 & 0.083280 & 0.087790 & 0.051920 & 0.054743 & 0.067894 & 0.071579 & 0.059741 & 0.062975 \\
\hline 600 & 0.041395 & 0.068012 & 0.076030 & 0.080140 & 0.047412 & 0.049960 & 0.061995 & 0.065346 & 0.054527 & 0.057487 \\
\hline 700 & 0.038318 & 0.062975 & 0.070380 & 0.074190 & 0.043884 & 0.046256 & 0.057389 & 0.060486 & 0.050490 & 0.053214 \\
\hline 800 & 0.035848 & 0.058918 & 0.065840 & 0.069400 & 0.041042 & 0.043277 & 0.053684 & 0.056585 & 0.047236 & 0.049784 \\
\hline 900 & 0.033790 & 0.055546 & 0.062070 & 0.065420 & 0.038710 & 0.040807 & 0.050607 & 0.053351 & 0.044531 & 0.046942 \\
\hline 1000 & 0.032066 & 0.052685 & 0.058900 & 0.062070 & 0.036711 & 0.038710 & 0.048020 & 0.050607 & 0.042238 & 0.044531 \\
\hline 1100 & 0.030576 & 0.050235 & 0.056150 & 0.059190 & 0.035006 & 0.036907 & 0.045786 & 0.048255 & 0.040278 & 0.042454 \\
\hline 1200 & 0.029263 & 0.048098 & 0.053760 & 0.056660 & 0.033516 & 0.035339 & 0.043826 & 0.046197 & 0.038553 & 0.040650 \\
\hline 1300 & 0.028126 & 0.046217 & 0.051650 & 0.054450 & 0.032203 & 0.033947 & 0.042120 & 0.044394 & 0.037044 & 0.039063 \\
\hline 1400 & 0.027087 & 0.044531 & 0.049760 & 0.052470 & 0.031027 & 0.032712 & 0.040572 & 0.042767 & 0.035692 & 0.037632 \\
\hline 1500 & 0.026186 & 0.043022 & 0.048080 & 0.050690 & 0.029988 & 0.031595 & 0.039200 & 0.041317 & 0.034496 & 0.036358 \\
\hline 1600 & 0.025343 & 0.041650 & 0.046550 & 0.049080 & 0.029028 & 0.030596 & 0.037965 & 0.040004 & 0.033398 & 0.035202 \\
\hline 1700 & 0.024598 & 0.040415 & 0.045160 & 0.047610 & 0.028165 & 0.029694 & 0.036828 & 0.038808 & 0.032399 & 0.034143 \\
\hline 1800 & 0.023892 & 0.039278 & 0.043900 & 0.046280 & 0.027362 & 0.028851 & 0.035790 & 0.037730 & 0.031478 & 0.033183 \\
\hline 1900 & 0.023265 & 0.038220 & 0.042730 & 0.045040 & 0.026636 & 0.028087 & 0.034829 & 0.036711 & 0.030654 & 0.032301 \\
\hline 2000 & 0.022677 & 0.037260 & 0.041650 & 0.043880 & 0.025970 & 0.027362 & 0.033947 & 0.035790 & 0.029870 & 0.031478 \\
\hline 2100 & 0.022128 & 0.036358 & 0.040630 & 0.042850 & 0.025343 & 0.026715 & 0.033124 & 0.034927 & 0.029145 & 0.030733 \\
\hline 2200 & 0.021619 & 0.035515 & 0.039710 & 0.041850 & 0.024755 & 0.026088 & 0.032379 & 0.034124 & 0.028479 & 0.030027 \\
\hline 2300 & 0.021148 & 0.034751 & 0.038830 & 0.040920 & 0.024206 & 0.025519 & 0.031654 & 0.033379 & 0.027852 & 0.029361 \\
\hline 2400 & 0.020698 & 0.034006 & 0.038000 & 0.040060 & 0.023696 & 0.024990 & 0.030988 & 0.032673 & 0.027264 & 0.028734 \\
\hline 2500 & 0.020286 & 0.033320 & 0.037240 & 0.039260 & 0.023226 & 0.024480 & 0.030360 & 0.032007 & 0.026715 & 0.028165 \\
\hline 2600 & 0.019874 & 0.032673 & 0.036510 & 0.038490 & 0.022775 & 0.024010 & 0.029772 & 0.031380 & 0.026205 & 0.027616 \\
\hline 2700 & 0.019502 & 0.032066 & 0.035850 & 0.037770 & 0.022344 & 0.023559 & 0.029224 & 0.030792 & 0.025715 & 0.027107 \\
\hline 2800 & 0.019169 & 0.031497 & 0.035200 & 0.037100 & 0.021952 & 0.023128 & 0.028694 & 0.030243 & 0.025245 & 0.026617 \\
\hline 2900 & 0.018836 & 0.030948 & 0.034570 & 0.036460 & 0.021560 & 0.022736 & 0.028185 & 0.029714 & 0.024814 & 0.026146 \\
\hline 3000 & 0.018502 & 0.030419 & 0.034010 & 0.035850 & 0.021207 & 0.022344 & 0.027714 & 0.029224 & 0.024382 & 0.025715 \\
\hline 3100 & 0.018208 & 0.029929 & 0.033460 & 0.035260 & 0.020854 & 0.021991 & 0.027264 & 0.028753 & 0.023990 & 0.025284 \\
\hline 3200 & 0.017914 & 0.029459 & 0.032930 & 0.034710 & 0.020521 & 0.021638 & 0.026832 & 0.028302 & 0.023618 & 0.024892 \\
\hline 3300 & 0.017640 & 0.029008 & 0.032420 & 0.034160 & 0.020208 & 0.021305 & 0.026421 & 0.027852 & 0.023246 & 0.024520 \\
\hline 3400 & 0.017385 & 0.028577 & 0.031930 & 0.033670 & 0.019914 & 0.020992 & 0.026048 & 0.027440 & 0.022912 & 0.024147 \\
\hline 3500 & 0.017130 & 0.028165 & 0.031480 & 0.033180 & 0.019620 & 0.020698 & 0.025656 & 0.027048 & 0.022579 & 0.023794 \\
\hline 3600 & 0.016895 & 0.027773 & 0.031050 & 0.032710 & 0.019345 & 0.020404 & 0.025304 & 0.026676 & 0.022266 & 0.023461 \\
\hline 3700 & 0.016660 & 0.027401 & 0.030620 & 0.032280 & 0.019090 & 0.020129 & 0.024970 & 0.026303 & 0.021952 & 0.023148 \\
\hline 3800 & 0.016444 & 0.027028 & 0.030200 & 0.031850 & 0.018836 & 0.019855 & 0.024637 & 0.025970 & 0.021678 & 0.022834 \\
\hline 3900 & 0.016229 & 0.026676 & 0.029810 & 0.031440 & 0.018600 & 0.019600 & 0.024304 & 0.025637 & 0.021384 & 0.022540 \\
\hline 4000 & 0.016033 & 0.026342 & 0.029440 & 0.031050 & 0.018365 & 0.019345 & 0.024010 & 0.025304 & 0.021129 & 0.022266 \\
\hline 4100 & 0.015837 & 0.026029 & 0.029090 & 0.030650 & 0.018130 & 0.019110 & 0.023716 & 0.024990 & 0.020854 & 0.021991 \\
\hline 4200 & 0.015641 & 0.025715 & 0.028730 & 0.030280 & 0.017914 & 0.018894 & 0.023422 & 0.024696 & 0.020619 & 0.021717 \\
\hline 4300 & 0.015464 & 0.025402 & 0.028400 & 0.029930 & 0.017699 & 0.018659 & 0.023148 & 0.024402 & 0.020364 & 0.021482 \\
\hline 4400 & 0.015288 & 0.025127 & 0.028070 & 0.029600 & 0.017503 & 0.018444 & 0.022893 & 0.024128 & 0.020129 & 0.021227 \\
\hline 4500 & 0.015112 & 0.024833 & 0.027750 & 0.029260 & 0.017307 & 0.018248 & 0.022638 & 0.023853 & 0.019914 & 0.020992 \\
\hline 4600 & 0.014955 & 0.024559 & 0.027460 & 0.028950 & 0.017111 & 0.018052 & 0.022383 & 0.023598 & 0.019698 & 0.020756 \\
\hline 4700 & 0.014778 & 0.024304 & 0.027170 & 0.028640 & 0.016934 & 0.017856 & 0.022148 & 0.023344 & 0.019482 & 0.020541 \\
\hline 4800 & 0.014641 & 0.024049 & 0.026870 & 0.028340 & 0.016758 & 0.017660 & 0.021913 & 0.023108 & 0.019286 & 0.020325 \\
\hline 5000 & 0.014347 & 0.023559 & 0.026340 & 0.027750 & 0.016425 & 0.017307 & 0.021482 & 0.022638 & 0.018894 & 0.019914 \\
\hline
\end{tabular}


Acoustic Telemetry Studies of Juvenile Chinook Salmon Survival at the Lower Columbia Projects in 2006 


\section{Appendix K}

Model Estimates of One-Half 95\% Confidence Intervals on Detection and Survival Statistics for Subyearling Chinook Salmon Based on Single-Release Survival Models for Summer 2006 
Acoustic Telemetry Studies of Juvenile Chinook Salmon Survival at the Lower Columbia Projects in 2006 


\section{Appendix K}

\section{Model Estimates of One-half 95\% Confidence Intervals on Detection and Survival Statistics for Subyearling Chinook Salmon Based on Single-Release Survival Models for Summer 2006}

All predicted estimates of 95\% confidence intervals (CI) are based upon summer 2006 estimates of survival and detection probabilities, and sample-size estimates associated with a one-half $95 \%$ CIs of $2 \%$, $3 \%, 4 \%$, and $5 \%$ on primary array survival (S1) are highlighted when listed.

Table K.1. Predictions of One-half 95\% Confidence Intervals $(\mathrm{Cl})$ on Survival of Fish Traveling from the Little Goose Tailrace to Array 1J (S1) and from Array 1J to Array 1T (S2), on Associated Detection Probabilities P1 and P2, and on the Joint Probability $(\lambda)$ as a Function of Possible Total Numbers that Could be Released.

\begin{tabular}{|c|c|c|c|c|c|}
\hline $\begin{array}{l}\text { Release } \\
\text { Number }\end{array}$ & $\begin{array}{l}\text { One half } \\
95 \% \mathrm{Cl} \\
\text { on S1 }\end{array}$ & $\begin{array}{l}\text { One-half } \\
95 \% \mathrm{Cl} \\
\text { on S2 }\end{array}$ & $\begin{array}{l}\text { One-half } \\
95 \% \mathrm{Cl} \\
\text { on P1 }\end{array}$ & $\begin{array}{l}\text { One-half } \\
95 \% \mathrm{Cl} \\
\text { on P2 }\end{array}$ & $\begin{array}{l}\text { One-half } \\
95 \% \mathrm{Cl} \\
\text { on Lamda }\end{array}$ \\
\hline 300 & 0.044923 & 0.012250 & 0.058330 & 0.051960 & 0.054860 \\
\hline 400 & 0.038906 & 0.010604 & 0.050509 & 0.045002 & 0.047510 \\
\hline 500 & 0.034790 & 0.009486 & 0.045178 & 0.040258 & 0.042493 \\
\hline 600 & 0.031772 & 0.008663 & 0.041238 & 0.036750 & 0.038788 \\
\hline 700 & 0.029420 & 0.008016 & 0.038181 & 0.034026 & 0.035907 \\
\hline 800 & 0.027518 & 0.007507 & 0.035711 & 0.031811 & 0.033594 \\
\hline 900 & 0.025931 & 0.007076 & 0.033673 & 0.030008 & 0.031674 \\
\hline 1000 & 0.024598 & 0.006703 & 0.031948 & 0.028459 & 0.030047 \\
\hline 1100 & 0.023461 & 0.006390 & 0.030458 & 0.027146 & 0.028655 \\
\hline 1200 & 0.022462 & 0.006135 & 0.029165 & 0.025990 & 0.027420 \\
\hline 1300 & 0.021580 & 0.005880 & 0.028028 & 0.024970 & 0.026342 \\
\hline 1400 & 0.020796 & 0.005664 & 0.027009 & 0.024049 & 0.025402 \\
\hline 1500 & 0.020090 & 0.005488 & 0.026088 & 0.023246 & 0.024539 \\
\hline 1600 & 0.019443 & 0.005312 & 0.025264 & 0.022501 & 0.023755 \\
\hline 1700 & 0.018875 & 0.005155 & 0.024500 & 0.021834 & 0.023050 \\
\hline 1800 & 0.018346 & 0.004998 & 0.023814 & 0.021207 & 0.022403 \\
\hline 1900 & 0.017856 & 0.004861 & 0.023187 & 0.020639 & 0.021795 \\
\hline 2000 & 0.017405 & 0.004743 & 0.022599 & 0.020129 & 0.021246 \\
\hline 2100 & 0.016974 & 0.004626 & 0.022050 & 0.019639 & 0.020737 \\
\hline 2200 & 0.016582 & 0.004528 & 0.021540 & 0.019188 & 0.020247 \\
\hline 2300 & 0.016229 & 0.004430 & 0.021070 & 0.018757 & 0.019816 \\
\hline 2400 & 0.015876 & 0.004332 & 0.020619 & 0.018365 & 0.019384 \\
\hline 2500 & 0.015562 & 0.004253 & 0.020208 & 0.017993 & 0.018992 \\
\hline 2600 & 0.015268 & 0.004155 & 0.019816 & 0.017660 & 0.018640 \\
\hline 2700 & 0.014974 & 0.004077 & 0.019443 & 0.017326 & 0.018287 \\
\hline 2800 & 0.014700 & 0.004018 & 0.019090 & 0.017013 & 0.017954 \\
\hline 3000 & 0.014210 & 0.003881 & 0.018444 & 0.016425 & 0.017346 \\
\hline
\end{tabular}


Table K.2. Predictions of One-half $95 \%$ Confidence Intervals $(\mathrm{Cl})$ on Survival of Fish Traveling from the Little Goose Tailrace to Array 1T (S1) and from Array 1T to Array 1B (S2), on Associated Detection Probabilities P1 and P2, and on the Joint Probability $(\lambda)$ as a Function of Possible Total Numbers that Could be Released.

\begin{tabular}{|c|c|c|c|c|c|}
\hline $\begin{array}{l}\text { Release } \\
\text { Number }\end{array}$ & $\begin{array}{l}\text { One half } \\
95 \% \mathrm{Cl} \\
\text { on S1 } \\
\end{array}$ & $\begin{array}{l}\text { One-half } \\
95 \% \mathrm{Cl} \\
\text { on } \mathrm{S} 2 \\
\end{array}$ & $\begin{array}{l}\text { One-half } \\
95 \% \mathrm{Cl} \\
\text { on P1 }\end{array}$ & $\begin{array}{l}\text { One-half } \\
95 \% \mathrm{Cl} \\
\text { on P2 }\end{array}$ & $\begin{array}{l}\text { One-half } \\
95 \% \mathrm{Cl} \\
\text { on Lamda }\end{array}$ \\
\hline 300 & 0.041062 & 0.056134 & 0.024030 & 0.002920 & 0.002920 \\
\hline 400 & 0.035574 & 0.048608 & 0.020815 & 0.002528 & 0.002528 \\
\hline 500 & 0.031811 & 0.043473 & 0.018620 & 0.002254 & 0.002254 \\
\hline 600 & 0.029047 & 0.039690 & 0.016993 & 0.002058 & 0.002058 \\
\hline 700 & 0.026891 & 0.036750 & 0.015739 & 0.001901 & 0.001901 \\
\hline 800 & 0.025147 & 0.034378 & 0.014720 & 0.001784 & 0.001784 \\
\hline 900 & 0.023716 & 0.032399 & 0.013877 & 0.001686 & 0.001686 \\
\hline 1000 & 0.022501 & 0.030752 & 0.013152 & 0.001588 & 0.001588 \\
\hline 1100 & 0.021442 & 0.029322 & 0.012544 & 0.001529 & 0.001529 \\
\hline 1200 & 0.020541 & 0.028067 & 0.012015 & 0.001450 & 0.001450 \\
\hline 1300 & 0.019737 & 0.026970 & 0.011544 & 0.001392 & 0.001392 \\
\hline 1400 & 0.019012 & 0.025990 & 0.011113 & 0.001352 & 0.001352 \\
\hline 1500 & 0.018365 & 0.025108 & 0.010741 & 0.001313 & 0.001313 \\
\hline 1600 & 0.017777 & 0.024304 & 0.010408 & 0.001254 & 0.001254 \\
\hline 1700 & 0.017248 & 0.023579 & 0.010094 & 0.001235 & 0.001235 \\
\hline 1800 & 0.016758 & 0.022912 & 0.009800 & 0.001196 & 0.001196 \\
\hline 1900 & 0.016327 & 0.022305 & 0.009545 & 0.001156 & 0.001156 \\
\hline 2000 & 0.015915 & 0.021736 & 0.009310 & 0.001137 & 0.001137 \\
\hline 2100 & 0.015523 & 0.021207 & 0.009075 & 0.001098 & 0.001098 \\
\hline 2200 & 0.015170 & 0.020737 & 0.008879 & 0.001078 & 0.001078 \\
\hline 2300 & 0.014837 & 0.020266 & 0.008683 & 0.001058 & 0.001058 \\
\hline 2400 & 0.014524 & 0.019855 & 0.008487 & 0.001039 & 0.001039 \\
\hline 2500 & 0.014230 & 0.019443 & 0.008330 & 0.001019 & 0.001019 \\
\hline 2600 & 0.013955 & 0.019071 & 0.008154 & 0.001000 & 0.001000 \\
\hline 2700 & 0.013681 & 0.018718 & 0.008016 & 0.000980 & 0.000980 \\
\hline 2800 & 0.013446 & 0.018365 & 0.007860 & 0.000960 & 0.000960 \\
\hline 3000 & 0.012995 & 0.017758 & 0.007605 & 0.000921 & 0.000921 \\
\hline
\end{tabular}


Table K.3. Predictions of One-half $95 \%$ Confidence Intervals $(\mathrm{Cl})$ on Survival of Fish Traveling from the Little Goose Tailrace to Array 1B (S1) and from Array 1B to Array 2B (S2), on Associated Detection Probabilities P1 and P2, and on the Joint Probability $(\lambda)$ as a Function of Possible Total Numbers that Could be Released.

\begin{tabular}{|rrrr|}
\hline $\begin{array}{r}\text { Release } \\
\text { Number }\end{array}$ & $\begin{array}{l}\text { One half } \\
\text { 95\% Cl } \\
\text { on S1 }\end{array}$ & $\begin{array}{l}\text { One-half } \\
\text { 95\% Cl } \\
\text { on P1 }\end{array}$ & $\begin{array}{l}\text { One-half } \\
\text { 95\% Cl } \\
\text { on Lamda }\end{array}$ \\
\hline \hline 300 & 0.044355 & 0.201740 & 0.200140 \\
400 & 0.038416 & 0.174710 & 0.173320 \\
500 & 0.034359 & 0.156270 & 0.155020 \\
600 & 0.031360 & 0.142650 & 0.141510 \\
700 & 0.029047 & 0.132060 & 0.131010 \\
800 & 0.027166 & 0.123540 & 0.122560 \\
900 & 0.025617 & 0.116480 & 0.115540 \\
1000 & 0.024304 & 0.110500 & 0.109620 \\
1100 & 0.023167 & 0.105350 & 0.104510 \\
1200 & 0.022187 & 0.100880 & 0.100060 \\
1300 & 0.021305 & 0.096920 & 0.096140 \\
1400 & 0.020541 & 0.093390 & 0.092650 \\
1500 & 0.019835 & 0.090220 & 0.089490 \\
1600 & 0.019208 & 0.087360 & 0.086650 \\
1700 & 0.018640 & 0.084750 & 0.084060 \\
1800 & 0.018110 & 0.082360 & 0.081690 \\
1900 & 0.017620 & 0.080160 & 0.079520 \\
2000 & 0.017170 & 0.078130 & 0.077520 \\
2100 & 0.016758 & 0.076240 & 0.075640 \\
2200 & 0.016386 & 0.074500 & 0.073910 \\
2300 & 0.016013 & 0.072850 & 0.072280 \\
2400 & 0.015680 & 0.071320 & 0.070760 \\
2500 & 0.015366 & 0.069890 & 0.069330 \\
2600 & 0.015072 & 0.068520 & 0.067970 \\
2700 & 0.014778 & 0.067250 & 0.066720 \\
3000 & 0.014034 & 0.063800 & 0.063290 \\
\hline & & & 0.065500 \\
\hline 800 & 0.014524 & 0.066030 & \\
\hline
\end{tabular}


Table K.4. Predictions of One-half $95 \%$ Confidence Intervals $(\mathrm{Cl})$ on Survival of Fish Traveling from the JDA Tailrace to Array $1 \mathrm{~J}$ (S1) and from Array 1J to Array 1T (S2), on Associated Detection Probabilities $\mathrm{P} 1$ and $\mathrm{P} 2$, and on the Joint Probability $(\lambda)$ as a Function of Possible Total Numbers that Could be Released.

\begin{tabular}{|c|c|c|c|c|c|}
\hline $\begin{array}{l}\text { Release } \\
\text { Number }\end{array}$ & $\begin{array}{l}\text { One half } \\
95 \% \mathrm{Cl} \\
\text { on S1 }\end{array}$ & $\begin{array}{l}\text { One-half } \\
95 \% \mathrm{Cl} \\
\text { on S2 }\end{array}$ & $\begin{array}{l}\text { One-half } \\
95 \% \mathrm{Cl} \\
\text { on P1 }\end{array}$ & $\begin{array}{l}\text { One-half } \\
95 \% \mathrm{Cl} \\
\text { on P2 }\end{array}$ & $\begin{array}{l}\text { One-half } \\
95 \% \mathrm{Cl} \\
\text { on Lamda }\end{array}$ \\
\hline 300 & 0.009232 & 0.006821 & 0.006625 & 0.020717 & 0.027264 \\
\hline 400 & 0.007997 & 0.005900 & 0.005743 & 0.017934 & 0.023598 \\
\hline 500 & 0.007154 & 0.005272 & 0.005135 & 0.016052 & 0.021109 \\
\hline 600 & 0.006527 & 0.004822 & 0.004684 & 0.014641 & 0.019267 \\
\hline 700 & 0.006056 & 0.004469 & 0.004332 & 0.013563 & 0.017836 \\
\hline 800 & 0.005664 & 0.004175 & 0.004057 & 0.012681 & 0.016699 \\
\hline 900 & 0.005331 & 0.003940 & 0.003822 & 0.011956 & 0.015739 \\
\hline 1000 & 0.005057 & 0.003744 & 0.003626 & 0.011348 & 0.014935 \\
\hline 1100 & 0.004822 & 0.003567 & 0.003450 & 0.010819 & 0.014230 \\
\hline 1200 & 0.004626 & 0.003410 & 0.003312 & 0.010349 & 0.013622 \\
\hline 1300 & 0.004430 & 0.003273 & 0.003175 & 0.009957 & 0.013093 \\
\hline 1400 & 0.004273 & 0.003156 & 0.003058 & 0.009584 & 0.012622 \\
\hline 1500 & 0.004136 & 0.003058 & 0.002960 & 0.009271 & 0.012191 \\
\hline 1600 & 0.003998 & 0.002960 & 0.002862 & 0.008977 & 0.011799 \\
\hline 1700 & 0.003881 & 0.002862 & 0.002783 & 0.008702 & 0.011446 \\
\hline 1800 & 0.003763 & 0.002783 & 0.002705 & 0.008448 & 0.011133 \\
\hline 1900 & 0.003665 & 0.002705 & 0.002626 & 0.008232 & 0.010839 \\
\hline 2000 & 0.003587 & 0.002646 & 0.002568 & 0.008016 & 0.010564 \\
\hline 2100 & 0.003489 & 0.002568 & 0.002509 & 0.007820 & 0.010310 \\
\hline 2200 & 0.003410 & 0.002509 & 0.002450 & 0.007644 & 0.010074 \\
\hline 2300 & 0.003332 & 0.002470 & 0.002391 & 0.007487 & 0.009839 \\
\hline 2400 & 0.003273 & 0.002411 & 0.002332 & 0.007330 & 0.009643 \\
\hline 2500 & 0.003195 & 0.002372 & 0.002293 & 0.007174 & 0.009447 \\
\hline 2600 & 0.003136 & 0.002313 & 0.002254 & 0.007036 & 0.009251 \\
\hline 2700 & 0.003077 & 0.002274 & 0.002215 & 0.006899 & 0.009094 \\
\hline 2800 & 0.003018 & 0.002234 & 0.002176 & 0.006782 & 0.008918 \\
\hline 3000 & 0.002920 & 0.002156 & 0.002097 & 0.006546 & 0.008624 \\
\hline
\end{tabular}


Table K.5. Predictions of One-half 95\% Confidence Intervals $(\mathrm{Cl})$ on Survival of Fish Traveling from the JDA Tailrace to Array 1T (S1) and from Array 1T to Array 1B (S2), on Associated Detection Probabilities P1 and P2, and on the Joint Probability $(\lambda)$ as a Function of Possible Total Numbers that Could be Released.

\begin{tabular}{|c|c|c|c|c|c|}
\hline $\begin{array}{l}\text { Release } \\
\text { Number }\end{array}$ & $\begin{array}{l}\text { One half } \\
95 \% \mathrm{Cl} \\
\text { on S1 }\end{array}$ & $\begin{array}{l}\text { One-half } \\
95 \% \mathrm{Cl} \\
\text { on S2 }\end{array}$ & $\begin{array}{l}\text { One-half } \\
95 \% \mathrm{Cl} \\
\text { on P1 }\end{array}$ & $\begin{array}{l}\text { One-half } \\
95 \% \mathrm{Cl} \\
\text { on P2 }\end{array}$ & $\begin{array}{l}\text { One-half } \\
95 \% \mathrm{Cl} \\
\text { on Lamda }\end{array}$ \\
\hline 300 & 0.043218 & 0.011329 & 0.013798 & 0.001254 & 0.000118 \\
\hline 400 & 0.037436 & 0.009800 & 0.011956 & 0.001078 & 0.000098 \\
\hline 500 & 0.033477 & 0.008761 & 0.010702 & 0.000960 & 0.000098 \\
\hline 600 & 0.030556 & 0.007997 & 0.009761 & 0.000882 & 0.000078 \\
\hline 700 & 0.028302 & 0.007409 & 0.009036 & 0.000823 & 0.000078 \\
\hline 800 & 0.026460 & 0.006938 & 0.008448 & 0.000764 & 0.000078 \\
\hline 900 & 0.024951 & 0.006527 & 0.007977 & 0.000725 & 0.000078 \\
\hline 1000 & 0.023677 & 0.006194 & 0.007566 & 0.000686 & 0.000059 \\
\hline 1100 & 0.022579 & 0.005919 & 0.007213 & 0.000647 & 0.000059 \\
\hline 1200 & 0.021619 & 0.005664 & 0.006899 & 0.000627 & 0.000059 \\
\hline 1300 & 0.020756 & 0.005429 & 0.006625 & 0.000608 & 0.000059 \\
\hline 1400 & 0.020012 & 0.005233 & 0.006390 & 0.000588 & 0.000059 \\
\hline 1500 & 0.019326 & 0.005057 & 0.006174 & 0.000568 & 0.000059 \\
\hline 1600 & 0.018718 & 0.004900 & 0.005978 & 0.000549 & 0.000059 \\
\hline 1700 & 0.018150 & 0.004763 & 0.005802 & 0.000529 & 0.000059 \\
\hline 1800 & 0.017640 & 0.004626 & 0.005645 & 0.000510 & 0.000059 \\
\hline 1900 & 0.017170 & 0.004488 & 0.005488 & 0.000490 & 0.000039 \\
\hline 2000 & 0.016738 & 0.004390 & 0.005351 & 0.000490 & 0.000039 \\
\hline 2100 & 0.016327 & 0.004273 & 0.005214 & 0.000470 & 0.000039 \\
\hline 2200 & 0.015954 & 0.004175 & 0.005096 & 0.000470 & 0.000039 \\
\hline 2300 & 0.015602 & 0.004096 & 0.004978 & 0.000451 & 0.000039 \\
\hline 2400 & 0.015288 & 0.003998 & 0.004880 & 0.000451 & 0.000039 \\
\hline 2500 & 0.014974 & 0.003920 & 0.004782 & 0.000431 & 0.000039 \\
\hline 2600 & 0.014680 & 0.003842 & 0.004684 & 0.000431 & 0.000039 \\
\hline 2700 & 0.014406 & 0.003783 & 0.004606 & 0.000412 & 0.000039 \\
\hline 2800 & 0.014151 & 0.003704 & 0.004528 & 0.000412 & 0.000039 \\
\hline 3000 & 0.013661 & 0.003587 & 0.004371 & 0.000392 & 0.000039 \\
\hline
\end{tabular}


Table K.6. Predictions of One-half 95\% Confidence Intervals $(\mathrm{Cl})$ on Survival of Fish Traveling from the John Day Tailrace to Array 1B (S1) and from Array 1B to Array 2B (S2), on Associated Detection Probabilities P1 and P2, and on the Joint Probability $(\lambda)$ as a Function of Possible Total Numbers that Could be Released.

\begin{tabular}{|rccr||}
\hline $\begin{array}{r}\text { Release } \\
\text { Number }\end{array}$ & $\begin{array}{l}\text { One half } \\
\text { 95\% Cl } \\
\text { on S1 }\end{array}$ & $\begin{array}{l}\text { One-half } \\
\text { 95\% Cl } \\
\text { on P1 }\end{array}$ & $\begin{array}{l}\text { One-half } \\
\text { 95\% Cl } \\
\text { on Lamda }\end{array}$ \\
\hline \hline 300 & 0.064386 & 0.072128 & 0.072461 \\
400 & 0.055762 & 0.062465 & 0.062759 \\
500 & 0.049862 & 0.055860 & 0.056134 \\
600 & 0.045531 & 0.050999 & 0.051234 \\
700 & 0.042140 & 0.047216 & 0.047432 \\
800 & 0.039416 & 0.044159 & 0.044374 \\
900 & 0.037162 & 0.041650 & 0.041826 \\
1000 & 0.035260 & 0.039514 & 0.039690 \\
1100 & 0.033614 & 0.037671 & 0.037848 \\
1200 & 0.032183 & 0.036064 & 0.036221 \\
1300 & 0.030929 & 0.034653 & 0.034810 \\
1400 & 0.029812 & 0.033379 & 0.033536 \\
1500 & 0.028792 & 0.032262 & 0.032399 \\
1600 & 0.027871 & 0.031223 & 0.031380 \\
1700 & 0.027048 & 0.030302 & 0.030439 \\
1800 & 0.026284 & 0.029439 & 0.029576 \\
1900 & 0.025578 & 0.028655 & 0.028792 \\
2000 & 0.024931 & 0.027930 & 0.028067 \\
2100 & 0.024324 & 0.027264 & 0.027381 \\
2200 & 0.023775 & 0.026636 & 0.026754 \\
2300 & 0.023246 & 0.026048 & 0.026166 \\
2400 & 0.022756 & 0.025500 & 0.025617 \\
2500 & 0.022305 & 0.024990 & 0.025108 \\
2600 & 0.021874 & 0.024500 & 0.024618 \\
2700 & 0.021462 & 0.024049 & 0.024147 \\
3000 & 0.021070 & 0.023618 & 0.023716 \\
\hline & & 0.022814 & 0.022912 \\
\hline \hline
\end{tabular}


Table K.7. Predictions of One-half 95\% Confidence Intervals $(\mathrm{Cl})$ on Survival of Fish Traveling from the TDA Tailrace to Array 1T (S1) and from Array 1T to Array 1B (S2), on Associated Detection Probabilities $\mathrm{P} 1$ and $\mathrm{P} 2$, and on the Joint Probability $(\lambda)$ as a Function of Possible Total Numbers that Could be Released.

\begin{tabular}{|c|c|c|c|c|c|}
\hline $\begin{array}{l}\text { Release } \\
\text { Number }\end{array}$ & $\begin{array}{l}\text { One half } \\
95 \% \mathrm{Cl} \\
\text { on S1 }\end{array}$ & $\begin{array}{l}\text { One-half } \\
95 \% \mathrm{Cl} \\
\text { on S2 }\end{array}$ & $\begin{array}{l}\text { One-half } \\
95 \% \mathrm{Cl} \\
\text { on P1 }\end{array}$ & $\begin{array}{l}\text { One-half } \\
95 \% \mathrm{Cl} \\
\text { on P2 }\end{array}$ & $\begin{array}{l}\text { One-half } \\
95 \% \mathrm{Cl} \\
\text { on Lamda }\end{array}$ \\
\hline 300 & 0.019678 & 0.023167 & 0.011035 & 0.001176 & 0.002626 \\
\hline 400 & 0.017032 & 0.020051 & 0.009545 & 0.001019 & 0.002274 \\
\hline 500 & 0.015249 & 0.017934 & 0.008546 & 0.000902 & 0.002038 \\
\hline 600 & 0.013916 & 0.016386 & 0.007801 & 0.000823 & 0.001862 \\
\hline 700 & 0.012877 & 0.015170 & 0.007213 & 0.000764 & 0.001725 \\
\hline 800 & 0.012054 & 0.014190 & 0.006762 & 0.000725 & 0.001607 \\
\hline 900 & 0.011368 & 0.013367 & 0.006370 & 0.000686 & 0.001509 \\
\hline 1000 & 0.010780 & 0.012681 & 0.006037 & 0.000647 & 0.001431 \\
\hline 1100 & 0.010270 & 0.012093 & 0.005762 & 0.000608 & 0.001372 \\
\hline 1200 & 0.009839 & 0.011584 & 0.005508 & 0.000588 & 0.001313 \\
\hline 1300 & 0.009447 & 0.011133 & 0.005292 & 0.000568 & 0.001254 \\
\hline 1400 & 0.009114 & 0.010721 & 0.005096 & 0.000549 & 0.001215 \\
\hline 1500 & 0.008800 & 0.010349 & 0.004939 & 0.000529 & 0.001176 \\
\hline 1600 & 0.008526 & 0.010035 & 0.004782 & 0.000510 & 0.001137 \\
\hline 1700 & 0.008271 & 0.009722 & 0.004626 & 0.000490 & 0.001098 \\
\hline 1800 & 0.008036 & 0.009447 & 0.004508 & 0.000470 & 0.001078 \\
\hline 1900 & 0.007820 & 0.009212 & 0.004390 & 0.000470 & 0.001039 \\
\hline 2000 & 0.007624 & 0.008977 & 0.004273 & 0.000451 & 0.001019 \\
\hline 2100 & 0.007428 & 0.008761 & 0.004175 & 0.000451 & 0.001000 \\
\hline 2200 & 0.007272 & 0.008546 & 0.004077 & 0.000431 & 0.000960 \\
\hline 2300 & 0.007115 & 0.008369 & 0.003979 & 0.000431 & 0.000941 \\
\hline 2400 & 0.006958 & 0.008193 & 0.003900 & 0.000412 & 0.000921 \\
\hline 2500 & 0.006821 & 0.008016 & 0.003822 & 0.000412 & 0.000902 \\
\hline 2600 & 0.006684 & 0.007860 & 0.003744 & 0.000392 & 0.000882 \\
\hline 2700 & 0.006566 & 0.007722 & 0.003685 & 0.000392 & 0.000882 \\
\hline 2800 & 0.006448 & 0.007585 & 0.003606 & 0.000392 & 0.000862 \\
\hline 3000 & 0.006213 & 0.007330 & 0.003489 & 0.000372 & 0.000823 \\
\hline
\end{tabular}


Table K.8. Predictions of One-half 95\% Confidence Intervals (Cl) on Survival of Fish Traveling from The Dalles Tailrace to Array 1B (S1) and from Array 1B to Array 2B (S2), on Associated Detection Probabilities $\mathrm{P} 1$ and $\mathrm{P} 2$, and on the Joint Probability $(\lambda)$ as a Function of Possible Total Numbers that Could be Released.

\begin{tabular}{|rrrr||}
\hline $\begin{array}{r}\text { Release } \\
\text { Number }\end{array}$ & $\begin{array}{l}\text { One half } \\
\text { 95\% Cl } \\
\text { on S1 }\end{array}$ & $\begin{array}{l}\text { One-half } \\
\text { 95\% Cl } \\
\text { on P1 }\end{array}$ & $\begin{array}{l}\text { One-half } \\
\text { 95\% Cl } \\
\text { on Lamda }\end{array}$ \\
\hline \hline 300 & 0.054527 & 0.058349 & 0.063465 \\
400 & 0.047236 & 0.050529 & 0.054958 \\
500 & 0.042238 & 0.045198 & 0.049157 \\
600 & 0.038553 & 0.041258 & 0.044884 \\
700 & 0.035711 & 0.038200 & 0.041552 \\
800 & 0.033398 & 0.035731 & 0.038867 \\
900 & 0.031478 & 0.033692 & 0.036652 \\
1000 & 0.029870 & 0.031968 & 0.034770 \\
1100 & 0.028479 & 0.030478 & 0.033144 \\
1200 & 0.027264 & 0.029165 & 0.031732 \\
1300 & 0.026205 & 0.028028 & 0.030498 \\
1400 & 0.025245 & 0.027009 & 0.029380 \\
1500 & 0.024382 & 0.026088 & 0.028381 \\
1600 & 0.023618 & 0.025264 & 0.027479 \\
1700 & 0.022912 & 0.024520 & 0.026656 \\
1800 & 0.022266 & 0.023814 & 0.025911 \\
1900 & 0.021678 & 0.023187 & 0.025225 \\
2000 & 0.021129 & 0.022599 & 0.024578 \\
2100 & 0.020619 & 0.022050 & 0.023990 \\
2200 & 0.020129 & 0.021540 & 0.023442 \\
2300 & 0.019698 & 0.021070 & 0.022912 \\
2400 & 0.019286 & 0.020619 & 0.022442 \\
2500 & 0.018894 & 0.020208 & 0.021991 \\
2600 & 0.018522 & 0.019816 & 0.021560 \\
2700 & 0.018169 & 0.019443 & 0.021148 \\
2800 & 0.017856 & 0.019090 & 0.020776 \\
3000 & 0.017248 & 0.018444 & 0.020070 \\
\hline & & & \\
\hline
\end{tabular}


Table K.9. Predictions of One-half $95 \%$ Confidence Intervals $(\mathrm{Cl})$ on Survival of Fish Traveling from the Bonneville Tailrace to Array 1B (S1) and from Array 1B to Array 2B (S2), on Associated Detection Probabilities P1 and P2, and on the Joint Probability $(\lambda)$ as a Function of Possible Total Numbers that Could be Released.

\begin{tabular}{|cccc||}
\hline $\begin{array}{c}\text { Release } \\
\text { Number }\end{array}$ & $\begin{array}{l}\text { One half } \\
\text { 95\% Cl } \\
\text { on S1 }\end{array}$ & $\begin{array}{l}\text { One-half } \\
\text { 95\% Cl } \\
\text { on P1 }\end{array}$ & $\begin{array}{l}\text { One-half } \\
\text { 95\% Cl } \\
\text { on Lamda }\end{array}$ \\
\hline \hline 300 & 0.035476 & 0.049255 & 0.050235 \\
400 & 0.030713 & 0.042669 & 0.043512 \\
500 & 0.027479 & 0.038161 & 0.038906 \\
600 & 0.025088 & 0.034829 & 0.035515 \\
700 & 0.023226 & 0.032242 & 0.032889 \\
800 & 0.021717 & 0.030164 & 0.030772 \\
900 & 0.020482 & 0.028440 & 0.029008 \\
1000 & 0.019424 & 0.026989 & 0.027518 \\
1100 & 0.018522 & 0.025735 & 0.026244 \\
1200 & 0.017738 & 0.024637 & 0.025127 \\
1300 & 0.017032 & 0.023657 & 0.024128 \\
1400 & 0.016425 & 0.022795 & 0.023265 \\
1500 & 0.015856 & 0.022030 & 0.022462 \\
1600 & 0.015366 & 0.021325 & 0.021756 \\
1700 & 0.014896 & 0.020698 & 0.021109 \\
1800 & 0.014484 & 0.020110 & 0.020502 \\
1900 & 0.014092 & 0.019580 & 0.019953 \\
2000 & 0.013740 & 0.019071 & 0.019463 \\
2100 & 0.013406 & 0.018620 & 0.018992 \\
2200 & 0.013093 & 0.018189 & 0.018561 \\
2300 & 0.012818 & 0.017797 & 0.018150 \\
2400 & 0.012544 & 0.017424 & 0.017758 \\
2500 & 0.012289 & 0.017072 & 0.017405 \\
2600 & 0.012054 & 0.016738 & 0.017072 \\
2700 & 0.011819 & 0.016425 & 0.016738 \\
2800 & 0.011603 & 0.016131 & 0.016444 \\
3000 & 0.011211 & 0.015582 & 0.015896 \\
\hline
\end{tabular}


Table K.10. Predictions of One-half 95\% Confidence Intervals $(\mathrm{Cl})$ on Survival of Fish Traveling from the B2CC to Array 1B (S1) and from Array 1B to Array 2B (S2), on Associated Detection Probabilities P1 and P2, and on the Joint Probability $(\lambda)$ as a Function of Possible Total Numbers that Could be Released.

\begin{tabular}{|cccc||}
\hline $\begin{array}{c}\text { Release } \\
\text { Number }\end{array}$ & $\begin{array}{l}\text { One half } \\
\mathbf{9 5 \% ~ C l} \\
\text { on S1 }\end{array}$ & $\begin{array}{l}\text { One-half } \\
\mathbf{9 5 \%} \text { Cl } \\
\text { on P1 }\end{array}$ & $\begin{array}{l}\text { One-half } \\
\text { 95\% Cl } \\
\text { on Lamda }\end{array}$ \\
\hline \hline 300 & 0.033928 & 0.043982 & 0.053626 \\
400 & 0.029380 & 0.038102 & 0.046432 \\
500 & 0.026284 & 0.034084 & 0.041532 \\
600 & 0.023990 & 0.031105 & 0.037906 \\
700 & 0.022207 & 0.028792 & 0.035104 \\
800 & 0.020776 & 0.026930 & 0.032830 \\
900 & 0.019580 & 0.025402 & 0.030948 \\
1000 & 0.018581 & 0.024088 & 0.029361 \\
1100 & 0.017718 & 0.022971 & 0.028008 \\
1200 & 0.016974 & 0.021991 & 0.026813 \\
1300 & 0.016307 & 0.021129 & 0.025754 \\
1400 & 0.015700 & 0.020364 & 0.024814 \\
1500 & 0.015170 & 0.019678 & 0.023971 \\
1600 & 0.014700 & 0.019051 & 0.023226 \\
1700 & 0.014249 & 0.018483 & 0.022520 \\
1800 & 0.013857 & 0.017954 & 0.021893 \\
1900 & 0.013485 & 0.017483 & 0.021305 \\
2000 & 0.013132 & 0.017032 & 0.020756 \\
2100 & 0.012818 & 0.016621 & 0.020266 \\
2200 & 0.012524 & 0.016248 & 0.019796 \\
2300 & 0.012250 & 0.015896 & 0.019365 \\
2400 & 0.011995 & 0.015562 & 0.018953 \\
2500 & 0.011760 & 0.015229 & 0.018581 \\
2600 & 0.011525 & 0.014935 & 0.018208 \\
2700 & 0.011309 & 0.014661 & 0.017875 \\
2800 & 0.011113 & 0.014406 & 0.017542 \\
3000 & 0.010721 & 0.013916 & 0.016954 \\
\hline
\end{tabular}


Table K.11. Predictions of One-half 95\% Confidence Intervals $(\mathrm{Cl})$ on Survival of Fish Traveling from the B2 JBS to Array 1B (S1) and from Array 1B to Array 2B (S2), on Associated Detection Probabilities P1 and P2, and on the Joint Probability $(\lambda)$ as a Function of Possible Total Numbers that Could be Released.

\begin{tabular}{|clll||}
\hline $\begin{array}{c}\text { Release } \\
\text { Number }\end{array}$ & $\begin{array}{l}\text { One half } \\
\text { 95\% Cl } \\
\text { on S1 }\end{array}$ & $\begin{array}{l}\text { One-half } \\
\text { 95\% Cl } \\
\text { on P1 }\end{array}$ & $\begin{array}{l}\text { One-half } \\
\text { 95\% Cl } \\
\text { on Lamda }\end{array}$ \\
\hline \hline 300 & 0.048726 & 0.055860 & 0.062073 \\
400 & 0.042199 & 0.048373 & 0.053763 \\
500 & 0.037730 & 0.043257 & 0.048079 \\
600 & 0.034457 & 0.039494 & 0.043904 \\
700 & 0.031889 & 0.036574 & 0.040631 \\
800 & 0.029831 & 0.034202 & 0.038024 \\
900 & 0.028126 & 0.032242 & 0.035848 \\
1000 & 0.026695 & 0.030596 & 0.034006 \\
1100 & 0.025441 & 0.029165 & 0.032418 \\
1200 & 0.024363 & 0.027930 & 0.031046 \\
1300 & 0.023402 & 0.026832 & 0.029831 \\
1400 & 0.022560 & 0.025852 & 0.028734 \\
1500 & 0.021795 & 0.024970 & 0.027754 \\
1600 & 0.021090 & 0.024186 & 0.026872 \\
1700 & 0.020462 & 0.023461 & 0.026088 \\
1800 & 0.019894 & 0.022795 & 0.025343 \\
1900 & 0.019365 & 0.022187 & 0.024676 \\
2000 & 0.018875 & 0.021638 & 0.024049 \\
2100 & 0.018424 & 0.021109 & 0.023461 \\
2200 & 0.017993 & 0.020619 & 0.022932 \\
2300 & 0.017601 & 0.020168 & 0.022422 \\
2400 & 0.017228 & 0.019757 & 0.021952 \\
2500 & 0.016876 & 0.019345 & 0.021501 \\
2600 & 0.016542 & 0.018973 & 0.021090 \\
2700 & 0.016248 & 0.018620 & 0.020698 \\
2800 & 0.015954 & 0.018287 & 0.020325 \\
3000 & 0.015406 & 0.017660 & 0.019639 \\
\hline
\end{tabular}


Table K.12. Predictions of One-half $95 \%$ Confidence Intervals $(\mathrm{Cl})$ on Survival of Fish Traveling from the Bonneville Spillway to Array 1B (S1) and from Array 1B to Array 2B (S2), on Associated Detection Probabilities P1 and P2, and on the Joint Probability $(\lambda)$ as a Function of Possible Total Numbers that Could be Released.

\begin{tabular}{|cccc||}
\hline $\begin{array}{c}\text { Release } \\
\text { Number }\end{array}$ & $\begin{array}{l}\text { One half } \\
\text { 95\% Cl } \\
\text { on S1 }\end{array}$ & $\begin{array}{l}\text { One-half } \\
\text { 95\% Cl } \\
\text { on P1 }\end{array}$ & $\begin{array}{l}\text { One-half } \\
\text { 95\% Cl } \\
\text { on Lamda }\end{array}$ \\
\hline \hline 300 & 0.048980 & 0.053234 & 0.059956 \\
400 & 0.042414 & 0.046099 & 0.051920 \\
500 & 0.037946 & 0.041219 & 0.046432 \\
600 & 0.034633 & 0.037632 & 0.042395 \\
700 & 0.032066 & 0.034849 & 0.039259 \\
800 & 0.029988 & 0.032595 & 0.036711 \\
900 & 0.028283 & 0.030733 & 0.034614 \\
1000 & 0.026832 & 0.029145 & 0.032830 \\
1100 & 0.025578 & 0.027793 & 0.031321 \\
1200 & 0.024500 & 0.026617 & 0.029968 \\
1300 & 0.023540 & 0.025558 & 0.028792 \\
1400 & 0.022677 & 0.024637 & 0.027754 \\
1500 & 0.021913 & 0.023794 & 0.026813 \\
1600 & 0.021207 & 0.023050 & 0.025970 \\
1700 & 0.020580 & 0.022364 & 0.025186 \\
1800 & 0.019992 & 0.021736 & 0.024480 \\
1900 & 0.019463 & 0.021148 & 0.023834 \\
2000 & 0.018973 & 0.020619 & 0.023226 \\
2100 & 0.018522 & 0.020110 & 0.022658 \\
2200 & 0.018091 & 0.019659 & 0.022148 \\
2300 & 0.017699 & 0.019228 & 0.021658 \\
2400 & 0.017326 & 0.018816 & 0.021207 \\
2500 & 0.016974 & 0.018444 & 0.020776 \\
2600 & 0.016640 & 0.018071 & 0.020364 \\
2700 & 0.016327 & 0.017738 & 0.019992 \\
2800 & 0.016033 & 0.017424 & 0.019620 \\
3000 & 0.015484 & 0.016836 & 0.018953 \\
\hline
\end{tabular}


Table K.13. Predictions of One-half 95\% Confidence Intervals (Cl) on Survival of Fish Traveling from the Bonneville Spillway to Array 1B (S1) and from Array 1B to Array 2B (S2), on Associated Detection Probabilities P1 and P2, and on the Joint Probability $(\lambda)$ as a Function of Possible Total Numbers that Might Pass Under a High 24-h Spill Treatment

\begin{tabular}{|rrrr||}
\hline $\begin{array}{r}\text { Release } \\
\text { Number }\end{array}$ & $\begin{array}{l}\text { One half } \\
\text { 95\% Cl } \\
\text { on S1 }\end{array}$ & $\begin{array}{l}\text { One-half } \\
\text { 95\% Cl } \\
\text { on P1 }\end{array}$ & $\begin{array}{l}\text { One-half } \\
\text { 95\% Cl } \\
\text { on Lamda }\end{array}$ \\
\hline \hline 300 & 0.0591 & 0.0664 & 0.0664 \\
400 & 0.0512 & 0.0575 & 0.0575 \\
500 & 0.0458 & 0.0515 & 0.0515 \\
600 & 0.0418 & 0.0470 & 0.0470 \\
700 & 0.0387 & 0.0435 & 0.0435 \\
800 & 0.0362 & 0.0407 & 0.0407 \\
900 & 0.0341 & 0.0383 & 0.0383 \\
1000 & 0.0324 & 0.0364 & 0.0364 \\
1100 & 0.0309 & 0.0347 & 0.0347 \\
1200 & 0.0295 & 0.0332 & 0.0332 \\
1300 & 0.0284 & 0.0319 & 0.0319 \\
1400 & 0.0273 & 0.0307 & 0.0307 \\
1500 & 0.0264 & 0.0297 & 0.0297 \\
1600 & 0.0256 & 0.0288 & 0.0288 \\
1700 & 0.0248 & 0.0279 & 0.0279 \\
1800 & 0.0241 & 0.0271 & 0.0271 \\
1900 & 0.0235 & 0.0264 & 0.0264 \\
2000 & 0.0229 & 0.0257 & 0.0257 \\
2100 & 0.0223 & 0.0251 & 0.0251 \\
2200 & 0.0218 & 0.0245 & 0.0245 \\
2300 & 0.0213 & 0.0240 & 0.0240 \\
2400 & 0.0209 & 0.0235 & 0.0235 \\
2500 & 0.0205 & 0.0230 & 0.0230 \\
2600 & 0.0201 & 0.0226 & 0.0226 \\
2700 & 0.0197 & 0.0221 & 0.0221 \\
3000 & 0.0187 & 0.0210 & 0.0210 \\
\hline & & & \\
\hline \hline
\end{tabular}


Table K.14. Predictions of One-half 95\% Confidence Intervals (Cl) on Survival of Fish Traveling from the Bonneville Spillway to Array 1B (S1) and from Array 1B to Array 2B (S2), on Associated Detection Probabilities P1 and P2, and on the Joint Probability $(\lambda)$ as a Function of Possible Total Numbers that that Might Pass Under Biological-Opinion Spill Treatment (75,000 cfs Day and Gas-cap Night Spill)

\begin{tabular}{|rrrr||}
\hline $\begin{array}{r}\text { Release } \\
\text { Number }\end{array}$ & $\begin{array}{l}\text { One half } \\
\text { 95\% Cl } \\
\text { on S1 }\end{array}$ & $\begin{array}{l}\text { One-half } \\
\text { 95\% Cl } \\
\text { on P1 }\end{array}$ & $\begin{array}{l}\text { One-half } \\
\text { 95\% Cl } \\
\text { on Lamda }\end{array}$ \\
\hline \hline 300 & 0.0514 & 0.0455 & 0.0613 \\
400 & 0.0445 & 0.0394 & 0.0531 \\
500 & 0.0398 & 0.0353 & 0.0475 \\
600 & 0.0363 & 0.0322 & 0.0434 \\
700 & 0.0336 & 0.0298 & 0.0402 \\
800 & 0.0315 & 0.0279 & 0.0376 \\
900 & 0.0297 & 0.0263 & 0.0354 \\
1000 & 0.0281 & 0.0249 & 0.0336 \\
1100 & 0.0268 & 0.0238 & 0.0320 \\
1200 & 0.0257 & 0.0228 & 0.0307 \\
1300 & 0.0247 & 0.0219 & 0.0295 \\
1400 & 0.0238 & 0.0211 & 0.0284 \\
1500 & 0.0230 & 0.0204 & 0.0274 \\
1600 & 0.0222 & 0.0197 & 0.0266 \\
1700 & 0.0216 & 0.0191 & 0.0258 \\
1800 & 0.0210 & 0.0186 & 0.0250 \\
1900 & 0.0204 & 0.0181 & 0.0244 \\
2000 & 0.0199 & 0.0176 & 0.0238 \\
2100 & 0.0194 & 0.0172 & 0.0232 \\
2200 & 0.0190 & 0.0168 & 0.0227 \\
2300 & 0.0186 & 0.0164 & 0.0221 \\
2400 & 0.0182 & 0.0161 & 0.0217 \\
2500 & 0.0178 & 0.0158 & 0.0212 \\
2600 & 0.0174 & 0.0155 & 0.0208 \\
2700 & 0.0171 & 0.0152 & 0.0204 \\
3000 & 0.0162 & 0.0144 & 0.0194 \\
\hline & & & \\
\hline
\end{tabular}




\section{Appendix L \\ Model Estimates of One-Half 95\% Confidence Intervals on Detection and Survival Statistics for Subyearling Chinook Salmon Based on Paired-Release Survival Models for Summer 2006}


Acoustic Telemetry Studies of Juvenile Chinook Salmon Survival at the Lower Columbia Projects in 2006 


\section{Appendix L}

\section{Model Estimates of One-Half 95\% Confidence Intervals on Detection and Survival Statistics for Subyearling Chinook Salmon Based on Paired- Release Survival Models for Summer 2006}

All predicted estimates of 95\% confidence intervals (CI) are based upon summer 2006 estimates of survival and detection probabilities, and sample-size estimates associated with a one-half $95 \%$ CIs of about $2 \%, 3 \%, 4 \%$, and $5 \%$ on the primary-array survival of treatment fish (S1 in the third column) are highlighted when listed.

Table L.1. Predictions of One-half 95\% Confidence Intervals (Cl) on Survivals of Control and Treatment Fish Traveling to Array $1 \mathrm{~T}$ (S1) and from Array 1T to Array 2T (S2), on Associated Detection Probabilities P1 and P2, and on the Joint Probabilities $(\lambda)$ as a Function of Possible Total Numbers that Could be Released. Release locations include the JDA tailrace (treatment) and The Dalles Tailrace (controls) to assess TDA survival.

\begin{tabular}{|c|c|c|c|c|c|c|c|c|c|c|}
\hline $\begin{array}{l}\text { Release } \\
\text { Number }\end{array}$ & $\begin{array}{c}\text { One } \\
\text { half } \\
95 \% \mathrm{Cl} \\
\text { on } \\
\text { Control } \\
\text { S1 } \\
\end{array}$ & $\begin{array}{l}\text { One half } \\
95 \% \mathrm{Cl} \\
\text { on } \\
\text { Treatment } \\
\text { S1 } \\
\end{array}$ & $\begin{array}{c}\text { One } \\
\text { half } \\
95 \% \mathrm{Cl} \\
\text { on } \\
\text { Control } \\
\text { S2 } \\
\end{array}$ & $\begin{array}{c}\text { One half } \\
95 \% \mathrm{Cl} \\
\text { on } \\
\text { Treatment } \\
\text { S2 } \\
\end{array}$ & $\begin{array}{c}\text { One } \\
\text { half } \\
95 \% \mathrm{Cl} \\
\text { on } \\
\text { Control } \\
\text { P1 } \\
\end{array}$ & $\begin{array}{c}\text { One half } \\
95 \% \mathrm{Cl} \\
\text { on } \\
\text { Treatment } \\
\text { P1 } \\
\end{array}$ & $\begin{array}{c}\text { One } \\
\text { half } \\
95 \% \mathrm{Cl} \\
\text { on } \\
\text { Control } \\
\text { P2 } \\
\end{array}$ & $\begin{array}{c}\text { One half } \\
95 \% \mathrm{Cl} \\
\text { on } \\
\text { Treatment } \\
\text { P2 } \\
\end{array}$ & $\begin{array}{c}\text { One } \\
\text { half } \\
95 \% \mathrm{Cl} \\
\text { on } \\
\text { Control } \\
\text { Lamda } \\
\end{array}$ & $\begin{array}{c}\text { One half } \\
95 \% \mathrm{Cl} \\
\text { on } \\
\text { Treatment } \\
\text { Lamda } \\
\end{array}$ \\
\hline 300 & 0.019718 & 0.049882 & 0.023206 & 0.025578 & 0.012936 & 0.014269 & 0.001176 & 0.001294 & 0.002626 & 0.002901 \\
\hline 400 & 0.019718 & 0.044002 & 0.023206 & 0.022148 & 0.012936 & 0.012368 & 0.001176 & 0.001117 & 0.002626 & 0.002509 \\
\hline 500 & 0.019718 & 0.040062 & 0.023206 & 0.019816 & 0.012936 & 0.011054 & 0.001176 & 0.001000 & 0.002626 & 0.002234 \\
\hline 600 & 0.019718 & 0.037201 & 0.023206 & 0.018091 & 0.012936 & 0.010094 & 0.001176 & 0.000921 & 0.002626 & 0.002038 \\
\hline 700 & 0.019718 & 0.035025 & 0.023206 & 0.016738 & 0.012936 & 0.009349 & 0.001176 & 0.000843 & 0.002626 & 0.001901 \\
\hline 800 & 0.019718 & 0.033300 & 0.023206 & 0.015660 & 0.012936 & 0.008742 & 0.001176 & 0.000784 & 0.002626 & 0.001764 \\
\hline 900 & 0.019718 & 0.031889 & 0.023206 & 0.014759 & 0.012936 & 0.008232 & 0.001176 & 0.000745 & 0.002626 & 0.001666 \\
\hline 1000 & 0.019718 & 0.030713 & 0.023206 & 0.014014 & 0.012936 & 0.007820 & 0.001176 & 0.000706 & 0.002626 & 0.001588 \\
\hline 1100 & 0.019718 & 0.029714 & 0.023206 & 0.013348 & 0.012936 & 0.007448 & 0.001176 & 0.000666 & 0.002626 & 0.001509 \\
\hline 1200 & 0.019718 & 0.028851 & 0.023206 & 0.012779 & 0.012936 & 0.007134 & 0.001176 & 0.000647 & 0.002626 & 0.001450 \\
\hline 1300 & 0.019718 & 0.028106 & 0.023206 & 0.012289 & 0.012936 & 0.006860 & 0.001176 & 0.000627 & 0.002626 & 0.001392 \\
\hline 1400 & 0.019718 & 0.027440 & 0.023206 & 0.011838 & 0.012936 & 0.006605 & 0.001176 & 0.000608 & 0.002626 & 0.001333 \\
\hline 1500 & 0.019718 & 0.026872 & 0.023206 & 0.011446 & 0.012936 & 0.006390 & 0.001176 & 0.000568 & 0.002626 & 0.001294 \\
\hline 1600 & 0.019718 & 0.026342 & 0.023206 & 0.011074 & 0.012936 & 0.006174 & 0.001176 & 0.000568 & 0.002626 & 0.001254 \\
\hline 1700 & 0.019718 & 0.025892 & 0.023206 & 0.010741 & 0.012936 & 0.005998 & 0.001176 & 0.000549 & 0.002626 & 0.001215 \\
\hline 1800 & 0.019718 & 0.025460 & 0.023206 & 0.010447 & 0.012936 & 0.005821 & 0.001176 & 0.000529 & 0.002626 & 0.001176 \\
\hline 1900 & 0.019718 & 0.025088 & 0.023206 & 0.010172 & 0.012936 & 0.005664 & 0.001176 & 0.000510 & 0.002626 & 0.001156 \\
\hline 2000 & 0.019718 & 0.024735 & 0.023206 & 0.009898 & 0.012936 & 0.005527 & 0.001176 & 0.000510 & 0.002626 & 0.001117 \\
\hline 2100 & 0.019718 & 0.024402 & 0.023206 & 0.009663 & 0.012936 & 0.005390 & 0.001176 & 0.000490 & 0.002626 & 0.001098 \\
\hline 2200 & 0.019718 & 0.024108 & 0.023206 & 0.009447 & 0.012936 & 0.005272 & 0.001176 & 0.000470 & 0.002626 & 0.001078 \\
\hline 2300 & 0.019718 & 0.023834 & 0.023206 & 0.009232 & 0.012936 & 0.005155 & 0.001176 & 0.000470 & 0.002626 & 0.001039 \\
\hline 2400 & 0.019718 & 0.023579 & 0.023206 & 0.009036 & 0.012936 & 0.005037 & 0.001176 & 0.000451 & 0.002626 & 0.001019 \\
\hline 2500 & 0.019718 & 0.023344 & 0.023206 & 0.008859 & 0.012936 & 0.004939 & 0.001176 & 0.000451 & 0.002626 & 0.001000 \\
\hline 2600 & 0.019718 & 0.023128 & 0.023206 & 0.008683 & 0.012936 & 0.004841 & 0.001176 & 0.000431 & 0.002626 & 0.000980 \\
\hline 2700 & 0.019718 & 0.022932 & 0.023206 & 0.008526 & 0.012936 & 0.004763 & 0.001176 & 0.000431 & 0.002626 & 0.000960 \\
\hline 2800 & 0.019718 & 0.022736 & 0.023206 & 0.008369 & 0.012936 & 0.004665 & 0.001176 & 0.000431 & 0.002626 & 0.000941 \\
\hline 2900 & 0.019718 & 0.022560 & 0.023206 & 0.008232 & 0.012936 & 0.004586 & 0.001176 & 0.000412 & 0.002626 & 0.000921 \\
\hline 3000 & 0.019718 & 0.022383 & 0.023206 & 0.008095 & 0.012936 & 0.004508 & 0.001176 & 0.000412 & 0.002626 & 0.000921 \\
\hline 3100 & 0.019718 & 0.022226 & 0.023206 & 0.007958 & 0.012936 & 0.004430 & 0.001176 & 0.000412 & 0.002626 & 0.000902 \\
\hline 3200 & 0.019718 & 0.022070 & 0.023206 & 0.007840 & 0.012936 & 0.004371 & 0.001176 & 0.000392 & 0.002626 & 0.000882 \\
\hline 3300 & 0.019718 & 0.021932 & 0.023206 & 0.007703 & 0.012936 & 0.004312 & 0.001176 & 0.000392 & 0.002626 & 0.000882 \\
\hline 3400 & 0.019718 & 0.021795 & 0.023206 & 0.007605 & 0.012936 & 0.004234 & 0.001176 & 0.000392 & 0.002626 & 0.000862 \\
\hline 3500 & 0.019718 & 0.021678 & 0.023206 & 0.007487 & 0.012936 & 0.004175 & 0.001176 & 0.000372 & 0.002626 & 0.000843 \\
\hline 3600 & 0.019718 & 0.021540 & 0.023206 & 0.007389 & 0.012936 & 0.004116 & 0.001176 & 0.000372 & 0.002626 & 0.000843 \\
\hline 3700 & 0.019718 & 0.021442 & 0.023206 & 0.007291 & 0.012936 & 0.004057 & 0.001176 & 0.000372 & 0.002626 & 0.000823 \\
\hline 3800 & 0.019718 & 0.021325 & 0.023206 & 0.007193 & 0.012936 & 0.004018 & 0.001176 & 0.000372 & 0.002626 & 0.000804 \\
\hline 3900 & 0.019718 & 0.021227 & 0.023206 & 0.007095 & 0.012936 & 0.003959 & 0.001176 & 0.000353 & 0.002626 & 0.000804 \\
\hline 4000 & 0.019718 & 0.021109 & 0.023206 & 0.006997 & 0.012936 & 0.003900 & 0.001176 & 0.000353 & 0.002626 & 0.000784 \\
\hline
\end{tabular}


Table L.2. Predictions of One-half 95\% Confidence Intervals $(\mathrm{Cl})$ on Survivals of Control and Treatment Fish Traveling to Array 1B (S1) and from Array 1B to Array 2B (S2), on Associated Detection Probabilities $\mathrm{P} 1$ and $\mathrm{P} 2$, and on the Joint Probabilities $(\lambda)$ as a Function of Possible Total Numbers that Could be Released. Release locations include the TDA Tailrace (treatment) and BON Tailrace (controls) to assess BON survival.

\begin{tabular}{|c|c|c|c|c|c|c|}
\hline $\begin{array}{l}\text { Release } \\
\text { Number }\end{array}$ & $\begin{array}{l}95 \% \mathrm{Cl} \\
\text { on } \\
\text { Control } \\
\text { S1 }\end{array}$ & $\begin{array}{c}\text { 95\% Cl } \\
\text { on } \\
\text { Treatment } \\
\text { S1 }\end{array}$ & $\begin{array}{l}95 \% \mathrm{Cl} \\
\text { on } \\
\text { Control } \\
\text { P1 }\end{array}$ & $\begin{array}{c}\text { 95\% Cl } \\
\text { on } \\
\text { Treatment } \\
\text { P1 }\end{array}$ & $\begin{array}{c}95 \% \mathrm{Cl} \\
\text { on } \\
\text { Control } \\
\text { Lamda }\end{array}$ & $\begin{array}{c}95 \% \mathrm{Cl} \\
\text { on } \\
\text { Treatment } \\
\text { Lamda }\end{array}$ \\
\hline 2500 & 0.027479 & 0.049274 & 0.038161 & 0.042493 & 0.038906 & 0.043336 \\
\hline 600 & 0.027479 & 0.045982 & 0.038161 & 0.038788 & 0.038906 & 0.039572 \\
\hline 700 & 0.027479 & 0.043492 & 0.038161 & 0.035927 & 0.038906 & 0.036632 \\
\hline 800 & 0.027479 & 0.041513 & 0.038161 & 0.033594 & 0.038906 & 0.034261 \\
\hline 900 & 0.027479 & 0.039906 & 0.038161 & 0.031674 & 0.038906 & 0.032301 \\
\hline 1000 & 0.027479 & 0.038573 & 0.038161 & 0.030047 & 0.038906 & 0.030654 \\
\hline 1100 & 0.027479 & 0.037456 & 0.038161 & 0.028655 & 0.038906 & 0.029224 \\
\hline 1200 & 0.027479 & 0.036476 & 0.038161 & 0.02744 & 0.038906 & 0.027969 \\
\hline 1300 & 0.027479 & 0.035652 & 0.038161 & 0.026362 & 0.038906 & 0.026872 \\
\hline 1400 & 0.027479 & 0.034927 & 0.038161 & 0.025402 & 0.038906 & 0.025911 \\
\hline 1500 & 0.027479 & 0.034280 & 0.038161 & 0.024539 & 0.038906 & 0.025029 \\
\hline 1600 & 0.027479 & 0.033692 & 0.038161 & 0.023755 & 0.038906 & 0.024226 \\
\hline 1700 & 0.027479 & 0.033183 & 0.038161 & 0.02305 & 0.038906 & 0.0235 \\
\hline 1800 & 0.027479 & 0.032712 & 0.038161 & 0.022403 & 0.038906 & 0.022834 \\
\hline 1900 & 0.027479 & 0.032281 & 0.038161 & 0.021795 & 0.038906 & 0.022226 \\
\hline 2000 & 0.027479 & 0.031909 & 0.038161 & 0.021246 & 0.038906 & 0.021678 \\
\hline 2100 & 0.027479 & 0.031556 & 0.038161 & 0.020737 & 0.038906 & 0.021148 \\
\hline 2200 & 0.027479 & 0.031223 & 0.038161 & 0.020266 & 0.038906 & 0.020658 \\
\hline 2300 & 0.027479 & 0.030929 & 0.038161 & 0.019816 & 0.038906 & 0.020208 \\
\hline 2400 & 0.027479 & 0.030654 & 0.038161 & 0.019404 & 0.038906 & 0.019776 \\
\hline 2500 & 0.027479 & 0.030400 & 0.038161 & 0.019012 & 0.038906 & 0.019384 \\
\hline 2600 & 0.027479 & 0.030164 & 8161 & 0.01864 & 0.038906 & 0.019012 \\
\hline 2700 & 0.027479 & 0.029929 & 0.038161 & 0.018287 & 0.038906 & 0.018659 \\
\hline 2800 & 0.027479 & 0.029714 & 0.038161 & 0.017954 & 0.038906 & 0.018306 \\
\hline 2900 & 0.027479 & 0.029537 & 0.038161 & 0.01764 & 0.038906 & 0.017993 \\
\hline 3000 & 0.027479 & 0.029341 & 0.038161 & 0.017346 & 0.038906 & 0.017699 \\
\hline 3100 & 0.027479 & 0.029165 & 0.038161 & 0.017072 & 0.038906 & 0.017405 \\
\hline 3200 & 0.027479 & 0.029008 & 0.038161 & 0.016797 & 0.038906 & 0.01713 \\
\hline 3300 & 0.027479 & 0.028851 & 0.038161 & 0.016542 & 0.038906 & 0.016876 \\
\hline 3400 & 0.027479 & 0.028714 & 0.038161 & 0.016307 & 0.038906 & 0.016621 \\
\hline 3500 & 0.027479 & 0.028577 & 0.038161 & 0.016072 & 0.038906 & 0.016386 \\
\hline 3600 & 0.027479 & 0.028440 & 0.038161 & 0.015837 & 0.038906 & 0.01615 \\
\hline 3700 & 0.027479 & 0.028322 & 0.038161 & 0.015621 & 0.038906 & 0.015935 \\
\hline 3800 & 0.027479 & 0.028204 & 0.038161 & 0.015425 & 0.038906 & 0.015719 \\
\hline 3900 & 0.027479 & 0.028087 & 0.038161 & 0.01521 & 0.038906 & 0.015523 \\
\hline 4000 & 0.027479 & 0.027969 & 0.038161 & 0.015033 & 0.038906 & 0.015327 \\
\hline 4100 & 0.027479 & 0.027871 & 0.038161 & 0.014837 & 0.038906 & 0.015131 \\
\hline 4200 & 0.027479 & 0.027773 & 0.038161 & 0.014661 & 0.038906 & 0.014955 \\
\hline 4300 & 0.027479 & 0.027675 & 0.038161 & 0.014484 & 0.038906 & 0.014778 \\
\hline 4400 & 0.027479 & 0.027597 & 0.038161 & 0.014328 & 0.038906 & 0.014602 \\
\hline 4500 & 0.027479 & 0.027499 & 0.038161 & 0.014171 & 0.038906 & 0.014445 \\
\hline 4600 & 0.027479 & 0.027420 & 0.038161 & 0.014014 & 0.038906 & 0.014288 \\
\hline 4700 & 0.027479 & 0.027342 & 0.038161 & 0.013857 & 0.038906 & 0.014132 \\
\hline 4800 & 0.027479 & 0.027264 & 0.038161 & 0.01372 & 0.038906 & 0.013994 \\
\hline 5000 & 0.027479 & 0.027126 & 0.038161 & 0.013446 & 0.038906 & 0.013700 \\
\hline
\end{tabular}




\section{Appendix M}

\section{Detection History Data for 2006}

(on accompanying CD) 
Acoustic Telemetry Studies of Juvenile Chinook Salmon Survival at the Lower Columbia Projects in 2006 


\section{Appendix M}

\section{Detection History Data for 2006}

Table M.1. List of Appendix CSV Files on the Accompanying CD*

\begin{tabular}{|cc|}
\hline File & Description \\
\hline \hline Appendix M - Detection History Data for 2006.CSV & All captured history data 2006 \\
\hline
\end{tabular}

*A CD with Table M1 accompanies the final report. 
Table M.2. Definitions of Variables in Headings of Appendix M Table on the Accompanying CD.

\begin{tabular}{|c|c|}
\hline Variable & Definition \\
\hline Season & Release season Spring/Summer \\
\hline AcousticTagCode & Acoustic Tag Code \\
\hline TagCode & PIT tag code \\
\hline ActivationDate & Acoustic Tag Activation date \\
\hline Rel_Date2 & Fish release date and time \\
\hline ReleaseLoc & Fish Release Location \\
\hline JDA0 & Tag detected at John Day Dam egress array, 0 for not detected and 1 for detected \\
\hline JDA1 & Tag detected at John Day Dam primary array, 0 for not detected and 1 for detected \\
\hline JDA2 & Tag detected at John Day Dam secondary array, 0 for not detected and 1 for detected \\
\hline JDA3 & Tag detected at John Day Dam tertiary array, 0 for not detected and 1 for detected \\
\hline TDA1 & Tag detected at The Dalles Dam primary array, 0 for not detected and 1 for detected \\
\hline TDA2 & Tag detected at The Dalles Dam secondary array, 0 for not detected and 1 for detected \\
\hline TDA3 & Tag detected at The Dalles Dam tertiary array, 0 for not detected and 1 for detected \\
\hline TDA4 & Tag detected at Bonneville Dam spillway forebay array, 0 for not detected and 1 for detected \\
\hline BON1 & Tag detected at Bonneville Dam primary array, 0 for not detected and 1 for detected \\
\hline BON2 & Tag detected at Bonneville Dam secondary array, 0 for not detected and 1 for detected \\
\hline BON3 & Tag detected at Bonneville Dam tertiary array, 0 for not detected and 1 for detected \\
\hline JDA0_TIME & First detected date and time at John Day Dam Egrass array (downstream of the dam) \\
\hline JDA1_TIME & First detected date and time at John Day Dam primary array (downstream of the dam) \\
\hline JDA2_TIME & First detected date and time at John Day Dam secondary array (downstream of the dam) \\
\hline JDA3_TIME & First detected date and time at John Day Dam tertiary array (downstream of the dam) \\
\hline TDA1_TIME & First detected date and time at The Dalles Dam primary array (downstream of the dam) \\
\hline TDA2_TIME & First detected date and time at The Dalles Dam secondary array (downstream of the dam) \\
\hline TDA3_TIME & First detected date and time at The Dalles Dam tertiary array (downstream of the dam) \\
\hline TDA4_TIME & Last detected date and time at Bonneville Dam spillway forebay array \\
\hline BON1_TIME & First detected date and time at Bonneville Dam primary array (downstream of the dam) \\
\hline BON2_TIME & First detected date and time at Bonneville Dam secondary array (downstream of the dam) \\
\hline BON3_TIME & First detected date and time at Bonneville Dam tertiary array (downstream of the dam) \\
\hline
\end{tabular}

